Mineração de dados de anemia falciforme e priapismo

\author{
Mina Cintho Ozahata \\ TESE APRESENTADA \\ $\mathrm{AO}$ \\ Instituto De MatemáticA e EstatísticA \\ DA \\ UNIVERSIDADE DE SÃo PAULO \\ PARA \\ OBTENÇÃO DO TÍTULO \\ $\mathrm{DE}$ \\ Doutor em CiênCIAS obtido no Programa Bioinformática
}

Programa Interunidades de Pós-Graduação em Bioinformática

Orientador: Prof. Dr. João Eduardo Ferreira 


\section{Mineração de dados de anemia falciforme e priapismo}

Esta versão da tese contém as correções e alterações sugeridas pela Comissão Julgadora durante a defesa da versão original do trabalho, realizada em 02/07/2019. Uma cópia da versão original está disponível no

Instituto de Matemática e Estatística da Universidade de São Paulo.

Comissão Julgadora:

- Prof $^{a}$. Dra . João Eduardo Ferreira (orientador) - IME-USP

- Prof. Dr. Luciano Vieira de Araújo - EACH-USP

- Prof. Dr. Diogo Meyer - IB-USP

- Prof. Dr. Cesar de Almeida Neto - Fundação Pró-Sangue Hemocentro de São Paulo

- Prof. Dr. Luciano Digiampietri - EACH-USP 


\section{Agradecimentos}

Ao meu orientador, Prof. Dr. João Eduardo Ferreira, por toda a atenção, paciência, conselhos e apoio durante todos esses anos.

À Dra Ester Cerdeira Sabino por toda dedicação, atenção e colaboração na orientação deste trabalho.

À minha família, em especial ao meu marido Bruno Yoiti Ozahata, meus pais, Seiji Cintho e Tereza Doi Cintho, minhas irmãs, Camila Yoko Cintho e Talita Yumi Cintho pelo apoio e carinho.

Aos meus amigos Lívia Garcia Pedroso, Natan Costa Lima, Daniela Toledo Thomazella e Juliana Duz Ricarte pela amizade e incentivo.

À Coordenação de Aperfeiçoamento de Pessoal de Nível Superior (CAPES) pelo apoio financeiro.

A todos os colaboradores do projeto REDS-III que tornaram possível o desenvolvimento deste trabalho. 


\section{Resumo}

O avanço de novas tecnologias tem conduzido à geração de grandes volumes de dados biológicos, provenientes, por exemplo, de sequenciamento de genomas, expressão de genes e proteínas, estrutura de proteínas e RNAs, análise de imagens, formulários eletrônicos e exames médicos. Com o intuito de transformar esses volumosos conjuntos de dados brutos em informação e conhecimento que sejam compreensíveis e interpretáveis, técnicas de mineração de dados têm sido aplicadas no estudos de diversos processos biológicos, como a predição de genes, funções de genes, fenótipos, módulos regulatórios, estrutura de proteínas, função de proteínas e descoberta de interações moleculares.

Cada conjunto de dados tem suas particularidades, demandando o emprego de distintas metodologias de análises e algoritmos de reconhecimento de padrões, como Florestas Aleatórias, Redes Neurais, Deep Learning, Modelo Oculto de Markov, Máquina de Vetores de Suporte, K-médias e Análise de Componentes Principais. A escolha do algoritmo a ser utilizado é influenciada por fatores como o tipo dos dados, a forma como são gerados, sua natureza, suas características e o objetivo do estudo.

Assim, este trabalho teve como objetivo explorar técnicas de reconhecimento de padrões e estatística aplicadas a um conjunto de dados biológicos envolvendo pacientes com anemia falciforme, para extração de informação e conhecimento sobre os processos, fenômenos e sistemas biológicos envolvidos na doença. Foram realizadas análises de um conjunto de dados diverso, proveniente de registros clínicos, entrevistas com pacientes, exames clínicos e sequenciamento de polimorfismos de nucleotídeo único. Os dados demandam diferentes abordagens de análises, exploração e revelação da estrutura de dados intrínseca.

Em uma análise inicial, foram aplicados algoritmos de reconhecimento de padrões a dados clínicos de pacientes com anemia falciforme, com o objetivo de obter grupos contendo pacientes similares. Os algoritmos PCAMix, PAM e TwoStep clustering foram capazes de gerar grupos homogêneos de pacientes, sendo que estes grupos apresentam distintas características clínicas e diferentes níveis de gravidade da doença quando comparados entre si. Os resultados indicam que características como idade, níveis de bilirrubina, histórico de transfusões, dor aguda da anemia falciforme, síndrome torácica aguda, acidente vascular cerebral, infarto cerebral silencioso, ataque isquêmico transitório, úlcera de pernas, moyamoya, ferritina, contagem de reticulócitos, retinopatias, ataques epiléticos e hemossiderose transfusional são importantes para a definição de grupos homogêneos de pacientes, que apresentem distintos níveis de gravidade de anemia falciforme quando comparados entre si.

Adicionalmente à análise de agrupamento, o conjunto de pacientes com histórico de priapismo, uma das complicações da anemia falciforme, foi estudado. O objetivo desta análise foi caracterizar clinicamente os pacientes com histórico de priapismo, e investigar fatores genéticos que alterassem o risco da doença. Observou-se que o priapismo ocorreu mais frequentemente em pacientes com genótipo HbSS, estando associado a idades mais avançadas e à ocorrência de hipertensão pulmonar e necrose avascular. Dois novos SNPs foram associados à ocorrência de priapismo, bem como houve indicativo de replicação da associação do gene TGFBR3 ao risco da doença. 


\section{Abstract}

Technology has been producing large biological datasets of genome sequences, gene and protein expression, RNA and protein structure, images, electronic questionnaires and laboratory test results. In order to extract information and knowledge from these large datasets, data mining techniques have been used in the investigation of a wide range of biological processes, with the goal of predicting gene, gene function, phenotype, regulatory modules, molecular interaction, protein function and protein structure.

Each dataset has different characteristics and demands the application of different statistical methodologies and pattern recognition algorithms, such as Random Forests, Neural Networks, Deep Learning, Markov Hidden Model, Support Vector Machine, K-means and Principal Component Analysis. The choice of the algorithm depends on data type, data generation, data characteristics and goal of the study.

Therefore, the goal of this work was to explore pattern recognition and statistical techniques in a biological dataset on sickle cell disease patients, in order to extract information and knowledge about the biological systems, processes and mechanisms associated with the disease. A diverse dataset was analyzed, containing data from medical records, patient interviews, laboratory tests and single nucleotide polymorphisms. The dataset requires a variety of analysis approaches, in order to explore and reveal the hidden data structure.

In an initial investigation, pattern recognition algorithms were used in the analysis of clinical data from sickle cell patients, in order to obtain clusters containing similar patients. PCAMix, PAM and TwoStep clustering algorithms generated homogeneous clusters of patients that display different clinical characteristics and different levels of disease severity. The results show that age, bilirubin levels, transfusion history, vasoocclusive pain episodes, acute chest syndrome, infarctive stroke, hemorrhagic stroke, ischemic attack, leg ulcers, moyamoya, ferritin, reticulocyte count, retinopathy, seizures and transfusional hemosiderosis are important to define homogeneous patient clusters, with distinct levels of sickle cell severity.

Additionally, the patients with history of priapism, a sickle cell related complication, were studied. The goal of the study was to characterize patients with priapism history and investigate genetic factors that modify the risks of the disease. Priapism more frequently occurred among patients with HbSS genotype and was associated with older age and occurrence of pulmonary hypertension and avascular necrosis. Two novel SNPs were associated with priapism and there was evidence of replication of a previously reported association of TGFBR3 with priapism risk. 


\section{Sumário}

Lista de Abreviaturas $\quad$ xi

Lista de Figuras $\quad$ xiii

Lista de Tabelas $\quad$ xv

1 Introdução $\quad 1$

1.1 Motivação . . . . . . . . . . . . . . . . . . . . . . . . . . 1

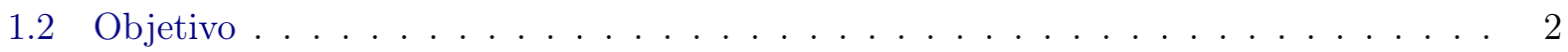

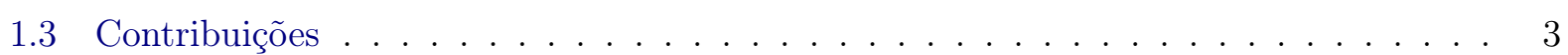

1.4 Organização do Trabalho . . . . . . . . . . . . . . . . . . . 3

2 Fundamentos Biológicos $\quad 5$

2.1 Anemia Falciforme . . . . . . . . . . . . . . . . . . . . 5

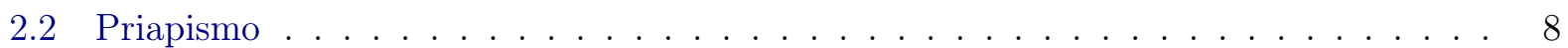

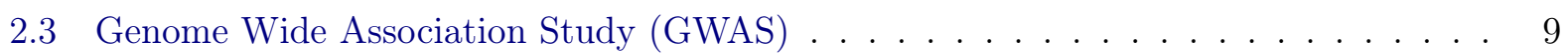

3 Fundamentos Computacionais $\quad 13$

3.1 Reconhecimento de Padrões . . . . . . . . . . . . . . . . . . . . . . . . 13

3.2 Análise de Componentes Principais e Métodos Derivados . . . . . . . . . . . . . . . 14

3.2.1 Análise de Componentes Principais (PCA) . . . . . . . . . . . . . . . 14

3.2 .2 Análise de Correspondência Múltipla (MCA) . . . . . . . . . . . . 16

3.2.3 Análise de Componentes Principais de Variáveis Misturadas Numéricas e Categóricas $(\mathrm{PCAMix}) \ldots \ldots \ldots \ldots \ldots \ldots$

3.3 Agrupamento . . . . . . . . . . . . . . . . . . . . 20

3.3.1 K-medóides ou Partition Around Medoids (PAM) . . . . . . . . . . . . . 21

Gower . . . . . . . . . . . . . . . . . . . . 22

Silhouette . . . . . . . . . . . . . . . . 22

3.3.2 Agrupamento TwoStep ou BIRCH . . . . . . . . . . . . . . . . . 23

Log-verossimilhança . . . . . . . . . . . . . . . . . . . . . . . . . . . . . . . . .

Critério de informação Bayesiana . . . . . . . . . . . . . . . . 25

3.4 Análise de sobrevivência . . . . . . . . . . . . . . . . . . . . 26

3.4 .1 Kaplan-Meier . . . . . . . . . . . . . . . . . . . . . 26 
4 Trabalhos Relacionados

4.1 Trabalhos relacionados à heterogeneidade da anemia falciforme . . . . . . . . . . . . 29

4.2 Trabalhos relacionados ao agrupamento de pacientes . . . . . . . . . . . . . 31

4.3 Trabalhos relacionados ao priapismo na anemia falciforme . . . . . . . . . . . 32

4.4 Conclusão sobre os trabalhos relacionados . . . . . . . . . . . . . . . . . . . 33

5 Anemia Falciforme $\quad 35$

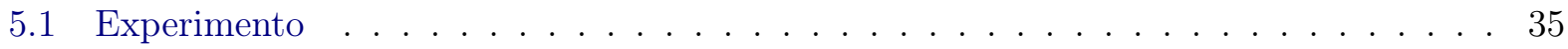

5.1.1 NHLBI Retrovirus Epidemiology Donor Study II e III - REDS II e III . . . . 35

5.1.2 REDS-III e o Brazil Sickle Cell Disease Cohort . . . . . . . . . . . . . . . . 35

Relações Genótipo-Fenótipo em Anemia Falciforme . . . . . . . . . . . . 36

5.1 .3 Agrupamento . . . . . . . . . . . . . . . . . . . . . . . . 38

Seleção de pacientes para o agrupamento . . . . . . . . . . . . . . . . 38

Seleção de caraterísticas para o agrupamento . . . . . . . . . . . . . . . 38

Métodos de Agrupamento . . . . . . . . . . . . . . . . . . . . . . . . . . 40

Agrupamento TwoStep . . . . . . . . . . . . . . . . . . . 40

K-medóides . . . . . . . . . . . . . . . . . . . . . 40

Análise de Componentes Principais de Variáveis Misturadas Numéricas

e Categóricas (PCAMix) . . . . . . . . . . . . . 41

Caracterização de grupos . . . . . . . . . . . . . . . . . . . . . 44 4

5.2 Resultados - Agrupamento - pacientes HbSC . . . . . . . . . . . . . . . . . . . 42

5.2.1 Pacientes com menos de 18 anos de idade . . . . . . . . . . . . . . . . . 42

Comparação dos resultados dos algoritmos . . . . . . . . . . . . . . . . . . 44

Caracterização dos grupos . . . . . . . . . . . . . . . . . . . 4 45

5.2 .2 Pacientes com 18 anos de idade ou mais . . . . . . . . . . . . . . . . . 47

Comparação dos resultados dos algoritmos . . . . . . . . . . . . . . . . 48

Caracterização dos grupos . . . . . . . . . . . . . . . . . . . . . . . . . 49

5.3 Resultados - Agrupamento - pacientes HbSS e $H b S \beta 0$. . . . . . . . . . . . . . 50

5.3.1 Pacientes com menos de 18 anos de idade . . . . . . . . . . . . . . . . 50

Comparação dos resultados dos algoritmos . . . . . . . . . . . . . . . . 52

Caracterização dos grupos . . . . . . . . . . . . . . . . . . . . . . . 53

Agrupamento TwoStep e PAM . . . . . . . . . . . . . 53

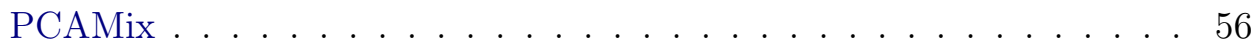

5.3.2 Pacientes com 18 anos de idade ou mais . . . . . . . . . . . . . . . 58

Comparação dos resultados dos algoritmos . . . . . . . . . . . . . . . . . 60

Caracterização dos grupos . . . . . . . . . . . . . . . . . . . 6 61

Agrupamento TwoStep . . . . . . . . . . . . . . . . . . . . . . 61

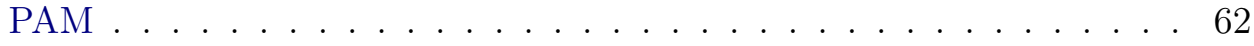

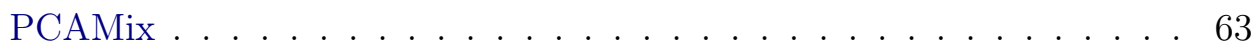

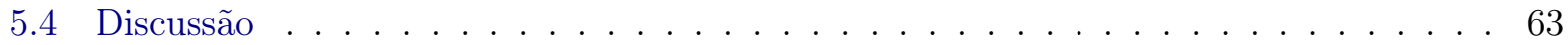

6 Priapismo $\quad 65$

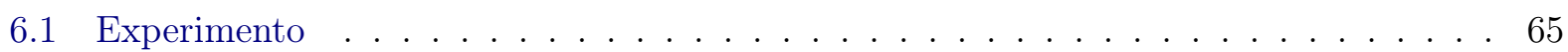

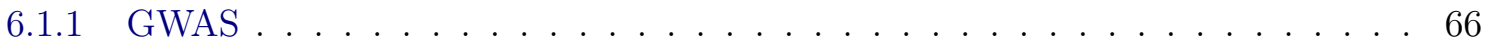


6.2 Resultados . . . . . . . . . . . . . . . . . . . . . . 69

6.2 .1 Características gerais dos pacientes . . . . . . . . . . . 69

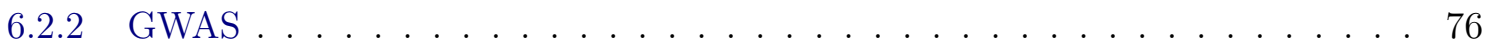

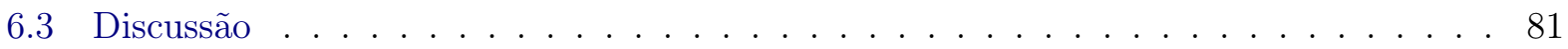

7 Conclusão $\quad 85$

7.1 Trabalhos futuros e limitações . . . . . . . . . . . . . . . . . . . . . 86

$\begin{array}{ll}\text { Referências Bibliográficas } & 89\end{array}$

$\begin{array}{ll}\text { Apêndice } & 105\end{array}$

A Aprovação do Brazil Sickle Cell Disease Cohort-CONEP . . . . . . . . . . . . . . 106

B Aprovação do Brazil Sickle Cell Disease Cohort - CEP . . . . . . . . . . . . . . . . 120

C Questionários de inscrição do REDS-III . . . . . . . . . . . . . . . . . . . 123

D Questionários de acompanhamento 1 do REDS-III . . . . . . . . . . . . . . . 193

E Questionários de acompanhamento 2 do REDS-III . . . . . . . . . . . . . . 307 


\title{
Lista de Abreviaturas
}

\author{
AVC Acidente vascular cerebral \\ CA Análise de correspondência \\ CNP Polimorfismo de número de cópias \\ DNA Ácido desoxirribonucleico \\ GWAS Estudo de associação genômica ampla \\ HbA Hemoglobina A \\ HBA1 Hemoglobina $\alpha 1$ \\ HBB Subunidade $\beta$ da hemoglobina, $\beta$-globina, hemoglobina- $\beta$ ou hemoglobina subunidade $\beta$ \\ $\mathrm{HbF} \quad$ Hemoglobina $\mathrm{F}$ ou hemoglobina fetal \\ HbS Hemoglobina B \\ HIV Vírus da imunodeficiência humana \\ HLA Human leukocyte antigen allele \\ LD Linkage disequilibrium \\ HDL Lactato desidrogenase \\ MAF Minor allele frequency \\ MCA Análise de Correspondência Múltipla \\ NO Ácido nítrico \\ PAM Partição ao redor dos medóides \\ PCA Análise de Componentes Principais \\ PCAMix Principal Component Analysis of Mixed Data \\ PCV Packed cell volume \\ RNA Ácido ribonucleico \\ SCD Sickle cell disease \\ SVD Decomposição em valores singulares \\ SNP Polimorfismo de nucleotídeo único
}




\section{Lista de Figuras}

2.1 Comparação do formato de eritrócitos de camundongo normais e com anemia falciforme oxigenados e desoxigenados. Imagem de (Chang et al., 1998). . . . . . . . . . 5

2.2 Figura de Anele et al. (2015) representando a relação entre as vias de cGMP e PDE5 com a biodisponibilidade de NO, hemólise e priapismo. A via superior mostra uma ereção normal e a via inferior a ocorrência de priapismo. Na via superior, a PDE5 hidrolisa a cGMP, levando ao estado de flacidez. Na via inferior, o baixo nível de PDE5 leva ao priapismo. . . . . . . . . . . . . . . . . . . 9

4.1 Estratégia sugerida em Anele et al. (2015) para tratamento de casos de priapismo. . 33

5.1 Silhouette PAM com pacientes HbSC com idade menor a 18 anos . . . . . . . . . . . 42

5.2 Componentes principais: PC1 versus PC3 - pacientes HbSC com idade menor a 18

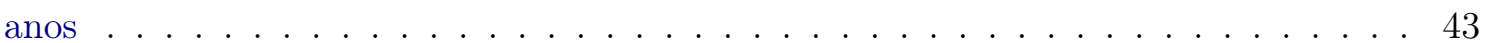

5.3 Silhouette PAM com pacientes HbSC com 18 anos ou mais . . . . . . . . . . . . . . 47

5.4 Componentes principais: PC1 versus PC2 - pacientes HbSC com 18 anos ou mais . . 47

5.5 Silhouette PAM com pacientes HbSS e $H b S \beta 0$ com idade menor a 18 anos . . . . . . 51

5.6 Componentes principais: PC1 versus PC3 - pacientes HbSS e HbS $\beta 0$ com idade

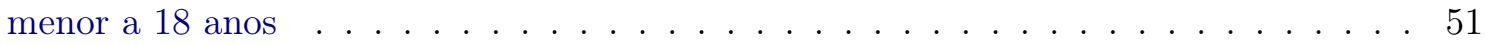

5.7 Silhouette PAM com pacientes HbSS e $H b S \beta 0$ com idade igual ou maior a 18 anos . 58

5.8 Componentes principais: PC2 versus PC3 - pacientes HbSS e HbS $\beta 0$ com idade igual ou maior a 18 anos . . . . . . . . . . . . . . . . . . . . . . . 58

6.1 Diagrama de consorte contendo a seleção de pacientes com anemia falciforme para análise estatística de caracterização de pacientes com priapismo e para a análise de

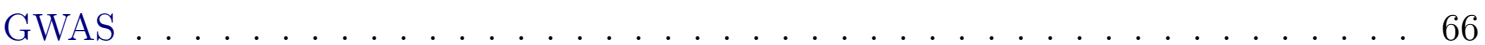

6.2 Etapas envolvidas na obtenção dos dados de SNPs e no Genome Wide Association

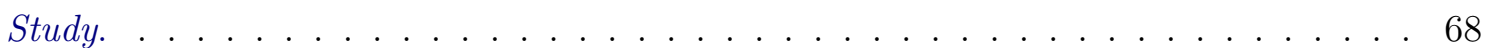

6.3 Idade dos pacientes no primeiro episódio de priapismo $\ldots \ldots \ldots$. . . . . . . 70

6.4 Estimativa de tempo para ocorrência de priapismo com método Kaplan-Meier . . . . 71

6.5 Gráfico Q-Q do logaritmo dos p-valores observados (eixo y) versus os esperados (eixo

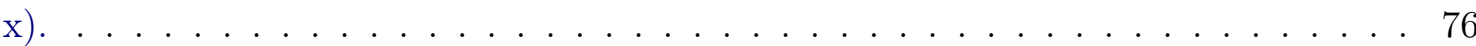

6.6 Gráfico Manhattan da função: $\left(-\log _{10} p\right.$ - valores $)$ para os resultados de associação do priapismo e os SNPs dada suas posições em cada cromossomo. A linha horizontal indica um valor sugestivo de significância no genoma inteiro de $5 \times 10^{-8}$. 
6.7 Gráfico locusZoom regional do cromossomo 6 e o SNP rs77635018. O eixo y representa o negativo do logaritmo dos p-valores para a associação dos SNPs com priapismo. Os SNPs são representados como pontos, com as cores codificando os níveis de desequilíbrio de ligação com o SNP rs77635018. O eixo x mostra as posições relativas dos SNPs no cromossomo, representando a taxa de recombinação em centimorgans (cM) por megabase $(\mathrm{Mb})$.

6.8 Gráfico locusZoom regional do cromossomo 3 e o SNP rs190103771. O eixo y representa o negativo do logaritmo dos p-valores para a associação dos SNPs com priapismo.Os SNPs são representados como pontos, com as cores codificando os níveis de desequilíbrio de ligação com o SNP rs190103771. O eixo x mostra as posições relativas dos SNPs no cromossomo, representando a taxa de recombinação em centimorgans $(\mathrm{cM})$ por megabase $(\mathrm{Mb})$

6.9 Gráfico locusZoom regional do cromossomo 1 e o SNP rs3103333. O eixo y representa o negativo do logaritmo dos p-valores para a associação dos SNPs com priapismo.Os SNPs são representados como pontos, com as cores codificando os níveis de desequilíbrio de ligação com o SNP rs3103333. O eixo x mostra as posições relativas dos SNPs no cromossomo, representando a taxa de recombinação em centimorgans (cM) por megabase $(\mathrm{Mb})$ 


\section{Lista de Tabelas}

2.1 Algumas das mutações no gene HBB que podem compor heterozigose com HbS . . . 6

4.1 Biomarcadores empregados no agrupamento de pacientes com anemia falciforme em Du et al. (2018) . . . . . . . . . . . . . . . . . . . . . 30

4.2 Associações de genes com priapismo sugeridas por GWAS . . . . . . . . . . . . . 32

5.1 Amostra dos dados coletados no REDS-III Brazil SCD Cohort . . . . . . . . . . 37

5.2 Variáveis usadas no agrupamento de pacientes . . . . . . . . . . . . . . . . . . 39

5.3 Variáveis usadas para caracterização de grupos de pacientes . . . . . . . . . . . . . . 41

5.4 BIC - agrupamento TwoStep de pacientes HbSC com idade menor a 18 anos . . . . . 42

5.5 Comparação dos resultados dos algoritmos - TwoStep e PAM - pacientes HbSC com idade menor a 18 anos . . . . . . . . . . . . . . . . . . . . . . 44

5.6 Comparação dos resultados dos algoritmos - PCAMix e PAM - pacientes HbSC com idade menor a 18 anos . . . . . . . . . . . . . . . . . . . . . . . . 44

5.7 Comparação dos resultados dos algoritmos - PCAMix e TwoStep - pacientes HbSC com idade menor a 18 anos . . . . . . . . . . . . . . . . . . . . . 44

5.8 Agrupamento PAM de pacientes HbSC com menos de 18 anos - variáveis binárias . . 45

5.9 Agrupamento PAM de pacientes HbSC com menos de 18 anos - variáveis numéricas . 45

5.10 BIC - agrupamento agrupamento TwoStep de pacientes HbSC com 18 anos ou mais . 47

5.11 Comparação dos resultados dos algoritmos - TwoStep e PAM - pacientes HbSC com 18 anos ou mais . . . . . . . . . . . . . . . . . . . . . . . . . . . 48

5.12 Comparação dos resultados dos algoritmos - PAM e PCAMix - pacientes HbSC com 18 anos ou mais . . . . . . . . . . . . . . . . . . . . . . . . 48

5.13 Comparação dos resultados dos algoritmos - TwoStep e PCAMix - pacientes HbSC com 18 anos ou mais . . . . . . . . . . . . . . . . . . . . . . 48

5.14 Agrupamento PAM de pacientes HbSC com 18 anos ou mais - variáveis binárias . . . 49

5.15 Agrupamento PAM de pacientes HbSC com 18 anos ou mais - variáveis numéricas . . 49

5.16 BIC - agrupamento TwoStep de pacientes HbSS e HbS $\beta 0$ com idade menor a 18 anos 50

5.17 Comparação dos resultados dos algoritmos - TwoStep e PAM - pacientes HbSS e $H b S \beta 0$ com idade menor a 18 anos . . . . . . . . . . . . . . . . . . 52

5.18 Comparação dos resultados dos algoritmos - PCAMix e PAM - pacientes HbSS e HbS $\beta 0$ com idade menor a 18 anos . . . . . . . . . . . . . . . . . . . . 52

5.19 Comparação dos resultados dos algoritmos - PCAMix e TwoStep - pacientes HbSS e $H b S \beta 0$ com idade menor a 18 anos . . . . . . . . . . . . . . . . . . . . 52 
5.20 Agrupamento TwoStep de pacientes HbSS e HbS $\beta 0$ com idade menor a 18 anos variáveis binárias . . . . . . . . . . . . . . . . . . . . . . . . 53

5.21 Agrupamento TwoStep de pacientes HbSS e HbS $\beta 0$ com idade menor a 18 anos variáveis numéricas . . . . . . . . . . . . . . . . . . . . . . . . . . 53

5.22 Agrupamento PCAMix de pacientes HbSS e HbS $\beta 0$ com idade menor a 18 anos variáveis binárias . . . . . . . . . . . . . . . . . . . . . . . . . 56

5.23 Agrupamento PCAMix de pacientes HbSS e HbS $\beta 0$ com idade menor a 18 anos variáveis numéricas . . . . . . . . . . . . . . . . . . . . . . . . . . 56

$5.24 \mathrm{BIC}$ - agrupamento TwoStep de pacientes HbSS e HbS $\beta 0$ com idade igual ou maior a 18 anos ............................... . . . 5

5.25 Comparação dos resultados dos algoritmos - HbSS e HbS $\beta 0$ clusters - PAM e TwoStep - pacientes HbSS e HbSß0 com idade menor a 18 anos . . . . . . . . . . . . . . . . . 60

5.26 Comparação dos resultados dos algoritmos - PAM e PCAMix - pacientes HbSS e $H b S \beta 0$ com idade menor a 18 anos . . . . . . . . . . . . . . . . . . . . . . . . . . . . 60

5.27 Comparação dos resultados dos algoritmos - TwoStep e PCAMix - pacientes HbSS e $H b S \beta 0$ com idade menor a 18 anos . . . . . . . . . . . . . . . . . . . . . . . . . . . 60

5.28 Agrupamento TwoStep de pacientes HbSS e HbS $\beta 0$ com idade igual ou maior a 18 anos - variáveis binárias . . . . . . . . . . . . . . . . . . . . . . . 61

5.29 Agrupamento TwoStep de pacientes HbSS e $\operatorname{HbS} \beta 0$ com idade maior a 18 anos variáveis numéricas . . . . . . . . . . . . . . . . . . . . . . . . . . . . . 61

5.30 Agrupamento PAM de pacientes $\mathrm{HbSS}$ e $\mathrm{HbS} \beta 0$ com idade igual ou maior a 18 anos - variáveis binárias . . . . . . . . . . . . . . . . . . . . . . . . . . . . . . 62

5.31 Agrupamento PAM de pacientes $\mathrm{HbSS}$ e $\mathrm{HbS} \beta 0$ com idade igual ou maior a 18 anos - variáveis numéricas

5.32 Agrupamento PCAMix de pacientes $\mathrm{HbSS}$ e $\mathrm{HbS} \beta 0$ com idade igual ou maior a 18 anos - variáveis binárias . . . . . . . . . . . . . . . . . . . . . . . . . . 63

5.33 Agrupamento PCAMix de pacientes $\mathrm{HbSS}$ e $\mathrm{HbS} \beta 0$ com idade igual ou maior a 18 anos - variáveis numéricas . . . . . . . . . . . . . . . . . . . . . . . . . . 63

6.1 Características sociodemográficas de pacientes com e sem histórico de priapismo. . . 69

6.2 Tabela Kaplan-Meier com o tempo para ocorrência do primeiro episódio de priapismo 72

6.3 Genótipos de pacientes com e sem histórico de priapismo. . . . . . . . . . . . . . . 72

6.4 Idade de pacientes com e sem histórico de priapismo. . . . . . . . . . . . . . . . . 72

6.5 Características clínicas de pacientes com e sem histórico de priapismo. . . . . . . . . 73

6.6 Complicações clínicas de pacientes com e sem histórico de priapismo. . . . . . . . . . 73

6.7 Episódios de priapismo entre visitas . . . . . . . . . . . . . . . . . . . . . . . . . . . 74

6.8 SNPs associados com priapismo com significância no genoma inteiro (P-valor $<10^{-8}$ ) 76 


\section{Capítulo 1}

\section{Introdução}

\subsection{Motivação}

Grandes conjuntos de dados biológicos têm sido produzidos por meio do desenvolvimento de tecnologias ligadas às áreas de genômica e proteômica. Esses conjuntos abrangem dados provenientes de sequenciamento de genomas, expressão de genes e proteínas, mutações gênicas, estrutura de proteínas e RNAs, genômica comparativa, sistemas biológicos, análise de imagens e interação de proteínas.

Tais conjuntos de dados podem ser utilizados na solução de diversas perguntas biológicas, como a predição de estruturas de proteínas, predição de genes e suas funções, identificação de elementos regulatórios da expressão gênica, modelagem de sistemas, diagnóstico e tratamento de doenças, modelagem de interação de proteínas, elucidação de relações filogenéticas e etc. Com intuito de solucionar esses desafios, a bioinformática compreende o armazenamento, extração, organização, análise e interpretação desses dados, com objetivo de gerar conhecimento para a compreensão de processos, fenômenos ou sistemas biológicos.

No entanto, constantemente esses dados incluem informações complementares resultantes de complexos processos biológicos, provenientes de registros clínicos, genômicos e proteômicos, por exemplo, sendo originários de distintas fontes, e portanto, de natureza diversa. A integração e interpretação desse tipo de dados de conteúdo genotípico e fenotípico, com estrutura heterogênea é um importante desafio biológico. Frequentemente, os dados são de grande dimensionalidade, possuem imprecisões em sua definição ou aferição e ruídos. Portanto, demandam técnicas específicas de planejamento de estudos, integração de dados de naturezas distintas, sofisticadas análises computacionais, interpretação e sumarização de resultados.

A demanda de solução para tal tipo de desafio direciona, paralelamente à evolução da genômica e proteômica, o desenvolvimento de técnicas de manipulação de dados de grandes dimensões e escalas, além da integração de fontes extremamente heterogêneas de dados. Por conseguinte, ferramentas computacionais têm se tornado essenciais na transformação desses dados em informação e conhecimento.

Consequentemente, áreas como a de mineração de dados são conduzidas ao desenvolvimento de métodos eficientes e escaláveis que sejam capazes de tratar esses conjuntos de dados. Esses métodos têm como propósito a extração de informações e síntese de relações entre os dados, produzindo novas informações.

Na mineração de dados, os métodos de reconhecimento de padrões realizam investigações sobre 
tendências na estrutura dos dados e padrões latentes, organizando a informação de forma que seja compreensível e interpretável. Assim, algoritmos de reconhecimento de padrões na área de bioinformática são empregados na solução de diversas questões biológicas. Por exemplo, há estudos que utilizam esses algoritmos na análise de dados de microarranjos (Costa et al., 2007), espectrometria de massa (Sun e Markey, 2011) e experimentos de sequenciamento de nova geração (Ohler et al., 2002). Esses estudos têm como finalidade, por exemplo, a predição de genes (Korf, 2004), funções de genes (Qi et al., 2006), fenótipos (Yang et al., 2012), módulos regulatórios (Kelley et al., 2016), estrutura de proteínas (Agathocleous et al., 2010), função de proteínas (Juncker et al., 2009) e descoberta de interações moleculares (Mohamed et al., 2010).

$\mathrm{Na}$ solução dessas distintas questões são empregados variados algoritmos, como por exemplo, florestas aleatórias ( $\mathrm{Li}$ et al., 2015), redes neurais, (Xu et al., 2007), deep learning (Xu et al., 2014), modelo oculto de Markov (Ernst e Kellis, 2012), máquina de vetores de suporte (Verma e Melcher, 2012), K-médias (Gehlenborg et al., 2010; Li et al., 2016; Sturn et al., 2002), análise de componentes principais (Chen et al., 2010; Gehlenborg et al., 2010; Ma, 2007; Sturn et al., 2002) e etc. A escolha da técnica a ser aplicada aos dados é influenciada por fatores como o tipo dos dados, a forma como são gerados, sua natureza, suas características e o objetivo do estudo. Distintos conjuntos de dados com suas características particulares demandam diferentes processos de captura, tratamento, limpeza, processamento e, sobretudo, metodologias específicas de análise, interpretação, representação e sumarização de resultados.

Por conseguinte, o presente trabalho tem como objetivo a exploração de distintas abordagens de mineração de dados, contemplando suas premissas, particularidades e embasamentos teóricos, em grandes e heterogêneos conjuntos de dados, considerando seus contextos, atributos e propriedades, com o propósito de propiciar conhecimento exploratório, auxiliando na descrição e esclarecimento de processos biológicos.

De forma mais específica, o estudo apresentado nesta tese buscou empregar técnicas de mineração de dados na caracterização das relações entre atributos clínicos de pacientes com anemia falciforme. A exploração desse conjunto de dados auxiliará na elucidação dos padrões de ocorrência das diversas manifestações fenotípicas relacionadas à doença e suas relações e associações.

Adicionalmente, um estudo mais detalhado de uma das manifestações fenotípicas da anemia falciforme, o priapismo, foi realizado. Este estudo procurou caracterizar os pacientes que apresentaram tal complicação e os fatores de risco associados. Para tanto, foram analisadas características particulares do grupo de pacientes e foi realizado um estudo de associação genômica ampla, na busca de se definir genótipos associados a variações no risco do priapismo em pacientes com anemia falciforme.

\subsection{Objetivo}

Este trabalho tem como objetivo explorar técnicas de mineração de dados aplicadas a um diverso e complexo conjunto de dados biológicos para extração de informação e revelação da estrutura intrínseca dos dados. Para tanto, em um estudo de caso, são investigados os padrões de ocorrência de complicações decorrentes da anemia falciforme e seus fatores de risco. Os conjuntos de dados são provenientes de registros clínicos, entrevistas com pacientes, exames clínicos e sequenciamento de polimorfismos de nucleotídeo único (SNPs) em amplitude genômica. Tais dados são resultado de 
uma compilação de dados fenotípicos e genotípicos com complexas associações e interações. Possuem características específicas, demandando diferentes abordagens de análises na exploração e revelação da estrutura latente dos dados.

\subsection{Contribuições}

Propomos a aplicação de métodos de mineração de dados a um conjunto de dados de pacientes com anemia falciforme. Esse conjunto de dados de diversas fontes e naturezas, descreve o curso da doença nos pacientes de distintos perfis. Estão incluídos dados laboratoriais e de registros médicos de portadores de anemia falciforme em combinação com dados de sequenciamento de polimorfismos de nucleotídeo único. Também são investigados dados de fenótipos clínicos como síndrome torácica aguda, necrose avascular de osso, dores frequentes, priapismo e outros indicadores de gravidade na anemia falciforme e a possibilidade de suas associações a componentes genéticos.

Esse conjunto de dados deve ser capaz de auxiliar na análise para caracterização e elucidação dos motivos que levam a grandes variações na apresentação fenotípica da anemia falciforme. Essa análise é importante, visto que pacientes com anemia falciforme estão sujeitos a uma multiplicidade de complicações agudas e crônicas que ainda não se consegue prever. Além disso, essas complicações apresentam grande diversidade com relação às manifestações clínicas, padrões e gravidade (Makani et al., 2013).

O maior entendimento sobre os fatores envolvidos na variabilidade clínica da anemia falciforme é necessário para o aperfeiçoamento da estimativa de gravidade e do curso da doença, bem como do tratamento dos pacientes, tornando possível a tomada de decisões específicas para um dado paciente. Adicionalmente, contribui para o desenvolvimento de novos tratamentos, direcionando o desenvolvimento de terapias com alvo em fatores particulares para um dado fenótipo.

A análise do conjunto de dados é desafiadora considerando-se o volume de dados, que implica em dificuldades como a necessidade de seleção dos atributos dos dados mais informativos, não redundantes e relevantes. É também de grande importância a escolha de algoritmos escaláveis e eficientes, que sejam capazes de explorar a estrutura e extrair o conhecimento dos dados. Ainda, os grandes conjuntos de dados dificultam a interpretação, síntese e visualização da informação. Ademais, a heterogeneidade dos dados torna a seleção da medida de similaridade mais complexa, considerando-se a necessidade de avaliação dos dados, com exame de seus distintos aspectos e a necessidade de escolha de uma medida de comparação entre os dados adequada.

Tendo em vista tais dificuldades, este trabalho pretende responder a seguinte pergunta: "Quais técnicas de mineração de dados são as mais adequadas para a caracterização das relações entre fatores genotípicos e fenotípicos em pacientes de anemia falciforme?".

\subsection{Organização do Trabalho}

No capítulo 2 apresentamos os conceitos biológicos, descrevendo a anemia falciforme, seus aspectos principais e sua heterogeneidade fenotípica. Nesse capítulo também é descrito o priapismo, como uma das importantes manifestações fenotípicas da anemia falciforme e os conceitos básicos envolvidos em estudos de associação genômica ampla.

No capítulo 3 são expostos os conceitos computacionais envolvidos no desenvolvimento deste 
trabalho, com uma descrição geral do campo de mineração de dados e reconhecimento de padrões, bem como os algoritmos empregados.

No capítulo 4 é apresentada uma síntese dos trabalhos relacionados ao estudo da heterogeneidade na gravidade da anemia falciforme, ao priapismo na anemia falciforme, concluindo com uma síntese de suas contribuições.

No capítulo 5 é detalhada a análise de agrupamento de pacientes com anemia falciforme. Na seção 5.1 é delineado o progresso do coorte Brazil Sickle Cell Disease, com a obtenção de seu extenso banco de dados. Também é descrita a metodologia empregada no agrupamento de pacientes com anemia falciforme, bem como os dados utilizados. Nas seções 5.2 e 5.3 são descritos os resultados obtidos a partir da análise exploratória dos dados com algoritmos de agrupamento, dividindo os pacientes por genótipo e idade, assim como a caracterização dos grupos. Na seção 5.4 são discutidos os resultados da análise de agrupamento de pacientes com anemia falciforme.

No capítulo 6 é detalhada a análise de pacientes com anemia falciforme e histórico de priapismo. Na seção 6.1 é descrita a metodologia empregada na análise dos dados de paciente com priapismo, bem como os dados utilizados. Na seção 6.2 tem-se uma análise descritiva dos pacientes do sexo masculino que tiveram pelo menos um episódio de priapismo, caracterizando aspectos socioeconômicos, bem como clínicos dos pacientes. Ainda na seção 6.2 após a análise descritiva, são apresentados os resultados da análise de associação genômica ampla. Nos capítulos 6.3 são discutidos os resultados obtidos neste trabalho

Por fim, no capítulo 7 é apresentada a conclusão do trabalho e são sugeridos trabalhos de pesquisas futuras. 


\section{Capítulo 2}

\section{Fundamentos Biológicos}

\subsection{Anemia Falciforme}

A anemia falciforme (sickle cell disease, SCD) é uma doença sanguínea hereditária monogênica que acomete mais de 13 milhões de indivíduos globalmente (Piel et al., 2017; Weatherall, 2010), com o nascimento de 3.000 pessoas em média com a doença por ano no Brasil (de Atenção à Saúde et al., 2013). A prevalência dessa doença é mais alta em regiões da África subsaariana, bacia mediterrânea, oriente médio e Índia. A alta prevalência de anemia falciforme coincide com regiões de altas prevalências históricas de malária, uma vez que, na forma heterozigota, confere resistência a essa doença (Piel et al., 2010).

\section{Normal}

\section{Anemia Falciforme}

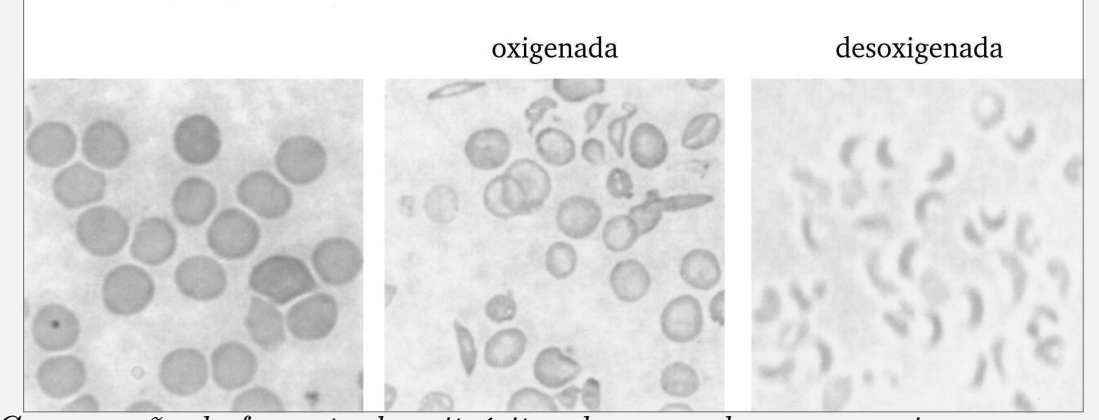

Figura 2.1: Comparação do formato de eritrócitos de camundongo normais e com anemia falciforme oxigenados e desoxigenados. Imagem de (Chang et al., 1998).

A anemia falciforme é causada por uma mutação no gene HBB (subunidade $\beta$ da hemoglobina) que suscita a produção de hemoglobinas $\mathrm{S}(\mathrm{HbS})$ ao invés de hemoglobinas $\mathrm{A}(\mathrm{HbA})$. A HbA é um tetrâmero com duas cadeias $\beta$ e duas $\alpha$ e a produção de HbS advém de uma substituição de valina por ácido glutâmico (de GAG para GTG) no códon 6 da subunidade $\beta$, constituindo uma cadeia $\left(\beta^{S}\right)$ (Strasser, 1999).

As mutações que levam à produção de hemoglobinas S podem estar presentes na forma heterozigota de $\mathrm{HbS}$ com $\mathrm{HbA}$, identificando indivíduos portadores; ou homozigota com HbS, variações menos frequentes como heterozigotos $\mathrm{HbS}$ e $\mathrm{HbC}, \mathrm{HbE}, \mathrm{HbD}$ ou talassemia, por exemplo, identifi- 
cando pacientes com anemia falciforme (Tabela 2.1). Pacientes homozigotos $\mathrm{HbS}$ ou heterozigotos com $\mathrm{HbS}$ e $\beta^{0}$ talassemia, chamados de $\mathrm{HbSS}$ e $\mathrm{HbS} / \beta^{0}$, respectivamente, geralmente possuem fenótipo moderadamente grave ou grave; heterozigotos com $\mathrm{HbS}$ e $\mathrm{HbC}$, chamados de $\mathrm{HbSC}$, geralmente possuem gravidade clínica intermediária; heterozigotos com $\mathrm{HbS}$ e talassemia $\beta^{+}$, chamados de $\mathrm{HbS} /$ talassemia $\beta^{+}$, geralmente possuem gravidade leve a moderada variando com grupo étnico; pacientes $\mathrm{HbS}$ com persistência hereditária de hemoglobina fetal ( $\mathrm{HbF}$, ou $\mathrm{Hb}$ fetal), chamados de S/HPHP, possuem fenótipo bastante leve ou sem sintomas e heterozigotos HbS e HbE são raros e geralmente possuem leves sintomas clínicos (Stuart e Nagel, 2004).

Tabela 2.1: Algumas das mutações no gene HBB que podem compor heterozigose com $H b S$

\begin{tabular}{cc} 
Genótipo & Mutação (HBB) \\
\hline HbS & Glu6Val \\
HbC & Glu6Lys \\
HbD & Glu121Gln \\
HbE & Glu26Lys \\
Hb Quebec-Chori & Thr87Ile \\
Hb K Woolwich & Lys132Gln
\end{tabular}

Assim, a polimerização das hemoglobinas $\mathrm{S}$ desoxigenadas caracteriza a doença, mediante a ligação da valina a sítios complementares adjacentes, ocasionando a perda de cátions e água no eritrócito. Esses polímeros se alinham, dando origem a eritrócitos de formatos irreversíveis com membranas danificadas, maior rigidez e perda de elasticidade (como na Figura 2.1), interferindo na flexibilidade da célula. Ademais, a reologia da célula é alterada, bem como a expressão de moléculas relacionadas à adesão celular (Piel et al., 2017). A polimerização é influenciada por fatores como o grau de oxigenação, concentração de HbS e HbF no eritrócito, pH e hidratação (Stuart e Nagel, 2004).

Com a polimerização, os repetidos danos na membrana e a perda de elasticidade conduzem à vaso-oclusão, hemólise e inflamação. A hemólise contribui significativamente para o desenvolvimento de anemia, vasculopatia, deficiência de óxido nítrico (NO) e inflamação (Kato et al., 2009). A vasooclusão ocorre por adesão inicial de reticulócitos e eritrócitos densos ao endotélio, posterior adesão de leucócitos e eritrócitos com formato irreversível (Kaul et al., 1989, 2000), ocasionando isquemia (fluxo sanguíneo inadequado) de tecidos e crises graves de dor. A inflamação é iniciada por sinais provocados por alterações nas membranas das hemácias, a hemólise, a hipóxia e os danos de isquemia e reperfusão (Costa e Conran, 2016). A inflamação induz o recrutamento de leucócitos, processos vaso-oclusivos e outras complicações, resultando em um estado de inflação crônica (Costa e Conran, 2016) que, por usa vez, promove danos crônicos aos órgãos.

$\mathrm{Na}$ anemia falciforme praticamente quaisquer órgãos e tecidos do corpo ficam susceptíveis a complicações, provocando sintomas como crises recorrentes de dor aguda e síndrome torácica aguda (Bender e Seibel, 2014). Essa condição também propicia acidentes vasculares cerebrais, anemia hemolítica (Roseff, 2008), complicações cardíacas, gastrointestinais, hepatobiliares, musculares, esqueléticas, dermatológicas, neurológicas, oftalmológicas, pulmonares, renais, hepáticas, distúrbios no crescimento e desenvolvimento de síndromes de dor (Ballas et al., 2010). Como consequência dos episódios de vaso oclusão e hemólise, ocorrem processos como disfunção endotelial, deficiência de NO, inflamação, stress oxidativo, lesões de reperfusão, hipercoagulabilidade, maior adesividade de neutrófilos e ativação de plaquetas (Piel et al., 2017). 
A anemia falciforme, por conseguinte, inclui complicações de diferentes naturezas, como vasooclusão, hemólise, disfunção endotelial e inflamação (Kato et al., 2017). Postula-se que pacientes com anemia falciforme possam ser classificados em indivíduos com maior ocorrência de hemólise ou maior ocorrência de episódios de vaso-oclusão.

A maior ocorrência de hemólise estaria relacionada a doenças como auto-esplenectomia, hipertensão pulmonar, trombose pulmonar, vasculopatia, priapismo, úlcera nas pernas, acidente vascular, cerebral e disfunção renal (Kato et al., 2007). A vaso-oclusão e viscosidade sanguínea, estariam relacionados a osteonecrose, síndrome torácica aguda e episódios de dor (Kato et al., 2007).

Desta forma, pacientes com anemia falciforme estão sujeitos a uma vasta variedade de complicações agudas e crônicas, que podem estar relacionadas a distintos aspectos da doença. Apesar da tentativa de classificar os pacientes de acordo com a natureza das complicações, tais complicações se apresentam em ampla diversidade com relação às manifestações clínicas, padrões e gravidades (Makani et al., 2013). Essa diversidade ainda não é completamente compreendida e não é possível prever o curso da doença para um dado paciente. Mesmo quando se considera apenas um dos diversos genótipos, não há uniformidade nas manifestações fenotípicas da doença em diferentes pacientes.

São assim possíveis distintos resultados clínicos, ocorrendo casos de óbito na infância, recorrentes crises de dor vaso oclusivas, múltiplos problemas em órgãos e até relativo bem-estar em idades mais avançadas (Chui e Dover, 2001). Essa diversidade é observada mesmo levando-se em consideração diferentes sexo, gênero, e diversidades ambientais e socioeconômicas, como fatores climáticos, de qualidade de ar, altitude, por exemplo. Além de diferenças entre pessoas, também ocorrem variações da manifestação da doença em um mesmo paciente ao longo dos anos (Ballas et al., 2012). Essa amplitude de possibilidades para o curso da doença, dificulta a previsão do desenrolar das manifestações dos sintomas e complicações, bem como decisões de tratamento e aconselhamento de pacientes.

Somando-se à variação das manifestações clínicas, também se verifica variação na gravidade das complicações dos pacientes. A gravidade varia, por exemplo, com o genótipo da anemia falciforme, sendo que indivíduos homozigotos para $\mathrm{HbS}$, em geral, apresentam maior gravidade, pacientes portadores homozigotos ou heterozigotos para $\alpha$-talassemia são menos graves e pacientes heterozigotos HbS e HbC são os menos graves (Kato et al., 2007). No entanto, a complexidade dessa heterogeneidade não é completamente explicada pelos distintos heterozigotos $\mathrm{HbS}$ e $\mathrm{HbC}$, HbE, HbD ou pela talassemia (Habara e Steinberg, 2016) e outras variações genéticas, chamados genes pleiotrópicos ou de fatores secundários, que afetam a ocorrência de manifestações clínicas da doença. Por exemplo, fatores genéticos relacionados à velocidade de destruição das células deformadas, formação de células densas e adesão ao endotélio alteram o curso da doença (Stuart e Nagel, 2004). Tais fatores ainda não são completamente compreendidos e, portanto, estudos de associações entre genótipos e fenótipos são necessários para que essas variações sejam identificadas.

O entendimento da variabilidade clínica da anemia falciforme e os fatores que a influenciam se faz necessário no aperfeiçoamento da estimativa de gravidade e do curso da doença, bem como do tratamento dos pacientes, tornando possível a tomada de decisões específicas para um dado paciente. Adicionalmente, auxilia no desenvolvimento de novos tratamentos, direcionando o desenvolvimento de terapias com alvo em fatores particulares para um dado fenótipo. 


\subsection{Priapismo}

O priapismo é definido como uma indesejada, prolongada e dolorosa ereção, podendo causar complicações como necrose do tecido, fibrose, disfunção erétil e impotência (El-Bahnasawy et al., 2002; Spycher e Hauri, 1986). Pode ser gago, ou recorrente, definido como episódios repetidos intercalados a períodos de detumescência (Montague et al., 2003) ou major, tendo durações maiores do que 6 horas.

O priapismo é uma complicação comum em pacientes do sexo masculino com anemia falciforme. Acredita-se que sua taxa de prevalência seja de 30 a $45 \%$ em pacientes com genótipo HbSS (Adeyoju et al., 2002; Bruno et al., 2001; Emond et al., 1980; Fowler Jr et al., 1991), dos quais aproximadamente $30 \%$ resulta em disfunção erétil (Adeyoju et al., 2002).

O priapismo é classificado em low-flow ou high-flow. No priapismo low-flow há oclusão de efluxo venoso, gerando isquemia, baixa oxigenação nos corpos cavernosos e dor (Montague et al., 2003). Já o priapismo high-flow é mais frequentemente relacionado a traumas e danos arteriais, não ocorrendo isquemia. Assim, em pacientes com anemia falciforme, é mais comum o tipo low-flow (Broderick, 2012), que se postula ser causado pela deformação da hemácia dentro dos sinusoides dos corpos cavernosos do pênis durante a ereção resultando em estase venosa. Desta forma, ocorreria hipóxia e acidose, que levariam a maior deformação dos eritrócitos, além de resposta inflamatória que possivelmente levaria à fibrose e impotência (Diggs, 1965).

Dentre os pacientes com anemia falciforme que sofrem de priapismo, $75 \%$ têm o primeiro episódio antes dos 20 anos de idade (Adeyoju et al., 2002). Não há completo consenso quanto ao tratamento dessa complicação, havendo controvérsias, sendo possíveis abordagens para o tratamento a hidratação, analgesia, anestesia, o uso de tranquilizantes leves, estrogênio, transfusões de sangue, sedação, antagonistas muscarínicos, antifibrinolíticos, vasodilatadores, anticoagulantes, modificadores de HbF e procedimentos cirúrgicos (Adeyoju et al., 2002; Baron e Leiter, 1978). Em casos mais extremos recorre-se a cirurgia, que frequentemente causa impotência.

Inicialmente, o priapismo foi então associado à ocorrência de oclusão vascular e isquemia, como consequência do efluxo diminuído de sangue dos corpos cavernosos (Burnett, 2003; Kimmelsteil, 1948). Postulava-se que o efluxo reduzido se dava pela interação dos eritrócitos disformes com células endoteliais, leucócitos, plaquetas e outros componentes do plasma, resultando em obstrução vascular. A isquemia leva à necrose e à apoptose do tecido endotelial e muscular (Spycher e Hauri, 1986) e a anóxia e acidose causam a incapacidade de contração muscular por meio de estímulos $\alpha$-adrenérgicos (Broderick et al., 1994; De Tejada et al., 1997; Muneer et al., 2005). Ademais, a hipóxia e o stress oxidativo induzem fatores de crescimento como fator de transformação do crescimento $\beta$ (TGF- $\beta$ ), um fator de crescimento que foi associado a inflamação em tecidos, aumento de colágeno e fibrose em animais (Ul-hasan et al., 1998).

No entanto, estudos mais recentes também têm associado o priapismo em pacientes com anemia falciforme com perturbações na via de transdução de sinal do óxido nítrico (NO), que possui grande importância nas vias mediadoras da ereção (Champion et al., 2005). A hemólise estaria então envolvida, uma vez que compromete a disponibilidade de NO pelas vias metabólicas de NO, guanosina monofosfato cíclica (cGMP) e fosfodiesterase 5 (PDE5) (Figura 2.2). Adicionalmente, NO reduz a inflamação e aderência celular promovendo dilatação dos vasos (De Caterina et al., 1995) por meio da ativação da via cGMP, que é inativada pela PDE5 (Corbin e Francis, 1999). Ainda, o 


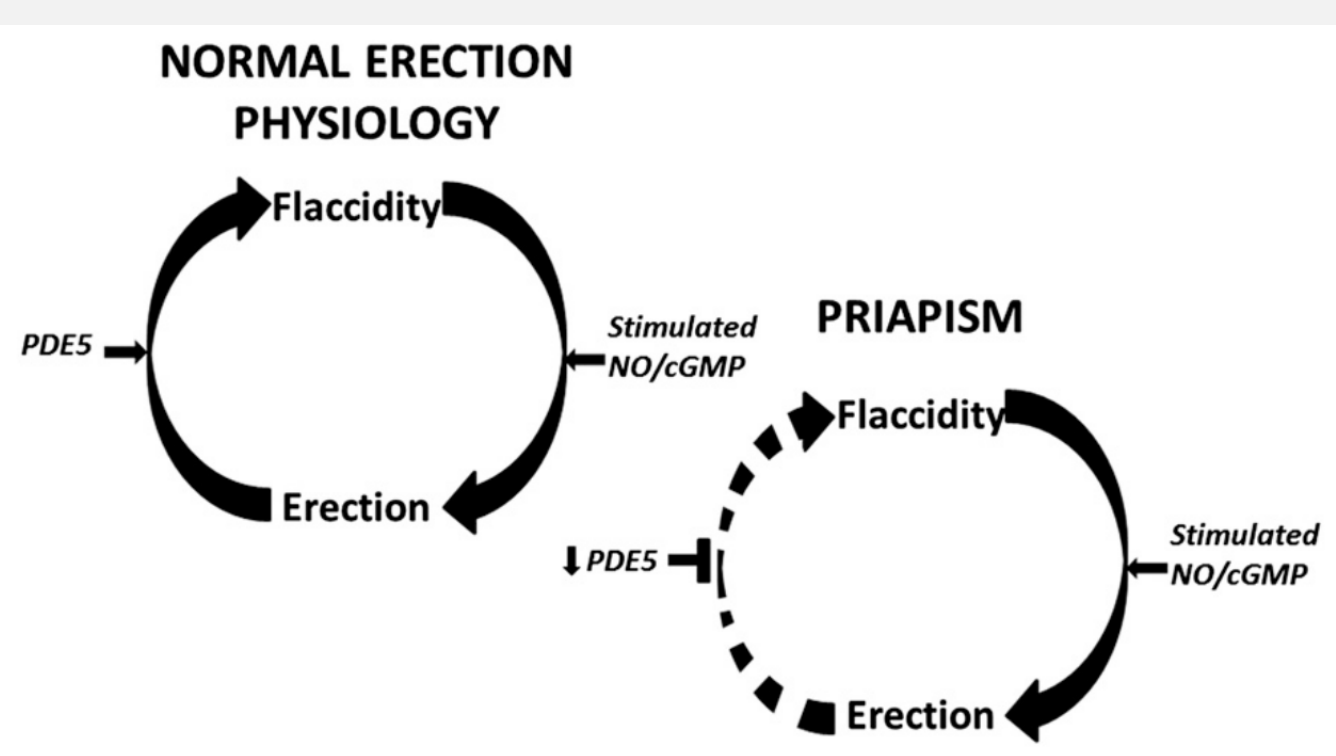

Figura 2.2: Figura de Anele et al. (2015) representando a relação entre as vias de cGMP e PDE5 com a biodisponibilidade de NO, hemólise e priapismo. A via superior mostra uma ereção normal e a via inferior a ocorrência de priapismo. Na via superior, a PDE5 hidrolisa a cGMP, levando ao estado de flacidez. Na via inferior, o baixo nível de PDE5 leva ao priapismo.

priapismo estaria associado ao excesso de adenosina, RhoA/Rho-kinase (ROCK) e regulação de opiorfina (Bivalacqua et al., 2004, 2012; Chitaley et al., 2001a; Claudino et al., 2009; Fu et al., 2014; Hurt et al., 2002; Kanika et al., 2009; Mi et al., 2008; Ning et al., 2014; Wang et al., 2002).

Estudos posteriores investigaram a associação de polimorfismos de nucleotídeo único em genes candidatos ao risco de priapismo em pacientes com anemia falciforme. Foram encontradas associações entre priapismo e o gene klotho $(\mathrm{KL})$, associado à funções vasculares e à via do NO (Nolan et al., 2005a); o transforming growth factor- $\beta$ receptor type III (TGFBR3), relacionado às vias inflamatórias; o aquaporin (AQP1) envolvido na hidratação; o integrin $\alpha v$ (ITGAV), que codifica um receptor relacionado à adesão celular em reticulócitos e a subunidade A1 do fator de coagulação XIII (F13A1) que possui importante papel no sistema de coagulação.

Embora associações tenham sido encontradas previamente, apenas estudo com genes candidatos foram realizados, sem validação desses resultados e com reduzido espectro de polimorfismos investigados. Assim, os mecanismos biológicos que resultam no priapismo ainda não são completamente compreendidos, bem como todos os fatores genéticos que modificam os riscos de priapismo ou os melhores tratamentos. Portanto, a realização de estudos de associação genômica ampla (GWASs) com amplitude genômica e a identificação de componentes genéticos que alterem os riscos da ocorrência de priapismo podem auxiliar na elucidação dos processos patológicos e nas vias metabólicas relacionadas a essa complicação, bem como validar resultados prévios.

\subsection{Genome Wide Association Study (GWAS)}

Na exploração de relações genótipo-fenótipo, estudos de associação genômica ampla (Genome Wide Association Study, ou GWAS) testam a associação estatística por meio da observação de 
diferenças nas frequências de variações genômicas ao longo de todo genoma em, por exemplo, grupos de não portadores e portadores de doenças provenientes de uma mesma população. A amplitude genômica desta análise remove o viés com relação às funções e vias metabólicas, característica intrínseca a análises de genes candidatos, em que as regiões estudadas são selecionadas de acordo com conhecimento prévio.

Variações genéticas presentes em grupo de portadores de um traço podem indicar sítios genômicos que codificam genes implicados no traço, na regulação da expressão de tais genes ou regiões em desequilíbrio de ligação (linkage disequilibrium, $L D$, quando alelos em diferentes loci estão correlacionados) com sequências envolvidas com o fenótipo. Assim, a associação de uma variação com um fenótipo pode ser direta, com o genótipo que influencia o fenótipo, chamado de SNP funcional, sendo diretamente genotipado, ou indireta, em que uma variação estatisticamente relacionada ao fenótipo é genotipada, chamada SNP tag, uma vez que funciona como uma etiqueta para a região próxima em LD (Bush e Moore, 2012).

No entanto, mais comumente, doenças têm padrões bastante complexos de herdabilidade, ou seja, a quantidade de variância fenotípica que pode ser explicada por fatores genéticos. A herdabilidade de uma doença frequentemente envolve um grande número de loci cromossomais e variantes que influenciam na susceptibilidade à doença. A descoberta dessas variações contribui para a elucidação dos mecanismos biológicos de doenças funcionando como um passo inicial para análises adicionais que revelem seus processos genéticos.

Assim, em GWAS um vasto conjunto de marcadores genéticos são genotipados ao longo do genoma. Esses marcadores têm sua associação a uma enfermidade, por exemplo, testada, baseandose na premissa de que variações comuns sejam responsáveis pelo risco de doenças complexas. O objetivo de tal estudo é encontrar fatores genéticos de baixa penetrância, ou seja, com pequenos efeitos, que quando somados alteram a probabilidade de que um fenótipo se manifeste, elevando o risco ou conferindo proteção a uma doença. Assim, busca-se melhor compreender os fatores genéticos que alteram os riscos da ocorrência de doenças geneticamente complexas e não mendelianas.

Uma forma de variação genética frequentemente investigada em GWAS é o SNP, a variação mais comum no genoma humano. SNPs são alterações de bases únicas que ocorrem em aproximadamente uma a cada mil bases (Wang et al., 1998), totalizando um número aproximado de 10.000.000 de SNPs no genoma humano (Kruglyak e Nickerson, 2001). Os SNPs são variantes em posições específicas do genoma que podem contribuir para a predisposição de um fenótipo, comumente ocorrendo na forma de dois alelos, sendo genotipados e medidos com base na frequência do alelo mais raro na população, ou minor allele frequency (MAF) (Bush e Moore, 2012). SNPs podem afetar regiões de controle de transcrição de proteínas, de splicing de RNA ou a estabilidade do transcrito de mRNA, ocasionando alterações na expressão de um gene. Adicionalmente, SNPs podem afetar a sequência de uma proteína, ocasionando consequências funcionais.

Com intuito de elucidar as relações entre variações genéticas e fenótipos, estudos de associação genética procuram por genótipos que ocorram concomitantemente com um fenótipo em maior frequência do que esperado ao acaso. Procura-se encontrar padrões de polimorfismos variáveis em indivíduos que estejam associados a fenótipos (Balding, 2006). A associação de uma região genômica com um fenótipo indica que o polimorfismo influencia na ocorrência do fenótipo, tendo uma função na incidência da doença ou sendo um traço quantitativo que altera o risco da doença, ou o polimorfismo está em desequilíbrio de ligação com o polimorfismo influenciando a doença. O objetivo 
desses estudos é identificar genes ou regiões genômicas que influenciem na ocorrência do fenótipo e que sejam seus componentes herdáveis.

Na aplicação de GWAS é necessário considerar alguns fatores que possam gerar relações espúrias. A estratificação de população, por exemplo, implica na existência de grupos genéticos na população de estudo. Estes grupos apresentarão diferentes frequências alélicas, decorrentes da diferença entre as populações fundadoras que os compõem, representando indivíduos com distintas histórias evolutivas e diferentes históricos genéticos. Neste caso, se os grupos de indivíduos com e sem a doença não apresentarem a mesma distribuição de grupos genéticos, ou caso a população de estudo não tenha se reproduzido aleatoriamente por diversas gerações, um SNP associado a um grupo genético, pode ser erroneamente associado ao traço (Pericak-Vance, 1998).

Para evitar os efeitos da estratificação de população, os indivíduos a serem comparados devem pertencer a uma mesma população. No entanto, uma subestrutura genética sútil ainda pode ocorrer e gerar associações espúrias. Assim, para detectar diferenças de ancestralidade, pode-se empregar a análise de componentes principais (Price et al., 2006). Nesta análise, as observações são os indivíduos e as variáveis os SNPs. Os componentes principais calculados podem então ser utilizados como covariantes para correção da estratificação de população.

Em GWAS também é necessário considerar a covariância desconhecida ou ignorada entre indivíduos causadas por parentesco, ou parentescos crípticos. O parentesco críptico representa um fator de confusão na análise de associação, inflando a taxa de falsos positivos. Parentescos ou amostras replicadas também podem introduzir viés em GWAS, uma vez que geram representações exageradas de genótipos, fazendo com que as frequências alélicas da amostra não representem mais as da população. As relações de parentesco ou duplicações são verificadas com a medida de identidade por estado (identity by state, IBS), que calcula a proporção média de alelos compartilhados (Anderson et al., 2010). Além do cálculo da IBS, é utilizado o cálculo da identidade por descendência (identity by descent, IBD), que estima o grau de ancestralidade recente compartilhada (Anderson et al., 2010).

Um fator que também pode introduzir viés nos GWAS são os marcadores que apresentem grandes desvios do equilíbrio de Hardy-Weinberg (HWE). O HWE torna possível a estimativa de alelos e genótipos ao longo das gerações. Marcadores que desviem do HWE podem ser resultado de erros no processo de genotipagem (Anderson et al., 2010), e por este motivo, são removidos da análise.

Finalmente, para que esse modelo de estudo seja capaz de detectar associações significativas é necessário que se tenha amostras grandes o suficiente com populações representativas, para que se tenha uma avaliação robusta da evidência de associação. Também é necessário que se tenha alelos polimórficos que representem uma boa cobertura da extensão completa do genoma e métodos analíticos com bom poder estatístico (Cantor et al., 2010). Adicionalmente, podem interferir nos resultados erros de genotipagem e erros na definição clara de fenótipos bem definidos.

GWAS são, portanto, capazes de realizar buscas ao longo de todo genoma, conseguindo atingir o objetivo de identificar variações que comumente ocorram em uma população e que estejam associadas a um traço (Bush e Moore, 2012). GWAS tem sido aplicado com intuito de se identificar variantes genéticos comuns que apontem predisposições a dados fenótipos. A descoberta dessas variações contribui para a elucidação dos mecanismos biológicos de doenças, por exemplo, funcionando como um passo inicial para análises adicionais que revelem seus processos genéticos.

GWASs já foram empregados no estudo de diversas doenças, como degeneração macular 
(Maller et al., 2006), doença de Crohn (Barrett et al., 2008), diabetes tipo 1 (Barrett et al., 2009; Todd et al., 2007) e tipo 2 (Sladek et al., 2007; Zeggini et al., 2007), câncer de próstata (Gudmundsson et al., 2007; Yeager et al., 2007) e câncer de mama (Easton et al., 2007; Hunter et al., 2007), entre outros, revelando associações genéticas com traços complexos. Logo, a realização de um GWAS pode auxiliar na identificação de modificadores genéticos ligados à anemia falciforme e às complicações decorrentes da enfermidade, provendo esclarecimento de suas bases genéticas e fornecendo uma melhor compreensão sobre os mecanismos da doença. 


\section{Capítulo 3}

\section{Fundamentos Computacionais}

\subsection{Reconhecimento de Padrões}

Com a rápida evolução da tecnologia proporcionando uma vasta capacidade de produção e armazenamento de extensos conjuntos de dados, ferramentas computacionais têm se tornado essenciais na extração e transformação de volumosos dados brutos em conhecimento. Essas ferramentas são necessárias para o processamento, análise, interpretação e sumarização de grandes volumes de dados, revelando estruturas intrínsecas.

No entanto, o grande volume de dados traz novos desafios para as metodologias de análises computacionais. Além da dificuldade da manipulação do grande volume de dados, que requer grandes capacidades de processamento, frequentemente é necessário tratar dados provenientes de distintas fontes, apresentando representações e naturezas diversas. Assim, novas tecnologias que geram novos e extensos conjuntos de dados, impulsionam e estimulam o desenvolvimento de novas e aperfeiçoamento de antigas técnicas computacionais.

A área de reconhecimento de padrões é um exemplo desse estímulo, se tornando cada vez mais popular em diversas áreas, inclusive na aplicação de análises de dados biológicos. Algoritmos de reconhecimento de padrões extraem informações, sintetizando suas relações e gerando conhecimento, abrangendo processos que transformam dados brutos em informações com aplicações práticas. O reconhecimento de padrões é uma abordagem que visa a organização e agrupamento dos dados, viabilizando o entendimento e aprendizado e realizando abordagens exploratórias sugerindo direções para novas descobertas.

Para alcançar seus objetivos, métodos de reconhecimento de padrões nos dados requerem representações simples, compactas e representativas. É necessário que sejam considerados os atributos mais descritivos, discriminatórios, informativos e que facilitem a geração e compreensão da informação (Jain et al., 1999). Uma representação frequentemente empregada em diversas abordagens de reconhecimento de padrões descreve os dados de acordo com um vetor contendo suas características, medidas ou atributos. Uma instância dos dados, chamada de vetor de características ou padrão, pode ser representado como um vetor $x_{i}$ :

$$
x_{i}=\left(x_{i 1}, x_{i 2}, \ldots, x_{i m}\right)
$$


sendo que $i$ representa o i-ésimo dado no conjunto de dados e $m$ é o número total de características, ou a dimensionalidade do vetor.

Essa forma de representação possibilita o emprego de métodos de cálculo de similaridade entre os dados que, conjuntamente com a metodologia dos algoritmos de reconhecimento de padrões, permitem a sugestão de hipóteses sobre seus relacionamentos. A escolha de métodos de comparação, ou medidas de similaridades, entre os dados abrange uma ampla variedade de possibilidades e geralmente envolve subjetividade e escolhas como a natureza (discreta, contínua ou binária), escala (nominal, ordinal ou intervalar) e outras características (Johnson e Wichern, 1982). A comparação entre os vetores permite delinear propriedades em comum, que são capazes de organizar e agrupar os dados. A escolha da medida de similaridade influencia na disposição dos dados e, consequentemente, pode influenciar na elucidação de seu relacionamento.

Além da grande diversidade de medidas de similaridades existentes, há ainda uma ampla gama de abordagens que podem ser aplicadas na solução de desafios relacionados ao reconhecimento de padrões. Cada abordagem possui suas características, capacidades e finalidades, sendo mais adequados a determinados conjuntos e tipos de dados, requerendo e se limitando a diversos tamanhos de conjuntos de dados. A escolha da abordagem mais adequada a ser empregada dependerá das características, especificidades, suposições a priori e conhecimento prévio sobre os dados.

\subsection{Análise de Componentes Principais e Métodos Derivados}

\subsubsection{Análise de Componentes Principais (PCA)}

A Análise de Componentes Principais (PCA) (Jolliffe, 1986) é uma técnica usada no reconhecimento de padrões que extrai características de dados com extensas quantidades de variáveis. PCA transforma variáveis correlacionadas em um menor número de variáveis não correlacionadas que expliquem a maior parte possível da variação dos dados. Portanto, o número de atributos é reduzido, contudo, de forma a minimizar a perda de informação e criando atributos informativos e não redundantes a partir dos originais.

Em consequência, a PCA é capaz de sintetizar o conjunto de dados, gerando variáveis não correlacionadas, chamados de componentes principais, que coletivamente expliquem a maior parte da variabilidade. Frequentemente é usada para redução de dimensão, compressão de dados, extração de características e visualização de dados (Jolliffe, 2002).

Em PCA, também chamado de transformação Karhunen-Loéve, a dimensionalidade dos dados é reduzida por meio de uma projeção ortogonal em um espaço linear de menor dimensão, maximizando a variância (Hotelling, 1933). Se trata de uma projeção linear que maximiza a distância média quadrática entre pontos e projeções (Person, 1901).

O algoritmo de Análise de Componentes Principais assume linearidade, ou seja, que a média e a variância sejam suficientes para descrever a distribuição de probabilidade; que as maiores variâncias sejam mais importantes para a representação dos dados e que os componentes principais sejam ortogonais. Considerando-se essas suposições, a busca pelos componentes principais é reduzida à busca de autovalores e autovetores (Jolliffe e Cadima, 2016).

Dada uma matriz de dados $m \times n$ : 


$$
X=\left[x_{1}, x_{2}, \ldots, x_{m}\right]^{T},
$$

sendo $m$ o número de atributos dos dados e $n$ o número de dados, a PCA pode ser definida como a busca pelo mapeamento linear:

$$
Y=P X,
$$

sendo $P$ uma matriz ortonormal $m \times m$ cujas linhas são a nova base dos vetores para expressar $X$ e que as variáveis $Y$ não são correlacionadas e estão em ordem decrescente com relação à variância.

Uma boa escolha de $P$ engloba a minimização de erro e redundância, que implicam no cálculo da matriz de covariância. Para qualquer $P$ ortogonal, a matriz covariância para $Y, S_{Y}$, é dada por:

$$
\begin{aligned}
S_{Y} & =\frac{1}{n-1} Y Y^{T} \\
& =\frac{1}{n-1}(P X)(P X)^{T} \\
& =\frac{1}{n-1} P X X^{T} P^{T} \\
& =\frac{1}{n-1} P\left(X X^{T}\right) P^{T} \\
S_{Y} & =\frac{1}{n-1} P A P^{T}
\end{aligned}
$$

Sendo $A=X X^{T}$, simétrica, pode ser escrita como:

$$
A=E D E^{T},
$$

em que $D$ é uma matriz diagonal e $E$ uma matriz de autovetores de $A$ organizados como colunas. Assim, se for $D$ uma matriz diagonal com os autovalores $\lambda_{1}, \ldots, \lambda_{m}$ de $A$ na diagonal tal que $\lambda_{1} \geq \lambda_{2} \geq \ldots \geq \lambda_{m} \geq 0$ e $P$ uma matriz ortogonal cujas colunas são os autovetores correspondentes $u_{1}, \ldots, u_{m}$. Então:

$$
P=E^{T} \text { e } A=P^{T} D P .
$$

Uma vez que a inversa de uma matriz ortonormal é a sua transposta, $P^{-1}=P^{T}$ e: 


$$
\begin{aligned}
S_{Y} & =\frac{1}{n-1} P A P^{T} \\
& =\frac{1}{n-1} P\left(P^{T} D P\right) P^{T} \\
& =\frac{1}{n-1}\left(P P^{T}\right) D\left(P P^{T}\right) \\
& =\frac{1}{n-1}\left(P P^{-1}\right) D\left(P P^{-1}\right) \\
S_{Y} & =\frac{1}{n-1} D
\end{aligned}
$$

a escolha de $P$ diagonaliza $S_{Y}$ e o i-ésimo valor da diagonal de $S_{Y}$ contém a variância de $X$ ao longo da $i^{- \text {sima }}$ coluna de $P$. Por consequência, as linhas de $P$ serão os componentes principais de $X$.

Assim, o algoritmo geral para PCA é dado por (Duda et al., 2012):

1. Organize os padrões em uma matriz $X_{m \times n}$, sendo $m$ o número de atributos dos dados e $n$ o número de dados

2. Calcule a média para cada atributo

3. Subtraia a média de cada respectivo atributo dos valores na matriz

4. Calcule a matriz covariância $\frac{1}{n-1} X X^{T}$

5. Calcule os autovetores da covariância

6. Selecione os autovetores com maiores autovalores

Quando não há muito conhecimento prévio sobre os dados, a análise de componentes principais possui a vantagem de ser um método não paramétrico para extração de informação relevante. Já foi previamente aplicada em diversos domínios, por exemplo, na análise de dados relacionados a pacientes com Alzheimer (Merhof et al., 2011), estudos de genoma (Price et al., 2006), expressão gênica (Lu et al., 2011), desenvolvimento de drogas (Steindl et al., 2005) e reconhecimento de faces (Zhou et al., 2013). No entanto, uma limitação dessa técnica é a impossibilidade de aplicação em casos em que os dados incluem variáveis não numéricas, pois não é possível calcular a média e variância necessárias para a descrição da distribuição de probabilidade.

\subsubsection{Análise de Correspondência Múltipla (MCA)}

A Análise de Correspondência Múltipla foi descrita múltiplas vezes (Burt, 1950; Fisher, 1940; Guttman, 1941; Hayashi, 1951) e por isso possui uma variedade de diferentes nomes como optimal scaling, optimal ou appropriate scoring, dual scaling, análise de homogeneidade, scalogram analysis e método de quantificação. Por esse motivo, também há diversas abordagens para execução da análise de MCA, mas que se convertem em resultados equivalentes (Tenenhaus e Young, 1985).

MCA é uma abordagem exploratória de redução de dimensão dos dados, aplicada quando os dados são representados por variáveis categóricas. MCA utiliza uma representação de variáveis categóricas em espaços multidimensionais de forma a explorar suas relações. MCA não possui nenhuma condição com relação à distribuição dos dados (Di Franco, 2016) e por isso possui grande 
abrangência em sua aplicabilidade.

MCA visa resumir a relação entre múltiplas variáveis categóricas, reduzindo grandes números de variáveis pela construção de novas. Desta forma, MCA é comparada à PCA, mas com a distinção de ser apropriada para a análise de variáveis categóricas e não numéricas. Assim, como em PCA, MCA compõem novas variáveis, chamadas de fatores, de forma análoga aos componentes principais em PCA, maximizando a inércia, uma medida de dispersão baseada no $\chi^{2}$, sendo equivalente à variância em PCA. Além da semelhança ao PCA, MCA é uma extensão de Análise Correspondência (CA), que emprega o mesmo procedimento utilizado em MCA, contudo, considerando apenas duas variáveis categóricas, ao invés de múltiplas. Para tanto, as instâncias são representadas como pontos no espaço e considera-se que pontos próximos possuem categorias similares (Greenacre e Hastie, 1987).

Em MCA calcula-se uma matriz indicadora, também chamada de tabela disjuntiva completa, construída com a codificação binária das categorias de cada variável. Assim, na matriz indicadora $G_{n \times m}, n$ é o número de instâncias e $m$ a soma do número de categorias de todas variáveis. Uma instância dos dados é representada como uma linha da matriz, e cada coluna da matriz representa uma das variáveis categóricas, sendo que cada categoria que a variável pode assumir corresponde a uma coluna.

A matriz indicadora recebe pesos:

$$
Z=(n+m)^{-1} G
$$

sendo N o grand total da tabela $G$. Dessa tabela, são obtidos os perfis, sendo um perfil uma linha ou coluna expressa em relação ao total de seus elementos. Assim, é calculada a Decomposição em Valores Singulares (SVD) de:

$$
D_{r}^{-\frac{1}{2}}\left(Z-r c^{t}\right) D_{c}^{-\frac{1}{2}}=\left(\frac{1}{n^{\frac{1}{2}} m}\right)\left(G-m 1 c^{T}\right) D_{c} \frac{-1}{2},
$$

sendo $r=P 1$ a média do perfil de coluna (ou a massa de linha), com elementos iguais às frequências marginais divididas por

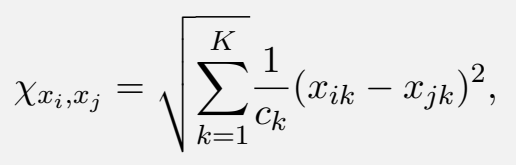

sendo $x_{i}$ e $x_{j}$ duas instâncias, e $c_{j}$ a média do elemento j. Assim, a distância qui-quadrado é calculada com base em contagens relativas e padronizada com base na média e não variância. As distâncias qui-quadrado são então utilizadas para geração dos fatores ortogonais.

A partir do espaço gerado pelos fatores ortogonais é possível projetar as observações e visualizar suas relações, bem como das variáveis e suas relações. Também é possível verificar as contribuições das variáveis e suas categorias para a formação dos fatores, ou seja, observar quais categorias 
contribuem com maior importância para a variação dos dados.

MCA já foi utilizado em análises de dados biológicos como a classificação da progressão de doenças renais (Shi et al., 2017), investigação da relação entre nutrição e resultados clínicos em pacientes com neoplasia (LEANDRO-MERHI e AQUINO, 2017), associação entre malária e fatores socioeconômicos, geográficos e demográficos (Ayele et al., 2014).

\subsubsection{Análise de Componentes Principais de Variáveis Misturadas Numéricas e Categóricas (PCAMix)}

PCA e MCA são técnicas que visam reduzir a dimensionalidade dos dados, sendo aplicadas em análises exploratórias de dados, com o intuito de sintetizar informação. No entanto, PCA somente pode ser empregada em análises envolvendo variáveis numéricas e MCA em análises envolvendo variáveis categóricas.

Em casos em que se tem dados de diferentes tipos, ou mixed data, uma possível alternativa é a Principal Component Analysis of Mixed Data (PCAMix). A PCAMix é capaz de reduzir dimensões em circunstâncias em que os atributos dos dados abrangem tipos numéricos e categóricos, combinando, como casos especiais, a PCA em que se tem apenas variáveis numéricas, e a MCA em que se tem apenas variáveis categóricas.

Na abordagem de PCAMix implementada em (Chavent et al., 2014) é utilizada a Generalized Singular Value Decomposition na matriz de dados pré-processada. Assim, seja $n$ o número de observações, $p_{1}$ de variáveis numéricas, $p_{2}$ de variáveis categóricas e $m$ o número total de categorias considerando-se todas as variáveis categóricas, dá-se a matriz de dados:

$$
Z=\left[Z_{1}, Z_{2}\right]
$$

composta pela concatenação das matrizes $Z_{1}$ e $Z_{2}$, sendo $Z_{1}$ a matriz $n \times p_{1}$ composta pelas $p_{1}$ variáveis numéricas normalizadas e $Z_{2}$ a matriz composta pelas centralização da matriz indicadora $G$, como na análise de MCA, gerada a partir das $p_{2}$ variáveis categóricas. Assim, tem-se as matrizes diagonais de pesos $N$ tal que

$$
N=\frac{1}{n} \mathbb{I}_{n}
$$

e $M$ tal que as primeiras $p_{1}$ colunas têm peso 1 e as $m$ seguintes $\frac{n}{n_{s}}$, sendo $s=1, \ldots, m$ e $n_{s}$ é dado pelo número de observações com a $s$-ésima categoria.

A partir da matriz Z, a Generalized Singular Value Decomposition (GSVD) é calculada:

$$
Z=U \Lambda V^{t}
$$

sendo: 
- $\Lambda$ a matriz diagonal $r \times r, r$ o posto matricial $(r a n k)$ de $\mathrm{Z}$, de valores singulares de $Z M Z^{t} N$ e $Z^{t} N Z M$

- $U$ a matriz com os primeiros $r$ autovetores de $Z M Z^{t} N$ tal que $U^{t} N U=\mathbb{I}_{r}$, sendo $\mathbb{I}_{r}$ a matriz identidade $r \times r$

- $V$ é a matriz $p \times r$ dos primeiros $r$ autovetores de $Z^{t} N Z M$ tal que $V^{t} M V=\mathbb{I}_{r}$

- $N$ e $M$ matrizes quadradas positivas definidas, sendo $N$ em $\mathbb{R}^{n}$ e $M$ em $\mathbb{R}^{p}$

O cálculo da GSVD de $Z$ é dado pela Decomposição em Valores Singulares (SVD) de:

$$
\tilde{Z}=N^{\frac{1}{2}} Z M^{\frac{1}{2}}
$$

que é equivalente a GSVD com métrica $\mathbb{I}_{n}$ em $\mathbb{R}_{n}$ e $\mathbb{I}_{p}$ em $\mathbb{R}_{p}$, tal que:

$$
\tilde{Z}=\tilde{U} \tilde{\Lambda} \tilde{V}^{t}
$$

sendo $\Lambda=\tilde{\Lambda}, U=N^{\frac{-1}{2}} \tilde{U}, V=M^{\frac{-1}{2}} \tilde{V}$.

Assim, os scores dos fatores das linhas são dados por:

$$
F=Z M V \text { ou } F=U \Lambda
$$

e os scores dos fatores das colunas são dados por:

$$
A^{*}=M V \Lambda
$$

tal que:

$$
A^{*}=\left[\begin{array}{c}
A_{1}^{*} \\
A_{2}^{*}
\end{array}\right]
$$

sendo que $A_{1}^{*}$ contém os $p_{1}$ scores dos fatores das variáveis numéricas e $A_{2}^{*}$ os $m$ scores dos fatores de todas categóricas.

Assim, de forma análoga à PCA e MCA, na PCAMix são geradas novas variáveis, chamadas de componentes principais, a partir das variáveis originais. Esses componentes são combinações lineares não correlacionadas das colunas de $Z$, a matriz que contém os vetores de atributos pré-processados, e explicam a maior parte da inércia, ou variância dos dados independentemente do tamanho da amostra, de $Z$. Os componentes principais estão relacionados com as variáveis originais por meio 
dos squared loadings. No caso de variáveis numéricas, os squared loadings são dados pela correlação quadrada:

$$
r^{2}\left(f_{i}, x_{j}\right)=a_{j i}^{* 2}
$$

sendo $f_{i}$ o componente principal, $x_{j}$ a j-ésima variável no vetor de características, $a_{j i}^{*}$ o elemento na j-ésima linha e i-ésima coluna de A*. No caso de variáveis categóricas, os squared loadings são dados pela razão de correlação:

$$
\eta^{2}\left(f_{i} \mid x_{j}\right)=\sum_{s \in I_{j}} \frac{n}{n_{s}} a_{s i}^{* 2}
$$

sendo $I_{j}$ os índices das categorias assumidas pela variável $j, n_{s}$ o número de observações que assumem a categoria $s, n$ o número total de observações, $f_{i}$ o componente principal, $x_{j}$ a j-ésima variável no vetor de características e $a_{j i}^{*}$ o elemento na j-ésima linha e i-ésima coluna de A*. Assim, $r^{2}\left(f_{i}, x_{j}\right)$ e $\eta^{2}\left(f_{i} \mid x_{j}\right)$ assumem valores entre 0 e 1 . Esses valores representam a contribuição de uma dada variável na construção do componente principal.

PCA e MCA são abordagens que além do embasamento teórico, possuem grande apelo por permitir interpretação geométrica e representação gráfica dos resultados. Em ambas análises, os dados podem ser representados em gráficos que são capazes de demonstrar visualmente as relações entre variáveis que caracterizam os dados, bem como as instâncias dos dados. De forma análoga, PCAMix também permite que as instâncias, variáveis numéricas e categorias dos dados sejam representados no espaço gerado pelos vetores dos componentes, sendo os fatores suas coordenadas. Essa representação facilita a interpretação e compreensão da análise, sumarizando a informação extraída do conjunto de dados.

\subsection{Agrupamento}

Outro exemplo de técnica de extração de dados é o agrupamento, o qual gera subconjuntos a partir do conjunto total de dados, de forma que os grupos contenham padrões similares. Os grupos são gerados considerando-se importantes características dos padrões e uma medida de similaridade.

A medida de similaridade extrai informação dos atributos para comparação dos padrões e seu agrupamento. Como resultado, objetos que pertencem ao mesmo grupo são mais similares do que objetos de grupos distintos (Jain et al., 1999). O principal objetivo da análise é encontrar padrões, explorando a relação entre os atributos dos dados e realizando uma avaliação de sua estrutura. O agrupamento é o aprendizado não supervisionado de conceitos ocultos nos dados (Berkhin, 2006).

Algoritmos de agrupamento podem ser hierárquicos ou particionais. O agrupamento hierárquico procede unindo (algoritmo aglomerativo) ou dividindo (algoritmo divisivo) elementos de um conjunto de dados de forma a produzir partições aninhadas que podem ser representadas em dendrogramas. Por outro lado, o agrupamento particional procura por uma partição única sem sobreposições que otimize um certo critério (Jain et al., 1999). 
Embora algoritmos hierárquicos possam obter diferentes níveis de partições, em geral, suas complexidades temporais e espaciais tipicamente são maiores (DAY, 1992). Por exemplo, a complexidade temporal $O\left(n^{2} \log n\right)$ (Kurita, 1991) e $O\left(n^{2} l\right)$ espacial (Choudhury e Murty, 1990) de algoritmos aglomerativos (que iniciam com os dados em grupos individuais e então são sucessivamente unidos) são problemáticas quando se tem grandes conjuntos de dados.

O agrupamento frequentemente tem sido aplicado na análise de volumosos conjuntos de dados. Por exemplo, em estudos de expressão gênica (Cypess et al., 2013), transcriptômica (Mukherjee et al., 2014), proteômica (Höhner et al., 2013), metabolômica (Broeckling et al., 2014), predições de estrutura de proteínas (Kaplan et al., 2004; Krasnogor e Pelta, 2004; Raval et al., 2012) e redes regulatórias de genes (Bilu e Linial, 2002; Tavazoie et al., 1999).

\subsubsection{K-medóides ou Partition Around Medoids (PAM)}

O algoritmo Partition Around Medoids ou K-medóides (Kaufman e Rousseeuw, 1987) é um exemplo de agrupamento particional em que o conjunto completo dos dados é dividido em $k$ grupos disjuntos. PAM é derivado do popular algoritmo K-médias, que foi modificado com a intensão de se obter maior robustez com relação à sensibilidade a outliers. Para tanto, PAM utiliza instâncias do conjunto de dados como representantes dos grupos, sendo esses decisivos na tomada de decisão de agrupamento. O representante, chamado de medóide, é o elemento localizado na região do espaço mais próxima ao centro do grupo cuja dissimilaridade média aos outros elementos do grupo é mínima. Assim, a escolha do medóide é dada considerando-se a função objetivo:

$$
\underset{S}{\operatorname{argmin}} \sum_{i=1}^{k} \sum_{x \in S_{i}} D\left(x, m_{i}\right)
$$

sendo $x$ um elemento do grupo $S_{i} ; m_{i}, m_{1}, \ldots, m_{k}$ os medoídes representantes dos $k$ grupos; $D\left(x, m_{i}\right)$ a dissimilaridade entre $x$ e $m_{i}$ de um mesmo grupo e $S_{1}, \ldots, S_{k}$ os grupos disjuntos gerados pelo algoritmo, tal que $S=\left\{S_{1}, \ldots, S_{k}\right\}$ configura o conjunto completo de dados. A partir da escolha dos medóides, as outras instâncias de dados são atribuídas aos grupos, considerando-se o medóide mais próximo.

Consequentemente, o algoritmo de PAM é dado por:

1. Dado $k$ o número de grupos a serem gerados, escolha como medóides $k$ instâncias dos dados de forma aleatória, ou $m_{1}, \ldots, m_{k}$

2. Atribua cada instância restante ao medóide mais próximo, de acordo com a função de dissimilaridade $D\left(x, m_{i}\right)$

3. Recalcule o medóide de cada um dos $k$ grupos

4. Repita os dois passos anteriores até que não haja alteração dos medóides

tendo complexidade $O\left(k(n-k)^{2}\right)$ por iteração, sendo $n$ o tamanho total do conjunto de dados e $k$ o número de grupos. 


\section{Gower}

No agrupamento PAM, a decisão de atribuição das instâncias de dados aos grupos é feita de acordo com sua similaridade aos medóides. Em casos de análises de dados binários em conjunto com dados numéricos, o coeficiente de similaridade de Gower (Gower, 1971) pode ser empregado, sendo capaz de comparar dados numéricos, ordinais e categóricos.

O coeficiente de similaridade geral de Gower entre duas instâncias $x_{i}$ e $x_{j}$ é dado por:

$$
s\left(x_{i}, x_{j}\right)=\frac{\sum_{k=1}^{p} s_{k}\left(x_{i k}, x_{j k}\right) \delta\left(x_{i k}, x_{j k}\right)}{\sum_{k=1}^{p} \delta_{k}\left(x_{i k}, x j k\right)}
$$

sendo $\mathrm{p}$ o número de variáveis, $\delta\left(x_{i k}, x_{j k}\right)=0$ se $i$ ou $j$ possuem valores ausentes em $k$, e $\delta\left(x_{i k}, x_{j k}\right)=1$ caso contrário, e para variáveis qualitativas:

- $s_{k}\left(x_{i k}, x_{j k}\right)=1$, caso $i$ e $j$ sejam equivalentes ou

- $s_{k}\left(x_{i k}, x_{j k}\right)=0$, caso $i$ e $j$ não sejam equivalentes

e para variáveis quantitativas:

$$
s_{k}\left(x_{i k}, x_{j k}\right)=1-\frac{\left|x_{i k}-x_{j k}\right|}{R_{k}}
$$

sendo $R_{k}$ o intervalo de valores possíveis para variável $k$. A partir da medida de similaridade descrita acima, é possível derivar a distância, ou medida de dissimilaridade,

$$
d\left(x_{i}, x_{j}\right)=1-s\left(x_{2}-x_{j}\right)
$$

Assim, nesse cálculo uma padronização das variáveis é aplicada, dividindo-se os valores pela extensão do intervalo assumido por cada variável, e todas variáveis assumem valores no intervalo $[0,1]$. Variáveis binárias contribuem para a similaridade se ambas instâncias assumirem valor 1 e outras variáveis contribuem com a diferença absoluta entre as instâncias dividida pela extensão do intervalo da variável. Finalmente, a similaridade entre duas instâncias de dados é representada pela soma das similaridades de todas variáveis.

\section{Silhouette}

Na aplicação do algoritmo PAM em um dado conjunto de dados é necessário estabelecer um valor para o parâmetro $k$, o número de grupos a serem gerados. Para essa escolha do número ótimo de grupos contidos nos dados, pode ser aplicada a métrica Silhouette (Rousseeuw, 1987). 
O coeficiente Silhouette é a distância média entre grupos, medindo a distância entre um elemento e outros grupos vizinhos. Desta forma, estima-se o quão similar uma instância é dos outros elementos do grupo, ou seja, a coesão dos dados que compõem um grupo, comparado com os outros grupos, ou seja, a separação entre os diferentes grupos.

Desta forma, calcula-se, para cada $x_{i}$ em $C_{i}$, o quão dissimilar $x_{i}$ é do seu próprio grupo $C_{i}$ :

$$
a\left(x_{i}\right)=\frac{1}{\left|C_{i}\right|-1} \sum_{x_{j} \in C_{i}, x_{i} \neq x_{j}} d\left(x_{i}, x_{j}\right)
$$

dado que $d\left(x_{i}, x_{j}\right)$ é a distância entre as instâncias $x_{i}$ e $x_{j}$ dos dados. Adicionalmente, para cada $x_{i}$ em $C_{i}$, calcula-se o quão dissimilar $x_{i}$ é dos outros grupos $C_{i}$ :

$$
b\left(x_{i}\right)=\min _{k \neq i} \frac{1}{\left|C_{k}\right|} \sum_{j \in C_{k}} d\left(x_{i}, x_{j}\right)
$$

A partir destes valores, o Silhouette é dado por (Rousseeuw, 1987):

$$
\begin{gathered}
s\left(x_{i}\right)=\frac{b\left(x_{i}\right)-a\left(x_{i}\right)}{\max \left\{a\left(x_{i}\right), b\left(x_{i}\right)\right\}}, \text { se }\left|C_{i}\right|>1 \\
\text { ou } \\
s\left(x_{i}\right)=0, \text { se }\left|C_{i}\right|=1 .
\end{gathered}
$$

O Silhouette assume valores entre 1 e -1 , tal que valores próximos de 1 indicam maiores distâncias entre o elemento e os grupos vizinhos, valores próximos de 0 indicam que o elemento está próximo da região de decisão entre os grupos e valores próximos de -1 indicam maior proximidade do elemento a outro grupo. Desta forma, um coeficiente com valores mais altos indica uma configuração com grupos coesos e bem separados.

\subsubsection{Agrupamento TwoStep ou BIRCH}

Em análises com conjuntos de dados extensos, as complexidades de tempo e espaço dos algoritmos hierárquicos tornam proibitivas a aplicação de tais soluções. Contudo, o Balanced Iterative Reducing and Clustering using Hierarchies (Zhang et al., 1996), ou BIRCH, é um algoritmo de agrupamento hierárquico que é capaz de alcançar complexidades de tempo e espaço $O(n)$, sendo $n$ o número de padrões.

O BIRCH armazena informações resumidas sobre os grupos em uma estrutura de árvore dinâmica. Desta forma, não é necessário armazenar toda a informação sobre cada um dos padrões em cada um dos grupos. O algoritmo é escalável, uma vez que a árvore guarda a informação mínima necessária para tomar as decisões de agrupamento, ou seja, calcular variâncias e as distâncias entre os grupos e padrões.

Em contraste com outros algoritmos hierárquicos, cada decisão tomada na construção da árvore é realizada localmente, sem a necessidade de se analisar todos os padrões. Também possui a vantagem 
de ser tolerante a outliers, que são definidos como padrões localizados em regiões esparsas, fora de regiões densas que contém e constituem os grupos.

O algoritmo incremental e dinamicamente cria uma árvore balanceada por pesos de grupos de atributos $(C F$, cluster features):

$$
C F=(N, \overrightarrow{L S}, S S)
$$

sendo $N$ o número de padrões no grupo, $\overrightarrow{L S}$ a soma linear dos $N$ padrões, ou:

$$
\overrightarrow{L S}=\sum_{i=1}^{N} \vec{X}_{i}
$$

e $S S$ é o quadrado da soma dos $N$ padrões, ou:

$$
\overrightarrow{S S}=\sum_{i=1}^{N} \vec{X}_{i}^{2}
$$

Nessa árvore, os nós que não são folhas possuem no máximo $B$ (fator de ramificação ou branching factor) entradas e são descritos por $C F_{i}$ e child $_{i}$. Uma $C F_{i}$ é a característica de agrupamento representando o subgrupo associado e um child $_{i}$ é um apontador para o i-ésimo nó filho. Cada nó folha possui no máximo $L$ entradas $C F$, satisfazendo o limite $T$ (threshold) para o diâmetro do grupo e consiste de um $C F_{i}$, sendo $i=1, \ldots, L$.

BIRCH inicia na fase 1 construindo uma árvore $C F$ a partir dos $N$ padrões. Cada padrão desloca-se para baixo na árvore a partir da raiz para a folha $C F$ mais próxima de acordo com alguma métrica de distância. Então, são possíveis dois casos:

1. Se a folha não possui mais do que $B$ entradas, o padrão é inserido na folha e a informação na folha é atualizada

2. Se o nó folha possuir mais do que $B$ entradas, o nó é dividido. O par mais distante de entradas é usado como semente e as outras entradas designadas de acordo com a proximidade a esses nós. Além disso, um novo nó é inserido no nó pai para que se descreva a nova folha.

Em ambos casos, quando a folha está cheia e quando não está, ainda é necessário atualizar a informação de cada nó não folha no caminho para a folha em que o padrão foi inserido. Para tanto, se todos nós no caminho não estiverem cheios, serão atualizados. Caso contrário, divisões necessárias são realizadas em níveis mais elevados até que se atinja a raiz.

Se o algoritmo utilizar toda a memória antes de terminar de construir a árvore, o algoritmo aumenta o limite $T$ e é reiniciado. Desta forma, a árvore será menor, uma vez que o parâmetro $T$ é inversamente proporcional ao tamanho da árvore. Um grupo em BIRCH é uma folha e seus subgrupos, uma representação bastante compacta, visto que cada folha é um subgrupo e não apenas um padrão. 
Após a geração da árvore, a fase 2 é opcional, na qual é reconstruída a árvore inicial, removendo outliers e agrupando subgrupos em grupos maiores, reduzindo-os. Na fase 3, um algoritmo de agrupamento global ou semi-global é empregado para agrupar as entradas nas folhas da árvore, por exemplo, o K-médias ou um algoritmo hierárquico. A fase 4, também opcional, refina os grupos usando os centróides da fase 3 e designando cada padrão aos grupos baseando-se em distâncias.

\section{Log-verossimilhança}

O agrupamento TwoStep emprega como medida de distância entre os dados o logaritmo da verossimilhança. A verossimilhança representa a probabilidade de uma instância dos dados pertencerem a um grupo, de forma a se maximizar a verossimilhança do dado em função dos grupos gerados. Considera-se assim que valores mais observados são os mais prováveis e, portanto, a convergência da estimativa depende do tamanho da amostra utilizada.

Frequentemente, no cálculo da verossimilhança, utiliza-se o logaritmo da verossimilhança por se tratar de uma função de crescimento monotônico. Desta forma, a maximização do logaritmo da verossimilhança leva à maximização da verossimilhança. Assim, a função log-verossimilhança é dada por (Duda et al., 2012):

$$
l(\theta)=\ln \left(p\left(C_{i} \mid \theta\right)\right)
$$

sendo que:

$$
p\left(C_{i} \mid \theta\right)=\prod_{k=1}^{n} p\left(x_{k} \mid \theta\right)
$$

$C_{i}$ é o $i$-ésimo grupo, $x_{k}$ a $k$-ésima instância dos dados, e $\theta$ o vetor de características que representa a instância $k$.

\section{Critério de informação Bayesiana}

Na escolha do número ótimo de grupos a serem criados, pode se comparar os modelos gerados a partir de diferentes parâmetros, estimando seu desempenho e escolhendo o melhor. Em casos em que se emprega a maximização do logaritmo da verossimilhança no modelo, o Critério de Informação Bayesiana (BIC), ou Schwartz's Bayesian Criterion, pode ser aplicado. O BIC é calculado por:

$$
B I C=-2 \hat{L}+K \log N
$$

sendo,

$$
\hat{L}=p(x \mid \hat{\theta}, M)
$$


sendo M um modelo, $x$ os dados observados, $\hat{\theta}$ os valores dos parâmetros no modelo que otimiza a função verossimilhança, $N$ o número de observações e $K$ número de parâmetros estimados. Assim, a escolha do modelo ótimo depende do número de parâmetros estimados $K$ e do número de observações $N$. O BIC penaliza modelos mais complexos (Friedman et al., 2001), selecionando o modelo com a maior aproximação de probabilidade posterior.

\subsection{Análise de sobrevivência}

A análise de sobrevivência é uma técnica que auxilia na interpretação de dados de medida de tempo para a ocorrência de um evento (Kleinbaum, 1998). Nesse tipo de análise, modela-se a função de tempo para a primeira ocorrência de um evento, ou tempo de sobrevivência, em um único evento ocorrendo por indivíduo.

Uma dificuldade recorrente na análise de sobrevivência é a chamada censura. A censura ocorre quando a informação sobre o indivíduo se limita a um certo intervalo de tempo, após o qual não se tem mais informações. Em tais casos, o evento pode não ter ocorrido até o final da observação e não se tem o tempo exato de quanto tempo levou até a ocorrência do evento, ou se esse evento ocorreu. Assim, para a aplicabilidade da análise, é necessário que esta considere esse tipo de situação.

Para a análise de sobrevivência, é necessário determinar um tempo de início, em que se começa a contagem de tempo, o tempo de duração da observação e o estado ao final da observação. O estado final indica a ocorrência do evento ou não até o fim do tempo de observação. Os casos em que o evento ocorre durante a observação, mas não se tem o tempo exato em que o evento ocorreu são chamados de censura à esquerda. Os casos nos quais o período de acompanhamento é finalizado ou não se pode mais acompanhar o indivíduo são chamados de censura à direita.

Na censura à esquerda sabe-se apenas que o tempo até a ocorrência do evento é menor ou igual ao tempo observado. Na censura à direita, sabe-se que o tempo até a ocorrência do evento é igual ou maior ao tempo observado.

Assim, denota-se por $T$ a variável aleatória para o tempo até a ocorrência do evento e $d$ uma variável binária indicando evento, em que $d$ recebe valor 1 , ou censura, em que $d$ recebe valor 0. Define-se $S(t)$ então a chamada função de sobrevivência, ou seja, a probabilidade de o evento não ocorrer até o tempo $t$ para um indivíduo (Kleinbaum, 1998). A função de sobrevivência é importante porque a probabilidade de sobrevivência em diferentes valores de $t$ propicia um resumo das informações contidas nos dados.

\subsubsection{Kaplan-Meier}

A estimativa Kaplan-Meier (Kaplan e Meier, 1958) é uma abordagem não paramétrica de análise de sobrevivência empregada na predição de tempo transcorrido até o acontecimento de um evento (tempo-para-o-evento). Também pode ser interpretada como a probabilidade de um período determinado de tempo transcorrer sem o acontecimento do evento, ou tempo de sobrevida sem censura. Essa análise é utilizada especialmente em casos em que há observações incompletas, em que o evento não ocorreu durante o período de observação ou não é mais possível acompanhar o indivíduo por algum outro motivo. Para tais casos, não se sabe quanto tempo passou até que o evento tenha ocorrido, ou se o evento ocorreu ou ocorrerá. 
Assim, o estimador da função de tempo para o evento de Kaplan-Meier, ou sua função de sobrevivência, é dado por (Kaplan e Meier, 1958):

$$
\widehat{S}(t)=\prod_{i: t_{i} \leq t}\left(1-\frac{d_{i}}{n_{i}}\right)
$$

sendo $\widehat{S}(t)$ a probabilidade de que o evento ocorra depois de $t, t_{i}$ o tempo transcorrido até pelo menos um evento ocorrer, $d_{i}$ o número de eventos que ocorreram antes do tempo $t_{i}$ e $n_{i}$ o número de indivíduos para os quais se tem a informação de que o evento não ocorreu no tempo $t_{i}$.

Portanto, a função de sobrevivência é dada pelo produto de probabilidades condicionais. O valor da função em $t_{f}$ é limitada pelo produto de termos até o tempo $t_{f}$. Em um dado momento $t_{f}$, a fração é a probabilidade condicional de que o evento não ocorra passado o tempo $t_{f}$ dado que o indivíduo ainda está no conjunto de risco, ou seja, que o evento ainda não tenha ocorrido ou que não tenha havido censura.

A partir da função de sobrevivência, um gráfico pode ser construído para visualização e sumarização dos dados. O gráfico permite a compreensão da distribuição de ocorrência do evento.

O objetivo da análise de sobrevivência com a estimativa Kaplan-Meier é estimar a função de sobrevivência, bem como comparar e visualizar as relações entre variáveis explicativas da sobrevivência (Kleinbaum, 1998). 


\section{Capítulo 4}

\section{Trabalhos Relacionados}

\subsection{Trabalhos relacionados à heterogeneidade da anemia falciforme}

Com o intuito de esclarecer a heterogeneidade na gravidade da anemia falciforme, estudos realizados anteriormente mostraram que fatores ambientais, conjuntamente com variantes genéticos alteram o curso da doença. Por exemplo, fatores como o clima, poluição, nível de monóxido de carbono e exercício afetam a condição dos pacientes (Tewari et al., 2015). No entanto, o estado nutricional, acesso a cuidados médicos e outros fatores socioeconômicos são principalmente notáveis entre países de diferentes níveis de rendas (Tewari et al., 2015).

Embora fatores ambientais influenciem, fatores genéticos também contribuem para a gravidade clínica e a resposta às medicações, podendo modular a anemia falciforme, por meio de variações regulatórias, genes polimórficos e distintos polimorfismo de nucleotídeo único. Trabalhos anteriores investigaram fatores genéticos e, em especial, modificadores de níveis de hemoglobina F mostraramse capazes de alterar manifestações da doença (Menzel e Thein, 2009). A HbF é capaz de amenizar as complicações da anemia falciforme devido a menor tendência à polimerização do HbS, por meio da formação de híbridos $\mathrm{HbS} / \mathrm{HbF}$ (Nagel et al., 1979). Além da HbF, a herança concomitante de $\alpha$-talassemia também interfere na gravidade da doença, diminuindo a concentração média de hemoglobina corpuscular nos eritrócitos, o número de células densas e a taxa hemolítica (Stuart e Nagel, 2004). A $\alpha$-talassemia também inibe a polimerização da HbS e a hemólise (Higgs et al., 1982), resultando em menor mortalidade. A concentração de $\mathrm{HbF}$ e $\alpha$-talassemia são importantes no estabelecimento do curso da enfermidade, mas não explicam definitivamente todos os resultados (Steinberg, 2009). A complexidade da doença dificulta a definição dos fatores relacionados e estudos anteriores só foram capazes de explicar pequena parte da variação (Gardner e Thein, 2016).

A anemia falciforme possui uma patofisiologia bastante complexa e suas complicações são muito diversas e podem afetar quase todos órgãos e tecidos. Alguns estudos postulam que um grupo de complicações está relacionado a hemólise e disfunções endoteliais e outro grupo a viscosidade do sangue e a episódios de vaso-oclusão (Alexander et al., 2004; Ballas, 1991; Kato et al., 2007). No grupo relacionado à hemólise e disfunções endoteliais, os pacientes teriam níveis mais elevados de lactato desidrogenase (HDL) e menos elevados de hematócritos (packed cell volume, PCV). Nesse grupo, a ocorrência de $\alpha$-talassemia reduziria a concentração média de hemoglobina, densidade do eritrócito e hemólise, no entanto, a hemoglobina fetal manifestaria um efeito protetor mais baixo (Habara e Steinberg, 2016). Adicionalmente, a hemólise ocasionaria a vasoconstrição, considerandose que quando a hemólise ocorre, a hemoglobina consome NO, que normalmente atua na conversão de 
GTP para cGMP, conduzindo à vasodilatação. Portanto, esse grupo de complicações seria composto pela hipertensão pulmonar, priapismo, úlcera de pernas e acidente vascular cerebral (Kato et al., 2007).

Em contrapartida, no grupo de complicações relacionadas à viscosidade e vaso-oclusão, pacientes compreenderiam menores níveis de HDL, números mais altos de eritrócitos e PCV (Habara e Steinberg, 2016). Ademais, os pacientes com complicações desse tipo que não são portadores de $\alpha$-talassemia possuem maior viscosidade e desfrutam de maiores efeitos protetivos contra gravidade da doença por parte da HbF (Habara e Steinberg, 2016). Assim, fazem parte desse grupo de complicações os episódios de dor aguda, osteonecrose e síndrome torácica aguda (Kato et al., 2007).

Embora essa classificação auxilie na idealização de subfenótipos e possíveis estratégias para o tratamento, os grupos não são disjuntos, se sobrepõem e alguns especialistas acreditam ser uma simplificação (Habara e Steinberg, 2016). Ainda, tal classificação não é aplicável a crianças, uma vez que possuem menores índices de complicações (van der Land et al., 2013).

Tabela 4.1: Biomarcadores empregados no agrupamento de pacientes com anemia falciforme em Du et al. (2018)

\begin{tabular}{c} 
Biomarcador \\
\hline Lactato desidrogenase \\
Fosfatase alcalina \\
Transaminase glutâmico-oxalacética \\
Bilirrubina total \\
Albumina sérica \\
Ácido úrico \\
Nitrogênio ureico no sangue \\
Creatinina \\
Nível de hemoglobina fetal \\
Contagem de reticulócitos \\
Plaquetas \\
Contagem de monócitos \\
Contagem de linfócitos \\
Contagem de eosinófilos \\
Volume corpuscular médio \\
Contagem de leucócitos \\
Nível de hemoglobina
\end{tabular}

Também com intuito de classificar pacientes com anemia falciforme, Du et al. (2018) empregou técnicas de agrupamento em dados de pacientes com anemia falciforme. Foi realizado um agrupamento de 17 biomarcadores (Tabela 4.1) com o objetivo de encontrar marcadores de morbidade e mortalidade em anemia falciforme. Foram gerados 8 grupos de pacientes de acordo com os níveis dos biomarcadores. Após o agrupamento, complicações foram associadas aos diferentes grupos para avaliar o perfil dos pacientes.

O primeiro grupo possui pacientes com marcadores padronizados próximo de zero e que serviram de base para comparações com os outros grupos. O segundo grupo contém pacientes com problemas renais, altos índices de hemoglobina fetal, baixos índices de hemólise e plaquetas. Esse grupo engloba pacientes com genótipo HbSC, com menor probabilidade de eventos de dor, mortalidade e acidente vascular cerebral (AVC). O terceiro grupo possui pacientes com menos problemas renais, maiores níveis de anemia, hemoglobina fetal e plaquetas. Inclui pacientes HbSS, com menores ocorrência de episódios de dor, maior mortalidade, AVC e úlcera de pernas. O quarto grupo abrange pacientes 
com maiores índices de hemólise, hemoglobina fetal e plaquetas. Os pacientes são HbSS, com menos ocorrências de dor, mortalidade, necrose avascular de osso e ataques epiléticos. O quinto grupo integra os pacientes HbSC com menores índices de hemólise, mais problema renais, menores níveis de $\mathrm{HbF}$, menores níveis de plaquetas. O sexto grupo une pacientes HbSS com menores índices de hemólise, plaquetas, maiores ocorrências de AVC, ataques epiléticos e síndrome torácica aguda. O sétimo grupo compõe-se de indivíduos HbSS com problemas renais, necrose avascular de osso e síndrome torácica aguda. O oitavo grupo inclui pacientes com maiores índices de hemólise e problemas renais.

A análise de Du et al. (2018) mostra que biomarcadores são capazes de predizer hemólise e níveis de $\mathrm{HbF}$ e sugere ser possível predizer o risco de complicações. O estudo também sugere que a divisão das complicações de acordo com a maior ocorrência de hemólise e vaso-oclusão é simplista, envolvendo outros importantes fatores na ocorrência das complicações.

Também na busca por grupos fenotípicos em pacientes com anemia falciforme, Alexander et al. (2004) aplicou uma modelagem Bayesiana latente (Dunson, 2000). Foram utilizadas como atributos dos pacientes níveis de hemoglobina total, volume celular médio, contagem de reticulócitos, contagem de célula nucleada, contagem de plaquetas, nível de $\mathrm{HbF}$, crise aplástica, síndrome torácica aguda, sequestro esplênico agudo, hiperesplenismo, dactilite, crise de dor aguda, crise de dor abdominal, úlcera na perna, acidente vascular cerebral e septicemia. Dunson (2000) encontrou grupos de pacientes com crises de dor aguda e pacientes com úlcera de perna. O grupo de indivíduos com úlcera de pernas foi ainda subdividido em mais ou menos crises de dor, dactilite, meningite/septicemia e síndrome torácica aguda.

\subsection{Trabalhos relacionados ao agrupamento de pacientes}

O reconhecimento de grupos fenotípicos em pacientes com doenças heterogêneas compreendendo características clínicas e biológicas com abrangentes variações pode auxiliar nas tomadas de decisões do tratamento e no desenvolvimento de novos tratamentos. Metodologias de agrupamento já foram empregadas previamente na busca de grupos de pacientes com fenótipos similares com doenças heterogêneas. Ahlqvist et al. (2018) e Seymour et al. (2019), por exemplo, buscam agrupar pacientes com diabetes e sépsis, respectivamente.

Em Ahlqvist et al. (2018), foram aplicados K-médias e agrupamento TwoStep em 8990 pacientes com diabetes. A diabetes atualmente é classificada em tipo 1 e tipo 2 , no entanto, o tipo 2 apresenta pacientes com grande variabilidade fenotípica. Assim, foi realizado agrupamento de pacientes com diabetes baseando-se em seis variáveis: anticorpos para glutamato descarboxilase, idade no diagnóstico, índice de massa corporal (IMC), hemoglobina glicada $\left(H b A_{1 c}\right)$ e estimativas de função de célula $\beta$ (responsável por sintetizar e secretar o hormônio insulina) e resistência à insulina. Os resultados mostraram a formação de 5 grupos fenotípicos, incluindo um grupo com pacientes mais resistentes a insulina e maior risco de problemas renais e outro com pacientes com deficiência de insulina. Os grupos apresentaram diferentes características, diferindo na progressão da doença e nos riscos de complicações.

O agrupamento de pacientes com sépsis, descrito em Seymour et al. (2019), utilizou o método K-médias em 16552 pacientes. A sépsis é definida como uma resposta imune desregulada à infecção, denotando uma definição bastante abrangente. 29 variáveis foram consideradas para o agrupamento, 
incluindo bilirrubina, transaminase glutâmico-oxalacética, alanina aminotransferase, hemoglobina, razão normalizada internacional (RNI), plaquetas, escala de coma de Glasgow, frequência cardíaca, pressão arterial sistólica, bicarbonato, troponina, lactato no soro, frequência respiratória, saturação de oxigênio, pressão de oxigênio no sangue arterial, temperatura, taxa de sedimentação de eritrócitos, contagem de leucócitos, contagem de neutrófilos prematuros, proteína C-Reactiva, creatinina no soro, idade, sexo, Elixhauser, albumina, cloreto, sódio, glicose, nitrogênio ureico no sangue. O algoritmo K-médias gerou 4 grupos fenotípicos, sendo um primeiro grupo com pacientes que foram menos frequentemente tratados com vasopressores, um segundo grupo com pacientes mais velhos, doenças crônicas e disfunções renais, um terceiro grupo com mais inflamação e disfunção pulmonar e um quarto grupo com disfunção no fígado e choque séptico. Os grupos representam padrões de resposta do hospedeiro e características clínicas, além de estarem relacionados com a heterogeneidade de efeitos no tratamento.

\subsection{Trabalhos relacionados ao priapismo na anemia falciforme}

Tabela 4.2: Associações de genes com priapismo sugeridas por GWAS

\begin{tabular}{ccc} 
Gene & Nome & Associação \\
\hline AQP1 & aquaporin & priapismo \\
F1A31 & subunidade A1 do fator de coagulação XIII & priapismo \\
ITGAV & integrin $\alpha \mathrm{v}$ & priapismo \\
KL & klotho & priapismo \\
TGFBR3 & transforming growth factor- $\beta$ receptor type III & priapismo
\end{tabular}

Postula-se que o priapismo em pacientes com anemia falciforme seja associado à ocorrência de hipertensão pulmonar, acidente vascular cerebral, úlcera de pernas e mortalidade. A associação entre essas complicações seria dada através dos maiores índices de hemólise que ocorreriam nesses pacientes, com biomarcadores como HDL, bilirrubina e reticulócito sendo marcadores dos níveis de hemólise (Kato et al., 2006, 2007).

Consistente com essas associação em casos mais graves, a frequência do priapismo é maior entre pacientes com genótipo HbSS e menor entre pacientes com genótipo HbSC (Fowler Jr et al., 1991; Hamre et al., 1990; Sharpsteen et al., 1993). No entanto, os motivos dessas prevalências não são bem evidenciados, e os mecanismos envolvidos na ocorrência do priapismo ainda não são bem conhecidos. Propõe-se que a maioria dos casos seja decorrente de um estado de baixo ou inexistente fluxo sanguíneo arterial para os corpos cavernosos (Broderick, 2012). Esse baixo fluxo estaria relacionado à deformação das hemácias nos sinusóides dos corpos cavernosos (Bruno et al., 2001).

No entanto, outros estudos correlacionam o priapismo à hemólise, por intermédio do NO. O NO atua na vasodilatação e a hemoglobina livre limitaria sua biodisponibilidade (Reiter et al., 2002). Com a menor biodisponibilidade do NO, o equilíbrio seria deslocado em direção à vasoconstrição, causando o priapismo.

Além das investigações diretas de vias metabólicas, os mecanismos de ocorrência do priapismo podem ser estudados por meio de sua associação com variações genéticas. Assim, estudos buscando associações do priapismo com genes candidatos foram realizados. Nesses estudos, o priapismo foi associado com o gene klotho (KL), transforming growth factor- $\beta$ receptor type III (TGFBR3), aquaporin (AQP1), integrin $\alpha v$ (ITGAV) e a subunidade A1 do fator de coagulação XIII (F13A1). O 


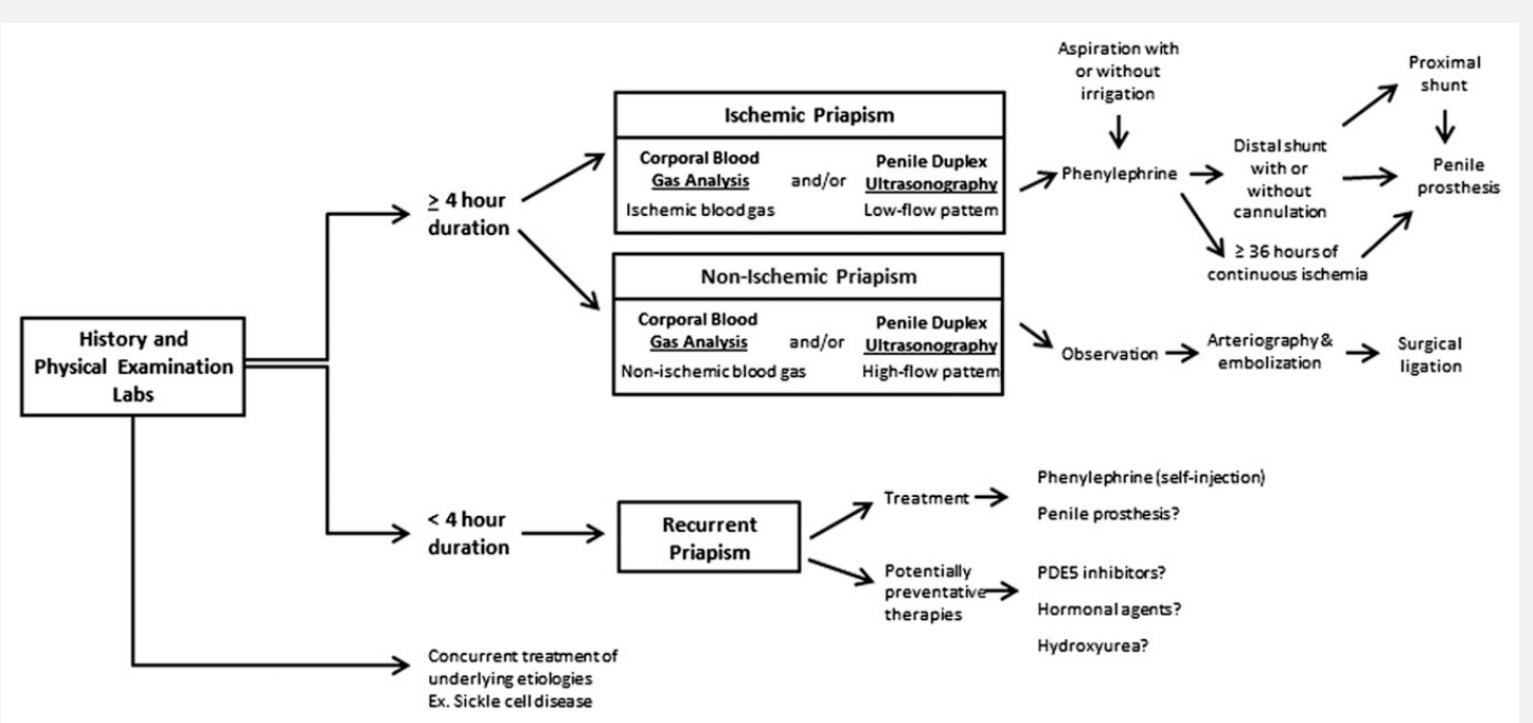

Figura 4.1: Estratégia sugerida em Anele et al. (2015) para tratamento de casos de priapismo.

gene KL codifica para uma proteína de membrana correlacionada a funções vasculares, como expressão de fatores de crescimento de crescimento endotelial e liberação de NO no endotélio. O TGFBR3 está associado à migração e transformação de células no endotélio, e foi anteriormente relacionado a outros fenótipos decorrentes da anemia falciforme. O gene AQP1 codifica para um canal de água de eritrócitos e células endoteliais, estando associado à vida útil do eritrócito (Mori et al., 1996). O gene ITGAV codifica para uma proteína de superfície envolvida na adesão de hemácias (Kaul et al., 2000; Zennadi et al., 2004). Finalmente, o gene F13A1 tem importante papel na estabilização de coágulos de fibrina e estando relacionado a risco de trombose (Scott et al., 2004). No entanto, esses resultados ainda não foram replicados e se faz necessário realizar estudos adicionais.

Uma das consequências da falta de conhecimento na patofisiologia do priapismo é a falta de concordância no seu tratamento. Na prática, frequentemente se observa abordagens conservadoras como transfusão, sendo raramente realizados procedimentos urológicos (Lee et al., 2013). No entanto, a literatura recomenda outras abordagens para a ocorrência de episódios, incluindo tratamentos preventivos em casos de recorrências e procedimentos em episódios mais graves e prolongados (Figura 4.1).

\subsection{Conclusão sobre os trabalhos relacionados}

Alguns fatores modificadores dos riscos de complicações da anemia falciforme já são conhecidos, como o genótipo HBB, a $\mathrm{HbF}$ e a $\alpha$-talassemia. Postula-se também que haja uma divisão das complicações em um grupo relacionado a maior viscosidade do sangue e a episódios de vaso-oclusão e outro grupo relacionado a maiores índices de hemólise e disfunções endoteliais. Adicionalmente, biomarcadores mostraram-se capazes de predizer os níveis de hemólise e HbF, bem como agrupar pacientes com diferentes características clínicas.

Apesar de estudos posteriores terem investigado biomarcadores que influenciam na heterogeneidade da anemia falciforme e as relações entre as complicações decorrentes da doença, novos estudos 
podem ajudar a confirmar e esclarecer tais conjunturas. Adicionalmente, estudos posteriores aplicaram metodologias de agrupamento em doenças heterogêneas como diabetes e sépsis, sendo capaz de encontrar grupos fenotípicos em pacientes. Assim, é importante que sejam realizadas investigações com métodos de agrupamento sobre as interações e associações entre complicações e testes laboratoriais em relação ao curso da doença. Com isso, os resultados obtidos, validando ou não conhecimento prévio, colaborariam com uma melhor compreensão das manifestações da doença e dos riscos das complicações.

Ainda no estudo das complicações relacionadas à anemia falciforme, o priapismo acomete uma grande porcentagem dos homens, e tem maior incidência em pacientes de genótipo HbSS, mas não há muitos estudos realizados com pacientes de outros genótipos. Essa complicação ainda estaria associada à ocorrência de hipertensão pulmonar, acidente vascular cerebral e úlcera de pernas. Além disso, a patofisiologia, as vias e os fatores de risco envolvidos na ocorrência do priapismo ainda não são bem conhecidos.

Apesar de estudos posteriores terem investigados genes candidatos relacionados ao risco de priapismo e alguns polimorfismos terem sido encontrados, nenhuma busca em nível genômico foi realizada. Assim, a realização de um GWAS com o propósito de investigar associações em abrangência genômica poderia contribuir na elucidação do priapismo. Esse tipo de análise é importante uma vez que ainda não são completamente conhecidas as vias metabólicas envolvidas no processo. 


\section{Capítulo 5}

\section{Anemia Falciforme}

\subsection{Experimento}

\subsubsection{NHLBI Retrovirus Epidemiology Donor Study II e III - REDS II e III}

Os estudos National Heart, Lung, and Blood Institute (NHLBI) International Recipient Epidemiology and Donor Evaluation Study (REDS)-II e III foram concebidos por um grupo de pesquisa internacional que visa a segurança transfusional e adequação de abastecimento de sangue. O grupo engloba parceiros no Brasil, Estados Unidos, China e África do Sul. Diversos projetos compõem o REDS-II e REDS-III, incluindo estudos sobre a caracterização da utilização e epidemiologia relacionados a produtos do sangue (Karafin et al., 2017), o risco do vírus da imunodeficiência humana (HIV) e outras infecções transmitidas por transfusão (Sabino et al., 2015), a identificação de características dos doadores de sangue que impactam estoques de bancos de sangue (Kanias et al., 2017) e a caracterização dos desenlaces envolvidos no recebimento de transfusões (Bloch et al., 2015).

Os NHLBI REDS-II e III são estudos retrospectivos cross-sectionais de doadores de sangue realizados com a colaboração de três importantes hemocentros públicos brasileiros de 2007 a 2017. Participam deste estudo a Fundação Pró-Sangue em São Paulo, a Fundação Hemominas em Minas Gerais e a Fundação Hemope em Pernambuco. A Fundação Pró-Sangue é o maior banco de sangue da América Latina. Realiza a coleta, teste e processamento de 90.000 unidades de sangue anualmente, representando aproximadamente $33 \%$ do sangue coletado no sistema público de São Paulo. Já a Fundação Hemominas é responsável por $92 \%$ da coleta de sangue do Estado de Minas Gerais (dat), os quais são processados e distribuídos a 76 hospitais em 32 cidades. Finalmente, a Fundação Hemope coleta aproximadamente 75.000 unidades de sangue por ano, fornecendo $98 \%$ das unidades e componentes de sangue necessárias em sua região.

\subsubsection{REDS-III e o Brazil Sickle Cell Disease Cohort}

Os pacientes portadores de anemia falciforme envolvidos no REDS-III Brazil Sickle Cell Disease Cohort recebem transfusões e outros cuidados em hemocentros, uma vez que transfusões são componentes vitais no tratamento de complicações da doença (Roseff, 2008). Nos hemocentros das cidades de Belo Horizonte, Rio de Janeiro, Recife, São Paulo, Montes Claros e Juiz de Fora, por exemplo, são tratados aproximadamente 10.000 pacientes com anemia falciforme. Portanto, dentro do programa REDS-III foi realizado um estudo coorte com objetivo de se caracterizar as consequências da doença, a utilização de sangue e as taxas de ocorrência de doenças infecciosas, como o HIV, 
na população com anemia falciforme no Brasil (Kleinman et al., 2014).

Para este coorte de anemia falciforme, pacientes da população ativa dos hemocentros de Belo Horizonte, Rio de Janeiro, Recife, São Paulo, Montes Claros e Juiz de Fora foram selecionados aleatoriamente como participantes elegíveis do estudo. De uma lista de 9676 pacientes dos hemocentros com pelo menos uma visita clínica nos últimos 3 anos, foram selecionados aleatoriamente os participantes elegíveis do estudo. Nesta seleção, foi realizada uma estratificação com relação à idade, sexo e genótipo da anemia falciforme de forma proporcional à população de cada hemocentro, de forma que a amostra refletisse a população de estudo. Os pacientes elegíveis foram então recrutados durante suas visitas clínicas, totalizando 2793 pacientes recrutados.

O REDS-III Brazil Sickle Cell Disease Cohort coletou informações sobre pacientes com anemia falciforme, integrado a um repositório de amostras de sangue e dados de genotipagem. Foram coletados e armazenados dados clínicos, laboratoriais, de transfusões e de amostras de sangue (Kleinman et al., 2014). Os dados do Brazil Sickle Cell Disease Cohort são capazes de prover informações de enorme importância na investigação de relações fenótipo-genótipo na evolução e na diversidade das manifestações clínicas da anemia falciforme. Permitem, por exemplo, definir a incidência de manifestações específicas de anemia falciforme, descrever parâmetros laboratoriais e seus resultados clínicos, identificar variações genéticas que interfiram no curso da doença e os riscos de ocorrência de complicações associadas à doença, entre outros (Kleinman et al., 2014).

Durante o período do estudo, os participantes realizaram visitas anuais aos hemocentros para coleta de informações demográficas, relacionadas à anemia e às transfusões realizadas. Essas informações foram coletadas por meio de entrevistas e análise de registros médicos (Apêndice C). Adicionalmente, até o presente momento, duas visitas de acompanhamento foram finalizadas, nas quais foram coletadas informações sobre o estado de saúde atual e eventos médicos que ocorreram desde o recrutamento (Apêndices D e E). Uma amostra dos dados coletados está representada na Tabela 5.1.

Complementarmente aos dados coletados em questionários, foram coletadas amostras de sangue. Através destas amostras, o genótipo dos pacientes foi testado por meio de genotipagem específica com pirosequenciamento da hemoglobina. Em casos em que houve discordância com os registros dos pacientes, sequenciamento Sanger do éxon 1 e 2 do gene de beta globina foi realizado. Após esses procedimentos, alguns pacientes ainda não possuíam definição precisa de seus genótipos, sendo necessária análise adicional no Hemoglobinopathy Reference Laboratory at UCSF Benioff Children's Hospital Oakland (CHO). No CHO, o éxon 3 da beta globina e íntrons das regiões promotoras foram sequenciados, sendo capazes de determinar os genótipos.

Os projetos REDS-III passaram por aprovação do CONEP (Apêndice A), dos comitês de ética institucionais, dos comitês de ética locais em cada centro participante (Apêndice B) e da University of California at San Francisco.

\section{Relações Genótipo-Fenótipo em Anemia Falciforme}

No REDS-III Brazil Sickle Cell Disease Cohort grandes volumes de dados fenotípicos foram coletados bem como históricos de transfusão e status de aloimunização, oferecendo uma grande oportunidade para estudos de associação fenótipo-genótipo no amplo espectro de manifestações de anemia falciforme. Para tanto, foram realizados estudos de tipificação de polimorfismos de nucleotídeo único em genomas completos para identificação de SNPs associados à importantes fenótipos 
Tabela 5.1: Amostra dos dados coletados no REDS-III Brazil SCD Cohort

\begin{tabular}{|c|c|}
\hline Categoria & Dados Específicos Coletados \\
\hline \multicolumn{2}{|l|}{ Entrevista } \\
\hline Entrevista com Paciente/Família 1 - medidas & Peso, altura, pressão sanguínea, saturação de oxigênio \\
\hline Entrevista com Paciente/Família 2 - demográfico & $\begin{array}{l}\text { Raça, emprego/nível escolar, estado civil, renda, } \\
\text { transfusão recebida em outras instituições, visitas } \\
\text { não agendadas devido à anemia, não pode ir à } \\
\text { escola/trabalho devido a dores relacionadas à anemia, } \\
\text { uso de tabaco/álcool, histórico de gravidez }\end{array}$ \\
\hline \multicolumn{2}{|l|}{ Revisão do Registro Médico } \\
\hline Internações & $\begin{array}{l}\text { Diagnóstico de dispensa e duração da estadia para } \\
\text { todas admissões nos últimos } 12 \text { meses }\end{array}$ \\
\hline Histórico Cirúrgico & Data e tipo de todas cirurgias \\
\hline Histórico de Medicações & Medicações usadas nos últimos 12 meses \\
\hline Exames Selecionados de Screening ou de Diagnóstico & $\begin{array}{l}\text { Resultados do Doppler Transcraniano, MRI e MRA } \\
\text { do cérebro, ecocardiograma, exames de função pulmonar } \\
\text { e análise de urina realizados nos últimos } 12 \text { meses }\end{array}$ \\
\hline Resultados de Exames de Doenças Infecciosas & $\begin{array}{l}\text { Resultado de exames de Hepatite B e C, HIV, sífilis, } \\
\text { HTLV, Chagas nos últimos } 12 \text { meses }\end{array}$ \\
\hline Exames Baseline & Hemograma completo, reticulócito, $\mathrm{HbF}, \mathrm{HDL}$ \\
\hline Sobrecarga de Ferro & $\begin{array}{l}\text { Bilirrubina total, creatinina, ferritina, biópsia de fígado, } \\
\text { MRI realizado nos últimos } 12 \text { meses }\end{array}$ \\
\hline Dados de Banco de Sangue/Transfusão & $\mathrm{ABO} / \mathrm{RBC}$ fenótipo, histórico de anticorpo \\
\hline Histórico de Transfusão & Número de unidades transfundidas na vida do paciente, \\
\hline Transfusão nos últimos 12 meses & $\begin{array}{l}\text { Indicação, método de transfusão e reações associadas } \\
\text { para todas unidades nos últimos } 12 \text { meses }\end{array}$ \\
\hline Dados de unidades de transfusão nos últimos 12 meses & $\begin{array}{l}\text { Fenótipo, idade, estado de leucoredução de todas } \\
\text { unidades de transfusão nos últimos } 12 \text { meses }\end{array}$ \\
\hline Resultados de anemia falciforme & $\begin{array}{l}\text { Síndrome torácica aguda (diagnosticada e número de } \\
\text { episódios nos últimos } 12 \text { meses), episódios de dor } \\
\text { vaso oclusivos (diagnosticada e número de episódios nos } \\
\text { últimos } 12 \text { meses). Histórico de hemossiderose } \\
\text { transfusional, cardiomiopatia, hipertensão pulmonária, } \\
\text { AVC, doença cerebral vascular, doença pulmonária } \\
\text { restritiva/obstrutiva,doppler transcraniano, } \\
\text { anormal/condicional, sequestro esplênico, asma, úlceras } \\
\text { na perna, necrose avascular de osso, falha renal, } \\
\text { priapismo, Hepatite B/C, HIV, Chagas }\end{array}$ \\
\hline
\end{tabular}


relacionados ao curso do desenvolvimento da anemia falciforme. Para tanto, um grupo de especialistas nas áreas de eritrócitos, plaquetas, grupos sanguíneos, transfusão, anemia falciforme, artéria cerebelar inferior posterior, síndrome das pernas inquietas, metabolismo de ferro e outras doenças foram consultados para identificação de genes e variantes genéticos para a criação de um SNP array. Também foi realizada pesquisa extensiva de mineração de recursos de bioinformática no Pubmed, GTEX e o catálogo GWA SNP, além de consulta ao catálogo de variações da Affymetrix.

Um array foi então montado, enriquecido com SNPs para obtenção de boa cobertura do genoma inteiro em populações de distintas descendências. O TM-Array inclui 549.000 SNPs cobrindo minor allele frequencies (MAF) de $5 \%$ em descendentes de europeus, africanos e da Ásia oriental. SNPs relacionados a 141 genes de ferro, 3.856 genes de plaquetas, 1.285 genes de RBC, 238 citocinas, 155 TGF e 48 genes de anemia falciforme foram incluídos. Adicionalmente, 145 SNPs relevantes a transplantes, 13 SNPs associados a síndrome das pernas inquietas, 3885 SNPs relacionados a doenças do sangue e ferro, 729 SNPs de genes em grupos sanguíneos, todos 34.000 SNPs previamente associados a doenças em estudos GWAs e 125 SNPs em genes de coagulação e citocina também foram incluídos. O array possibilita também a deteç̧ão de alterações de cópias de locis alfa globina, beta globina e Rh-CDE com aproximadamente 1000 polimorfismos de número de cópias (copy number polymorphisms, CNPs). O TM-Array inclui ainda 1200 SNPs Y e mitocondriais, aproximadamente 80.000 SNPs não sinônimos com MAF maior que 1\%, 14.000 SNPs com regiões HLA/KIR (killer cell immunoglobulin-like receptor) e 2000 SNPs em genes absorção, distribuição, metabolismo, e excreção (ADME). No total, o TM-Array inclui 875.188 SNPs e 1000 CNPs.

O REDS-III Brazil Sickle Cell Disease Cohort coletou um grande volume de informações, incluindo dados fenotípicos e genotípicos para caracterização da anemia falciforme. Estes dados devem ser capazes de auxiliar no esclarecimento da variabilidade de manifestações da doença nos pacientes, bem como ajudar na compreensão da variabilidade dos possíveis cursos da doença. A identificação de marcadores genéticos envolvidos na diversidade fenotípica da anemia falciforme ajudará a orientar a tomada de decisões no tratamento de pacientes e a escolha de novos possíveis alvos para o desenvolvimento de novas terapias.

\subsubsection{Agrupamento}

\section{Seleção de pacientes para o agrupamento}

Com a definição dos genótipos de anemia falciforme de cada paciente, visto que sabe-se que pacientes com genótipo HbSS e HbS $\beta 0$ desenvolvem fenótipos mais graves quando comparados com pacientes com genótipo HbSC (Stuart e Nagel, 2004), pacientes HbSS e HbS $\beta 0$ foram analisados separadamente de pacientes HbSC na análise de agrupamento. Além de realizar o agrupamento separadamente por genótipo, os pacientes também foram separados em grupos com até 18 anos e com 18 anos ou mais, dado que a idade também interfere na gravidade da doença e na ocorrência de complicações.

\section{Seleção de caraterísticas para o agrupamento}

Da totalidade de dados coletados, complicações, sintomas e resultados de exames clínicos que são importantes para a definição de subfenótipos foram selecionados para o procedimento de agrupamento. A seleção foi realizada a partir de estudos anteriores que mostram a importância de 
Tabela 5.2: Variáveis usadas no agrupamento de pacientes

\begin{tabular}{ccc} 
Nome da variável & Variável & Tipo dos dados \\
\hline$n$ _admacchest & número de hospitalizações por & numérico \\
$n$ síndrome torácica aguda & número de hospitalizações por \\
episódio doloroso agudo & numérico \\
indirect_bilirubin & bilirrubina indireta & \\
lactate & lactato desidrogenase & numérico \\
total_bilirubin & bilirrubina total & numérico \\
hbf_result & hemoglobina F & numérico \\
acutpainscd & numérico \\
chestdiag & episódio doloroso agudo da doença falciforme & binário \\
elevtcd & síndrome torácica aguda/pneumonia & binário \\
hemstroke & diagnóstico de doppler transcraniano anormal ou condicional & binário \\
infarstroke & acidente vascular cerebral hemorrágico & binário \\
ischattack & acidente vascular cerebral - infarto & binário \\
legulcer & ataque isquêmico transitório & binário \\
moya & úlcera na perna & binário \\
retinopathy & moyamoya & binário \\
silentinfar & acidente vascular cerebral - infarto cerebral silencioso & binário \\
transfhem & hemossiderose transfusional & binário
\end{tabular}

algumas características dos pacientes para a definição de subfenótipos e do conhecimento de especialistas. Os dados selecionados incluem características que são capazes de distinguir os pacientes considerando-se os tipos e natureza de suas complicações como consequência da anemia falciforme. O grupo de características selecionadas inclui informações sobre história clínica, resultados de exames e ocorrência de doenças, incluindo um conjunto diversificado de dados, como descrito na Tabela 5.2 . 


\section{Métodos de Agrupamento}

Com o objetivo de buscar por grupos de pacientes que apresentam complicações similares como consequência da anemia falciforme, algoritmos de agrupamento foram aplicados às características selecionadas. Os algoritmos e medidas de similaridade foram selecionados de acordo com as propriedades e natureza dos dados. Portanto, os algoritmos escolhidos deveriam ser capazes de analisar grandes volumes de indivíduos e características, além de dados numéricos contínuos e binários. As medidas de similaridade a serem escolhidas também deveriam ser adequadas para análises de dados numéricos contínuos e binários. Adicionalmente, distintas metodologias de agrupamento foram selecionadas, de forma a se comparar os resultados de distintas abordagens. Portanto, foi selecionada A Análise de Componentes Principais de Variáveis Misturadas Numéricas e Categóricas (PCAMix), uma técnica de redução de dimensão em reconhecimento de padrões; a PAM, um algoritmo de agrupamento particional; e o TwoStep Clustering um algoritmo de agrupamento hierárquico.

\section{Agrupamento TwoStep}

O agrupamento TwoStep do SPSS (versão 17) (sps, 2008) é um algoritmo de agrupamento que pode ser empregado na análise de grandes conjuntos de dados de diversos tipos. Em um primeiro passo, o algoritmo armazena em uma estrutura de dados em formato de árvore toda a informação necessária para a realização do agrupamento. Em um segundo passo, a informação armazenada na árvore é utilizada para agrupar os dados em um procedimento hierárquico aglomerativo. A abordagem de dois passos permite a análise de grandes conjuntos de dados, uma vez que o primeiro passo age como uma fase de pré-processamento que resume os dados. A função log-verossimilhança foi usada como medida de similaridade, calculando uma distribuição de probabilidade das variáveis e permitindo a aplicação do algoritmo em dados de diferentes tipos.

O Critério de Informação Bayesiana (BIC) (Schwarz et al., 1978) foi empregado na determinação do número ótimo de grupos e é baseado na probabilidade de se obter os dados observados, supondose que o modelo sendo testado tenha os gerado.

\section{K-medóides}

O algoritmo K-medóides ou PAM é uma alternativa para o popular método K-médias em casos em que são integrados dados categóricos e binários. PAM é similar ao K-médias de forma que é particional e tem como objetivo minimizar a distância entre elementos em um grupo. No entanto, usa os próprios elementos do grupo para representar seu centro, chamados de medóides, diferentemente do K-médias que emprega a média de todos elementos no grupo para representar os centróides. Além disso, a média utilizada no cálculo de centróides é sensível a presença de outliers, tornando o algoritmo vulnerável a sua presença, uma vez que desloca o centróide em sua direção, levando a uma representação incorreta do grupo. Uma vez que PAM utiliza um elemento do grupo na sua representação, o algoritmo é mais robusto com relação à presença de outliers. No entanto, uma desvantagem de PAM está na sua complexidade de tempo, sendo que possui complexidade de $O\left(k(n-k)^{2}\right)$ por iteração, enquanto K-médias possui complexidade de $O(n k)$ por iteração, considerando-se que em geral $k$ e $t$ são consideravelmente menores que $n$. Assim, a implementação do PAM em R do pacote cluster (Maechler et al., 2018) foi utilizada.

Para definição do número ótimo de grupos, a implementação do Silhouette do pacote em R 
cluster foi empregada. O Silhouette mede a coesão dos grupos, como a similaridade dos elementos em um mesmo grupo, e a separação dos grupos, como a similaridade de um elemento aos outros grupos aos quais não pertence (Rousseeuw, 1987), podendo avaliar dados de diferentes tipos e ser utilizada com qualquer medida de similaridade. Gower (Gower, 1971) foi usado como medida de similaridade, uma vez que é capaz de avaliar variados tipos de dados. Essa medida de similaridade calcula a distância de Jaccard para dados binários e usa a fórmula $S_{i j k}=1-\frac{x_{i k}-x_{j k}}{r_{k}}$ para dados contínuos, sendo $x_{i k}$ o valor da $k$-ésima variável para o $i$-ésimo indivíduo, $x_{j k}$ o valor da $k$-ésima variável para o $j$-ésimo indivíduo e $r_{k}$ o intervalo de valores assumidos pela $k$-ésima variável.

\section{Análise de Componentes Principais de Variáveis Misturadas Numéricas e Categóricas (PCAMix)}

A análise de componentes principais de variáveis misturadas numéricas e categóricas do pacote em R PCAmixdata (Chavent et al., 2014) foi utilizada. PCAmix é baseado na Decomposição de Valor Singular Generalizada (GSVD), aplicando MCA quando todas variáveis são categóricas e PCA quando todas variáveis são numéricas. Portanto, similaridades de variáveis numéricas são calculadas como distâncias Euclideanas e de variáveis categóricas baseadas em distância $\chi^{2}$. PCAmix pode ser usada na análise de dados categóricos e numéricos, com a vantagem de permitir a representação de seus resultados de forma gráfica intuitiva e informativa, representando as relações entre variáveis e instâncias dos dados.

\section{Caracterização de grupos}

Tabela 5.3: Variáveis usadas para caracterização de grupos de pacientes

\begin{tabular}{ccc} 
Nome da variável & Variável & Tipo dos dados \\
\hline direct_bilirubin & bilirrubina direta & numérico \\
ferritin & ferritina & numérico \\
acsequest & sequestro esplênico agudo & binário \\
aplastic & episódio aplástico & binário \\
avanecros & necrose avascular quadril / ombro & binário \\
cardinsuff & insuficiência cardíaca & binário \\
cholecystect & colecistectomia & binário \\
cholelisludg & colelitíase & binário \\
dactylitis & dactilite (síndrome mão-pé) & binário \\
delayreact & reação transfusional hemolítica tardia & binário \\
hepatseq & sequestro hepático & binário \\
hipreplace & artroplastia de quadril & binário \\
hyperhemol & hiperhemólise relacionada à transfusão & binário \\
lasereye & cirurgia oftalmológica a laser & binário \\
rethemor & hemorragia retiniana & binário \\
seizures & convulsão & binário \\
sepsis & sépsis/bacteremia & binário \\
splenectomy & esplenectomia & binário \\
thromboemb & tromboembolismo venoso & binário \\
vitrectomy & vitrectomia & binário \\
vitrhemor & hemorragia vítrea & binário \\
history_transf & histórico de transfusão & binário \\
current_hydrox & tratamento com Hidroxiuréia atualmente & binário \\
& &
\end{tabular}

Para a caracterização dos pacientes em cada grupo, variáveis relacionadas à anemia falciforme foram selecionadas (Tabela 5.3). Os dados incluem complicações, resultados de exames e história 
clínica que são decorrência da anemia falciforme.

Os grupos resultantes foram comparados em relação à ocorrência de doenças que ocorrem concomitantemente com anemia falciforme e resultados de exames com objetivo de identificar as características que distinguem os pacientes de cada grupo. Porcentagens de pacientes que possuem as comorbidades no momento da inscrição no estudo ou média de resultados de exames foram comparadas por meio de análise de variância (ANOVA) ou teste Kruskal-Wallis no caso de variáveis contínuas e teste Chi-quadrado ou teste exato de Fisher com correção de Bonferroni para determinar significância para testes múltiplos. Adicionalmente, testes post-hoc foram utilizados entre grupos.

Com objetivo de comparar os resultados dos algoritmos, grupos provenientes de diferentes algoritmos foram comparados dois a dois. Na comparação, as porcentagens de pacientes coincidindo nos dois grupos foram calculadas. Com essa comparação, pode-se inferir se há composição de pacientes similar considerando-se os dois grupos.

\subsection{Resultados - Agrupamento - pacientes HbSC}

\subsubsection{Pacientes com menos de 18 anos de idade}

Tabela 5.4: BIC - agrupamento TwoStep de pacientes HbSC com idade menor a 18 anos

\begin{tabular}{ccc} 
Número de grupos & BIC & Diferença BIC \\
\hline 1 & 1281,122 & \\
$\mathbf{2}$ & $\mathbf{1 1 0 5 , 6 8 5}$ & $\mathbf{- 1 7 5 , 4 3 7}$ \\
3 & 1098,852 & $-6,833$ \\
4 & 1100,960 & 2,108 \\
5 & 1131,015 & 30,056 \\
6 & 1175,761 & 44,745
\end{tabular}

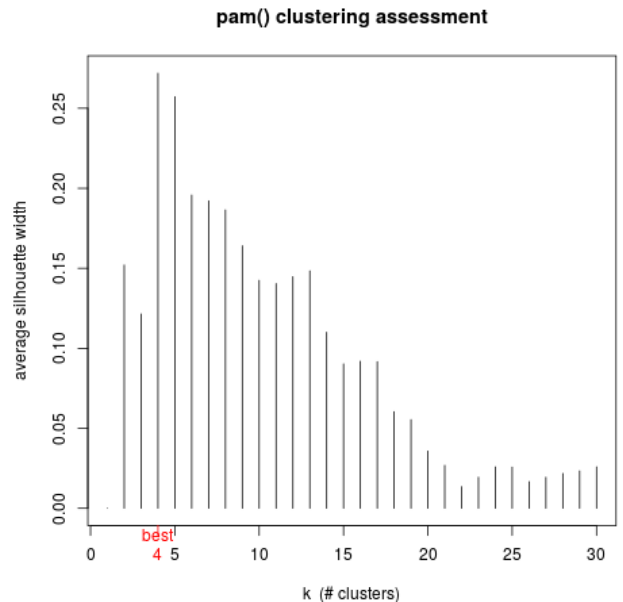

Figura 5.1: Silhouette PAM com pacientes HbSC com idade menor a 18 anos

O agrupamento TwoStep com BIC agrupou os pacientes HbSC com idade menor a 18 anos em 2 grupos, compreendendo 78 e 66 pacientes (Tabela 5.4). PAM com Silhouettte de valor de 0.27 (Figura 5.1), gerou 4 grupos contendo 113, 63, 126 e 88 indivíduos. Gráficos para o primeiro e terceiro componentes principais apontam a separação dos pacientes em 3 grupos (Figura 5.2). Na análise dos resultados do PCAMix, pacientes foram considerados outliers caso estivessem localizados em 


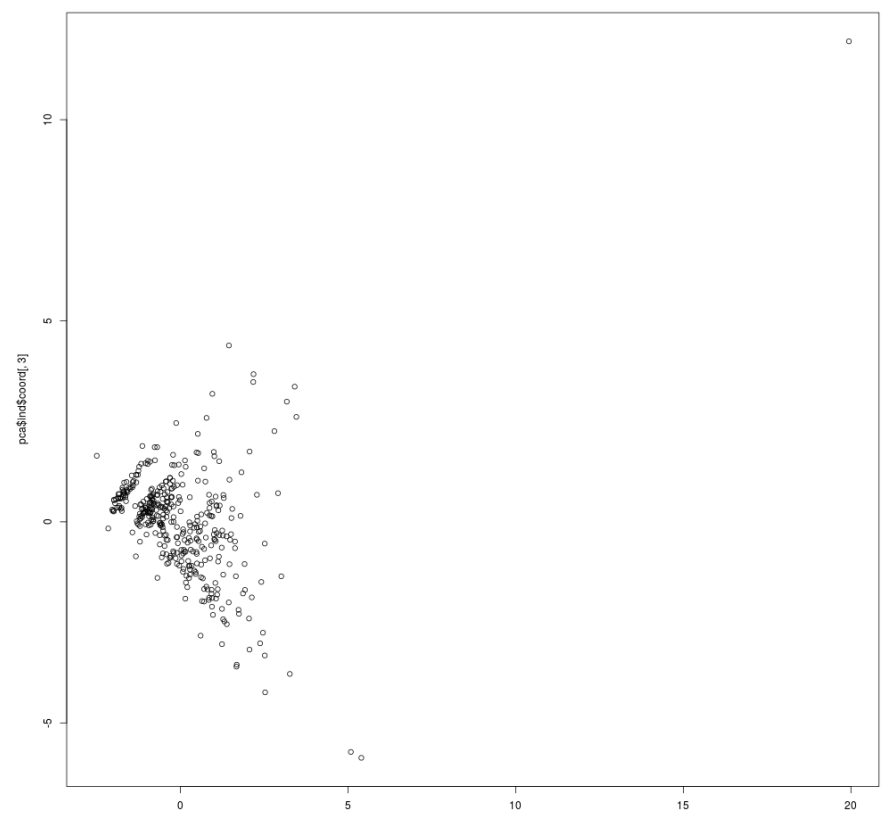

Figura 5.2: Componentes principais: PC1 versus PC3 - pacientes HbSC com idade menor a 18 anos

regiões mais afastadas do centro dos grupos. Consequentemente, os grupos formados pelo PCAMix são compostos por 47, 52 e 110 pacientes. 


\section{Comparação dos resultados dos algoritmos}

Tabela 5.5: Comparação dos resultados dos algoritmos - TwoStep e PAM - pacientes HbSC com idade menor a 18 anos

\begin{tabular}{cccc} 
& & \multicolumn{2}{c}{ TwoStep } \\
& & $\begin{array}{c}\text { grupo 1 } \\
(\mathrm{n}=78)\end{array}$ & $\begin{array}{c}\text { grupo 2 } \\
(\mathrm{n}=66)\end{array}$ \\
\hline \multirow{4}{*}{ PAM } & grupo 1 $(\mathrm{n}=113)$ & $\mathbf{8 7 \%}$ & $13 \%$ \\
& grupo 2 $(\mathrm{n}=63)$ & $0 \%$ & $\mathbf{1 0 0 \%}$ \\
& grupo 3 $(\mathrm{n}=126)$ & $\mathbf{8 9} \%$ & $11 \%$ \\
& grupo 4 $(\mathrm{n}=88)$ & $5 \%$ & $\mathbf{9 5} \%$
\end{tabular}

Tabela 5.6: Comparação dos resultados dos algoritmos - PCAMix e PAM - pacientes HbSC com idade menor a 18 anos

\begin{tabular}{cccccc} 
& & \multicolumn{4}{c}{ PAM } \\
& & grupo 1 & grupo 2 & grupo 3 & grupo 4 \\
& & $(\mathrm{n}=113)$ & $(\mathrm{n}=63)$ & $(\mathrm{n}=126)$ & $(\mathrm{n}=88)$ \\
\hline \multirow{3}{*}{ PCAMix } & grupo 1 $(\mathrm{n}=47)$ & $3 \%$ & $\mathbf{8 9} \%$ & $2 \%$ & $6 \%$ \\
& grupo 2 $(\mathrm{n}=52)$ & $25 \%$ & $3 \%$ & $19 \%$ & $\mathbf{5 3} \%$ \\
& grupo 3 $(\mathrm{n}=110)$ & $\mathbf{4 2} \%$ & $0 \%$ & $\mathbf{5 5 \%}$ & $3 \%$
\end{tabular}

Tabela 5.7: Comparação dos resultados dos algoritmos - PCAMix e TwoStep - pacientes HbSC com idade menor a 18 anos

\begin{tabular}{cccc} 
& & \multicolumn{2}{c}{ TwoStep } \\
& & grupo 1 & grupo 2 \\
& & $(\mathrm{n}=78)$ & $(\mathrm{n}=66)$ \\
\hline \multirow{3}{*}{ PCAMix } & grupo 1 $(\mathrm{n}=47)$ & $3 \%$ & $\mathbf{9 7 \%}$ \\
& grupo 2 $(\mathrm{n}=52)$ & $31 \%$ & $\mathbf{6 9 \%}$ \\
& grupo 3 $(\mathrm{n}=110)$ & $\mathbf{9 5} \%$ & $5 \%$
\end{tabular}

Comparando os grupos de pacientes HbSC com idade menor de 18 anos, embora os distintos algoritmos tenham dado origem a distintas quantidades de grupos, houve uma correspondência quanto à composição de cada grupo (Tabela 5.5, 5.6 e 5.7). A Tabela 5.5 indica que o algoritmo PAM refinou ambos grupos gerados pelo algoritmo TwoStep, dividindo-os em dois. Em comparação com PCAMix, PAM originou um grupo equivalente ao primeiro grupo, dissociou o terceiro grupo em dois e criou outro grupo com a maioria dos pacientes do segundo grupo. O algoritmo PCAMix gerou um grupo equivalente ao primeiro grupo do TwoStep e separou o segundo em dois. 


\section{Caracterização dos grupos}

Tabela 5.8: Agrupamento PAM de pacientes HbSC com menos de 18 anos - variáveis binárias

\begin{tabular}{ccccc} 
Variável & \multicolumn{4}{c}{ Porcentagem de ocorrência } \\
& $\begin{array}{cccc}\text { grupo 1 } \\
(\mathrm{n}=113)\end{array}$ & $\begin{array}{c}\text { grupo 2 } \\
(\mathrm{n}=126)\end{array}$ & $\begin{array}{c}\text { grupo 3 } \\
(\mathrm{n}=88)\end{array}$ & $\begin{array}{c}\text { grupo 4 } \\
(\mathrm{n}=63)\end{array}$ \\
\hline acutpainscd & 100 & 0 & 81 & 100 \\
chestdiag & 66 & 0 & 9 & 0 \\
history transf & 33 & 16 & 53 & 20
\end{tabular}

Tabela 5.9: Agrupamento PAM de pacientes HbSC com menos de 18 anos - variáveis numéricas

\begin{tabular}{ccccc} 
Variável & \multicolumn{4}{c}{ Média (desvio padrão) } \\
& $\begin{array}{c}\text { grupo 1 } \\
(\mathrm{n}=109)\end{array}$ & $\begin{array}{c}\text { grupo 2 } \\
(\mathrm{n}=62)\end{array}$ & $\begin{array}{c}\text { grupo 3 } \\
(\mathrm{n}=119)\end{array}$ & $\begin{array}{c}\text { grupo 4 } \\
(\mathrm{n}=87)\end{array}$ \\
\hline age & $12,31(3,44)$ & $6,41(4,75)$ & $10,47(4,09)$ & $8,69(3,87)$ \\
n_admacchest & $1,06(1,32)$ & $0(0)$ & $1,95(2,18)$ & $0(0)$ \\
n_admacutpain & $2,10(1,97)$ & $0(0)$ & $2,68(3,9)$ & $0,86(1,19)$ \\
direct_bilirubin $(\mathrm{mg} / \mathrm{dL})$ & $0,41(0,16)$ & $0,25(0,15)$ & $0,27(0,15)$ & $0,29(0,18)$ \\
indirect_bilirubin $(\mathrm{mg} / \mathrm{dL})$ & $0,77(0,41)$ & $0,31(0,28)$ & $0,25(0,16)$ & $0,21(0,12)$ \\
total_bilirubin $(\mathrm{mg} / \mathrm{dL})$ & $1,18(0,49)$ & $0,55(0,37)$ & $0,52(0,2)$ & $0,50(0,21)$
\end{tabular}

Os pacientes HbSC com menos de 18 anos foram agrupados seguindo diferentes padrões de gravidade da doença. O algoritmo TwoStep deu origem a um grupo incluindo pacientes menos graves (segundo grupo TwoStep), que foi refinado em dois grupos pelos algoritmos PAM e (segundo e quarto grupos PAM) e PCAMix (primeiro e segundo grupo PCAMix). Os pacientes mais graves foram agregados em grupos análogos pelos algoritmos TwoStep e PCAMix (primeiro grupo TwoStep e terceiro grupo PCAMix), que foi refinado pelo algoritmo PAM (primeiro e terceiro grupo PAM).

O segundo grupo gerado pelo algoritmo PAM, similar ao primeiro grupo PCAMix e segundo grupo TwoStep, inclui pacientes com menor grau de gravidade da doença, mais jovens (idade média 6,4 anos), que não tem episódios de dor aguda da anemia falciforme ( $0 \%$ teve episódios, com média de 0 admissões hospitalares causadas por episódios de dor da anemia falciforme) ou diagnóstico de síndrome torácica aguda ou pneumonia ( $0 \%$ foram diagnosticados, com uma média de 0 admissões hospitalares causadas por síndrome torácica aguda ou pneumonia). Os pacientes ainda possuem níveis intermediários de bilirrubina indireta (média de $0,31 \mathrm{mg} / \mathrm{dL}$ ) e níveis mais baixos de bilirrubina direta e total (médias de $0,25 \mathrm{mg} / \mathrm{dL}$ e $0,55 \mathrm{mg} / \mathrm{dL}$, respectivamente).

O quarto grupo obtido pelo algoritmo PAM, similar ao segundo grupo PCAMix e TwoStep, também representa pacientes com menor grau de gravidade da doença. No entanto, os pacientes são mais velhos (idade média de 8,7 anos), com histórico de episódios de dor aguda da anemia falciforme (100\% tiveram algum episódio e a média de admissões por episódio de dor aguda da anemia falciforme é de 0,86 ) e com níveis mais baixos de bilirrubina indireta (média de 0,21 mg/dL) quando comparado com pacientes no segundo grupo PAM.

O terceiro grupo PAM, contendo pacientes do primeiro grupo TwoStep e terceiro grupo PCAMix, engloba pacientes com fenótipo mais grave que tiveram episódios de dor aguda da anemia falciforme (81\% tiveram episódios, com uma média de 2,68 admissões hospitalares por dor aguda da anemia falciforme) e síndrome torácica aguda ou pneumonia (90\% tiveram episódios, com uma média de 
1,95 admissões hospitalares por síndrome torácica aguda ou pneumonia). Os pacientes desse grupo possuem histórico de transfusões de sangue (53\%) e possuem níveis de bilirrubina mais baixos (média de $0,25 \mathrm{mg} / \mathrm{dL}$ de bilirrubina indireta, $0,27 \mathrm{mg} / \mathrm{dL}$ de bilirrubina direta e $0,52 \mathrm{mg} / \mathrm{dL}$ de bilirrubina total).

O primeiro grupo PAM, contendo pacientes do primeiro grupo TwoStep terceiro grupo PCAMix, também contém pacientes com manifestações mais graves. No entanto, em comparação com os pacientes do terceiro grupo PAM, os pacientes são mais velhos (idade méia de 12,31 anos), têm menos diagnósticos de dor aguda da anemia falciforme ou pneumonia ( $66 \%$ foram diagnosticados, com uma média de 1,06 internações hospitalares causadas por dor aguda da anemia falciforme ou pneumonia) e possuem histórico de transfusões (33\%). Adicionalmente, os pacientes possuem níveis mais altos de bilirrubina (média de $0,77 \mathrm{mg} / \mathrm{dL}$ de bilirrubina indireta, $0,41 \mathrm{mg} / \mathrm{dL}$ de bilirrubina direta e $1,18 \mathrm{mg} / \mathrm{dL}$ de bilirrubina total). 


\subsubsection{Pacientes com 18 anos de idade ou mais}

Tabela 5.10: BIC - agrupamento agrupamento TwoStep de pacientes HbSC com 18 anos ou mais

\begin{tabular}{ccc} 
Número de grupos & BIC & Diferença BIC \\
\hline 1 & 617,399 & \\
$\mathbf{2}$ & $\mathbf{5 8 7 , 1 4 2}$ & $\mathbf{- 3 0 , 2 5 7}$ \\
3 & 614,845 & 27,703 \\
4 & 646,854 & 32,009 \\
5 & 686,772 & 39,918 \\
6 & 746,921 & 60,149
\end{tabular}

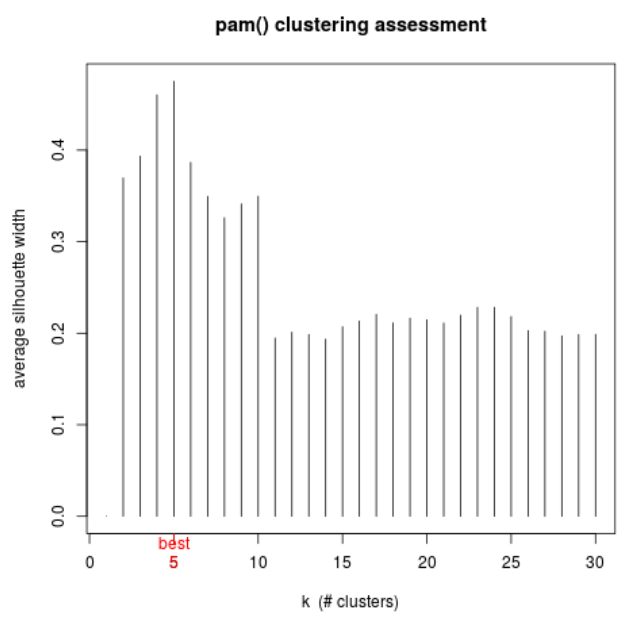

Figura 5.3: Silhouette PAM com pacientes HbSC com 18 anos ou mais

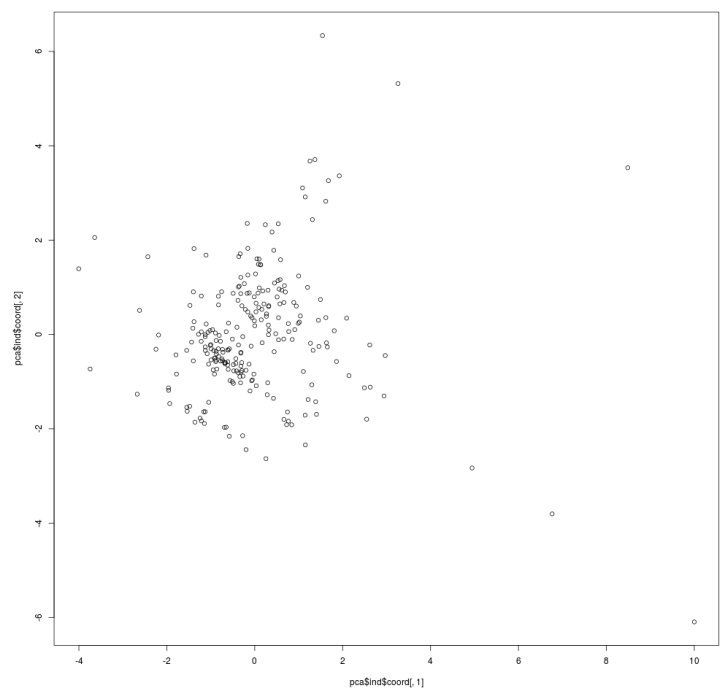

Figura 5.4: Componentes principais: PC1 versus PC2 - pacientes HbSC com 18 anos ou mais

O agrupamento TwoStep com BIC gerou dois grupo com os pacientes HbSC com 18 anos ou mais compostos de 30 e 20 indivíduos (Tabela 5.10). PAM com Silhouette 0, 48 instituiu 5 grupos contendo 80, 84, 47, 25 e 9 pacientes (Figura 5.3). Finalmente, PCAMix separou os pacientes em 3 grupos abrangendo 10, 36 e 191 pacientes (Figura 5.4). 


\section{Comparação dos resultados dos algoritmos}

Tabela 5.11: Comparação dos resultados dos algoritmos - TwoStep e PAM - pacientes HbSC com 18 anos ou mais

\begin{tabular}{cccc} 
& & \multicolumn{2}{c}{ TwoStep } \\
& & Grupo 1 & Grupo 2 \\
& & $(\mathrm{n}=30)$ & $(\mathrm{n}=20)$ \\
\hline \multirow{5}{*}{ PAM } & Grupo 1 - $(\mathrm{n}=80)$ & $0 \%$ & $\mathbf{1 0 0} \%$ \\
& Grupo 2 - $(\mathrm{n}=84)$ & $\mathbf{1 0 0} \%$ & $0 \%$ \\
& Grupo 3 - $(\mathrm{n}=47)$ & $38 \%$ & $\mathbf{6 2} \%$ \\
& Grupo 4 - $(\mathrm{n}=25)$ & $\mathbf{1 0 0 \%}$ & $0 \%$ \\
& Grupo 5 - $(\mathrm{n}=9)$ & $\mathbf{7 5} \%$ & $25 \%$
\end{tabular}

Tabela 5.12: Comparação dos resultados dos algoritmos - PAM e PCAMix - pacientes HbSC com 18 anos ou mais

\begin{tabular}{ccccc} 
& & \multicolumn{3}{c}{ PCAMix } \\
& & $\begin{array}{c}\text { Grupo 1 } \\
(\mathrm{n}=10)\end{array}$ & $\begin{array}{c}\text { Grupo 2 } \\
(\mathrm{n}=36)\end{array}$ & $\begin{array}{c}\text { Grupo 3 } \\
(\mathrm{n}=191)\end{array}$ \\
\hline \multirow{5}{*}{ PAM } & Grupo 1 - $(\mathrm{n}=80)$ & $1 \%$ & $9 \%$ & $\mathbf{9 0 \%}$ \\
& Grupo 2 - $(\mathrm{n}=84)$ & $1 \%$ & $5 \%$ & $\mathbf{9 4 \%}$ \\
& Grupo 3 - $(\mathrm{n}=47)$ & $0 \%$ & $9 \%$ & $\mathbf{9 1 \% \%}$ \\
& Grupo 4 - $(\mathrm{n}=25)$ & $8 \%$ & $\mathbf{8 8} \%$ & $4 \%$ \\
& Grupo 5 - $(\mathrm{n}=9)$ & $\mathbf{1 0 0} \%$ & $0 \%$ & $0 \%$
\end{tabular}

Tabela 5.13: Comparação dos resultados dos algoritmos - TwoStep e PCAMix - pacientes HbSC com 18 anos ou mais

\begin{tabular}{cccc} 
& & \multicolumn{2}{c}{ TwoStep } \\
& & Grupo 1 & Grupo 2 \\
& & $(\mathrm{n}=30)$ & $(\mathrm{n}=20)$ \\
\hline \multirow{3}{*}{ PCAMix } & Grupo 1 $(\mathrm{n}=10)$ & $33 \%$ & $\mathbf{6 7 \%}$ \\
& Grupo 2 $(\mathrm{n}=36)$ & $\mathbf{7 7 \%}$ & $23 \%$ \\
& Grupo 3 $(\mathrm{n}=191)$ & $\mathbf{5 2} \%$ & $\mathbf{4 8} \%$
\end{tabular}

Embora os algoritmos tenham definido diferentes números de grupos para os pacientes HbSC com 18 anos ou mais, pode-se observar uma correspondência entre os grupos (Tabela 5.11, 5.12 e 5.13). O primeiro grupo TwoStep foi dividido em três diferentes grupos por PAM e o segundo grupo TwoStep foi dividido em dois. O primeiro grupo TwoStep é similar ao segundo grupo PCAMix e o segundo TwoStep é similar ao primeiro grupo PCAMix. O PCAMix também formou um terceiro grupo contendo alguns pacientes do primeiro e segundo grupos do TwoStep. 


\section{Caracterização dos grupos}

Tabela 5.14: Agrupamento PAM de pacientes $H b S C$ com 18 anos ou mais - variáveis binárias

\begin{tabular}{cccccc} 
Variável & Grupo 1 & Porcentagem de ocorrência & \\
& Grupo 2 & Grupo 3 & Grupo 4 & Grupo 5 \\
& $(\mathrm{n}=80)$ & $(\mathrm{n}=84)$ & $(\mathrm{n}=47)$ & $(\mathrm{n}=25)$ & $(\mathrm{n}=9)$ \\
\hline acutpainscd & 100 & 100 & 98 & 0 & 89 \\
chestdiag & 100 & 0 & 58 & 8 & 43 \\
current_hydrox & 9 & 10 & 21 & 0 & 67 \\
infarstroke & 0 & 0 & 0 & 8 & 100 \\
lasereye & 5 & 5 & 47 & 0 & 0 \\
retinopathy & 0 & 0 & 100 & 12 & 43 \\
silentinfar & 0 & 0 & 0 & 0 & 38
\end{tabular}

Tabela 5.15: Agrupamento PAM de pacientes HbSC com 18 anos ou mais - variáveis numéricas

\begin{tabular}{cccccc} 
Variável & Grupo 1 & Grupo 2 & Grupo 3 & Grupo 4 & Grupo 5 \\
& $(\mathrm{n}=80)$ & $(\mathrm{n}=84)$ & $(\mathrm{n}=47)$ & $(\mathrm{n}=25)$ & $(\mathrm{n}=9)$ \\
\hline n_admacchest & $2,28(2,75)$ & $0(0)$ & $0,8(1,2)$ & $0,04(0,20)$ & $0,57(0,79)$ \\
n_admacutpain & $6,32(7,93)$ & $3,02(4,41)$ & $4,94(8,92)$ & 0 & $2,5(0)$
\end{tabular}

Com relação às características fenotípicas dos pacients HbSC com 18 anos ou mais, os algoritmos os destinaram a grupos com diferentes categorias de gravidade. Um grupo com pacientes com fenótipo menos grave foi criado pelo TwoStep e PCAMix (primeiro grupo TwoStep e segundo grupo PCAMix), que foi dividido em três grupos pelo PAM (segundo, quarto e quinto grupos PAM). TwoStep também gerou um grupo com pacientes com quadro clínico mais grave que foi dividido em dois grupos pelo PCAMix (primeiro e terceiro grupos PCAMix) e em dois pelo PAM (PAM primeiro e terceiro grupos).

Pacientes HbSC com 18 anos ou mais e fenótipos menos graves foram agrupados no quarto grupo PAM, que inclui pacientes do primeiro grupo TwoStep e do segundo grupo PCAMix. O grupo inclui pacientes que não tiveram episódios de dor aguda da anemia falciforme $(0 \%$ teve episódios, com uma média de 0 internações hospitalares causadas por dor aguda da anemia falciforme) ou diagnóstico de síndrome torácica aguda ou pneumonia ( $8 \%$ de diagnose, com média de 0,04 internações hospitalares causadas por síndrome torácica aguda ou pneumonia). Os pacientes não foram tratados com hidroxiuréia (0\%), não tiveram infarto cerebral silencioso (0\%), tiveram menos casos de retinopatias ( $12 \%$ tiveram retinopatias, com $0 \%$ de cirurgias a laser) e acidente vascular cerebral ( $8 \%$ ).

Pacientes HbSC menos graves que experienciaram episódios de dor aguda da anemia falciforme (100\%, com média de 3,02 hospitalizações causadas por episódios de dor aguda da anemia falciforme) foram agrupados no segundo grupo PAM, correspondente ao primeiro grupo TwoStep e terceiro grupo PCAMix.

O quinto grupo PAM, que inclui pacientes do primeiro grupo TwoStep e do primeiro grupo PCAMix, contém pacientes que tiveram episódios de dor aguda da anemia falciforme $(89 \%$ tiveram episódios, com uma média de 2,5 internações hospitalares causadas por dor aguda da anemia falciforme) e diagnóstico de síndrome torácica aguda ou pneumonia (43\% de diagnose, com média de 0,57 internações hospitalares causadas por síndrome torácica aguda ou pneumonia), são tratados 
com hidroxiuréia (67\%), tiveram acidente vascular cerebral (100\%) e infarto cerebral silencioso $(38 \%)$.

O primeiro grupo PAM, contendo pacientes do segundo grupo TwoStep e do terceiro grupo PCAMix, possui pacientes que tiveram episódios de dor aguda da anemia falciforme ( $100 \%$ tiveram episódios, com uma média de 6,32 internações hospitalares causadas por dor aguda da anemia falciforme) e diagnóstico de síndrome torácica aguda ou pneumonia (100\% de diagnose, com média de 2,28 internações hospitalares causadas por síndrome torácica aguda ou pneumonia), são menos frequentemente tratados com hidroxiuréia (9\%), não tiveram retinopatias $(0 \%$, com $5 \%$ de cirurgias a laser), acidente vascular cerebral $(0 \%)$ ou infarto cerebral silencioso $(0 \%)$.

O terceiro grupo PAM, contendo pacientes do segundo grupo TwoStep e do terceiro grupo PCAMix, possui pacientes que tiveram episódios de dor aguda da anemia falciforme (98\% tiveram episódios, com uma média de 4,94 internações hospitalares causadas por dor aguda da anemia falciforme) e diagnóstico de síndrome torácica aguda ou pneumonia (58\% de diagnose, com média de 0, 8 internações hospitalares causadas por síndrome torácica aguda ou pneumonia), menos frequentemente são tratados com hidroxiuréia (21\%), tiveram retinopatias $(100 \%$, com $47 \%$ de cirurgias a laser) e não tiveram acidente vascular cerebral (0\%) e infarto cerebral silencioso $(0 \%)$.

\subsection{Resultados - Agrupamento - pacientes HbSS e $H b S \beta 0$}

\subsubsection{Pacientes com menos de 18 anos de idade}

Tabela 5.16: BIC - agrupamento TwoStep de pacientes HbSS e HbS $\beta 0$ com idade menor a 18 anos

\begin{tabular}{ccc} 
Número de grupos & BIC & Diferença BIC \\
\hline 1 & 7280,888 & \\
2 & 6438,213 & $-842,675$ \\
3 & 5954,013 & $-484,200$ \\
4 & 5606,832 & $-347,181$ \\
$\mathbf{5}$ & $\mathbf{5 3 5 6 , 1 6 5}$ & $\mathbf{- 2 5 0 , 6 6 7}$ \\
6 & 5259,244 & $-96,921$ \\
7 & 5193,564 & $-65,680$ \\
8 & 5156,878 & $-36,686$ \\
9 & 5144,586 & $-12,292$ \\
10 & 5148,211 & 3,624 \\
11 & 5169,471 & 21,260
\end{tabular}

Pacientes HbSS e $H b S \beta 0$ com menos de 18 anos foram agrupados pelo algoritmo TwoStep e BIC em 5 grupos incluindo 93, 59, 131, 134 e 205 pacientes (Tabela 5.16). No entanto, PAM e Silhouette, com valor 0.38, geraram 2 grupos acomodando 829 e 271 pacientes (Figura 5.5). O algoritmo PCAMix agrupou os pacientes em 3 grupos compreendendo 711, 273 e 110 pacientes (Figura 5.6). 


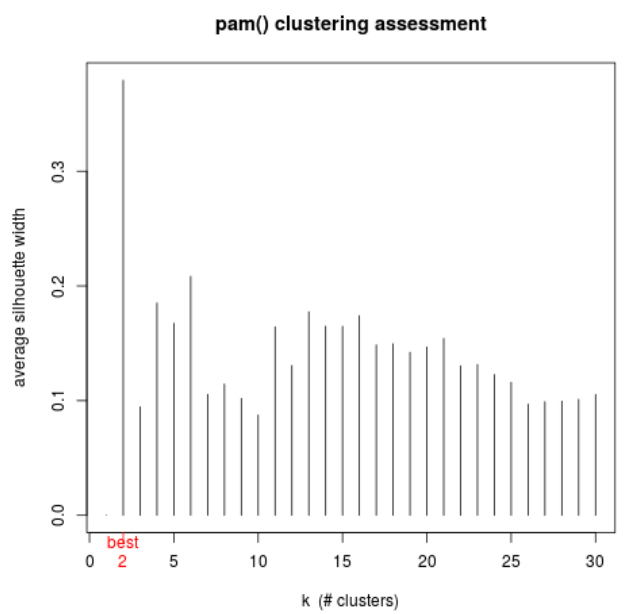

Figura 5.5: Silhouette PAM com pacientes HbSS e HbSß0 com idade menor a 18 anos

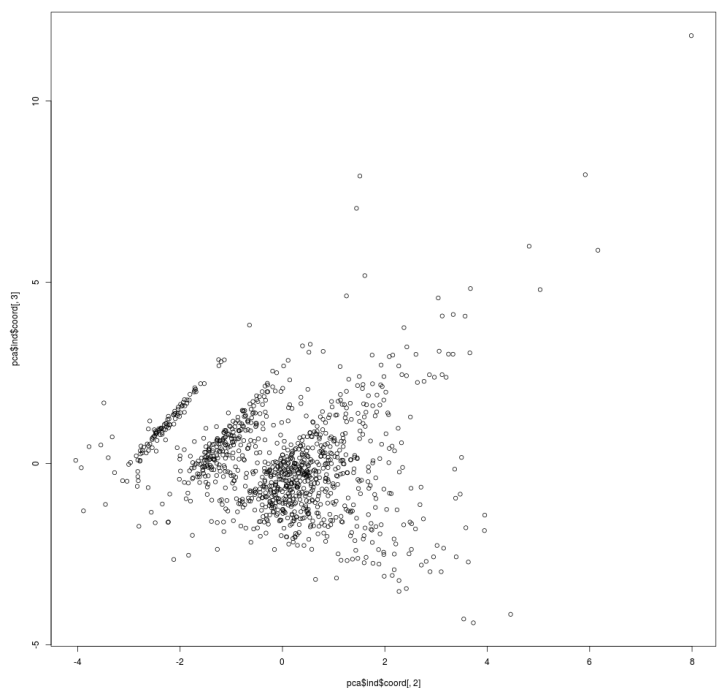

Figura 5.6: Componentes principais: PC1 versus PC3 - pacientes HbSS e HbS $\beta 0$ com idade menor a 18 anos 


\section{Comparação dos resultados dos algoritmos}

Tabela 5.17: Comparação dos resultados dos algoritmos - TwoStep e PAM - pacientes HbSS e HbS $\beta 0$ com idade menor a 18 anos

\begin{tabular}{lccc} 
& & \multicolumn{2}{c}{ PAM } \\
& & Grupo 1 & Grupo 2 \\
& Grupo 1 - $(\mathrm{n}=93)$ & $25 \%$ & $\mathbf{7 5 \%}$ \\
\hline \multirow{5}{*}{ TwoStep } & Grupo 2 - $(\mathrm{n}=59)$ & $\mathbf{8 1} \%$ & $19 \%$ \\
& Grupo 3 - $(\mathrm{n}=131)$ & $22 \%$ & $\mathbf{7 8} \%$ \\
& Grupo 4- $(\mathrm{n}=134)$ & $\mathbf{1 0 0} \%$ & $0 \%$ \\
& Grupo 5 - $(\mathrm{n}=205)$ & $\mathbf{9 9} \%$ & $1 \%$
\end{tabular}

Tabela 5.18: Comparação dos resultados dos algoritmos - PCAMix e PAM - pacientes HbSS e HbS $\beta 0$ com idade menor a 18 anos

\begin{tabular}{cccc} 
& & \multicolumn{2}{c}{ PAM } \\
& & $\begin{array}{c}\text { Grupo 1 } \\
(\mathrm{n}=829)\end{array}$ & $\begin{array}{c}\text { Grupo 2 } \\
(\mathrm{n}=271)\end{array}$ \\
\hline \multirow{3}{*}{ PCAMix } & Grupo 1 $-(\mathrm{n}=711)$ & $\mathbf{7 0} \%$ & $30 \%$ \\
& Grupo 2 $-(\mathrm{n}=273)$ & $\mathbf{8 3} \%$ & $17 \%$ \\
& Grupo 3- $\mathrm{n}=110$ & $\mathbf{9 0} \%$ & $10 \%$
\end{tabular}

Tabela 5.19: Comparação dos resultados dos algoritmos - PCAMix e TwoStep - pacientes HbSS e HbS $\beta 0$ com idade menor a 18 anos

\begin{tabular}{ccccc} 
& & \multicolumn{3}{c}{ PCAMix } \\
& & $\begin{array}{c}\text { Grupo 1 } \\
(\mathrm{n}=711)\end{array}$ & $\begin{array}{c}\text { Grupo 2 } \\
(\mathrm{n}=273)\end{array}$ & $\begin{array}{c}\text { Grupo 3 } \\
(\mathrm{n}=110)\end{array}$ \\
\hline \multirow{5}{*}{ TwoStep } & Grupo 1 $(\mathrm{n}=93)$ & $48 \%$ & $35 \%$ & $16 \%$ \\
& Grupo 2 $(\mathrm{n}=59)$ & $\mathbf{9 6 \%}$ & $4 \%$ & $0 \%$ \\
& Grupo 3 $(\mathrm{n}=131)$ & $\mathbf{6 2} \%$ & $27 \%$ & $11 \%$ \\
& Grupo 4 $(\mathrm{n}=134)$ & $7 \%$ & $\mathbf{6 0 \%}$ & $33 \%$ \\
& Grupo 5 $(\mathrm{n}=205)$ & $\mathbf{1 0 0} \%$ & $0 \%$ & $0 \%$
\end{tabular}

Apesar dos algoritmos PAM e TwoStep terem agrupado os pacientes HbSS e HbS $\beta 0$ com menos de 18 anos em distintas quantidades de grupos, 2 e 5 grupos, respectivamente, houve uma correspondência entre os mesmos com relação aos pacientes que os compõem (Tabela 5.17). O primeiro grupo PAM foi segmentado em três diferentes grupos pelo TwoStep (segundo, quarto e quinto grupos). O segundo grupo PAM foi subdividido em dois grupos pelo TwoStep (primeiro e terceiro grupos). No entanto, comparando os resultados do PCAMix com PAM e TwoStep, o PCAMix agrupou os pacientes em grupos não comparáveis com relação aos pacientes que os compõem (Tabelas 5.18 e $5.19)$ 
Caracterização dos grupos

\section{Agrupamento TwoStep e PAM}

Tabela 5.20: Agrupamento TwoStep de pacientes HbSS e HbSBO com idade menor a 18 anos - variáveis binárias

\begin{tabular}{cccccc} 
Variável & \multicolumn{6}{c}{ Porcentagem de ocorrência } & \\
& Grupo 1 & Grupo 2 & Grupo 3 & Grupo 4 & Grupo 5 \\
& $(\mathrm{n}=93)$ & $(\mathrm{n}=59)$ & $(\mathrm{n}=131)$ & $(\mathrm{n}=134)$ & $(\mathrm{n}=205)$ \\
\hline acutpainscd & 82 & 97 & 80 & 40 & 100 \\
chestdiag & 78 & 95 & 71 & 28 & 100 \\
cholecystect & 18 & 47 & 12 & 7 & 15 \\
cholelisludg & 23 & 59 & 22 & 13 & 25 \\
current_hydrox & 43 & 39 & 62 & 18 & 58 \\
elevtcd & 52 & 19 & 100 & 0 & 0 \\
history_transf & 100 & 98 & 93 & 66 & 92 \\
infarstroke & 74 & 3 & 1 & 0 & 0 \\
ischattack & 23 & 5 & 0 & 0 & 0 \\
legulcer & 0 & 8 & 1 & 0 & 0 \\
moya & 23 & 5 & 1 & 0 & 0 \\
retinopathy & 1 & 17 & 0 & 1 & 0 \\
seizures & 29 & 14 & 7 & 2 & 4 \\
silentinfar & 44 & 5 & 1 & 0 & 0 \\
transfhem & 73 & 12 & 15 & 1 & 2
\end{tabular}

Tabela 5.21: Agrupamento TwoStep de pacientes HbSS e HbSBO com idade menor a 18 anos - variáveis numéricas

\begin{tabular}{|c|c|c|c|c|c|}
\hline \multirow[b]{2}{*}{ Variável } & \multicolumn{5}{|c|}{ Média (desvio padrão) } \\
\hline & $\begin{array}{l}\text { Grupo } 1 \\
(\mathrm{n}=93)\end{array}$ & $\begin{array}{l}\text { Grupo } 2 \\
(\mathrm{n}=59)\end{array}$ & $\begin{array}{l}\text { Grupo } 3 \\
(\mathrm{n}=131)\end{array}$ & $\begin{array}{c}\text { Grupo } 4 \\
(\mathrm{n}=134)\end{array}$ & $\begin{array}{c}\text { Grupo } 5 \\
(\mathrm{n}=205)\end{array}$ \\
\hline \multirow[t]{2}{*}{ age (years) } & 11,57 & 12,49 & 9,71 & 6,433 & 10,03 \\
\hline & $(3,52)$ & $(3,8)$ & $(3,49)$ & $(4,66)$ & $(4,35)$ \\
\hline \multirow[t]{2}{*}{ hbf $(\%)$} & 4,46 & 8,75 & 10,1 & 13,9 & 14,99 \\
\hline & $(5,76)$ & $(5,52)$ & $(7,59)$ & $(8,86)$ & $(9,89)$ \\
\hline \multirow[t]{2}{*}{ n_admacchest } & 2,19 & 3,19 & 2,16 & 0,65 & 3,68 \\
\hline & $(2,38)$ & $(2,35)$ & $(2,58)$ & $(1,41)$ & $(3,07)$ \\
\hline \multirow[t]{2}{*}{ n_admacutpain } & 2,51 & 3,07 & 2,53 & 1,17 & 5,45 \\
\hline & $(3,38)$ & $(2,83)$ & $(3,13)$ & $(2,52)$ & $(6,58)$ \\
\hline \multirow{2}{*}{ direct_bilirubin $(\mathrm{mg} / \mathrm{dL})$} & 0,47 & 0,57 & 0,42 & 0,36 & 0,34 \\
\hline & $(0,27)$ & $(0,22)$ & $(0,24)$ & $(0,21)$ & $(0,18)$ \\
\hline \multirow[t]{2}{*}{ ferritin $(\mathrm{ng} / \mathrm{ml})$} & 4315,51 & 496,85 & 1537,35 & 463,25 & 511,42 \\
\hline & $(14399,62)$ & $(552,73)$ & $(8740,54)$ & $(1012,05)$ & $(572,62)$ \\
\hline \multirow[t]{2}{*}{ indirect_bilirubin $(\mathrm{mg} / \mathrm{dL})$} & 1 & 2,8 & 0,92 & 0,71 & 0,66 \\
\hline & $(0,89)$ & $(2,46)$ & $(0,74)$ & $(0,53)$ & $(0,51)$ \\
\hline \multirow[t]{2}{*}{ lactate $(\mathrm{U} / \mathrm{L})$} & 676,4 & 933,98 & 607,18 & 511,9 & 530,86 \\
\hline & $(376,99)$ & $(633,55)$ & $(306,24)$ & $(248,67)$ & $(220,17)$ \\
\hline \multirow[t]{2}{*}{ total_bilirubin $(\mathrm{mg} / \mathrm{dL})$} & 1,47 & 3,38 & 1,34 & 1,07 & 1 \\
\hline & (1) & $(2,53)$ & $(0,84)$ & $(0,64)$ & $(0,6)$ \\
\hline \multirow[t]{2}{*}{ retic $(\%)$} & 11,18 & 11,78 & 11,99 & 10,36 & 9,26 \\
\hline & $(5,8)$ & $(5,25)$ & $(5,43)$ & $(5,14)$ & $(5,05)$ \\
\hline \multirow[t]{2}{*}{ transn_unitransf } & 1,15 & 0,47 & 0,43 & 0,39 & 0,38 \\
\hline & $(0,34)$ & $(0,6)$ & $(0,56)$ & $(0,63)$ & $(0,63)$ \\
\hline
\end{tabular}

Pacientes HbSS e HbS $\beta 0$ com idade menor a 18 anos foram agrupados pelo TwoStep em 5 dife- 
rentes grupos compreendendo 93, 59, 131, 134 e 205 pacientes. O grupo com pacientes com fenótipo menos grave, o quarto grupo, inclui parte dos pacientes do primeiro grupo PAM. Esse grupo é composto por pacientes que sofrem menos episódios de dor aguda da anemia falciforme (40\%, com média de 1,17 internações hospitalizações por dor aguda da anemia falciforme) e diagnóstico de síndrome torácica aguda ou pneumonia (28\%, com média de 0,65 internações por síndrome torácica aguda ou pneumonia). Os pacientes experimentaram menos complicações (7\% colecistectomia, 13\% colelitíase, $0 \%$ acidente vascular cerebral, $0 \%$ ataque isquêmico transitório, $0 \%$ úlcera de pernas, $0 \%$ moyamoya, $1 \%$ retinopatia, $2 \%$ ataques epiléticos, $0 \%$ infarto cerebral silencioso e $1 \%$ hemossiderose transfusional). Os pacientes apresentam menores níveis de bilirrubina $(0,71 \mathrm{mg} / \mathrm{dL}$ indireta, $0,36 \mathrm{mg} / \mathrm{dL}$ direta e $1,07 \mathrm{mg} / \mathrm{dL}$ total) e ferritina $(463,25 \mathrm{ng} / \mathrm{ml})$, no entanto, níveis mais altos de HbF $(13,9 \%)$ e reticulócito $(10,36 \%)$.

O terceiro grupo, que compreende pacientes do segundo grupo PAM, é constituído por pacientes que sofreram episódios de dor aguda da anemia falciforme (80\%, com média de 2,53 internações hospitalizações por dor aguda da anemia falciforme) e diagnóstico de síndrome torácica aguda ou pneumonia (71\%, com média de 2,16 internações por síndrome torácica aguda ou pneumonia). Os pacientes apresentam níveis moderadamente mais baixos de $\mathrm{HbF}(10,1 \%)$ e valores moderadamente mais altos de outros biomarcadores $(0,92 \mathrm{mg} / \mathrm{dL}$ de bilirrubina indireta, $0,422 \mathrm{mg} / \mathrm{dL}$ de bilirrubina direta e 1, $34 \mathrm{mg} / \mathrm{dL}$ de bilirrubina total, 1537, $35 \mathrm{de} \mathrm{ng} / \mathrm{ml}$ ferritina, 607, $18 \mathrm{U} / \mathrm{L}$ de HDL e 11,99\% de reticulócito). Os pacientes apresentam complicações similares em comparação com os pacientes no quarto grupo, no entanto, são mais frequentemente tratados com hidroxiuréia (62\%), possuem mais histórico de transfusões (93\%), ataques epiléticos (7\%) e hemossiderose transfusional (15\%) e todos possuem doppler transcraniano anormal.

O primeiro grupo, que contém pacientes do segundo grupo PAM, engloba pacientes que tiveram menos episódios de dor aguda da anemia falciforme (82\%, com média de 2, 50 internações hospitalizações por dor aguda da anemia falciforme) e diagnóstico de síndrome torácica aguda ou pneumonia (78\%, com média de 2, 19 internações por síndrome torácica aguda ou pneumonia). Comparando-se com o terceiro grupo, os pacientes mais frequentemente possuem histórico de transfusões (100\%, com uma média de 1, 15 unidades por transfusão em transfusões nos últimos 12 meses), acidente vascular cerebral (74\%), moyamoya (23\%), ataques epiléticos (29\%), infarto cerebral silencioso (44\%) e hemossiderose transfusional (73\%), doppler transcraniano anormal $(52 \%)$ e são menos frequentemente tratados com hidroxiuréia $(43 \%)$. Os pacientes também manifestam níveis mais baixos de $\operatorname{HbF}(4,46 \%)$ e ferritina $(4315,51 \mathrm{ng} / \mathrm{ml})$.

O segundo grupo, contendo pacientes do primeiro grupo PAM, inclui mais pacientes que sofrem episódios de dor aguda da anemia falciforme (97\%, com média de 3, 07 internações hospitalizações por dor aguda da anemia falciforme) e diagnóstico de síndrome torácica aguda ou pneumonia (95\%, com média de 3,19 internações por síndrome torácica aguda ou pneumonia). Comparando-se com o primeiro grupo, os pacientes mais frequentemente passaram por colecistectomia (47\%), colelitíase (59\%), ulcera de pernas (8\%), moyamoya (5\%) e retinopatia (17\%), no entanto, tem menos transcraniano doppler anormais (19\%), hemossiderose transfusional (12\%), acidente vascular cerebral (3\%), ataque isquêmico transitório (5\%), ataque epilético (14\%) e infarto cerebral silencioso (5\%). Adicionalmente, os pacientes possuem níveis mais baixos de ferritina $(496,85 \mathrm{ng} / \mathrm{ml})$ e mais altos de bilirrubina (indireta $2,80 \mathrm{mg} / \mathrm{dL}$, direta $0,57 \mathrm{mg} / \mathrm{dL}$, total $3,38 \mathrm{mg} / \mathrm{dL}$ ) e lactato desidrogenase $(933,98 \mathrm{U} / \mathrm{L})$. 
O quinto grupo, contendo pacientes do primeiro grupo PAM, possui pacientes que tiveram episódios de dor aguda da anemia falciforme (100\%, com média de 5, 45 internações hospitalizações por dor aguda da anemia falciforme) e diagnóstico de síndrome torácica aguda ou pneumonia (100\%, com média de 3, 68 internações por síndrome torácica aguda ou pneumonia). Em comparação com o segundo grupo, os pacientes manifestam níveis mais altos de $\mathrm{HbF}(14,99 \%)$, não possuem doppler transcraniano anormal (0\%), acidente vascular cerebral (0\%), ataque isquêmico transitório (0\%), úlcera de perna $(0 \%)$, moyamoya $(0 \%)$, ataques epiléticos $(4 \%)$, infarto cerebral silencioso $(0 \%)$ e hemossiderose transfusional (2\%). Os pacientes apresentam níveis mais altos de $\operatorname{HbF}(14,99 \%)$ e mais baixos de bilirrubina (indireta $0,66 \mathrm{mg} / \mathrm{dL}$, direta $0,34 \mathrm{mg} / \mathrm{dL}$ e total $1 \mathrm{mg} / \mathrm{dL}$ ), ferritina (511, 42ng/ml) e lactato desidrogenase $(530,86 \mathrm{U} / \mathrm{L})$. 


\section{PCAMix}

Tabela 5.22: Agrupamento PCAMix de pacientes HbSS e HbSBO com idade menor a 18 anos - variáveis binárias

\begin{tabular}{cccc} 
Variável & \multicolumn{3}{c}{ Porcentagem de ocorrência } \\
& Grupo 1 & Grupo 2 & Grupo 3 \\
$(\mathrm{n}=711)$ & $(\mathrm{n}=273)$ & $(\mathrm{n}=110)$ \\
\hline acsequest & 33 & 28 & 15 \\
acutpainscd & 99 & 75 & 5 \\
chestdiag & 99 & 32 & 4 \\
cholecystect & 17 & 7 & 7 \\
cholelisludg & 26 & 14 & 11 \\
current_hydrox & 46 & 23 & 19 \\
dactylitis & 29 & 17 & 7 \\
history_transf & 93 & 72 & 57 \\
infarstroke & 6 & 12 & 15 \\
moya & 2 & 4 & 8
\end{tabular}

Tabela 5.23: Agrupamento PCAMix de pacientes HbSS e HbSBO com idade menor a 18 anos - variáveis numéricas

\begin{tabular}{cccc} 
Variável & \multicolumn{3}{c}{ Média (desvio padrão) } \\
& Grupo 1 & Grupo 2 & Grupo 3 \\
& $(\mathrm{n}=711)$ & $(\mathrm{n}=273)$ & $(\mathrm{n}=110)$ \\
\hline age & $10.63(4.04)$ & $8.87(4.68)$ & $6.86(4.43)$ \\
$\mathrm{n} \_$admacchest & 3.395 & 0.572 & 0.045 \\
$\mathrm{n}$ _admacutpain & 4.675 & 1.311 & 0.046
\end{tabular}

O terceiro grupo PCAMix para pacientes $\operatorname{HbSS}$ e $\operatorname{HbS} \beta 0$ com idade menor a 18 anos possui pacientes menos graves. Os pacientes são mais jovens (idade média de 6.85 anos), que não tiveram episódios de dor aguda da anemia falciforme (5\%, com média de 0.05 internações hospitalizações por dor aguda da anemia falciforme) e diagnóstico de síndrome torácica aguda ou pneumonia (4\%, com média de 0.05 internações por síndrome torácica aguda ou pneumonia). Os pacientes também não realizaram colecistectomia (7\%), não tiveram colelitíase (11\%), dactitlite (7\%), menos frequentemente possuem histórico de transfusões (57\%), acidente vascular cerebral (15\%), moyamoya (8\%), sequestro esplênico agudo (15\%) e são tratados com hidroxiuréia (19\%).

O segundo grupo do PCAMix possui pacientes que experimentaram episódios de dor aguda da anemia falciforme (75\%, com média de 1.31 internações hospitalizações por dor aguda da anemia falciforme) e diagnóstico de síndrome torácica aguda ou pneumonia (32\%, com média de 0.57 internações por síndrome torácica aguda ou pneumonia), colecistectomia (7\%), colelitíase (14\%), dactilite (17\%), histórico de transfusões $(72 \%)$, acidente vascular cerebral (12\%), moyamoya (4\%), sequestro esplênico agudo (28\%) e são tratados com hidroxiuréia (23\%).

Os pacientes com características clínicas mais graves foram agrupadas no primeiro grupo PCAMix, contendo pacientes que tiveram episódios de dor aguda da anemia falciforme (99\%, com média de 4.68 internações hospitalizações por dor aguda da anemia falciforme) e diagnóstico de síndrome torácica aguda ou pneumonia (99\%, com média de 3.4 internações por síndrome torácica aguda ou pneumonia), colecistectomia (17\%), colelitíase (26\%), dactilite $(29 \%)$, histórico de transfusões 
(93\%), sequestro esplênico agudo (33\%), são tratados com hidroxiuréia (46\%), raramente tiveram acidente vascular cerebral (6\%) ou moyamoya $(2 \%)$. 


\subsubsection{Pacientes com 18 anos de idade ou mais}

Tabela 5.24: BIC - agrupamento TwoStep de pacientes HbSS e HbS $\beta 0$ com idade igual ou maior a 18 anos

\begin{tabular}{ccc} 
Número de grupos & BIC & Diferença BIC \\
\hline 1 & 4491,085 & \\
$\mathbf{2}$ & $\mathbf{3 9 8 5 , 3 4 1}$ & $\mathbf{- 5 0 5 , 7 4 3}$ \\
3 & 3781,729 & $-203,612$ \\
4 & 3671,562 & $-110,167$ \\
5 & 3591,644 & $-79,917$ \\
6 & 3573,517 & $-18,127$
\end{tabular}

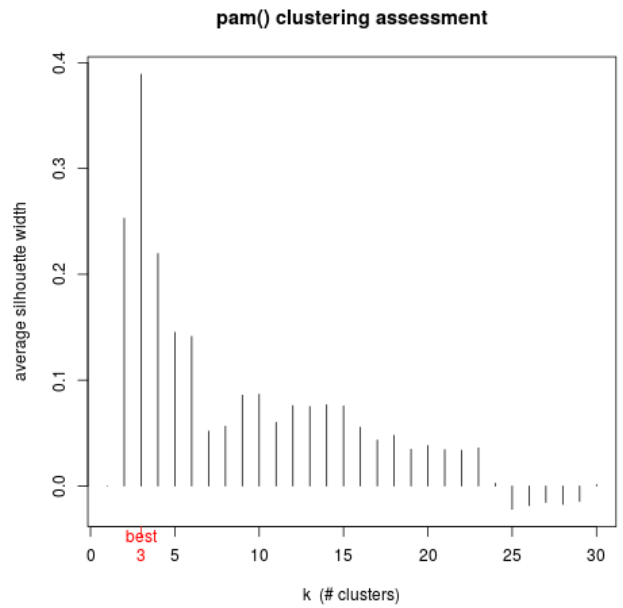

Figura 5.7: Silhouette PAM com pacientes HbSS e HbS $\beta 0$ com idade igual ou maior a 18 anos

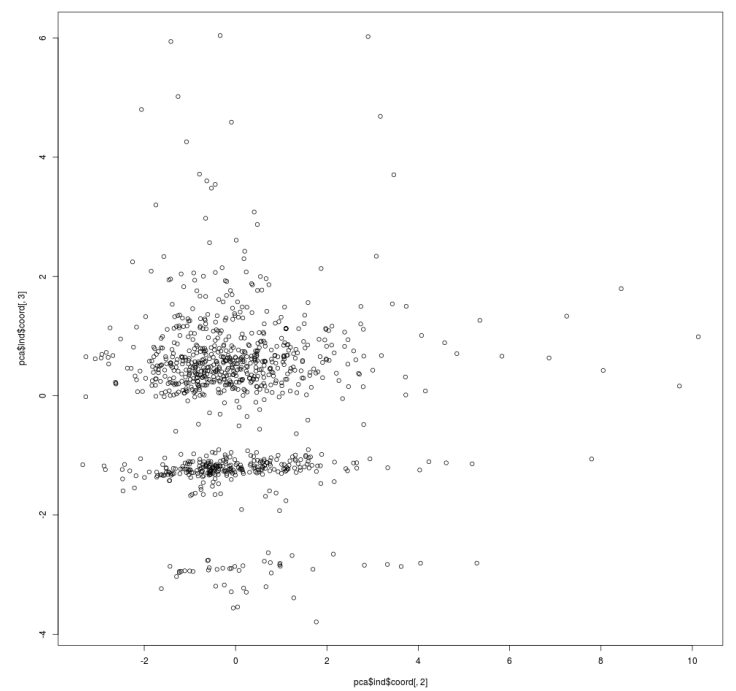

Figura 5.8: Componentes principais: PC2 versus PC3 - pacientes HbSS e HbSß0 com idade igual ou maior a 18 anos

O agrupamento TwoStep com BIC aplicado ao conjunto de pacientes HbSS e HbS $\beta 0$ com 18 anos ou mais gerou 2 grupos, com 98 e 258 indivíduos (Tabela 5.24). No entanto, o algoritmo PAM com Silhouette de 0,39, agrupou os pacientes em três grupos contendo 690, 192 e 68 pacientes (Figura 5.5). Finalmente, o algoritmo PCAMix agrupou os pacientes em três grupos incluindo 39, 
274 e 663 indivíduos (Figura 5.8). 


\section{Comparação dos resultados dos algoritmos}

Tabela 5.25: Comparação dos resultados dos algoritmos - HbSS e HbSßO clusters - PAM e TwoStep pacientes HbSS e HbS $\beta 0$ com idade menor a 18 anos

\begin{tabular}{cccc} 
& & \multicolumn{2}{c}{ TwoStep } \\
& & Grupo 1 & Grupo 2 \\
& & $(\mathrm{n}=98)$ & $(\mathrm{n}=258)$ \\
\hline \multirow{3}{*}{ PAM } & Grupo 1 $(\mathrm{n}=690)$ & $13 \%$ & $\mathbf{8 7 \%}$ \\
& Grupo 2 $(\mathrm{n}=192)$ & $33 \%$ & $\mathbf{6 7 \%}$ \\
& Grupo 3 $(\mathrm{n}=68)$ & $\mathbf{1 0 0} \%$ & $0 \%$
\end{tabular}

Tabela 5.26: Comparação dos resultados dos algoritmos - PAM e PCAMix-pacientes HbSS e HbS $\beta 0$ com idade menor a 18 anos

\begin{tabular}{ccccc} 
& & & PAM & \\
& & $\begin{array}{c}\text { Grupo 1 } \\
(\mathrm{n}=690)\end{array}$ & $\begin{array}{c}\text { Grupo 2 } \\
(\mathrm{n}=192)\end{array}$ & $\begin{array}{c}\text { Grupo 3 } \\
(\mathrm{n}=68)\end{array}$ \\
\hline \multirow{3}{*}{ PCAMix } & Grupo 1 $(\mathrm{n}=39)$ & $\mathbf{7 7 \%}$ & $15 \%$ & $8 \%$ \\
& Grupo 2 $(\mathrm{n}=274)$ & $\mathbf{7 4 \%}$ & $21 \%$ & $5 \%$ \\
& Grupo 3 $(\mathrm{n}=663)$ & $\mathbf{7 4 \%}$ & $19 \%$ & $7 \%$
\end{tabular}

Tabela 5.27: Comparação dos resultados dos algoritmos - TwoStep e PCAMix - pacientes HbSS e HbSß0 com idade menor a 18 anos

\begin{tabular}{cccc} 
& & \multicolumn{2}{c}{ TwoStep } \\
& & $\begin{array}{c}\text { Grupo 1 } \\
(\mathrm{n}=77)\end{array}$ & $\begin{array}{c}\text { Grupo 2 } \\
(\mathrm{n}=173)\end{array}$ \\
\hline \multirow{3}{*}{ PCAMix } & Grupo 1- $(\mathrm{n}=656)$ & $33 \%$ & $\mathbf{6 7 \%}$ \\
& Grupo 2 $-(\mathrm{n}=190)$ & $32 \%$ & $\mathbf{6 8} \%$ \\
& Grupo 3- $\mathrm{n}=104$ & $22 \%$ & $\mathbf{7 8} \%$
\end{tabular}

Apesar dos algoritmos PAM e TwoStep agruparem os pacientes com 18 anos ou mais de idade em 3 e 2 grupos, respectivamente, houve uma correspondência entre a composição dos grupos. O segundo grupo TwoStep foi dividido em dois diferentes grupos pelo PAM (primeiro e segundo grupos PAM). O terceiro grupo PAM é correspondente em termos de pacientes que o compõem ao primeiro grupo TwoStep. No entanto, comparando os grupos gerados por PAM e TwoStep aos grupos PCAMix, não houve semelhança quanto aos pacientes que os constituem. 


\section{Caracterização dos grupos}

\section{Agrupamento TwoStep}

Tabela 5.28: Agrupamento TwoStep de pacientes HbSS e HbSßO com idade igual ou maior a 18 anos variáveis binárias

\begin{tabular}{ccc} 
Variável & $\begin{array}{c}\text { Porcentagem de ocorrência } \\
\text { Grupo 1 } \\
(\mathrm{n}=98)\end{array}$ & $\begin{array}{c}\text { Grupo 2 } \\
(\mathrm{n}=258)\end{array}$ \\
\hline elevtcd & 26 & 2 \\
history_transf & 100 & 91 \\
infarstroke & 61 & 0 \\
ischattack & 13 & 1 \\
retinopathy & 17 & 8 \\
seizures & 32 & 4 \\
silentinfar & 28 & 1 \\
transfhem & 7 & 3
\end{tabular}

Tabela 5.29: Agrupamento TwoStep de pacientes HbSS e HbSBO com idade maior a 18 anos - variáveis numéricas

\begin{tabular}{ccc} 
Variável & \multicolumn{2}{c}{ Média (desvio padrão) } \\
& $\begin{array}{c}\text { Grupo 1 } \\
(\mathrm{n}=98)\end{array}$ & $\begin{array}{c}\text { Grupo 2 } \\
(\mathrm{n}=258)\end{array}$ \\
\hline hbf & $5,98(6,55)$ & $12,46(9,29)$ \\
$\mathrm{n}$ _admacchest & $4,2(6,02)$ & $2,59(3,13)$ \\
ferritin & 5122,408 & 1023,349 \\
transn_unitransf & $4,59(28,61)$ & $0,38(0,64)$
\end{tabular}

O algoritmo TwoStep dividiu os pacientes HbSS e $\mathrm{HbS} \beta 0$ com 18 anos ou mais em dois grupos, contendo 98 e 258 pacientes. O primeiro grupo é constituído por pacientes com fenótipo mais grave, que tiveram diagnóstico de síndrome torácica aguda ou pneumonia (média de 4, 2 internações por síndrome torácica aguda ou pneumonia), doppler transcraniano anormal (26\%), histórico de transfusões (100\%, com média de 4,6 unidades transfundidas em uma transfusão nos últimos 12 meses), acidente vascular cerebral (61\%), ataque isquêmico transitório (13\%), ataques epiléticos $(32 \%)$, infarto cerebral silencioso $(28 \%)$ e hemossiderose transfusional $(70 \%)$. Os pacientes também apresentam níveis mais altos de ferritina $(5122,41 \mathrm{ng} / \mathrm{ml})$ e $\mathrm{HbF}(5,98 \%)$.

O segundo grupo é constituído por pacientes com menor grau de gravidade, que não tiveram diagnóstico de síndrome torácica aguda ou pneumonia (média de 2, 6 internações por síndrome torácica aguda ou pneumonia) e histórico de transfusão (91\%, com média de 0,38 unidades transfundidas em média por transfusão nos últimos 12 meses). Os pacientes não possuem doppler transcraniano anormal $(2 \%)$, não sofreram acidente vascular cerebral (0\%), ataque isquêmico transitório (1\%), ataques epiléticos (4\%), infarto cerebral silencioso (1\%) e hemossiderose transfusional (3\%). Os pacientes também possuem níveis mais baixos de ferritina $(1023,35 \mathrm{ng} / \mathrm{ml})$ e $\mathrm{HbF}(12,46 \%)$. 
PAM

Tabela 5.30: Agrupamento PAM de pacientes HbSS e HbSßO com idade igual ou maior a 18 anos - variáveis binárias

\begin{tabular}{cccc} 
Variável & \multicolumn{3}{c}{ Porcentagem de ocorrência } \\
& $\begin{array}{c}\text { Grupo 1 } \\
(\mathrm{n}=690)\end{array}$ & $\begin{array}{c}\text { Grupo 2 } \\
(\mathrm{n}=192)\end{array}$ & $\begin{array}{c}\text { Grupo 3 } \\
(\mathrm{n}=68)\end{array}$ \\
\hline elevtcd & 4 & 3 & 28 \\
history_transf & 91 & 97 & 100 \\
infarstroke & 4 & 5 & 97 \\
ischattack & 2 & 3 & 21 \\
legulcer & 1 & 100 & 7 \\
moya & 0 & 1 & 20 \\
seizures & 7 & 3 & 47 \\
silentinfar & 2 & 3 & 34 \\
thromboemb & 1 & 7 & 4 \\
transfhem & 5 & 2 & 87
\end{tabular}

Tabela 5.31: Agrupamento PAM de pacientes HbSS e HbSBO com idade igual ou maior a 18 anos - variáveis numéricas

\begin{tabular}{cccc} 
Variável & Grupo 1 & $\begin{array}{c}\text { Média } \\
\text { Grupo 2 } \\
(\mathrm{n}=690)\end{array}$ & $\begin{array}{c}\text { Grupo 3 } \\
(\mathrm{n}=68)\end{array}$ \\
\hline age & $29,68(10,23)$ & $36,77(10,49)$ & $26,27(8,27)$ \\
hbf & $11,79(9,22)$ & $12,97(11,63)$ & $6,86(7,11)$ \\
ferritin & $1229,02(5643,3)$ & $1588,97(7324,61)$ & $4163,99(12031,22)$ \\
transn_unitransf & $0,79(10,68)$ & $0,86(4,55)$ & $1,19(0,59)$
\end{tabular}

O primeiro grupo de pacientes HbSS e HbS $\beta 0$ com 18 anos ou mais apresentam níveis mais altos de hemoglobina fetal $(11,79 \%)$.

O segundo grupo PAM inclui pacientes com fenótipo intermediário, com níveis mais altos de hemoglobina fetal $(12,966 \%)$, trombose $(7 \%)$ e úlcera de pernas $(100 \%)$.

O terceiro grupo PAM contém pacientes mais graves, com histórico de transfusão $(100 \%$ com média de 1,19 unidades transfundidas por transfusão nos últimos 12 meses), doppler transcraniano anormal (28\%), acidente vascular cerebral (97\%), ataque isquêmico transitório (21\%), moyamoya (20\%), ataques epiléticos (47\%), infarto cerebral silencioso (34\%), hemossiderose transfusional $(87 \%)$ e níveis mais altos de ferritina $(4163,99 \mathrm{ng} / \mathrm{ml})$. 


\section{PCAMix}

Tabela 5.32: Agrupamento PCAMix de pacientes HbSS e HbSBO com idade igual ou maior a 18 anos variáveis binárias

\begin{tabular}{cccc} 
Variável & \multicolumn{3}{c}{ Porcentagem de ocorrência } \\
& $\begin{array}{c}\text { Grupo 1 } \\
(\mathrm{n}=39)\end{array}$ & $\begin{array}{c}\text { Grupo 2 } \\
(\mathrm{n}=274)\end{array}$ & $\begin{array}{c}\text { Grupo 3 } \\
(\mathrm{n}=663)\end{array}$ \\
\hline acutpainscd & 0 & 94 & 100 \\
chestdiag & 0 & 6 & 99
\end{tabular}

Tabela 5.33: Agrupamento PCAMix de pacientes HbSS e HbSßO com idade igual ou maior a 18 anos variáveis numéricas

\begin{tabular}{cccc} 
Variável & \multicolumn{3}{c}{ Média (desvio padrão) } \\
& Grupo 1 & Grupo 2 & Grupo 3 \\
& $(\mathrm{n}=39)$ & $(\mathrm{n}=274)$ & $(\mathrm{n}=663)$ \\
\hline age & $35,39(13,81)$ & $31,94(10,81)$ & $29,83(9,8)$ \\
$\mathrm{n}$ _admacchest & $0(0)$ & $0,12(0,58)$ & $3,8(3,3)$ \\
n_admacutpain & $0(0)$ & $9,01(15,88)$ & $11,95(32,41)$ \\
HDL & $533,21(349,28)$ & $610,45(371,62)$ & $701,83(463,98)$
\end{tabular}

O primeiro grupo PCAMix para pacientes $\mathrm{HbSS}$ e $\mathrm{HbS} \beta 0$ com idade igual ou maior a 18 anos acomoda pacientes menos graves, mais velhos (idade média de 35, 39 anos), que não experienciaram episódios de dor aguda da anemia falciforme (0\%, com 0 admissões hospitalares causadas por dor aguda da anemia falciforme) e síndrome torácica aguda ou pneumonia ( $0 \%$ de diagnose, com média de 0 admissões hospitalares causadas por síndrome torácica aguda ou pneumonia)

O segundo grupo PCAMix inclui pacientes que experimentaram episódios de dor aguda da anemia falciforme (94\%, com média de 9,01 admissões hospitalares causadas por dor aguda da anemia falciforme), no entanto, não tem diagnóstico de síndrome torácica aguda (6\% de diagnose, com média de 0,12 admissões hospitalares causadas por síndrome torácica aguda ou pneumonia)

Finalmente, o terceiro grupo PCAMix contém pacientes que são mais jovens, com fenótipo mais grave, que tiveram dor aguda da anemia falciforme (100\%, com média de 1,95 admissões hospitalares causadas por dor aguda da anemia falciforme) e tem diagnóstico de síndrome torácica aguda (99\% de diagnose, com média de 3, 8 admissões hospitalares causadas por síndrome torácica aguda ou pneumonia)

\subsection{Discussão}

Este trabalho é uma análise exploratória, com algoritmos de agrupamento investigando o desempenho de diversos métodos, conceitos e abordagens de agrupamento. Teve como objetivo investigar associações entre os diferentes fenótipos da anemia falciforme e as relações entre suas complicações. Os algoritmos PAM, TwoStep e PCAMix deram origem a grupos de pacientes com genótipo HbSC similares com relação aos pacientes que os compõem, apresentando, no entanto, diferentes níveis de granularidade em seu agrupamento. Os grupos encontrados mostram similaridades e segmentaram os pacientes de acordo com diferentes níveis de gravidade em suas características clínicas. Para 
pacientes com genótipos $\mathrm{HbSS}$ e $\operatorname{HbS} \beta 0$, no entanto, o PCAMix divergiu com relação ao PAM e TwoStep, gerando grupos distintos com relação a suas composições. Contudo, os algoritmos PAM e TwoStep geraram grupos similares, agrupando os pacientes de acordo com os diferentes níveis de gravidade. Foi possível identificar nos resultados do PAM para pacientes adultos HbSS e HbS $\beta 0$ que acidente vascular cerebral e úlcera de pernas definiram diferentes grupos. Já no agrupamento de pacientes HbSC, acidente vascular cerebral e retinopatia definiram grupos distintos. Adicionalmente, a classificação de grupos ligados à hemólise e disfunções endoteliais em oposição à viscosidade do sangue e vaso-oclusão não foi observada.

Em relação aos pacientes HbSC, os 3 algoritmos agruparam os pacientes de forma similar. Os agrupamentos TwoStep e PCAMix produziram grupos mais abrangentes, com menor especificidade, dividindo pacientes de acordo com fenótipos mais e menos graves. Já o algoritmo PAM resultou em grupos mais refinados, com maior diversidade nos níveis de apresentação das complicações. Os resultados sugerem que idade, níveis de bilirrubina, histórico de transfusão, dor aguda da anemia falciforme e síndrome torácica aguda sejam variáveis importantes para agrupar os pacientes e definir grupos de fenótipos para o genótipo HbSC. O fato de a metodologia PAM separar acidente vascular cerebral e retinopatia em diferentes grupos de HbSC adultos deve ser destacada. Ambas complicações são de grande importância e possuem tratamentos profiláticos distintos.

No agrupamento de pacientes HbSS e $\mathrm{HbS} \beta 0$, PAM e TwoStep resultaram em grupos comparáveis com relação aos pacientes que o compõem. O algoritmo PCAMix, no entanto, gerou grupos de pacientes sem correspondência, quando comparado com o agrupamento PAM e TwoStep. No entanto, todos os 3 algoritmos sugerem que um grande número de variáveis seja necessário para agrupar os pacientes. Variáveis como idade, níveis de bilirrubina, histórico de transfusões, dor aguda da anemia falciforme, síndrome torácica aguda, infarto, ataque isquêmico transitório, úlcera de pernas, moyamoya, ferritina, contagem de reticulócitos, retinopatias, ataques epiléticos e hemossiderose transfusional se mostraram importantes para o agrupamento dos pacientes. Os grupos identificados por todos métodos estudados refletiram diferentes níveis de gravidade. No entanto, PAM revelou que, entre pacientes adultos, acidente vascular cerebral e úlcera de perna são características que geram grupos diferentes.

A divergência no agrupamento de pacientes $\operatorname{HbSS}$ e $\operatorname{HbS} \beta 0$, pode estar relacionada à maior complexidade e variabilidade dos fenótipos apresentados pelos pacientes com este genótipo. A maior complexidade poderia demandar um maior número de pacientes representando cada grupo, de forma que os algoritmos sejam capazes de identificar esses padrões nos dados. Embora o coorte REDS-III SCD tenha recrutado um grande número de participantes, um número ainda maior de pacientes pode ser necessário para se identificar uma composição refinada de grupo de pacientes, uma vez que o agrupamento envolve associações com grande número de complicações. 


\section{Capítulo 6}

\section{Priapismo}

\subsection{Experimento}

No REDS-III Brazil Sickle Cell Disease Cohort, dados sobre características sociodemográficas e desfechos clínicos foram coletados sobre cada paciente. Os pacientes do sexo masculino tiveram seus registros médicos analisados a respeito do histórico de priapismo, incluindo o registro do ano do primeiro episódio. Complementarmente, foram compilados resultados de testes laboratoriais e registradas ocorrências de outras complicações, que podem estar associados ao priapismo. Durante as visitas de acompanhamento, foram investigadas ocorrências de episódios de priapismo. Foram coletados dados sobre o número de recorrências, o tempo de duração, o tratamento realizado e a ocorrência de priapismo gago. Finalmente, foi realizada genotipagem com relação a mutações na hemoglobina por pirosequenciamento de alelo específico. Quando os registros médicos e o pirosequenciamento não apresentavam consenso, a confirmação por meio de sequenciamento Sanger foi empregada (como descrito em Carneiro-Proietti et al. (2010)).

Para caracterização dos pacientes com anemia falciforme que sofrem de priapismo, foram discriminados pacientes do sexo masculino de qualquer genótipo que experienciaram pelo menos um episódio de priapismo e pacientes do sexo masculino de qualquer um dos genótipos sem histórico de priapismo. Pacientes com histórico de priapismo foram comparados com pacientes sem histórico de priapismo com relação a características demográficas. Uma vez que o genótipo e a idade estão associados à ocorrência de priapismo, para uma análise de características clínicas associadas ao priapismo, foi realizado emparelhamento com base no genótipo e idade dos pacientes. Para pacientes com menos de 18 anos foi considerado intervalo de dois anos de diferença e para pacientes com 18 ou mais anos foi considerado intervalo de 6 anos. Foi obtida uma proporção de 1 caso para 2 controles, com exceção de 2 pacientes com genótipo $H b S \beta 0$ para os quais não foram encontrados emparelhamentos, sendo então excluídos da análise. As comparações entre os grupos foram realizadas aplicando-se teste $\chi$-quadrado no caso de variáveis categóricas e teste de Wilcoxon-Mann-Whitney no caso de variáveis contínuas.

A partir da idade do primeiro episódio de priapismo, o método Kaplan-Meier (Kaplan e Meier, 1958) foi empregado para estimar o tempo para a primeira ocorrência. Para essa análise, foram excluídos pacientes com genótipo HbSC, uma vez que a prevalência do priapismo nesse grupo foi destoante na comparação com os outros genótipos. 


\subsubsection{GWAS}

Dentre o total 1314 pacientes do sexo masculino inscritos no coorte, pacientes com genótipos $\mathrm{HbSS}, \mathrm{HbS} \beta 0$ e $\mathrm{Hb} \beta+$ foram selecionados entre casos e controles para o GWAS. Pacientes com genótipos SC não foram considerados na análise uma vez que o priapismo ocorre menos frequentemente nestes pacientes (Fowler Jr et al., 1991; Sharpsteen et al., 1993). Desta forma, foram considerados na seleção de casos, homens $\mathrm{HbSS}, \mathrm{HbS} \beta 0$ ou $\mathrm{Hb} \beta+$ que têm histórico de pelo menos um episódio de priapismo. Controles foram selecionados entre pacientes do sexo masculino com genótipo HbSS, $\mathrm{HbS} \beta 0$ ou $\mathrm{Hb} \beta+$ que nunca tiveram episódios de priapismo. Um total de 169 casos e 433 controles com dados genotípicos disponíveis foram selecionados (Figura 6.1).

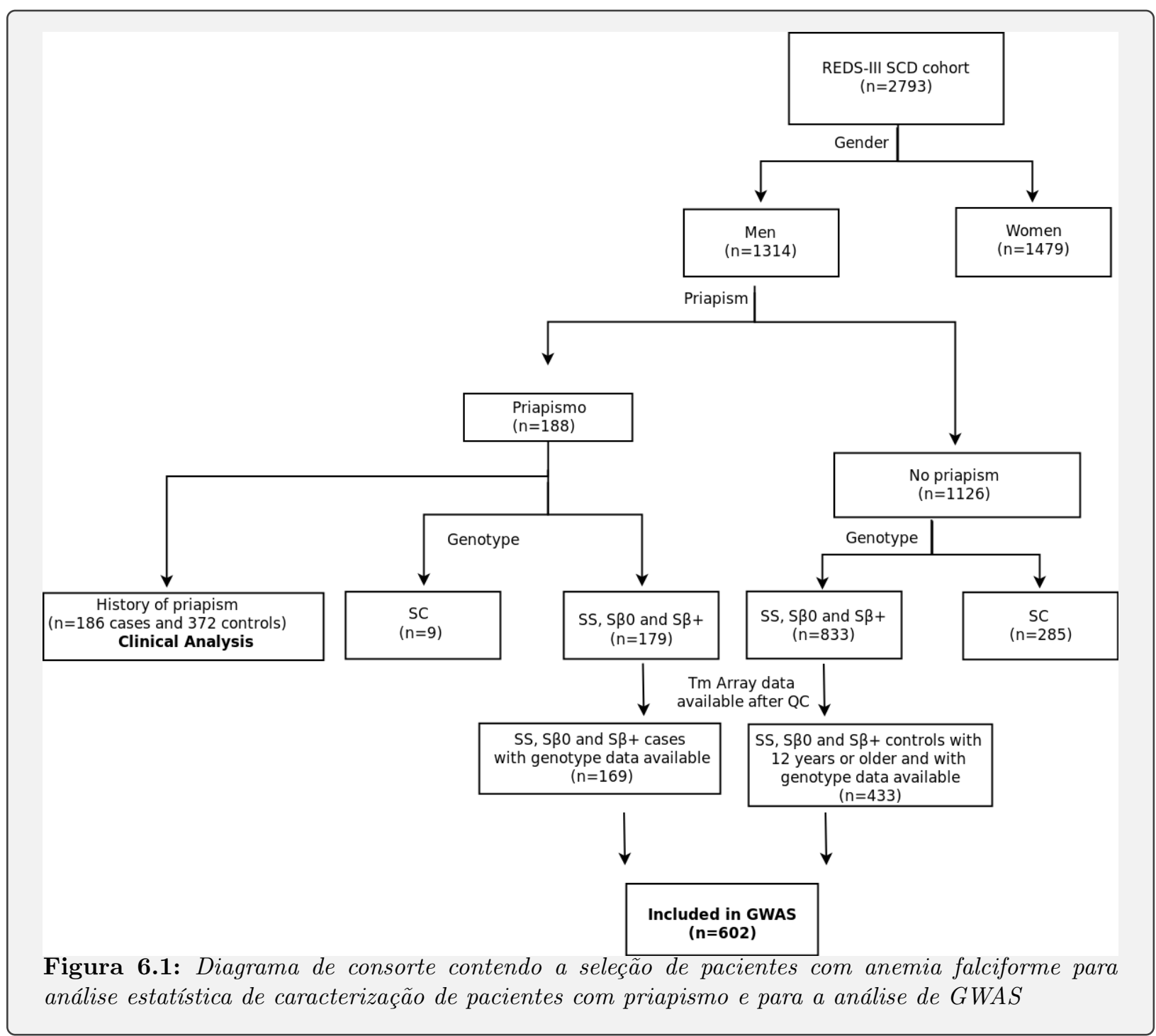

A genotipagem de SNPs foi realizada a partir de amostras coletadas dos pacientes de sangue periférico, com um microarranjo customizado chamado de Transfusion Medicine Array (TMArray; Affymetrix, Santa Clara, CA, USA) (Guo et al., 2018). O microarranjo TM inclui 549.000 SNPs e foi enriquecido com polimorfismos relacionados ao sangue e a transfusões. A determinação das sequências foram intermediadas pelo Axiom Analysis Suite Software (Affymetrix 
ThermoFisher Scientific, Waltham, MA, USA) e pelo Axiom HLA Analysis software (Affymetrix) especificamente para regiões dos alelos de antígeno leucocitário humano (human leukocyte antigen alleles, HLA). Polimorfismos de número de cópias (copy number polymorphisms, CNPs) foram investigados com Axiom CNV Summary Tools e análises adicionais com PennCNV (http://penncnv.openbioinformatics.org/en/latest/).

Para identificar a associação da variação com um fenótipo, cada SNP analisado no estudo é utilizado como variável independente em uma análise de regressão logística. Regressões logísticas estimam parâmetros em uma combinação linear de variáveis independentes, permitindo o uso de covariantes. Regressões logísticas têm como resultado um modelo linear que prediz a probabilidade de um resultado binário. Nessa regressão, a variável dependente é o estado de caso controle ou de portador da doença e o alelo com menor frequência de um SNP é a variável independente. A regressão resulta em um odds ratio, seu erro padrão ou intervalo de confiança, uma estatística e um p-valor para o teste do odds ratio. Assim, são realizadas inúmeras regressões logísticas, uma para cada SNP, o que leva a necessidade de ajuste para controle de Erro do tipo I. A correção para múltiplos testes frequentemente é realizada com correção de Bonferroni, com base em um valor de 0.05 de nível de Erro de tipo I para 1.000.000 de testes estatísticos, sendo assim considerados p-valores menores que $5 \times 10^{-8}$. Por realizar um extenso número de testes estatísticos, considerar pvalores bastante baixos e os efeitos genéticos serem pequenos, o poder estatístico GWAS é bastante reduzido caso não se disponha de grandes números de casos e controles.

A Figura 6.2 apresenta todos os passos de controle de qualidade dos dados para obtenção das sequências de SNPs, bem como as etapas de análise realizadas no GWAS. Em um passo inicial de qualidade de controle, as amostras com valores de controle de qualidade de dish menor que 0,85 ou call rates menores que $97 \%$ foram excluídas. Plates com métricas de qualidade de controle de plate menores que $95 \%$ ou com call rates média menor que $98,5 \%$ também foram excluídos. No controle de qualidade de SNP, SNP Polisher foi utilizado e SNPs nas categorias recomendadas (PolyHighRes, MonoHighRes, NoMinorHom e Hemizygous) foram mantidos. Amostras com definições de sexo inconsistentes, considerando-se a genotipagem e registros médicos foram excluídos. SNPs com call rates menores ou iguais a $97 \%$ ou desviando do equilíbrio de Hardy-Weinberg (HWE) (HWE_P menor ou igual a $10^{-4}$ ) também foram excluídos.

Somando-se aos SNPs sequenciados por microarrays, é possível expandir o conjunto de SNPs disponível para análise por meio da imputação. A imputação estima genótipos baseando-se em conjuntos de SNPs de referência com alta densidade de SNPs. O conjunto referência é usado como representação de modelos de haplótipos para comparação. Assim, haplótipos em comum são empregados para inferência de genótipos não presentes no microarray. Sendo assim, para a imputação de SNPs adicionais, o Phasing, para estimação de haplótipos, foi realizado com SHAPEIT (Delaneau et al., 2008) e a imputação com IMPUTE2 (Howie et al., 2009) com haplótipos derivados do 1000 Genomes Project Phase 3 (Consortium et al., 2015) como referência.

A subestrutura de população foi determinada por Análise de componentes principais (PCA) usando EIGENSTRAT (Price et al., 2006). Plink (Purcell et al., 2007) foi utilizado no cálculo de identidade por descendência (identity-by-descent, IBD). Quando pares de indivíduos possuíam PI_HAT maior igual a 0, 4 ou identidade por sequência (identity-by-sequence, IBS) maior ou igual a 0, 9, o membro do par com menor call rate foi excluído do PCA. Foram utilizados SNPs autossomais com poda de desequilíbrio de ligação, apenas considerando-se pacientes sem parentesco. Os 10 


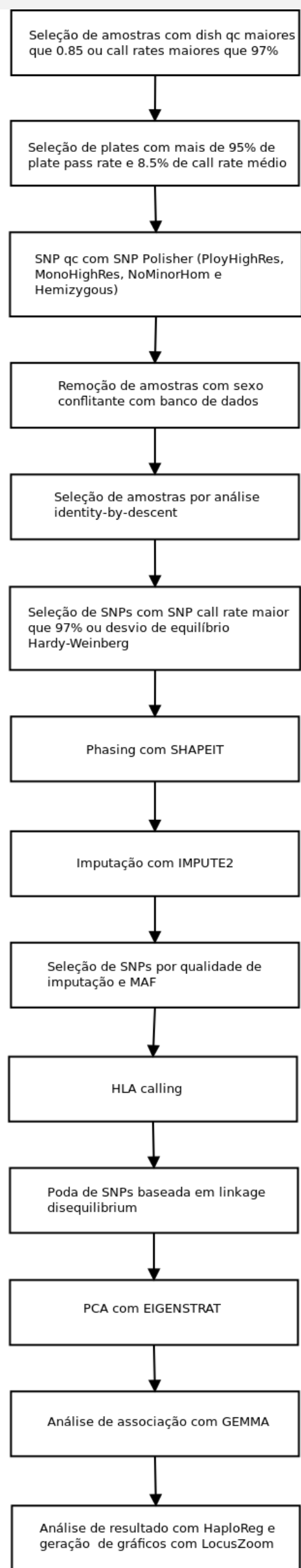

Figura 6.2: Etapas envolvidas na obtenção dos dados de SNPs e no Genome Wide Association Study. 
primeiros componentes principais foram incluídos na análise de associação para ajustar a subestrutura de população. A análise de associação foi realizada com GEMMA (Zhou e Stephens, 2014) com modelo logístico misto, ajustando a idade como covariante, bem como o cryptic kinship relatedness

A ferramenta online HaploReg (v4.1) (Ward e Kellis, 2011) foi empregada na exploração dos genes mais próximos aos SNPs com significância genômica. LocusZoom (Pruim et al., 2010) foi usado para gerar gráficos LocusZoom, com estimativa de LD 1000 genome phase 3. P-valores foram considerados estatisticamente e genomicamente significativos se acima de $10^{-8}$, para correção de múltiplos testes, e foram considerados variantes com menor frequência alélica (minor frequency allele, MAF) maior que 0.05, já que associações de SNPs com MAFs menores não seriam robustas por serem originadas por um número muito pequeno de indivíduos.

\subsection{Resultados}

\subsubsection{Características gerais dos pacientes}

Tabela 6.1: Características sociodemográficas de pacientes com e sem histórico de priapismo.

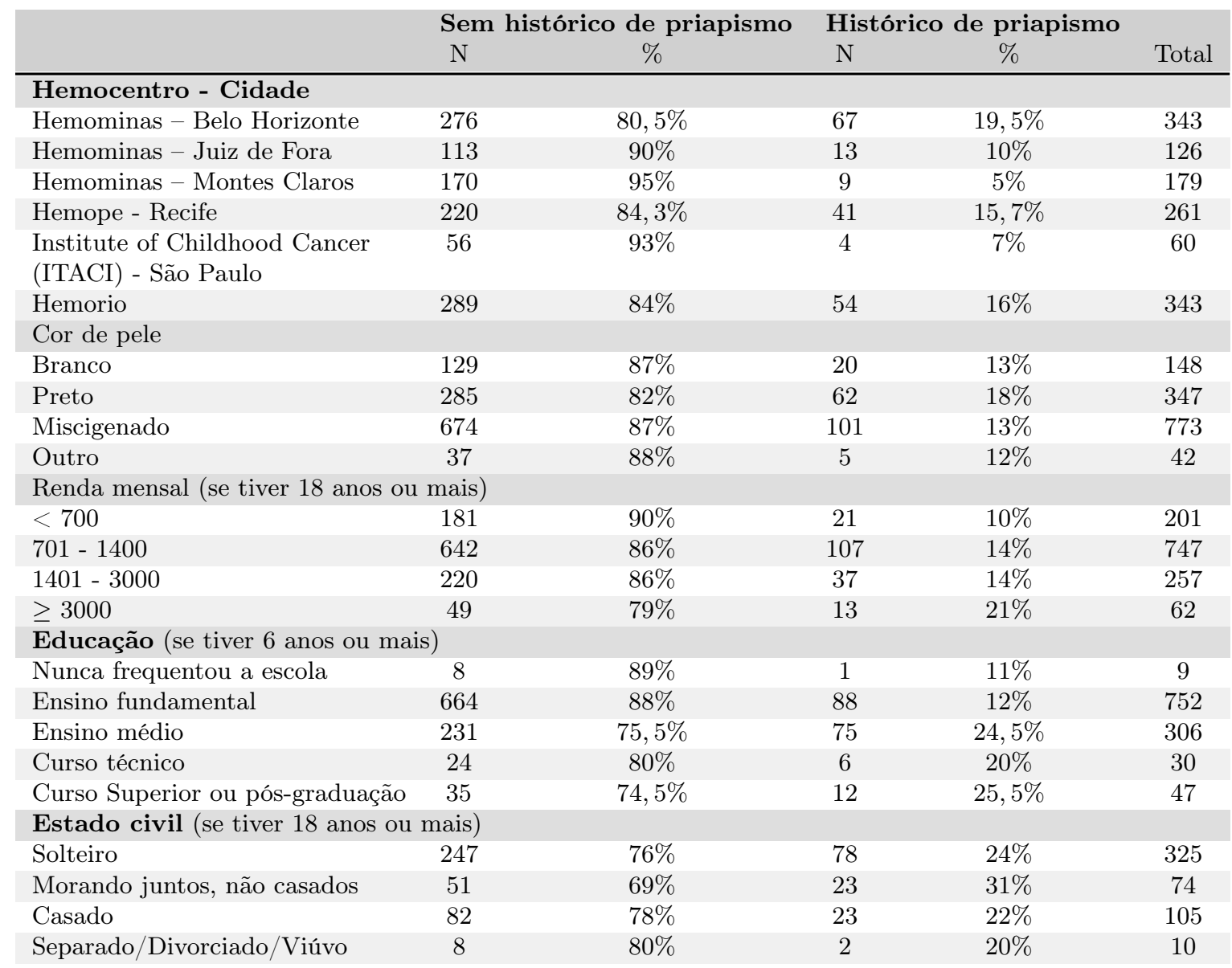

Entre todos pacientes recrutados pelo coorte REDS-III SCD, 1314 são homens com idades entre 0 e 77, dos quais 188 (14.31\%) tiveram episódios de priapismo pelo menos uma vez na vida (Figura 6.1). Entre os 188 casos, estão incluídos 51 (6.9\%) dos 745 pacientes com menos de 18 anos e 137 (24.1\%) dos homens com 18 anos ou mais. A maioria dos pacientes que apresentaram priapismo são do Hemominas Belo Horizonte (36\%). Os casos são principalmente miscigenados 


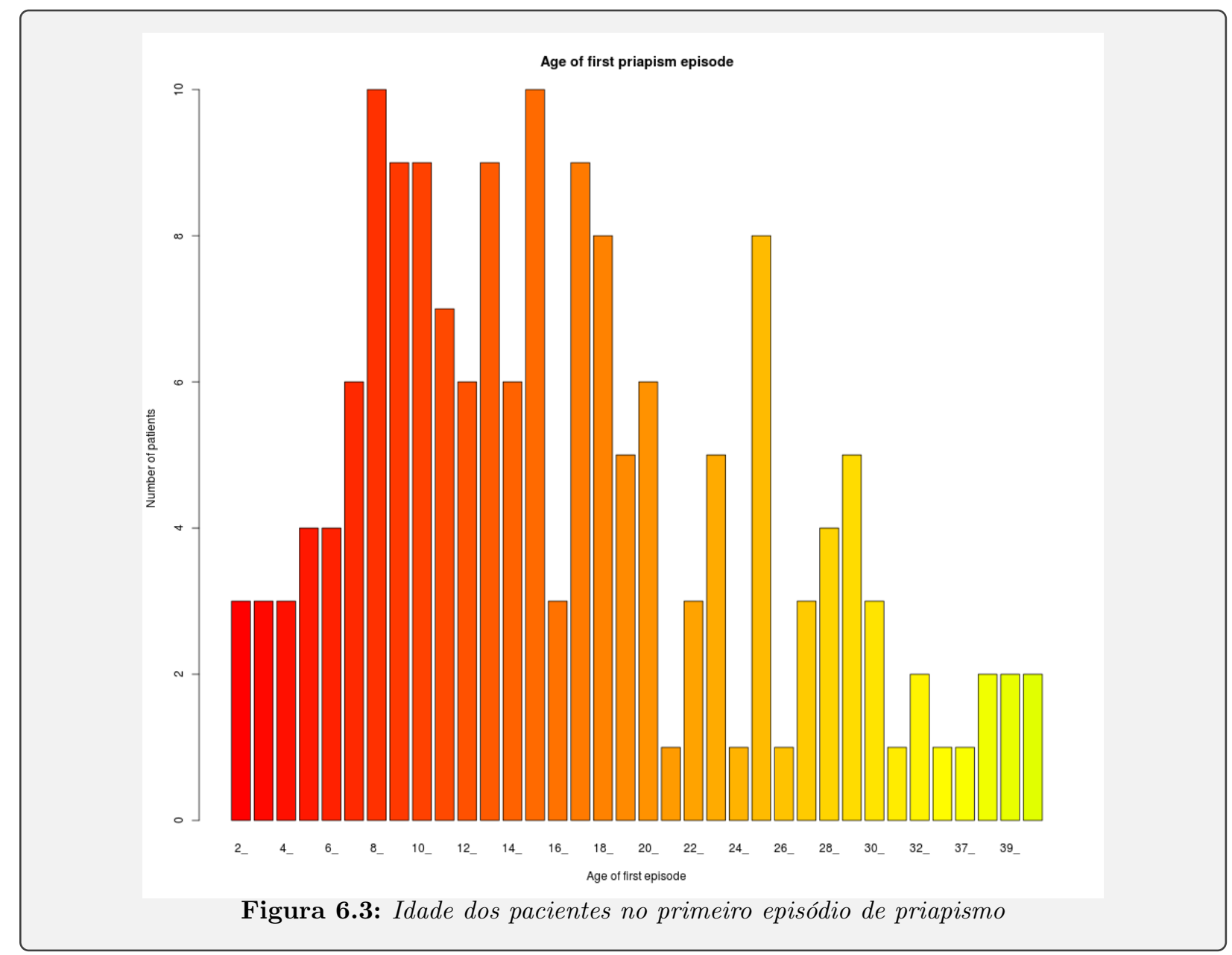


(54\%), solteiros(62\%), com educação em nível fundamental $(48.5 \%)$ e possuem uma renda média mensal de $R \$ 701$ a $R \$ 1400(60 \%)$ (Tabela 6.1$)$.

A idade média do primeiro episódio de priapismo foi de 16.4 anos e a mediana de 15 anos, com mínimo de 2 e máximo de 41 anos. 25\% dos casos ocorreram antes dos 10 anos de idade, $60 \%$ ocorreram antes dos 20 anos e o intervalo de maior concentração de casos inclui as idades entre 8 e 15 anos (5\%) (Figura 6.3).

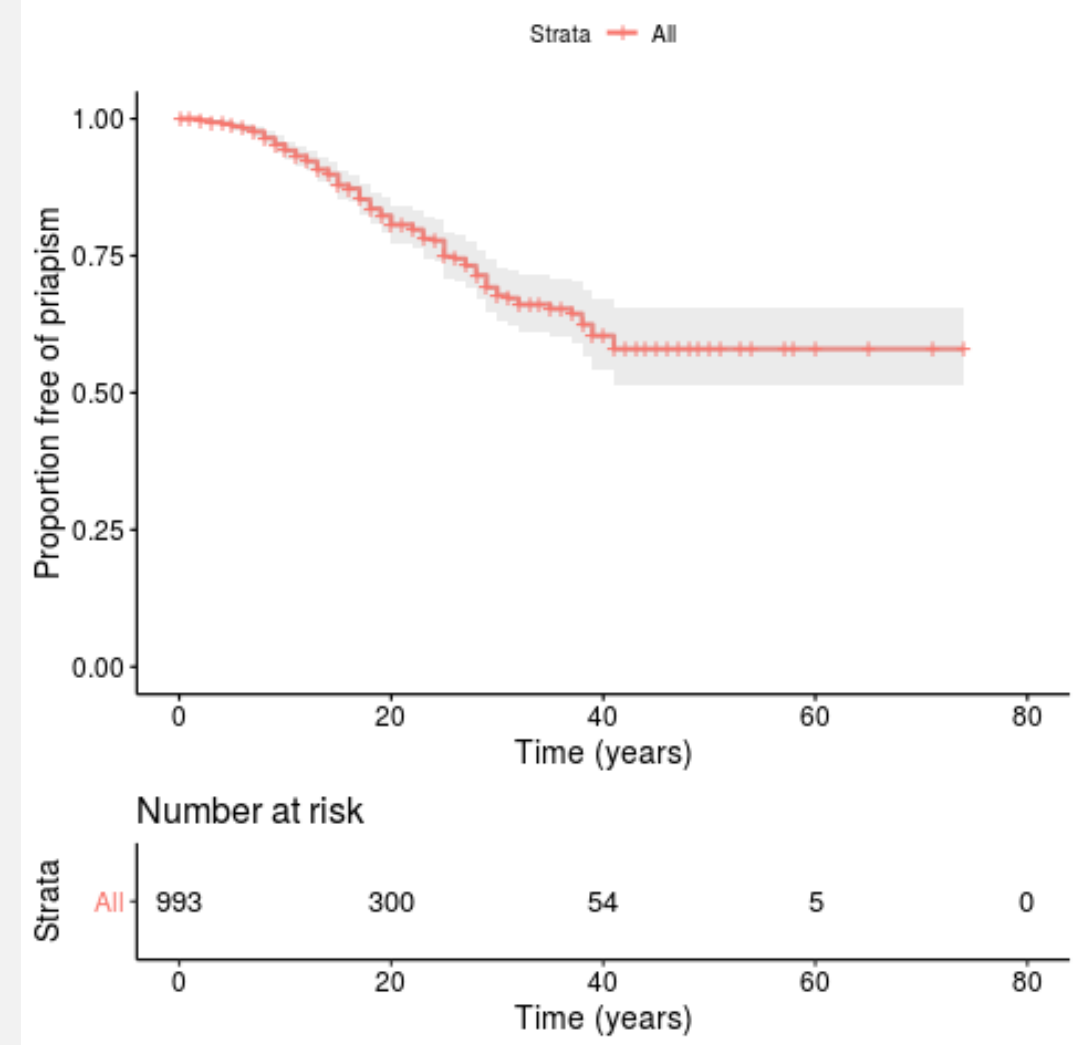

Figura 6.4: Estimativa de tempo para ocorrência de priapismo com método Kaplan-Meier

Para a análise de sobrevivência com método Kaplan-Meier foram selecionados 993 pacientes com genótipos HbSS, HbS $\beta 0$ e $\operatorname{HbS} \beta+$. Dentre esses, 158 possuem histórico de priapismo e 835 nunca tiveram priapismo. Um gráfico foi gerado (Figura 6.4), contendo a curva de sobrevivência com intervalo de confiança bilateral de 0,95. A análise (Figura 6.4 e Tabela 6.2) mostrou que $80 \%$ dos pacientes incluídos na análise permanecem livres de episódios de priapismo até os 20 anos de idade. O gráfico também mostrou que a probabilidade cumulativa de sobrevivência ao evento de priapismo tem distribuição aproximadamente homogênea até os 40 anos, quando se estabiliza e mantém-se aproximadamente igual ao se atingir idades mais avançadas.

O grupo de pacientes que passaram por episódios de priapismo foi comparado com o grupo de pacientes que nunca tiveram tal complicação. Para tanto, foi realizada uma análise de emparelhamento, com base na idade e genótipo de hemoglobina. A comparação dos grupos foi realizada com base na variação de diferentes dados clínicos, incluindo contagem de reticulócitos, HbF, hemoglobina, plaqueta, leucócito, bilirrubina total e indireta. Também foram comparadas as incidências de 
Tabela 6.2: Tabela Kaplan-Meier com o tempo para ocorrência do primeiro episódio de priapismo

\begin{tabular}{|c|c|c|c|c|c|c|}
\hline Tempo & $\mathrm{N}$ em risco & $\mathbf{N}$ de eventos & Sobrevivência & Erro padrão & $\begin{array}{c}\text { Limite } \\
\text { inferior } 95 \% \text { IC }\end{array}$ & $\begin{array}{c}\text { Limite } \\
\text { superior } 95 \% \text { IC }\end{array}$ \\
\hline 2 & 985 & 3 & 0,997 & 0,00176 & 0,994 & 1,000 \\
\hline 3 & 959 & 3 & 0,994 & 0,00251 & 0,989 & 0,999 \\
\hline 4 & 928 & 3 & 0,991 & 0,00311 & 0,985 & 0,997 \\
\hline 5 & 890 & 4 & 0,986 & 0,00381 & 0,979 & 0,994 \\
\hline 6 & 849 & 3 & 0,983 & 0,00430 & 0,974 & 0,991 \\
\hline 7 & 813 & 5 & 0,977 & 0,00505 & 0,967 & 0,987 \\
\hline 8 & 774 & 9 & 0,965 & 0,00625 & 0,953 & 0,978 \\
\hline 9 & 738 & 9 & 0,954 & 0,00730 & 0,940 & 0,968 \\
\hline 10 & 680 & 8 & 0,942 & 0,00822 & 0,926 & 0,959 \\
\hline 11 & 633 & 7 & 0,932 & 0,00903 & 0,914 & 0,950 \\
\hline 12 & 593 & 6 & 0,922 & 0,00972 & 0,904 & 0,942 \\
\hline 13 & 551 & 9 & 0,907 & 0,01078 & 0,886 & 0,929 \\
\hline 14 & 503 & 5 & 0,898 & 0,01140 & 0,876 & 0,921 \\
\hline 15 & 464 & 10 & 0,879 & 0,01270 & 0,854 & 0,904 \\
\hline 16 & 425 & 3 & 0,873 & 0,01310 & 0,847 & 0,899 \\
\hline 17 & 396 & 9 & 0,853 & 0,01438 & 0,825 & 0,882 \\
\hline 18 & 356 & 7 & 0,836 & 0,01543 & 0,806 & 0,867 \\
\hline 19 & 328 & 5 & 0,823 & 0,01621 & 0,792 & 0,856 \\
\hline 20 & 300 & 6 & 0,807 & 0,01723 & 0,774 & 0,841 \\
\hline 22 & 260 & 3 & 0,798 & 0,01785 & 0,763 & 0,833 \\
\hline 23 & 241 & 5 & 0,781 & 0,01895 & 0,745 & 0,819 \\
\hline 24 & 227 & 1 & 0,778 & 0,01917 & 0,741 & 0,816 \\
\hline 25 & 214 & 8 & 0,749 & 0,02103 & 0,708 & 0,791 \\
\hline 26 & 192 & 1 & 0,745 & 0,02128 & 0,704 & 0,788 \\
\hline 27 & 178 & 3 & 0,732 & 0,02212 & 0,690 & 0,777 \\
\hline 28 & 167 & 4 & 0,715 & 0,02327 & 0,670 & 0,762 \\
\hline 29 & 159 & 5 & 0,692 & 0,02461 & 0,646 & 0,742 \\
\hline 30 & 144 & 3 & 0,678 & 0,02547 & 0,630 & 0,730 \\
\hline 31 & 134 & 1 & 0,673 & 0,02577 & 0,624 & 0,725 \\
\hline 32 & 117 & 2 & 0,661 & 0,02658 & 0,611 & 0,715 \\
\hline 35 & 87 & 1 & 0,654 & 0,02734 & 0,602 & 0,709 \\
\hline 37 & 71 & 1 & 0,644 & 0,02847 & 0,591 & 0,703 \\
\hline 38 & 65 & 2 & 0,625 & 0,03085 & 0,567 & 0,688 \\
\hline 39 & 61 & 2 & 0,604 & 0,03306 & 0,543 & 0,672 \\
\hline 41 & 50 & 2 & 0,580 & 0,03588 & 0,514 & 0,655 \\
\hline
\end{tabular}

Tabela 6.3: Genótipos de pacientes com e sem histórico de priapismo.

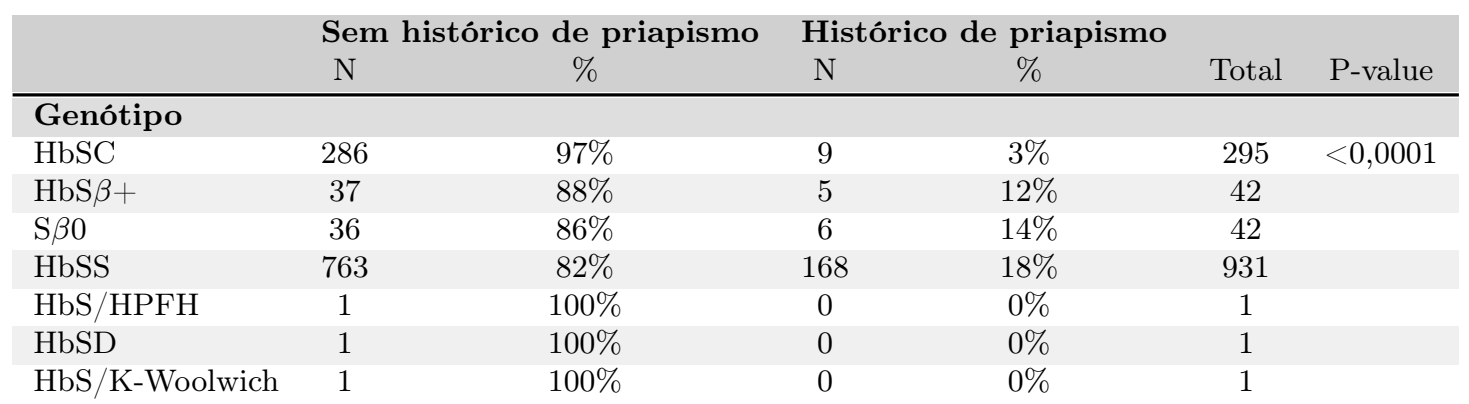

Tabela 6.4: Idade de pacientes com e sem histórico de priapismo.

\begin{tabular}{|c|c|c|c|c|c|c|}
\hline & \multicolumn{2}{|c|}{ Sem histórico de priapismo } & \multicolumn{2}{|c|}{ Histórico de priapismo } & \multirow[b]{2}{*}{ Total } & \multirow[b]{2}{*}{$\mathrm{P}$-value } \\
\hline & $\mathrm{N}$ & $\%$ & $\mathrm{~N}$ & $\%$ & & \\
\hline \multicolumn{7}{|l|}{ Idade } \\
\hline 00-09 & 360 & $94 \%$ & 22 & $6 \%$ & 382 & $<0,0001$ \\
\hline $10-17$ & 334 & $92 \%$ & 29 & $8 \%$ & 363 & \\
\hline $18-29$ & 252 & $76 \%$ & 79 & $24 \%$ & 331 & \\
\hline $30-41$ & 113 & $73 \%$ & 42 & $27 \%$ & 155 & \\
\hline $42-60+$ & 66 & $80 \%$ & 16 & $20 \%$ & 82 & \\
\hline
\end{tabular}


Tabela 6.5: Características clinicas de pacientes com e sem histórico de priapismo.

\begin{tabular}{|c|c|c|c|c|c|}
\hline & \multicolumn{2}{|c|}{ Sem histórico de priapismo $(\mathrm{N}=372)$} & \multicolumn{2}{|c|}{ Histórico de priapismo $(\mathrm{N}=186)$} & \multirow[b]{2}{*}{ P-value } \\
\hline & (Média/Mediana) & Intervalo & (Média/Mediana) & Intervalo & \\
\hline \multicolumn{6}{|l|}{ Exames } \\
\hline $\begin{array}{l}\text { Reticulócitos } \\
(\%)\end{array}$ & $(10,15 / 9,5)$ & $(1 / 25,8)$ & $(10,36 / 9,77)$ & $(0,8 / 26,2)$ & 0,66 \\
\hline $\begin{array}{l}\text { Bilirubina } \\
\text { total }(\mathrm{mg} / \mathrm{dL})\end{array}$ & $(1,76 / 1,35)$ & $(0,12 / 15,21)$ & $(1,75 / 1,37)$ & $(0,13 / 12,37)$ & 0,86 \\
\hline $\operatorname{HbF}(\%)$ & $(10,9 / 6,95)$ & $(0,1 / 45)$ & $(11,3 / 8,9)$ & $(0,1 / 42)$ & 0,36 \\
\hline $\begin{array}{l}\text { Bilirubina } \\
\text { indireta }(\mathrm{mg} / \mathrm{dL})\end{array}$ & $(1,2 / 0,87)$ & $(0 / 12,11)$ & $(1,26 / 0,87)$ & $(0,02 / 11,29)$ & 0,73 \\
\hline $\begin{array}{l}\text { Leucocyte } \\
\left(\mathrm{mm}^{3}\right)\end{array}$ & $(11218 / 10810)$ & $(2370 / 28800)$ & $(10664,06 / 10200)$ & $(3560 / 23700)$ & 0,11 \\
\hline $\begin{array}{l}\text { Hemoglobina } \\
(\mathrm{g} / \mathrm{dL})\end{array}$ & $(8,82 / 8,6)$ & $(3,52 / 15,9)$ & $(9,04 / 8,98)$ & $(4,86 / 15,7)$ & 0,11 \\
\hline $\begin{array}{l}\text { Plaquetas } \\
\left(\mathrm{mm}^{3}\right)\end{array}$ & $(396572 / 38700)$ & $(82000 / 999000)$ & $(396182 / 373200)$ & $(89800 / 930500)$ & 0,94 \\
\hline
\end{tabular}

Tabela 6.6: Complicações clínicas de pacientes com e sem histórico de priapismo.

\begin{tabular}{|c|c|c|c|c|c|c|}
\hline & \multicolumn{2}{|c|}{$\begin{array}{c}\text { Sem histórico de } \\
\text { priapismo }(\mathrm{N}=372)\end{array}$} & \multicolumn{2}{|c|}{$\begin{array}{c}\text { Histórico de } \\
\text { priapismo }(\mathrm{N}=186)\end{array}$} & \multirow[b]{2}{*}{ Total } & \multirow[b]{2}{*}{$\mathrm{P}$-value } \\
\hline & $\mathrm{N}$ & $\%$ & $\mathrm{~N}$ & $\%$ & & \\
\hline \multicolumn{7}{|l|}{ Complicações } \\
\hline Hipertensão pulmonar & 33 & $9 \%$ & 28 & $15 \%$ & 61 & 0,05 \\
\hline Úlcera de perna & 66 & $18 \%$ & 31 & $17 \%$ & 97 & 0,83 \\
\hline Episódio de dor aguda da doença falciforme & 348 & $94 \%$ & 176 & $95 \%$ & 524 & 0,84 \\
\hline Síndrome Torácica Aguda/Pneumonia & 262 & $72 \%$ & 146 & $80 \%$ & 408 & 0,07 \\
\hline Necrose avascular-quadril e ombro & 42 & $11 \%$ & 36 & $19 \%$ & 78 & 0,01 \\
\hline Acidente vascular cerebral isquêmico & 39 & $10 \%$ & 17 & $9 \%$ & 5 & 0,74 \\
\hline
\end{tabular}


outras complicações relacionadas a anemia falciforme como hipertensão pulmonar, acidente vascular cerebral isquêmico, úlcera de perna, episódio de dor aguda da doença falciforme, síndrome torácica aguda/pneumonia e necrose avascular-quadril /ombro.

A maioria dos pacientes com histórico de priapismo tem genótipo HbSS $(89.4 \%$ do total de casos e $18 \%$ do total de homens HbSS), um menor número tem genótipo $\mathrm{HbS} \beta+(3 \%$ do total de casos e $12 \%$ dos homens $\operatorname{HbS} \beta+$ ) e $\operatorname{HbS} \beta 0$ (3\% do total de casos e $14 \%$ do total de homens $\mathrm{HbS} \beta 0$ ). Pacientes com genótipo HbSC que tiveram episódios de priapismo são proporcionalmente mais raros (5\% do número total de casos e 3\% do total de 295 homens HbSC). Não houve ocorrência de priapismo em pacientes com genótipos com menor representatividade neste trabalho, como SD, S/HPFH, S/K_Woolwich ou Hb S/Quebec-Chori (Tabela 6.3).

Não houve diferença estatística entre os grupos com relação à medida de biomarcadores (Tabela 6.5). Entre as complicações decorrentes da anemia falciforme, foram associadas à ocorrência do priapismo a hipertensão pulmonar e necrose avascular-quadril e ombro (Tabela 6.6).

Tabela 6.7: Episódios de priapismo entre visitas

\begin{tabular}{|c|c|}
\hline & $\begin{array}{c}\text { Número total } \\
\text { de episódios } \\
\text { N }(\%)\end{array}$ \\
\hline \multicolumn{2}{|l|}{ Número de episódios } \\
\hline 1 & $21(57 \%)$ \\
\hline 2 & $11(30 \%)$ \\
\hline 3 & $3(8 \%)$ \\
\hline 5 & $1(2,5 \%)$ \\
\hline 6 & $1(2,5 \%)$ \\
\hline \multicolumn{2}{|l|}{ Duração } \\
\hline 1 & $10(16 \%)$ \\
\hline 2 & $6(9,5 \%)$ \\
\hline 3 & $11(17,5 \%)$ \\
\hline 4 & $2(3 \%)$ \\
\hline 6 & $6(9,5 \%)$ \\
\hline não sabe & $28(44,5 \%)$ \\
\hline \multicolumn{2}{|l|}{ Priapismo gago } \\
\hline Sim & $8(13 \%)$ \\
\hline Não & $31(49 \%)$ \\
\hline Não sabe & $24(38 \%)$ \\
\hline \multicolumn{2}{|l|}{ Tratamento } \\
\hline Analgésico & $1(2 \%)$ \\
\hline Aspiração & $7(11 \%)$ \\
\hline Antibiótico & $1(2 \%)$ \\
\hline Aspiração e transfusão & $4(6 \%)$ \\
\hline Analgésico, hidratação e transfusão & $1(2 \%)$ \\
\hline Analgésico e transfusão & $1(2 \%)$ \\
\hline Analgesico, morfina e transfusão & $1(2 \%)$ \\
\hline Aspiração, finasterida e transfusão & $3(4 \%)$ \\
\hline Finasterida & $4(6 \%)$ \\
\hline Finasterida e estrogênio & $1(2 \%)$ \\
\hline Hidroxiuréia & $1(1 \%)$ \\
\hline Medicamento não descrito & $2(3 \%)$ \\
\hline Transfusão & $8(12 \%)$ \\
\hline Sem tratamento & $18(28 \%)$ \\
\hline Não sabe & $11(17 \%)$ \\
\hline
\end{tabular}

Durante o período entre a inscrição no estudo e a segunda visita de acompanhamento, 37 dos pacientes tiveram priapismo, dos quais 13 tiveram um episódio de priapismo pela primeira vez e 24 já haviam experienciado episódios antes da inscrição no estudo. Durante esse período, a maioria 
dos pacientes teve apenas 1 episódio (21 de 37, 57\%), no entanto, 16 dos 37 pacientes tiveram de 2 a 6 episódios. Os episódios duraram de 1 a 6 horas, sendo a duração mais frequente de 1 (16\%) ou 3 horas (17.5\%) e uma menor parte sendo composta de casos de priapismo repetitivos com duração maior que 4 horas, ou priapismo "gago"(13\%) (Tabela 6.7).

Os pacientes que tiveram episódios durante o período de acompanhamento frequentemente não receberam tratamento $(28 \%)$ e entre os que receberam tratamento, o tratamento mais empregado foi o de transfusões (12\%). O restante dos pacientes foi tratado em uma variada gama de tratamentos e combinação de tratamentos (Tabela 6.7). 


\subsubsection{GWAS}

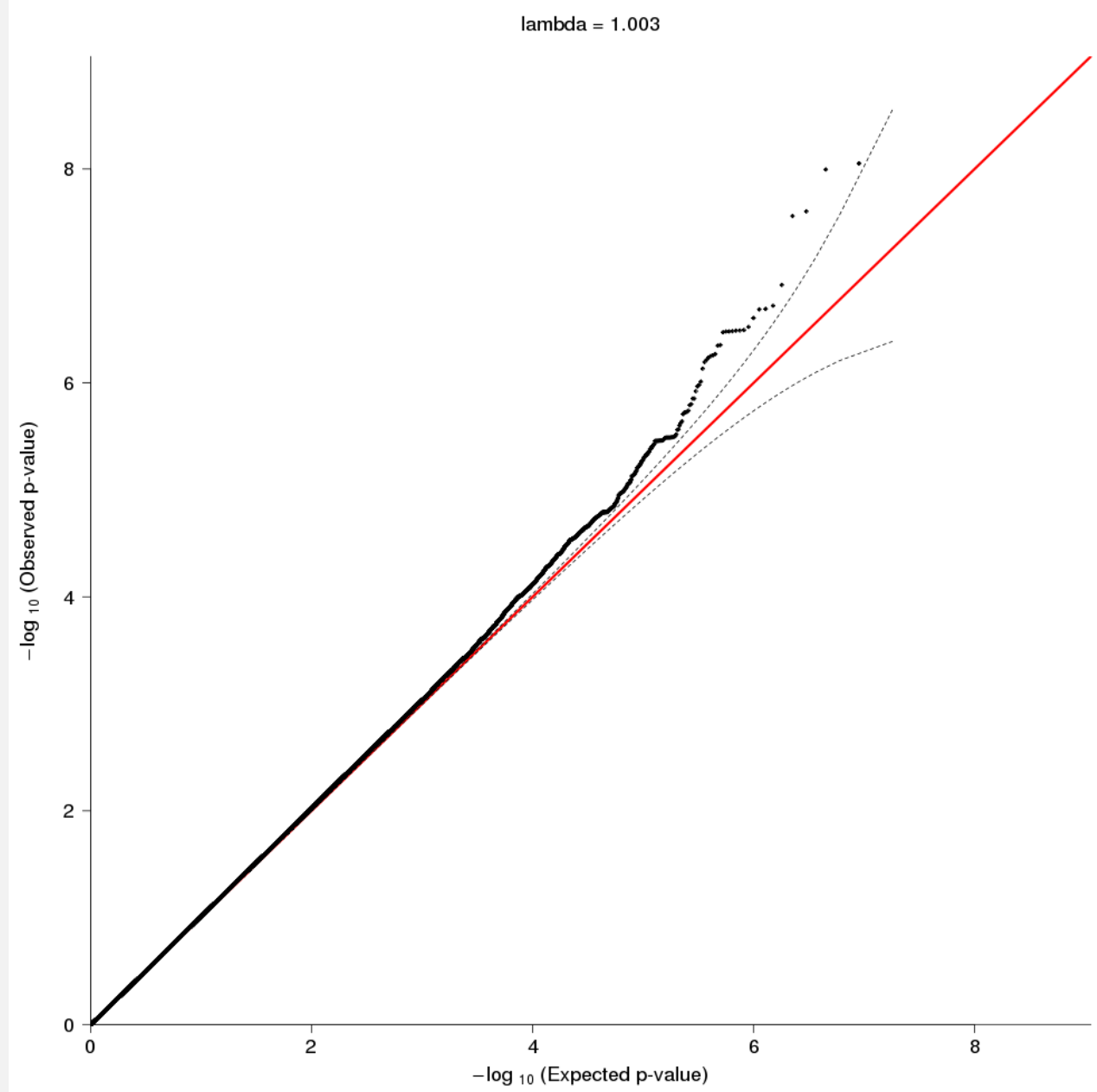

Figura 6.5: Gráfico $Q-Q$ do logaritmo dos p-valores observados (eixo y) versus os esperados (eixo $x)$.

\begin{tabular}{cccc} 
Cromossomo & SNP & Locus & P-valor \\
\hline 6 & rs77635018 & long intergenic non-protein coding RNA 2537 (LINC02537) & $8,9 \times 10^{-9}$ \\
6 & rs116116525 & long intergenic non-protein coding RNA 2537 (LINC02537) & $1 \times 10^{-8}$ \\
6 & rs60503510 & long intergenic non-protein coding RNA 2537 (LINC02537) & $2,5 \times 10^{-8}$ \\
3 & rs190103771 & N acetylated alpha-linked acidic dipeptidase like 2 (NAALADL2) & $2,8 \times 10^{-8}$
\end{tabular}

Tabela 6.8: SNPs associados com priapismo com significância no genoma inteiro (P-valor $<10^{-8}$ )

Após os procedimentos de controle de qualidade, um conjunto final de 831.797 SNPs foi utilizado no GWAS. Foram incluídos 169 pacientes HbSS, $H b S \beta 0$ e $H b S \beta+$ com histórico de priapismo e 433 HbSS, $H b S \beta 0$ e $H b S \beta+$ sem nenhum histórico de priapismo, com 12 ou mais anos (Figura 6.1). A análise não mostrou viés de p-valor $\left(\chi_{G C}=1.003\right)$ e o gráfico Q-Q (Figura 6.5) sugere que não há inflação genômica ou fatores de confusão adicionais.

A figura 6.6 mostra a distribuição dos p-valores para a associação dos SNPs e o priapismo, sintetizando os resultados do GWAS. O SNP rs77635018 atingiu significância genômica $\left(\mathrm{P}\right.$-valor $\left.<10^{-8}\right)$ 


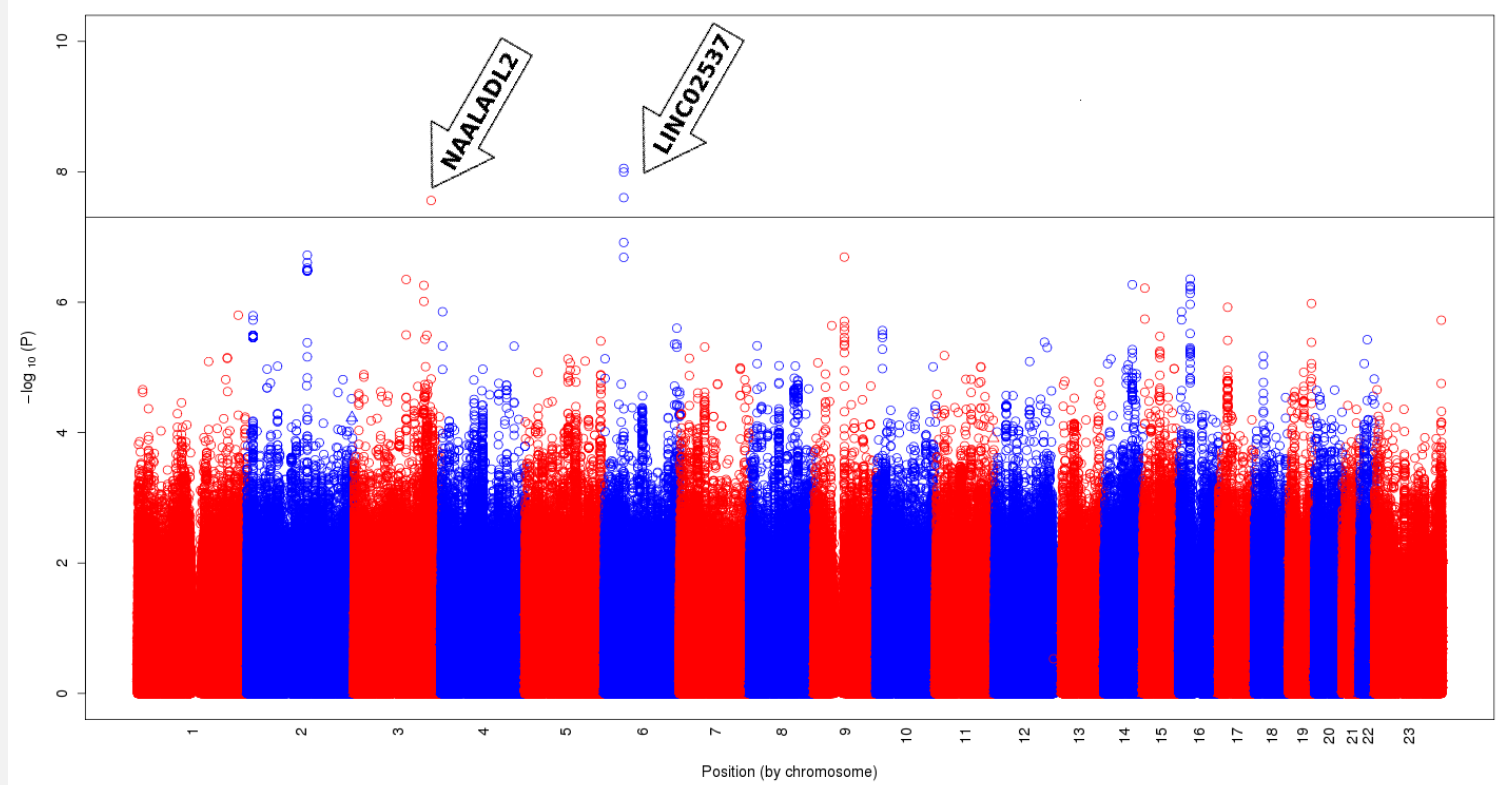

Figura 6.6: Gráfico Manhattan da função: (- $\log _{10} p$-valores) para os resultados de associação do priapismo e os SNPs dada suas posições em cada cromossomo. A linha horizontal indica um valor sugestivo de significância no genoma inteiro de $5 \times 10^{-8}$.

e os SNPs rs116116525, rs60503510, rs190103771 alcançaram valores próximos ao valor de significância genômica (Tabela 6.8). O SNP rs190103771 está localizado em uma região intrônica do cromossomo 3q26.31, contendo o gene $N$ acetylated alpha-linked acidic dipeptidase like 2 (NAALADL2) (Figura 6.8). Os outros 3 SNPs estão localizados no cromossomo 6p21.1 em uma região não intrônica, contendo o long intergenic non-protein coding RNA 2537 (LINC02537) (Figura 6.7).

Em uma análise restrita a regiões com associações previamente reportadas em estudos com genes candidatos, o SNP rs3103333 mostrou significância nominal $\left(p=2 \times 10^{-4}\right)$. Esse $p$-valor sugere evidência de associação do priapismo com o transforming growth factor beta receptor 3 (TGFBR3) (Figura 6.9). Outros SNPs previamente reportados não mostraram p-valores maiores que $\mathrm{p}=10^{-3}$. 


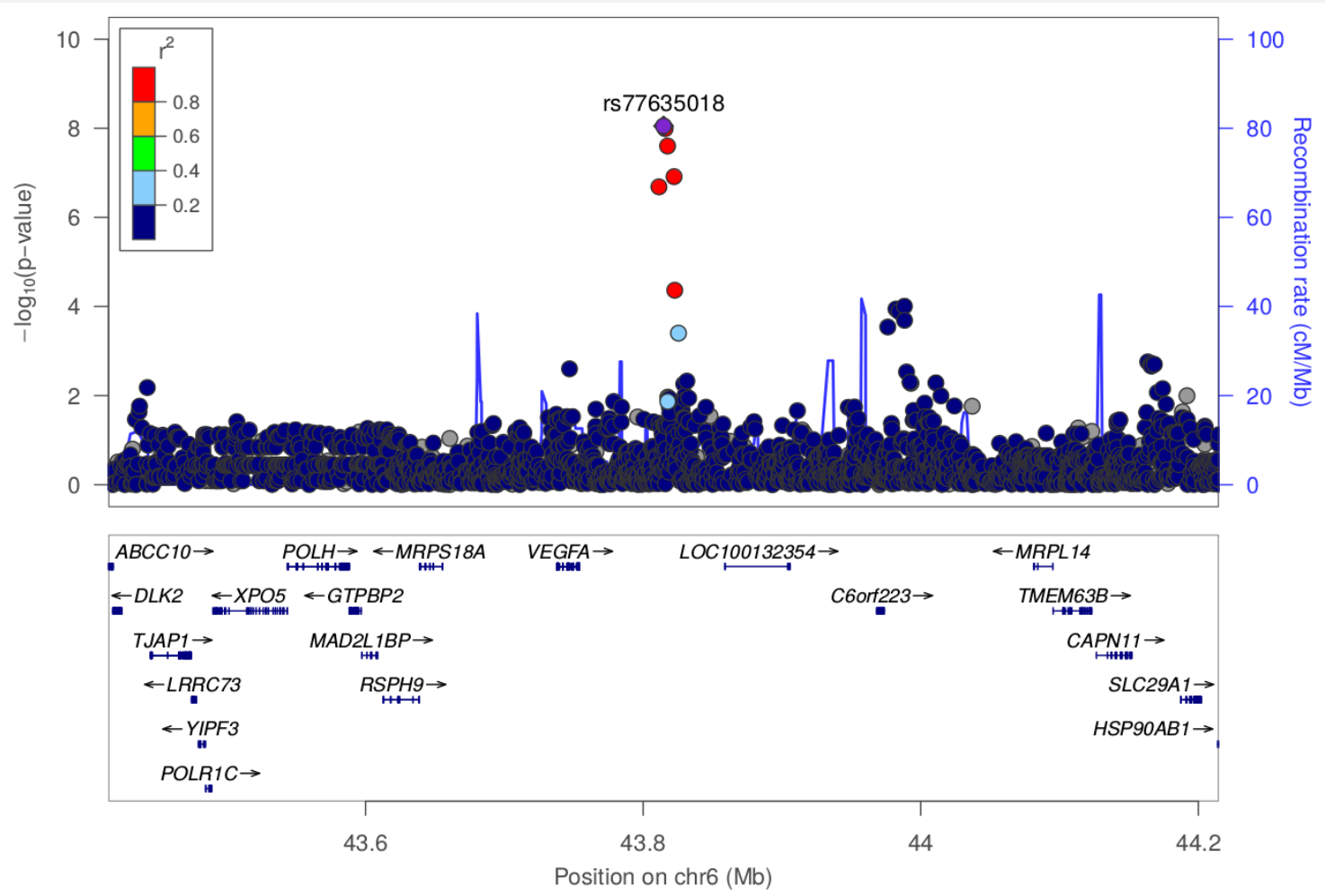

Figura 6.7: Gráfico locusZoom regional do cromossomo 6 e o SNP rs77635018. O eixo y representa o negativo do logaritmo dos p-valores para a associação dos SNPs com priapismo. Os SNPs são representados como pontos, com as cores codificando os níveis de desequilíbrio de ligação com o SNP rs77635018. O eixo x mostra as posições relativas dos SNPs no cromossomo, representando a taxa de recombinação em centimorgans (cM) por megabase (Mb). 


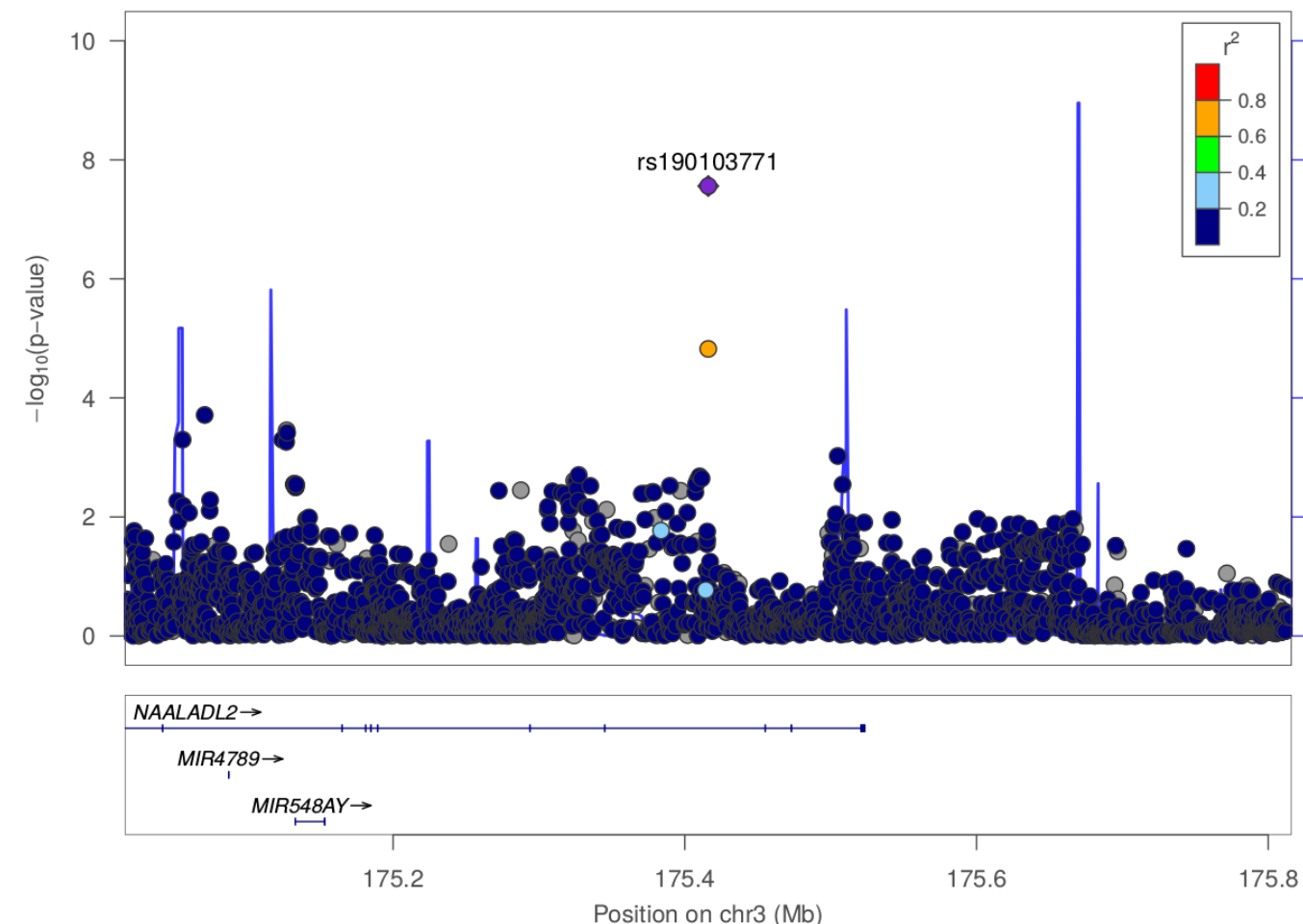

Figura 6.8: Gráfico locusZoom regional do cromossomo 3 e o SNP rs1901037r1. O eixo y representa o negativo do logaritmo dos p-valores para a associação dos SNPs com priapismo.Os SNPs são representados como pontos, com as cores codificando os níveis de desequilíbrio de ligação com o SNP rs190103771. O eixo $x$ mostra as posições relativas dos SNPs no cromossomo, representando a taxa de recombinação em centimorgans (cM) por megabase (Mb). 


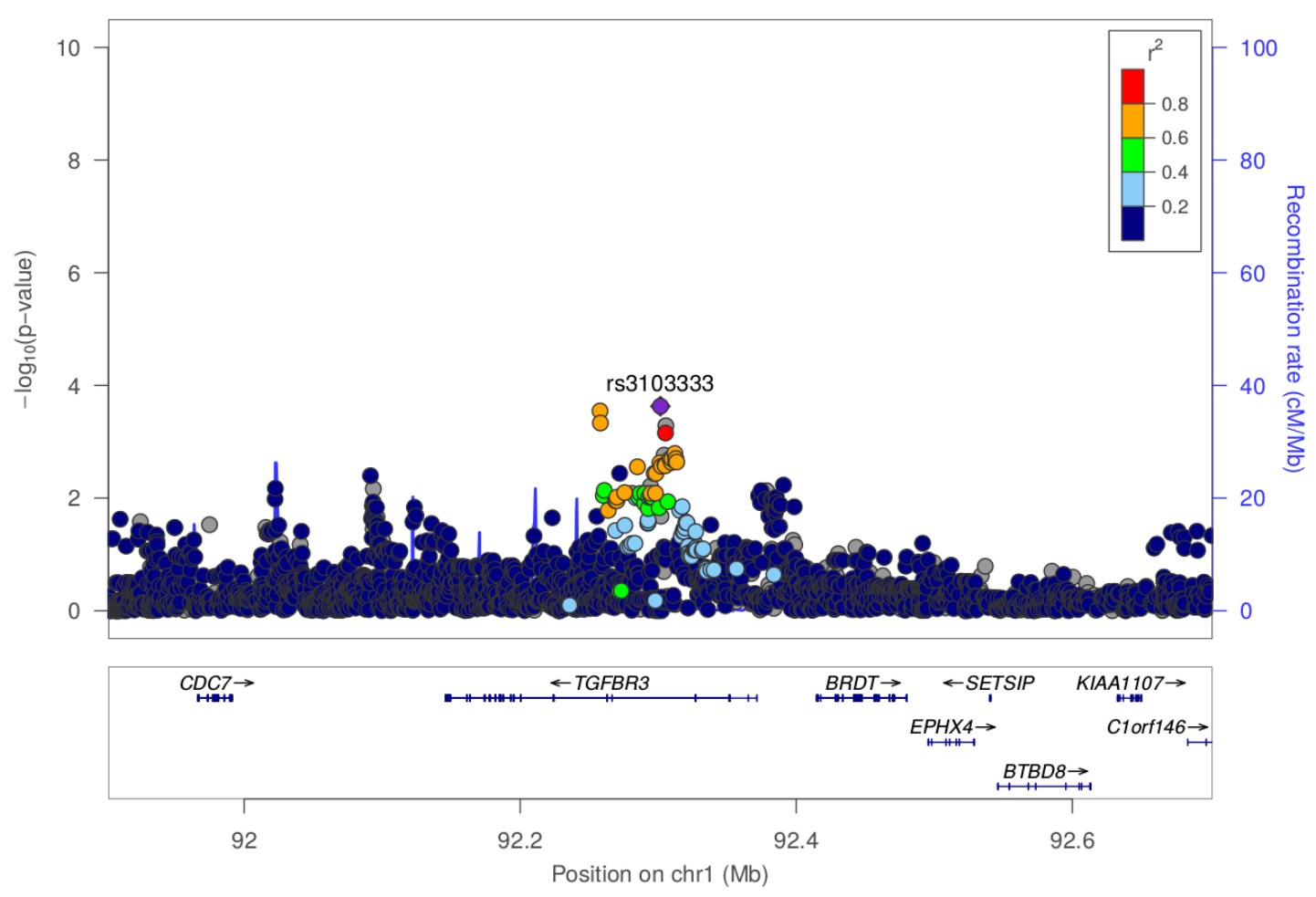

Figura 6.9: Gráfico locusZoom regional do cromossomo 1 e o SNP rs3103333. O eixo y representa o negativo do logaritmo dos p-valores para a associação dos SNPs com priapismo.Os SNPs são representados como pontos, com as cores codificando os níveis de desequilíbrio de ligação com o SNP rs3103333. O eixo x mostra as posições relativas dos SNPs no cromossomo, representando a taxa de recombinação em centimorgans (cM) por megabase ( $M b)$. 


\subsection{Discussão}

Este trabalho avaliou preditores clínicos e genéticos do priapismo em um grande coorte de pacientes brasileiros com anemia falciforme. Mostraram associação com priapismo maiores idades, hipertensão pulmonar e necrose avascular. Um GWAS replicou a associação de um SNP no gene TGFBR3 e identificou 2 novos marcadores genéticos associados ao priapismo com significância funcional desconhecida.

No presente coorte, o priapismo apresentou uma prevalência ( $24 \%$ em adultos) menor do que previamente reportada de 30 a 45\% (Adeyoju et al., 2002; Bruno et al., 2001; Elliott et al., 2007; Emond et al., 1980; Fowler Jr et al., 1991; Serjeant e Hambleton, 2015). Entre os pacientes de 0 a 18 anos de idade, a prevalência foi de $6.9 \%$, mais próxima de estudos posteriores (12\% (Hamre et al., 1990), 6.4\% (Tarry et al., 1987) e 3.6\% Furtado et al. (2012)).

A idade média do primeiro episódio foi de 16.4 anos, próximo de resultados apresentados posteriormente (12 anos em Mantadakis et al. (1999), 19 anos em Fowler Jr et al. (1991) e 15 anos em Adeyoju et al. (2002)). Os primeiros episódios se acumulam antes dos 20 anos (60\%), principalmente entre 8 e 15 anos de idade, um valor abaixo do reportado em Adeyoju et al. (2002) (75\%). Há um segundo pico de incidência entre os 24 e 26 anos, como de acordo com os dados de outro estudo (Bruno et al., 2001; Serjeant e Hambleton, 2015). Essa tendência bimodal também foi observada em Hamre et al. (1990), em intervalos de idade similares. A idade mínima foi de 2 anos e a máxima de 41 anos, um intervalo mais extenso do que o observado em Sharpsteen et al. (1993) de 5 a 37 e menos extenso do que o observado em (Bruno et al., 2001) de 2 a 55.

Há predomínio do genótipo HbSS entre os pacientes que já tiveram priapismo, totalizando 89\% dos casos, próximo do observado em Hamre et al. (1990) (81\%) e Sharpsteen et al. (1993) (87\%). Embora pacientes SS tenham um maior risco de ocorrência de priapismo, essa complicação não é restrita ao genótipo HbSS, uma vez que alguns casos também foram observados em pacientes $\operatorname{HbS} \beta 0$ (14\% de todos pacientes $\operatorname{HbS} \beta 0), \operatorname{HbS} \beta+(12 \%$ de todos pacientes $\operatorname{HbS} \beta+)$ e $\operatorname{HbSC}(3 \%$ de todos pacientes $\mathrm{HbSC}$ ). Embora indivíduos $\operatorname{HbS} \beta+$ tipicamente exibam fenótipos mais brandos, há heterogeneidade relacionada a mutações $\beta$-talassemia, que resultam em diferenças na quantidades de produções de hemoglobina A. Neste coorte, muitos participantes com $\mathrm{HbS} \beta+$ possuem mutações $\beta+$ mais graves, o que poderiam explicar a maior prevalência de priapismo nos participantes $\mathrm{HbS} \beta+$. Em pacientes $\mathrm{HbSC}$ os casos foram mais raros, resultado consistente com alguns estudos (0 de 10 em Fowler Jr et al. (1991) e 3 de 91 em Sharpsteen et al. (1993)), embora prevalência de $20 \%$ e $19 \%$ (16 de 82) tenham sido reportadas ((Hamre et al., 1990; Lionnet et al., 2012), respectivamente).

A análise de sobrevivência com o método Kaplan-Meier, mostra uma probabilidade cumulativa de sobrevivência ao evento de priapismo de $80 \%$ aos 20 anos de idade (Figura 6.4), similar ao observado em Adeyoju et al. (2002). Também em Adeyoju et al. (2002) observa-se uma estabilização nas novas ocorrências em idades mais avançadas, embora tenha ocorrido posteriormente ao observado em Adeyoju et al. (2002) (40 anos neste estudo e 30 em Adeyoju et al. (2002)).

Níveis de bilirrubina não se mostraram associados ao priapismo, embora a associação com biomarcadores tenha sido reportada previamente (Cita et al., 2016; Nolan et al., 2005b). Postula-se que o priapismo esteja associado à hemólise (Cita et al., 2016; Kato et al., 2006; Nolan et al., 2005b), como um resultado do comprometimento da biodisponibilidade do NO, que possui um importante papel na ereção. Durante episódios de hemólise, a hemoglobina livre consome NO, que seria utilizado 
na conversão de GTP em cGMP para indução de vasodilatação. Portanto, o equilíbrio é deslocado em direção à vasoconstrição, favorecendo a ocorrência de priapismo (Kato et al., 2007).

Acredita-se também que o priapismo esteja associado à hipertensão pulmonar, acidente vascular cerebral e úlcera de perna, sendo a hemólise um biomarcador para estas complicações (Ballas, 1991). Neste trabalho observou-se associação da hipertensão pulmonar, no entanto, úlcera de perna e acidente vascular cerebral não atingiram significância estatística. Adicionalmente, necrose avascular, que tem pressuposta associação com viscosidade do sangue, e, portanto, seria mais comum em pacientes com anemia falciforme com maiores níveis de hemoglobina e menos hemólise (Ballas, 1991; Furtado et al., 2012; Kato et al., 2007), se mostrou associada com priapismo neste coorte.

$28 \%$ dos episódios de priapismo durante o período de acompanhamento não foram tratados. Alguns desses podem ter sido resolvidos antes que ajuda médica fosse obtida, uma vez que $81 \%$ dos episódios não tratados tiveram de 1 a 2 horas de duração. Dentre os pacientes que receberam tratamento, a maioria recebeu tratamento de abordagem conservadora como já observado posteriormente (Lee et al., 2013). Adicionalmente, uma grande variedade de tratamentos e combinação de tratamentos foi realizada, mostrando a falta de consenso no estabelecimento das melhores práticas no tratamento do priapismo.

Embora o priapismo seja uma complicação bastante comum em pacientes com anemia falciforme, os mecanismos envolvidos na ocorrência de priapismo não são completamente compreendidos. Estudos sugerem que alterações nas vias metabólicas do NO/PDE5 e na sinalização da adenosina podem estar relacionadas com o priapismo (Champion et al., 2005; Lin et al., 2003; Mi et al., 2008), bem como excesso de adenosina, RhoA/Rho-kinase e regulação de opiorfina (Bivalacqua et al., 2004; Chitaley et al., 2001a; Hurt et al., 2002; Ning et al., 2014; Wang et al., 2002). Alterações nas vias NO/PDE5 resultariam em priapismo, uma vez que têm papel importante nos mecanismos de controle da ereção (Champion et al., 2005; Corbin, 2004; Lin et al., 2003). A adenosina, importante vasodilatador, e sua sinalização são partes do controle regulatório do sistema de transdução de sinal que interage com a via da PDE5 (Christ et al., 1997; Mi et al., 2008; Prieto, 2008; Tostes et al., 2007). ROCK é um fator vasoconstrictor envolvido com a regulação da endothelial NO synthase (eNOS) e a via RhoA/ROCK altera funções eréteis (Bivalacqua et al., 2004; Chitaley et al., 2001a,b; Mills et al., 2001; Musicki et al., 2009; Wang et al., 2002). Opiorfinas são pentapeptídeos associados à função erétil (Davies, 2009; Thanawala et al., 2008), cujas ativações e expressões exacerbadas podem causar relaxamento da musculatura lisa (Tong et al., 2006). No entanto, as regiões genômicas identificadas pelo GWAS com associação ao priapismo atingindo significância genômica identificadas nesse trabalho estão relacionadas a outras vias metabólicas.

Nós identificamos quatro SNPs significantemente associadaos ao priapismo na região de LINC02537 e do gene NAALADL2. LINC02537 é um RNA longo, intergênico e sem proteína associada (long intergenic non-protein coding). O LINC02537 não tem função desconhecida, mas, foi previamente associado com a variação fenotípica do vascular endothelial growth factor (VEGF) (Choi et al., 2016; Wang et al., 2018), um fator de crescimento associado ao câncer de próstata (Fryczkowski et al., 2018; Green et al., 2007; Peyromaure et al., 2007; Sfar et al., 2006; Ye et al., 2018). O NAALADL2 é amplamente expresso na próstata, e embora também tenha função desconhecida, foi previamente associado com a doença de Kawasaki, uma doença pediátrica vascular autoimune (Burgner et al., 2009); o tromboembolismo venoso (Greliche et al., 2013) e o câncer de próstata (Whitaker et al., 2014). A proximidade do gene NAALADL2 a genes envolvidos no 
desenvolvimento e manutenção vascular (Berndt et al., 2015) sugere possível relação com vias metabólicas vasculares. Estudos adicionais são necessários para determinação da implicação funcional de LINC02537 e NAALADL2 na ocorrência do priapismo.

Em concordância com evidências posteriores na literatura, nossos dados também mostram que o gene TGFBR3 possui um papel na patofisiologia do priapismo. TGFBR3 é parte da superfamília de proteínas transforming growth factor-beta, um proteoglicano de membrana expresso em células endoteliais, que age como cofator em vias inflamatórias. Membros da superfamília TGF- $\beta$ são importantes na modulação da hematopoiese, função endotelial, crescimento celular, diferenciação de leucócitos e angiogênese (Derynck e Zhang, 2003). O TGFBR3 é importante para a migração e transformação de células no endotélio (Brown et al., 1999), tendo sido previamente associado ao risco de acidente vascular cerebral (Sebastiani et al., 2005), úlcera de perna (Nolan et al., 2006), bacteremia (Adewoye et al., 2006) e priapismo (Elliott et al., 2007). Hipotetiza-se que o TGFBR3 também esteja relacionado à gravidade da anemia falciforme e à sobrevivência (Ashley-Koch et al., 2005). 


\section{Capítulo 7}

\section{Conclusão}

O estudo de processos biológicos complexos, em geral, envolve um conjunto de dados bastante diverso, e requer grandes volumes de dados para serem elucidados. Assim, diversos métodos de mineração de dados, como os algoritmos de reconhecimento de padrões, podem ser aplicados na investigação desses processos. A anemia falciforme, apesar de representar uma doença monogênica com herança mendeliana, apresenta uma grande heterogeneidade em suas manifestações fenotípicas. Os diferentes genótipos dos pacientes explicam uma pequena parte dessa diversidade, mas ainda há grande heterogeneidade mesmo quando se considera um único genótipo. Assim, este trabalho teve como objetivo responder a seguinte pergunta: "Quais técnicas de mineração de dados são as mais adequadas para a caracterização das relações entre fatores genotípicos e fenotípicos em pacientes de anemia falciforme?".

Para tanto, foram empregados diversos métodos estatísticos e de reconhecimento de padrões em um banco de dados de pacientes com anemia falciforme. O objetivo do trabalho foi extrair informação e conhecimento desses dados brutos. Buscou-se melhor compreender as relações entre biomarcadores da doença e a ocorrência de complicações por meio da aplicação de técnicas de reconhecimento de padrões e a geração de grupos de pacientes com características clínicas similares. Essa análise procurou ratificar e verificar o conhecimento prévio da importância de diferentes biomarcadores da doença, bem como a divisão dos pacientes em grupos relacionados a ocorrência de complicações associadas à hemólise e disfunção endotelial e grupos relacionados a ocorrência de complicações associadas à viscosidade do sangue e vaso-oclusão. Adicionalmente, foram investigadas as características particulares dos pacientes com anemia falciforme com histórico de priapismo, com objetivo de melhor descrever tais pacientes. Foram investigadas as prevalências nos diferentes genótipos presentes no estudo, bem como sua postulada associação com a hipertensão pulmonar, o acidente vascular cerebral e a úlcera de pernas. Finalmente, foram investigados fatores de risco que interferem na ocorrência da complicação por meio de um GWAS, que é capaz de revelar variações genéticas envolvidas em amplitude genômica.

Assim, a análise exploratória de dados apresentada neste trabalho gerou grupos de pacientes com anemia falciforme com características similares. Os agrupamentos obtidos pelos algoritmos PCAMix, PAM e TwoStep clustering dividiram os pacientes em diferentes níveis de gravidade, destacando atributos. Diferentes algoritmos com distintas abordagens de reconhecimento de padrão mostraram que características como idade, níveis de bilirrubina, histórico de transfusões, dor aguda da anemia falciforme, síndrome torácica aguda, acidente vascular cerebral, ataque isquêmico transitório, infarto cerebral silencioso, úlcera de pernas, moyamoya, ferritina, contagem de reticulócitos, retinopatias, 
ataques epiléticos e hemossiderose transfusional são importantes para o agrupamento dos pacientes.

O agrupamento de pacientes com genótipo HbSC obteve maior consenso entre os algoritmos. Esses grupos apresentaram menos atributos dissimilares, sendo mais homogêneos quanto às características clínicas de seus integrantes. Já no agrupamento de pacientes HbSS e HbS $\beta 0$, o PCAMix gerou grupos não análogos quando comparado com os algoritmos PAM e Two Step clustering. Os pacientes com genótipos HbSS e $\mathrm{HbS} \beta 0$ parecem apresentar padrões mais complexos de características clínicas, apresentando mais atributos dissimilares entre os grupos. Além disso, a combinação de variáveis de tipos numéricos e categóricos utilizadas no agrupamento dos pacientes pode dificultar a busca por grupos pelos algoritmos. O cálculo de medidas de similaridades de atributos categóricos e numéricos requer a consideração de diferentes escalas e intervalos, podendo não refletir exatamente as relações entre as variáveis.

Entre as três diferentes metodologias de agrupamento empregadas neste estudo, o algoritmo PAM foi o que gerou grupos de pacientes mais refinados, tanto para pacientes HbSC, como para pacientes HbSS e HbS $\beta 0$. Desta forma, o PAM pode ser considerado o mais pertinente para o agrupamento destes pacientes, considerando-se o conjunto de características utilizadas neste estudo. O algoritmo PAM apontou que acidente vascular cerebral e retinopatia geram distintos grupos de pacientes HbSS e HbS $\beta 0$ adultos. PAM também indicou que, para pacientes HbSC adultos, acidente vascular cerebral e retinopatia formam grupos distintos.

Adicionalmente ao agrupamento de pacientes de acordo com características clínicas, foi descrito o fardo do priapismo em pacientes com anemia falciforme. Foram identificados fatores clínicos associados a sua progressão, como a idade, o genótipo HbSS, hipertensão pulmonar e necrose avascular. Também foi descrita a abordagem empregada no tratamento destes pacientes. Essas descobertas estendem o nosso conhecimento com relação à doença e os fatores de risco associados ao priapismo em anemia falciforme.

Ainda no estudo do priapismo, esse trabalho realizou o primeiro GWAS para identificação de fatores genéticos associados ao seu risco em indivíduos com anemia falciforme. Essa abordagem permite a investigação de variações genéticas abrangendo todo genoma, não se restringindo a regiões específicas e eliminando viés na análise. Foi encontrado indício de replicação de resultado posterior, bem como identificados novos marcadores genéticos possivelmente associados ao risco da doença.

O trabalho desenvolvido na análise de agrupamento deu origem a um artigo que será submetido na BMC Bioinformatics e a análise de priapismo gerou um artigo que foi submetido na Journal of Sexual Medicine.

\subsection{Trabalhos futuros e limitações}

A maioria dos pacientes com anemia falciforme no Brasil recebe o tratamento por meio do Sistema Único de Saúde (SUS) (Carneiro-Proietti et al., 2018). No entanto, os pacientes podem receber tratamento em diferentes unidades de atendimento. Como não há comunicação entre as diferentes unidades e nem um sistema de centralização de informação, uma vez que a coleta dos dados deste coorte foi realizada pela revisão dos prontuários médicos dos pacientes em um dado hemocentro, alguns dados podem ter sido perdidos. Assim, a qualidade dos dados coletados por este coorte pode ter sido afetada pela falta de completude das informações sobre os pacientes, acarretando uma limitação para este estudo. 
Um fator que pode ter prejudicado a análise de pacientes com anemias falciforme com episódios de priapismo é o constrangimento dos pacientes. Os pacientes podem se sentir constrangidos em procurar atendimento médico, em relatar o episódio em sua visita de acompanhamento clínico, ou podem não compreender a associação entre o episódio de priapismo à anemia falciforme. Esses fatos podem ocasionar a aferição de um número menor de casos e em uma estimativa errônea da prevalência da complicação. Uma limitação adicional deste estudo na análise de pacientes com priapismo, está na caracterização dos episódios, uma vez que os dados coletados neste coorte não incluíam dados sobre o tipo de priapismo ocorrido, low-flow ou highflow. Por este motivo, não foi possível distinguir entre as prevalências destes tipos de priapismo nos pacientes estudados.

Como trabalhos futuros, o agrupamento de pacientes com genótipo HbSS e HbS $\beta 0$ poderia ser refinado, caso fosse realizado com um conjunto maior de pacientes e de atributos, possibilitando a geração de grupos ainda mais homogêneos. No entanto, a obtenção de extenso banco de dados é complicada, visto que a coleta de dados de um volume tão extenso de informações é bastante custosa e complexa. No estudo de pacientes que tiveram episódios de priapismo, a prevalência em genótipos mais raros pode ser investigada. No GWAS, pode-se empregar uma abordagem de admixture mapping na investigação de fatores genéticos associados ao risco do priapismo, de forma a se aumentar o poder estatístico da análise. Além disso, os SNPs que foram associados com a complicação requerem investigações com relação ao seu papel e contribuição para a patofisiologia da doença. 


\section{Referências Bibliográficas}

dat() Datasus. 2009. http://w3.datasus.gov.br/datasus/datasus.php. Citado na pág. 35

sps(2008) Spss statistics for windows (version 17.0), 2008. Citado na pág. 40

Adewoye et al.(2006) Adeboye H Adewoye, Vikki G Nolan, Qianli Ma, Clinton Baldwin, Diego F Wyszynski, John J Farrell, Lindsay A Farrer e Martin H Steinberg. Association of polymorphisms of igf1r and genes in the transforming growth factor- $\beta$ /bone morphogenetic protein pathway with bacteremia in sickle cell anemia. Clinical infectious diseases, 43(5):593-598. Citado na pág. 83

Adeyoju et al.(2002) AB Adeyoju, ABK Olujohungbe, J Morris, A Yardumian, D Bareford, A Akenova, O Akinyanju, K Cinkotai e PH O'reilly. Priapism in sickle-cell disease; incidence, risk factors and complications-an international multicentre study. BJU international, 90(9):898902. Citado na pág. 8, 81

Agathocleous et al.(2010) Michalis Agathocleous, Georgia Christodoulou, Vasilis Promponas, Chris Christodoulou, Vassilis Vassiliades e Antonis Antoniou. Protein secondary structure prediction with bidirectional recurrent neural nets: Can weight updating for each residue enhance performance? Em IFIP International Conference on Artificial Intelligence Applications and Innovations, páginas 128-137. Springer. Citado na pág. 2

Ahlqvist et al.(2018) Emma Ahlqvist, Petter Storm, Annemari Käräjämäki, Mats Martinell, Mozhgan Dorkhan, Annelie Carlsson, Petter Vikman, Rashmi B Prasad, Dina Mansour Aly, Peter Almgren et al. Novel subgroups of adult-onset diabetes and their association with outcomes: a data-driven cluster analysis of six variables. The lancet Diabetes $\mathcal{E}$ endocrinology, 6(5):361-369. Citado na pág. 31

Alexander et al.(2004) Neal Alexander, Douglas Higgs, George Dover e Graham R Serjeant. Are there clinical phenotypes of homozygous sickle cell disease? British journal of haematology, 126 (4):606-611. Citado na pág. 29, 31

Anderson et al.(2010) Carl A Anderson, Fredrik H Pettersson, Geraldine M Clarke, Lon R Cardon, Andrew P Morris e Krina T Zondervan. Data quality control in genetic case-control association studies. Nature protocols, 5(9):1564. Citado na pág. 11

Anele et al.(2015) Uzoma A Anele, Brian V Le, Linda MS Resar e Arthur L Burnett. How i treat priapism. Blood, páginas blood-2014. Citado na pág. xiii, 9, 33

Ashley-Koch et al.(2005) Allison E Ashley-Koch, Laura M De Castro, Felicia Lennon-Graham, Jude Jonassaint, Terry L Jackson, Jennifer Price, Jason Galloway, Susan Jones, Eldrida Randall, Charles Packman et al. Clinical and genetic profiles of the aging sickle cell patient., 2005. Citado na pág. 83

Ayele et al.(2014) Dawit Ayele, Temesgen Zewotir e Henry Mwambi. Multiple correspondence analysis as a tool for analysis of large health surveys in african settings. African health sciences, 14(4):1036-1045. Citado na pág. 18 
Balding(2006) David J Balding. A tutorial on statistical methods for population association studies. Nature Reviews Genetics, 7(10):781-791. Citado na pág. 10

Ballas(1991) Samir K Ballas. Sickle cell anemia with few painful crises is characterized by decreased red cell deformability and increased number of dense cells. American journal of hematology, 36(2):122-130. Citado na pág. 29, 82

Ballas et al.(2010) Samir K Ballas, Susan Lieff, Lennette J Benjamin, Carlton D Dampier, Matthew M Heeney, Carolyn Hoppe, Cage S Johnson, Zora R Rogers, Kim Smith-Whitley, Winfred C Wang et al. Definitions of the phenotypic manifestations of sickle cell disease. American journal of hematology, 85(1):6-13. Citado na pág. 6

Ballas et al.(2012) Samir K Ballas, Muge R Kesen, Morton F Goldberg, Gerard A Lutty, Carlton Dampier, Ifeyinwa Osunkwo, Winfred C Wang, Carolyn Hoppe, Ward Hagar, Deepika S Darbari et al. Beyond the definitions of the phenotypic complications of sickle cell disease: an update on management. The Scientific World Journal, 2012. Citado na pág. 7

Baron e Leiter(1978) Michael Baron e Elliot Leiter. The management of priapism in sickle cell anemia. The Journal of urology, 119(5):610-611. Citado na pág. 8

Barrett et al.(2008) Jeffrey C Barrett, Sarah Hansoul, Dan L Nicolae, Judy H Cho, Richard H Duerr, John D Rioux, Steven R Brant, Mark S Silverberg, Kent D Taylor, M Michael Barmada et al. Genome-wide association defines more than 30 distinct susceptibility loci for crohn's disease. Nature genetics, 40(8):955-962. Citado na pág. 12

Barrett et al.(2009) Jeffrey C Barrett, David G Clayton, Patrick Concannon, Beena Akolkar, Jason D Cooper, Henry A Erlich, Cécile Julier, Grant Morahan, Jørn Nerup, Concepcion Nierras et al. Genome-wide association study and meta-analysis find that over 40 loci affect risk of type 1 diabetes. Nature genetics, 41(6):703-707. Citado na pág. 12

Bender e Seibel(2014) MA Bender e Gabrielle Douthitt Seibel. Sickle cell disease. Citado na pág. 6

Berkhin(2006) Pavel Berkhin. A survey of clustering data mining techniques. Em Grouping multidimensional data, páginas 25-71. Springer. Citado na pág. 20

Berndt et al.(2015) Sonja I Berndt, Zhaoming Wang, Meredith Yeager, Michael C Alavanja, Demetrius Albanes, Laufey Amundadottir, Gerald Andriole, Laura Beane Freeman, Daniele Campa, Geraldine Cancel-Tassin et al. Two susceptibility loci identified for prostate cancer aggressiveness. Nature communications, 6:6889. Citado na pág. 83

Bilu e Linial(2002) Yonatan Bilu e Michal Linial. The advantage of functional prediction based on clustering of yeast genes and its correlation with non-sequence based classifications. Journal of Computational Biology, 9(2):193-210. Citado na pág. 21

Bivalacqua et al.(2004) Trinity J Bivalacqua, Hunter C Champion, Mustafa F Usta, Selim Cellek, Kanchan Chitaley, R Clinton Webb, Ronald L Lewis, Thomas M Mills, Wayne JG Hellstrom e Philip J Kadowitz. Rhoa/rho-kinase suppresses endothelial nitric oxide synthase in the penis: a mechanism for diabetes-associated erectile dysfunction. Proceedings of the National Academy of Sciences, 101(24):9121-9126. Citado na pág. 9, 82

Bivalacqua et al.(2012) Trinity J Bivalacqua, Biljana Musicki, Omer Kutlu e Arthur L Burnett. New insights into the pathophysiology of sickle cell disease-associated priapism. The journal of sexual medicine, 9(1):79-87. Citado na pág. 9

Bloch et al.(2015) Evan M Bloch, Robert L Crookes, Jennifer Hull, Sue Fawcus, Rajesh Gangaram, John Anthony, Charlotte Ingram, Solomuzi Ngcobo, Julie Croxford, Darryl V Creel et al. The impact of human immunodeficiency virus infection on obstetric hemorrhage and blood transfusion in south africa. Transfusion, 55(7):1675-1684. Citado na pág. 35 
Broderick(2012) Gregory A Broderick. Priapism and sickle-cell anemia: Diagnosis and nonsurgical therapy. The journal of sexual medicine, 9(1):88-103. Citado na pág. 8, 32

Broderick et al.(1994) Gregory A Broderick, David Gordon, Joseph Hypolite e Robert M Levin. Anoxia and corporal smooth muscle dysfunction: a model for ischemic priapism. The Journal of urology, 151(1):259-262. Citado na pág. 8

Broeckling et al.(2014) CD Broeckling, FA Afsar, S Neumann, A Ben-Hur e JE Prenni. Ramclust: A novel feature clustering method enables spectral-matching-based annotation for metabolomics data. Analytical chemistry, 86(14):6812-6817. Citado na pág. 21

Brown et al.(1999) Christopher B Brown, Angelique S Boyer, Raymond B Runyan e Joey V Barnett. Requirement of type iii tgf- $\beta$ receptor for endocardial cell transformation in the heart. Science, 283(5410):2080-2082. Citado na pág. 83

Bruno et al.(2001) Dieter Bruno, Delbert R Wigfall, Sherri A Zimmerman, Philip M Rosoff e John S Wiener. Genitourinary complications of sickle cell disease. The Journal of urology, 166 (3):803-811. Citado na pág. 8, 32, 81

Burgner et al.(2009) David Burgner, Sonia Davila, Willemijn B Breunis, Sarah B Ng, Yi Li, Carine Bonnard, Ling Ling, Victoria J Wright, Anbupalam Thalamuthu, Miranda Odam et al. A genome-wide association study identifies novel and functionally related susceptibility loci for kawasaki disease. PLoS genetics, 5(1):e1000319. Citado na pág. 82

Burnett(2003) AL Burnett. Priapism pathophysiology: clues to prevention. International journal of impotence research, 15(S5):S80. Citado na pág. 8

Burt(1950) Cyril Burt. The factorial analysis of qualitative data. British Journal of Statistical Psychology, 3(3):166-185. Citado na pág. 16

Bush e Moore(2012) William S Bush e Jason H Moore. Genome-wide association studies. PLoS Comput Biol, 8(12):e1002822. Citado na pág. 10, 11

Cantor et al.(2010) Rita M Cantor, Kenneth Lange e Janet S Sinsheimer. Prioritizing gwas results: a review of statistical methods and recommendations for their application. The American Journal of Human Genetics, 86(1):6-22. Citado na pág. 11

Carneiro-Proietti et al.(2010) Anna Bárbara Carneiro-Proietti, Ester C Sabino, Divaldo Sampaio, Fernando A Proietti, Thelma T Gonçalez, Cláudia DL Oliveira, João E Ferreira, Jing Liu, Brian Custer, George B Schreiber et al. Demographic profile of blood donors at three major brazilian blood centers: results from the international reds-ii study, 2007 to 2008. Transfusion, 50(4):918-925. Citado na pág. 65

Carneiro-Proietti et al.(2018) Anna BF Carneiro-Proietti, Shannon Kelly, Carolina Miranda Teixeira, Ester C Sabino, Cecilia S Alencar, Ligia Capuani, Tassila P Salomon Silva, Aderson Araujo, Paula Loureiro, Cláudia Máximo et al. Clinical and genetic ancestry profile of a large multi-centre sickle cell disease cohort in brazil. British journal of haematology, 182(6):895-908. Citado na pág. 86

Champion et al.(2005) Hunter C Champion, Trinity J Bivalacqua, Eiki Takimoto, David A Kass e Arthur L Burnett. Phosphodiesterase-5a dysregulation in penile erectile tissue is a mechanism of priapism. Proceedings of the National Academy of Sciences, 102(5):1661-1666. Citado na pág. 8, 82

Chang et al.(1998) Judy C Chang, Ronghua Lu, Chin Lin, Shan-Mei Xu, Yuet Wai Kan, Susanna Porcu, Elaine Carlson, Michael Kitamura, Suya Yang, Linda Flebbe-Rehwaldt et al. Transgenic knockout mice exclusively expressing human hemoglobin s after transfer of a 240 -kb $\beta$ s-globin 
yeast artificial chromosome: A mouse model of sickle cell anemia. Proceedings of the National Academy of Sciences, 95(25):14886-14890. Citado na pág. xiii, 5

Chavent et al.(2014) Marie Chavent, Vanessa Kuentz-Simonet, Amaury Labenne e Jérôme Saracco. Multivariate analysis of mixed data: The pcamixdata $\mathrm{r}$ package. arXiv preprint arXiv:1411.4911. Citado na pág. 18, 41

Chen et al.(2010) Xi Chen, Lily Wang, Bo Hu, Mingsheng Guo, John Barnard e Xiaofeng Zhu. Pathway-based analysis for genome-wide association studies using supervised principal components. Genetic epidemiology, 34(7):716-724. Citado na pág. 2

Chitaley et al.(2001a) Kanchan Chitaley, David S Weber e R Clinton Webb. Rhoa/rho-kinase, vascular changes, and hypertension. Current hypertension reports, 3(2):139-144. Citado na pág. 9, 82

Chitaley et al.(2001b) Kanchan Chitaley, Christopher J Wingard, R Clinton Webb, Heather Branam, Vivienne S Stopper, Ronald W Lewis e Thomas M Mills. Antagonism of rho-kinase stimulates rat penile erection via a nitric oxide-independent pathway. Nature medicine, 7(1):119. Citado na pág. 82

Choi et al.(2016) Seung Hoan Choi, Daniela Ruggiero, Rossella Sorice, Ci Song, Teresa Nutile, Albert Vernon Smith, Maria Pina Concas, Michela Traglia, Caterina Barbieri, Ndeye Coumba Ndiaye et al. Six novel loci associated with circulating vegf levels identified by a meta-analysis of genome-wide association studies. PLoS genetics, 12(2):e1005874. Citado na pág. 82

Choudhury e Murty(1990) Sabyasachy Choudhury e M Narasimha Murty. A divisive scheme for constructing minimal spanning trees in coordinate space. Pattern Recognition Letters, 11(6): 385-389. Citado na pág. 21

Christ et al.(1997) GJ Christ, S Richards e A Winkler. Integrative erectile biology: the role of signal transduction and cell-to-cell communication in coordinating corporal smooth muscle tone and penile erection. International journal of impotence research, 9(2):69. Citado na pág. 82

Chui e Dover(2001) David HK Chui e George J Dover. Sickle cell disease: no longer a single gene disorder. Current opinion in pediatrics, 13(1):22-27. Citado na pág. 7

Cita et al.(2016) Kizzy-Clara Cita, Laurent Brureau, Nathalie Lemonne, Marie Billaud, Philippe Connes, Séverine Ferdinand, Benoit Tressières, Vanessa Tarer, Maryse Etienne-Julan, Pascal Blanchet et al. Men with sickle cell anemia and priapism exhibit increased hemolytic rate, decreased red blood cell deformability and increased red blood cell aggregate strength. PloS one, 11(5):e0154866. Citado na pág. 81

Claudino et al.(2009) Mário Angelo Claudino, Carla Fernanda Franco-Penteado, Marcus Alexandre Finzi Corat, Ana Paula Gimenes, Luiz Augusto Correa Passos, Edson Antunes e Fernando Ferreira Costa. Increased cavernosal relaxations in sickle cell mice priapism are associated with alterations in the no-cgmp signaling pathway. The journal of sexual medicine, 6(8):21872196. Citado na pág. 9

Consortium et al.(2015) 1000 Genomes Project Consortium et al. A global reference for human genetic variation. Nature, 526(7571):68. Citado na pág. 67

Corbin e Francis(1999) Jackie D Corbin e Sharron H Francis. Cyclic gmp phosphodiesterase-5: target of sildenafil. Journal of Biological Chemistry, 274(20):13729-13732. Citado na pág. 8

Corbin(2004) JD Corbin. Mechanisms of action of pde5 inhibition in erectile dysfunction. International journal of impotence research, 16(S1):S4. Citado na pág. 82 
Costa e Conran(2016) Fernando Ferreira Costa e Nicola Conran. Sickle cell anemia: From basic science to clinical practice. Springer. Citado na pág. 6

Costa et al.(2007) Ivan G Costa, Roland Krause, Lennart Opitz e Alexander Schliep. Semisupervised learning for the identification of syn-expressed genes from fused microarray and in situ image data. BMC bioinformatics, 8(Suppl 10):S3. Citado na pág. 2

Cypess et al.(2013) Aaron M Cypess, Andrew P White, Cecile Vernochet, Tim J Schulz, Ruidan Xue, Christina A Sass, Tian Liang Huang, Carla Roberts-Toler, Lauren S Weiner, Cathy Sze et al. Anatomical localization, gene expression profiling and functional characterization of adult human neck brown fat. Nature medicine, 19(5):635-639. Citado na pág. 21

Davies(2009) Kelvin Paul Davies. The role of opiorphins (endogenous neutral endopeptidase inhibitors) in urogenital smooth muscle biology. The journal of sexual medicine, 6:286-291. Citado na pág. 82

DAY(1992) WILLIAM HE DAY. Complexity theory: An introduction for practitioners of classification. World Scientific Publishing Co., Inc., River Edge, NJ. Citado na pág. 21

de Atenção à Saúde et al.(2013) Secretaria de Atenção à Saúde, Brasil e Departamento de Atenção Especializada. Doença falciforme: condutas básicas para tratamento, 2013. Citado na pág. 5

De Caterina et al.(1995) Raffacle De Caterina, Peter Libby, Hai-Bing Peng, Victor J Thannickal, TB Rajavashisth, Michael Anthony Gimbrone, W Soo Shin e James K Liao. Nitric oxide decreases cytokine-induced endothelial activation. nitric oxide selectively reduces endothelial expression of adhesion molecules and proinflammatory cytokines. The Journal of clinical investigation, 96(1): 60-68. Citado na pág. 8

De Tejada et al.(1997) Inigo Saenz De Tejada, Noel N Kim, Jennifer T Daley, Ramin Royai, Joseph Hypolite, Gregory A Broderick, Fernando Garcia-Diaz e Robert Levin. Acidosis impairs rabbit trabecular smooth muscle contractility. The Journal of urology, 157(2):722-726. Citado na pág. 8

Delaneau et al.(2008) Olivier Delaneau, Cédric Coulonges e Jean-François Zagury. Shape-it: new rapid and accurate algorithm for haplotype inference. BMC bioinformatics, 9(1):540. Citado na pág. 67

Derynck e Zhang(2003) Rik Derynck e Ying E Zhang. Smad-dependent and smad-independent pathways in tgf- $\beta$ family signalling. Nature, 425(6958):577. Citado na pág. 83

Di Franco(2016) Giovanni Di Franco. Multiple correspondence analysis: one only or several techniques? Quality \& Quantity, 50(3):1299-1315. Citado na pág. 16

Diggs(1965) LW Diggs. Sickle cell crises: Ward burdick award contribution. American Journal of Clinical Pathology, 44(1):1-19. Citado na pág. 8

Du et al.(2018) Mengtian Du, Sarah Van Ness, Victor Gordeuk, Sayed M Nouraie, Sergei Nekhai, Mark Gladwin, Martin H Steinberg e Paola Sebastiani. Biomarker signatures of sickle cell disease severity. Blood Cells, Molecules, and Diseases. Citado na pág. xv, 30, 31

Duda et al.(2012) Richard O Duda, Peter E Hart e David G Stork. Pattern classification. John Wiley \& Sons. Citado na pág. 16, 25

Dunson(2000) David B Dunson. Bayesian latent variable models for clustered mixed outcomes. Journal of the Royal Statistical Society: Series B (Statistical Methodology), 62(2):355-366. Citado na pág. 31 
Easton et al.(2007) Douglas F Easton, Karen A Pooley, Alison M Dunning, Paul DP Pharoah, Deborah Thompson, Dennis G Ballinger, Jeffery P Struewing, Jonathan Morrison, Helen Field, Robert Luben et al. Genome-wide association study identifies novel breast cancer susceptibility loci. Nature, 447(7148):1087-1093. Citado na pág. 12

El-Bahnasawy et al.(2002) MS El-Bahnasawy, A Dawood e A Farouk. Low-flow priapism: risk factors for erectile dysfunction. BJU international, 89(3):285-290. Citado na pág. 8

Elliott et al.(2007) Laine Elliott, Allison E Ashley-Koch, Laura De Castro, Jude Jonassaint, Jennifer Price, Kenneth I Ataga, Marc C Levesque, J Brice Weinberg, James R Eckman, Eugene P Orringer et al. Genetic polymorphisms associated with priapism in sickle cell disease. British journal of haematology, 137(3):262-267. Citado na pág. 81, 83

Emond et al.(1980) Alan M Emond, Roy Holman, Richard J Hayes e Graham R Serjeant. Priapism and impotence in homozygous sickle cell disease. Archives of Internal Medicine, 140(11):14341437. Citado na pág. 8,81

Ernst e Kellis(2012) Jason Ernst e Manolis Kellis. Chromhmm: automating chromatin-state discovery and characterization. Nature methods, 9(3):215-216. Citado na pág. 2

Fisher(1940) Ronald A Fisher. The precision of discriminant functions. Annals of Eugenics, 10 (1):422-429. Citado na pág. 16

Fowler Jr et al.(1991) Jackson E Fowler Jr, Mabel Koshy, Michael Strub e Stephen K Chinn. Priapism associated with the sickle cell hemoglobinopathies: prevalence, natural history and sequelae. The Journal of urology, 145(1):65-68. Citado na pág. 8, 32, 66, 81

Friedman et al.(2001) Jerome Friedman, Trevor Hastie e Robert Tibshirani. The elements of statistical learning, volume 1. Springer series in statistics New York. Citado na pág. 26

Fryczkowski et al.(2018) M Fryczkowski, RJ Buldak, T Hejmo, M Kukla e K Żwirska-Korczala. Circulating levels of omentin, leptin, vegf, and hgf and their clinical relevance with psa marker in prostate cancer. Disease markers, 2018. Citado na pág. 82

Fu et al.(2014) Shibo Fu, Moses Tarndie Tar, Arnold Melman e Kelvin Paul Davies. Opiorphin is a master regulator of the hypoxic response in corporal smooth muscle cells. The FASEB Journal, 28(8):3633-3644. Citado na pág. 9

Furtado et al.(2012) Paulo Sampaio Furtado, Milena Paiva Costa, Flávia Ribeiro do Prado Valladares, Leandro Oliveira Da Silva, Maurício Lordêlo, Isa Lyra e Ubirajara Barroso. The prevalence of priapism in children and adolescents with sickle cell disease in brazil. International journal of hematology, 95(6):648-651. Citado na pág. 81, 82

Gardner e Thein(2016) Kate Gardner e Swee Lay Thein. Genetic factors modifying sickle cell disease severity. Em Sickle Cell Anemia, páginas 371-397. Springer. Citado na pág. 29

Gehlenborg et al.(2010) Nils Gehlenborg, Seán I O’Donoghue, Nitin S Baliga, Alexander Goesmann, Matthew A Hibbs, Hiroaki Kitano, Oliver Kohlbacher, Heiko Neuweger, Reinhard Schneider, Dan Tenenbaum et al. Visualization of omics data for systems biology. Nature methods, 7 : S56-S68. Citado na pág. 2

Gower(1971) John C Gower. A general coefficient of similarity and some of its properties. Biometrics, páginas 857-871. Citado na pág. 22, 41

Green et al.(2007) Melanie ML Green, Crispin T Hiley, Jonathan H Shanks, Ian C Bottomley, Catharine ML West, Richard A Cowan e Ian J Stratford. Expression of vascular endothelial growth factor (vegf) in locally invasive prostate cancer is prognostic for radiotherapy outcome. International Journal of Radiation Oncology* Biology* Physics, 67(1):84-90. Citado na pág. 82 
Greenacre e Hastie(1987) Michael Greenacre e Trevor Hastie. The geometric interpretation of correspondence analysis. Journal of the American statistical association, 82(398):437-447. Citado na pág. 17

Greliche et al.(2013) Nicolas Greliche, Marine Germain, Jean-Charles Lambert, William Cohen, Marion Bertrand, Anne-Marie Dupuis, Luc Letenneur, Mark Lathrop, Philippe Amouyel, PierreEmmanuel Morange et al. A genome-wide search for common snp x snp interactions on the risk of venous thrombosis. BMC medical genetics, 14(1):36. Citado na pág. 82

Gudmundsson et al.(2007) Julius Gudmundsson, Patrick Sulem, Andrei Manolescu, Laufey T Amundadottir, Daniel Gudbjartsson, Agnar Helgason, Thorunn Rafnar, Jon T Bergthorsson, Bjarni A Agnarsson, Adam Baker et al. Genome-wide association study identifies a second prostate cancer susceptibility variant at 8q24. Nature genetics, 39(5):631-637. Citado na pág. 12

Guo et al.(2018) Yuelong Guo, Michael P Busch, Mark Seielstad, Stacy Endres-Dighe, Connie M Westhoff, Brendan Keating, Carolyn Hoppe, Aarash Bordbar, Brian Custer, Adam S Butterworth et al. Development and evaluation of a transfusion medicine genome wide genotyping array. Transfusion. Citado na pág. 66

Guttman(1941) Louis Guttman. The quantification of a class of attributes: A theory and method of scale construction. The Prediciton of Personal Adjustment. Citado na pág. 16

Habara e Steinberg(2016) Alawi Habara e Martin H Steinberg. Minireview: Genetic basis of heterogeneity and severity in sickle cell disease. Experimental Biology and Medicine, 241(7): 689-696. Citado na pág. 7, 29, 30

Hamre et al.(1990) MR Hamre, EP Harmon, DV Kirkpatrick, NJ Barrios, MJ Stern e JR Humbert. Priapism as a complication of sickle cell disease. Journal of Pediatric Hematology/Oncology, 12(1):108. Citado na pág. 32, 81

Hayashi(1951) Chikio Hayashi. On the prediction of phenomena from qualitative data and the quantification of qualitative data from the mathematico-statistical point of view. Annals of the institute of statistical mathematics, 3(1):69-98. Citado na pág. 16

Higgs et al.(1982) Douglas R Higgs, Beverley E Aldridge, Janette Lamb, John B Clegg, David J Weatherall, Richard J Hayes, Yvonne Grandison, Yvonne Lowrie, Karlene P Mason, Beryl E Serjeant et al. The interaction of alpha-thalassemia and homozygous sickle-cell disease. New England Journal of Medicine, 306(24):1441-1446. Citado na pág. 29

Höhner et al.(2013) Ricarda Höhner, Johannes Barth, Leonardo Magneschi, Daniel Jaeger, Anna Niehues, Till Bald, Arthur Grossman, Christian Fufezan e Michael Hippler. The metabolic status drives acclimation of iron deficiency responses in chlamydomonas reinhardtii as revealed by proteomics based hierarchical clustering and reverse genetics. Molecular \& Cellular Proteomics, 12(10):2774-2790. Citado na pág. 21

Hotelling(1933) Harold Hotelling. Analysis of a complex of statistical variables into principal components. Journal of educational psychology, 24(6):417. Citado na pág. 14

Howie et al.(2009) Bryan N Howie, Peter Donnelly e Jonathan Marchini. A flexible and accurate genotype imputation method for the next generation of genome-wide association studies. PLoS genetics, 5(6):e1000529. Citado na pág. 67

Hunter et al.(2007) David J Hunter, Peter Kraft, Kevin B Jacobs, David G Cox, Meredith Yeager, Susan E Hankinson, Sholom Wacholder, Zhaoming Wang, Robert Welch, Amy Hutchinson et al. A genome-wide association study identifies alleles in fgfr2 associated with risk of sporadic postmenopausal breast cancer. Nature genetics, 39(7):870-874. Citado na pág. 12 
Hurt et al.(2002) K Joseph Hurt, Biljana Musicki, Michael A Palese, Julie K Crone, Robyn E Becker, John L Moriarity, Solomon H Snyder e Arthur L Burnett. Akt-dependent phosphorylation of endothelial nitric-oxide synthase mediates penile erection. Proceedings of the National Academy of Sciences, 99(6):4061-4066. Citado na pág. 9, 82

Jain et al.(1999) Anil K Jain, M Narasimha Murty e Patrick J Flynn. Data clustering: a review. ACM computing surveys (CSUR), 31(3):264-323. Citado na pág. 13, 20

Johnson e Wichern(1982) Richard Arnold Johnson e Dean W. Wichern. Applied multivariate statistical analysis. Prentice-Hall. Citado na pág. 14

Jolliffe(1986) Ian Jolliffe. Principal component analysis. Springer, 3 edição. Citado na pág. 14

Jolliffe(2002) Ian Jolliffe. Principal component analysis. Wiley Online Library, 3 edição. Citado na pág. 14

Jolliffe e Cadima(2016) Ian T Jolliffe e Jorge Cadima. Principal component analysis: a review and recent developments. Phil. Trans. R. Soc. A, 374(2065):20150202. Citado na pág. 14

Juncker et al.(2009) Agnieszka S Juncker, Lars J Jensen, Andrea Pierleoni, Andreas Bernsel, Michael L Tress, Peer Bork, Gunnar Von Heijne, Alfonso Valencia, Christos A Ouzounis, Rita Casadio et al. Sequence-based feature prediction and annotation of proteins. Genome biology, 10 (2):1. Citado na pág. 2

Kanias et al.(2017) Tamir Kanias, Marion C Lanteri, Grier P Page, Yuelong Guo, Stacy M Endres, Mars Stone, Sheila Keating, Alan E Mast, Ritchard G Cable, Darrell J Triulzi et al. Ethnicity, sex, and age are determinants of red blood cell storage and stress hemolysis: results of the reds-iii rbc-omics study. Blood advances, 1(15):1132-1141. Citado na pág. 35

Kanika et al.(2009) Nirmala Devi Kanika, Moses Tar, Yuehong Tong, Dwaraka Srinivasa Rao Kuppam, Arnold Melman e Kelvin Paul Davies. The mechanism of opiorphin-induced experimental priapism in rats involves activation of the polyamine synthetic pathway. American Journal of Physiology-Cell Physiology, 297(4):C916-C927. Citado na pág. 9

Kaplan e Meier(1958) Edward L Kaplan e Paul Meier. Nonparametric estimation from incomplete observations. Journal of the American statistical association, 53(282):457-481. Citado na pág. $26,27,65$

Kaplan et al.(2004) Noam Kaplan, Moriah Friedlich, Menachem Fromer e Michal Linial. A functional hierarchical organization of the protein sequence space. BMC bioinformatics, 5(1): 196. Citado na pág. 21

Karafin et al.(2017) Matthew S Karafin, Roberta Bruhn, Matt Westlake, Marian T Sullivan, Walter Bialkowski, Gustaf Edgren, Nareg H Roubinian, Ronald G Hauser, Daryl J Kor, Debra Fleischmann et al. Demographic and epidemiologic characterization of transfusion recipients from four us regions: evidence from the reds-iii recipient database. Transfusion, 57(12):2903-2913. Citado na pág. 35

Kato et al.(2006) Gregory J Kato, Vicki McGowan, Roberto F Machado, Jane A Little, James Taylor, Claudia R Morris, James S Nichols, Xunde Wang, Mirjana Poljakovic, Sidney M Morris et al. Lactate dehydrogenase as a biomarker of hemolysis-associated nitric oxide resistance, priapism, leg ulceration, pulmonary hypertension, and death in patients with sickle cell disease. Blood, 107(6):2279-2285. Citado na pág. 32, 81

Kato et al.(2007) Gregory J Kato, Mark T Gladwin e Martin H Steinberg. Deconstructing sickle cell disease: reappraisal of the role of hemolysis in the development of clinical subphenotypes. Blood reviews, 21(1):37-47. Citado na pág. 7, 29, 30, 32, 82 
Kato et al.(2009) Gregory J Kato, Robert P Hebbel, Martin H Steinberg e Mark T Gladwin. Vasculopathy in sickle cell disease: Biology, pathophysiology, genetics, translational medicine, and new research directions. American journal of hematology, 84(9):618-625. Citado na pág. 6

Kato et al.(2017) Gregory J Kato, Martin H Steinberg e Mark T Gladwin. Intravascular hemolysis and the pathophysiology of sickle cell disease. The Journal of clinical investigation, 127(3):750760. Citado na pág. 7

Kaufman e Rousseeuw(1987) Leonard Kaufman e Peter Rousseeuw. Clustering by means of medoids. North-Holland. Citado na pág. 21

Kaul et al.(1989) Dhananjaya K Kaul, Mary E Fabry e Ronald L Nagel. Microvascular sites and characteristics of sickle cell adhesion to vascular endothelium in shear flow conditions: pathophysiological implications. Proceedings of the National Academy of Sciences, 86(9):3356-3360. Citado na pág. 6

Kaul et al.(2000) DK Kaul, HM Tsai, XD Liu, MT Nakada, RL Nagel e BS Coller. Monoclonal antibodies to $\alpha \mathrm{v} \beta 3$ (7e3 and lm609) inhibit sickle red blood cell-endothelium interactions induced by platelet-activating factor: Presented in part at the inserm symposium, paris, france, september 2, 1995 (ref 24), and at the 40th annual meeting of the american society of hematology, miami, fl, december 7, 1998. Blood, 95(2):368-374. Citado na pág. 6, 33

Kelley et al.(2016) David R Kelley, Jasper Snoek e John L Rinn. Basset: Learning the regulatory code of the accessible genome with deep convolutional neural networks. Genome research. Citado na pág. 2

Kimmelsteil(1948) P Kimmelsteil. Vascular occlusion and ischemic infarction in sickle cell disease. The American journal of the medical sciences, 216(1):11. Citado na pág. 8

Kleinbaum(1998) David G Kleinbaum. Survival analysis, a self-learning text. Biometrical Journal: Journal of Mathematical Methods in Biosciences, 40(1):107-108. Citado na pág. 26, 27

Kleinman et al.(2014) Steven Kleinman, Michael P Busch, Edward L Murphy, Hua Shan, Paul Ness e Simone A Glynn. The national heart, lung, and blood institute recipient epidemiology and donor evaluation study (reds-iii): a research program striving to improve blood donor and transfusion recipient outcomes. Transfusion, 54(3pt2):942-955. Citado na pág. 36

Korf(2004) Ian Korf. Gene finding in novel genomes. BMC bioinformatics, 5(1):1. Citado na pág. 2

Krasnogor e Pelta(2004) Natalio Krasnogor e David A Pelta. Measuring the similarity of protein structures by means of the universal similarity metric. Bioinformatics, 20(7):1015-1021. Citado na pág. 21

Kruglyak e Nickerson(2001) Leonid Kruglyak e Deborah A Nickerson. Variation is the spice of life. Nature genetics, 27(3):234. Citado na pág. 10

Kurita(1991) Takio Kurita. An efficient agglomerative clustering algorithm using a heap. Pattern Recognition, 24(3):205-209. Citado na pág. 21

LEANDRO-MERHI e AQUINO(2017) Vânia Aparecida LEANDRO-MERHI e José Luiz Braga de AQUINO. Relationship between nutritional status and the clinical outcomes of patients with and without neoplasms according to multiple correspondence analysis. Arquivos de gastroenterologia, 54(2):148-155. Citado na pág. 18

Lee et al.(2013) Brian R Lee, Gerald M Woods e Jignesh Dalal. Epidemiology, management and outcome of priapism in children and adolescents with sickle cell disease: a pediatric health information system database analysis, 2013. Citado na pág. 33, 82 
Li et al.(2016) Danping Li, Lei Wang, Zhong Xue e Stephen TC Wong. When discriminative kmeans meets grassmann manifold: Disease gene identification via a general multi-view clustering method. Em 2016 IEEE-EMBS International Conference on Biomedical and Health Informatics (BHI), páginas 364-367. IEEE. Citado na pág. 2

Li et al.(2015) Jeffery Li, Travers Ching, Sijia Huang e Lana X Garmire. Using epigenomics data to predict gene expression in lung cancer. BMC bioinformatics, 16(5):1. Citado na pág. 2

Lin et al.(2003) Guiting Lin, Zhong-Cheng Xin, Tom F Lue e Ching-Shwun Lin. Up and downregulation of phosphodiesterase-5 as related to tachyphylaxis and priapism. The Journal of urology, 170(2):S15-S19. Citado na pág. 82

Lionnet et al.(2012) François Lionnet, Nadjib Hammoudi, Katia Stankovic Stojanovic, Virginie Avellino, Gilles Grateau, Robert Girot e Jean-Philippe Haymann. Hemoglobin sc disease complications: a clinical study of 179 cases. haematologica, 97(8):1136-1141. Citado na pág. 81

Lu et al.(2011) Jun Lu, Robnet T Kerns, Shyamal D Peddada e Pierre R Bushel. Principal component analysis-based filtering improves detection for affymetrix gene expression arrays. Nucleic acids research, 39(13):e86-e86. Citado na pág. 16

Ma(2007) Steven Ma. Principal component analysis in linear regression survival model with microarray data. Journal of Data Science, 5(2):183-198. Citado na pág. 2

Maechler et al.(2018) Martin Maechler, Peter Rousseeuw, Anja Struyf, Mia Hubert e Kurt Hornik. cluster: Cluster Analysis Basics and Extensions, 2018. R package version 2.0.7-1 — For new features, see the 'Changelog' file (in the package source). Citado na pág. 40

Makani et al.(2013) J Makani, TN Williams e K Marsh. Sickle cell disease in africa: burden and research priorities. Annals of tropical medicine and parasitology. Citado na pág. 3, 7

Maller et al.(2006) Julian Maller, Sarah George, Shaun Purcell, Jes Fagerness, David Altshuler, Mark J Daly e Johanna M Seddon. Common variation in three genes, including a noncoding variant in cfh, strongly influences risk of age-related macular degeneration. Nature genetics, 38 (9):1055-1059. Citado na pág. 12

Mantadakis et al.(1999) Elpis Mantadakis, Joe Don Cavender, Zora R Rogers, David H Ewalt e George R Buchanan. Prevalence of priapism in children and adolescents. J. Pediatr Hematol Oncol, 21(6). Citado na pág. 81

Menzel e Thein(2009) Stephan Menzel e Swee Lay Thein. Genetic architecture of hemoglobin f control. Current opinion in hematology, 16(3):179-186. Citado na pág. 29

Merhof et al.(2011) Dorit Merhof, Pawel J Markiewicz, Günther Platsch, Jerome Declerck, Markus Weih, Johannes Kornhuber, Torsten Kuwert, Julian C Matthews e Karl Herholz. Optimized data preprocessing for multivariate analysis applied to $99 \mathrm{mtc}$-ecd spect data sets of alzheimer's patients and asymptomatic controls. Journal of Cerebral Blood Flow \& Metabolism, 31(1):371-383. Citado na pág. 16

Mi et al.(2008) Tiejuan Mi, Shahrzad Abbasi, Hong Zhang, Karen Uray, Janci L Chunn, Ling Wei Xia, Jose G Molina, Norman W Weisbrodt, Rodney E Kellems, Michael R Blackburn et al. Excess adenosine in murine penile erectile tissues contributes to priapism via a $2 \mathrm{~b}$ adenosine receptor signaling. The Journal of clinical investigation, 118(4):1491-1501. Citado na pág. 9, 82

Mills et al.(2001) Thomas M Mills, Kanchan Chitaley, Christopher J Wingard, Ronald W Lewis e R Clinton Webb. Effect of rho-kinase inhibition on vasoconstriction in the penile circulation. Journal of Applied Physiology, 91(3):1269-1273. Citado na pág. 82 
Mohamed et al.(2010) Thahir P Mohamed, Jaime G Carbonell e Madhavi K Ganapathiraju. Active learning for human protein-protein interaction prediction. BMC bioinformatics, 11(1):1. Citado na pág. 2

Montague et al.(2003) Drogo K Montague, Jonathan Jarow, Gregory A Broderick, Roger R Dmochowski, Jeremy PW Heaton, Tom F Lue, Ajay Nehra, Ira D Sharlip e ERECTILE DYSFUNCTION GUIDELINE UPDATE PANEL †. American urological association guideline on the management of priapism. The Journal of urology, 170(4 Part 1):1318-1324. Citado na pág. 8

Mori et al.(1996) S Mori, JC Mathai, GM Preston e BL Smith. Functional analysis of aquaporin-1 deficient red cells. Citado na pág. 33

Mukherjee et al.(2014) Kamalika Mukherjee, Brittany A Edgett, Harrison W Burrows, Cecilia Castro, Julian L Griffin, Adel Giaid Schwertani, Brendon J Gurd e Colin D Funk. Whole blood transcriptomics and urinary metabolomics to define adaptive biochemical pathways of high-intensity exercise in 50-60 year old masters athletes. PloS one, 9(3):e92031. Citado na pág. 21

Muneer et al.(2005) A Muneer, S Cellek, A Dogan, PD Kell, DJ Ralph e S Minhas. Investigation of cavernosal smooth muscle dysfunction in low flow priapism using an in vitro model. International journal of impotence research, 17(1):10. Citado na pág. 8

Musicki et al.(2009) Biljana Musicki, Ashley E Ross, Hunter C Champion, Arthur L Burnett e Trinity J Bivalacqua. Posttranslational modification of constitutive nitric oxide synthase in the penis. Journal of andrology, 30(4):352-362. Citado na pág. 82

Nagel et al.(1979) Ronald L Nagel, Robert M Bookchin, Joyce Johnson, Dominique Labie, Henri Wajcman, William A Isaac-Sodeye, George R Honig, Gino Schiliro, John H Crookston e Keiten Matsutomo. Structural bases of the inhibitory effects of hemoglobin $\mathrm{f}$ and hemoglobin a2 on the polymerization of hemoglobin s. Proceedings of the National Academy of Sciences, 76(2):670-672. Citado na pág. 29

Ning et al.(2014) Chen Ning, Jiaming Wen, Yujin Zhang, Yingbo Dai, Wei Wang, Weiru Zhang, Lin Qi, Almut Grenz, Holger K Eltzschig, Michael R Blackburn et al. Excess adenosine a2b receptor signaling contributes to priapism through hif- $1 \alpha$ mediated reduction of pde5 gene expression. The FASEB Journal, 28(6):2725-2735. Citado na pág. 9, 82

Nolan et al.(2005a) Vikki G Nolan, Clinton Baldwin, Qianli Ma, Diego F Wyszynski, Yvonne Amirault, John J Farrell, Alice Bisbee, Stephen H Embury, Lindsay A Farrer e Martin H Steinberg. Association of single nucleotide polymorphisms in klotho with priapism in sickle cell anaemia. British journal of haematology, 128(2):266-272. Citado na pág. 9

Nolan et al.(2005b) Vikki G Nolan, Diego F Wyszynski, Lindsay A Farrer e Martin H Steinberg. Hemolysis-associated priapism in sickle cell disease. Blood, 106(9):3264-3267. Citado na pág. 81

Nolan et al.(2006) Vikki G Nolan, Adeboye Adewoye, Clinton Baldwin, Ling Wang, Qianli Ma, Diego F Wyszynski, John J Farrell, Paola Sebastiani, Lindsay A Farrer e Martin H Steinberg. Sickle cell leg ulcers: associations with haemolysis and snps in klotho, tek and genes of the tgf$\beta /$ bmp pathway. British journal of haematology, 133(5):570-578. Citado na pág. 83

Ohler et al.(2002) Uwe Ohler, Guo-chun Liao, Heinrich Niemann e Gerald M Rubin. Computational analysis of core promoters in the drosophila genome. Genome biology, 3(12):1. Citado na pág. 2

Pericak-Vance(1998) Margaret A Pericak-Vance. Linkage disequilibrium and allelic association. John Wiley \& Sons, Inc. New York, New York, USA. Citado na pág. 11

Person(1901) K Person. On lines and planes of closest fit to system of points in space. philiosophical magazine, 2, 559-572, 1901. Citado na pág. 14 
Peyromaure et al.(2007) Michaël Peyromaure, Philippe Camparo, Cécile Badoual, Aurélien Descazeaud e Anh-Tuan Dinh-Xuan. The expression of vascular endothelial growth factor is associated with the risk of cancer progression after radical prostatectomy. BJU international, 99(5): 1150-1153. Citado na pág. 82

Piel et al.(2010) Frédéric B Piel, Anand P Patil, Rosalind E Howes, Oscar A Nyangiri, Peter W Gething, Thomas N Williams, David J Weatherall e Simon I Hay. Global distribution of the sickle cell gene and geographical confirmation of the malaria hypothesis. Nature communications, 1:104. Citado na pág. 5

Piel et al.(2017) Frédéric B Piel, Martin H Steinberg e David C Rees. Sickle cell disease. New England Journal of Medicine, 376(16):1561-1573. Citado na pág. 5, 6

Price et al.(2006) Alkes L Price, Nick J Patterson, Robert M Plenge, Michael E Weinblatt, Nancy A Shadick e David Reich. Principal components analysis corrects for stratification in genome-wide association studies. Nature genetics, 38(8):904. Citado na pág. 11, 16, 67

Prieto(2008) D Prieto. Physiological regulation of penile arteries and veins. International journal of impotence research, 20(1):17. Citado na pág. 82

Pruim et al.(2010) Randall J Pruim, Ryan P Welch, Serena Sanna, Tanya M Teslovich, Peter S Chines, Terry P Gliedt, Michael Boehnke, Gonçalo R Abecasis e Cristen J Willer. Locuszoom: regional visualization of genome-wide association scan results. Bioinformatics, 26(18):2336-2337. Citado na pág. 69

Purcell et al.(2007) Shaun Purcell, Benjamin Neale, Kathe Todd-Brown, Lori Thomas, Manuel AR Ferreira, David Bender, Julian Maller, Pamela Sklar, Paul IW De Bakker, Mark J Daly et al. Plink: a tool set for whole-genome association and population-based linkage analyses. The American Journal of Human Genetics, 81(3):559-575. Citado na pág. 67

Qi et al.(2006) Yuan Qi, Patrycja E Missiuro, Ashish Kapoor, Craig P Hunter, Tommi S Jaakkola, David K Gifford e Hui Ge. Semi-supervised analysis of gene expression profiles for lineage-specific development in the caenorhabditis elegans embryo. Bioinformatics, 22(14):e417-e423. Citado na pág. 2

Raval et al.(2012) Alpan Raval, Stefano Piana, Michael P Eastwood, Ron O Dror e David E Shaw. Refinement of protein structure homology models via long, all-atom molecular dynamics simulations. Proteins: Structure, Function, and Bioinformatics, 80(8):2071-2079. Citado na pág. 21

Reiter et al.(2002) Christopher D Reiter, Xunde Wang, Jose E Tanus-Santos, Neil Hogg, Richard O Cannon III, Alan N Schechter e Mark T Gladwin. Cell-free hemoglobin limits nitric oxide bioavailability in sickle-cell disease. Nature medicine, 8(12):1383. Citado na pág. 32

Roseff(2008) SD Roseff. Sickle cell disease: a review. Immunohematology/American Red Cross, 25(2):67-74. Citado na pág. 6, 35

Rousseeuw(1987) Peter J Rousseeuw. Silhouettes: a graphical aid to the interpretation and validation of cluster analysis. Journal of computational and applied mathematics, 20:53-65. Citado na pág. $22,23,41$

Sabino et al.(2015) Ester C Sabino, Paula Loureiro, Maria Esther Lopes, Ligia Capuani, Christopher McClure, Dhuly Chowdhury, Claudia Di-Lorenzo-Oliveira, Lea C Oliveira, Jeffrey M Linnen, Tzong-Hae Lee et al. Transfusion-transmitted dengue and associated clinical symptoms during the 2012 epidemic in brazil. The Journal of infectious diseases, 213(5):694-702. Citado na pág. 35

Schwarz et al.(1978) Gideon Schwarz et al. Estimating the dimension of a model. The annals of statistics, 6(2):461-464. Citado na pág. 40 
Scott et al.(2004) Eleanor M Scott, Robert AS Ariëns e Peter J Grant. Genetic and environmental determinants of fibrin structure and function: relevance to clinical disease. Arteriosclerosis, thrombosis, and vascular biology, 24(9):1558-1566. Citado na pág. 33

Sebastiani et al.(2005) Paola Sebastiani, Marco F Ramoni, Vikki Nolan, Clinton T Baldwin e Martin H Steinberg. Genetic dissection and prognostic modeling of overt stroke in sickle cell anemia. Nature genetics, 37(4):435. Citado na pág. 83

Serjeant e Hambleton(2015) G Serjeant e I Hambleton. Priapism in homozygous sickle cell disease: a 40-year study of the natural history. The West Indian medical journal, 64(3):175. Citado na pág. 81

Seymour et al.(2019) Christopher W Seymour, Jason N Kennedy, Shu Wang, Chung-Chou H Chang, Corrine F Elliott, Zhongying Xu, Scott Berry, Gilles Clermont, Gregory Cooper, Hernando Gomez et al. Derivation, validation, and potential treatment implications of novel clinical phenotypes for sepsis. Jama, 321(20):2003-2017. Citado na pág. 31

Sfar et al.(2006) Sana Sfar, Elham Hassen, Hamadi Saad, Faouzi Mosbah e Lotfi Chouchane. Association of vegf genetic polymorphisms with prostate carcinoma risk and clinical outcome. Cytokine, 35(1-2):21-28. Citado na pág. 82

Sharpsteen et al.(1993) J Randolph Sharpsteen, Darleen Powars, Cage Johnson, Zora R Rogers, W Donald Williams e Ralph J Posch. Multisystem damage associated with tricorporal priapism in sickle cell disease. The American journal of medicine, 94(3):289-295. Citado na pág. 32, 66, 81

Shi et al.(2017) Huilan Shi, Tiekun Yan, Dong Li, Junya Jia, Wenya Shang, Li Wei e Zhenfeng Zheng. Detection of renal hypoxia in lupus nephritis using blood oxygen level-dependent $\mathrm{mr}$ imaging: a multiple correspondence analysis. Kidney and Blood Pressure Research, 42(1):123135. Citado na pág. 18

Sladek et al.(2007) Robert Sladek, Ghislain Rocheleau, Johan Rung, Christian Dina, Lishuang Shen, David Serre, Philippe Boutin, Daniel Vincent, Alexandre Belisle, Samy Hadjadj et al. A genome-wide association study identifies novel risk loci for type 2 diabetes. Nature, 445(7130): 881-885. Citado na pág. 12

Spycher e Hauri(1986) MA Spycher e D Hauri. The ultrastructure of the erectile tissue in priapism. The Journal of urology, 135(1):142-147. Citado na pág. 8

Steinberg(2009) Martin H Steinberg. Genetic etiologies for phenotypic diversity in sickle cell anemia. The Scientific World Journal, 9:46-67. Citado na pág. 29

Steindl et al.(2005) Theodora M Steindl, Carolyn E Crump, Frederick G Hayden e Thierry Langer. Pharmacophore modeling, docking, and principal component analysis based clustering: Combined computer-assisted approaches to identify new inhibitors of the human rhinovirus coat protein $\S$. Journal of medicinal chemistry, 48(20):6250-6260. Citado na pág. 16

Strasser(1999) Bruno J Strasser. Sickle cell anemia, a molecular disease. Science, 286(5444): 1488-1490. Citado na pág. 5

Stuart e Nagel(2004) Marie J Stuart e Ronald L Nagel. Sickle-cell disease. The Lancet, 364 (9442):1343-1360. Citado na pág. 6, 7, 29, 38

Sturn et al.(2002) Alexander Sturn, John Quackenbush e Zlatko Trajanoski. Genesis: cluster analysis of microarray data. Bioinformatics, 18(1):207-208. Citado na pág. 2

Sun e Markey(2011) Clement S Sun e Mia K Markey. Recent advances in computational analysis of mass spectrometry for proteomic profiling. Journal of Mass spectrometry, 46(5):443-456. Citado na pág. 2 
Tarry et al.(1987) WF Tarry, John W Duckett Jr e Howard McC Snyder III. Urological complications of sickle cell disease in a pediatric population. The Journal of urology, 138(3):592-594. Citado na pág. 81

Tavazoie et al.(1999) Saeed Tavazoie, Jason D Hughes, Michael J Campbell, Raymond J Cho e George M Church. Systematic determination of genetic network architecture. Nature genetics, 22(3):281-285. Citado na pág. 21

Tenenhaus e Young(1985) Michel Tenenhaus e Forrest W Young. An analysis and synthesis of multiple correspondence analysis, optimal scaling, dual scaling, homogeneity analysis and other methods for quantifying categorical multivariate data. Psychometrika, 50(1):91-119. Citado na pág. 16

Tewari et al.(2015) Sanjay Tewari, Valentine Brousse, Frédéric B Piel, Stephan Menzel e David C Rees. Environmental determinants of severity in sickle cell disease. haematologica, 100(9):11081116. Citado na pág. 29

Thanawala et al.(2008) V Thanawala, VJ Kadam e R Ghosh. Enkephalinase inhibitors: potential agents for the management of pain. Current drug targets, 9(10):887-894. Citado na pág. 82

Todd et al.(2007) John A Todd, Neil M Walker, Jason D Cooper, Deborah J Smyth, Kate Downes, Vincent Plagnol, Rebecca Bailey, Sergey Nejentsev, Sarah F Field, Felicity Payne et al. Robust associations of four new chromosome regions from genome-wide analyses of type 1 diabetes. Nature genetics, 39(7):857-864. Citado na pág. 12

Tong et al.(2006) Yuehong Tong, Moses Tar, Felix Davelman, George Christ, Arnold Melman e Kelvin P Davies. Variable coding sequence protein a1 as a marker for erectile dysfunction. BJU international, 98(2):396-401. Citado na pág. 82

Tostes et al.(2007) Rita C Tostes, Fernanda RC Giachini, Fernando S Carneiro, Romulo Leite, Edward W Inscho e R Clinton Webb. Determination of adenosine effects and adenosine receptors in murine corpus cavernosum. Journal of Pharmacology and Experimental Therapeutics, 322(2): 678-685. Citado na pág. 82

Ul-hasan et al.(1998) Maqsood Ul-hasan, Ahmed El-sakka, Celeste Lee, Tien-sze Yen, Rajvir Dahiya e Tom Lue. Expression of tgf-beta-1 mrna and ultrastructural alterations in pharmacologically induced prolonged penile erection in a canine model. The Journal of urology, 160(6): 2263-2266. Citado na pág. 8

van der Land et al.(2013) Veronica van der Land, Marjolein Peters, Bart J Biemond, Harriët Heijboer, Cornelis L Harteveld e Karin Fijnvandraat. Markers of endothelial dysfunction differ between subphenotypes in children with sickle cell disease. Thrombosis research, 132(6):712-717. Citado na pág. 30

Verma e Melcher(2012) Ruchi Verma e Ulrich Melcher. A support vector machine based method to distinguish proteobacterial proteins from eukaryotic plant proteins. BMC bioinformatics, 13 (15):1. Citado na pág. 2

Wang et al.(1998) David G Wang, Jian-Bing Fan, Chia-Jen Siao, Anthony Berno, Peter Young, Ron Sapolsky, Ghassan Ghandour, Nancy Perkins, Ellen Winchester, Jessica Spencer et al. Largescale identification, mapping, and genotyping of single-nucleotide polymorphisms in the human genome. Science, 280(5366):1077-1082. Citado na pág. 10

Wang et al.(2002) Hua Wang, Masumi Eto, William D Steers, Andrew P Somlyo e Avril V Somlyo. Rhoa-mediated ca2+ sensitization in erectile function. Journal of Biological Chemistry, 277(34): 30614-30621. Citado na pág. 9, 82 
Wang et al.(2018) Yumin Wang, Fan Zhang, Junjun Wang, Lijuan Hu, Feng Jiang, Jian Chen, Jie Chen e Liangxing Wang. Incrna loc100132354 promotes angiogenesis through vegfa/vegfr2 signaling pathway in lung adenocarcinoma. Cancer management and research, 10:4257. Citado na pág. 82

Ward e Kellis(2011) Lucas D Ward e Manolis Kellis. Haploreg: a resource for exploring chromatin states, conservation, and regulatory motif alterations within sets of genetically linked variants. Nucleic acids research, 40(D1):D930-D934. Citado na pág. 69

Weatherall(2010) David J Weatherall. The inherited diseases of hemoglobin are an emerging global health burden. Blood, 115(22):4331-4336. Citado na pág. 5

Whitaker et al.(2014) HC Whitaker, LL Shiong, JD Kay, H Grönberg, AY Warren, A Seipel, F Wiklund, B Thomas, P Wiklund, JL Miller et al. N-acetyl-l-aspartyl-l-glutamate peptidaselike 2 is overexpressed in cancer and promotes a pro-migratory and pro-metastatic phenotype. Oncogene, 33(45):5274. Citado na pág. 82

$\mathrm{Xu}$ et al.(2007) Rui Xu, Donald Wunsch II e Ronald Frank. Inference of genetic regulatory networks with recurrent neural network models using particle swarm optimization. IEEE/ACM Transactions on Computational Biology and Bioinformatics (TCBB), 4(4):681-692. Citado na pág. 2

Xu et al.(2014) Yan Xu, Tao Mo, Qiwei Feng, Peilin Zhong, Maode Lai, I Eric e Chao Chang. Deep learning of feature representation with multiple instance learning for medical image analysis. Em 2014 IEEE International Conference on Acoustics, Speech and Signal Processing (ICASSP), páginas 1626-1630. IEEE. Citado na pág. 2

Yang et al.(2012) Peng Yang, Xiao-Li Li, Jian-Ping Mei, Chee-Keong Kwoh e See-Kiong Ng. Positive-unlabeled learning for disease gene identification. Bioinformatics, 28(20):2640-2647. Citado na pág. 2

Ye et al.(2018) Yun Ye, Su-Liang Li e Sheng-Yu Wang. Construction and analysis of mrna, mirna, lncrna, and tf regulatory networks reveal the key genes associated with prostate cancer. PloS one, 13(8):e0198055. Citado na pág. 82

Yeager et al.(2007) Meredith Yeager, Nick Orr, Richard B Hayes, Kevin B Jacobs, Peter Kraft, Sholom Wacholder, Mark J Minichiello, Paul Fearnhead, Kai Yu, Nilanjan Chatterjee et al. Genome-wide association study of prostate cancer identifies a second risk locus at 8q24. Nature genetics, 39(5):645-649. Citado na pág. 12

Zeggini et al.(2007) Eleftheria Zeggini, Michael N Weedon, Cecilia M Lindgren, Timothy M Frayling, Katherine S Elliott, Hana Lango, Nicholas J Timpson, John RB Perry, Nigel W Rayner, Rachel M Freathy et al. Replication of genome-wide association signals in uk samples reveals risk loci for type 2 diabetes. Science, 316(5829):1336-1341. Citado na pág. 12

Zennadi et al.(2004) Rahima Zennadi, Patrick C Hines, Laura M De Castro, Jean-Pierre Cartron, Leslie V Parise e Marilyn J Telen. Epinephrine acts through erythroid signaling pathways to activate sickle cell adhesion to endothelium via lw- $\alpha \mathrm{v} \beta 3$ interactions. Blood, 104(12):3774-3781. Citado na pág. 33

Zhang et al.(1996) Tian Zhang, Raghu Ramakrishnan e Miron Livny. Birch: an efficient data clustering method for very large databases. Em ACM Sigmod Record, number 2, páginas 103114. ACM. Citado na pág. 23

Zhou et al.(2013) Changjun Zhou, Lan Wang, Qiang Zhang e Xiaopeng Wei. Face recognition based on pca image reconstruction and lda. Optik-International Journal for Light and Electron Optics, 124(22):5599-5603. Citado na pág. 16 
Zhou e Stephens(2014) Xiang Zhou e Matthew Stephens. Efficient multivariate linear mixed model algorithms for genome-wide association studies. Nature methods, 11(4):407. Citado na pág. 69 
Apêndice 


\section{Apêndice A}

\section{Aprovação do Brazil Sickle Cell Disease Cohort - CONEP}

\section{COMISSÃO NACIONAL DE ÉTICA EM PESQUISA}

\section{PARECER CONSUBSTANCIADO DA CONEP}

\section{DADOS DO PROJETO DE PESQUISA}

Título da Pesquisa: Estudo longitudinal multicêntrico da doença falciforme no Brasil ¿ REDSIII Pesquisador: Ester cerdeira Sabino

Área Temática: Área 8. Pesquisa com cooperação estrangeira.

Versão: 5

CAAE: 02790812.0 .1001 .0065

Instituição Proponente: FUNDACAO FACULDADE DE MEDICINA

Patrocinador Principal: NATIONAL INSTITUTE OF HEALTH

\section{DADOS DO PARECER}

Número do Parecer: 347.972

Data da Relatoria: 29/07/2013

\section{Apresentação do Projeto:}

Trata-se da análise de recurso, razão pela qual o item em questão faz parte do Parecer inicial.

Objetivo da Pesquisa:

Trata-se da análise de recurso, razão pela qual o item em questão faz parte do Parecer inicial.

Avaliação dos Riscos e Benefícios:

Trata-se da análise de recurso, razão pela qual o item em questão faz parte do Parecer inicial.

Comentários e Considerações sobre a Pesquisa:

A pesquisa propõe a formação de banco de dados e de amostras armazenadas de indivíduos portadores de anemia falciforme no Brasil possibilitando o desenvolvimento de novos exames, tratamentos ou produtos que terão impacto na terapia transfusional da população falciforme no Brasil.

Considerações sobre os Termos de apresentação obrigatória:

Vide abaixo em "Conclusões ou Pendências e Lista de Inadequações".

Recomendações:

Vide abaixo em "Conclusões ou Pendências e Lista de Inadequações".

Conclusões ou Pendências e Lista de Inadequações:

1. Na pág. 4/7 do relatório de pesquisa lê-se: "Assim como em qualquer meio de armazenamento

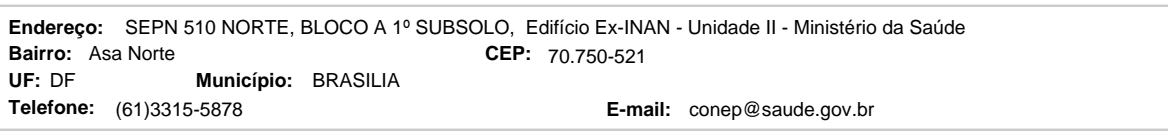




\section{COMISSÃO NACIONAL DE ÉTICA EM PESQUISA}

Continuação do Parecer: 347.972

de dados, existe uma pequena possibilidade de quebra de segurança das informações pessoais e genéticas do paciente". É considerado éticamente inaceitável que o pesquisador responsável não garanta o sigilo e a confidencialidade dos dados resultantes da pesquisa. Solicita-se adequação.

RESPOSTA: Para garantir a confidencialidade e sigilo dos participantes da pesquisa, nenhuma amostra será identificada nominalmente, mas por códigos. Apenas a pesquisadora responsável e funcionários designados por ela poderão associar os códigos que identificarão as amostras ao nome de cada participante da pesquisa.

ANÁLISE: A pesquisadora responsável apresenta formas de anonimização das amostras e dos dados coletados, entretanto, ainda mantém a afirmação sobre a possibilidade de quebra de segurança das informações nos documentos intitulados "Anexo 3 TCLE adulto A e C.docx.", página 3 de 6, item "Riscos de confidencialidade"; "Anexo 5 TCLE adulto B.docx", página 3 de 5, item "Riscos de confidencialidade"; "Anexo 4 TCLE menores A e C.docx", página 3 de 6, item "Riscos de confidencialidade"; "Anexo 6 TCLE menores B.docx", página 3 de 5, item "Riscos de confidencialidade". PENDÊNCIA NÃO ATENDIDA.

RECURSO: Tomamos todos os cuidados para garantir a confidencialidade de todos os participantes da pesquisa. Entretanto, entendemos que em qualquer situação existe a possibilidade de que essa quebra aconteça, podemos citar como exemplo situações em que hackers entraram em sistemas bancários ou 0 roubo de computadores/laptops. São situações imprevisíveis, que fogem ao nosso controle. Assim, em atenção à Resolução 196/96, IV,1.b, que exige que o TCLE descreva ¿os desconfortos e riscos possíveis $i$, a equipe de pesquisa compartilha o sentimento de que estamos sendo mais éticos se informarmos esse risco. Desta maneira, consideramos importante manter esse alerta nos TCLE: ¿existe uma pequena possibilidade de quebra de segurança.¿.

Durante a audiência, o membro da CONEP que nos recebeu também concordou que esta informação pode e deve fazer parte do nosso TCLE. Ele sugeriu, entretanto que mudássemos a frase seguinte enfatizando que estamos garantindo confidencialidade e tomando todas as medidas possíveis.

Assim este paragrafo fica redigido da seguinte forma (em negrito a nova frase enfatizando que a confidencialidade está garantida):

¿Porém, assim como em qualquer meio de armazenamento de dados, existe uma pequena possibilidade de quebra de segurança. No entanto tomaremos todas as medidas para manter seus dados em sigilo e garantir a sua privacidade. Para garantir sua confidencialidade, nenhuma amostra será identificada com seu nome, mas por códigos. Apenas a pesquisadora responsável e funcionários designados por ela poderão associar os códigos que identificarão as amostras ao

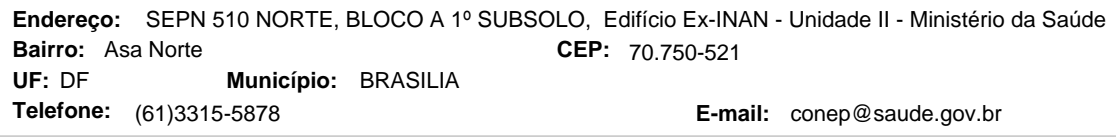




\section{COMISSÃO NACIONAL DE ÉTICA EM PESQUISA}

Patationtem

Continuação do Parecer: 347.972

nome de cada participante da pesquisa. $¿$.

Conforme solicitado, esse trecho foi alterado nos seguintes documentos: ¿TCLE adulto A e C julho $2013 i$, ¿TCLE adultos B julho 2013i.

Nos documentos ¿TCLE menores A e C julho 2013 $i$ e $i$ TCLE menores B julho $2013 i$, o trecho foi alterado para:

¿Porém, assim como em qualquer meio de armazenamento de dados, existe uma pequena possibilidade de quebra de segurança. No entanto tomaremos todas as medidas para manter os dados da criança ou adolescente, pelo qual você é responsável, em sigilo e garantir a privacidade dele/dela. Para garantir a confidencialidade, nenhuma amostra será identificada com o nome da criança ou do adolescente, mas por códigos. Apenas a pesquisadora responsável e funcionários designados por ela poderão associar os códigos que identificarão as amostras ao nome de cada participante da pesquisa. ¿

ANÁLISE: PENDÊNCIA ATENDIDA.

2. Na página 4/7, item "Metodologia Proposta", lê-se: "Trata-se de um estudo longitudinal multicêntrico a ser desenvolvido com o acompanhamento por três anos da história clinica do paciente com doença falciforme. Estudos observacionais descritivos e comparativos serão desenvolvidos durante o decorrer da pesquisa". Solicita-se que sejam detalhadas todas as etapas metodológicas a serem cumpridas para o desenvolvimento da pesquisa.

RESPOSTA: Este é um estudo de coorte onde um número considerável de variáveis será coletado (as variáveis estão descritas no apêndice do questionário). As frequências básicas destas variáveis ainda não são conhecidas. Inicialmente, será feita uma distribuição de frequências, para que possamos avaliar como as variáveis se comportam. Então, na medida em que conhecermos as frequências básicas das doenças poderá ser calculado o poder para determinadas análises associativas. O plano de análise inicial será o seguinte:

Distribuição das frequências demográficas - análise das características demográficas da população estudada: idade, sexo, cor da pele, escolaridade, dentre outras. Distribuição das complicações da Doença Falciforme na população estudada. Correlações entre as variáveis demográficas, sociais com as patologias apresentadas e o tratamento realizado pelos centros. Comparação dos centros entre si, tendo em vista as características da população e as complicações e quadro clínico, evolução da doença, tipo de tratamentos. A priori não poderemos descrever todas as análises possíveis, podemos descrever e estamos fazendo todas as variáveis que serão colhidas (o questionário foi anexado). Se houver qualquer proposta de modificação em relação ao tipo de

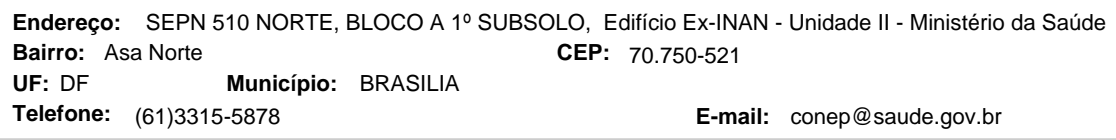




\section{COMISSÃO NACIONAL DE ÉTICA EM PESQUISA}

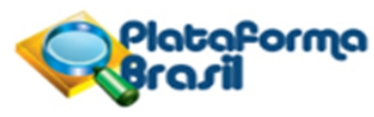

Continuação do Parecer: 347.972

informação coletada ou exame realizado será feita uma re-submissão ao CEP, para aprovação prévia. Todos os procedimentos de análise e seus resultados, bem como as publicações produzidas serão reportados nos relatórios anuais do projeto.

ANÁLISE: A pesquisadora responsável apresenta como resposta a esta pendência, a descrição das etapas metodológicas a serem cumpridas durante o estudo. Entretanto não foi descrito no item ¿Metodologia Proposta $i$ do projeto de pesquisa, as etapas a serem cumpridas durante o estudo. PENDÊNCIA NÃO ATENDIDA.

RECURSO: segue em anexo o projeto, arquivo ¿Projeto Falciforme julho 2013 ¿ incluindo no item Metodologia as etapas metodológicas descritas acima.

ANÁLISE: PENDÊNCIA ATENDIDA.

3. Na página 4/7, item "Metodologia Proposta", lê-se: "Estudos observacionais descritivos e comparativos serão desenvolvidos durante o decorrer da pesquisa". É necessário que sejam esclarecidos quais os estudos que serão desenvolvidos durante o decorrer da pesquisa e quais estratégias metodológicas serão utilizadas para o desenvolvimentos dos mesmos. Solicita-se adequação.

RESPOSTA: Esta questão está respondida no item 2, acima.

ANÁLISE: A pesquisadora responsável apresenta como resposta a esta pendência, a descrição das etapas metodológicas a serem cumpridas durante o estudo. Entretanto não foi descrito no item ¿Metodologia Proposta $i$ do projeto de pesquisa, quais os estudos que serão desenvolvidos durante o decorrer da pesquisa e quais estratégias metodológicas serão utilizadas para o desenvolvimento dos mesmos. PENDÊNCIA NÃO ATENDIDA.

RECURSO: Todos os estudos foram descritos no projeto de pesquisa. Segue em anexo o projeto, incluindo no item Metodologia as etapas metodológicas descritas acima. O que queremos dizer com estudos observacionais é, por exemplo: suponhamos que 600 casos apresentem síndrome torácica aguda. Se isso acontecer teremos numero suficiente para fazer uma análise sobre as variáveis associadas a esta morbidade entre pacientes com anemia falciforme. Entretanto, caso essa síndrome seja encontrada em apenas 6 indivíduos, não será possível achar correlação com esta morbidade. Nós não sabemos a priori qual a frequência das comorbidades. No entanto enviaremos relatórios anuais aos CEP e informaremos todos os achados e os novos passos.

ANÁLISE: PENDÊNCIA ATENDIDA.

4. Quanto ao TCLE intitulado "TCLE para adulto, etapas A e C.pdf":

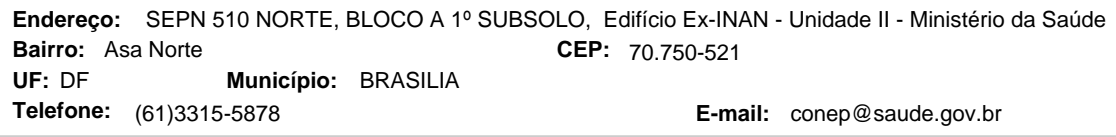




\section{COMISSÃO NACIONAL DE ÉTICA EM PESQUISA}

Continuação do Parecer: 347.972

a) PENDÊNCIA ATENDIDA NO PARECER CONEP 285.862

b) PENDÊNCIA ATENDIDA NO PARECER CONEP 285.862

c) PENDÊNCIA ATENDIDA NO PARECER CONEP 285.862

d) PENDÊNCIA ATENDIDA NO PARECER CONEP 285.862

e) PENDÊNCIA ATENDIDA NO PARECER CONEP 285.862

f) Na página 2/5 do documento, item "O que vai acontecer se eu concordar em participar do estudo e doar meu material biológico?" lê-se: "Suas amostras ficarão armazenadas permanentemente no repositório". É importante que seja estabelecido o tempo de guarda do material biológico no repositório. O prazo de armazenamento de material biológico humano em Biorrepositório deve estar de acordo com o cronograma da pesquisa correspondente e pode ser autorizado por até dez anos (item 12 da Resolução CNS 441). Solicita-se adequação.

RESPOSTA: Em atenção à solicitação do parecer CONEP e à Resolução 441/11, item 12.I, o trecho foi alterado para: "Suas amostras ficarão armazenadas no Biorrepositório durante a realização dessa pesquisa e poderão permanecer armazenadas por até 10 anos, ou mais, caso o Biorrepositório seja renovado pelo Comitê de Ética".

ANÁLISE: O trecho alterado acima citado pelo pesquisador responsável, não se encontra de forma idêntica (Ipsis litteris) ao apresentado no documento intitulado "TCLE para adulto, etapas A e C.pdf", apesar do sentido da frase continuar o mesmo. PENDÊNCIA PARCIALMENTE ATENDIDA.

RECURSO: Conforme solicitado, o trecho "Suas amostras ficarão armazenadas no Biorrepositório durante a realização dessa pesquisa e poderão permanecer armazenadas por até 10 anos, ou mais, caso o Biorrepositório seja renovado pelo Comitê de Ética" foi recortado e colado nos anexos ¿TCLE adultos A e C julho 2013i e ¿TCLE menores A e C julho 2013i.

ANÁLISE: PENDÊNCIA ATENDIDA.

g) Nas páginas 2 e 3/5, do documento, item "Riscos de confidencialidade" lê-se: "Porém, assim como em qualquer meio de armazenamento de dados, existe uma pequena possibilidade de quebra de segurança. Contudo, trabalharemos muito para manter seus dados em sigilo". É considerado eticamente inaceitável a não garantia do pesquisador responsável quanto à confidencialidade dos dados resultantes da pesquisa. Solicita-se adequação.

RESPOSTA: Foi acrescentada a seguinte frase: "Para garantir sua confidencialidade e sigilo, nenhuma amostra será identificada com seu nome, mas por códigos. Apenas a pesquisadora responsável e funcionários designados por ela poderão associar os códigos que identificarão as

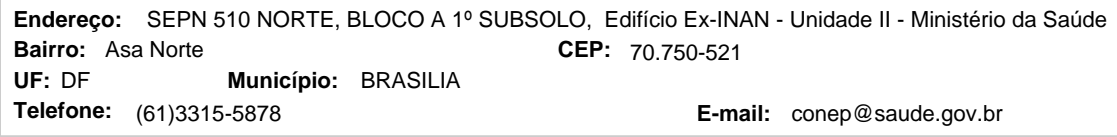




\section{COMISSÃO NACIONAL DE ÉTICA EM PESQUISA}

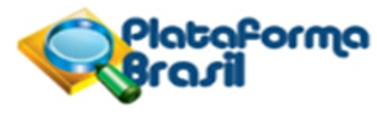

Continuação do Parecer: 347.972

amostras ao nome de cada participante da pesquisa."

ANÁLISE: A pesquisadora responsável apresenta formas de anonimização das amostras e dos dados coletados, entretanto, ainda mantém a afirmação sobre a possibilidade de quebra de segurança das informações obtidas. PENDÊNCIA NÃO ATENDIDA.

RECURSO: Tomamos todos os cuidados para garantir a confidencialidade de todos os participantes da pesquisa. Entretanto, entendemos que em qualquer situação existe a possibilidade de que essa quebra aconteça, podemos citar como exemplo situações em que hackers entraram em sistemas bancários ou 0 roubo de computadores/laptops. São situações imprevisíveis, que fogem ao nosso controle. Assim, em atenção à Resolução 196/96, IV,1.b, que exige que o TCLE descreva ¿os desconfortos e riscos possíveis ¿ , a equipe de pesquisa compartilha o sentimento de que estamos sendo mais éticos se informarmos esse risco. Desta maneira, consideramos importante manter esse alerta nos TCLE: ¿existe uma pequena possibilidade de quebra de segurança. $i$. Durante a audiência, o membro da CONEP que nos recebeu também concordou que esta informação pode e deve fazer parte do nosso TCLE. Ele sugeriu, entretanto que mudássemos a frase seguinte enfatizando que estamos garantindo confidencialidade e tomando todas as medidas possíveis. Assim este paragrafo fica redigido da seguinte forma (em negrito a nova frase enfatizando que a confidencialidade está garantida): ¿Porém, assim como em qualquer meio de armazenamento de dados, existe uma pequena possibilidade de quebra de segurança. No entanto tomaremos todas as medidas para manter seus dados em sigilo e garantir a sua privacidade. Para garantir sua confidencialidade, nenhuma amostra será identificada com seu nome, mas por códigos. Apenas a pesquisadora responsável e funcionários designados por ela poderão associar os códigos que identificarão as amostras ao nome de cada participante da pesquisa. $¿$ Conforme solicitado, o trecho acima foi alterado no anexo ¿TCLE adultos A e C julho 2013i.

ANÁLISE: PENDÊNCIA ATENDIDA.

h) PENDÊNCIA ATENDIDA NO PARECER CONEP 285.862

i) PENDÊNCIA ATENDIDA NO PARECER CONEP 285.862

j) PENDÊNCIA ATENDIDA NO PARECER CONEP 285.862

k) PENDÊNCIA ATENDIDA NO PARECER CONEP 285.862

l) PENDÊNCIA ATENDIDA NO PARECER CONEP 285.862

m) PENDÊNCIA ATENDIDA NO PARECER CONEP 285.862

n) PENDÊNCIA ATENDIDA NO PARECER CONEP 285.862

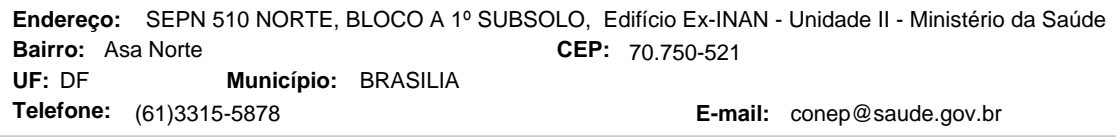




\section{COMISSÃO NACIONAL DE ÉTICA EM PESQUISA}

Continuação do Parecer: 347.972

5. Quanto ao TCLE intitulado "TCLE para adultos etapa B.pdf":

a) PENDÊNCIA ATENDIDA NO PARECER CONEP 285.862

6. No documento TCLE intitulado "TCLE para adultos etapa B.pdf":

a) Nas páginas 2 e 3/4 do documento, item "Riscos de confidencialidade", lê-se: "Porém, assim como em qualquer meio de armazenamento de dados, existe uma pequena possibilidade de quebra de segurança. Contudo, trabalharemos muito para manter os seus dados em sigilo". O termo "trabalharemos muito para manter os seus dados em sigilo" não traz a garantia do pesquisador responsável quanto à manutenção da confidencialidade dos dados resultantes da pesquisa, o que é eticamente inaceitável. Solicita-se adequação. RESPOSTA: Foi acrescentada a seguinte frase, na sequencia da frase citada: "Para garantir sua confidencialidade e sigilo, nenhuma amostra será identificada com seu nome, mas por códigos, como por exemplo, AB123. Apenas a pesquisadora responsável e funcionários designados por ela poderão associar os códigos que identificarão as amostras ao nome de cada participante da pesquisa.".

ANÁLISE: A pesquisadora responsável apresenta formas de anonimização das amostras e dos dados coletados, entretanto, ainda mantém a afirmação sobre a possibilidade de quebra de segurança das informações dos documentos. Ademais, a frase não se encontra de forma idêntica (Ipsis litteris) ao apresentado no documento intitulado "Anexo 5 TCLE adulto B.docx". PENDÊNCIA NÃO ATENDIDA. RECURSO: Tomamos todos os cuidados para garantir a confidencialidade de todos os participantes da pesquisa. Entretanto, entendemos que em qualquer situação existe a possibilidade de que essa quebra aconteça, podemos citar como exemplo situações em que hackers entraram em sistemas bancários ou o roubo de computadores/laptops. São situações imprevisíveis, que fogem ao nosso controle. Assim, em atenção à Resolução 196/96, IV,1.b, que exige que o TCLE descreva ¿os desconfortos e riscos possíveis $i$, a equipe de pesquisa compartilha o sentimento de que estamos sendo mais éticos se informarmos esse risco. Desta maneira, consideramos importante manter esse alerta nos TCLE: ¿existe uma pequena possibilidade de quebra de segurança. $i$. Durante a audiência, o membro da CONEP que nos recebeu também concordou que esta informação pode e deve fazer parte do nosso TCLE. Ele sugeriu, entretanto que mudássemos a frase seguinte enfatizando que estamos garantindo confidencialidade e tomando todas as medidas possíveis.

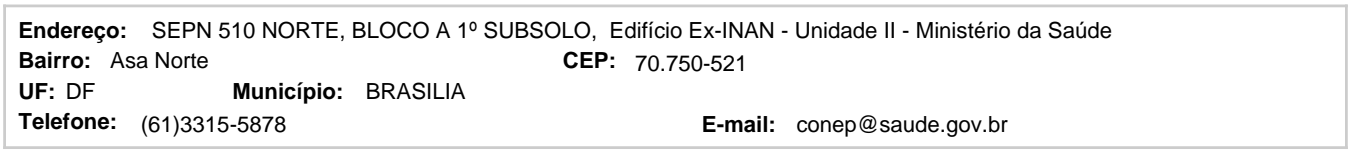




\section{COMISSÃO NACIONAL DE ÉTICA EM PESQUISA}

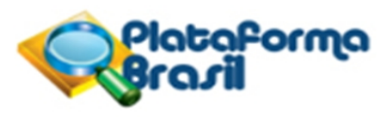

Continuação do Parecer: 347.972

Assim este paragrafo fica redigido da seguinte forma (em negrito a nova frase enfatizando que a confidencialidade está garantida): ¿Porém, assim como em qualquer meio de armazenamento de dados, existe uma pequena possibilidade de quebra de segurança. No entanto tomaremos todas as medidas para manter seus dados em sigilo e garantir a sua privacidade. Para garantir sua confidencialidade, nenhuma amostra será identificada com seu nome, mas por códigos. Apenas a pesquisadora responsável e funcionários designados por ela poderão associar os códigos que identificarão as amostras ao nome de cada participante da pesquisa. $¿$ Conforme solicitado, o trecho acima foi alterado no anexo ¿TCLE adulto B julho 2013i.

ANÁLISE: PENDÊNCIA ATENDIDA.

b) PENDÊNCIA ATENDIDA NO PARECER CONEP 285.862

c) PENDÊNCIA ATENDIDA NO PARECER CONEP 285.862

d) PENDÊNCIA ATENDIDA NO PARECER CONEP 285.862

e) PENDÊNCIA ATENDIDA NO PARECER CONEP 285.862

f) PENDÊNCIA ATENDIDA NO PARECER CONEP 285.862

7. Quanto ao TCLE intitulado "TCLE para menores etapas A e C.pdf":

\section{a) PENDÊNCIA ATENDIDA NO PARECER CONEP 285.862}

b) Na página 2/5 do documento, item: "O que vai acontecer se eu concordar com a participação do meu depende no estudo e doação material biológico dele?", lê-se: "As amostras do paciente ficarão armazenadas permanentemente no repositório". Deve ser informado que as amostras que constituirão o biorrepositório poderão ser armazenadas por até 10 anos, de acordo com o Art. 1ํㅜ, item 12 da Resolução CNS 441/2011: "O prazo de armazenamento de material biológico humano em Biorrepositório deve estar de acordo com o cronograma da pesquisa correspondente e pode ser autorizado por até dez anos.". Solicita-se adequação.

RESPOSTA: Em atenção à solicitação do parecer CONEP e à Resolução 441/11, item 12.I e 12.II, o trecho foi alterado para: "Suas amostras ficarão armazenadas no Biorrepositório durante a realização dessa pesquisa e poderão permanecer armazenadas por até 10 anos, ou mais caso o Comitê de Ética em Pesquisa aprove".

ANÁLISE: A pesquisadora responsável acrescentou a frase ao documento intitulado "Anexo 4 TCLE menores A e C.docx", esclarecendo o tempo de permanência das amostras em Biorepositório, em

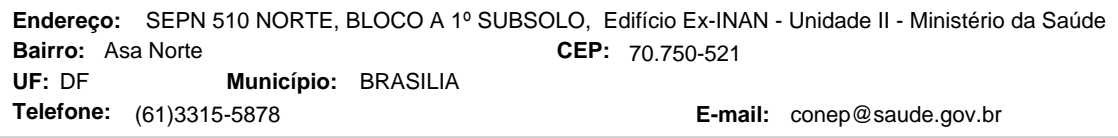




\section{COMISSÃO NACIONAL DE ÉTICA EM PESQUISA}

Continuação do Parecer: 347.972

atendimento a essa solicitação. Entretanto, não retirou a frase do parágrafo em que é dito: "As amostras do paciente ficarão armazenadas permanentemente no repositório", o que pode vir a gerar dúvidas aos participantes em relação ao tempo de retenção do material biológico coletado, se permanentemente ou se por dez anos. PENDÊNCIA NÃO ATENDIDA.

RECURSO: O trecho: "As amostras do paciente ficarão armazenadas permanentemente no repositório", foi excluído do ¿TCLE menores A e C julho 2013 ¿ e do ¿TCLE adultos A e C julho 2013 ¿.

ANÁLISE: PENDÊNCIA ATENDIDA.

c) Na página 3/5 do documento, item "Riscos de confidencialidade", lê-se: "Porém, assim como em qualquer meio de armazenamento de dados, existe uma pequena possibilidade de quebra de segurança. Contudo, trabalharemos muito para manter os dados do paciente em sigilo.". O termo ¿"rabalharemos muito para manter os seus dados em sigilo" não traz a garantia do pesquisador responsável quanto à manutenção da confidencialidade dos dados resultantes da pesquisa, o que é eticamente inaceitável. Solicita-se adequação. RESPOSTA: Foi acrescentada a seguinte frase: "Para garantir sua confidencialidade e sigilo, nenhuma amostra será identificada com seu nome, mas por códigos. Apenas a pesquisadora responsável e funcionários designados por ela poderão associar os códigos que identificarão as amostras ao nome de cada participante da pesquisa."

ANÁLISE: A pesquisadora responsável apresenta formas de anonimização das amostras e dos dados coletados, entretanto, ainda mantém a afirmação sobre a possibilidade de quebra de segurança das informações dos documentos. PENDÊNCIA NÃO ATENDIDA.

RECURSO: Tomamos todos os cuidados para garantir a confidencialidade de todos os participantes da pesquisa. Entretanto, entendemos que em qualquer situação existe a possibilidade de que essa quebra aconteça, podemos citar como exemplo situações em que hackers entraram em sistemas bancários ou o roubo de computadores/laptops. São situações imprevisíveis, que fogem ao nosso controle. Assim, em atenção à Resolução 196/96, IV,1.b, que exige que o TCLE descreva ¿os desconfortos e riscos possíveis ¿ , a equipe de pesquisa compartilha o sentimento de que estamos sendo mais éticos se informarmos esse risco. Desta maneira, consideramos importante manter esse alerta nos TCLE: ¿existe uma pequena possibilidade de quebra de segurança. $i$. Durante a audiência, o membro da CONEP que nos recebeu também concordou que esta informação pode e deve fazer parte do nosso TCLE. Ele sugeriu, entretanto que mudássemos a frase seguinte enfatizando que estamos garantindo confidencialidade e tomando todas as medidas possíveis.

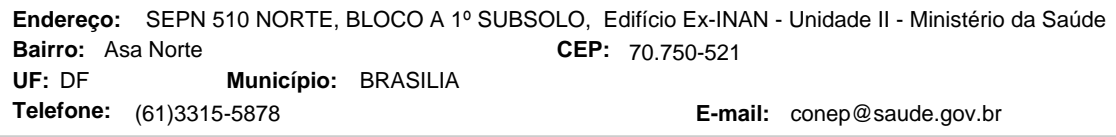




\section{COMISSÃO NACIONAL DE ÉTICA EM PESQUISA}

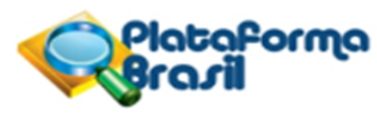

Continuação do Parecer: 347.972

Assim este paragrafo fica redigido da seguinte forma (em negrito a nova frase enfatizando que a confidencialidade está garantida): ¿Porém, assim como em qualquer meio de armazenamento de dados, existe uma pequena possibilidade de quebra de segurança. No entanto tomaremos todas as medidas para manter os dados da criança ou adolescente, pelo qual você é responsável, em sigilo e garantir a privacidade dele/dela. Para garantir a confidencialidade, nenhuma amostra será identificada com o nome da criança ou do adolescente, mas por códigos. Apenas a pesquisadora responsável e funcionários designados por ela poderão associar os códigos que identificarão as amostras ao nome de cada participante da pesquisa. $i$ Conforme solicitado, o trecho acima foi alterado no anexo ¿TCLE menores A e C julho $2013 i$.

ANÁLISE: PENDÊNCIA ATENDIDA.

d) PENDÊNCIA ATENDIDA NO PARECER CONEP 285.862

e) PENDÊNCIA ATENDIDA NO PARECER CONEP 285.862

f) PENDÊNCIA ATENDIDA NO PARECER CONEP 285.862

8. Quanto ao documento TCLE para menores etapa B:

a) PENDÊNCIA ATENDIDA NO PARECER CONEP 285.862

b) Na página 3/4 do documento, item "Riscos de confidencialidade", lê-se: "Porém, assim como em qualquer meio de armazenamento de dados, existe uma pequena possibilidade de quebra de segurança.". É eticamente inaceitável que o pesquisador não garanta a confidencialidade dos dados coletados e originados durante a realização da pesquisa. Solicita-se adequação.

RESPOSTA: Foi incluído o seguinte: "Para garantir a confidencialidade e sigilo do paciente, nenhuma amostra será identificada com seu nome, mas por códigos. Apenas a pesquisadora responsável e funcionários designados por ela poderão associar os códigos que identificarão as amostras ao nome de cada participante da pesquisa.".

ANÁLISE: A pesquisadora responsável apresenta formas de anonimização das amostras e dos dados coletados, entretanto, ainda mantém a afirmação sobre a possibilidade de quebra de segurança das informações dos documentos. PENDÊNCIA NÃO ATENDIDA.

RECURSO: Tomamos todos os cuidados para garantir a confidencialidade de todos os participantes da pesquisa. Entretanto, entendemos que em qualquer situação existe a possibilidade de que essa quebra aconteça, podemos citar como exemplo situações em que hackers entraram em sistemas

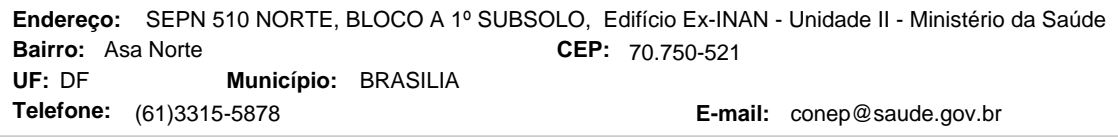




\section{COMISSÃO NACIONAL DE ÉTICA EM PESQUISA}

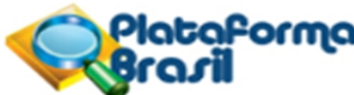

Continuação do Parecer: 347.972

bancários ou o roubo de computadores/laptops. São situações imprevisíveis, que fogem ao nosso controle. Assim, em atenção à Resolução 196/96, IV,1.b, que exige que o TCLE descreva ¿os desconfortos e riscos possíveis $i$, a equipe de pesquisa compartilha o sentimento de que estamos sendo mais éticos se informarmos esse risco. Desta maneira, consideramos importante manter esse alerta nos TCLE: ¿existe uma pequena possibilidade de quebra de segurança. $i$. Durante a audiência, o membro da CONEP que nos recebeu também concordou que esta informação pode e deve fazer parte do nosso TCLE. Ele sugeriu, entretanto que mudássemos a frase seguinte enfatizando que estamos garantindo confidencialidade e tomando todas as medidas possíveis. Assim este paragrafo fica redigido da seguinte forma (em negrito a nova frase enfatizando que a confidencialidade está garantida): ¿Porém, assim como em qualquer meio de armazenamento de dados, existe uma pequena possibilidade de quebra de segurança. No entanto tomaremos todas as medidas para manter os dados da criança ou adolescente, pelo qual você é responsável, em sigilo e garantir a privacidade dele/dela. Para garantir a confidencialidade, nenhuma amostra será identificada com o nome da criança ou do adolescente, mas por códigos. Apenas a pesquisadora responsável e funcionários designados por ela poderão associar os códigos que identificarão as amostras ao nome de cada participante da pesquisa. $¿$ Conforme solicitado, alteramos o trecho acima no anexo ¿TCLE menores B julho 2013i.

ANÁLISE: PENDÊNCIA ATENDIDA.

c) PENDÊNCIA ATENDIDA NO PARECER CONEP 285.862

d) PENDÉNCIA ATENDIDA NO PARECER CONEP 285.862

e) PENDÊNCIA ATENDIDA NO PARECER CONEP 285.862

9. Solicita-se que seja elaborado e apresentação dos Termos de Assentimento aos participantes menores de 18 anos. Os documentos devem ser elaborados em linguagem adequada às diferentes faixas etárias, podendo ser ilustrado.

RESPOSTA: Foram incluídos 3 modelos de Termos de Assentimento.

ANÁLISE:

a-Na página 1/3 do documento intitulado "CD REDS Aim B Assent Control Group_Portuguese receberam transfusão enviado.docx". O título da pesquisa apresentado no documento não é o mesmo apresentado na Folha de Rosto (mesmo se tratando de uma segunda fase de pesquisa, o título original deverá constar no documento, com um breve esclarecimento da fase da pesquisa).

Recurso: Incluímos, na verdade, 2 Termos de Assentimentos, agora renomeados para

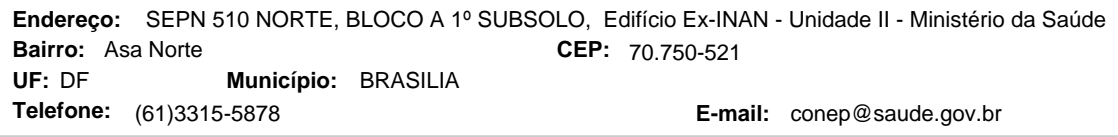




\section{COMISSÃO NACIONAL DE ÉTICA EM PESQUISA}

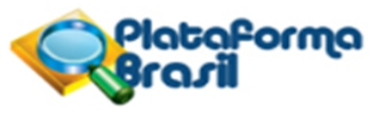

Continuação do Parecer: 347.972

¿Assentimento A e C julho 2013 ¿ e ¿Assentimento B julho 2013 ¿. Para atender à solicitação CONEP, incluímos nos 2 Termos de Assentimento o título original e o de cada subprojeto. Incluímos ainda um breve esclarecimento da fase da pesquisa. O texto do ¿Assentimento A e C julho 2013 ¿ ficou assim: ¿PROJETO: Estudo longitudinal multicêntrico da doença falciforme no Brasil - REDSIII Sub-projeto: Estabelecimento da coorte de Doença Falciforme, criação de banco de amostras biológicas e determinantes genéticos da aloimunização. Este é o primeiro subprojeto onde vamos coletar informações e sangue de crianças que tenham a mesma doença que você. Esta fase vai coletar as informações mais importantes do estudo para entender porque o sangue transfundido causa ou não reação em você. ¿ Incorporamos essa alteração também no ¿TCLE Adulto A e C julho 2013i, esse trecho foi alterado para: ¿ Titulo do projeto: Estudo longitudinal multicêntrico da Doença Falciforme no Brasil ¿ REDS III Sub-projeto: Estabelecimento da coorte de Doença Falciforme, criação de banco de amostras biológicas e determinantes genéticos da aloimunização. Você está sendo convidado a participar desse primeiro subprojeto, onde vamos coletar informações e sangue de pessoas que tenham a mesma doença que você. Esta fase vai coletar as informações mais importantes do estudo para entender porque o sangue transfundido causa ou não reação em você $i$ Incorporamos essa alteração também no ¿TCLE menores A e C julho 2013 $i$, esse trecho foi alterado para: ¿ Titulo do projeto: Estudo longitudinal multicêntrico da Doença Falciforme no Brasil ¿ REDS III - Parte I. Sub-projeto: Estabelecimento da coorte de Doença Falciforme, criação de banco de amostras biológicas e determinantes genéticos da aloimunização.

O paciente, menor de 18 anos, sob sua responsabilidade, está sendo convidado a participar desse primeiro subprojeto, onde vamos coletar informações e sangue de pessoas que tenham a doença falciforme. Esta fase vai coletar as informações mais importantes do estudo para entender porque o sangue transfundido causa ou não reação nas crianças ou adolescentes. ¿ O texto do ¿Assentimento B julho $2013 i$ ficou assim: ¿...projeto ¿Estudo longitudinal multicêntrico da doença falciforme no Brasil ¿ REDSIII $i$. Sub-projeto: ¿Mudanças nos perfis de expressão do RNAm e perfis de quimiocinas/citocinas associados a transfusões em subpopulações falciformes selecionadas $i$. Estamos convidando você a fazer parte desta pesquisa para entender melhor o que ocorre no sangue dos pacientes com doença falciforme após a transfusão de sangue. ¿ Incorporamos essa alteração também no ¿TCLE menores B julho 2013 ¿, esse trecho foi alterado para:

¿ Titulo do projeto: Estudo longitudinal multicêntrico da Doença Falciforme no Brasil ¿ REDS III Sub-projeto: ¿Mudanças nos perfis de expressão do RNAm e perfis de quimiocinas/citocinas associados a transfusões em subpopulações falciformes selecionadas $i$. O paciente, menor de 18 anos que esta sob sua responsabilidade, está sendo convidado a participar desta etapa, que tem o

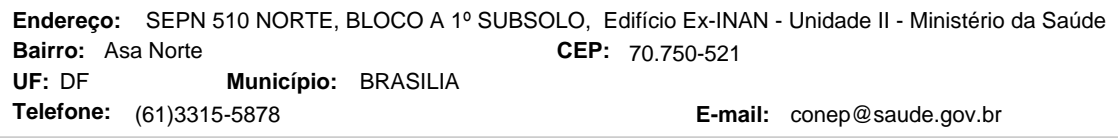




\section{COMISSÃO NACIONAL DE ÉTICA EM PESQUISA}

Continuação do Parecer: 347.972

objetivo de caracterizar o que ocorre no sangue dos pacientes com doença falciforme após a transfusão de sangue. ¿ Incorporamos essa alteração também no ¿TCLE adultos B julho $2013 i$, a redação ficou assim: ¿ Titulo do projeto: Estudo longitudinal multicêntrico da Doença Falciforme no Brasil ¿ REDS III Sub-projeto: ¿Mudanças nos perfis de expressão do RNAm e perfis de quimiocinas/citocinas associados a transfusões em subpopulações falciformes selecionadas $i$. Você está sendo convidado a participar desta etapa, que tem o objetivo de caracterizar a resposta imunológica e as variações genéticas que ocorrem após a transfusão de sangue em pacientes com doença falciforme. ¿ Desta maneira, os dois termos de assentimento e os 4 TCLE informam o titulo da pesquisa, tal como consta na folha de rosto, o título do respectivo subprojeto e um breve esclarecimento da fase da pesquisa.

ANÁLISE: PENDÊNCIA ATENDIDA.

b-Na página 1/3 do documento intitulado "SCD REDS Aim B Assent Control Group_Portuguese receberam transfusão enviado.docx", na frase: "Você pode escolher se deseja ou não que fazer parte deste estudo.". O texto necessita de revisão gramatical.

c-Na página 1/3 do documento intitulado "CD REDS Aim B Assent Control Group_Portuguese receberam transfusão enviado.docx", na frase; "Eu tenho que participar deste estudo de pesquisa? Você não tem que particiapr nesta pesquisa, se você não quiser.". O texto necessita de revisão gramatical.

d-Na página 2/3 do documento intitulado "SCD REDS Aim B Assent Control Group_Portuguese receberam transfusão enviado.docx", na frase: "Sempre que possível, iremos colher amostra de sangue junto com o sangue que precisa ser colhido para o seu tratamento, mas algumas vezes isso não será possivel e teremos que colher uma amostra de sangue só para a pesquisa". A frase está redigida de maneira confusa. Deverá ser escrita de forma mais clara e compreensível.

e-Na página 1/3 do documento intitulado "Informed Assent Aim A and C in Portuguese enviado.docx" O título da pesquisa apresentado no documento não é o mesmo apresentado na Folha de Rosto (mesmo se tratando de uma segunda fase de pesquisa, o título original deverá constar no documento, com um breve esclarecimento da fase da pesquisa).

PENDÊNCIA PARCIALMENTE ATENDIDA.

RECURSO: Esta resposta encontra-se no item 9a, acima.

ANÁLISE: PENDÊNCIA ATENDIDA.

\section{Situação do Parecer:}

Aprovado

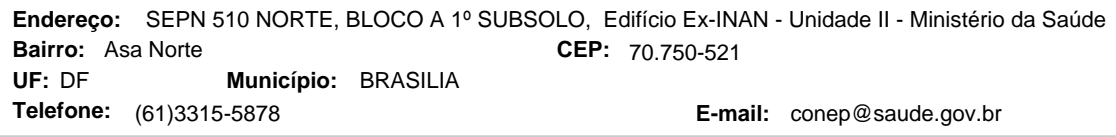




\section{COMISSÃO NACIONAL DE ÉTICA EM PESQUISA}

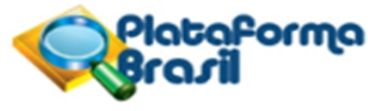

Continuação do Parecer: 347.972

\section{Considerações Finais a critério da CONEP:}

Diante do exposto, a Comissão Nacional de Ética em Pesquisa - CONEP, de acordo com as atribuições definidas na Resolução CNS 466/2012, manifesta-se pela aprovação do projeto de pesquisa proposto.

Situação: Protocolo aprovado.

BRASILIA, 06 de Agosto de 2013

Assinador por:

Jorge Alves de Almeida Venancio

(Coordenador)

Endereço: SEPN 510 NORTE, BLOCO A 1ํ SUBSOLO, Edifício Ex-INAN - Unidade II - Ministério da Saúde

Bairro: Asa Norte CEP: $70.750-521$

UF: DF Município: BRASILIA

Telefone: (61)3315-5878 E-mail: conep@saude.gov.br 


\section{Apêndice B}

\section{Aprovação do Brazil Sickle Cell Disease Cohort - CEP}

Plataforma Brasil - Ministério da Saúde

Faculdade de Medicina da Universidade de São Paulo - FMUSP

PROJETO DE PESQUISA

Título: Estudo longitudinal multicêntrico da doença falciforme no Brasil ¿ REDSIII

Área Temática:Área 8. Pesquisa com cooperação estrangeira.

Pesquisador: Ester cerdeira Sabino

Versão: 2

Instituição:Fundação Faculdade de Medicina - ICESP

CAAE: 02790812.0 .1001 .0065

\section{PARECER CONSUBSTANCIADO DO CEP}

\section{Número do Parecer: 75795}

Data da Relatoria: $\quad 08 / 08 / 2012$

\section{Apresentação do Projeto:}

A doença falciforme (DF) é um tipo de doença do sangue, hereditária das mais prevalentes que existem, com milhões de pessoas afetadas no mundo, sendo que aproximadamente 300.000 crianças nascem com a doença a cada ano. Sua patologia e mecanismos patofisiológicos são complexos e as pessoas acometidas pela doença sofrem graves complicações em praticamente todos os órgãos e sistemas corporais.

O Brasil tem atualmente entre 25.000 e 30.000 casos de doença falciforme e aproximadamente 7 milhões de portadores heterozigotos (AS), com o nascimento, por ano, de cerca de 3.500 novos bebês com a doença. A prevalência, o acompanhamento e assistência médica variam consideravelmente por estado. No Brasil, pacientes falciformes normalmente recebem atendimento na rede de hemocentros públicos ou universidades. Entretanto, muitos casos ainda permanecem sem diagnóstico ou com tratamento inadequado.

No período entre 2001 e 2005, o governo brasileiro elaborou uma série de novos regulamentos sobre a doença introduzindo a triagem de crianças para doença falciforme e o maior cuidado no acompanhamento dos casos.

Entretanto, não há ainda uma base de dados nacional ou uma rede organizada para pesquisas na área.

Pacientes com DF necessitam de transfusões intermitentemente para manifestações agudas, e a síndrome torácica aguda (STA) é o indicativo mais comum nesta situação. O estudo de um grupo americano sobre a STA, demonstrou que transfusões durante STA aumentam a oxigenação em média de 63 a $71 \mathrm{mmHg}$ demonstrando que a transfusão pode aliviar a disfunção de órgãos em portadores de DF. Investigações na caracterização da modulação imunológica pós-transfusão podem ajudar a elucidar os mecanismos dos benefícios transfusionais nos pacientes com doença falciforme.

O uso de uma base de dados centralizada está bem estabelecido na população com doença falciforme dos EUA, desde a criação, em 1978, da coorte do Estudo Cooperativo da Doença Falciforme dos EUA (US Cooperative Study of Sickle Cell Disease). Esta coorte ajudou a definir a historia natural da doença $e$ estabeleceu as bases para décadas de pesquisas que continuam a orientar o gerenciamento atual da doença. Baseado neste sucesso, os Centros Inclusivos de Doença Falciforme (Comprehensive Sickle Cell Centers \& CSCC) lançaram o CSCC Collaborative Data Project (CSCC C-Data) sob a direção do NHLBI em 2004. Esta base de dados envolveu avaliação exaustiva de complicações clínicas e parâmetros laboratoriais de todos os pacientes inscritos e rendeu muitas publicações importantes. Um protocolo auxiliar para coletar e armazenar o material biológico de pacientes inscritos no C-Data foi desenvolvido em 2005.

O Projeto Colaborativo de Dados (CSCC C-Data) e o protocolo genótipo-fenótipo relacionado servirão como um modelo para o estabelecimento da base de dados abrangente de informações clínicas e material biológico para a população falciforme do Brasil, sendo adaptados à realidade brasileira pelo grupo de pesquisadores deste estudo.

O estudo propõe o desenvolvimento de uma base de dados abrangente da população brasileira, com informações clínicas detalhadas, e a criação de um estoque de amostras biológicas (biorrepositório). O biorrepositório será no Laboratório de Virologia e Hematologia Tropical do Instituto de Medicina Tropical (IMT) da Universidade de São Paulo. Não será necessária a formação de um biorrepositório no exterior, pois as amostras serão enviadas apenas para a realização dos testes específicos previstos nos objetivos do projeto. Todo o material biológico humano, coletado e armazenado será mantido conforme normas técnicas, éticas e operacionais da instituição responsável e sob gerenciamento da pesquisadora principal, Ester Cerdeira Sabino, e estando de acordo com as normas da resolução CNS 347/2005 e 441/2011.

Em uma nova etapa do projeto, para avaliar o impacto das transfusões de sangue, serão selecionados pacientes para o estudo, de mudanças nos perfis de expressão do RNAm através do sistema Illumina 
HumanHT-12 v3 Expression BeadChip, de perfis de quimiocinas através de ensaios "multiplex $i$, assim como o estudo de genotipagem para identificar polimorfismos de um único nucleotídeo, estudo associados com aloimunização de hemácias. Amostras serão enviadas para o Laboratório Central do REDS III (Blood Systems Research Institute (BSRI) - Estados Unidos), onde serão realizados estes estudos. A remessa das amostras será feita com a autorização concedida pelo CNPq, publicada no Diário Oficial 16022012 Portaria 129 (anexo), obedecendo à legislação brasileira vigente para remessa das amostras biológicas para o exterior.

O estudo envolve participação de 3 hemocentros públicos brasileiros: Fundação Hemominas (Minas Gerais), Fundação Hemope (Pernambuco) e Fundação Hemorio (Rio de Janeiro).

Recrutamento de pacientes:

Antes de qualquer procedimento, o sujeito da pesquisa será solicitado a assinar o termo de consentimento livre e esclarecido (TCLE). Para cada etapa do estudo terá um TCLE específico. TCLE Parte I será para registrar a concordância do paciente em participar das etapas A e C. TCLE Parte II foi elaborado para aceite do paciente na etapa B. Para pacientes menores de 18 anos, o consentimento devera ser assinado pelos pais ou responsáveis.

$\mathrm{Na}$ etapa A espera-se inscrever aproximadamente de 6 a 7 mil pacientes com doença falciforme no estudo (70$80 \%$ dos 9000 existentes nos três hemocentros). Na etapa B será utilizado um painel de análise de quimiocinas e citocinas para avaliar mudanças em mediadores inflamatórios pós-transfusionais. Participarão dessa etapa 200 pacientes portadores de Doença Falciforme com histórico de transfusão, 200 pacientes hospitalizados com síndrome torácica aguda e 100 pacientes não transfundidos como controles. Na etapa C, serão selecionados do banco de dados 500 pacientes aloimunizados e 500 não aloimunizados, para caracterização de aloanticorpos e comparação da base genética.

\section{Objetivo da Pesquisa:}

Criar uma base de dados e um biorrepositório para estudo da doença falciforme na população brasileira para estudos futuros.

\section{Detalhamento:}

¿Estruturar uma base de dados eletrônica centralizada e abrangente sobre doença falciforme centralizando dados clínicos, laboratoriais e históricos de transfusões de pacientes atendidos nos três hemocentros participantes;

¿Estabelecer um banco de amostras para dar suporte a estudos biológicos sobre a patogenia falciforme e complicações transfusionais;

¿Caracterizar a modulação imunológica e as mudanças na expressão do RNAm que ocorrem após a transfusão em pacientes com doença falciforme, pela análise de painéis de citocinas e perfis da expressão genética serial;

¿Investigar a expressão genética e mudanças protéicas que ocorrem com a transfusão de sangue, investigar também as bases genéticas da aloimunização em pacientes com doença falciforme.

\section{Avaliação dos Riscos e Benefícios:}

Risco/desconforto:

Na coleta de sangue: pode causar uma dor leve quando a agulha é introduzida na veia, mas normalmente, não a longo prazo. Após o sangue ser coletado pode haver um pequeno hematoma onde a agulha foi inserida, que pode durar algumas horas ou dias.

Em ocasiões muito raras pode haver pequeno ferimento ou infecção onde a agulha foi inserida.

Risco na confidencialidade dos dados armazenados - As informações prestadas são confidenciais com a garantia de que o nome dos pacientes, seus dados pessoais e genéticos não serão usados em nenhum relatório publicado de pesquisa.

\section{Benefícios:}

Consta no TCLE que os participantes do estudo não terão nenhum benefício imediato direto, nem mesmo financeiro, no entanto através desta base de dados que será gerada, a pesquisa poderá ter um impacto na terapia transfusional para a população de doença falciforme no Brasil através do desenvolvimento de novas drogas, exames, tratamentos ou produtos, inclusive de valor comercial. 


\section{Comentários e Considerações sobre a Pesquisa:}

A pesquisa é uma iniciativa muito importante a longo prazo na medida em que pode trazer benefícios para os pacientes com a doença falciforme no Brasil. Investigações na modulação imunológica pós-transfusão podem ajudar a elucidar os mecanismos dos benefícios transfusionais aos pacientes com doença falciforme.

O TCLE nos seus termos está de acordo com a resolução CNS 196/96 e 441 de 12 maio de 2011 e por envolver uma instituição fora do Brasil, - Blood Systems Research Institute (BSRI) - Estados Unidos- existe também um documento formal desta Instituição declarando estar em cumprimento com a resolução 196/96. Diante do exposto e considerando que a metodologia, a avaliação de riscos/benefícios, procedimentos, e a utilização dos sujeitos na pesquisa (TCLE) está em conformidade com as exigências das resoluções do CNS/CONEP (196/96) pertinentes ao estudo com seres humanos e 441/11 relacionado ao uso de biorrepositório, este Comitê de Ética (CEP) se manifesta pela aprovação deste projeto.

\section{Considerações sobre os Termos de apresentação obrigatória:}

Nada a declarar

Recomendações:

Nada a Declarar

\section{Conclusões ou Pendências e Lista de Inadequações:}

Considerando que a metodologia, a avaliação de riscos/benefícios, procedimentos, e a utilização dos sujeitos na pesquisa (TCLE) está em conformidade com as exigências das resoluções do CNS/CONEP (196/96) pertinentes ao estudo com seres humanos e 441/11 relacionado ao uso de biorrepositório, este Comitê de Ética (CEP) se manifesta pela aprovação deste projeto.

\section{Situação do Parecer:}

Aprovado

Necessita Apreciação da CONEP:

Sim

Considerações Finais a critério do CEP:

Aprovado

\section{O presente projeto, seguiu nesta data para análise da CONEP e só tem o seu início autorizado após a aprovação pela mesma.}

SAO PAULO, 16 de Agosto de 2012

Assinado por

Roger Chammas 
Apêndice C

Questionários de inscrição do REDS-III

Questionário SCD Entrevista

Codebook impresso em 10/01/2018

\section{Módulo: 1 Entrevista - Parte 1}

1.1) Peso:

Pergunta Número Decimal

Nome da variável: weight_i1

Intervalo permitido: 5.0 - 200.0

1.2) Altura:

Pergunta Número Inteiro

Nome da variável: height_i1

Intervalo permitido: 30 - 250

1.3) Pressão arterial sistólica:

Pergunta Número Inteiro

Nome da variável: sist_press_i1

Intervalo permitido: 50 - 250

1.4) Pressão arterial diastólica:

Pergunta Número Inteiro

Nome da variável: diast_press_i1

Intervalo permitido: 10 - 120

1.5) Saturação de oxigênio:

Pergunta Número Decimal

Nome da variável: o2satur_result_i1

Intervalo permitido: 70.0 - 100.0

1.6) Você está em tratamento com Hidroxiureia atualmente?

Pergunta Alternativa Seleção Única

Nome da variável: current_hydrox_i1

Alternativas: (descrição - score)

1- Sim - 1.0

2- Não - 2.0

1.7) Você está participando de alguma pesquisa no momento?

Pergunta Alternativa Seleção Única

Nome da variável: part_othstudy_i1

Alternativas: (descrição - score)

1- Sim - 1.0

2- Não - 2.0

Planilha: Questões relacionadas a Outro estudo

Itens: (Descrição - Nome da variável)

Outro estudo - othstudy 
1.7.1) Qual é o nome do estudo?

Pergunta Texto

Nome da variável:_name_il

Número máximo de caracteres permitido: 100

1.7.2) Qual é o nome do pesquisador?

Pergunta Texto

Nome da variável: resear il

Número máximo de caracteres permitido: 100

1.7.3) Qual é o nome da instituição responsável?

Pergunta Texto

Nome da variável:_institut_i1

Número máximo de caracteres permitido: 100

1.7.4) Essa pesquisa envolve o uso de algum medicamento para você?

Pergunta Alternativa Seleção Unica

Nome da variável:_medicat_i1

Alternativas: (descrição - score)

1- Sim - 1.0

2- Não - 2.0

1.7.4.1) Qual o nome do medicamento?

Pergunta Texto

Nome da variável: namedic_i1

Número máximo de caracteres permitido: 100

\section{Módulo: 2- Entrevista - Parte 2}

2.0.1) Qual o sexo do participante?

Pergunta Alternativa Seleção Única

Nome da variável: gender

Alternativas: (descrição - score)

0-Masculino - 0.0

1-Feminino - 1.0

\subsection{2) Qual a idade do participante?}

Pergunta Número Inteiro

Nome da variável: age

Intervalo permitido: 0 - 150

2.1) Na sua opinião qual a cor da sua pele (classificação IBGE)?

Pergunta Alternativa Seleção Única

Nome da variável: color_i2

Alternativas: (descrição - score)

Branco/Caucasiano - 1.0

Preto/Negro - 2.0

Asiática/Amarela - 3.0

Mulato/Pardo - 4.0

Indígena - 5.0

Outra - 6.0

2.1.1) Se outro, especifique:

Pergunta Texto 
Nome da variável: othcolor_i2

Número máximo de caracteres permitido: 30

2.2) Quantos irmãos você tem?

Pergunta Número Inteiro

Nome da variável: $n \_s i b l i n \_i 2$

Intervalo permitido: 0 - 32

2.2.1) Quantos irmãos têm o mesmo pai e a mesma mãe biológicos que você?

Pergunta Número Inteiro

Nome da variável: $\mathrm{n} \_$samparentsiblin_i2

Intervalo permitido: 0 - 32

2.2.2) Dos seus irmãos que compartilham pelo menos um pai/uma mãe biológico, quantos tem a doença falciforme (não informar traço falciforme)

Pergunta Número Inteiro

Nome da variável: n_scdsiblin_i2

Intervalo permitido: 0 - 32

2.3) Atualmente você esta trabalhando?

Pergunta Alternativa Seleção Única

Nome da variável: act_working_i2

Alternativas: (descrição - score)

1- Sim - 1.0

2- Não - 2.0

2.4) Atualmente você esta estudando?

Pergunta Alternativa Seleção Única

Nome da variável: act_school_i2

Alternativas: (descrição - score)

1- Sim - 1.0

2- Não - 2.0

2.5) Qual período mais elevado que você cursou ou esta cursando?

Pergunta Alternativa Seleção Única

Nome da variável: schoollevel_i2

Alternativas: (descrição - score)

Nunca fui a escola - 1.0

Ensino Fundamental básico $\left(1^{\mathrm{a}}\right.$ a $\left.5^{\mathrm{a}}\right)-2.0$

Ensino Fundamental completo - 3.0

Ensino Médio $1^{\circ}$ a $3^{\circ}$ (Completo) - 4.0

Alfabetização de adultos - 5.0

Curso Técnico - 6.0

Curso Superior - 7.0

Mestrado - 8.0

Doutorado - 9.0 


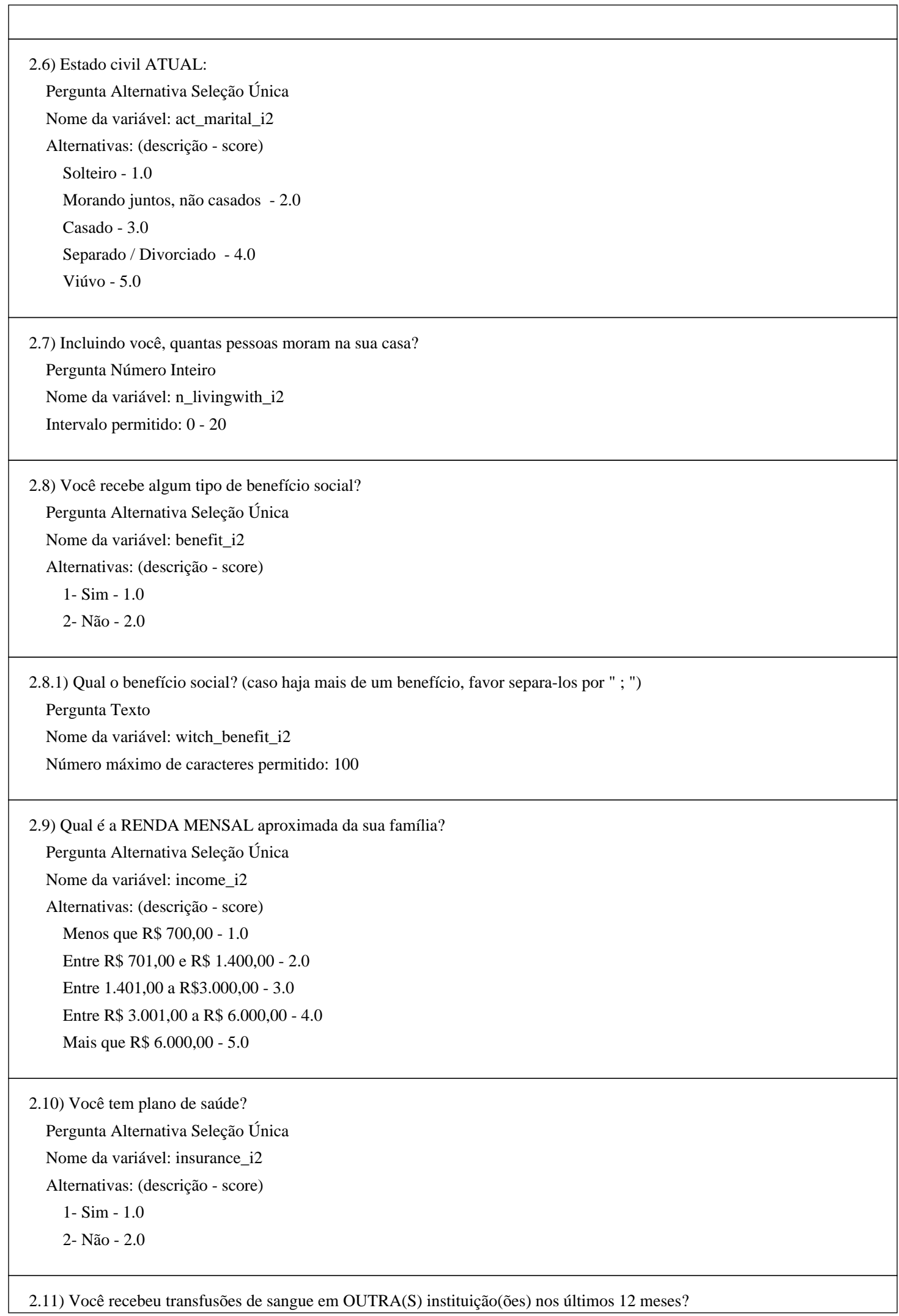


Pergunta Alternativa Seleção Única

Nome da variável: transf_othinstitut_i2

Alternativas: (descrição - score)

1- Sim - 1.0

2- Não - 2.0

2.11.1) Quantas transfusões foram realizadas em OUTRA(S) instituição(ões) nos últimos 12 meses? Pergunta Número Inteiro

Nome da variável: transf_howmany_i2

Intervalo permitido: 1 - 100

2.11.2) Qual(is) o(s) nome(s) da(s) OUTRA(S) instituição(ões) onde foi(ram) realizada(s) essa(s) transfusão(ões)?(favor separar as outras instituições por ";")

Pergunta Texto

Nome da variável: trans_wichinsitut_i2

Número máximo de caracteres permitido: 100

2.12) Desde que você foi diagnosticado como portador da Doença Falciforme, em quais Estados você recebeu transfusão de sangue? (marque todas as opções que se aplicam). Marque "Não se aplica" caso não tenha recebido transfusão

Pergunta Alternativa Seleção Múltipla

Nome da variável: transf_states_i2

Alternativas: (descrição - nome da variável - score)

Acre (AC) - _acre - 1.0

Alagoas (AL) - _alag - 2.0

Amapá (AP) - _amap - 3.0

Amazonas (AM) - _amazon - 4.0

Bahia (BA) - _bahia - 5.0

Ceará $(\mathrm{CE})$ - _ceara - 6.0

Distrito Federal (DF) - _distfed - 7.0

Espírito Santo (ES) - _espsant - 8.0

Goiás (GO) - _goias - 9.0

Maranhão (MA) - _maran - 10.0

Mato Grosso (MT) - _matogros - 12.0

Mato Grosso do Sul (MS) - _matosul - 13.0

Minas Gerais (MG) - _minas - 14.0

Pará (PA) - _para - 15.0

Paraíba (PB) - _paraiba - 16.0

Paraná (PR) - _parana - 17.0

Pernambuco (PE) - _pernambu - 18.0

Piauí (PI) - _piau - 19.0

Rio de Janeiro (RJ) - _riodejan - 20.0

Rio Grande do Norte (RN) - _rionorte - 21.0

Rio Grande do Sul (RS) - _riosul - 22.0

Rondônia (RO) - _rondo - 23.0

Roraima (RR) - _roraim - 24.0

Santa Catarina (SC) - _santacat - 25.0

São Paulo (SP) - _saopaul - 26.0 
Sergipe (SE) - _sergip - 27.0

Tocantins (TO) - _tocant - 28.0

2.13) Nos últimos 12 meses, quantas consultas não agendadas você fez a algum consultório médico, hospital, pronto socorro, ou clínica por causa da doença falciforme?

Pergunta Alternativa Seleção Única

Nome da variável: $n \_$unschedu_i2

Alternativas: (descrição - score)

$0-1.0$

$1-2.0$

2 a $3-3.0$

4 a $5-4.0$

6 a $10-5.0$

11 a $15-6.0$

16 a $20-7.0$

Mais que $20-8.0$

2.14) Nos últimos 12 meses, quantos dias de trabalho ou escola, você teve que faltar por causa da dor devido à doença falciforme? Caso você não trabalhe ou estude: Quantos dias você teve dificuldade em realizar suas atividades diárias, por causa da dor devido à doença falciforme?

Pergunta Alternativa Seleção Única

Nome da variável: $\mathrm{n} \_$dmissedyear_i2

Alternativas: (descrição - score)

$$
\begin{aligned}
& 0-1.0 \\
& 1-2.0 \\
& 2 \text { a } 3-3.0 \\
& 4 \text { a } 5-4.0 \\
& 6 \text { a } 10-5.0 \\
& 11 \text { a } 15-6.0 \\
& 16 \text { a } 20-7.0
\end{aligned}
$$

Mais que $20-8.0$

2.14.1) Nos últimos 30 dias, quantos dias de trabalho ou escola, você teve que faltar por causa da dor devido à doença falciforme? Caso você não trabalhe ou estude: Quantos dias você teve dificuldade em realizar suas atividades diárias, por causa da dor devido à doença falciforme?

Pergunta Número Inteiro

Nome da variável: $\mathbf{n} \_$dmissedmonth_i2

Intervalo permitido: 0 - 30

2.15.1) Você já teve a primeira menstruação?

Pergunta Alternativa Seleção Única

Nome da variável: menst_i2

Alternativas: (descrição - score)

1- Sim - 1.0

2- Não - 2.0 
2.15.1.1) Com qual idade você teve a primeira menstruação?

Pergunta Número Inteiro

Nome da variável: age_menst_i2

Intervalo permitido: 6 - 30

\subsection{1) Você está grávida?}

Pergunta Alternativa Seleção Única

Nome da variável: act_pregnant_i2

Alternativas: (descrição - score)

1- Sim - 1.0

2- Não - 2.0

2.16.2) Você já esteve grávida alguma vez na vida? (excluir gravidez atual, se aplicável) Pergunta Alternativa Seleção Única

Nome da variável: past_pregnant_i2

Alternativas: (descrição - score)

1- Sim - 1.0

2- Não - 2.0

2.16.3.1) Criança nascida viva e a termo:

Pergunta Número Inteiro

Nome da variável: n_term_i2

Intervalo permitido: 0 - 20

\subsubsection{2) Criança nascida viva prematura:}

Pergunta Número Inteiro

Nome da variável: $n \_$premature_i2

Intervalo permitido: 0 - 20

2.16.3.3) Gravidez incompleta, considerar aborto espontâneo, aborto induzido e natimorto:

Pergunta Número Inteiro

Nome da variável: $\mathrm{n} \_$abortion_i2

Intervalo permitido: 0 - 20

2.16.4) Alguma vez você já teve gravidez que resultou em nascimentos múltiplos? (por exemplo, gêmeos ou trigêmeos) Pergunta Alternativa Seleção Única

Nome da variável: multiple_birth_i2

Alternativas: (descrição - score)

1- Sim - 1.0

2- Não - 2.0

Planilha: Questões relacionadas a nascimento(s) múltiplo(s)

Itens: (Descrição - Nome da variável)

Nascimento múltiplo - multiple 
2.16.4.1) Marque o tipo de nascimento múltiplo:

Pergunta Alternativa Seleção Única

Nome da variável:_birth_i2

Alternativas: (descrição - score)

Gêmeos - 1.0

Trigêmeos - 2.0

Quadrigêmeos ou mais - 3.0

2.16.5) Você já recebeu transfusão durante a gravidez?

Pergunta Alternativa Seleção Única

Nome da variável: transf_pregnant_i2

Alternativas: (descrição - score)

1- Sim - 1.0

2- Não - 2.0

2.16.5.1) Você recebeu transfusão em mais de uma gravidez? Marque "Não se aplica" se a paciente teve apenas uma gravidez Pergunta Alternativa Seleção Única

Nome da variável: transfmore_pregnant_i2

Alternativas: (descrição - score)

1- Sim - 1.0

2- Não - 2.0

2.18.1) Alguma vez na sua vida, você fumou cigarros?

Pergunta Alternativa Seleção Única

Nome da variável: smoke_i2

Alternativas: (descrição - score)

1- Sim - 1.0

2- Não - 2.0

2.18.1.1) Durante toda a sua vida você já fumou pelo menos 100 cigarros? (100 cigarros $=5$ maços)

Pergunta Alternativa Seleção Única

Nome da variável: cig100_i2

Alternativas: (descrição - score)

1- Sim - 1.0

2- Não - 2.0

2.18.1.2) Nos últimos 30 dias, quantos dias você fumou cigarros? Caso o paciente não tenha fumado cigarros nos últimas 30 dias, preencha " 0 ".

Pergunta Número Inteiro

Nome da variável: past30d_smoke_i2

Intervalo permitido: 0 - 30

2.18.2) Alguma vez na sua vida você fumou cigarro de palha?

Pergunta Alternativa Seleção Única

Nome da variável: handroll_i2

Alternativas: (descrição - score)

1- Sim - 1.0

2- Não - 2.0 
2.18.2.1) Nos últimos 30 dias, quantos dias você fumou cigarro de palha? Caso o paciente não tenha fumado cigarro de palha nos últimas 30 dias, preencha " 0 ".

Pergunta Número Inteiro

Nome da variável: past30d_handroll_i2

Intervalo permitido: 0 - 30

2.18.3) Alguma vez na sua vida você usou tabaco de mascar ou cheirar (também conhecido como rapé ou fumo)? Pergunta Alternativa Seleção Única

Nome da variável: chewing_i2

Alternativas: (descrição - score)

1- Sim - 1.0

2- Não - 2.0

2.18.3.1) Nos últimos 30 dias, quantos dias você usou tabaco de mascar ou cheirar (também conhecido como rapé ou fumo)? Caso o paciente não tenha usado tabaco nos últimas 30 dias, preencha " 0 ".

Pergunta Número Inteiro

Nome da variável: past30d_chewing_i2

Intervalo permitido: 0 - 30

2.19.1) Alguma vez na sua vida, você tomou bebida alcoólica (cerveja, vinho, cachaça, uísque, etc)?

Pergunta Alternativa Seleção Única

Nome da variável: drink_i2

Alternativas: (descrição - score)

1- Sim - 1.0

2- Não - 2.0

2.19.2) Nos últimos 30 dias, quantos dias você bebeu pelo menos um copo de qualquer bebida alcoólica(cerveja, vinho, cachaça, whisky, rum, etc)? Caso o paciente não tenha ingerido bebida alcoólica nos últimas 30 dias, preencha "0".

Pergunta Número Inteiro

Nome da variável: past30d_drink_i2

Intervalo permitido: 0 - 30

2.19.3) Durante os últimos 30 dias, nos dias em que você bebeu, quanto em média você bebeu por dia? Registrar o número de doses de acordo com a seguinte definição: 1 taça de vinho $(160 \mathrm{~mL})=1$ dose 1 latinha de cerveja $(350 \mathrm{~mL})=1$ dose 1 bebida contendo algum destilado (cachaça, vodca, uísque, rum, etc) $=1$ dose

Pergunta Número Inteiro

Nome da variável: $\mathrm{n} \_$drinkpast30d_i2

Intervalo permitido: 1 - 99

2.19.4) Quantos dias, nos últimos 30 dias, você ingeriu 5 ou mais doses (para homens) ou 4 ou mais doses (para mulheres) numa mesma ocasião, considerando todos os tipos de bebidas alcoólicas?

Pergunta Número Inteiro

Nome da variável: ndays_more5_i2

Intervalo permitido: 0 - 30 
Pergunta Alternativa Seleção Única

Nome da variável: marijuana_i2

Alternativas: (descrição - score)

1- Sim - 1.0

2- Não - 2.0

2.20.1.1) Nos últimos 30 dias, quantos dias você usou maconha? Caso o paciente não tenha usado maconha nos últimas 30 dias, preencha "0".

Pergunta Número Inteiro

Nome da variável: past30d_marijuana_i2

Intervalo permitido: 0 - 30

2.20.2) Alguma vez na sua vida você usou crack?

Pergunta Alternativa Seleção Única

Nome da variável: crack_i2

Alternativas: (descrição - score)

1- Sim - 1.0

2- Não - 2.0

2.20.2.1) Nos últimos 30 dias, quantos dias você usou crack? Caso o paciente não tenha usado crack nos últimas 30 dias, preencha " 0 ",

Pergunta Número Inteiro

Nome da variável: past30d_crack_i2

Intervalo permitido: 0 - 30

2.20.3) Alguma vez na sua vida você usou drogas injetáveis ilegais?

Pergunta Alternativa Seleção Única

Nome da variável: illeg_injdrug_i2

Alternativas: (descrição - score)

1- Sim - 1.0

2- Não - 2.0

2.20.3.1) Nos últimos 30 dias, quantos dias você usou drogas injetáveis ilegais? Caso o paciente não tenha usado drogas injetáveis ilegais nos últimas 30 dias, preencha " 0 ".

Pergunta Número Inteiro

Nome da variável: past30d_injdrug_i2

Intervalo permitido: 0 - 30

2.20.3.2) Quais a(s) droga(s) injetável(is) ilegal (is) que você esta usando atualmente? (favor separar as outras drogas injetáveis ilegais por “;”)

Pergunta Texto

Nome da variável: wich_injdrug_i2

Número máximo de caracteres permitido: 100

2.20.4) Você atualmente usa quaisquer outras substâncias não prescritas ou não recomendadas pelo seu médico?

Pergunta Alternativa Seleção Única 
Nome da variável: act_othersubs_i2

Alternativas: (descrição - score)

1- Sim - 1.0

2- Não - 2.0

2.20.4.1) Qual(is) a(s) substância(s) não prescrita(s) ou não recomendada(s)pelo seu médico você está usando? (favor separar as outras substancias por ";”)

Pergunta Texto

Nome da variável: wich_othersubs_i2

Número máximo de caracteres permitido: 100 


\section{Módulo: 3- Internações hospitalares}

3.1) O paciente teve internações hospitalares nos ÚLTIMOS 12 MESES?

Pergunta Alternativa Seleção Única

Nome da variável: hospitalized_i3

Alternativas: (descrição - score)

1- Sim - 1.0

2- Não - 2.0

Planilha: Questões relacionadas a Internações Hospitalares:

Itens: (Descrição - Nome da variável)

Internação - admit

3.2) Data da internação:

Pergunta Data

Nome da variável:_date_i3

Intervalo permitido: 01/01/2011 - 31/12/2017

3.3) Data da alta:

Pergunta Data

Nome da variável:_dischdate_i3

Intervalo permitido: 01/01/2011 - 31/12/2017 
3.4) Diagnóstico 1:

Pergunta Alternativa Seleção Única

Nome da variável:_diag1_i3

Alternativas: (descrição - score)

1 Diagnóstico não localizado / Sem $2^{\circ} / 3^{\circ}$ diagnóstico - 1.0

2- Acidente vascular cerebral - Hemorrágico - 2.0

3- Acidente vascular cerebral - Infarto - 3.0

4 Anemina auto imune -4.0

5 Asma - 5.0

6 Ataque isquêmico transitório - 6.0

7 Cardiomiopatia - 7.0

8 Cirurgia programada - 8.0

9 Colecistite -9.0

10 Colelitiase - 10.0

11 Complicações oculares - 11.0

12 Convulsão - 12.0

13 Dactilite (sindrome mão-pé) - 13.0

14 Embolia Pulmonar - 14.0

15 Episódio aplástico - 15.0

16 Episódio de dor aguda da doença falciforme - 16.0

17 Febre, sem diagnósitco específico de infecção - 17.0

18 Hemossiderose Transfusional - 18.0

19 Hiperhemólise - 19.0

20 Hipertensão arterial sistêmica - 20.0

21 Hipertensão Pulmonar - 21.0

22 Infarto do Miocárdio - 22.0

23 Infecções graves - Sepses/bacteremia/Meningite - 23.0

24 Insuficiência cardiaca - 24.0

25 insuficiência renal - 25.0

26 Moya - Moya - 26.0

27 Necrose avascular-quadril /ombro - 27.0

28 Neuropatia (dor neuropática) - 28.0

29 Osteomielite (aguda ou crônica) - 29.0

30 Outras Infeccões - 30.0

31 Outro diagnóstico não relacionado à Doença Falciforme - 31.0

32 Pancreatite - 32.0

33 Pielonefrite - 33.0

34 Priapismo - 34.0

35 Reação transfusional hemolítica tardia - 35.0

36 Sequestro esplênico agudo - 36.0

37 Sequestro hepático - 37.0

38 Síndrome Nefrotica - 38.0

39 Síndrome Torácica Aguda/Pneumonia - 39.0

40 Úlceras de perna - 40.0

3.4.1) Especificar outra infecção (30) ou outro diagnóstico (31)

Pergunta Texto

Nome da variável:_othdiag1_i3

Número máximo de caracteres permitido: 100 
3.5) Diagnóstico 2:

Pergunta Alternativa Seleção Única

Nome da variável:_diag2_i3

Alternativas: (descrição - score)

1- Diagnóstico não localizado/Sem $2^{\circ}$ diagnóstico - 1.0

2- Acidente vascular cerebral - Hemorrágico - 2.0

3- Acidente vascular cerebral - Infarto - 3.0

4 Anemina auto imune -4.0

5 Asma - 5.0

6 Ataque isquêmico transitório - 6.0

7 Cardiomiopatia - 7.0

8 Cirurgia programada - 8.0

9 Colecistite -9.0

10 Colelitiase - 10.0

11 Complicações oculares - 11.0

12 Convulsão - 12.0

13 Dactilite (sindrome mão-pé) - 13.0

14 Embolia Pulmonar - 14.0

15 Episódio aplástico - 15.0

16 Episódio de dor aguda da doença falciforme - 16.0

17 Febre, sem diagnósitco específico de infecção - 17.0

18 Hemossiderose Transfusional - 18.0

19 Hiperhemólise - 19.0

20 Hipertensão arterial sistêmica - 20.0

21 Hipertensão Pulmonar - 21.0

22 Infarto do Miocárdio - 22.0

23 Infecções graves - Sepses/bacteremia/Meningite - 23.0

24 Insuficiência cardiaca - 24.0

25 insuficiência renal - 25.0

26 Moya - Moya - 26.0

27 Necrose avascular-quadril /ombro - 27.0

28 Neuropatia (dor neuropática) - 28.0

29 Osteomielite (aguda ou crônica) - 29.0

30 Outras Infeccões - 30.0

31 Outro diagnóstico não relacionado à Doença Falciforme - 31.0

32 Pancreatite - 32.0

33 Pielonefrite - 33.0

34 Priapismo - 34.0

35 Reação transfusional hemolítica tardia - 35.0

36 Sequestro esplênico agudo - 36.0

37 Sequestro hepático - 37.0

38 Síndrome Nefrotica - 38.0

39 Síndrome Torácica Aguda/Pneumonia - 39.0

40 Úlceras de perna - 40.0

3.5.1) Especificar outra infecção (30) ou outro diagnóstico (31)

Pergunta Texto

Nome da variável:_othdiag2_i3

Número máximo de caracteres permitido: 100 
3.6) Diagnóstico 3 :

Pergunta Alternativa Seleção Única

Nome da variável: _diag3_i3

Alternativas: (descrição - score)

1- Diagnóstico não localizado/Sem 3 odiagnóstico - 1.0

2- Acidente vascular cerebral - Hemorrágico - 2.0

3- Acidente vascular cerebral - Infarto - 3.0

4 Anemina auto imune - 4.0

5 Asma - 5.0

6 Ataque isquêmico transitório - 6.0

7 Cardiomiopatia - 7.0

8 Cirurgia programada -8.0

9 Colecistite -9.0

10 Colelitiase - 10.0

11 Complicações oculares - 11.0

12 Convulsão - 12.0

13 Dactilite (sindrome mão-pé) - 13.0

14 Embolia Pulmonar - 14.0

15 Episódio aplástico - 15.0

16 Episódio de dor aguda da doença falciforme - 16.0

17 Febre, sem diagnósitco específico de infecção - 17.0

18 Hemossiderose Transfusional - 18.0

19 Hiperhemólise - 19.0

20 Hipertensão arterial sistêmica - 20.0

21 Hipertensão Pulmonar - 21.0

22 Infarto do Miocárdio - 22.0

23 Infecções graves - Sepses/bacteremia/Meningite - 23.0

24 Insuficiência cardiaca - 24.0

25 insuficiência renal - 25.0

26 Moya - Moya - 26.0

27 Necrose avascular-quadril /ombro - 27.0

28 Neuropatia (dor neuropática) - 28.0

29 Osteomielite (aguda ou crônica) - 29.0

30 Outras Infeccões - 30.0

31 Outro diagnóstico não relacionado à Doença Falciforme - 31.0

32 Pancreatite - 32.0

33 Pielonefrite - 33.0

34 Priapismo - 34.0

35 Reação transfusional hemolítica tardia - 35.0

36 Sequestro esplênico agudo - 36.0

37 Sequestro hepático - 37.0

38 Síndrome Nefrotica - 38.0

39 Síndrome Torácica Aguda/Pneumonia - 39.0

40 Úlceras de perna - 40.0

3.6.1) Especificar outra infecção (30) ou outro diagnóstico (31)

Pergunta Texto

Nome da variável:_othdiag3_i3

Número máximo de caracteres permitido: 100

\section{Módulo: 4- Histórico de cirurgias}

4.0) O paciente já foi submetido a algum procedimento cirúrgico?

Pergunta Alternativa Seleção Única

Nome da variável: surgery_i4

Alternativas: (descrição - score)

1- Sim - 1.0

2- Não - 2.0

4.1) O paciente tem histórico de tonsilectomia?

Pergunta Alternativa Seleção Única

Nome da variável: tonsillectomy_i4

Alternativas: (descrição - score)

1- Sim - 1.0 
2- Não - 2.0

4.1.1) Quantas vezes a cirurgia de tonsilectomia foi realizada?

Pergunta Alternativa Seleção Única

Nome da variável: tonsillecn_i4

Alternativas: (descrição - score)

$1 \mathrm{vez}-1.0$

Mais de $1 \mathrm{vez}-2.0$

4.1.2) Alguma das tonsilectomia(s)necessitou de transfusão?

Pergunta Alternativa Seleção Única

Nome da variável: tonsillectransf_i4

Alternativas: (descrição - score)

1- Sim - 1.0

2- Não - 2.0

4.1.2.1) Quantas tonsilectomias necessitaram de transfusão?

Pergunta Alternativa Seleção Única

Nome da variável: tonsillectransfn_i4

Alternativas: (descrição - score)

Em uma cirurgia - 1.0

Em mais de uma cirurgia - 2.0

4.1.3) Em qual ano foi realizada a primeira tonsilectomia?

Pergunta Número Inteiro

Nome da variável: tonsillecyear_i4

Intervalo permitido: 1920 - 2017

4.2) O paciente tem histórico de esplenectomia?

Pergunta Alternativa Seleção Única

Nome da variável: splenectomy_i4

Alternativas: (descrição - score)

1- Sim - 1.0

2- Não - 2.0

4.2.1) A esplenectomia necessitou de transfusão?

Pergunta Alternativa Seleção Única

Nome da variável: splenectransf_i4

Alternativas: (descrição - score)

1- Sim - 1.0

2- Não - 2.0

4.2.2) Em qual ano foi realizada a esplenectomia?

Pergunta Número Inteiro

Nome da variável: splenecyear_i4

Intervalo permitido: 1920 - 2017 


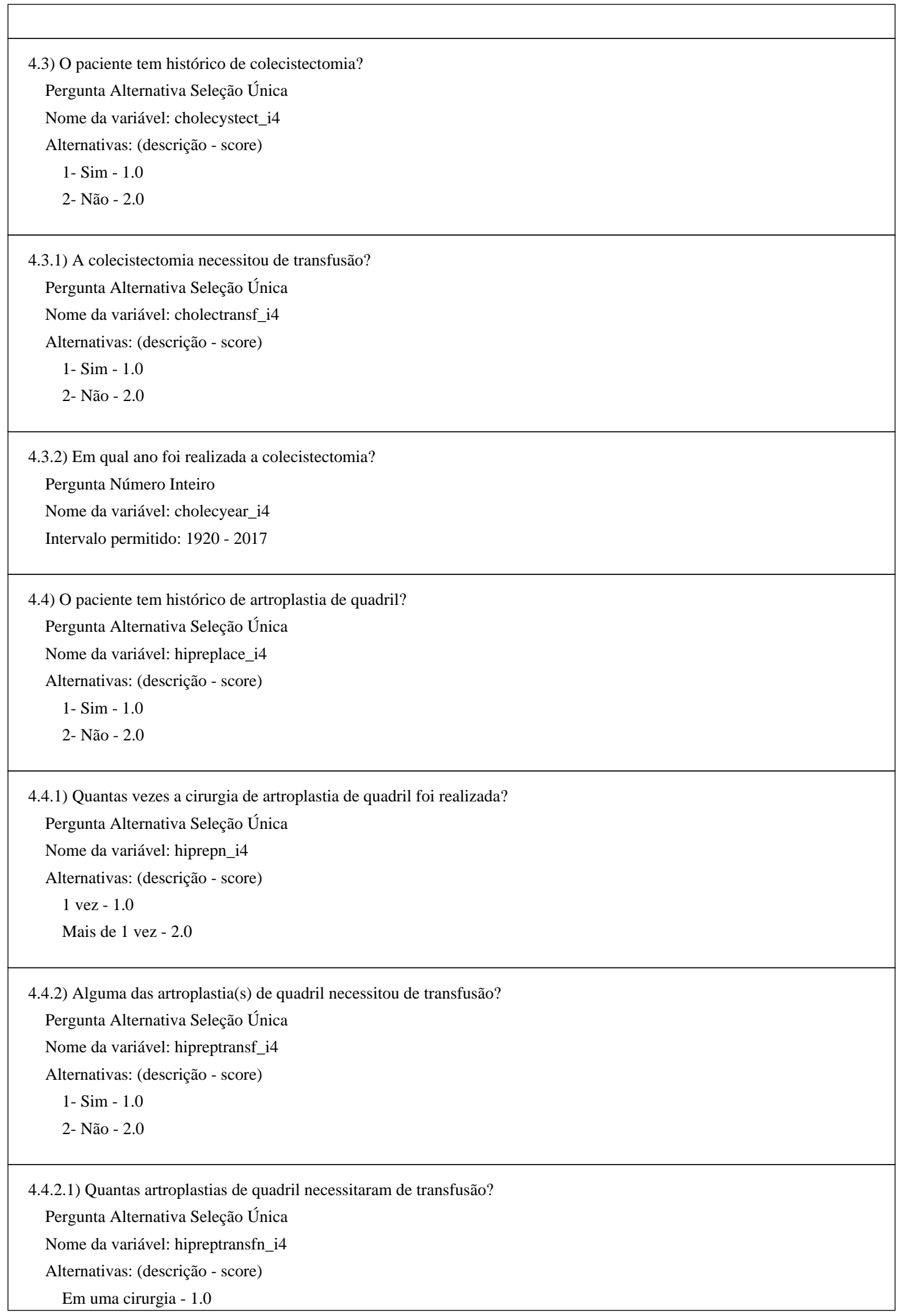


Em mais de uma cirurgia - 2.0

4.4.3) Em qual ano foi realizada a primeira artroplastia de quadril?

Pergunta Número Inteiro

Nome da variável: hiprepyear_i4

Intervalo permitido: 1920 - 2017

4.5) O paciente tem histórico de cirurgia oftalmológica a laser?

Pergunta Alternativa Seleção Única

Nome da variável: lasereye_i4

Alternativas: (descrição - score)

1- Sim - 1.0

2- Não - 2.0

4.5.1) Em qual ano foi realizada a cirurgia oftalmológica a laser?

Pergunta Número Inteiro

Nome da variável: lasereyeyear_i4

Intervalo permitido: 1920 - 2017

4.6) O paciente tem histórico de vitrectomia?

Pergunta Alternativa Seleção Única

Nome da variável: vitrectomy_i4

Alternativas: (descrição - score)

1- Sim - 1.0

2- Não - 2.0

4.6.1) A vitrectomia necessitou de transfusão?

Pergunta Alternativa Seleção Única

Nome da variável: vitrectransf_i4

Alternativas: (descrição - score)

1- Sim - 1.0

2- Não - 2.0

4.6.2) Em qual ano foi realizada a vitrectomia?

Pergunta Número Inteiro

Nome da variável: vitrecyear_i4

Intervalo permitido: 1920 - 2017

4.7) O paciente tem histórico de inserção de catéter venoso permanente?

Pergunta Alternativa Seleção Única

Nome da variável: insertioncath_i4

Alternativas: (descrição - score)

1- Sim - 1.0

2- Não - 2.0 


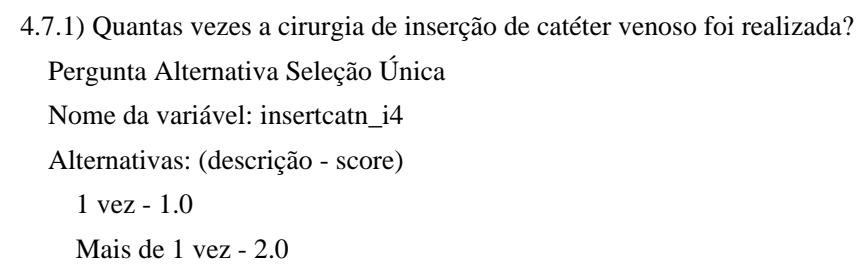

4.7.2) Alguma das cirurgias de inserção de catéter venoso permanente necessitou de transfusão? Pergunta Alternativa Seleção Única

Nome da variável: insertcattransf_i4

Alternativas: (descrição - score)
1- Sim - 1.0
2- Não - 2.0

4.7.2.1) Quantas cirurgias de inserção de catéter venoso permanente necessitaram de transfusão? Pergunta Alternativa Seleção Única

Nome da variável: insertcattransfn_i4

Alternativas: (descrição - score)

Em uma cirurgia - 1.0

Em mais de uma cirurgia - 2.0

4.7.3) Em qual ano foi realizada a primeira inserção de catéter venoso permanente?

Pergunta Número Inteiro

Nome da variável: insertcatyear_i4

Intervalo permitido: 1920 - 2017

4.8) O paciente tem histórico de remoção de catéter venoso permanente?

Pergunta Alternativa Seleção Única

Nome da variável: removalcath_i4

Alternativas: (descrição - score)

$$
\begin{aligned}
& \text { 1- Sim - } 1.0 \\
& \text { 2- Não - } 2.0
\end{aligned}
$$

4.8.1) Quantas vezes a cirurgia foi realizada?

Pergunta Alternativa Seleção Única

Nome da variável: removcatn_i4

Alternativas: (descrição - score)

$$
1 \mathrm{vez}-1.0
$$

Mais de $1 \mathrm{vez}-2.0$

4.8.2) Alguma das cirurgias de remoção de catéter venoso permanente necessitou de transfusão?

Pergunta Alternativa Seleção Única

Nome da variável: removcattransf_i4

Alternativas: (descrição - score)

1- Sim - 1.0

2- Não - 2.0 


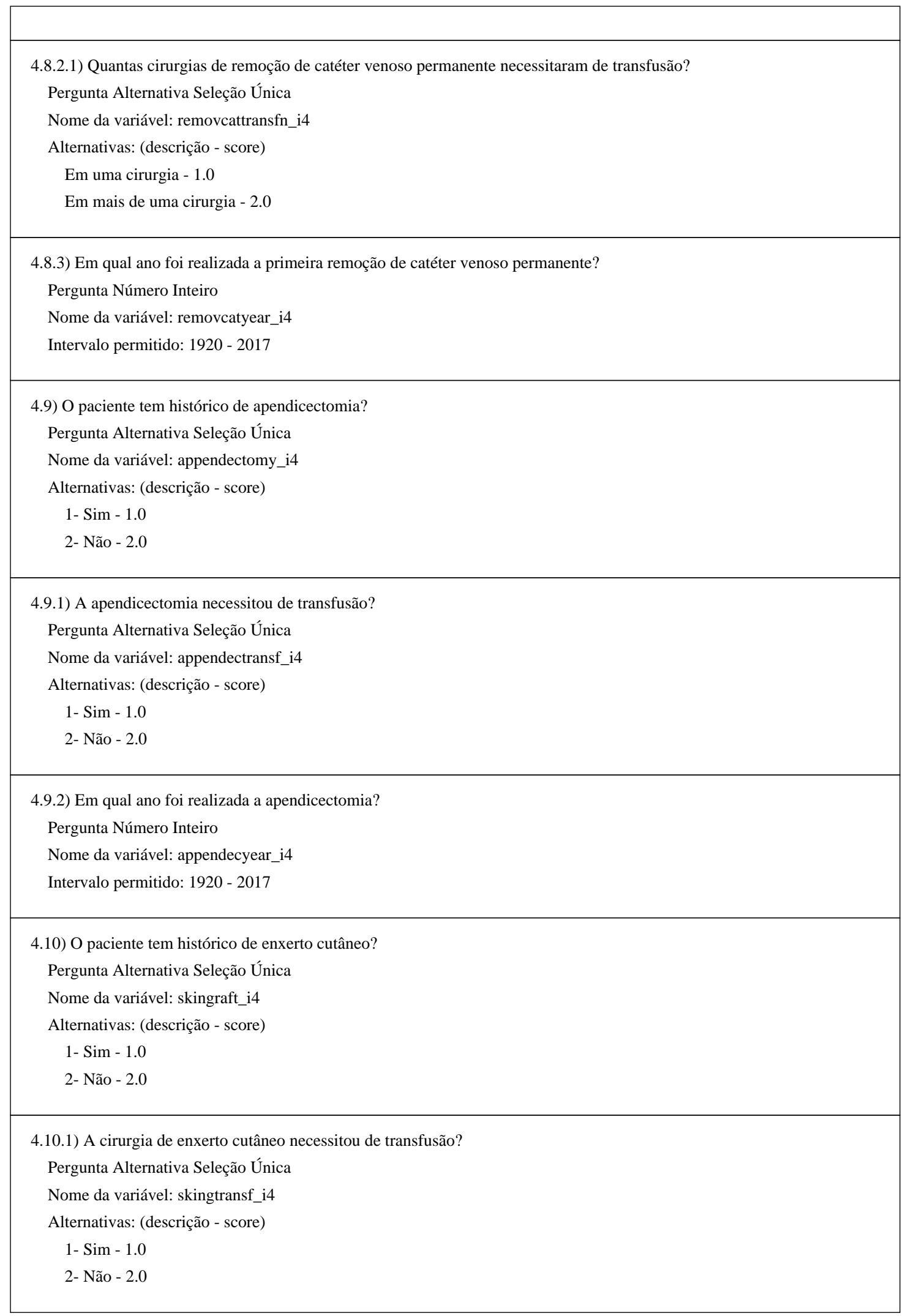




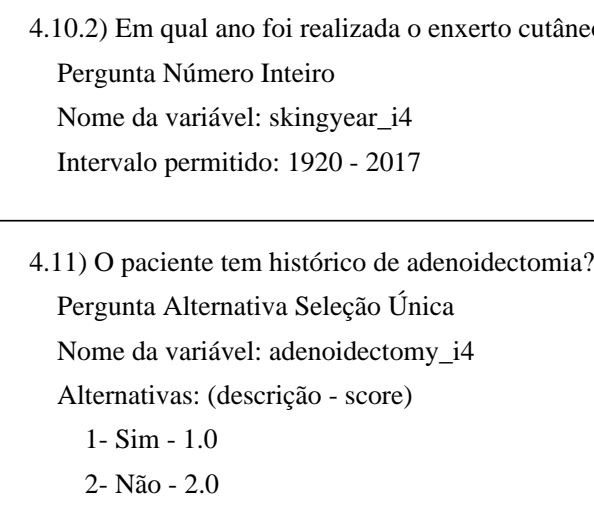

4.11.1) Quantas vezes a cirurgia de adenoidectomia foi realizada? Pergunta Alternativa Seleção Única

Nome da variável: adenoidecn_i4

Alternativas: (descrição - score)

$1 \mathrm{vez}-1.0$

Mais de 1 vez - 2.0

4.11.2) Alguma das adenoidectomia(s) necessitou de transfusão?

Pergunta Alternativa Seleção Única

Nome da variável: adenoidectransf_i4

Alternativas: (descrição - score)

1- Sim - 1.0

2- Não - 2.0

4.11.2.1) Quantas adenoidectomias necessitaram de transfusão?

Pergunta Alternativa Seleção Única

Nome da variável: adenoidectransfn_i4

Alternativas: (descrição - score)

Em uma cirurgia - 1.0

Em mais de uma cirurgia - 2.0

4.11.3) Em qual ano foi realizada a primeira adenoidectomia?

Pergunta Número Inteiro

Nome da variável: adenoidecyear_i4

Intervalo permitido: 1920 - 2017

4.12) O paciente foi submetido a outras cirurgias?

Pergunta Alternativa Seleção Única

Nome da variável: othsurg_i4

Alternativas: (descrição - score)
1- Sim - 1.0
2- Não - 2.0 
Planilha: Outras cirurgias

Itens: (Descrição - Nome da variável)

Outras cirurgias - othsurg

4.12.2) Especifique qual outra cirurgia:

Pergunta Texto

Nome da variável:_spec_i4

Número máximo de caracteres permitido: 100

4.12.3) Em qual ano foi realizada a outra cirurgia?

Pergunta Número Inteiro

Nome da variável: year i

Intervalo permitido: $1920-2017$

4.12.4) Esta outra cirurgia necessitou de transfusão?

Pergunta Alternativa Seleção Única

Nome da variável:_transf_i4

Alternativas: (descrição - score)

1 - Sim - 1.0

2- Não - 2.0

\section{Módulo: 5- Transplantes de Medula Óssea}

5.1) O paciente ALGUMA VEZ NA VIDA recebeu transplante de Medula Óssea?

Pergunta Alternativa Seleção Única

Nome da variável: stcell_i5

Alternativas: (descrição - score)

1- Sim - 1.0

2- Não - 2.0

5.2) Quantos transplantes de medula óssea?

Pergunta Número Inteiro

Nome da variável: $n \_s t c e l l \_i 5$

Intervalo permitido: 1 - 20

Planilha: Questões relacionadas ao transplante de medula óssea

Itens: (Descrição - Nome da variável)

Transplante de medula óssea - stcell

5.3) Data do transplante de medula óssea:

Pergunta Data

Nome da variável: date i5

Intervalo permitido: 01/01/1970 - 31/12/2017

5.4) Indicações para o transplante de medula óssea: (marque todas as opções que se aplicam)

Pergunta Alternativa Seleção Múltipla

Nome da variável:_ind_i5

Alternativas: (descrição - nome da variável - score)

Doppler transcraniano anormal - doppler i5 - 1.0

Historia de acidente vascular cerebral - stroke i5 - 2.0

Dor recorrente grave - _pain_i5 - 3.0

Síndrome torácica aguda recorrente - _acchest_i5 - 4.0

Outra - othind i5 - 100.0

5.4.1) Especifique outra indicação:

Pergunta Texto

Nome da variável:_specothind_i5

Número máximo de caracteres permitido: 100 
5.5) Instituição em que ocorreu o transplante:

Pergunta Texto

Nome da variável:_inst_i5

Número máximo de caracteres permitido: 100

5.6) Tipo de doador:

Pergunta Alternativa Seleção Única

Nome da variável:_dontype_i5

Alternativas: (descrição - score)

Irmão biológico - 1.0

Outro membro da família (não irmão) - 2.0

Sem relação de consanguinidade - 3.0

5.7) Tipo de doador HLA:

Pergunta Alternativa Seleção Única

Nome da variável:_donhla_i5

Alternativas: (descrição - score)

HLA compatível - 1.0

HLA incompatível - 2.0

5.8) Fonte de células-tronco:

Pergunta Alternativa Seleção Única

Nome da variável:_sour_i5

Alternativas: (descrição - score)

Medula óssea - 1.0

Sangue periférico - 2.0

Sangue do cordão umbilical - 3.0

\section{Módulo: 6- Medicamentos}

6.0) O paciente fez uso de algum medicamento nos últimos 12 meses?

Pergunta Alternativa Seleção Única

Nome da variável: medic_lastyear_i6

Alternativas: (descrição - score)

1- Sim - 1.0

2- Não - 2.0

6.1) Selecione todos os medicamentos usados pelo paciente NOS ÚLTIMOS 12 MESES: (marque todas as opções que se aplicam)

Pergunta Alternativa Seleção Múltipla

Nome da variável: medications_i6

Alternativas: (descrição - nome da variável - score)

Algum antibiótico profilático regularmente - prophyla_antib_i6 - 1.0

Analgésicos por 30 dias seguidos ou mais - analgesics_30d_i6 - 2.0

Anticonvulsivantes para crises convulsivas - antconv_seizures_i6 - 3.0

Anticonvulsivantes para dores neuropáticas - antconv_neuropat_i6 - 4.0

Antidepressivos - antidepressants_i6 - 5.0

Anti-hipertensivo - antihipert_i6 - 6.0

Bronco dilatador inalável - inhaledbroncdil_i6 - 7.0

Deferasirox - deferasirox_i6 - 8.0

Deferiprona - deferiprone_i6 - 9.0

Desferoxamina - desferoxamine_i6 - 10.0

Eritropoietina - erythropoietin_i6 - 11.0

Hidroxiuréia - hydroxyurea_i6 - 12.0

IECA - Inibidor da Enzima catalizadora da angiotensina - aceinhibitor_i6 - 13.0 
Oxigênio domiciliar - oxygen_home_i6 - 14.0

Varfarina - warfarin_i6 - 15.0

Vitamina D - dvitamin_i6 - 16.0

Outro(s) medicamento(s) - othermedic_i6 - 1000.0

6.1.1) Especifique qual(is) o(s) outro(s) medicamentos (favor separar os medicamentos por ";")

Pergunta Texto

Nome da variável: specothemed_i6

Número máximo de caracteres permitido: 200

\section{Módulo: 7- Testes de diagnóstico}

7.1) A doença falciforme do paciente foi detectada através de triagem neonatal/teste do pezinho?

Pergunta Alternativa Seleção Única

Nome da variável: newborn_diag_i7

Alternativas: (descrição - score)

1- Sim - 1.0

2- Não - 2.0

7.2) O paciente realizou exame doppler transcraniano nos últimos 12 meses?

Pergunta Alternativa Seleção Única

Nome da variável: tcd_i7

Alternativas: (descrição - score)

1- Sim - 1.0

2- Não - 2.0

Planilha: Questões relacionadas ao doppler transcraniano

Itens: (Descrição - Nome da variável)

Doppler transcraniano - tcd

7.2.1) Data do doppler transcraniano:

Pergunta Data

Nome da variável:_date_i7

Intervalo permitido: $01 / 01 / 2011-31 / 12 / 2017$

7.2.2) Resultado: Artéria cerebral média esquerda: (Caso a leitura do aparelho tenha sido inadequada, responda esta questão com o valor "0")

Pergunta Número Inteiro

Nome da variável:_resleftart_i7

Intervalo permitido: $0-400$

7.2.3) Resultado: Artéria cerebral média direita: (Caso a leitura do aparelho tenha sido inadequada, responda esta questão com o valor "0")

Pergunta Número Inteiro

Nome da variável:_resrigart_i7

Intervalo permitido: 0 - 400

7.2.4) Resultado: Distal da carótida interna esquerda: (Caso a leitura do aparelho tenha sido inadequada, responda esta questão com o valor "0")

Pergunta Número Inteiro

Nome da variável: resleftcarot_i7

Intervalo permitido: 0 - 400 
7.2.5) Resultado: Distal da carótida interna direita: (Caso a leitura do aparelho tenha sido inadequada, responda esta questão com o valor "0")

Pergunta Número Inteiro

Nome da variável:_resrigcarot_i7

Intervalo permitido: 0 - 400

7.3) O paciente realizou exame ressonância magnética craniana ou tomografia computadorizada nos últimos 12 meses? Pergunta Alternativa Seleção Única

Nome da variável: cranialmri_i7

Alternativas: (descrição - score)

1- Sim - 1.0

2- Não - 2.0

7.3.1) Data do exame de ressonância craniana

\section{Pergunta Data}

Nome da variável: cranialmri_date_i7

Intervalo permitido: 01/01/2011 - 31/12/2017

7.3.2) Resultado do exame de ressonância craniana

Pergunta Alternativa Seleção Única

Nome da variável: cranialmri_result_i7

Alternativas: (descrição - score)

Dentro da normalidade - 1.0

Alterado - 2.0

Inconclusivo - 3.0

7.3.2.1) Se o resultado do exame de ressonância craniana for alterado, descreva o resultado:

Pergunta Texto

Nome da variável: cranialmri_abnormal_i7

Número máximo de caracteres permitido: 200

7.4) O paciente realizou exame de ecocardiograma nos últimos 12 meses?

Pergunta Alternativa Seleção Única

Nome da variável: echo_i7

Alternativas: (descrição - score)

1- Sim -1.0

2- Não - 2.0

7.4.1) Data do exame de ecocardiograma:

Pergunta Data

Nome da variável: echo_date_i7

Intervalo permitido: 01/01/2011 - 31/12/2017

7.4.2) Resultado do exame de ecocardiograma:

Pergunta Alternativa Seleção Múltipla

Nome da variável: echo_result_i7

Alternativas: (descrição - nome da variável - score)

Normal - normal_i7 - 1.0 
Estenose mitral - mitstenos_i7 - 2.0

Regurgitação mitral - mitregurg_i7 - 3.0

Estenose tricúspide - tricustenos_i7 - 4.0

Insuficiência tricúspide - tricusregurg_i7 - 5.0

Estenose aórtica - aorticstenos_i7 - 6.0

Regurgitação aórtica - aorticregurg_i7 - 7.0

Estenose pulmonar - pulmstenos_i7 - 8.0

Regurgitação pulmonar - pulmregurg_i7 - 9.0

Outro - other_i7 - 100.0

7.4.2.1) Se outro, especifique:

Pergunta Texto

Nome da variável: specothecho_result_i7

Número máximo de caracteres permitido: 200

7.4.2.2) Registre a velocidade do jato da tricúspide:

Pergunta Número Decimal

Nome da variável: echo_tricuspid_i7

Intervalo permitido: 1.0 - 5.0

7.4.2.3) Registre a fração de ejeção do ventrículo esquerdo:

Pergunta Número Decimal

Nome da variável: echo_leflvent_i7

Intervalo permitido: $0.0-100.0$

7.4.2.4) Registre o resultado da pressão da artéria pulmonar

Pergunta Número Decimal

Nome da variável: pulmart_result_i7

Intervalo permitido: 4.0 - 99.0

7.5) O paciente realizou teste de função pulmonar nos últimos 12 meses?

Pergunta Alternativa Seleção Única

Nome da variável: lungtest_i7

Alternativas: (descrição - score)

1- Sim - 1.0

2- Não - 2.0

7.5.1) Data do teste de função pulmonar:

Pergunta Data

Nome da variável: lungtest_date_i7

Intervalo permitido: 01/01/2011 - 31/12/2017

\subsection{2) Resultado do teste de função pulmonar:}

Pergunta Alternativa Seleção Única

Nome da variável: lungtest_result_i7

Alternativas: (descrição - score) 
Dentro da normalidade - 1.0

Alterado - 2.0

Inconclusivo - 3.0

7.5.2.1) Se o resultado do teste de função pulmonar for alterado, descreva o resultado:

Pergunta Texto

Nome da variável: lungtest_abnoresult_i7

Número máximo de caracteres permitido: 200

7.6) O paciente realizou urinálise nos últimos 12 meses?

Pergunta Alternativa Seleção Única

Nome da variável: urinalys_i7

Alternativas: (descrição - score)

1- Sim - 1.0

2- Não - 2.0

7.6.1) Data da urinálise:

Pergunta Data

Nome da variável: urinalys_date_i7

Intervalo permitido: 01/01/2011 - 31/12/2017

7.6.2) Resultados da urinálise mais recente:

Pergunta Alternativa Seleção Única

Nome da variável: urinalys_result_i7

Alternativas: (descrição - score)

Microalbuminúria (30-300mg / g de albumina na urina creatinina) - 1.0

Macroalbuminúria (> $300 \mathrm{mg} / \mathrm{g}$ - $2 \mathrm{~g} / \mathrm{g}$ albumina na urina para creatinina) - 2.0

Proteinúria faixa nefrótica (> $2 \mathrm{~g} / \mathrm{g}$ albumina na urina para creatinina) - 3.0

Normal - 4.0

\section{Módulo: 8- Resultados Sorológicos}

8.1) O paciente realizou teste para Súfilis nos últimos 12 meses?

Pergunta Alternativa Seleção Única

Nome da variável: siphylis_i8

Alternativas: (descrição - score)

1- Sim - 1.0

2- Não - 2.0

8.1.1) Elisa para Sífilis:

Pergunta Alternativa Seleção Única

Nome da variável: elisa_i8

Alternativas: (descrição - score)

Positivo - 1.0

Negativo - 2.0 
Indeterminado - 3.0

Não realizado - 4.0

8.1.1.1) Data do Elisa para sífilis:

Pergunta Data

Nome da variável: siphelisa_date_i8

Intervalo permitido: 01/01/2012 - 31/12/2017

8.1.2) VDRL para Sífilis:

Pergunta Alternativa Seleção Única

Nome da variável: vdrl_i8

Alternativas: (descrição - score)

Positivo - 1.0

Negativo - 2.0

Não realizado -3.0

8.1.2.1) Data do VDRL para sífilis:

Pergunta Data

Nome da variável: siphvdrl_date_i8

Intervalo permitido: 01/01/2012 - 31/12/2017

8.2) O paciente realizou teste para Hepatite nos últimos 12 meses?

Pergunta Alternativa Seleção Única

Nome da variável: hepat_i8

Alternativas: (descrição - score)

1- Sim - 1.0

2- Não - 2.0

8.2.1) HBs-Ag (antígeno de superfície do vírus da hepatite B):

Pergunta Alternativa Seleção Única

Nome da variável: hepat_hbsag_i8

Alternativas: (descrição - score)

Positivo - 1.0

Negativo - 2.0

Indeterminado - 3.0

Não realizado - 4.0

8.2.1.1) Data do exame de HBs-Ag

Pergunta Data

Nome da variável: hbsag_date_i8

Intervalo permitido: 01/01/2012 - 31/12/2017

8.2.2) anti-HBs (anticorpo para o antigénio de superfície da hepatite B):

Pergunta Alternativa Seleção Única

Nome da variável: hepat_hbs_i8

Alternativas: (descrição - score) 
Positivo - 1.0

Negativo - 2.0

Indeterminado - 3.0

Não realizado -4.0

\subsubsection{1) Data do exame de anti-HBs}

Pergunta Data

Nome da variável: antihbs_date_i8

Intervalo permitido: 01/01/2012 - 31/12/2017

8.2.3) anti-HBC (anticorpo da hepatite B contra corion):

Pergunta Alternativa Seleção Única

Nome da variável: hepat_hbc_i8

Alternativas: (descrição - score)

Positivo - 1.0

Negativo - 2.0

Indeterminado - 3.0

Não realizado -4.0

\subsubsection{1) Data do exame de anti-HBC}

\section{Pergunta Data}

Nome da variável: antihbc_date_i8

Intervalo permitido: 01/01/2012 - 31/12/2017

8.2.4) anti-HCV (anticorpo contra o vírus da hepatite C):

Pergunta Alternativa Seleção Única

Nome da variável: hepat_hcv_i8

Alternativas: (descrição - score)

Positivo - 1.0

Negativo - 2.0

Indeterminado - 3.0

Não realizado - 4.0

\subsubsection{1) Data do exame de anti-HCV}

Pergunta Data

Nome da variável: antihcv_date_i8

Intervalo permitido: 01/01/2012 - 31/12/2017

\subsection{5) NAT HCV}

Pergunta Alternativa Seleção Única

Nome da variável: hepat_nathcv_i8

Alternativas: (descrição - score)

Positivo - 1.0

Negativo - 2.0

Indeterminado - 3.0

Não realizado - 4.0 


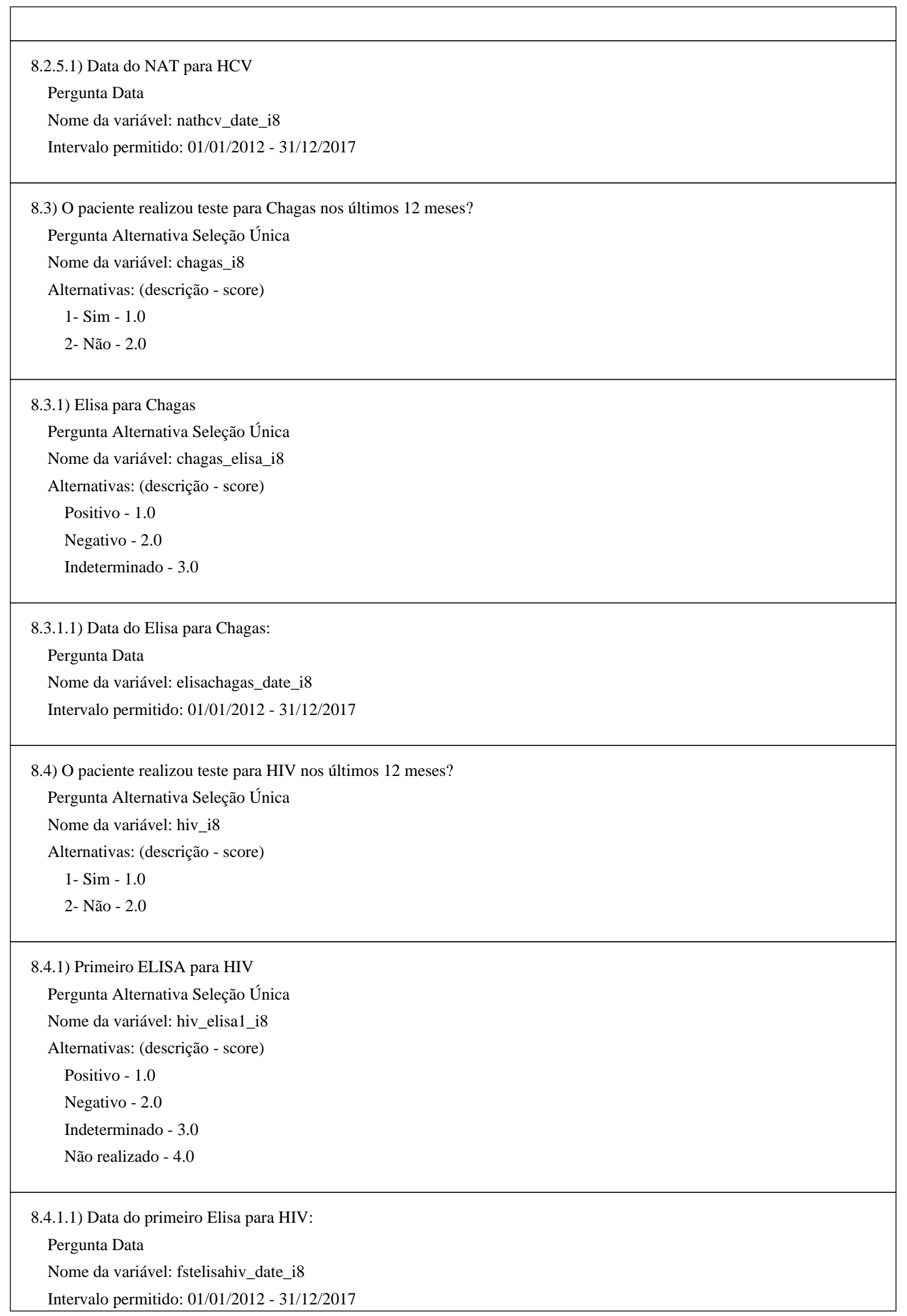




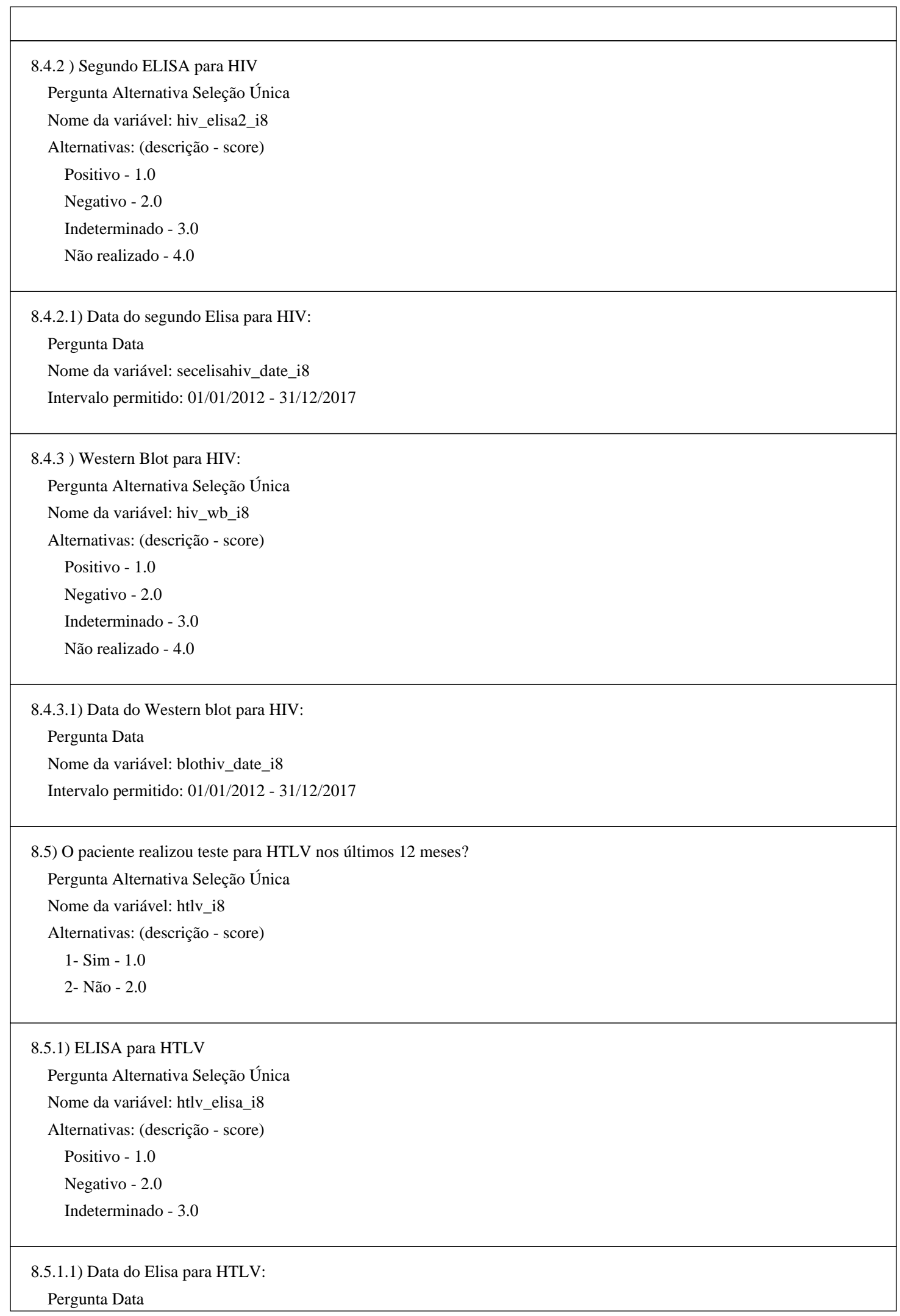




\begin{tabular}{|l|}
\hline Nome da variável: elisahtlv_date_i8 \\
Intervalo permitido: 01/01/2012 - 31/12/2017 \\
\hline 8.5.2) Western Blot para HTLV: \\
Pergunta Alternativa Seleção Única \\
Nome da variável: htlv_wb_i8 \\
Alternativas: (descrição - score) \\
$\quad$ Positivo - 1.0 \\
$\quad$ Negativo - 2.0 \\
Indeterminado - 3.0 \\
Não realizado - 4.0 \\
\hline 8.5.2.1) Western Blot HTLV positivo para: \\
Pergunta Alternativa Seleção Única \\
Nome da variável: htlv_wbtype_i8 \\
Alternativas: (descrição - score) \\
HTLV I - 1.0 \\
HTLV II - 2.0 \\
HTLV I / II - 3.0 \\
HTLV não tipado - 4.0 \\
Intervalo permitido: $01 / 01 / 2012$ - $31 / 12 / 2017$ \\
Pergunta Data
\end{tabular}

\section{Módulo: 9- Exames Laboratoriais}

9) O paciente possui exames laboratoriais realizados nos últimos 12 meses que cumprem os critérios citados acima? Pergunta Alternativa Seleção Única

Nome da variável: labs_i9

Alternativas: (descrição - score)
1- Sim - 1.0
2- Não - 2.0

9.1) O paciente realizou Hemograma?

Pergunta Alternativa Seleção Única

Nome da variável: cbc_i9

Alternativas: (descrição - score)
1- Sim - 1.0
2- Não - 2.0

9.1.1) Data do Hemograma:

Pergunta Data

Nome da variável: cbc_date_i9 
Intervalo permitido: 01/01/2011 - 31/12/2017

9.1.2) Resultado de hemoglobina:

Pergunta Número Decimal

Nome da variável: cbc_hbresult_i9

Intervalo permitido: 1.0 - 20.0

9.1.3) Resultado de leucócitos:

Pergunta Número Inteiro

Nome da variável: cbc_leukresult_i9

Intervalo permitido: 1000 - 50000

9.1.4) Resultado de plaquetas:

Pergunta Número Inteiro

Nome da variável: cbc_platresult_i9

Intervalo permitido: 50000 - 999999

9.1.5) No período do Hemograma o paciente estava em uso de Hidroxiureia?

Pergunta Alternativa Seleção Única

Nome da variável: cbc_hydrox_i9

Alternativas: (descrição - score)

1- Sim - 1.0

2- Não - 2.0

9.1.6) No período do Hemograma o paciente estava em tratamento com transfusão crônica? Pergunta Alternativa Seleção Única

Nome da variável: cbc_chrotransf_i9

Alternativas: (descrição - score)

1- Sim - 1.0

2- Não - 2.0

9.2) O paciente realizou exame de reticulócitos (contagem relativa)?

Pergunta Alternativa Seleção Única

Nome da variável: retic_i9

Alternativas: (descrição - score)

1- Sim - 1.0

2- Não - 2.0

9.2.1) Data do exame de reticulócitos:

Pergunta Data

Nome da variável: retic_date_i9

Intervalo permitido: 01/01/2011 - 31/12/2017

9.2.2 ) Resultado de reticulócitos(contagem relativa):

Pergunta Número Decimal

Nome da variável: retic_result_i9 


\begin{tabular}{|c|}
\hline $\begin{array}{l}\text { Nome da variável: retic_result_i9 } \\
\text { Intervalo permitido: } 0.01-100.0\end{array}$ \\
\hline $\begin{array}{l}\text { 9.2.3) No período dos exames o paciente estava em uso de Hidroxiureia? } \\
\text { Pergunta Alternativa Seleção Única } \\
\text { Nome da variável: retic_hydrox_i9 } \\
\text { Alternativas: (descrição - score) } \\
\text { 1- Sim - } 1.0 \\
\text { 2- Não - } 2.0\end{array}$ \\
\hline $\begin{array}{l}\text { 9.2.4) No período dos exames o paciente estava em tratamento com transfusão crônica? } \\
\text { Pergunta Alternativa Seleção Única } \\
\text { Nome da variável: retic_chrotransf_i9 } \\
\text { Alternativas: (descrição - score) } \\
\text { 1- Sim - } 1.0 \\
\text { 2- Não - } 2.0\end{array}$ \\
\hline $\begin{array}{l}\text { 9.3) O paciente realizou exame de hemoglobina F? } \\
\text { Pergunta Alternativa Seleção Única } \\
\text { Nome da variável: hbf_i9 } \\
\text { Alternativas: (descrição - score) } \\
\text { 1- Sim - } 1.0 \\
\text { 2- Não - } 2.0\end{array}$ \\
\hline $\begin{array}{l}\text { 9.3.1) Data do exame de hemoglobina F: } \\
\text { Pergunta Data } \\
\text { Nome da variável: hbf_date_i9 } \\
\text { Intervalo permitido: 01/01/2011 - 31/12/2017 }\end{array}$ \\
\hline $\begin{array}{l}\text { 9.3.2) Resultado de hemoglobina F: } \\
\text { Pergunta Número Decimal } \\
\text { Nome da variável: hbf_result_i9 } \\
\text { Intervalo permitido: } 0.01 \text { - } 100.0\end{array}$ \\
\hline $\begin{array}{l}\text { 9.3.3) No período dos exames o paciente estava em uso de Hidroxiureia? } \\
\text { Pergunta Alternativa Seleção Única } \\
\text { Nome da variável: hbf_hydrox_i9 } \\
\text { Alternativas: (descrição - score) } \\
\text { 1- Sim - } 1.0 \\
\text { 2- Não - } 2.0\end{array}$ \\
\hline $\begin{array}{l}\text { 9.3.4) No período dos exames o paciente estava em tratamento com transfusão crônica? } \\
\text { Pergunta Alternativa Seleção Única } \\
\text { Nome da variável: hbf_chrotransf_i9 } \\
\text { Alternativas: (descrição - score) } \\
\text { 1- Sim - } 1.0\end{array}$ \\
\hline
\end{tabular}


2- Não - 2.0

9.4) O paciente realizou exame de desidrogenase láctica?

Pergunta Alternativa Seleção Única

Nome da variável: ldh_i9

Alternativas: (descrição - score)

1- Sim - 1.0

2- Não - 2.0

9.4.1) Data do exame de desidrogenase láctica:

Pergunta Data

Nome da variável: ldh_date_i9

Intervalo permitido: 01/01/2011 - 31/12/2017

9.4.2) Resultado de desidrogenase láctica:

Pergunta Número Inteiro

Nome da variável: ldh_result_i9

Intervalo permitido: 0 - 9000

9.4.3) No período dos exames o paciente estava em uso de Hidroxiureia?

Pergunta Alternativa Seleção Única

Nome da variável: 1dh_hydrox_i9

Alternativas: (descrição - score)

1- Sim - 1.0

2- Não - 2.0

9.4.4) No período dos exames o paciente estava em tratamento com transfusão crônica?

Pergunta Alternativa Seleção Única

Nome da variável: ldh_chrotransf_i9

Alternativas: (descrição - score)

1- Sim - 1.0

2- Não - 2.0

9.5) O paciente realizou exame de creatinina?

Pergunta Alternativa Seleção Única

Nome da variável: creatin_i9

Alternativas: (descrição - score)

1- Sim - 1.0

2- Não - 2.0

9.5.1) Data do exame de creatinina:

Pergunta Data

Nome da variável: creatin_date_i9

Intervalo permitido: 01/01/2011 - 31/12/2017 


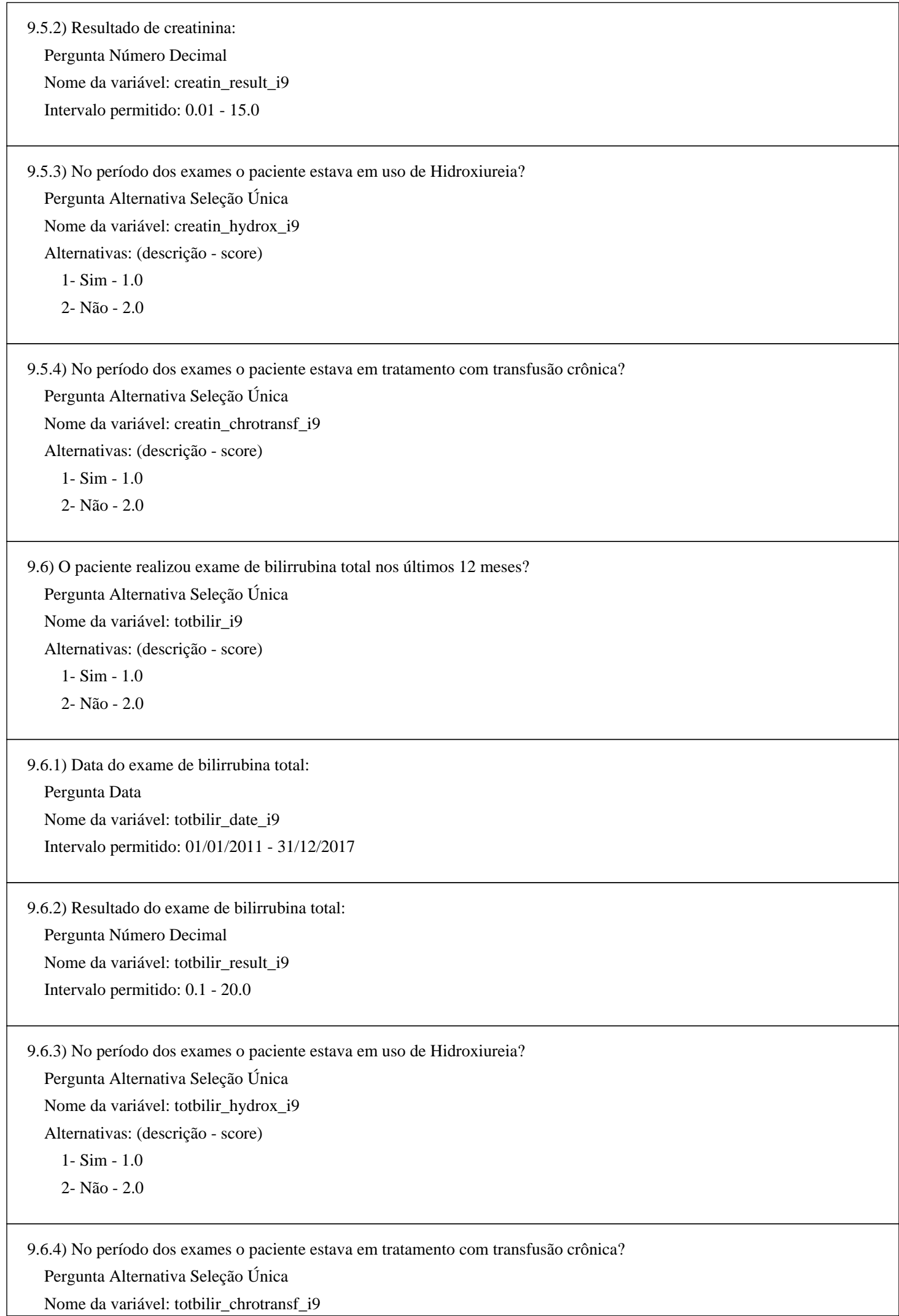




\begin{tabular}{|c|}
\hline $\begin{array}{l}\text { Alternativas: (descrição - score) } \\
\text { 1- Sim - } 1.0 \\
\text { 2- Não - } 2.0\end{array}$ \\
\hline $\begin{array}{l}\text { 9.7) O paciente realizou exame de bilirrubina direta nos últimos } 12 \text { meses? } \\
\text { Pergunta Alternativa Seleção Única } \\
\text { Nome da variável: dirbilir_i9 } \\
\text { Alternativas: (descrição - score) } \\
\text { 1- Sim - } 1.0 \\
\text { 2- Não - } 2.0\end{array}$ \\
\hline $\begin{array}{l}\text { 9.7.1) Data do exame de bilirrubina direta: } \\
\text { Pergunta Data } \\
\text { Nome da variável: dirbilir_date_i9 } \\
\text { Intervalo permitido: 01/01/2011 - 31/12/2017 }\end{array}$ \\
\hline $\begin{array}{l}\text { 9.7.2) Resultado do exame de bilirrubina direta: } \\
\text { Pergunta Número Decimal } \\
\text { Nome da variável: dirbilir_result_i9 } \\
\text { Intervalo permitido: } 0.01 \text { - } 99.0\end{array}$ \\
\hline $\begin{array}{l}\text { 9.7.3) No período dos exames o paciente estava em uso de Hidroxiureia? } \\
\text { Pergunta Alternativa Seleção Única } \\
\text { Nome da variável: dirbilir_hydrox_i9 } \\
\text { Alternativas: (descrição - score) } \\
\text { 1-Sim - } 1.0 \\
\text { 2- Não - } 2.0\end{array}$ \\
\hline $\begin{array}{l}\text { 9.7.4) No período dos exames o paciente estava em tratamento com transfusão crônica? } \\
\text { Pergunta Alternativa Seleção Única } \\
\text { Nome da variável: dirbilir_chrotransf_i9 } \\
\text { Alternativas: (descrição - score) } \\
\text { 1- Sim - } 1.0 \\
\text { 2- Não - } 2.0\end{array}$ \\
\hline
\end{tabular}

\section{Módulo: 10- Status de Ferro}

10) Foi realizado exame para medir o status de ferro nos últimos 12 meses?

Pergunta Alternativa Seleção Única

Nome da variável: iron_status_i10

Alternativas: (descrição - score)

$$
1 \text { - Sim - } 1.0
$$

2- Não - 2.0 


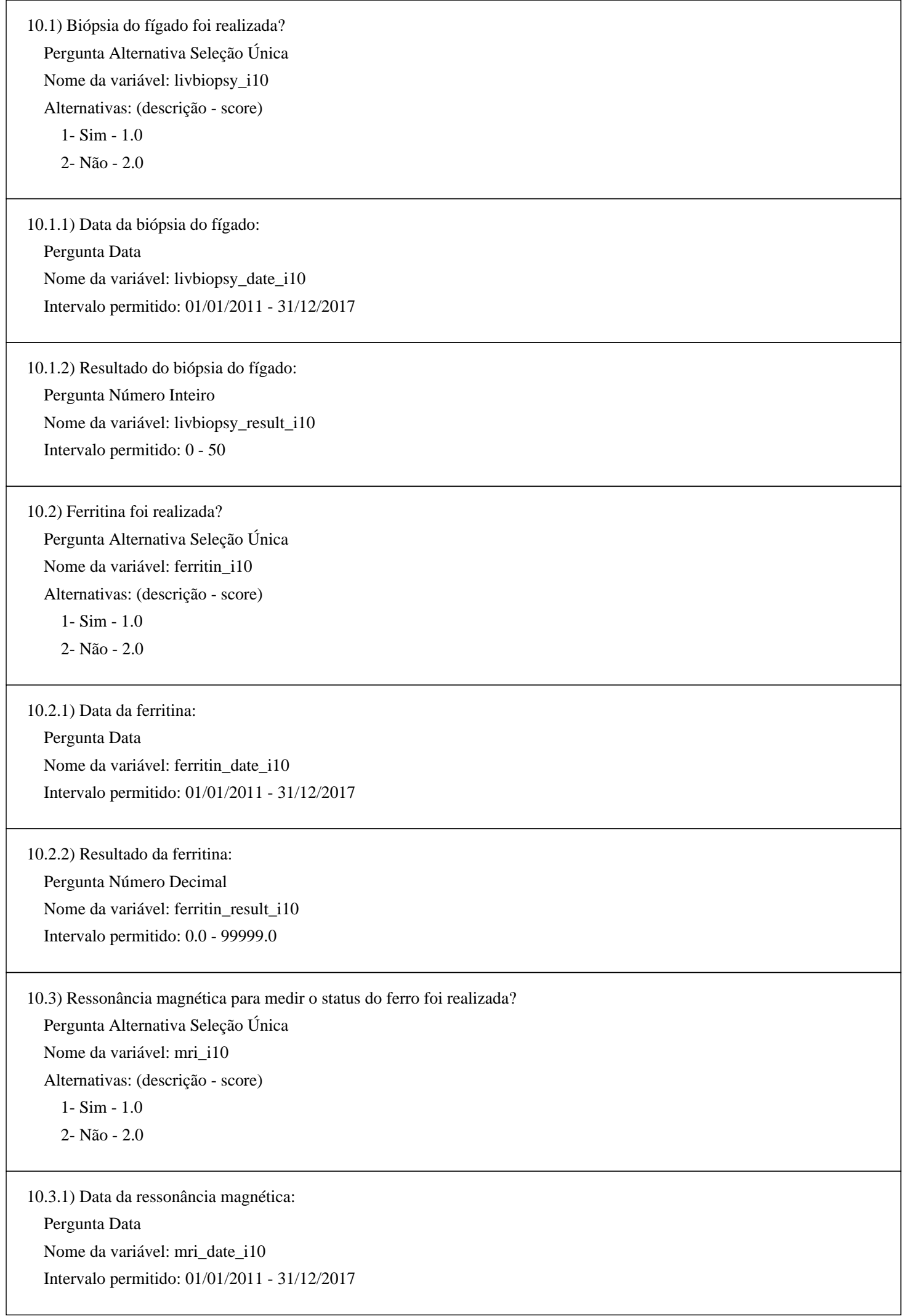




\begin{tabular}{|c|}
\hline $\begin{array}{l}\text { 10.3.2) Resultado ressonância magnética ferro hepático: } \\
\text { Pergunta Número Decimal } \\
\text { Nome da variável: mri_liviresult_i10 } \\
\text { Intervalo permitido: } 0.0 \text { - } 50.0\end{array}$ \\
\hline $\begin{array}{l}\text { 10.3.3) Resultado ressonância magnética ferro cardíaco: } \\
\text { Pergunta Número Decimal } \\
\text { Nome da variável: mri_heartresult_i10 } \\
\text { Intervalo permitido: } 0.0 \text { - } 100.0\end{array}$ \\
\hline $\begin{array}{l}\text { 10.4) Índice de saturação de transferrina foi realizada? } \\
\text { Pergunta Alternativa Seleção Única } \\
\text { Nome da variável: transferrin_i10 } \\
\text { Alternativas: (descrição - score) } \\
\text { 1-Sim - } 1.0 \\
\text { 2- Não - } 2.0\end{array}$ \\
\hline $\begin{array}{l}\text { 10.4.1) Data do índice de saturação de transferrina: } \\
\text { Pergunta Data } \\
\text { Nome da variável: transferrin_date_i10 } \\
\text { Intervalo permitido: 01/01/2011 - 31/12/2017 }\end{array}$ \\
\hline $\begin{array}{l}\text { 10.4.2) Resultado do índice de saturação de transferrina: } \\
\text { Pergunta Número Decimal } \\
\text { Nome da variável: transferrin_result_i10 } \\
\text { Intervalo permitido: } 0.0-100.0\end{array}$ \\
\hline
\end{tabular}

\section{Módulo: 11- Dados imuno-hematológicos do paciente}

11) Os dados imunológicos deste paciente podem ser extraídos do sistema eletrônico do hemocentro? Pergunta Alternativa Seleção Única

Nome da variável: immuno_extrac_i11

Alternativas: (descrição - score)

1- Sim - 1.0

2- Não - 2.0

11.1) Qual o grupo sanguíneo do paciente?

Pergunta Alternativa Seleção Única

Nome da variável: pat_bloodgp_i11

Alternativas: (descrição - score)
$\mathrm{O}+-1.0$
$\mathrm{A}+-2.0$
$\mathrm{B}+-3.0$
O- -4.0
A- - 5.0 
B- -6.0

$\mathrm{AB}+-7.0$

AB- -8.0

11.2) Foi realizado fenótipo do paciente?

Pergunta Alternativa Seleção Única

Nome da variável: pat_phenot_i11

Alternativas: (descrição - score)

1- Sim - 1.0

2- Não - 2.0

11.2.1) Qual o tipo do teste?

Pergunta Alternativa Seleção Única

Nome da variável: pat_typetest_i11

Alternativas: (descrição - score)

Sorológico - 1.0

Genético - 2.0

11.2.2) Sistema Rh Antígenos $C$

Pergunta Alternativa Seleção Única

Nome da variável: pat_rhcupp_i11

Alternativas: (descrição - score)

Positivo - 1.0

Negativo - 2.0

Não realizado - 3.0

11.2.3) Sistema $\mathrm{Rh}$ Antígenos c

Pergunta Alternativa Seleção Única

Nome da variável: pat_rhclow_i11

Alternativas: (descrição - score)

Positivo - 1.0

Negativo - 2.0

Não realizado - 3.0

11.2.4) Sistema Rh Antígenos E

Pergunta Alternativa Seleção Única

Nome da variável: pat_rheupp_i11

Alternativas: (descrição - score)

Positivo - 1.0

Negativo -2.0

Não realizado - 3.0

\subsection{5) Sistema Rh Antígenos e}

Pergunta Alternativa Seleção Única

Nome da variável: pat_rhelow_i11

Alternativas: (descrição - score) 
Positivo - 1.0

Negativo - 2.0

Não realizado - 3.0

\subsection{6) Sistema Rh Antígenos Cw}

Pergunta Alternativa Seleção Única

Nome da variável: pat_rhcwupp_i11

Alternativas: (descrição - score)

Positivo - 1.0

Negativo - 2.0

Não realizado - 3.0

\subsection{7) Sistema Kell Antígenos K}

Pergunta Alternativa Seleção Única

Nome da variável: pat_kellkupp_i11

Alternativas: (descrição - score)

Positivo - 1.0

Negativo - 2.0

Não realizado - 3.0

11.2.8) Sistema Kell Antígenos k

Pergunta Alternativa Seleção Única

Nome da variável: pat_kellklow_i11

Alternativas: (descrição - score)

Positivo - 1.0

Negativo - 2.0

Não realizado - 3.0

11.2.9) Sistema Kell Antígenos Kpa

Pergunta Alternativa Seleção Única

Nome da variável: pat_kellkpa_i11

Alternativas: (descrição - score)

Positivo - 1.0

Negativo - 2.0

Não realizado - 3.0

11.2.10) Sistema Kell Antígenos Kpb

Pergunta Alternativa Seleção Única

Nome da variável: pat_kellkpb_i11

Alternativas: (descrição - score)

Positivo - 1.0

Negativo - 2.0

Não realizado - 3.0

11.2.11) Sistema Duffy Antígenos Fya

Pergunta Alternativa Seleção Única 


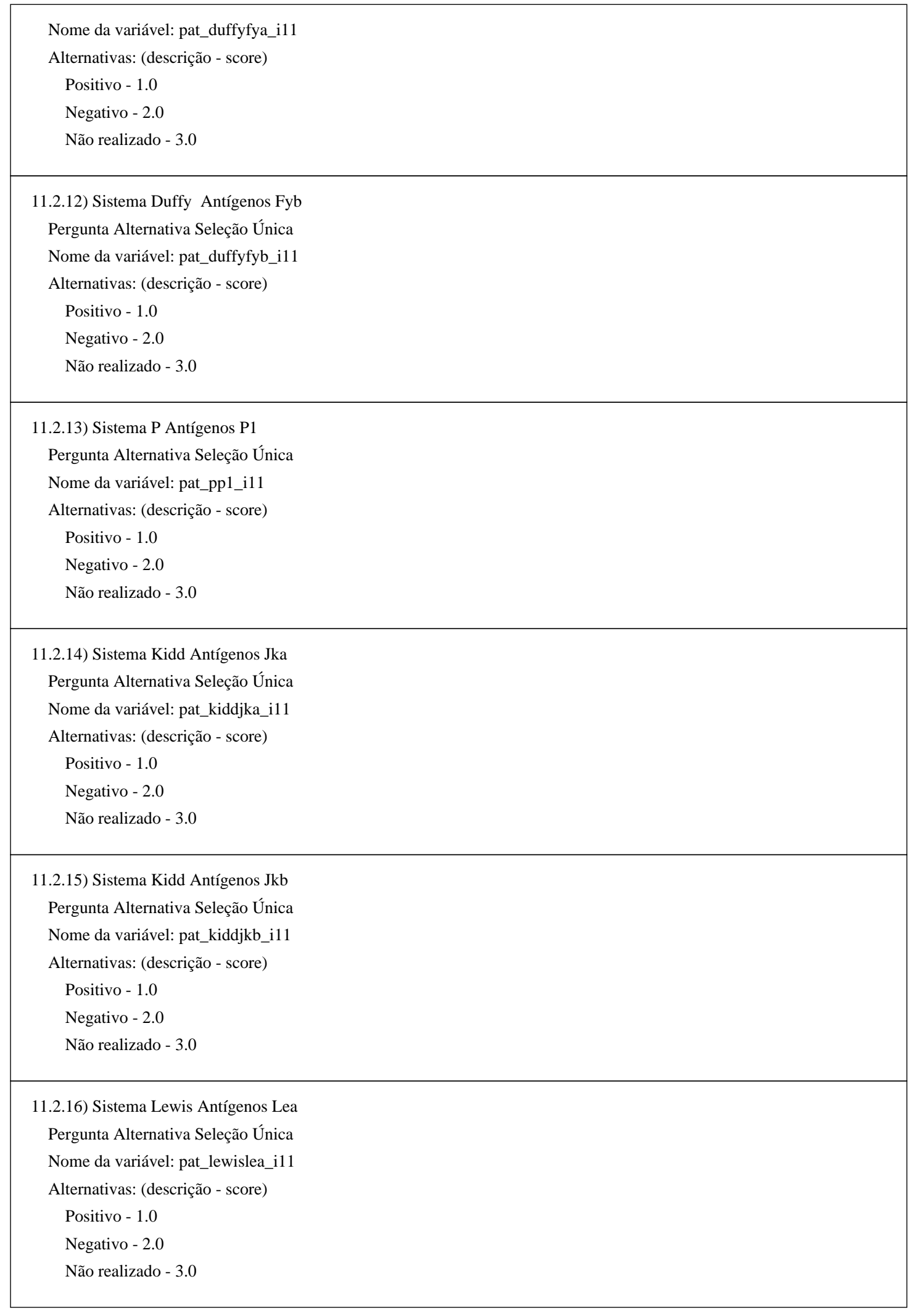


11.2.17) Sistema Lewis Antígenos Leb

Pergunta Alternativa Seleção Única

Nome da variável: pat_lewisleb_i11

Alternativas: (descrição - score)

Positivo - 1.0

Negativo - 2.0

Não realizado - 3.0

\subsubsection{8) Sistema MNS Antígenos M}

Pergunta Alternativa Seleção Única

Nome da variável: pat_mnsmupp_i11

Alternativas: (descrição - score)

Positivo - 1.0

Negativo - 2.0

Não realizado - 3.0

\subsubsection{9) Sistema MNS Antígenos N}

Pergunta Alternativa Seleção Única

Nome da variável: pat_mnsnupp_i11

Alternativas: (descrição - score)

Positivo - 1.0

Negativo - 2.0

Não realizado - 3.0

\subsubsection{0) Sistema MNS Antígenos S}

Pergunta Alternativa Seleção Única

Nome da variável: pat_mnssupp_i11

Alternativas: (descrição - score)

Positivo - 1.0

Negativo - 2.0

Não realizado - 3.0

\subsubsection{1) Sistema MNS Antígenos s}

Pergunta Alternativa Seleção Única

Nome da variável: pat_mnss_i11

Alternativas: (descrição - score)

Positivo - 1.0

Negativo - 2.0

Não realizado - 3.0

\subsubsection{2) Sistema Lutheran Antígenos Lua}

Pergunta Alternativa Seleção Única

Nome da variável: pat_lutheranlua_i11

Alternativas: (descrição - score)

Positivo - 1.0

Negativo - 2.0 
Não realizado - 3.0

11.2.23) Sistema Lutheran Antígenos Lub

Pergunta Alternativa Seleção Única

Nome da variável: pat_lutheranlub_i11

Alternativas: (descrição - score)

Positivo - 1.0

Negativo - 2.0

Não realizado - 3.0

11.2.24) Sistema Diego Antígenos Dia

Pergunta Alternativa Seleção Única

Nome da variável: pat_diegodia_i11

Alternativas: (descrição - score)

Positivo - 1.0

Negativo - 2.0

Não realizado - 3.0

11.2.25) Sistema Diego Antígenos Dib

Pergunta Alternativa Seleção Única

Nome da variável: pat_diegodib_i11

Alternativas: (descrição - score)

Positivo - 1.0

Negativo - 2.0

Não realizado - 3.0

11.3) O paciente alguma vez na vida já teve diagnóstico de anticorpos irregulares?

Pergunta Alternativa Seleção Única

Nome da variável: pat_rbc_i11

Alternativas: (descrição - score)

1- Sim - 1.0

2- Não - 2.0

11.3.1) AC eritrocitários $C$ identificados na P.A.I?

Pergunta Alternativa Seleção Única

Nome da variável: pai_cupp_i11

Alternativas: (descrição - score)

1- Sim - 1.0

2- Não - 2.0

11.3.1.1) Data em que o anticorpo eritrocitário $\mathrm{C}$ foi identificado pela primeira vez:

Pergunta Data

Nome da variável: date_cupp_i11

Intervalo permitido: 01/01/1920 - 31/12/2017 
Pergunta Alternativa Seleção Única

Nome da variável: pai_clow_i11

Alternativas: (descrição - score)

1- Sim - 1.0

2- Não - 2.0

11.3.2.1) Data em que o anticorpo eritrocitário c foi identificado pela primeira vez: Pergunta Data

Nome da variável: date_clow_i11

Intervalo permitido: 01/01/1920 - 31/12/2017

11.3.3) AC eritrocitários D identificados na P.A.I?

Pergunta Alternativa Seleção Única

Nome da variável: pai_dupp_i11

Alternativas: (descrição - score)

1- Sim - 1.0

2- Não - 2.0

11.3.3.1) Data em que o anticorpo eritrocitário D foi identificado pela primeira vez:

Pergunta Data

Nome da variável: date_dupp_i11

Intervalo permitido: 01/01/1920 - 31/12/2017

11.3.4) AC eritrocitários E identificados na P.A.I?

Pergunta Alternativa Seleção Única

Nome da variável: pai_eupp_i11

Alternativas: (descrição - score)

1- Sim - 1.0

2- Não - 2.0

11.3.4.1) Data em que o anticorpo eritrocitário E foi identificado pela primeira vez:

Pergunta Data

Nome da variável: date_eupp_i11

Intervalo permitido: 01/01/1920 - 31/12/2017

11.3.5) AC eritrocitários e identificados na P.A.I?

Pergunta Alternativa Seleção Única

Nome da variável: pai_elow_i11

Alternativas: (descrição - score)

1- Sim -1.0

2- Não - 2.0

11.3.5.1) Data em que o anticorpo eritrocitário e foi identificado pela primeira vez:

Pergunta Data

Nome da variável: date_elow_i11

Intervalo permitido: 01/01/1920 - 31/12/2017 


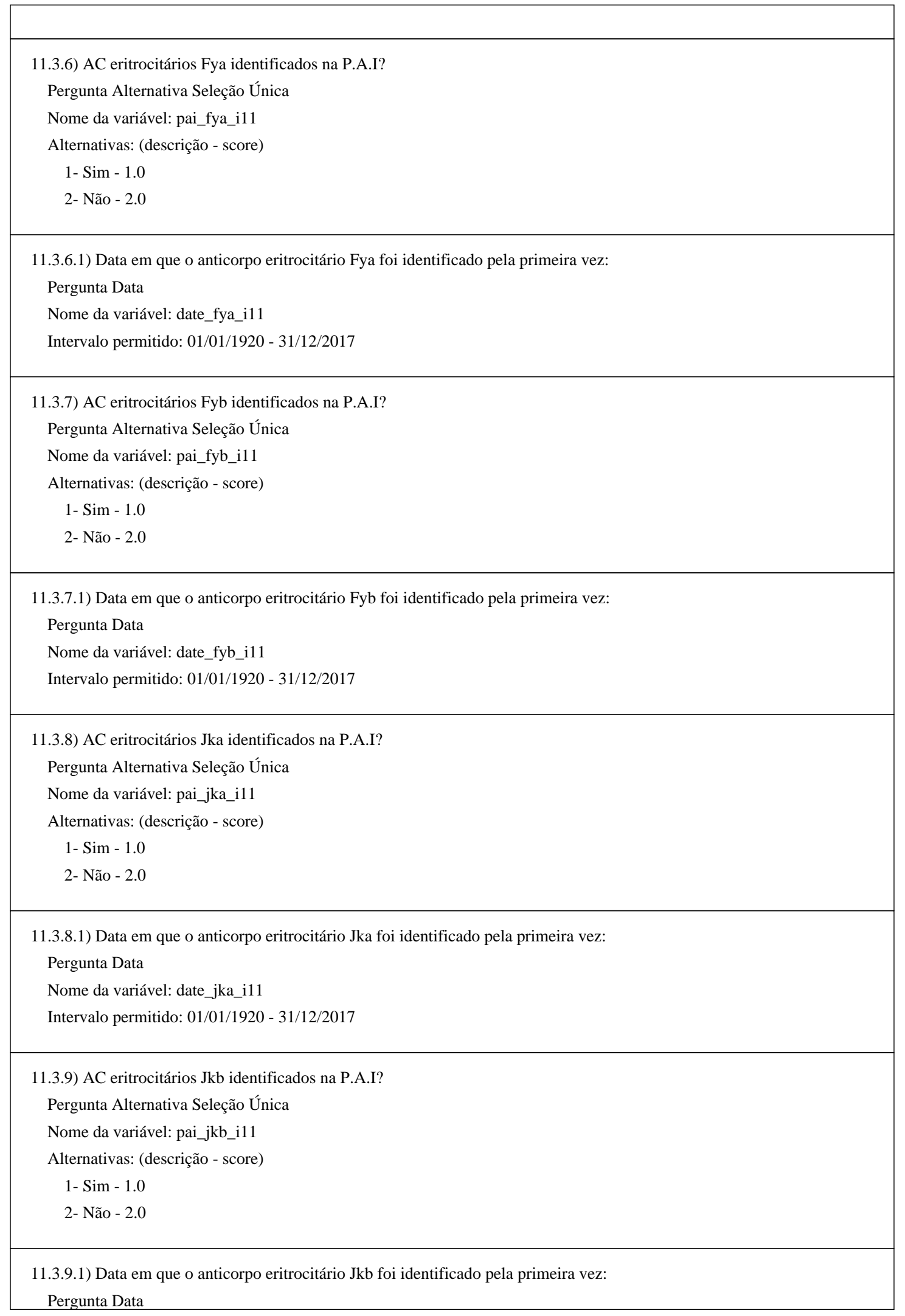


Pergunta Data

Nome da variável: date_jkb_i11

Intervalo permitido: 01/01/1920 - 31/12/2017

11.3.10) AC eritrocitários K identificados na P.A.I?

Pergunta Alternativa Seleção Única

Nome da variável: pai_kupp_i11

Alternativas: (descrição - score)

1- Sim - 1.0

2- Não - 2.0

11.3.10.1) Data em que o anticorpo eritrocitário $\mathrm{K}$ foi identificado pela primeira vez:

Pergunta Data

Nome da variável: date_kupp_i11

Intervalo permitido: 01/01/1920 - 31/12/2017

11.3.11) AC eritrocitários k identificados na P.A.I?

Pergunta Alternativa Seleção Única

Nome da variável: pai_klow_i11

Alternativas: (descrição - score)

1- Sim - 1.0

2- Não - 2.0

11.3.11.1) Data em que o anticorpo eritrocitário k foi identificado pela primeira vez:

Pergunta Data

Nome da variável: date_klow_i11

Intervalo permitido: 01/01/1920 - 31/12/2017

11.3.12) AC eritrocitários M identificados na P.A.I?

Pergunta Alternativa Seleção Única

Nome da variável: pai_mupp_i11

Alternativas: (descrição - score)

1- Sim - 1.0

2- Não - 2.0

11.3.12.1) Data em que o anticorpo eritrocitário M foi identificado pela primeira vez:

Pergunta Data

Nome da variável: date_mupp_i11

Intervalo permitido: 01/01/1920 - 31/12/2017

11.3.13) AC eritrocitários Lea identificados na P.A.I?

Pergunta Alternativa Seleção Única

Nome da variável: pai_lea_i11

Alternativas: (descrição - score)

1- Sim - 1.0

2- Não - 2.0 


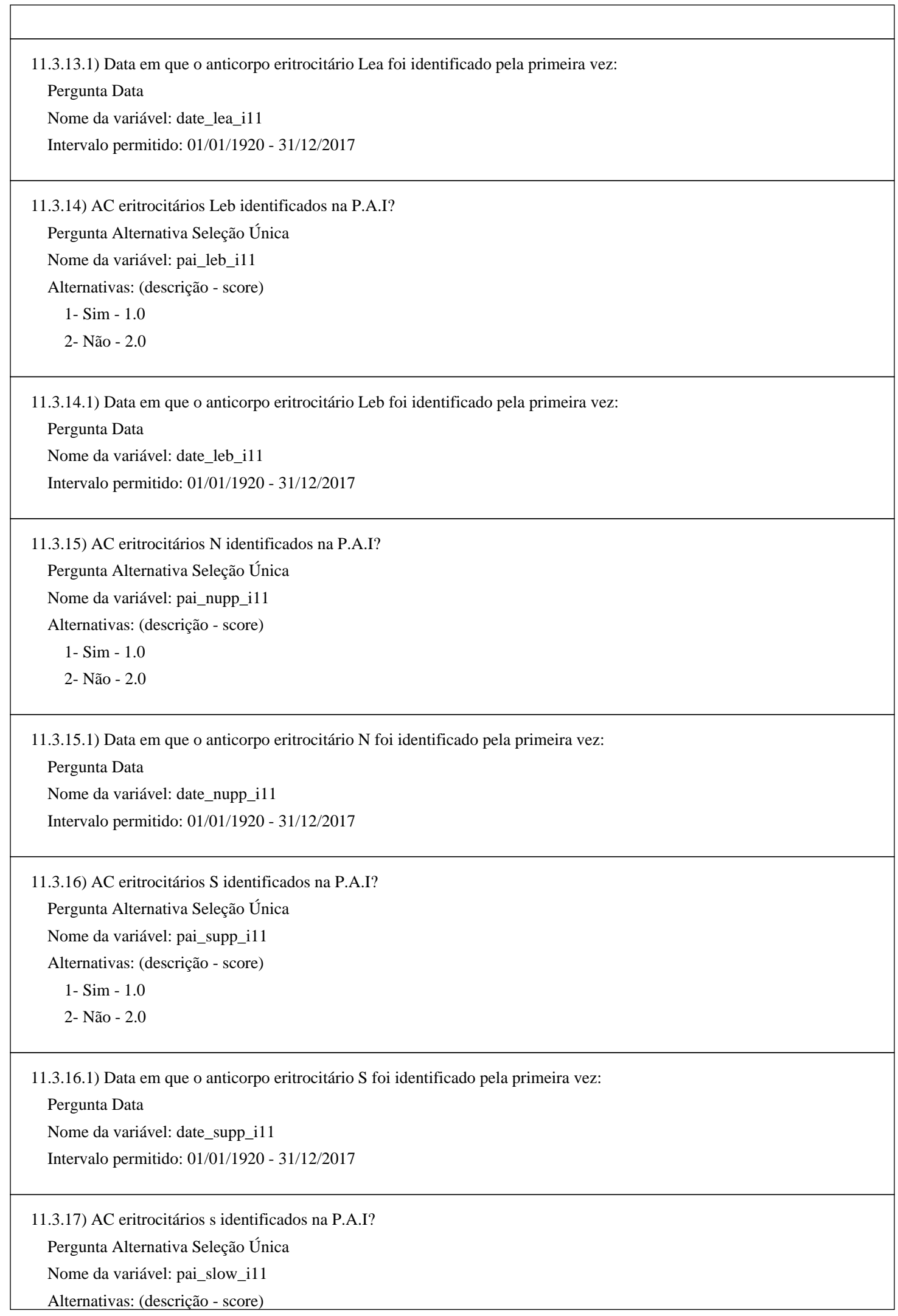




\begin{tabular}{|c|}
\hline $\begin{array}{l}\text { Alternativas: (descrição - score) } \\
\text { 1- Sim - } 1.0 \\
\text { 2- Não - } 2.0\end{array}$ \\
\hline $\begin{array}{l}\text { 11.3.17.1) Data em que o anticorpo eritrocitário s foi identificado pela primeira vez: } \\
\text { Pergunta Data } \\
\text { Nome da variável: date_slow_i11 } \\
\text { Intervalo permitido: } 01 / 01 / 1920 \text { - 31/12/2017 }\end{array}$ \\
\hline $\begin{array}{l}\text { 11.3.18) Auto-anticorpo eritrocitário frio identificados na P.A.I? } \\
\text { Pergunta Alternativa Seleção Única } \\
\text { Nome da variável: pai_cold_i11 } \\
\text { Alternativas: (descrição - score) } \\
\text { 1- Sim - } 1.0 \\
\text { 2- Não - } 2.0\end{array}$ \\
\hline $\begin{array}{l}\text { 11.3.18.1) Data em que o auto-anticorpo eritrocitário frio foi identificado pela primeira vez: } \\
\text { Pergunta Data } \\
\text { Nome da variável: date_cold_i1 } \\
\text { Intervalo permitido: } 01 / 01 / 1920 \text { - 31/12/2017 }\end{array}$ \\
\hline $\begin{array}{l}\text { 11.3.19) Auto-anticorpo eritrocitário quente identificados na P.A.I? } \\
\text { Pergunta Alternativa Seleção Única } \\
\text { Nome da variável: pai_warm_i11 } \\
\text { Alternativas: (descrição - score) } \\
\text { 1- Sim - } 1.0 \\
\text { 2- Não - } 2.0\end{array}$ \\
\hline $\begin{array}{l}\text { 11.3.19.1) Data em que o auto-anticorpo eritrocitário quente foi identificado pela primeira vez: } \\
\text { Pergunta Data } \\
\text { Nome da variável: date_warm_i11 } \\
\text { Intervalo permitido: 01/01/1920 - 31/12/2017 }\end{array}$ \\
\hline $\begin{array}{l}\text { 11.3.20) Outro anticorpo eritrocitário identificados na P.A.I? } \\
\text { Pergunta Alternativa Seleção Única } \\
\text { Nome da variável: pai_other_i11 } \\
\text { Alternativas: (descrição - score) } \\
\text { 1-Sim - } 1.0 \\
\text { 2- Não - } 2.0\end{array}$ \\
\hline $\begin{array}{l}\text { 11.3.20.1) Data em que outro anticorpo eritrocitário foi identificado pela primeira vez: } \\
\text { Pergunta Data } \\
\text { Nome da variável: date_other_i11 } \\
\text { Intervalo permitido: } 01 / 01 / 1920 \text { - 31/12/2017 }\end{array}$ \\
\hline
\end{tabular}


11.3.20.2) Se outro anticorpo eritrocitário foi identificado, especifique:

Pergunta Texto

Nome da variável: specoth_pai_i11

Número máximo de caracteres permitido: 100

\section{Módulo: 12- Transfusão}

12) O paciente já recebeu unidades de sangue em algum momento da sua vida?

Pergunta Alternativa Seleção Única

Nome da variável: transf_life_i12

Alternativas: (descrição - score)

1- Sim - 1.0

2- Não - 2.0

12.1) Quantas unidades foram transfundidas durante toda a vida?

Pergunta Alternativa Seleção Única

Nome da variável: n_transf_i12

Alternativas: (descrição - score)

$$
\begin{aligned}
& 1 \text { a } 5-1.0 \\
& 6 \text { a } 10-2.0 \\
& 11 \text { a } 20-3.0 \\
& 21 \text { a } 40-4.0 \\
& 41 \text { a } 60-5.0 \\
& 61 \text { a } 80-6.0 \\
& 81 \text { a } 100-7.0
\end{aligned}
$$

Mais de $100-8.0$

12.2) Quantos anos o paciente tinha quando fez a primeira transfusão de sangue? Para menores de um ano responda "0" anos. Pergunta Número Inteiro

Nome da variável: age_firstransf_i12

Intervalo permitido: 0 - 99

12.3) O paciente está atualmente em regime de transfusões crônicas?

Pergunta Alternativa Seleção Única

Nome da variável: act_chrtransf_i12

Alternativas: (descrição - score)
1- Sim - 1.0
2- Não - 2.0

12.3.1) Qual a indicação da transfusão crônica atual? (marque todos que se aplicam)

Pergunta Alternativa Seleção Múltipla

Nome da variável: indchtr_i12

Alternativas: (descrição - nome da variável - score)

Doppler transcraniano anormal - chtr_doppler_i12 - 1.0

Historia de acidente vascular cerebral - chtr_stroke_i12 - 2.0 
Dor recorrente grave - chtr_pain_i12 - 0.0

Síndrome torácica aguda recorrente - chtr_acchest_i12 - 3.0

Outra - chtr_othind_i12 - 100.0

12.3.2) Se outra indicação para transfusão crônica atual, especifique:

Pergunta Texto

Nome da variável: specoth_indchr_i12

Número máximo de caracteres permitido: 100

\section{Módulo: 13- Transfusões no último ano}

13) O paciente recebeu unidades de sangue nos últimos 12 meses?

Pergunta Alternativa Seleção Única

Nome da variável: bloodtransf_i13

Alternativas: (descrição - score)

1- Sim - 1.0

2- Não - 2.0

Planilha: Questões relacionadas a transfusões no último ano

Itens: (Descrição - Nome da variável)

Transfusão no último ano - trans

13.2) Data da transfusão:

Pergunta Data

Nome da variável:_date_i13

Intervalo permitido: 01/01/2011 - 31/12/2017

13.3) Quantas unidades foram transfundidas nessa transfusão?

Pergunta Número Inteiro

Nome da variável: $\mathrm{n}$ unitransf_i13

Intervalo permitido: $\overline{1}$ - 99

13.4) Qual a indicação da transfusão?

Pergunta Alternativa Seleção Única

Nome da variável:_ind_i13

Alternativas: (descrição - score)

Síndrome torácica aguda - 1.0

Seqüestro esplênico - 2.0

Crise aplástica - 3.0

Acidente vascular cerebral - 4.0

Falência múltipla dos órgãos - 5.0

Crise de dor / episodio vaso-oclusivo - 6.0

Preparação pré-operatória - 7.0

Anemia aguda sintomática - 8.0

Transfusões crônicas - 9.0

Outra -10.0

13.4.1) Especifique a outra indicação para transfusão:

Pergunta Texto

Nome da variável:_specothind_i13

Número máximo de caracteres permitido: 100

13.5) Qual o tipo de transfusão?

Pergunta Alternativa Seleção Única

Nome da variável: type i13

Alternativas: (descrição - score)

Simples - 1.0

Transfusão de troca automática - 2.0

Transfusão de troca manual - 3.0 
13.6) Houve reações associadas a transfusão? (marque todas opções que se aplicam)

Pergunta Alternativa Seleção Múltipla

Nome da variável:_reactions_i13

Alternativas: (descrição - nome da variável - score)

Sem reação associada - noreaction i14 - 1.0

Reação febril não hemolítica - _fnhtr_i14 - 2.0

Reação Séptica - _septic_i14 - 3.0

Trali - lesão pulmonar aguda relacionada à transfusão - _trali_i14 - 4.0

SCAT - sobrecarga circulatória associada à transfusão - taco_i14 - 5.0

Reação transfusional hemolítica aguda - hemolytic i14 - 6.0

Reação alérgica - _allergic_i14 - 100.0

13.6.1) Tipo de reação alérgica: (marque todas opcoes que se aplicam)

Pergunta Alternativa Seleção Múltipla

Nome da variável: _typeallergic_i13

Alternativas: (descrição - nome da variável - score)

Urticária - urticaria i13 - 1.0

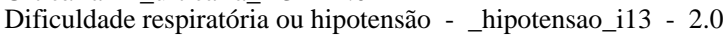

\section{Módulo: 14- Identificação do Número de Unidades Transfundidas no Último Ano}

14) Todos os dados imunológicos da bolsa recebida pelo paciente podem ser extraídos do sistema eletrônico do hemocentro? Pergunta Alternativa Seleção Única

Nome da variável: donimun_extrac_i14

Alternativas: (descrição - score)

1- Sim - 1.0

2- Não - 2.0

3- O paciente não recebeu transfusão nos últimos 12 meses / nunca recebeu transfusão - 3.0

Planilha: Questões sobre dados da bolsa do doador

Itens: (Descrição - Nome da variável)

Unidades transfundidas - unit

14.1) Data da transfusão desta bolsa:

Pergunta Data

Nome da variável: _transf_i14

Intervalo permitido: 01/01/2012 - 31/12/2017

14.2) Identificação da bolsa

Pergunta Texto

Nome da variável:_ident_i14

Número máximo de caracteres permitido: 15

14.3) Código do componente desta bolsa

Pergunta Texto

Nome da variável:_compcode_i14

Número máximo de caracteres permitido: 100

\section{Módulo: 15- História Clinica}

15.0) Data da primeira consulta do paciente neste hemocentro:

Pergunta Data

Nome da variável: date_firstappoint_i15

Intervalo permitido: 01/01/1920 - 31/12/2017

15.1) O paciente tem histórico de transfusão?

Pergunta Alternativa Seleção Única 


\begin{tabular}{|c|}
\hline $\begin{array}{l}\text { Nome da variável: history_transf_i15 } \\
\text { Alternativas: (descrição - score) } \\
\text { 1- Sim - } 1.0 \\
\text { 2- Não - } 2.0\end{array}$ \\
\hline $\begin{array}{l}\text { 15.1.1) O paciente já teve hiperhemólise relacionada à transfusão? } \\
\text { Pergunta Alternativa Seleção Única } \\
\text { Nome da variável: hyperhemol_i15 } \\
\text { Alternativas: (descrição - score) } \\
\text { 1- Sim - } 1.0 \\
\text { 2- Não - } 2.0\end{array}$ \\
\hline $\begin{array}{l}\text { 15.1.1.1) Ano do primeiro diagnóstico de hiperhemólise relacionada à transfusão: } \\
\text { Pergunta Número Inteiro } \\
\text { Nome da variável: year_hyperhemol_i15 } \\
\text { Intervalo permitido: } 1920 \text { - } 2017\end{array}$ \\
\hline $\begin{array}{l}\text { 15.1.2) O paciente já teve reação transfusional hemolítica tardia? } \\
\text { Pergunta Alternativa Seleção Única } \\
\text { Nome da variável: delayreact_i15 } \\
\text { Alternativas: (descrição - score) } \\
\text { 1- Sim - } 1.0 \\
\text { 2- Não - } 2.0\end{array}$ \\
\hline $\begin{array}{l}\text { 15.1.2.1) Ano do primeiro diagnóstico de reação transfusional hemolítica tardia: } \\
\text { Pergunta Número Inteiro } \\
\text { Nome da variável: year_delayreact_i15 } \\
\text { Intervalo permitido: } 1920 \text { - } 2017\end{array}$ \\
\hline $\begin{array}{l}\text { 15.1.3) O paciente já teve hemossiderose transfusional? } \\
\text { Pergunta Alternativa Seleção Única } \\
\text { Nome da variável: transfhem_i15 } \\
\text { Alternativas: (descrição - score) } \\
\text { 1- Sim - } 1.0 \\
\text { 2- Não - } 2.0\end{array}$ \\
\hline $\begin{array}{l}\text { 15.1.3.1) Ano do primeiro diagnóstico de hemossiderose transfusional: } \\
\text { Pergunta Número Inteiro } \\
\text { Nome da variável: year_transfhem_i15 } \\
\text { Intervalo permitido: } 1920 \text { - } 2017\end{array}$ \\
\hline $\begin{array}{l}\text { 15.2) O paciente já realizou Eco? } \\
\text { Pergunta Alternativa Seleção Única } \\
\text { Nome da variável: done_echo_i15 } \\
\text { Alternativas: (descrição - score) } \\
\text { 1-Sim - } 1.0\end{array}$ \\
\hline
\end{tabular}


2- Não - 2.0

15.2.1) O paciente já teve cardiomiopatia hipertrófica?

Pergunta Alternativa Seleção Única

Nome da variável: hypcard_i15

Alternativas: (descrição - score)

1- Sim - 1.0

2- Não - 2.0

15.2.1.1) Ano do primeiro diagnóstico de cardiomiopatia hipertrófica:

Pergunta Número Inteiro

Nome da variável: year_hypcard_i15

Intervalo permitido: 1920 - 2017

15.2.2) O paciente já teve cardiomiopatia dilatada?

Pergunta Alternativa Seleção Única

Nome da variável: dilatcard_i15

Alternativas: (descrição - score)

1- Sim - 1.0

2- Não - 2.0

15.2.2.1) Ano do primeiro diagnóstico de cardiomiopatia dilatada:

Pergunta Número Inteiro

Nome da variável: year_dilatcard_i15

Intervalo permitido: 1920 - 2017

15.2.3) O paciente já teve hipertensão pulmonar diagnosticada por ecocardiograma?

Pergunta Alternativa Seleção Única

Nome da variável: pulhypec_i15

Alternativas: (descrição - score)

1- Sim - 1.0

2- Não - 2.0

15.2.3.1) Ano do primeiro diagnóstico de hipertensão pulmonar diagnosticada por ecocardiograma: Pergunta Número Inteiro

Nome da variável: year_pulhypec_i15

Intervalo permitido: 1920 - 2017

15.3) O paciente já realizou Tomografia craniana ou MRI?

Pergunta Alternativa Seleção Única

Nome da variável: done_ctmri_i15

Alternativas: (descrição - score)

1- Sim - 1.0

2- Não - 2.0 


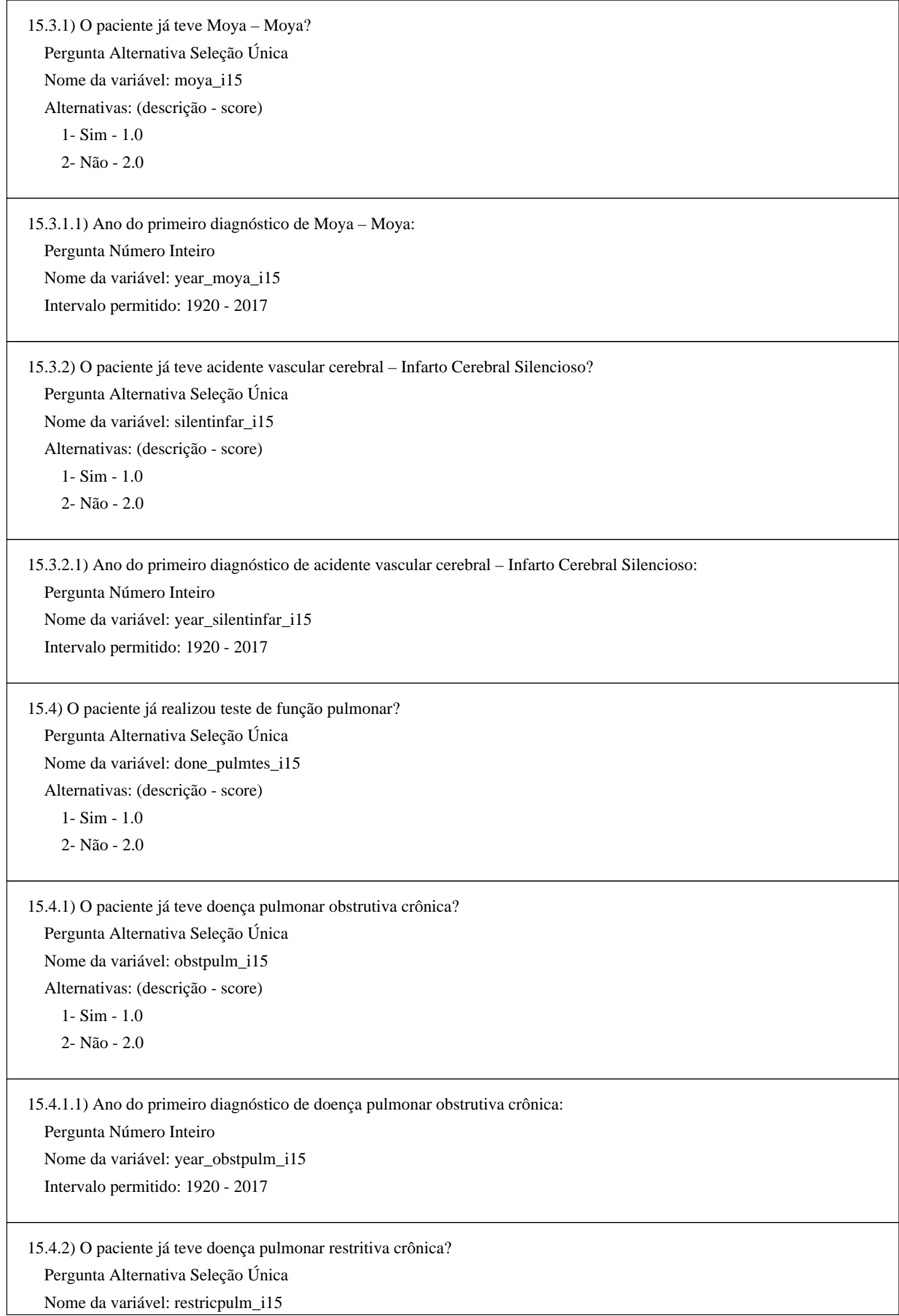




\begin{tabular}{|c|}
\hline $\begin{array}{l}\text { Alternativas: (descrição - score) } \\
\text { 1- Sim - } 1.0 \\
\text { 2- Não - } 2.0\end{array}$ \\
\hline $\begin{array}{l}\text { 15.4.2.1) Ano do primeiro diagnóstico de doença pulmonar restritiva crônica: } \\
\text { Pergunta Número Inteiro } \\
\text { Nome da variável: year_restricpulm_i15 } \\
\text { Intervalo permitido: } 1920 \text { - } 2017\end{array}$ \\
\hline $\begin{array}{l}\text { 15.5) O paciente já realizou Doppler transcraniano? } \\
\text { Pergunta Alternativa Seleção Única } \\
\text { Nome da variável: done_dtc_i15 } \\
\text { Alternativas: (descrição - score) } \\
\text { 1- Sim - } 1.0 \\
\text { 2- Não - } 2.0\end{array}$ \\
\hline $\begin{array}{l}\text { 15.5.1) O paciente já teve doppler transcraniano anormal ou condicional? } \\
\text { Pergunta Alternativa Seleção Única } \\
\text { Nome da variável: elevtcd_i15 } \\
\text { Alternativas: (descrição - score) } \\
\text { 1- Sim - } 1.0 \\
\text { 2- Não - } 2.0\end{array}$ \\
\hline $\begin{array}{l}\text { 15.5.1.1) Ano do primeiro diagnóstico de doppler transcraniano anormal ou condicional: } \\
\text { Pergunta Número Inteiro } \\
\text { Nome da variável: year_elevtcd_i15 } \\
\text { Intervalo permitido: } 1920 \text { - } 2017\end{array}$ \\
\hline $\begin{array}{l}\text { 15.6) O paciente já realizou cateterismo cardíaco? } \\
\text { Pergunta Alternativa Seleção Única } \\
\text { Nome da variável: done_catherer_i15 } \\
\text { Alternativas: (descrição - score) } \\
\text { 1-Sim - } 1.0 \\
\text { 2- Não - } 2.0\end{array}$ \\
\hline $\begin{array}{l}\text { 15.6.1) O paciente já teve hipertensão pulmonar diagnosticada por cateterismo? } \\
\text { Pergunta Alternativa Seleção Única } \\
\text { Nome da variável: pulmhyper_i15 } \\
\text { Alternativas: (descrição - score) } \\
\text { 1- Sim - } 1.0 \\
\text { 2- Não - } 2.0\end{array}$ \\
\hline $\begin{array}{l}\text { 15.6.1.1) Ano do primeiro diagnóstico de hipertensão pulmonar diagnosticada por cateterismo: } \\
\text { Pergunta Número Inteiro } \\
\text { Nome da variável: year_pulmhyper_i15 } \\
\text { Intervalo permitido: } 1920 \text { - } 2017\end{array}$ \\
\hline
\end{tabular}




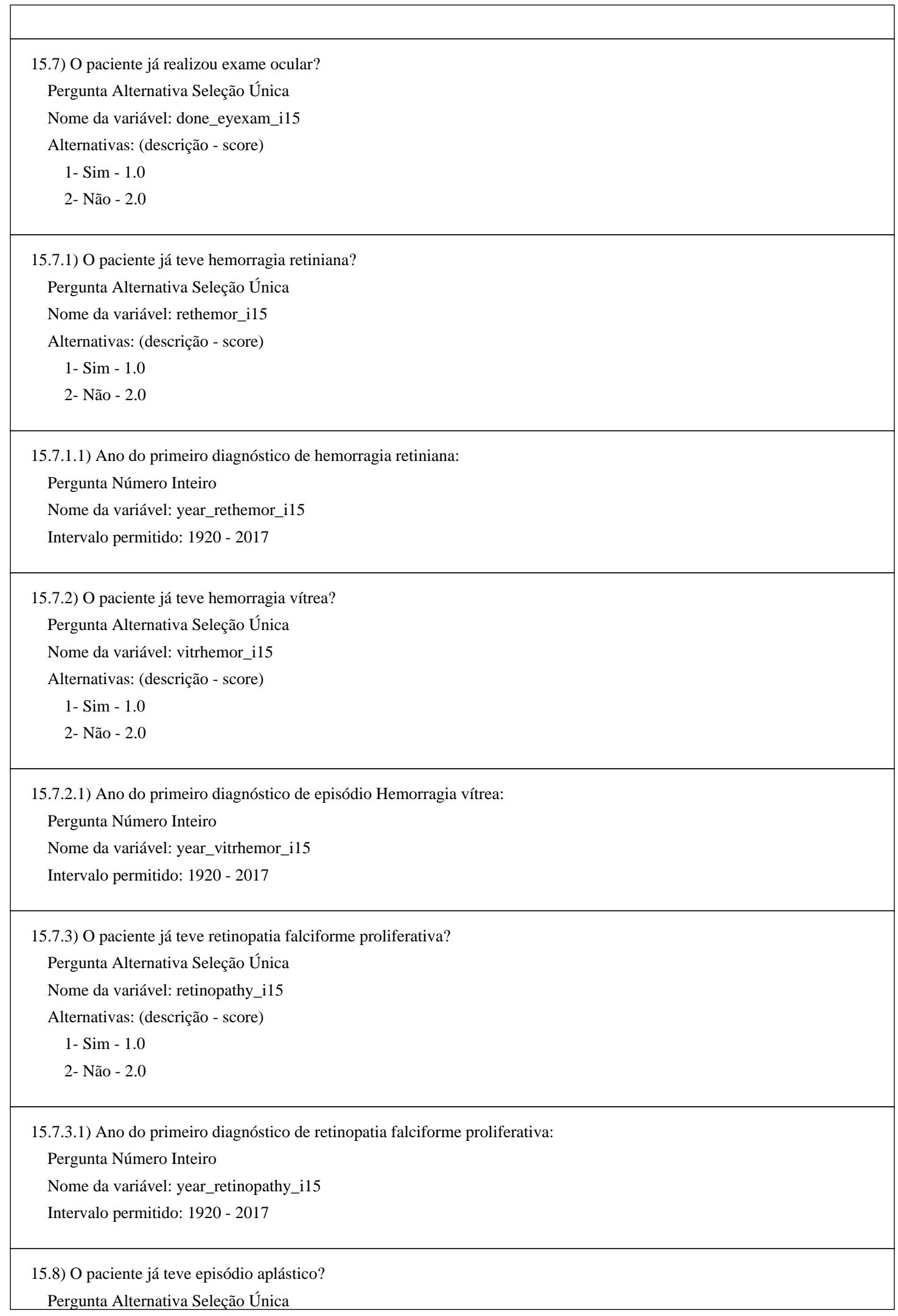


Pergunta Alternativa Seleção Única

Nome da variável: aplastic_i15

Alternativas: (descrição - score)

1- Sim - 1.0

2- Não - 2.0

15.8.1) Ano do primeiro diagnóstico de episódio aplástico:

Pergunta Número Inteiro

Nome da variável: year_aplastic_i15

Intervalo permitido: 1920 - 2017

15.9) O paciente já teve anemia auto imune?

Pergunta Alternativa Seleção Única

Nome da variável: aneautoim_i15

Alternativas: (descrição - score)

1- Sim - 1.0

2- Não - 2.0

15.9.1) Ano do primeiro diagnóstico de anemia auto imune:

Pergunta Número Inteiro

Nome da variável: year_aneautoim_i15

Intervalo permitido: 1920 - 2017

15.10) O paciente já teve sequestro esplênico agudo?

Pergunta Alternativa Seleção Única

Nome da variável: acsequest_i15

Alternativas: (descrição - score)

1- Sim - 1.0

2- Não - 2.0

15.10.1) Ano do primeiro diagnóstico de sequestro esplênico agudo:

Pergunta Número Inteiro

Nome da variável: year_acsequest_i15

Intervalo permitido: 1920 - 2017

15.11) O paciente já teve infarto do miocárdio?

Pergunta Alternativa Seleção Única

Nome da variável: myocarinfar_i15

Alternativas: (descrição - score)

1- Sim - 1.0

2- Não - 2.0

15.11.1) Ano do primeiro diagnóstico de infarto do miocárdio:

Pergunta Número Inteiro

Nome da variável: year_myocarinfar_i15

Intervalo permitido: 1920 - 2017 


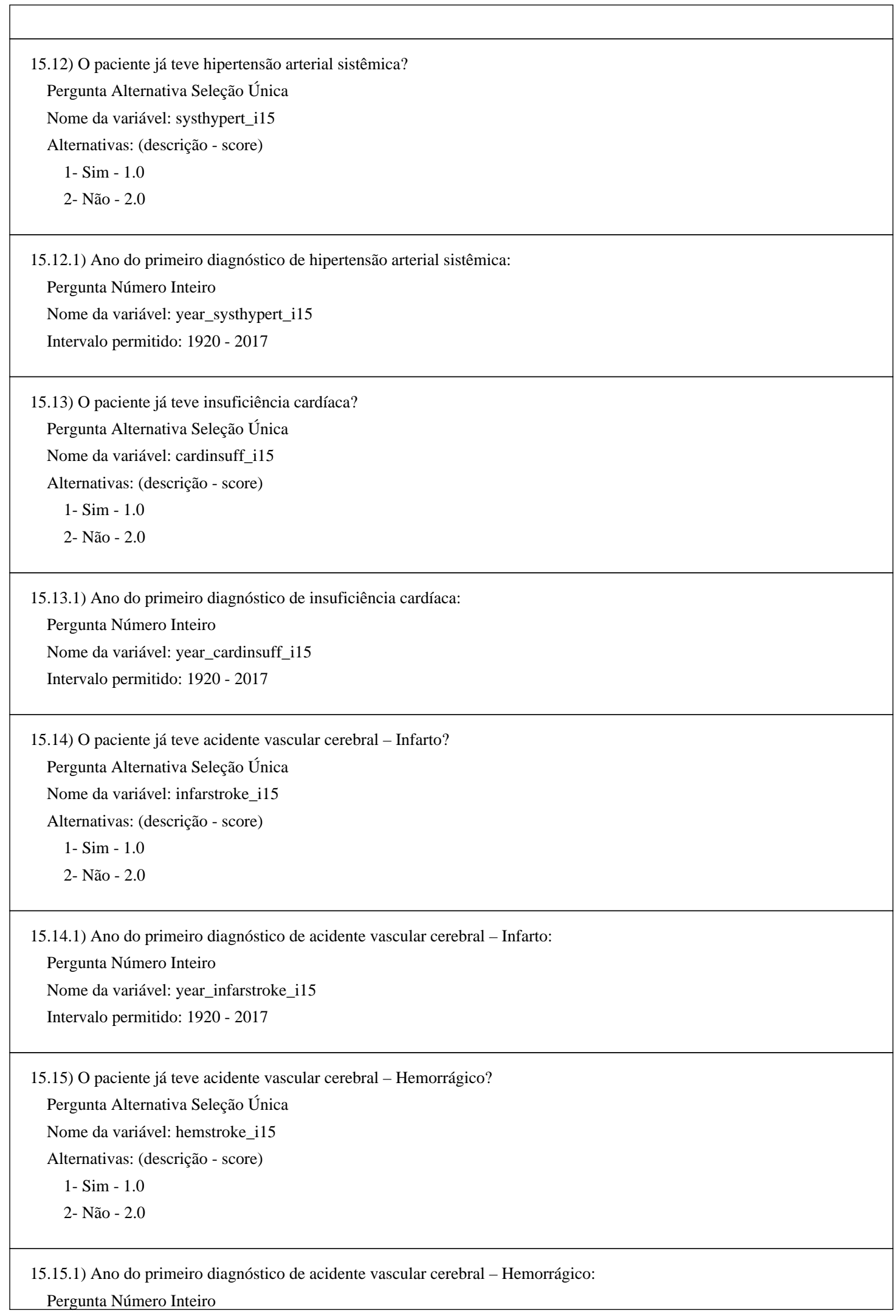


Pergunta Número Inteiro

Nome da variável: year_hemstroke_i15

Intervalo permitido: 1920 - 2017

15.16) O paciente já teve convulsão?

Pergunta Alternativa Seleção Única

Nome da variável: seizures_i15

Alternativas: (descrição - score)

1- Sim - 1.0

2- Não - 2.0

15.16.1) Ano do primeiro diagnóstico de convulsão:

Pergunta Número Inteiro

Nome da variável: year_seizures_i15

Intervalo permitido: 1920 - 2017

15.17) O paciente já teve ataque isquêmico transitório (AIT)?

Pergunta Alternativa Seleção Única

Nome da variável: ischattack_i15

Alternativas: (descrição - score)

1- Sim - 1.0

2- Não - 2.0

15.17.1) Ano do primeiro diagnóstico de ataque isquêmico transitório (AIT):

Pergunta Número Inteiro

Nome da variável: year_ischattack_i15

Intervalo permitido: 1920 - 2017

15.18) O paciente já teve colecistite?

Pergunta Alternativa Seleção Única

Nome da variável: cholecystitis_i15

Alternativas: (descrição - score)

1- Sim - 1.0

2- Não - 2.0

15.18.1) Ano do primeiro diagnóstico de colecistite:

Pergunta Número Inteiro

Nome da variável: year_cholecystitis_i15

Intervalo permitido: 1920 - 2017

15.19) O paciente já teve colelitíase?

Pergunta Alternativa Seleção Única

Nome da variável: cholelisludg_i15

Alternativas: (descrição - score)

1- Sim - 1.0

2- Não - 2.0 


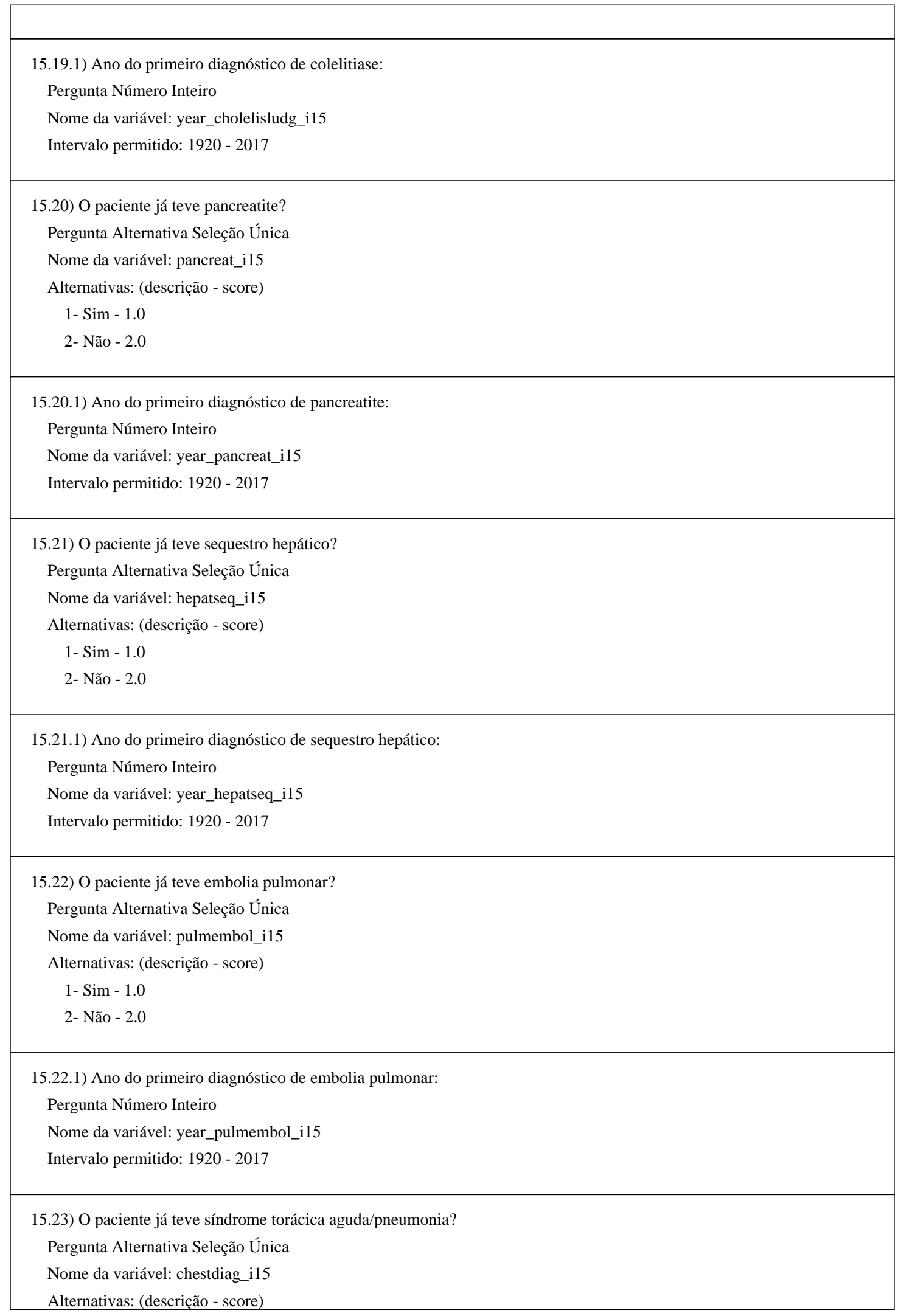




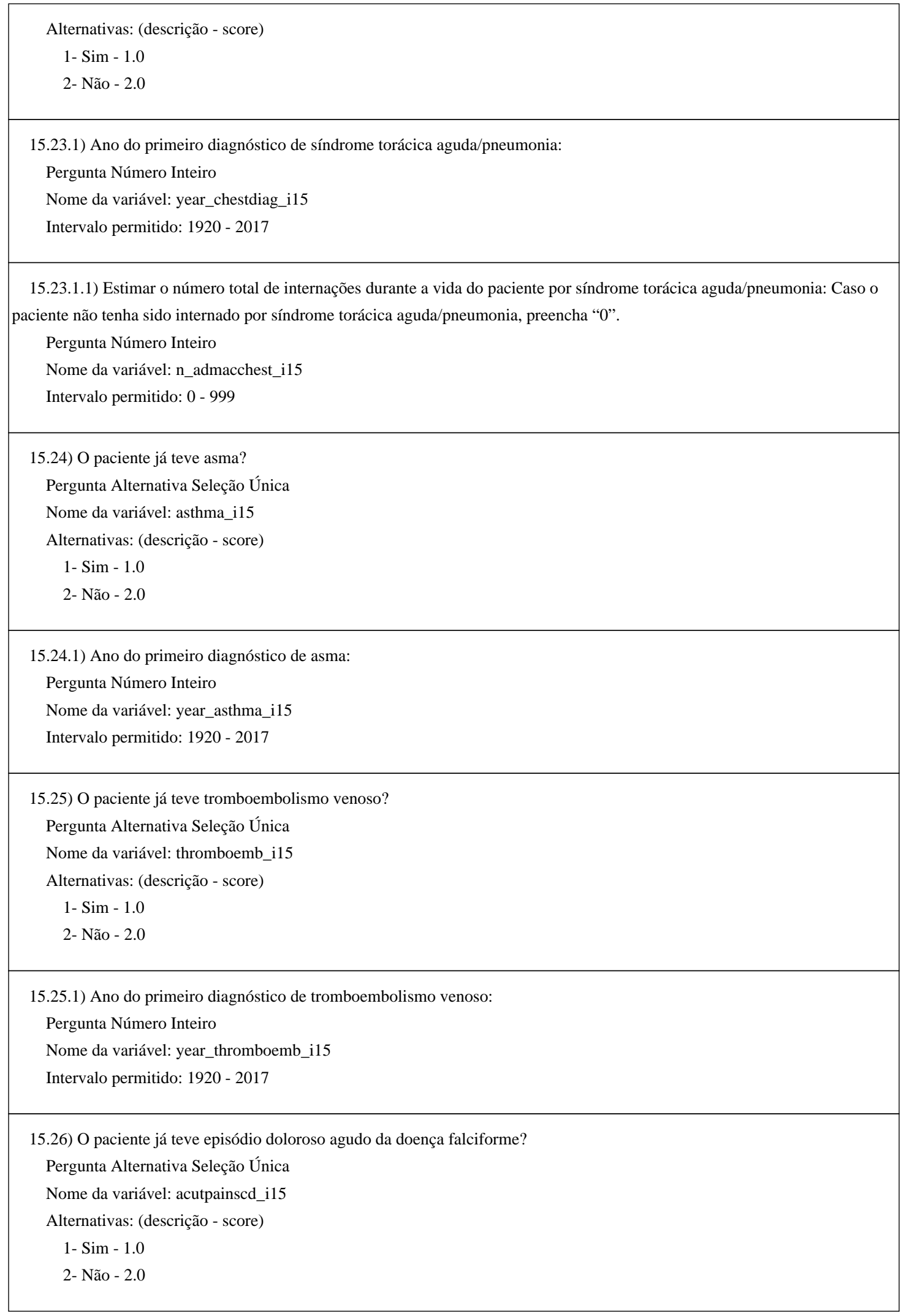




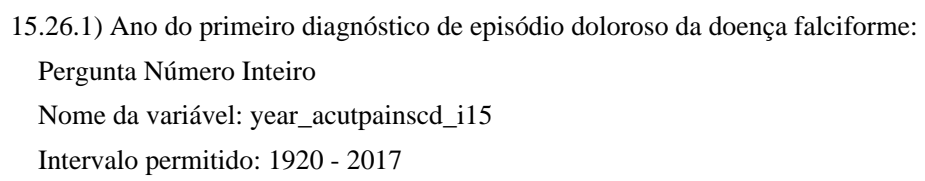

15.26.2.1) Estimar o número total de internações durante a vida do paciente por episódio doloroso agudo: Caso o paciente não tenha sido internado por episódio doloroso agudo, preencha " 0 ".

Pergunta Número Inteiro

Nome da variável: n_admacutpain_i15

Intervalo permitido: 0 - 999

15.27) O paciente já teve dor neuropática?

Pergunta Alternativa Seleção Única

Nome da variável: neuropat_i15

Alternativas: (descrição - score)

1- Sim - 1.0

2- Não - 2.0

15.27.1) Ano do primeiro diagnóstico de dor neuropática:

Pergunta Número Inteiro

Nome da variável: year_neuropat_i15

Intervalo permitido: 1920 - 2017

15.28) O paciente já teve dactilite (síndrome mão-pé)?

Pergunta Alternativa Seleção Única

Nome da variável: dactylitis_i15

Alternativas: (descrição - score)

1- Sim - 1.0

2- Não - 2.0

15.28.1) Ano do primeiro diagnóstico de dactilite:

Pergunta Número Inteiro

Nome da variável: year_dactylitis_i15

Intervalo permitido: 1920 - 2017

15.29) O paciente já teve cefaléia/enxaqueca?

Pergunta Alternativa Seleção Única

Nome da variável: migraine_i15

Alternativas: (descrição - score)

1- Sim - 1.0

2- Não - 2.0

15.29.1) Ano do primeiro diagnóstico de cefaléia/Enxaqueca:

Pergunta Número Inteiro

Nome da variável: year_migraine_i15

Intervalo permitido: 1920 - 2017 


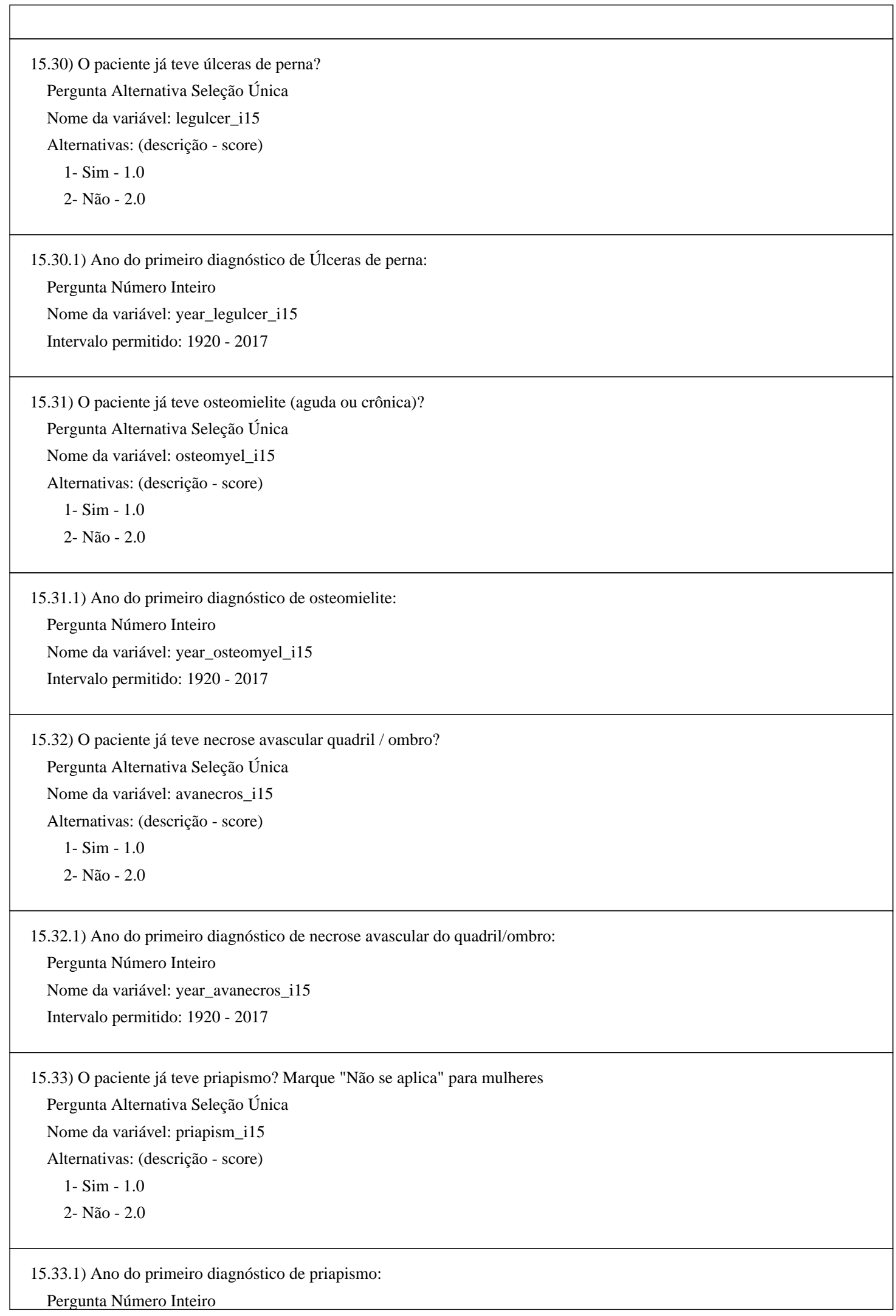


Pergunta Número Inteiro

Nome da variável: year_priapism_i15

Intervalo permitido: 1920 - 2017

15.34) O paciente já teve pielonefrite?

Pergunta Alternativa Seleção Única

Nome da variável: pyelonephr_i15

Alternativas: (descrição - score)

1- Sim - 1.0

2- Não - 2.0

15.34.1) Ano do primeiro diagnóstico de pielonefrite:

Pergunta Número Inteiro

Nome da variável: year_pyelonephr_i15

Intervalo permitido: 1920 - 2017

15.35) O paciente já teve insuficiência renal aguda?

Pergunta Alternativa Seleção Única

Nome da variável: acute_renalfail_i15

Alternativas: (descrição - score)

1- Sim - 1.0

2- Não - 2.0

15.35.1) Ano do primeiro diagnóstico de insuficiência renal aguda?

Pergunta Número Inteiro

Nome da variável: year_acrenalfail_i15

Intervalo permitido: 1920 - 2017

15.35.2) Foi necessário realizar diálise para tratar a insuficiência renal aguda?

Pergunta Alternativa Seleção Única

Nome da variável: dialy_acrenalfail_i15

Alternativas: (descrição - score)

1- Sim -1.0

2- Não - 2.0

15.36) O paciente já teve insuficiência renal crônica?

Pergunta Alternativa Seleção Única

Nome da variável: chronic_renalfail_i15

Alternativas: (descrição - score)

1- Sim - 1.0

2- Não - 2.0

15.36.1) Ano do primeiro diagnóstico de insuficiência renal crônica

Pergunta Número Inteiro

Nome da variável: year_chrenalfail_i15

Intervalo permitido: 1920 - 2017 


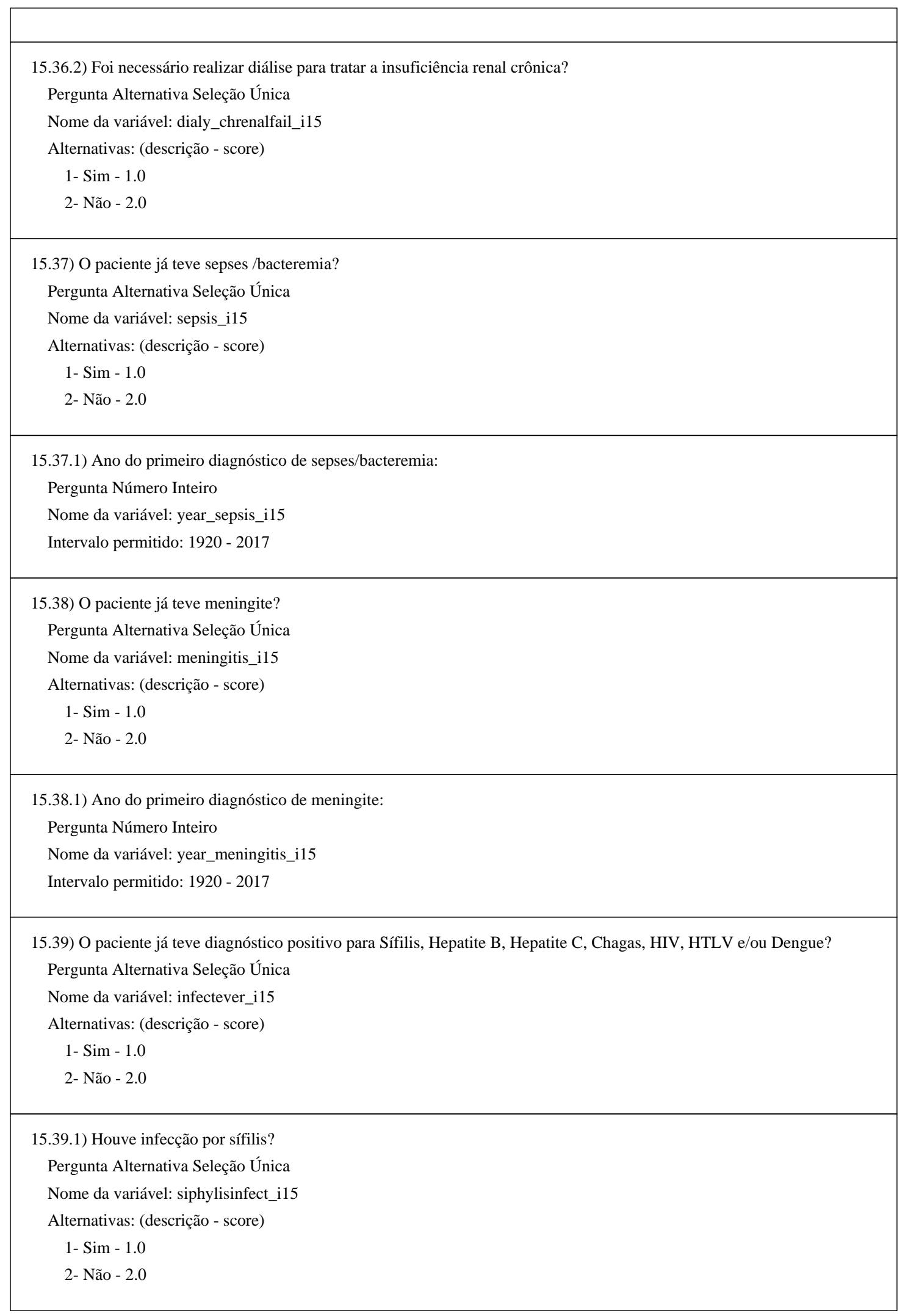




\footnotetext{
15.39.1.1) Ano do primeiro diagnóstico para sífilis:

Pergunta Número Inteiro

Nome da variável: year_siphylisinfect_i15

Intervalo permitido: 1920 - 2017
}

15.39.2) Houve infecção pelo vírus da hepatite B?

Pergunta Alternativa Seleção Única

Nome da variável: hbc_infection_i15

Alternativas: (descrição - score)

1- Sim - 1.0

2- Não - 2.0

15.39.2.1) Ano do primeiro diagnóstico para hepatite B:

Pergunta Número Inteiro

Nome da variável: year_hbcinfect_i15

Intervalo permitido: 1920 - 2017

15.39.2.2) Há suspeita de que a infecção por hepatite B foi transfusional? Marque "Não se aplica" caso o paciente não tenha recebido transfusão

Pergunta Alternativa Seleção Única

Nome da variável: hbc_infectransf_i15

Alternativas: (descrição - score)

1 - Sim - 1.0

2- Não - 2.0

15.39.3) Houve infecção pelo vírus da hepatite C?

Pergunta Alternativa Seleção Única

Nome da variável: hcv_infection_i15

Alternativas: (descrição - score)
1- Sim - 1.0
2- Não - 2.0

15.39.3.1) Ano do primeiro diagnóstico de hepatite C:

Pergunta Número Inteiro

Nome da variável: year_hcvinfect_i15

Intervalo permitido: 1920 - 2017

15.39.3.2) Há suspeita de que a infecção por hepatite $C$ foi transfusional? Marque "Não se aplica" caso o paciente não tenha recebido transfusão

Pergunta Alternativa Seleção Única

Nome da variável: hcv_infectransf_i15

Alternativas: (descrição - score)
1- Sim - 1.0
2- Não - 2.0 
Pergunta Alternativa Seleção Única

Nome da variável: chagas_infection_i15

Alternativas: (descrição - score)

1- Sim - 1.0

2- Não - 2.0

15.39.4.1) Ano do primeiro diagnóstico de Chagas:

Pergunta Número Inteiro

Nome da variável: year_chagasinfect_i15

Intervalo permitido: 1920 - 2017

15.39.4.2) Há suspeita de que a infecção por Chagas foi transfusional? Marque "Não se aplica" caso o paciente não tenha recebido transfusão

Pergunta Alternativa Seleção Única

Nome da variável: chagas_infectransf_i15

Alternativas: (descrição - score)

1- Sim - 1.0

2- Não - 2.0

15.39.5) Houve infecção por HIV?

Pergunta Alternativa Seleção Única

Nome da variável: hiv_infection_i15

Alternativas: (descrição - score)

1- Sim - 1.0

2- Não - 2.0

15.39.5.1) Ano do primeiro diagnóstico de HIV:

Pergunta Número Inteiro

Nome da variável: year_hivinfect_i15

Intervalo permitido: 1920 - 2017

15.39.5.2) Há suspeita de que a infecção por HIV foi transfusional? Marque "Não se aplica" caso o paciente não tenha recebido transfusão

Pergunta Alternativa Seleção Única

Nome da variável: hiv_infectransf_i15

Alternativas: (descrição - score)

1- Sim - 1.0

2- Não - 2.0

15.39.6) Houve infecção por HTLV?

Pergunta Alternativa Seleção Única

Nome da variável: htlv_infection_i15

Alternativas: (descrição - score)

1- Sim - 1.0

2- Não - 2.0 
15.39.6.1) Ano do primeiro diagnóstico de HTLV:

Pergunta Número Inteiro

Nome da variável: year_htlvinfect_i15

Intervalo permitido: 1920 - 2017

15.39.6.2) Há suspeita de que a infecção por HTLV foi transfusional? Marque "Não se aplica" caso o paciente não tenha recebido transfusão

Pergunta Alternativa Seleção Única

Nome da variável: htlv_infectransf_i15

Alternativas: (descrição - score)

1- Sim - 1.0

2- Não - 2.0

15.39.7) Houve infecção por Dengue?

Pergunta Alternativa Seleção Única

Nome da variável: dengue_infection_i15

Alternativas: (descrição - score)

1- Sim - 1.0

2- Não - 2.0

15.39.7.1) Ano do primeiro diagnóstico de Dengue:

Pergunta Número Inteiro

Nome da variável: year_dengueinfect_i15

Intervalo permitido: 1920 - 2017

15.39.7.2) Há suspeita de que a infecção por Dengue foi transfusional? Marque "Não se aplica" caso o paciente não tenha recebido transfusão

Pergunta Alternativa Seleção Única

Nome da variável: dengue_infectransf_i15

Alternativas: (descrição - score)

1- Sim - 1.0

2- Não - 2.0

15.40) O paciente tem algum outro diagnóstico NÃO RELACIONADO à Doença Falciforme:

Pergunta Alternativa Seleção Única

Nome da variável: oth_diaglive_i15

Alternativas: (descrição - score)

1- Sim - 1.0

2- Não - 2.0

Planilha: Outro diagnóstico NÃO RELACIONADO - replicável

Itens: (Descriçãa - Nome da variável)

Outro diagnóstico NÃO RELACIONADO - othdiaglive

15.40.1) Especifique o outro diagnóstico:

Pergunta Texto

Nome da variável:_spec_i15

Número máximo de caracteres permitido: 100 
15.40.2) Ano do primeiro diagnóstico de NÃO RELACIONADO à doença falciforme: Pergunta Número Inteiro

Nome da variável: _year_i1

Intervalo permitido: $1920-2017$ 
Apêndice D

\section{Questionários de acompanhamento 1 do REDS-III}

\section{Entrevista - Acompanhamento 1}

Codebook impresso em 08/01/2018

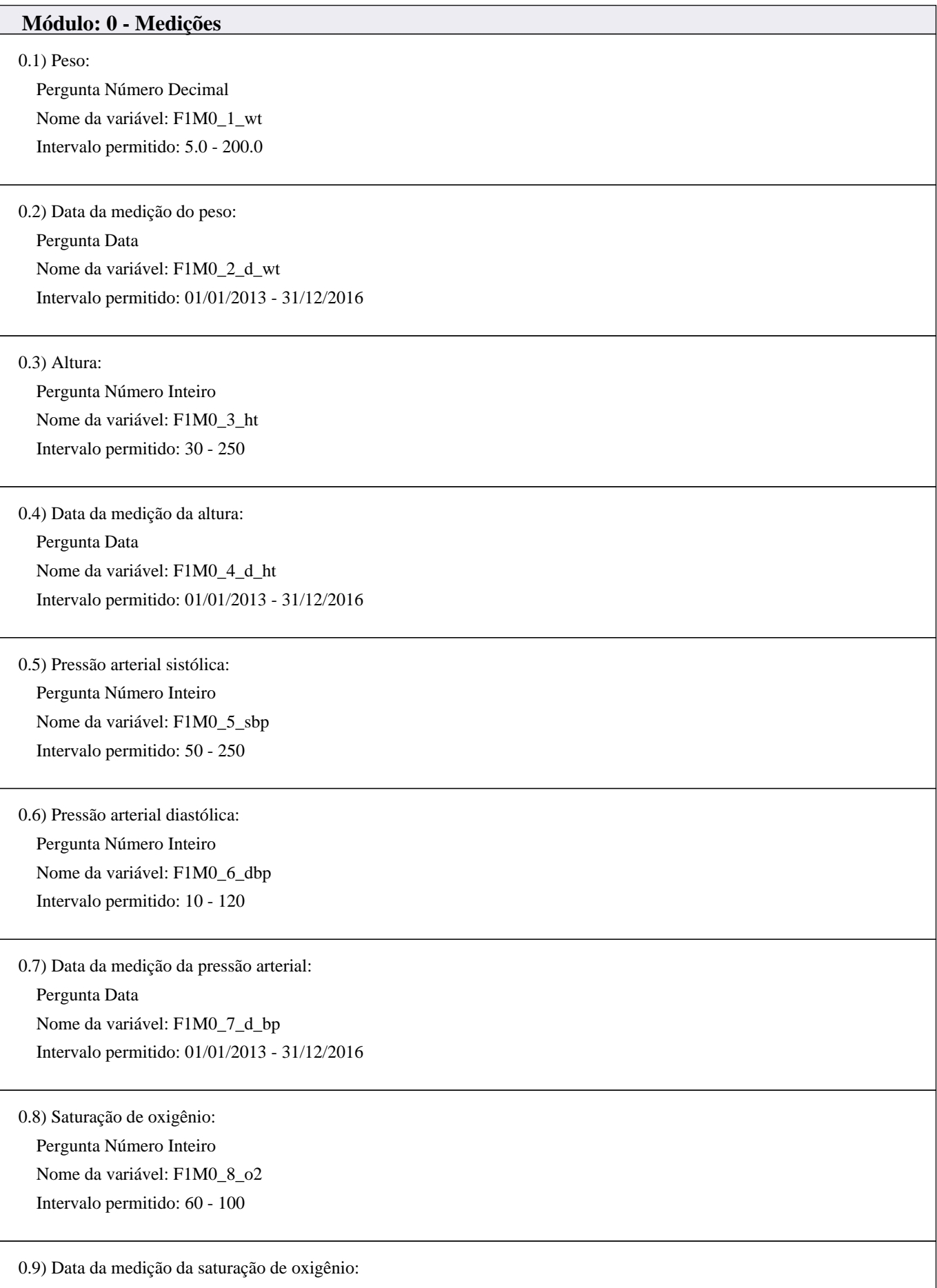


Pergunta Data

Nome da variável: F1M0_9_d_o2

Intervalo permitido: 01/01/2013 - 31/12/2016

0.10) Você está em tratamento com Hidroxiureia atualmente?

Pergunta Alternativa Seleção Única

Nome da variável: F1M0_10_hu

Alternativas: (descrição - score)

Sim -1.0

Não - 2.0

0.11) Você (ou seu filho) se esquece de tomar a hidroxiuréia:

Pergunta Alternativa Seleção Única

Nome da variável: F1M0_11_hu_c

Alternativas: (descrição - score)

Nunca / Raramente esquece - 4.0

De vez em quando esquece -3.0

Às vezes esquece - 2.0

Geralmente esquece - 1.0

Durante todo o tempo esquece - 0.0

\section{Módulo: 1 - Qualidade de Vida}

1) Houve permissão para perguntar as questões sobre Qualidade de Vida?

Pergunta Alternativa Seleção Única

Nome da variável: F1M1_pqol

Alternativas: (descrição - score)

Sim - 1.0

Não - 2.0

1.0) Qual sua idade?

Pergunta Número Inteiro

Nome da variável: F1M1_0_age

Intervalo permitido: 1 - 99

1.1) Nos últimos 12 meses, quantas crises de dor você teve?

Pergunta Alternativa Seleção Única

Nome da variável: F1M1_1_n_p

Alternativas: (descrição - score)

4 ou mais -0.0

$3-1.0$

$2-2.0$

$1-3.0$

Eu não tive crises de dor nos últimos 12 meses - 4.0 
1.2) Quando foi a sua última crise de dor?

Pergunta Alternativa Seleção Única

Nome da variável: F1M1_2_t_p

Alternativas: (descrição - score)

Eu nunca tive um episódio de dor - 0.0

Há mais de 5 anos atrás - 1.0

Há 1-5 anos atrás - 2.0

Há 7-11 meses atrás - 3.0

Há 1-6 meses atrás - 4.0

Há 1-4 semanas atrás - 5.0

Há menos de 1 semana atrás - 6.0

Eu estou tendo um episódio de dor agora - 7.0

1.3) Como você classificaria a gravidade da dor em sua última crise de dor?

Pergunta Alternativa Seleção Única

Nome da variável: F1M1_3_rate_p

Alternativas: (descrição - score)

0 - sem dor - 0.0

$1-1.0$

$2-2.0$

$3-3.0$

$4-4.0$

$5-5.0$

$6-6.0$

$7-7.0$

$8-8.0$

$9-9.0$

10 - a pior dor imaginável - 10.0

1.4) Quanto a sua última crise de dor interferiu na sua vida?

Pergunta Alternativa Seleção Única

Nome da variável: F1M1_4_life_p

Alternativas: (descrição - score)

Eu nunca tive uma crise de dor -0.0

Nem um pouco, eu fiz tudo o que eu costumo fazer - 1.0

Eu tive que reduzir cortar algumas atividades que eu costumo fazer - 2.0

Eu não pude fazer a maioria das atividades que costumo fazer - 3.0

Eu não pude cuidar de mim e precisei da ajuda de familiares ou amigos - 4.0

Eu não pude cuidar de mim e precisei da ajuda constante de familiares, amigos, médicos ou enfermeiros - 5.0

1.5) Quanto tempo durou a sua última crise de dor?

Pergunta Alternativa Seleção Única

Nome da variável: F1M1_5_long_p

Alternativas: (descrição - score)

Eu nunca tive uma crise de dor -0.0

Menos de 1 hora - 1.0

$1-12$ horas -2.0 
$13-23$ horas -3.0

$1-3$ dias -4.0

$4-6$ dias -5.0

1-2 semanas - 6.0

Mais de 2 semanas - 7.0

1.6) Nos últimos 7 dias, com que frequência você teve crises de dor tão fortes que você não pôde fazer nada por um dia inteiro?

Pergunta Alternativa Seleção Única

Nome da variável: F1M1_6_p_day

Alternativas: (descrição - score)

Nunca - 0.0

Raramente - 1.0

Às vezes - 2.0

Frequentemente - 3.0

Sempre -4.0

1.7) Nos últimos 7 dias, com que frequência você teve crises de dor tão fortes que você não pôde sair da cama? Pergunta Alternativa Seleção Única

Nome da variável: F1M1_7_p_bed

Alternativas: (descrição - score)

Nunca - 0.0

Raramente - 1.0

Às vezes - 2.0

Frequentemente - 3.0

Sempre -4.0

1.8) Nos últimos 7 dias, com que frequência você teve dor muito forte?

Pergunta Alternativa Seleção Única

Nome da variável: F1M1_8_sev_p

Alternativas: (descrição - score)

Nunca -0.0

Raramente - 1.0

Às vezes - 2.0

Frequentemente - 3.0

Sempre -4.0

1.9) Nos últimos 7 dias, com que frequência você teve crises de dor tão fortes que você teve que parar de fazer o que estava fazendo?

Pergunta Alternativa Seleção Única

Nome da variável: F1M1_9_p_stop

Alternativas: (descrição - score)

Nunca - 0.0

Raramente - 1.0

Às vezes - 2.0

Frequentemente - 3.0

Sempre -4.0 
Sempre -4.0

1.10) Nos últimos 7 dias, com que frequência você teve crises de dor tão fortes que foi difícil terminar o que você estava fazendo?

Pergunta Alternativa Seleção Única

Nome da variável: F1M1_10_p_finish

Alternativas: (descrição - score)

Nunca - 0.0

Raramente - 1.0

Às vezes -2.0

Frequentemente -3.0

Sempre -4.0

1.11) Nos últimos 7 dias, com que frequência suas juntas estavam muito duras quando você acordou? Pergunta Alternativa Seleção Única

Nome da variável: F1M1_11_f_stf

Alternativas: (descrição - score)

Nunca - 0.0

Raramente - 1.0

Às vezes - 2.0

Frequentemente -3.0

Sempre -4.0

1.12) Nos últimos 7 dias, com que frequência suas juntas ficaram muito duras durante o dia? Pergunta Alternativa Seleção Única

Nome da variável: F1M1_12_stf_day

Alternativas: (descrição - score)

Nunca - 0.0

Raramente - 1.0

Às vezes - 2.0

Frequentemente - 3.0

Sempre -4.0

1.13) Nos últimos 7 dias, com que frequência suas juntas ficaram muito duras durante o dia que você não pôde se mover? Pergunta Alternativa Seleção Única

Nome da variável: F1M1_13_nomove

Alternativas: (descrição - score)

Nunca - 0.0

Raramente - 1.0

Às vezes - 2.0

Frequentemente - 3.0

Sempre - 4.0

1.14) Nos últimos 7 dias, com que frequência você acordou tão rígido que você não pôde se mover?

Pergunta Alternativa Seleção Única

Nome da variável: F1M1_14_wake_stf 


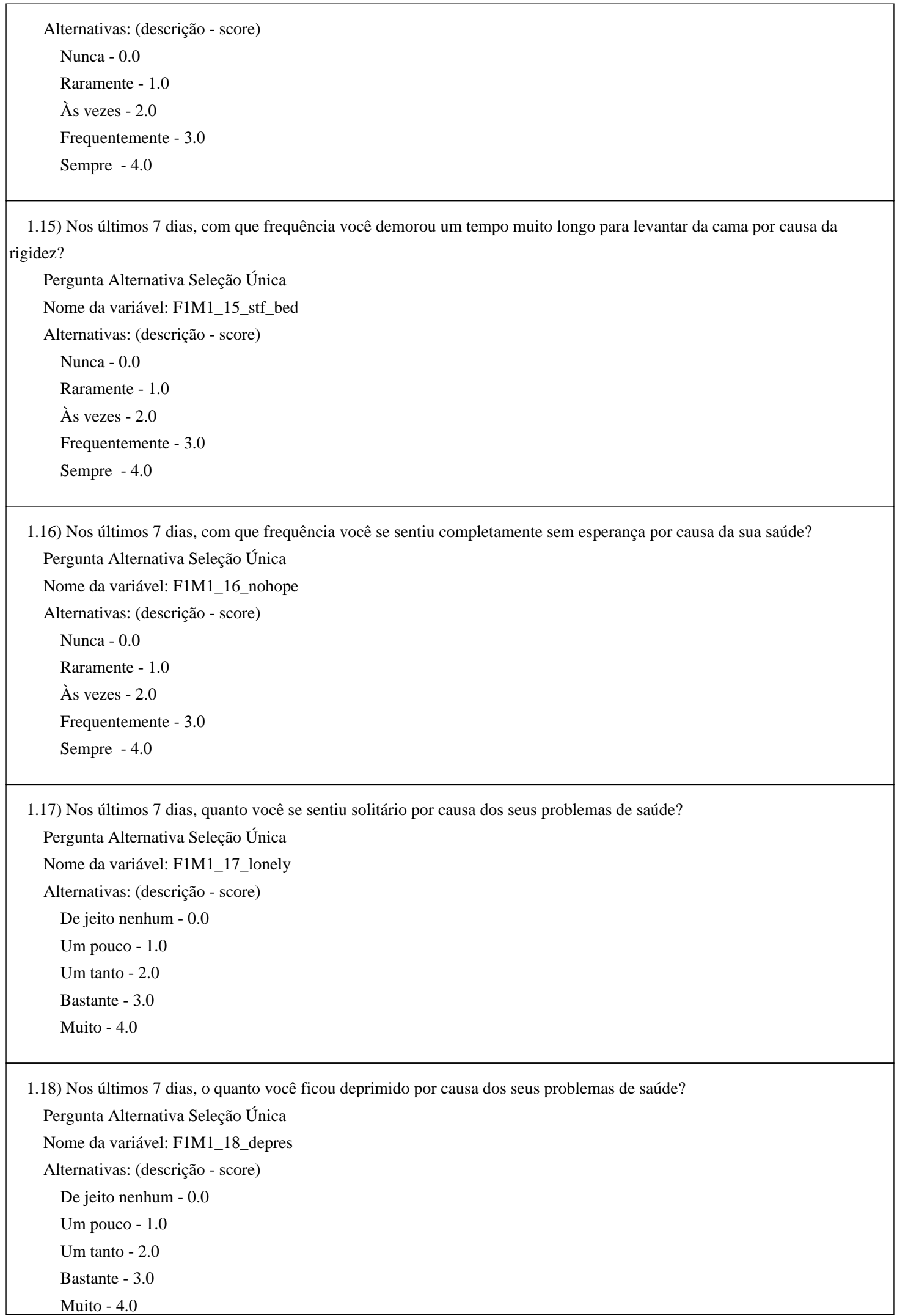


Muito - 4.0

1.19) Nos últimos 7 dias, quanto você se preocupou sobre ficar doente?

Pergunta Alternativa Seleção Única

Nome da variável: F1M1_19_wry_sick

Alternativas: (descrição - score)

De jeito nenhum - 0.0

Um pouco - 1.0

Um tanto - 2.0

Bastante - 3.0

Muito - 4.0

1.20) Nos últimos 7 dias, com que frequência você ficou muito preocupado sobre precisar ir para o hospital?

Pergunta Alternativa Seleção Única

Nome da variável: F1M1_20_wry_hos

Alternativas: (descrição - score)

Nunca - 0.0

Raramente - 1.0

Às vezes - 2.0

Frequentemente - 3.0

Sempre -4.0

1.21) Nos últimos 7 dias, com que frequência você ficou acordado a maior parte da noite porque você não conseguia dormir? Pergunta Alternativa Seleção Única

Nome da variável: F1M1_21_no_slp

Alternativas: (descrição - score)

Nunca - 0.0

Raramente - 1.0

Às vezes -2.0

Frequentemente -3.0

Sempre -4.0

1.22) Nos últimos 7 dias, com que frequência foi muito fácil para você conseguir dormir?

Pergunta Alternativa Seleção Única

Nome da variável: F1M1_22_eas_slp

Alternativas: (descrição - score)

Nunca - 0.0

Raramente - 1.0

Às vezes - 2.0

Frequentemente - 3.0

Sempre -4.0

1.23) Nos últimos 7 dias, com que frequência você teve muitas dificuldade para dormir? Pergunta Alternativa Seleção Única

Nome da variável: F1M1_23_trb_slp

Alternativas: (descrição - score) 
Nunca - 0.0

Raramente - 1.0

Às vezes - 2.0

Frequentemente - 3.0

Sempre -4.0

1.24) Nos últimos 7 dias, com que frequência você ficou acordado a noite toda porque você não conseguiu dormir? Pergunta Alternativa Seleção Única

Nome da variável: F1M1_24_up_all

Alternativas: (descrição - score)

Nunca - 0.0

Raramente - 1.0

Às vezes -2.0

Frequentemente - 3.0

Sempre -4.0

1.25) Nos últimos 7 dias, com que frequência você ficou acordado metade da noite porque você não conseguiu dormir? Pergunta Alternativa Seleção Única

Nome da variável: F1M1_25_up_hlf

Alternativas: (descrição - score)

Nunca - 0.0

Raramente - 1.0

Às vezes -2.0

Frequentemente - 3.0

Sempre -4.0

1.26) Nos últimos 30 dias, quanto você dependeu dos outros para cuidar de você por causa da sua saúde?

Pergunta Alternativa Seleção Única

Nome da variável: F1M1_26_oth_help

Alternativas: (descrição - score)

De jeito nenhum - 0.0

Um pouco - 1.0

Um tanto - 2.0

Bastante - 3.0

Muito - 4.0

1.27) Nos últimos 30 dias, com que frequência a sua saúde fez você ter menos disposição para fazer as suas coisas? Pergunta Alternativa Seleção Única

Nome da variável: F1M1_27_h_slow

Alternativas: (descrição - score)

Nunca - 0.0

Raramente - 1.0

Às vezes - 2.0

Frequentemente - 3.0

Sempre -4.0 
1.28) Nos últimos 30 dias, com que frequência sua saúde tornou mais difícil para você realizar suas atividades?

Pergunta Alternativa Seleção Única

Nome da variável: F1M1_28_h_hard

Alternativas: (descrição - score)

Nunca - 0.0

Raramente - 1.0

Às vezes - 2.0

Frequentemente -3.0

Sempre -4.0

1.29) Nos últimos 30 dias, com que frequência sua saúde te impediu de sair?

Pergunta Alternativa Seleção Única

Nome da variável: F1M1_29_h_out

Alternativas: (descrição - score)

Nunca - 0.0

Raramente - 1.0

Às vezes -2.0

Frequentemente - 3.0

Sempre -4.0

1.30) Nos últimos 30 dias o quanto sua saúde tornou difícil para você fazer atividades com seu amigos?

Pergunta Alternativa Seleção Única

Nome da variável: F1M1_30_h_frnd

Alternativas: (descrição - score)

De jeito nenhum - 0.0

Um pouco - 1.0

Um tanto - 2.0

Bastante - 3.0

Muito - 4.0

1.31) Eu sinto muita dor:

Pergunta Alternativa Seleção Única

Nome da variável: F1M1_31_p

Alternativas: (descrição - score)

Nunca $\quad-0.0$

Quase Nunca $\quad-1.0$

Algumas Vezes $\quad-2.0$

Frequentemente $\quad-3.0$

Quase sempre - 4.0

1.32) Eu sinto dor em todo meu corpo:

Pergunta Alternativa Seleção Única

Nome da variável: F1M1_32_p_body

Alternativas: (descrição - score)

Nunca $\quad-0.0$

Quase Nunca $\quad-1.0$

Algumas Vezes $\quad-2.0$ 


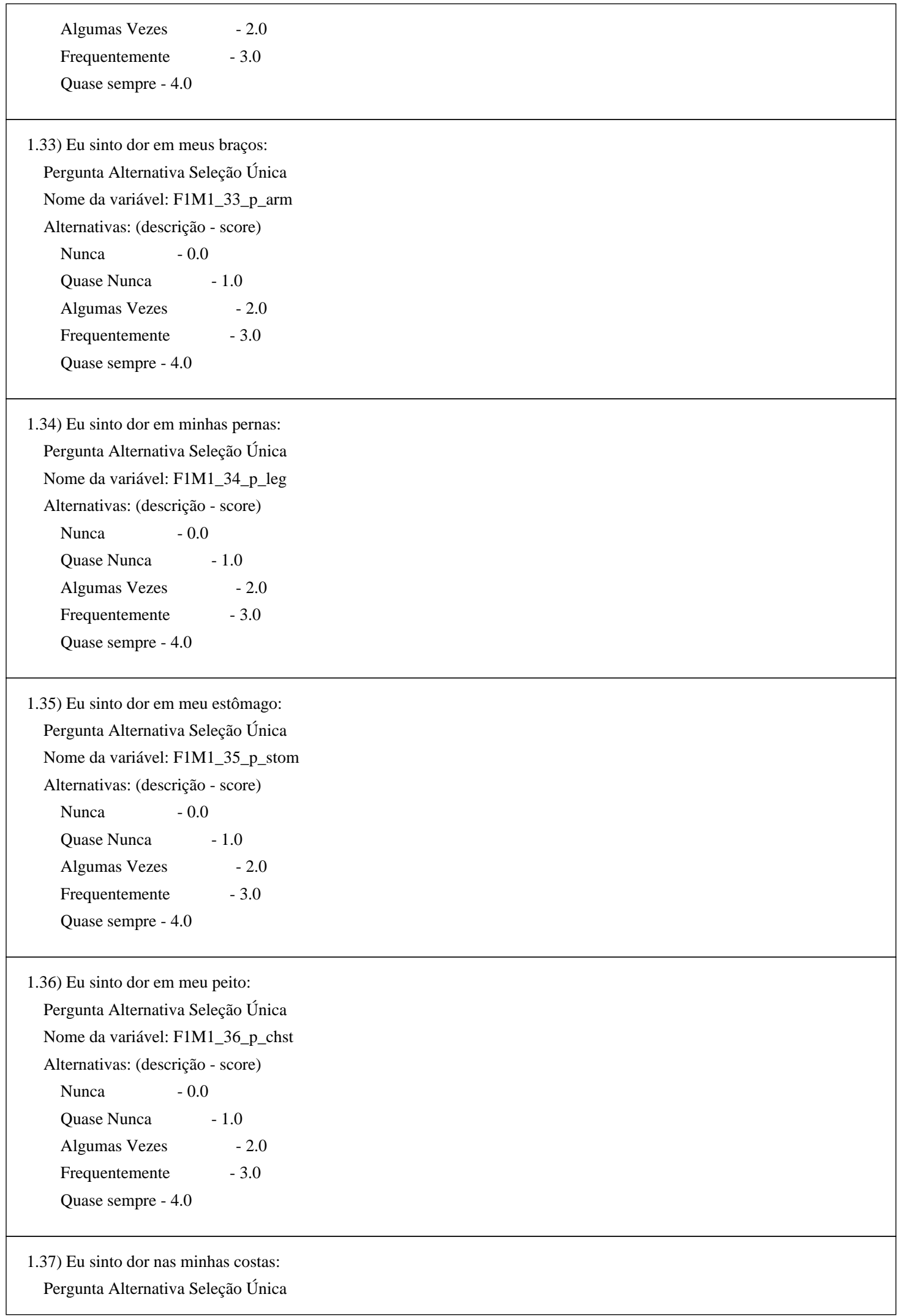




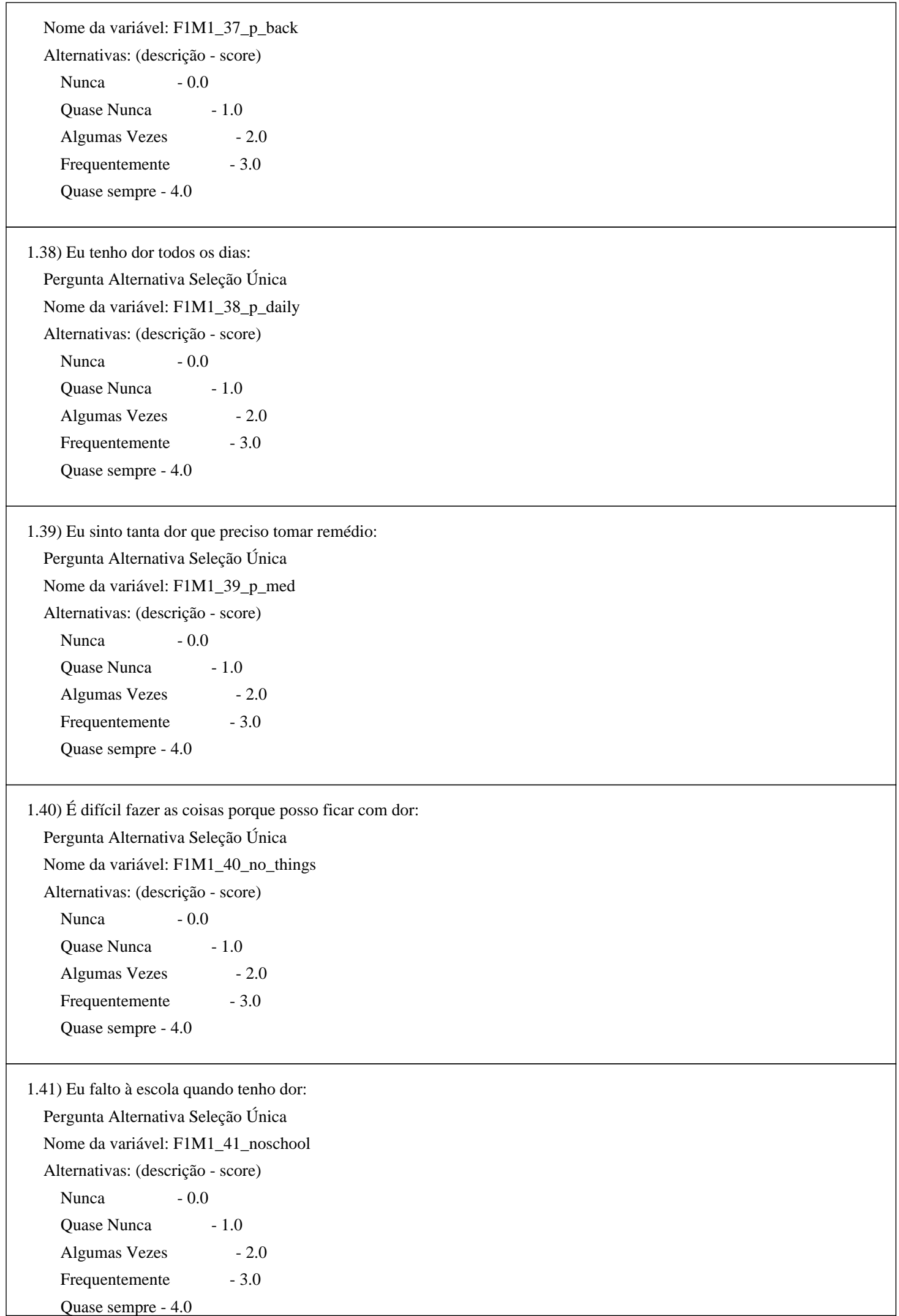


Quase sempre - 4.0

1.42) É difícil correr quando tenho dor:

Pergunta Alternativa Seleção Única

Nome da variável: F1M1_42_norun

Alternativas: (descrição - score)

$\begin{array}{lc}\text { Nunca } & -0.0 \\ \text { Quase Nunca } & -1.0 \\ \text { Algumas Vezes } & -2.0 \\ \text { Frequentemente } & -3.0 \\ \text { Quase sempre - } 4.0 & \end{array}$

1.43) É difícil me divertir quando tenho dor:

Pergunta Alternativa Seleção Única

Nome da variável: F1M1_43_nofun

Alternativas: (descrição - score)

$\begin{array}{lc}\text { Nunca } & -0.0 \\ \text { Quase Nunca } & -1.0 \\ \text { Algumas Vezes } & -2.0 \\ \text { Frequentemente } & -3.0 \\ \text { Quase sempre - } 4.0 & \end{array}$

1.44) Eu tenho dificuldade para me movimentar quando tenho dor:

Pergunta Alternativa Seleção Única

Nome da variável: F1M1_44_nomove

Alternativas: (descrição - score)

$\begin{array}{lc}\text { Nunca } & -0.0 \\ \text { Quase Nunca } & -1.0 \\ \text { Algumas Vezes } & -2.0 \\ \text { Frequentemente } & -3.0 \\ \text { Quase sempre }-4.0 & \end{array}$

1.45) É difícil ficar em pé quando tenho dor:

Pergunta Alternativa Seleção Única

Nome da variável: F1M1_45_nostand

Alternativas: (descrição - score)
Nunca $\quad-0.0$
Quase Nunca $\quad-1.0$
Algumas Vezes $\quad-2.0$
Frequentemente $\quad-3.0$
Quase sempre - 4.0

1.46) É difícil cuidar de mim mesmo quando tenho dor:

Pergunta Alternativa Seleção Única

Nome da variável: F1M1_46_nocare

Alternativas: (descrição - score) 


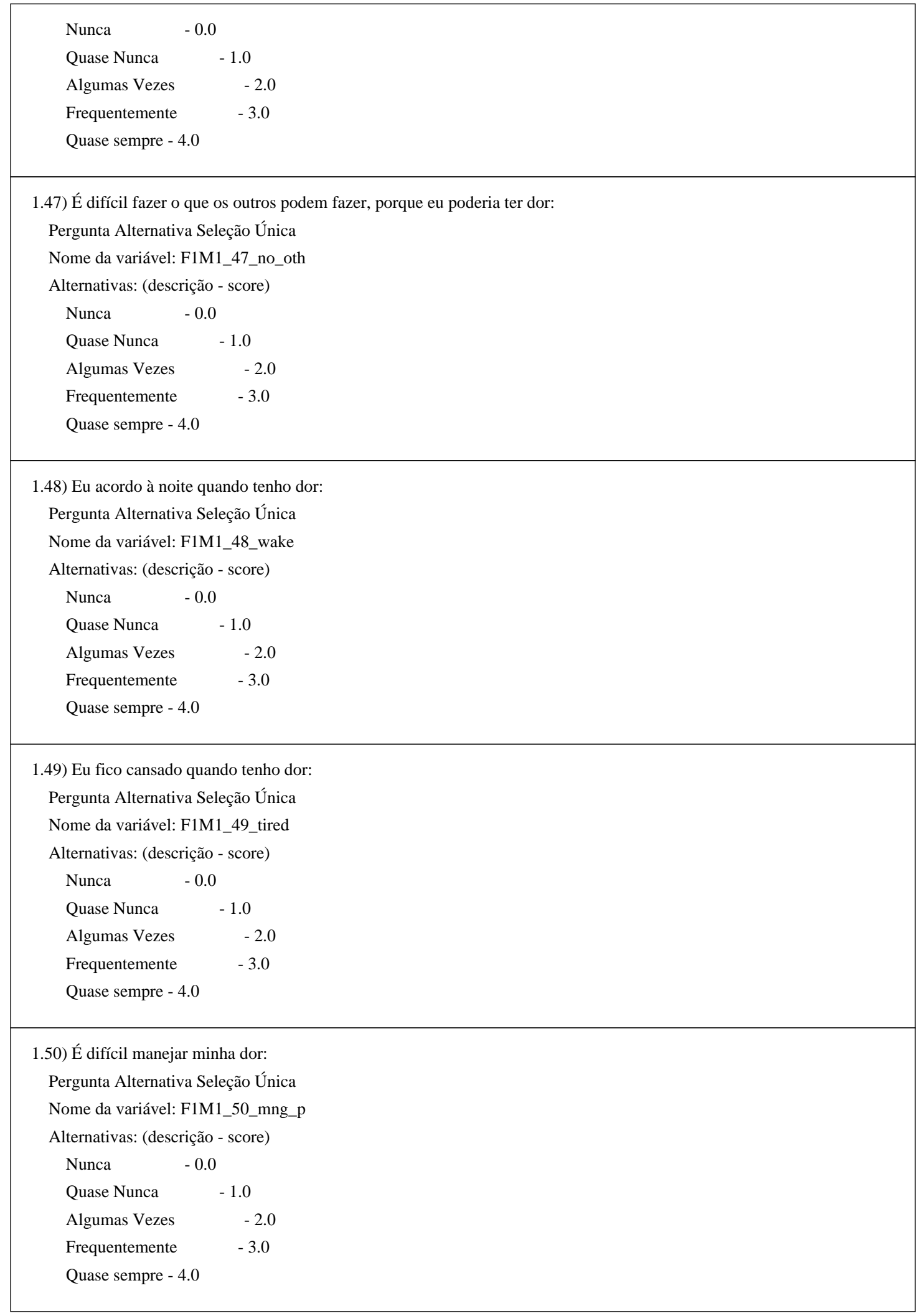




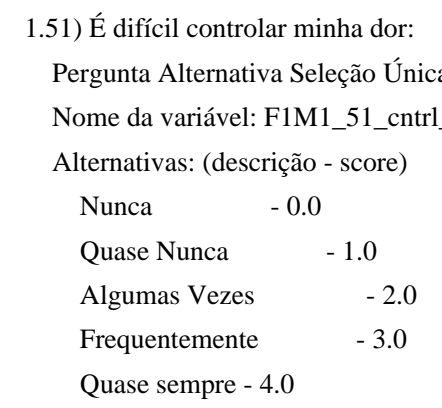

1.52) Eu me preocupo se vou ter dor:

Pergunta Alternativa Seleção Única

Nome da variável: F1M1_52_wor_p

Alternativas: (descrição - score)

$\begin{array}{lc}\text { Nunca } & -0.0 \\ \text { Quase Nunca } & -1.0 \\ \text { Algumas Vezes } & -2.0 \\ \text { Frequentemente } & -3.0 \\ \text { Quase sempre - 4.0 } & \end{array}$

1.53) Eu me preocupo se os outros não saberão o que fazer se eu tiver dor:

Pergunta Alternativa Seleção Única

Nome da variável: F1M1_53_wor_oth

Alternativas: (descrição - score)

$\begin{array}{lc}\text { Nunca } & -0.0 \\ \text { Quase Nunca } & -1.0 \\ \text { Algumas Vezes } & -2.0 \\ \text { Frequentemente } & -3.0 \\ \text { Quase sempre - 4.0 } & \end{array}$

1.54) Eu me preocupo quando estou longe de casa:

Pergunta Alternativa Seleção Única

Nome da variável: F1M1_54_wor_home

Alternativas: (descrição - score)

$\begin{array}{lc}\text { Nunca } & -0.0 \\ \text { Quase Nunca } & -1.0 \\ \text { Algumas Vezes } & -2.0 \\ \text { Frequentemente } & -3.0 \\ \text { Quase sempre - } 4.0 & \end{array}$

Quase sempre - 4.0

1.55) Eu me preocupo se poderei ter que ir a emergência:

Pergunta Alternativa Seleção Única

Nome da variável: F1M1_55_wor_er

Alternativas: (descrição - score)
Nunca
$-0.0$
Quase Nunca
$-1.0$

Algumas Vezes 


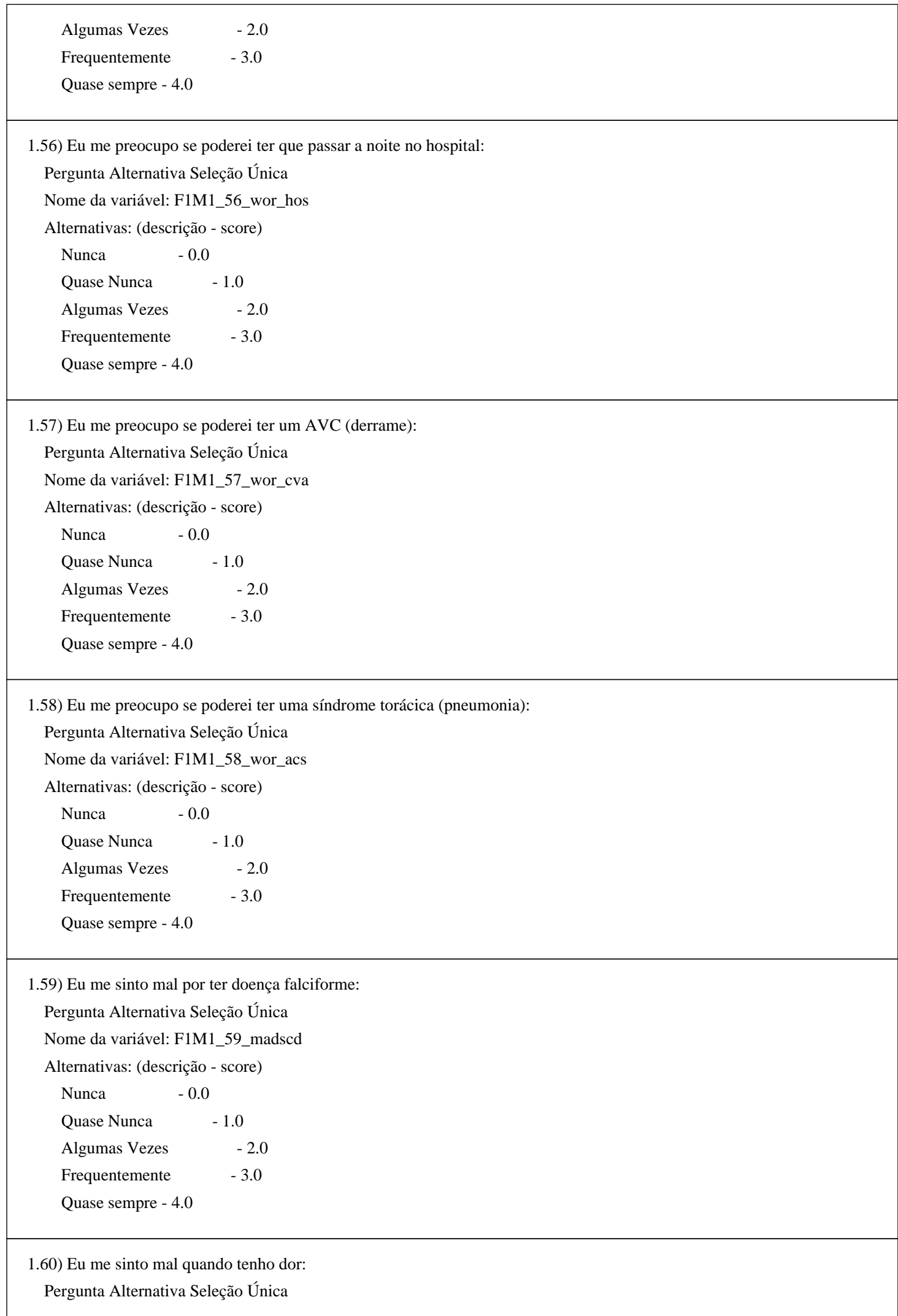


Nome da variável: F1M1_60_madvoe

Alternativas: (descrição - score)

$\begin{array}{lc}\text { Nunca } & -0.0 \\ \text { Quase Nunca } & -1.0 \\ \text { Algumas Vezes } & -2.0 \\ \text { Frequentemente } & -3.0 \\ \text { Quase sempre - } 4.0 & \end{array}$

1.61) É difícil lembrar de tomar meus remédios:

Pergunta Alternativa Seleção Única

Nome da variável: F1M1_61_nomed

Alternativas: (descrição - score)
Nunca
$-0.0$
Quase Nunca
$-1.0$
Algumas Vezes
$-2.0$
Frequentemente
$-3.0$
Quase sempre - 4.0

1.62) Eu não gosto de como me sinto após tomar meus remédios:

Pergunta Alternativa Seleção Única

Nome da variável: F1M1_62_feel_med

Alternativas: (descrição - score)
Nunca $\quad-0.0$
Quase Nunca $\quad-1.0$
Algumas Vezes $\quad-2.0$
Frequentemente $\quad-3.0$
Quase sempre - 4.0

1.63) Eu não gosto do sabor dos meus remédios:

Pergunta Alternativa Seleção Única

Nome da variável: F1M1_63_med_tast

Alternativas: (descrição - score)
Nunca
$-0.0$
Quase Nunca
$-1.0$
Algumas Vezes
$-2.0$
Frequentemente
$-3.0$
Quase sempre - 4.0

1.64) Meus remédios me deixam sonolento:

Pergunta Alternativa Seleção Única

Nome da variável: F1M1_64_med_slp

Alternativas: (descrição - score)
Nunca
$-0.0$
Quase Nunca
$-1.0$
Algumas Vezes
$-2.0$
Frequentemente
$-3.0$
Quase sempre - 4.0 
Quase sempre - 4.0

1.65) Eu me preocupo se meu remédio está funcionando:

Pergunta Alternativa Seleção Única

Nome da variável: F1M1_65_wor_med

Alternativas: (descrição - score)

$\begin{array}{lc}\text { Nunca } & -0.0 \\ \text { Quase Nunca } & -1.0 \\ \text { Algumas Vezes } & -2.0 \\ \text { Frequentemente } & -3.0 \\ \text { Quase sempre - } 4.0 & \end{array}$

1.66) Eu me preocupo se meu tratamento está funcionando:

Pergunta Alternativa Seleção Única

Nome da variável: F1M1_66_wor_tx

Alternativas: (descrição - score)

$\begin{array}{lc}\text { Nunca } & -0.0 \\ \text { Quase Nunca } & -1.0 \\ \text { Algumas Vezes } & -2.0 \\ \text { Frequentemente } & -3.0 \\ \text { Quase sempre - } 4.0 & \end{array}$

1.67) Meus remédios não me fazem sentir melhor:

Pergunta Alternativa Seleção Única

Nome da variável: F1M1_67_no_betr

Alternativas: (descrição - score)

$\begin{array}{lc}\text { Nunca } & -0.0 \\ \text { Quase Nunca } & -1.0 \\ \text { Algumas Vezes } & -2.0 \\ \text { Frequentemente } & -3.0 \\ \text { Quase sempre }-4.0 & \end{array}$

1.68) É difícil contar aos outros quando eu estou com dor:

Pergunta Alternativa Seleção Única

Nome da variável: F1M1_68_tell_oth

Alternativas: (descrição - score)

$\begin{array}{lc}\text { Nunca } & -0.0 \\ \text { Quase Nunca } & -1.0 \\ \text { Algumas Vezes } & -2.0 \\ \text { Frequentemente } & -3.0 \\ \text { Quase sempre - } 4.0 & \end{array}$

1.69) É difícil contar aos médicos e enfermeiros como eu me sinto:

Pergunta Alternativa Seleção Única

Nome da variável: F1M1_69_tell_md

Alternativas: (descrição - score) 


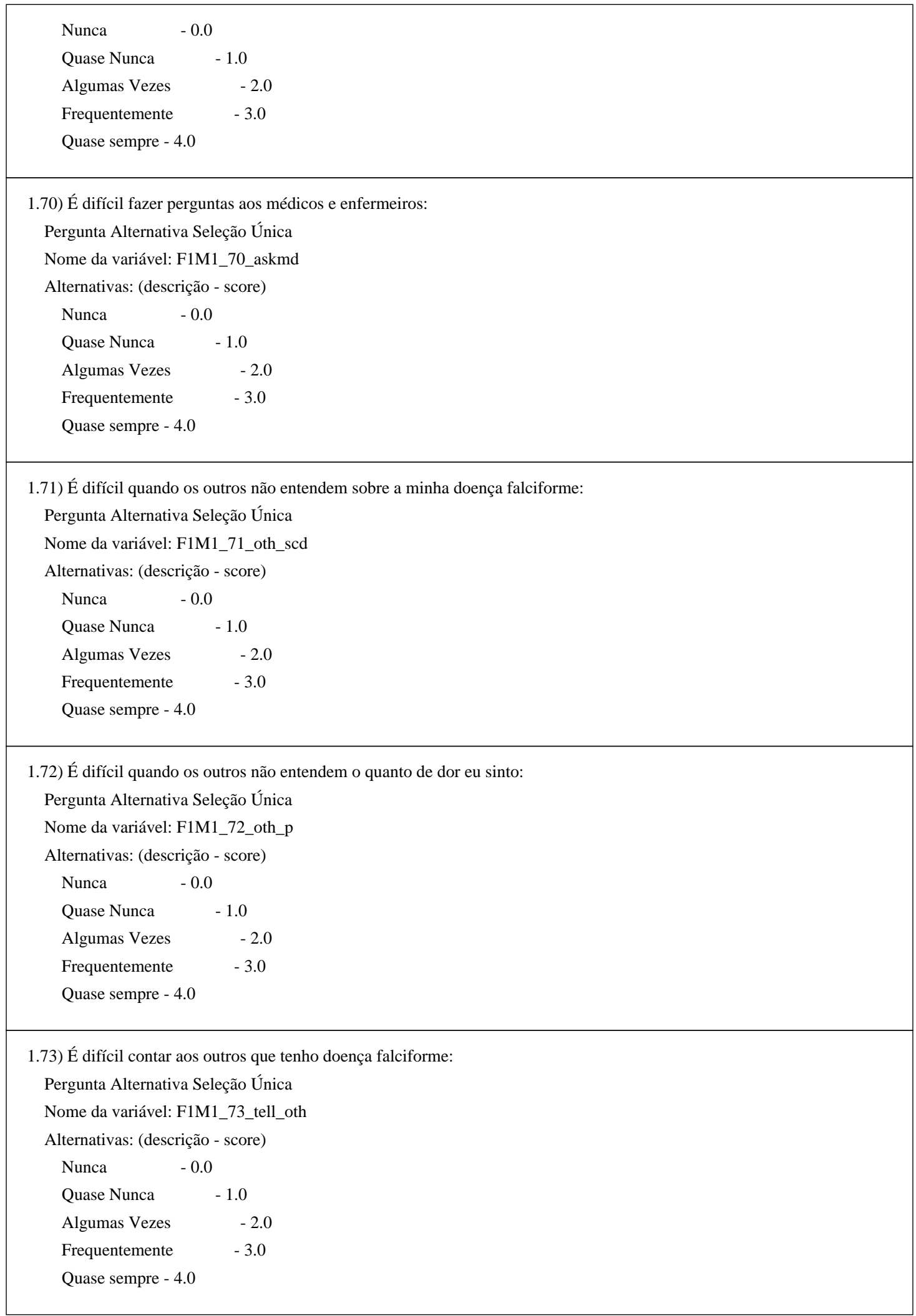




\section{Módulo: 2 - Entrevista}

2.1) Qual o sexo do paciente (registre sem perguntar ao paciente)

Pergunta Alternativa Seleção Única

Nome da variável: F1M2_1_sex

Alternativas: (descrição - score)

Masculino - 1.0

Feminino - 2.0

\section{2) Qual a sua idade?}

Pergunta Número Inteiro

Nome da variável: F1M2_2_age

Intervalo permitido: 0 - 99

2.3) Atualmente você esta estudando?

Pergunta Alternativa Seleção Única

Nome da variável: F1M2_3_sch

Alternativas: (descrição - score)

Sim - 1.0

Não -2.0

2.4) Nos últimos 30 dias, quantos dias de escola você teve que faltar por causa da dor devido à doença falciforme?

Pergunta Número Inteiro

Nome da variável: F1M2_4_m_sch

Intervalo permitido: 0 - 30

2.5) Atualmente você esta trabalhando?

Pergunta Alternativa Seleção Única

Nome da variável: F1M2_5_wor

Alternativas: (descrição - score)

Sim - 1.0

Não - 2.0

2.6) Qual o tipo do seu trabalho?

Pergunta Alternativa Seleção Única

Nome da variável: F1M2_6_ty_wor

Alternativas: (descrição - score)

Autonomo - 1.0

Emprego de tempo integral ( 8 ou mais horas diárias) - 2.0

Emprego de meio horário (menos de 8 horas diárias) - 3.0

2.7) Nos últimos 30 dias, quantos dias de trabalho você teve que faltar por causa da dor devido à doença falciforme?

Pergunta Número Inteiro

Nome da variável: F1M2_7_m_wor

Intervalo permitido: 0 - 30 


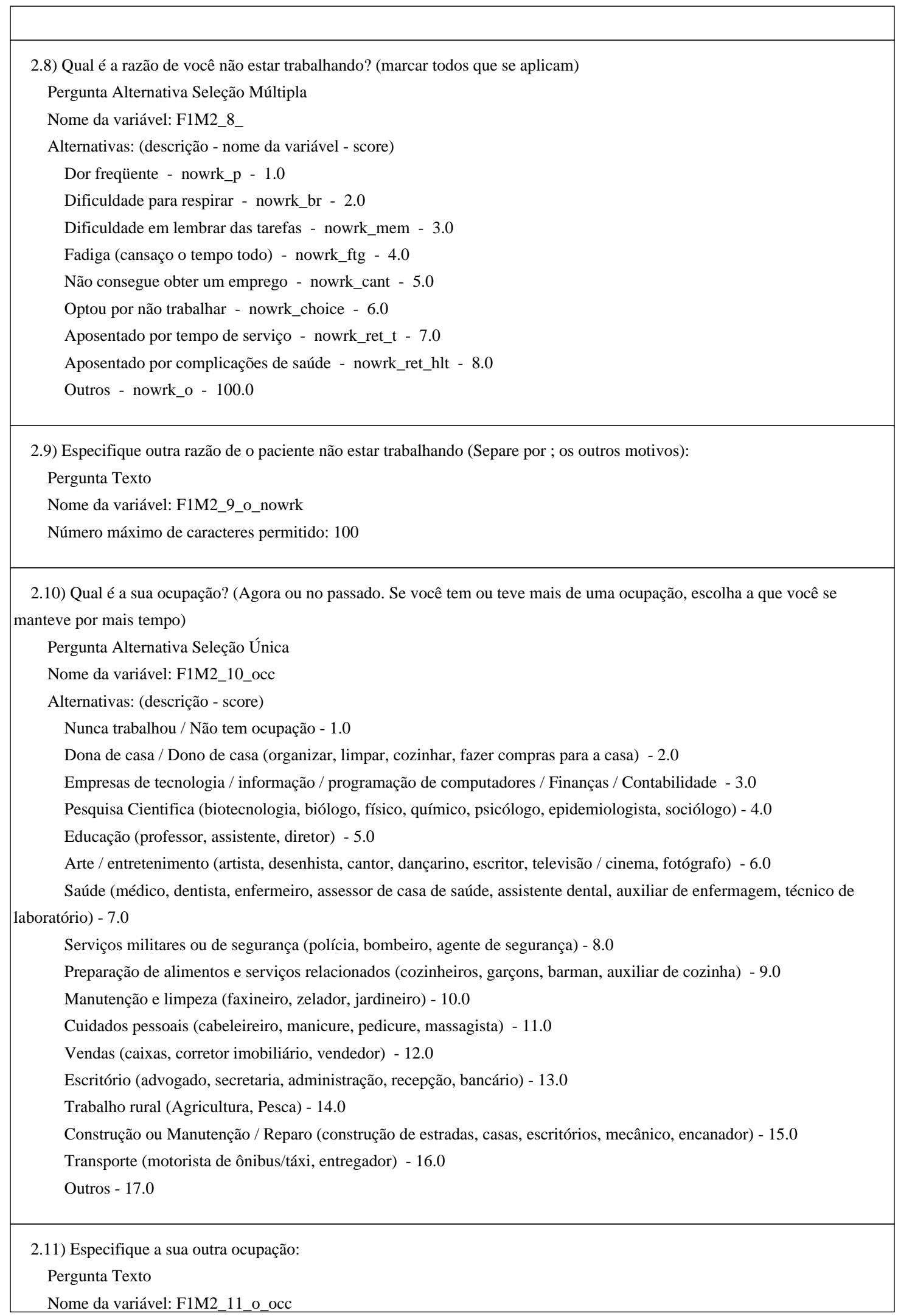


Nome da variável: F1M2_11_o_occ

Número máximo de caracteres permitido: 100

2.12) Nos últimos 30 dias, quantos dias você não foi capaz de realizar suas atividades diárias devido à dor falciforme? Pergunta Número Inteiro

Nome da variável: F1M2_12_n_act

Intervalo permitido: 0 - 30

2.13) Você recebe algum tipo de benefício social?

Pergunta Alternativa Seleção Única

Nome da variável: F1M2_13_ben

Alternativas: (descrição - score)

Sim -1.0

Não - 2.0

2.14) Qual o tipo de beneficio social você recebe?

Pergunta Alternativa Seleção Múltipla

Nome da variável: F1M2_14

Alternativas: (descrição - nome da variável - score)

LOAS - Lei orgânica da assistência social - ben_loas - 1.0

TFD - Tratamento fora do domicilio - ben_tfd - 2.0

Aposentadoria por invalidez - INPS / INSS (não considerar aposentadoria por tempo de serviço/contribuição) - ben_inss 3.0

Auxilio doença - ben_ad - 4.0

BPC - Beneficio de prestação continuada - ben_bpc - 5.0

Bolsa familia - ben_bf - 6.0

Cartão carioca - ben_cc - 7.0

Auxilio moradia - ben_am - 8.0

Bolsa escola - ben_be - 9.0

Outros - ben_o - 150.0

2.15) Especifique o outro beneficio social que você recebe (Separe com ; os outros benefício sociais):

Pergunta Texto

Nome da variável: F1M2_15_o_ben

Número máximo de caracteres permitido: 100

2.16) Qual é a RENDA MENSAL aproximada da sua família?

Pergunta Alternativa Seleção Única

Nome da variável: F1M2_16_inco

Alternativas: (descrição - score)

Menos que R $\$ 700,00$ - 1.0

Entre R $\$ 701,00$ e R $\$ 1.400,00-2.0$

Entre 1.401,00 a R \$3.000,00 - 3.0

Entre $\mathrm{R} \$ 3.001,00$ a $\mathrm{R} \$ 6.000,00-4.0$

Mais que $\mathrm{R} \$ 6.000,00$ - 5.0 
2.17) Você tem plano de saúde?

Pergunta Alternativa Seleção Única

Nome da variável: F1M2_17_ins

Alternativas: (descrição - score)

Sim -1.0

Não - 2.0

2.18) Qual o tipo do seu plano de saúde? (marque todas que se aplicam)

Pergunta Alternativa Seleção Múltipla

Nome da variável: F1M2_18_t_ins

Alternativas: (descrição - nome da variável - score)

Próprio - _your - 1.0

Empresarial - _corp - 2.0

2.26) Nos últimos 30 dias, quantas consultas não agendadas você fez a algum consultório médico, hospital, pronto socorro ou clínica por causa da doença falciforme?

Pergunta Número Inteiro

Nome da variável: F1M2_26_n_uns

Intervalo permitido: 0 - 31

2.27.0) Essa paciente respondeu "1- Sim" na questão 2.15.1 (variable: menst_i2) no questionário de inscrição? Pergunta Alternativa Seleção Única

Nome da variável: F1M2_27_0_ment_i2

Alternativas: (descrição - score)

Sim -1.0

Não - 2.0

2.27) Você já teve a primeira menstruação?

Pergunta Alternativa Seleção Única

Nome da variável: F1M2_27_fmc

Alternativas: (descrição - score)

Sim -1.0

Não - 2.0

2.28) Você entrou na menopausa (sem ciclo menstrual por 1 ano)?

Pergunta Alternativa Seleção Única

Nome da variável: F1M2_28_mps

Alternativas: (descrição - score)

Sim - 1.0

Não -2.0

\subsection{9) Você está grávida?}

Pergunta Alternativa Seleção Única

Nome da variável: F1M2_29_cpgt

Alternativas: (descrição - score)

Sim - 1.0 
Não - 2.0

2.30) Você já esteve grávida alguma vez na vida? (excluir gravidez atual, se aplicável)

Pergunta Alternativa Seleção Única

Nome da variável: F1M2_30_ev_pgt

Alternativas: (descrição - score)

Sim -1.0

Não - 2.0

Planilha: Questões relacionada a Gravidez

Itens: (Descrição - Nome da variável)

Gravidez - F1M2

2.31) Você recebeu transfusão crônica durante a gravidez (regular ou mensal)?

Pergunta Alternativa Seleção Única

Nome da variável:_31_chtx_pg

Alternativas: (descrição - score)

Sim -1.0

Não - 2.0

2.32) Você recebeu transfusão durante ou 5 dias após o parto?

Pergunta Alternativa Seleção Única

Nome da variável: _32_tx_deliv

Alternativas: (descrição - score)

Sim -1.0

Não - 2.0

2.33) Qual foi o tipo de parto?

Pergunta Alternativa Seleção Única

Nome da variável: _33_ty_deliv

Alternativas: (descrição - score)

Parto normal - 1.0

Cesario - 2.0

2.34) A gravidez resultou em:

Pergunta Alternativa Seleção Única

Nome da variável:_34_res_pgt

Alternativas: (descrição - score)

Nascimento a termo (9 meses completes e bebe nascido vivo) - 1.0

Nascimento prematuro ( não completou 9 meses e bebe nascido vivo) - 2.0

Aborto (induzido ou espontaneo) - 3.0

2.35) Você andou de moto nos últimos 12 meses?

Pergunta Alternativa Seleção Única

Nome da variável: F1M2_35_mbik

Alternativas: (descrição - score)

Sim - 1.0

Não - 2.0

2.36) Você andou de moto nos últimos 30 dias?

Pergunta Alternativa Seleção Única

Nome da variável: F1M2_36_mbik_130

Alternativas: (descrição - score)

Sim -1.0

Não -2.0

2.37) Quantos dias nos últimos 30 dias você andou de moto?

Pergunta Número Inteiro 
Nome da variável: F1M2_37_n_mbik

Intervalo permitido: 1 - 31

\subsection{8) Data da entrevista:}

\section{Pergunta Data}

Nome da variável: F1M2_38_d_int

Intervalo permitido: 01/01/2014 - 31/12/2016

2.39) Tipo de entrevista?

Pergunta Alternativa Seleção Única

Nome da variável: F1M2_39_ty_int

Alternativas: (descrição - score)

Presencial - 1.0

Por telefone - 2.0

\section{Módulo: Screening}

2.20) Selecione o hemocentro de recrutamento

Pergunta Alternativa Seleção Única

Nome da variável: F1M2_20_ins

Alternativas: (descrição - score)

Hemominas $\mathrm{HBH}-1.0$

Hemominas JFO - 2.0

Hemominas MOC - 3.0

Hemope - 4.0

Hemorio - 5.0

ITACI - 6.0

\section{Módulo: 2 - Entrevista HBH}

2.19) Nos últimos 12 meses, você recebeu algum tratamento para a doença falciforme em outra instituição? Pergunta Alternativa Seleção Única

Nome da variável: F1M2_19_tx_oins

Alternativas: (descrição - score)

Sim -1.0

Não - 2.0

2.20.1) HBH - Qual o nome da instituição onde você recebeu tratamento?

Pergunta Alternativa Seleção Múltipla

Nome da variável: F1M2_20_1

Alternativas: (descrição - nome da variável - score)

Central de Pediatria de Belo Horizonte - hbh_cp - 1.0

Hemominas de Divinopolis - hbh_div - 2.0

Hospital das Clinicas de Belo Horizonte - hbh_clin - 3.0 
Hospital da Baleia de Belo Horizonte - hbh_bal - 4.0

Hospital de Betim - hbh_bet - 5.0

Hospital Felicio Rocho de Belo Horizonte - hbh_fr - 6.0

Hospital Municipal de Contagem - hbh_mc - 7.0

Hospital Nossa Senhora da Conceicao de Para de Minas - hbh_nsc - 8.0

Hospital Nossa Senhora das Dores - hbh_nsd - 9.0

Hospital Odilon Behrens de Belo Horizonte - hbh_ob - 10.0

Hospital Santa Casa de Passos - hbh_scp - 11.0

Hospital Santa Casa de Belo Horizonte - hbh_scbh - 12.0

Hospital Sao Francisco de Assis - hbh_sf - 13.0

Ipsemg - Instituto de Previdência dos Servidores do Estado de Minas Gerais - hbh_ips - 14.0

Outra - hbh_o - 100.0

2.21.1) HBH - Especifique a outra INSTITUIÇÃO e CIDADE onde você recebeu tratamento nos últimos 12 meses (Separe por ; as outras instituições):

Pergunta Texto

Nome da variável: F1M2_21_1hbho

Número máximo de caracteres permitido: 100

2.22) Nos últimos 12 meses, você recebeu transfusões de sangue em outra instituição?

Pergunta Alternativa Seleção Única

Nome da variável: F1M2_22_tx_o

Alternativas: (descrição - score)

Sim -1.0

Não - 2.0

2.23.1) HBH - Qual o nome da instituição onde você recebeu transfusão?

Pergunta Alternativa Seleção Múltipla

Nome da variável: F1M2_23_1

Alternativas: (descrição - nome da variável - score)

Central de Pediatria de Belo Horizonte - hbhtx_cp - 1.0

Hemominas de Divinopolis - hbhtx_div - 2.0

Hospital das Clinicas de Belo Horizonte - hbhtx_clin - 3.0

Hospital da Baleia de Belo Horizonte - hbhtx_bal - 4.0

Hospital de Betim - hbhtx_bet - 5.0

Hospital Felicio Rocho de Belo Horizonte - hbhtx_fr - 6.0

Hospital Municipal de Contagem - hbhtx_mc - 7.0

Hospital Nossa Senhora da Conceicao de Para de Minas - hbhtx_nsc - 8.0

Hospital Nossa Senhora das Dores - hbhtx_nsd - 9.0

Hospital Odilon Behrens de Belo Horizonte - hbhtx_ob - 10.0

Hospital Santa Casa de Passos - hbhtx_scp - 11.0

Hospital Santa Casa de Belo Horizonte - hbhtx_scbh - 12.0

Hospital Sao Francisco de Assis - hbhtx_sf - 13.0

Ipsemg - Instituto de Previdência dos Servidores do Estado de Minas Gerais - hbhtx_ips - 14.0

Outra - hbhtx_o - 100.0 
2.24.1) HBH - Especifique a outra INSTITUIÇÃO e CIDADE onde você recebeu transfusão nos últimos 12 meses (Separe por ; as outras instituições):

Pergunta Texto

Nome da variável: F1M2_24_1hbh_otx

Número máximo de caracteres permitido: 100

2.25) Quantas transfusões foram realizadas em outra instituição nos últimos 12 meses?

Pergunta Número Inteiro

Nome da variável: F1M2_25_n_otx

Intervalo permitido: 0 - 100

\section{Módulo: 2 - Entrevista JFO}

2.19) Nos últimos 12 meses, você recebeu algum tratamento para a doença falciforme em outra instituição?

Pergunta Alternativa Seleção Única

Nome da variável: F1M2_19_tx_oins

Alternativas: (descrição - score)

Sim -1.0

Não -2.0

2.20.2 ) JFO - Qual o nome da instituição onde você recebeu tratamento?

Pergunta Alternativa Seleção Múltipla

Nome da variável: F1M2_20_2

Alternativas: (descrição - nome da variável - score)

Hospital Monte Sinai de Juiz de Fora - jfo_ms - 1.0

Hospital de Cataguases - jfo_cat - 2.0

Hospital Joao Penido de Juiz de Fora - jfo_jp - 3.0

Hospital Santa Isabel de Uba - jfo_si - 4.0

Hospital Universitario de Juiz de Fora - jfo_u - 5.0

Maternidade Terezinha de Jesus de Juiz de Fora - jfo_mtj - 6.0

Santa Casa de Juiz de Fora - jfo_sc - 7.0

Outra - jfo_o - 100.0

2.21.2) JFO - Especifique a outra INSTITUIÇÃO e CIDADE onde você recebeu tratamento nos últimos 12 meses (Separe por ; as outras instituições):

Pergunta Texto

Nome da variável: F1M2_21_2jfo_o

Número máximo de caracteres permitido: 100

2.22) Nos últimos 12 meses, você recebeu transfusões de sangue em outra instituição?

Pergunta Alternativa Seleção Única

Nome da variável: F1M2_22_tx_o

Alternativas: (descrição - score)

Sim -1.0

Não - 2.0 


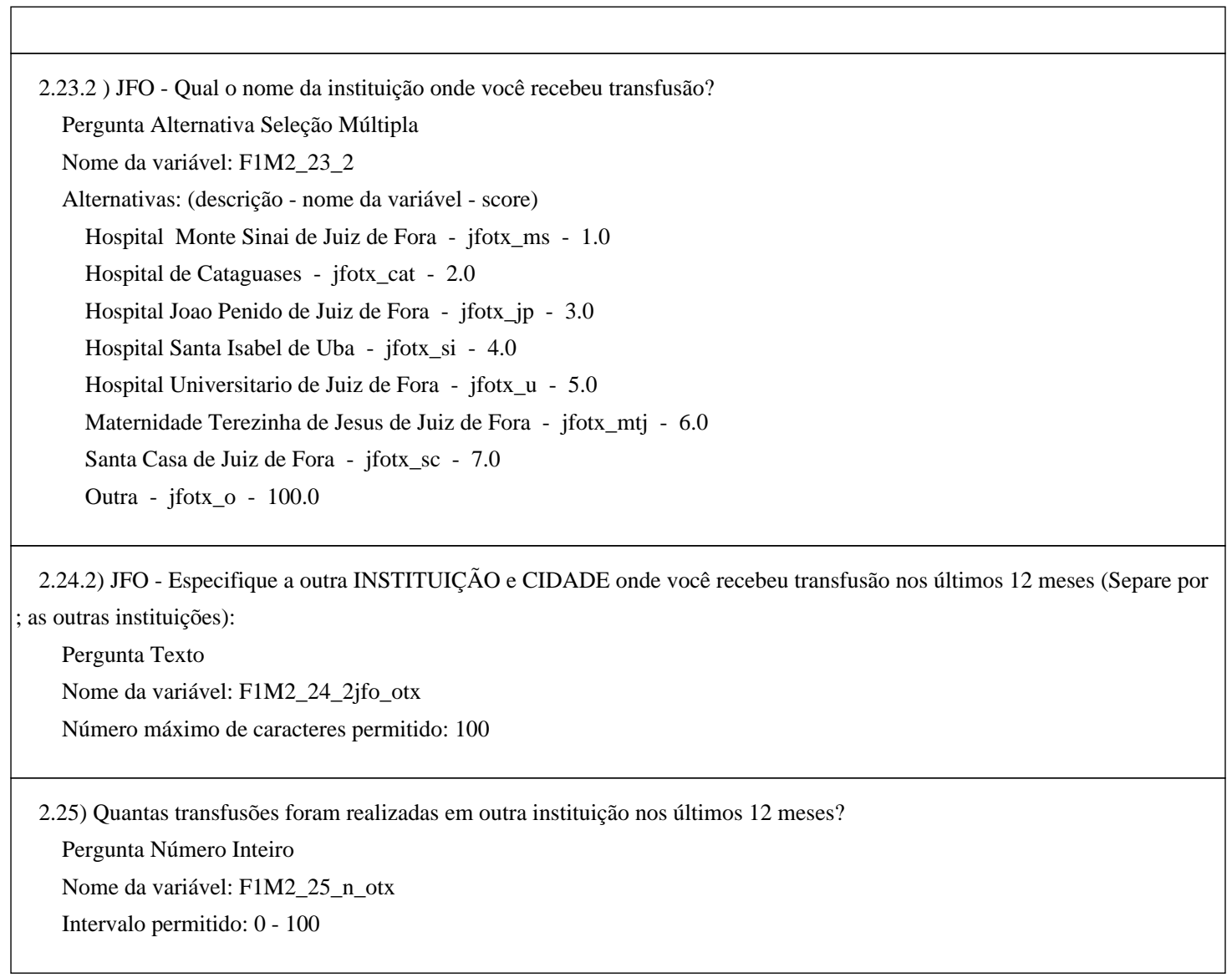

\section{Módulo: 2 - Entrevista MOC}

2.19) Nos últimos 12 meses, você recebeu algum tratamento para a doença falciforme em outra instituição? Pergunta Alternativa Seleção Única

Nome da variável: F1M2_19_tx_oins

Alternativas: (descrição - score)

Sim -1.0

Não -2.0

2.20.3 ) MOC - Qual o nome da instituição onde você recebeu tratamento?

Pergunta Alternativa Seleção Múltipla

Nome da variável: F1M2_20_3

Alternativas: (descrição - nome da variável - score)

Fundacao Hospital Dr. Moises Magalhaes Freire - moc_mmf - 1.0

Hospital de Bocaiuva - moc_boc - 2.0

Hospital de Brasilia de Minas - moc_bm - 3.0

Hospital Municipal de Januaria - moc_mj - 4.0

Hospital Pronto Socorro de Varzea da Palma - moc_psvp - 5.0

Hospital Santa Casa de Montes Claros - moc_scmc - 6.0

Hospital Sao Vicente de Paula - moc_svp - 7.0 
Hospital Universitario de Montes Claros - moc_u - 8.0

Outra - moc_o - 100.0

2.21.3) MOC - Especifique a outra INSTITUIÇÃO e CIDADE onde você recebeu tratamento nos últimos 12 meses (Separe por ; as outras instituições):

Pergunta Texto

Nome da variável: F1M2_21_3moc_o

Número máximo de caracteres permitido: 100

2.22) Nos últimos 12 meses, você recebeu transfusões de sangue em outra instituição?

Pergunta Alternativa Seleção Única

Nome da variável: F1M2_22_tx_o

Alternativas: (descrição - score)

Sim -1.0

Não - 2.0

2.23.3 ) MOC - Qual o nome da instituição onde você recebeu transfusão?

Pergunta Alternativa Seleção Múltipla

Nome da variável: F1M2_23_3

Alternativas: (descrição - nome da variável - score)

Fundacao Hospital Dr. Moises Magalhaes Freire - moctx_mmf - 1.0

Hospital de Bocaiuva - moctx_boc - 2.0

Hospital de Brasilia de Minas - moctx_bm - 3.0

Hospital Municipal de Januaria - moctx_mj - 4.0

Hospital Pronto Socorro de Varzea da Palma - moctx_psvp - 5.0

Hospital Santa Casa de Montes Claros - moctx_scmc - 6.0

Hospital Sao Vicente de Paula - moctx_svp - 7.0

Hospital Universitario de Montes Claros - moctx_u - 8.0

Outra - moctx_o - 100.0

2.24.3) MOC - Especifique a outra INSTITUIÇÃO e CIDADE onde você recebeu transfusão nos últimos 12 meses (Separe por ; as outras instituições):

Pergunta Texto

Nome da variável: F1M2_24_3moc_otx

Número máximo de caracteres permitido: 100

2.25) Quantas transfusões foram realizadas em outra instituição nos últimos 12 meses?

Pergunta Número Inteiro

Nome da variável: F1M2_25_n_otx

Intervalo permitido: 0 - 100

\section{Módulo: 2 - Entrevista Hemope}

2.19) Nos últimos 12 meses, você recebeu algum tratamento para a doença falciforme em outra instituição? Pergunta Alternativa Seleção Única 


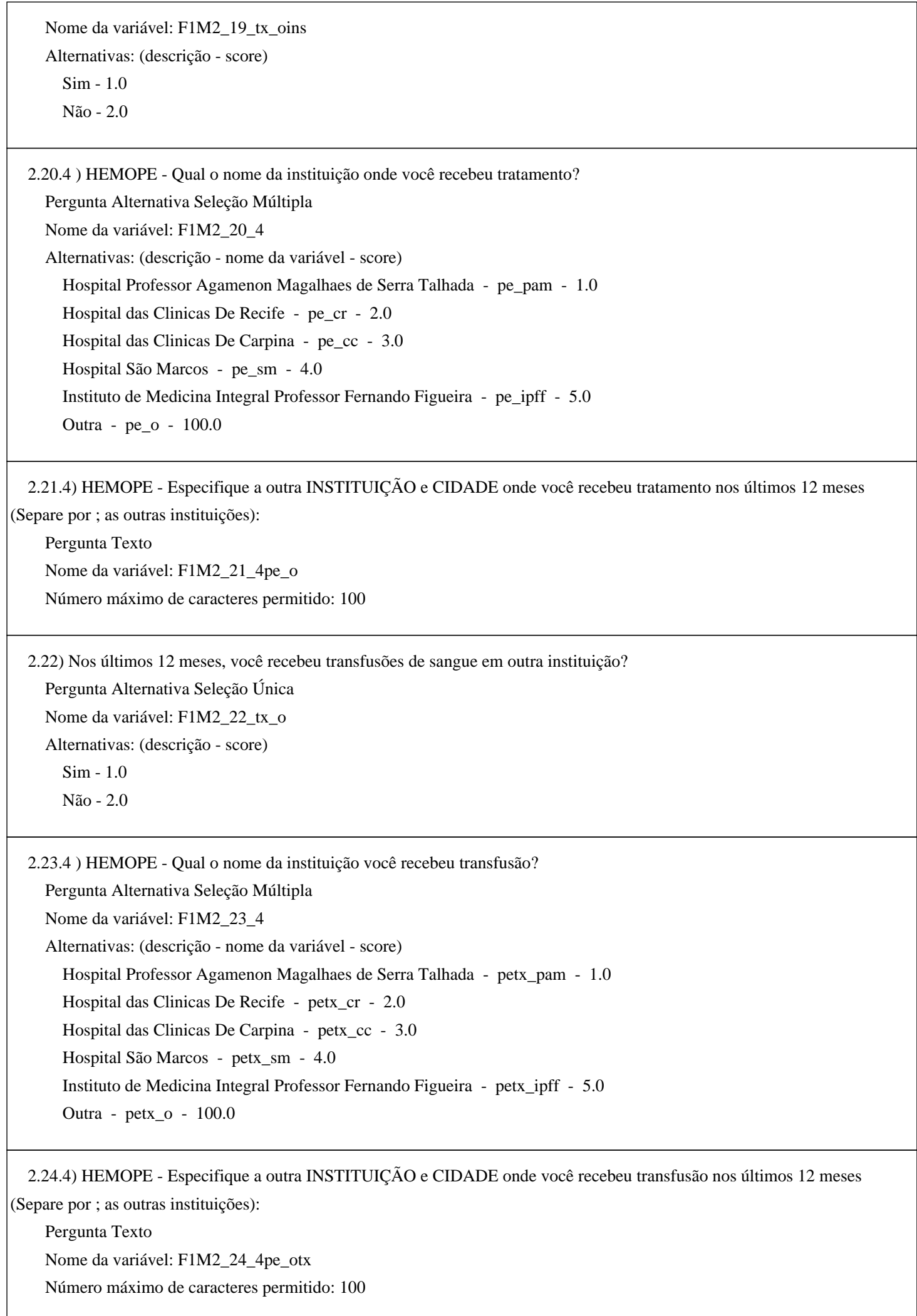


2.25) Quantas transfusões foram realizadas em outra instituição nos últimos 12 meses?

Pergunta Número Inteiro

Nome da variável: F1M2_25_n_otx

Intervalo permitido: 0 - 100

\section{Módulo: 2 - Entrevista Hemorio}

2.19) Nos últimos 12 meses, você recebeu algum tratamento para a doença falciforme em outra instituição?

Pergunta Alternativa Seleção Única

Nome da variável: F1M2_19_tx_oins

Alternativas: (descrição - score)

Sim - 1.0

Não - 2.0

2.20.5) HEMORIO - Qual o nome da instituição onde você recebeu tratamento?

Pergunta Alternativa Seleção Múltipla

Nome da variável: F1M2_20_5

Alternativas: (descrição - nome da variável - score)

Casa de Saude Nossa Senhora de Fatima - rj_csnsf - 1.0

Fundação Municipal Hospitalar de Macae - rj_fmhm - 2.0

Hospital Cardoso Fontes do Rio de Janeiro - rj_cfrj - 3.0

Hospital de Rio Bonito - rj_rb - 4.0

Hospital de Valenca - rj_v - 5.0

Hospital Federal da Lagoa do Rio de Janeiro - rj_fl - 6.0

Hospital Fernando Magalhaes do Rio de Janeiro - rj_fmag - 7.0

Hospital Ferreira Machado do Rio de Janeiro - rj_fmac - 8.0

Hospital Geral Dr. Beda - rj_gdb - 9.0

Hospital Geral Semiu do Rio de Janeiro - rj_gsrj - 10.0

Hospital Menino Jesus - rj_mj - 11.0

Hospital Municipal Souza Aguiar do Rio de Janeiro - rj_msa - 12.0

Hospital Nogueira de Souza do Rio de Janeiro - rj_ns - 13.0

Hospital Rocha Faria de Campo Grande - rj_rfcg - 14.0

Hospital Sao Joao Batista de Volta Redonda - rj_sjb - 15.0

Serviço de Assistência Médico-Cirúrgica Infantil - rj_inf - 16.0

Outra - rj_o - 100.0

2.21.5) HEMORIO - Especifique a outra INSTITUIÇÃO e CIDADE onde você recebeu tratamento nos últimos 12 meses (Separe por ; as outras instituições):

Pergunta Texto

Nome da variável: F1M2_21_5rj_o

Número máximo de caracteres permitido: 100

2.22) Nos últimos 12 meses, você recebeu transfusões de sangue em outra instituição?

Pergunta Alternativa Seleção Única

Nome da variável: F1M2_22_tx_o 


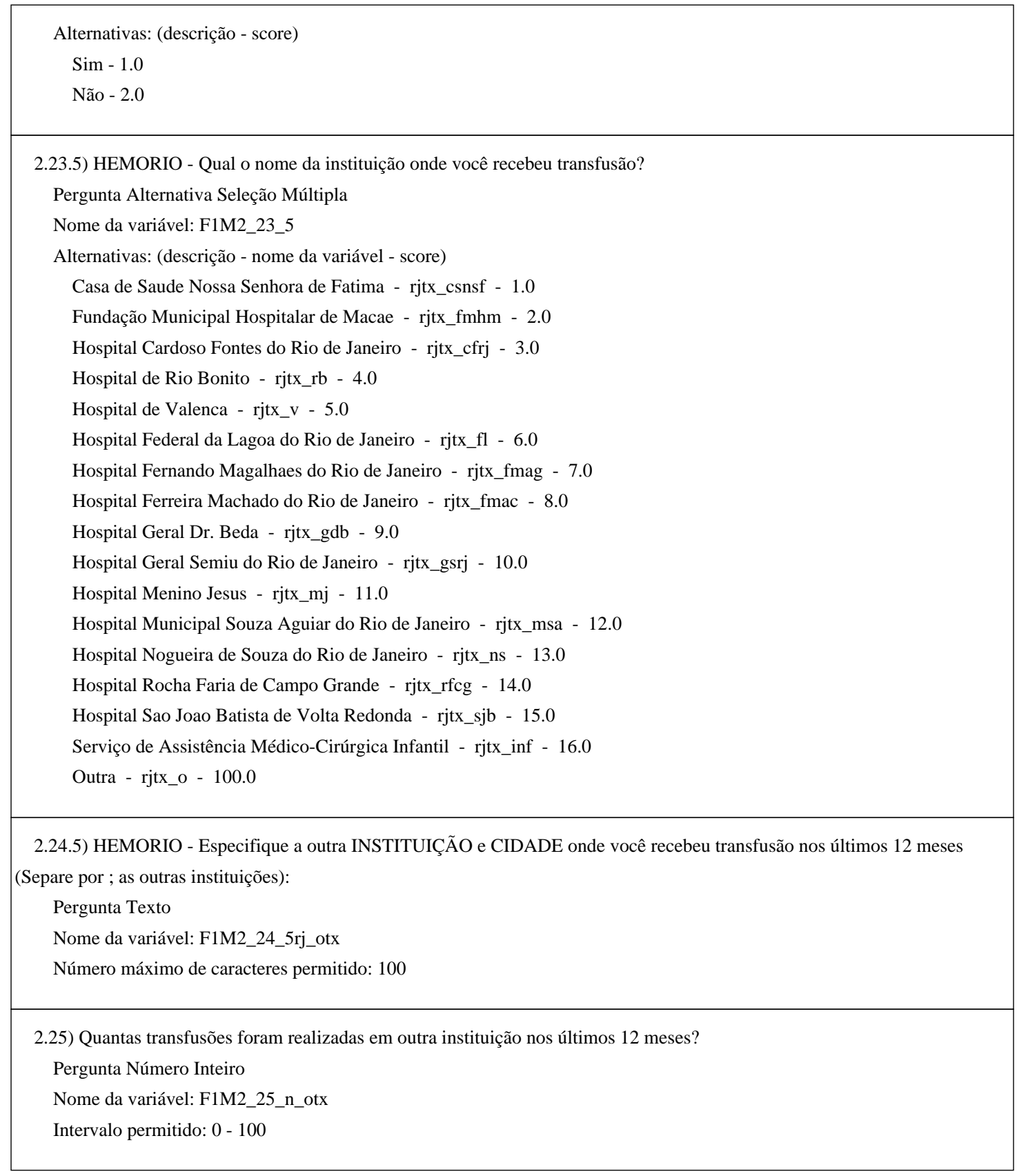

\section{Módulo: 2 - Entrevista ITACI}

2.19) Nos últimos 12 meses, você recebeu algum tratamento para a doença falciforme em outra instituição? Pergunta Alternativa Seleção Única

Nome da variável: F1M2_19_tx_oins

Alternativas: (descrição - score)

Sim - 1.0

Não - 2.0 


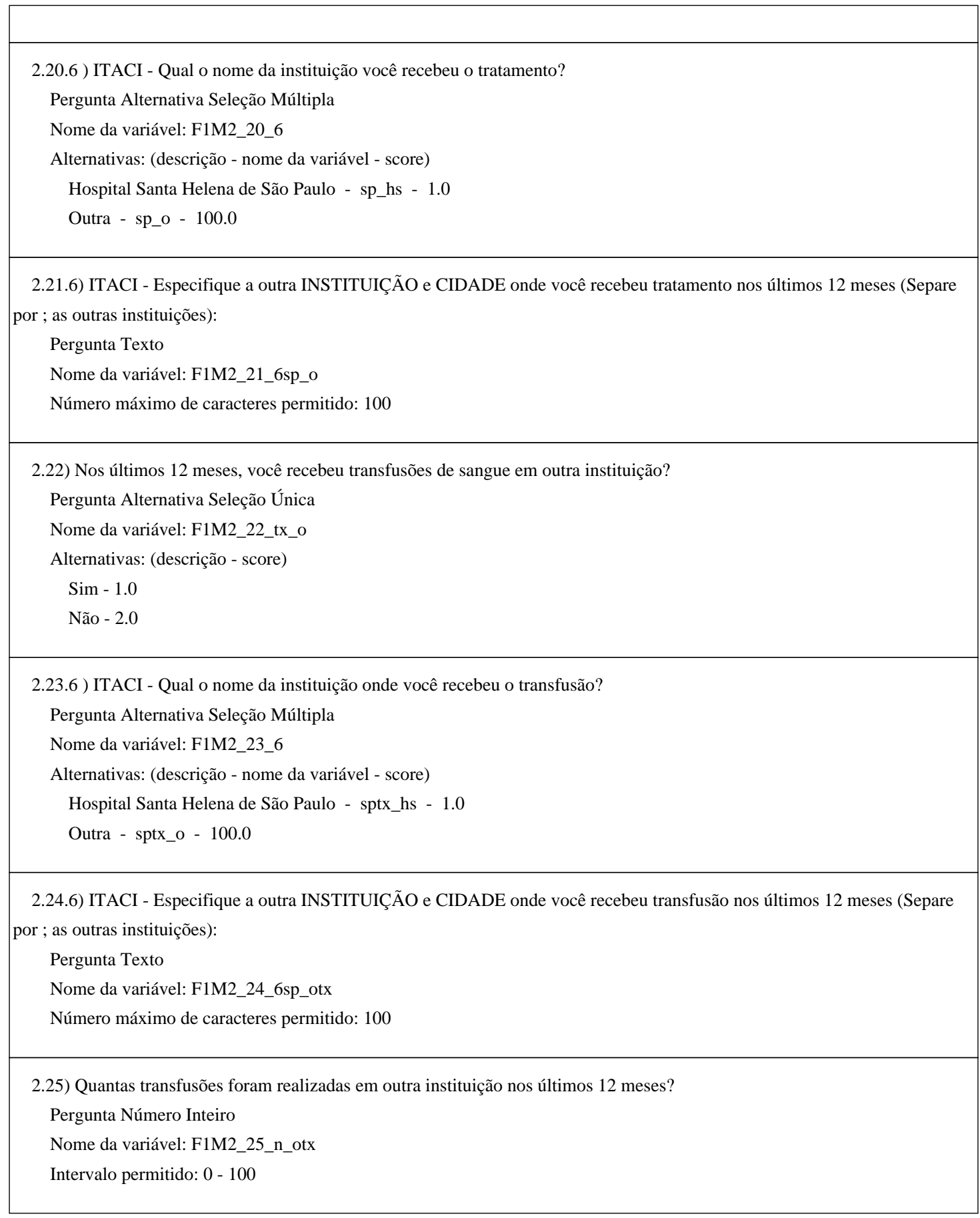




\section{Registro Médico - Acompanhamento 1}

Codebook impresso em 08/01/2018

\section{Módulo: 3 - Internações hospitalares}

3.1) O paciente teve internações hospitalares desde a sua inscrição no estudo? Pergunta Alternativa Seleção Única

Nome da variável: F1M3_1_hos

Alternativas: (descrição - score)

Sim -1.0

Não -2.0

Planilha: Questões relacionadas a internações hospitalares:

Itens: (Descrição - Nome da variável)

Internação - F1M3

3.2) Data da internação

Pergunta Data

Nome da variável: _2_d_adm

Intervalo permitido: $01 / 01 / 2013$ - 31/12/2016

3.3) Data da alta: (caso o paciente ainda esteja internado, marque "Não se aplica")

Pergunta Data

Nome da variável:_3_d_dc

Intervalo permitido: 01/01/2013 - 31/12/2016 
3.4) Diagnóstico 1:

Pergunta Alternativa Seleção Única

Nome da variável: 4 dx 1

Alternativas: (descrição - score)

Diagnóstico não localizado/Sem $2 \% 3^{\circ}$ diagnóstico - 1.0

Acidente vascular cerebral - Hemorrágico - 2.0

Acidente vascular cerebral - Infarto - 3.0

Anemia auto imune - 4.0

Asma - 5.0

Ataque isquêmico transitório - 6.0

Cardimiopatia - 7.0

Cirurgia programada - 8.0

Colecistite -9.0

Colelitíase - 10.0

Complicações oculares - 11.0

Convulsão - 12.0

Dactilite (síndrome mão-pé) - 13.0

Embolia Pulmonar - 14.0

Episódio aplástico - 15.0

Episodio de dor aguda da doença falciforme - 16.0

Febre, sem diagnóstico específico de infecção - 17.0

Hemossiderose Transfusional - 18.0

Hiperhemólise - 19.0

Hipertensão arterial sistêmica - 20.0

Hipertensão Pulmonar - 21.0

Infarto do Miocárdio - 22.0

Infecções graves - Sepses /bacteremia/Meningite - 23.0

Insuficiência cardíaca - 24.0

Insuficiência Renal - 25.0

Moya - Moya - 26.0

Necrose avascular-quadril / ombro Avascular - 27.0

Neuropatia (dor neuropática) - 28.0

Osteomielite (aguda ou crônica) - 29.0

Outras infeccões - 30.0

Outro diagnóstico não relacionado à Doença Falciforme - 31.0

Pancreatite - 32.0

Pielonefrite - 33.0

Priapismo - 34.0

Reação transfusional hemolítica tardia - 35.0

Sequestro esplênico agudo - 36.0

Sequestro hepático - 37.0

Síndrome nefrótica - 38.0

Síndrome Torácica Aguda/ Pneumonia - 39.0

Úlceras de perna - 40.0

3.5) Se outra infecção (30) ou outro diagnóstico não relacionado à Doença Falciforme (31), especifique: Pergunta Texto

Nome da variável: _5_dx1_o

Número máximo de caracteres permitido: 100 
3.6) Diagnóstico 2:

Pergunta Alternativa Seleção Única

Nome da variável: _6_dx2

Alternativas: (descrição - score)

Diagnóstico não localizado/Sem $2 \% 3^{\circ}$ diagnóstico - 1.0

Acidente vascular cerebral - Hemorrágico - 2.0

Acidente vascular cerebral - Infarto - 3.0

Anemia auto imune - 4.0

Asma - 5.0

Ataque isquêmico transitório - 6.0

Cardimiopatia - 7.0

Cirurgia programada - 8.0

Colecistite -9.0

Colelitíase - 10.0

Complicações oculares - 11.0

Convulsão - 12.0

Dactilite (síndrome mão-pé) - 13.0

Embolia Pulmonar - 14.0

Episódio aplástico - 15.0

Episodio de dor aguda da doença falciforme - 16.0

Febre, sem diagnóstico específico de infecção - 17.0

Hemossiderose Transfusional - 18.0

Hiperhemólise - 19.0

Hipertensão arterial sistêmica - 20.0

Hipertensão Pulmonar - 21.0

Infarto do Miocárdio - 22.0

Infecções graves - Sepses /bacteremia/Meningite - 23.0

Insuficiência cardíaca - 24.0

Insuficiência Renal - 25.0

Moya - Moya - 26.0

Necrose avascular-quadril / ombro Avascular - 27.0

Neuropatia (dor neuropática) - 28.0

Osteomielite (aguda ou crônica) - 29.0

Outras infeccões - 30.0

Outro diagnóstico não relacionado à Doença Falciforme - 31.0

Pancreatite - 32.0

Pielonefrite - 33.0

Priapismo - 34.0

Reação transfusional hemolítica tardia - 35.0

Sequestro esplênico agudo - 36.0

Sequestro hepático - 37.0

Síndrome nefrótica - 38.0

Síndrome Torácica Aguda/ Pneumonia - 39.0

Úlceras de perna - 40.0

3.7) Se outra infecção (30) ou outro diagnóstico não relacionado à Doença Falciforme (31), especifique: Pergunta Texto

Nome da variável: _7_dx2 o

Número máximo de caracteres permitido: 100 
3.8) Diagnóstico 3:

Pergunta Alternativa Seleção Única

Nome da variável: _8_dx3

Alternativas: (descrição - score)

Diagnóstico não localizado/Sem $2^{\circ} / 3^{\circ}$ diagnóstico - 1.0

Acidente vascular cerebral - Hemorrágico - 2.0

Acidente vascular cerebral - Infarto - 3.0

Anemia auto imune - 4.0

Asma - 5.0

Ataque isquêmico transitório - 6.0

Cardimiopatia - 7.0

Cirurgia programada - 8.0

Colecistite -9.0

Colelitíase - 10.0

Complicações oculares - 11.0

Convulsão - 12.0

Dactilite (síndrome mão-pé) - 13.0

Embolia Pulmonar - 14.0

Episódio aplástico - 15.0

Episodio de dor aguda da doença falciforme - 16.0

Febre, sem diagnóstico específico de infecção - 17.0

Hiperhemólise - 18.0

Hipertensão arterial sistêmica - 19.0

Hipertensão Pulmonar - 20.0

Hemossiderose Transfusional - 21.0

Infarto do Miocárdio - 22.0

Infecções graves - Sepses /bacteremia/Meningite - 23.0

Insuficiência cardíaca - 24.0

Insuficiência Renal - 25.0

Moya - Moya - 26.0

Necrose avascular-quadril / ombro Avascular - 27.0

Neuropatia (dor neuropática) - 28.0

Osteomielite (aguda ou crônica) - 29.0

Outras infeccões - 30.0

Outro diagnóstico não relacionado à Doença Falciforme - 31.0

Pancreatite - 32.0

Pielonefrite - 33.0

Priapismo - 34.0

Reação transfusional hemolítica tardia - 35.0

Sequestro esplênico agudo - 36.0

Sequestro hepático - 37.0

Síndrome nefrótica - 38.0

Síndrome Torácica Aguda/ Pneumonia - 39.0

Úlceras de perna - 40.0

3.9) Se outra infecção (30) ou outro diagnóstico não relacionado à Doença Falciforme (31), especifique: Pergunta Texto

Nome da variável:_9_dx3_o

Número máximo de caracteres permitido: 100

\section{Módulo: 4 - Histórico de cirurgias}

4.1) O paciente já foi submetido a algum procedimento cirúrgico desde a sua inscrição no estudo?

Pergunta Alternativa Seleção Única

Nome da variável: F1M4_1_surg

Alternativas: (descrição - score)

Sim -1.0

Não - 2.0

4.2) O paciente tem histórico de tonsilectomia desde a sua inscrição no estudo?

Pergunta Alternativa Seleção Única

Nome da variável: F1M4_2_ton

Alternativas: (descrição - score)

Sim -1.0 
Não -2.0

4.3) Data da tonsilectomia:

Pergunta Data

Nome da variável: F1M4_3_d_ton

Intervalo permitido: 01/01/2013 - 31/12/2016

4.4) Houve transfusão pré-operatória antes da cirurgia para evitar complicações na tonsilectomia?

Pergunta Alternativa Seleção Única

Nome da variável: F1M4_4_ton_ptx

Alternativas: (descrição - score)

Sim -1.0

Não - 2.0

4.5) Houve transfusão durante ou após a tonsilectomia?

Pergunta Alternativa Seleção Única

Nome da variável: F1M4_5_ton_tx

Alternativas: (descrição - score)

Sim -1.0

Não - 2.0

4.6) Qual foi a razão para a transfusão na tonsilectomia? (marcar apenas um)

Pergunta Alternativa Seleção Única

Nome da variável: F1M4_6_tontx_i

Alternativas: (descrição - score)

Agudização da anemia - 1.0

Desenvolvimento de síndrome torácica aguda - 2.0

Outro - 3.0

4.7) Especifique outra razão para a transfusão na tonsilectomia (separe por ; as outras razões para a transfusão): Pergunta Texto

Nome da variável: F1M4_7_tontx_o

Número máximo de caracteres permitido: 100

4.8) O paciente tem histórico de esplenectomia desde a sua inscrição no estudo?

Pergunta Alternativa Seleção Única

Nome da variável: F1M4_8_sp

Alternativas: (descrição - score)

Sim -1.0

Não - 2.0

4.9) Data da esplenectomia:

Pergunta Data

Nome da variável: F1M4_9_d_sp

Intervalo permitido: 01/01/2013 - 31/12/2016 


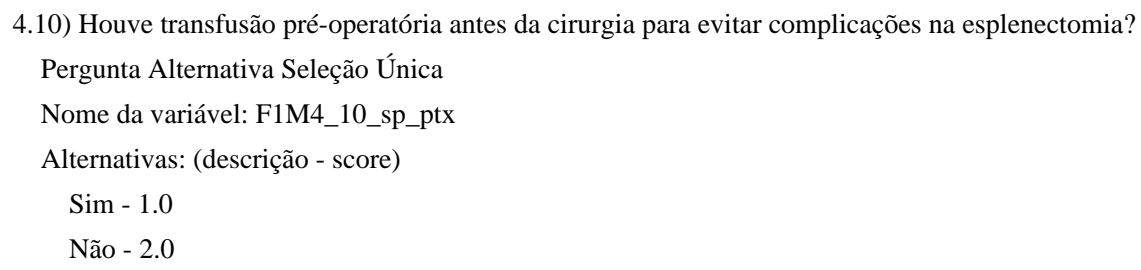

4.11) Houve transfusão durante ou após a esplenectomia?

Pergunta Alternativa Seleção Única

Nome da variável: F1M4_11_sp_tx

Alternativas: (descrição - score)

Sim -1.0

Não -2.0

4.12) Qual foi a razão para a transfusão na esplenectomia? (marcar apenas um)

Pergunta Alternativa Seleção Única

Nome da variável: F1M4_12_sptx_i

Alternativas: (descrição - score)

Agudização da anemia - 1.0

Desenvolvimento de síndrome torácica aguda - 2.0

Outro - 3.0

4.13) Especifique outra razão para a transfusão na esplenectomia (separe por ; as outras razões para a transfusão): Pergunta Texto

Nome da variável: F1M4_13_sptx_o

Número máximo de caracteres permitido: 100

4.14) O paciente tem histórico de colecistectomia desde a sua inscrição no estudo?

Pergunta Alternativa Seleção Única

Nome da variável: F1M4_14_cho

Alternativas: (descrição - score)

Sim - 1.0

Não - 2.0

\subsection{5) Data da colecistectomia:}

\section{Pergunta Data}

Nome da variável: F1M4_15_d_cho

Intervalo permitido: 01/01/2013 - 31/12/2016

4.16) Houve transfusão pré-operatória antes da cirurgia para evitar complicações na colecistectomia? Pergunta Alternativa Seleção Única

Nome da variável: F1M4_16_cho_ptx

Alternativas: (descrição - score)

Sim -1.0

Não - 2.0 


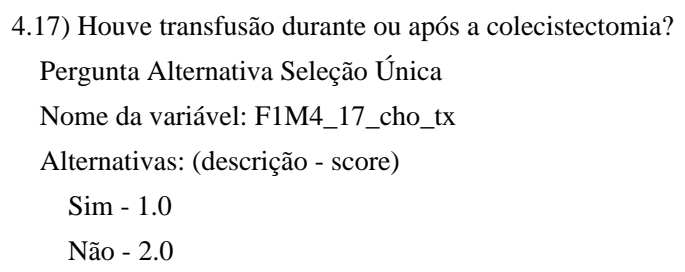

4.18) Qual foi a razão para a transfusão na colecistectomia? (marcar apenas um) Pergunta Alternativa Seleção Única

Nome da variável: F1M4_18_chotx_i

Alternativas: (descrição - score)

Agudização da anemia - 1.0

Desenvolvimento de síndrome torácica aguda - 2.0

Outro - 3.0

4.19) Especifique outra razão para a transfusão na colecistectomia (separe por ; as outras razões para a transfusão): Pergunta Texto

Nome da variável: F1M4_19_chotx_o

Número máximo de caracteres permitido: 100

4.20) O paciente tem histórico de artroplastia de quadril desde a sua inscrição no estudo?

Pergunta Alternativa Seleção Única

Nome da variável: F1M4_20_hip

Alternativas: (descrição - score)

Sim -1.0

Não - 2.0

4.21) Data da artroplastia de quadril:

Pergunta Data

Nome da variável: F1M4_21_d_hip

Intervalo permitido: 01/01/2013 - 31/12/2016

4.22) Houve transfusão pré-operatória antes da cirurgia para evitar complicações na artroplastia de quadril?

Pergunta Alternativa Seleção Única

Nome da variável: F1M4_22_hip_ptx

Alternativas: (descrição - score)

Sim -1.0

Não -2.0

4.23) Houve transfusão durante ou após a artroplastia de quadril?

Pergunta Alternativa Seleção Única

Nome da variável: F1M4_23_hip_tx

Alternativas: (descrição - score)

Sim -1.0

Não - 2.0 


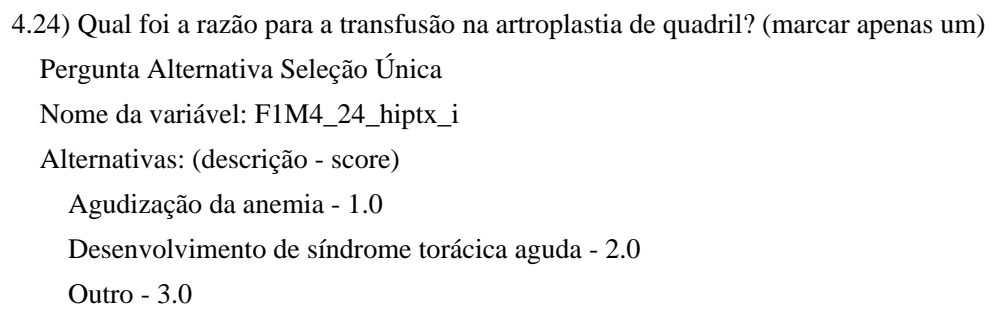

4.25) Especifique outra razão para a transfusão na artroplastia de quadril (separe por ; as outras razões para a transfusão): Pergunta Texto

Nome da variável: F1M4_25_hiptx_o

Número máximo de caracteres permitido: 100

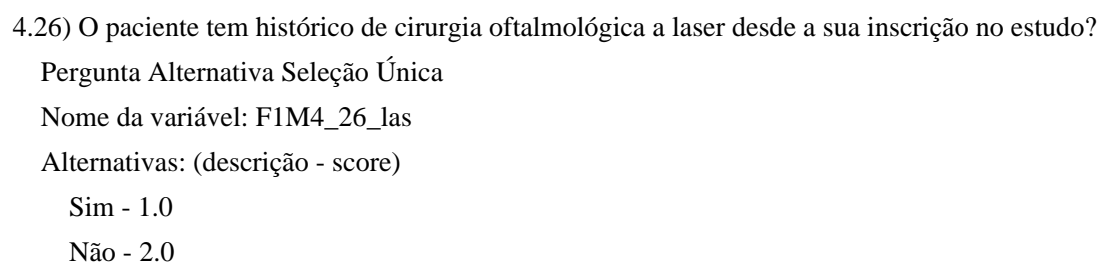

4.28) O paciente tem histórico de vitrectomia desde a sua inscrição no estudo?

Pergunta Alternativa Seleção Única

Nome da variável: F1M4_28_vit

Alternativas: (descrição - score)

Sim - 1.0

Não - 2.0

\subsection{9) Data da vitrectomia:}

\section{Pergunta Data}

Nome da variável: F1M4_29_d_vit

Intervalo permitido: 01/01/2013 - 31/12/2016

4.30) Houve transfusão pré-operatória antes da cirurgia para evitar complicações na vitrectomia? Pergunta Alternativa Seleção Única

Nome da variável: F1M4_30_vit_ptx

Alternativas: (descrição - score)

Sim -1.0

Não - 2.0

4.31) Houve transfusão durante ou após a vitrectomia?

Pergunta Alternativa Seleção Única 
Nome da variável: F1M4_31_vit_tx

Alternativas: (descrição - score)

Sim - 1.0

Não - 2.0

4.32) Qual foi a razão para a transfusão na vitrectomia? (marcar apenas um)

Pergunta Alternativa Seleção Única

Nome da variável: F1M4_32_vitx_i

Alternativas: (descrição - score)

Agudização da anemia - 1.0

Desenvolvimento de síndrome torácica aguda - 2.0

Outro - 3.0

4.33) Especifique outra razão para a transfusão na vitrectomia (separe por ; as outras razões para a transfusão):

Pergunta Texto

Nome da variável: F1M4_33_vitx_o

Número máximo de caracteres permitido: 100

4.34) O paciente tem histórico de inserção de cateter venoso permanente desde a sua inscrição no estudo?

Pergunta Alternativa Seleção Única

Nome da variável: F1M4_34_incat

Alternativas: (descrição - score)

Sim -1.0

Não - 2.0

4.35) Data da inserção de cateter venoso:

Pergunta Data

Nome da variável: F1M4_35_d_incat

Intervalo permitido: 01/01/2013 - 31/12/2016

4.36) Qual foi o tipo de cateter venoso?

Pergunta Alternativa Seleção Única

Nome da variável: F1M4_36_cath

Alternativas: (descrição - score)

Cateter totalmente implantado de lúmen simples - 1.0

Cateter totalmente implantado de duplo lúmen - 2.0

Cateter semi implantado/ tunelizado (Hickman, Broviac or Permcath) lúmen simples - 3.0

Cateter semi implantado/ tunelizado (Hickman, Broviac or Permcath) duplo lúmen - 4.0

Cateter Central de Inserção Periférica - PICC - 5.0

Outro -6.0

4.37) Especifique o outro tipo de catéter: (separe por ; os outros tipos de catéter):

Pergunta Texto

Nome da variável: F1M4_37_cath_o

Número máximo de caracteres permitido: 100 


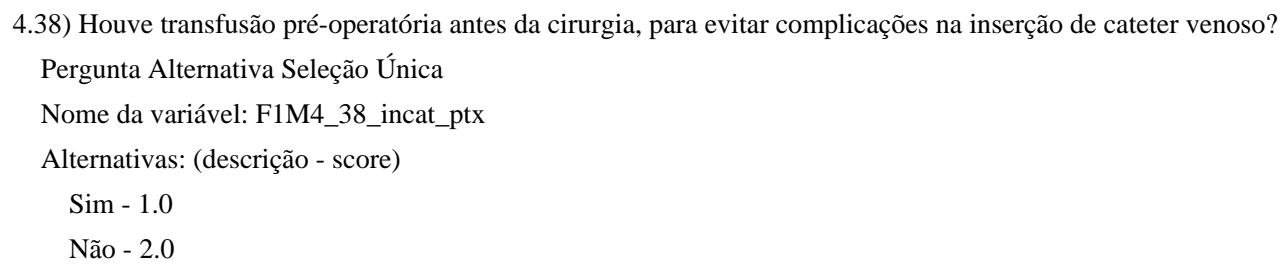

4.39) Houve transfusão durante ou após a inserção de cateter venoso?

Pergunta Alternativa Seleção Única

Nome da variável: F1M4_39_incat_tx

Alternativas: (descrição - score)

Sim -1.0

Não -2.0

4.40) Qual foi a razão para a transfusão na inserção de cateter venoso? (marcar apenas um)

Pergunta Alternativa Seleção Única

Nome da variável: F1M4_40_incatx_i

Alternativas: (descrição - score)

Agudização da anemia - 1.0

Desenvolvimento de síndrome torácica aguda -2.0

Outro - 3.0

4.41) Especifique outra razão para a transfusão na inserção de cateter venoso (separe por ; as outras razões para a transfusão): Pergunta Texto

Nome da variável: F1M4_41_incatx_o

Número máximo de caracteres permitido: 100

4.42) O paciente tem histórico de remoção de cateter venoso permanente desde a sua inscrição no estudo?

Pergunta Alternativa Seleção Única

Nome da variável: F1M4_42_ocat

Alternativas: (descrição - score)

Sim - 1.0

Não - 2.0

4.43) Data da remoção de cateter venoso:

Pergunta Data

Nome da variável: F1M4_43_d_ocat

Intervalo permitido: 01/01/2013 - 31/12/2016

4.44) Houve transfusão pré-operatória antes da cirurgia para evitar complicações na remoção de cateter venoso? Pergunta Alternativa Seleção Única

Nome da variável: F1M4_44_ocat_ptx

Alternativas: (descrição - score)

Sim - 1.0

Não - 2.0 


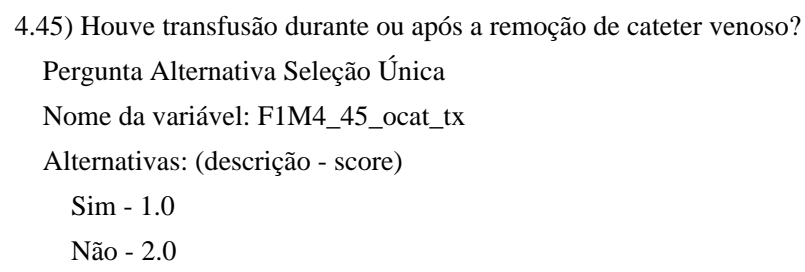

4.47) Especifique outra razão para a transfusão na remoção de cateter venoso (separe por ; as outras razões para a transfusão): Pergunta Texto

4.50) Houve transfusão pré-operatória antes da cirurgia para evitar complicações na apendicectomia? Pergunta Alternativa Seleção Única Nome da variável: F1M4_50_ap_ptx Alternativas: (descrição - score)

Sim -1.0

Não - 2.0

4.51) Houve transfusão durante ou após a apendicectomia? Pergunta Alternativa Seleção Única Nome da variável: F1M4_51_ap_tx Alternativas: (descrição - score)

Sim - 1.0

Não - 2.0 


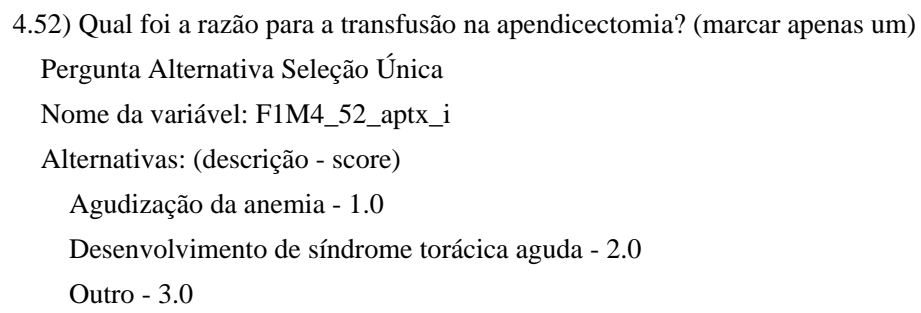

4.53) Especifique outra razão para a transfusão na apendicectomia (separe por ; as outras razões para a transfusão): Pergunta Texto

Nome da variável: F1M4_53_aptx_o

Número máximo de caracteres permitido: 100

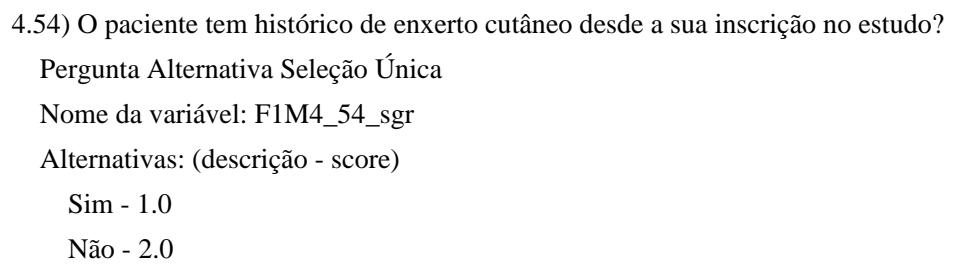

4.56) Houve transfusão pré-operatória antes da cirurgia para evitar complicações no enxerto cutâneo? Pergunta Alternativa Seleção Única Nome da variável: F1M4_56_sgr_ptx

Alternativas: (descrição - score)

Sim - 1.0

Não -2.0

4.57) Houve transfusão durante ou após o enxerto cutâneo?

Pergunta Alternativa Seleção Única

Nome da variável: F1M4_57_sgr_tx

Alternativas: (descrição - score)

Sim - 1.0

Não - 2.0

4.58) Qual foi a razão para a transfusão no enxerto cutâneo? (marcar apenas um) Pergunta Alternativa Seleção Única

Nome da variável: F1M4_58_sgrtx_i

Alternativas: (descrição - score)

Agudização da anemia - 1.0

Desenvolvimento de síndrome torácica aguda - 2.0

Outro - 3.0 


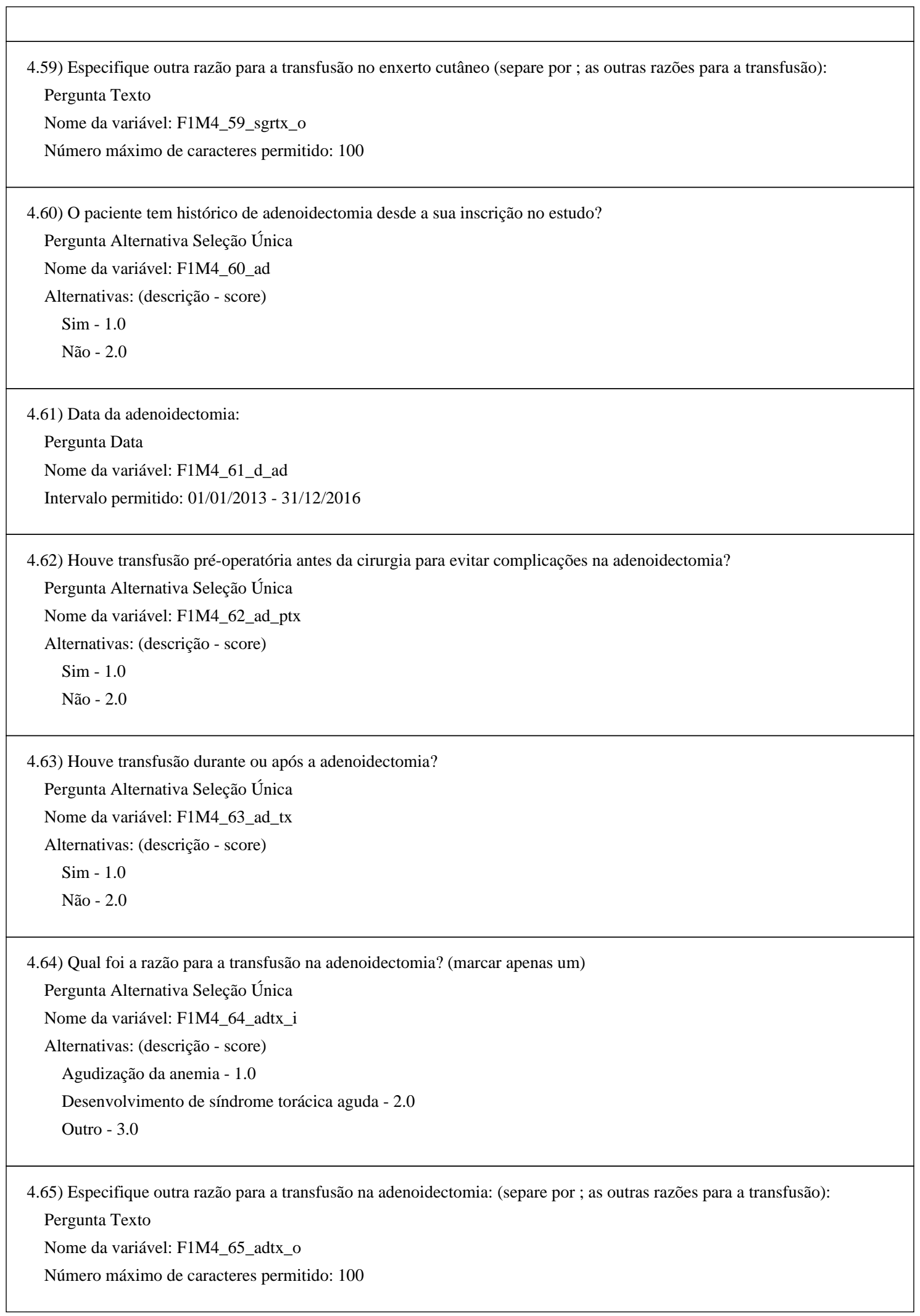




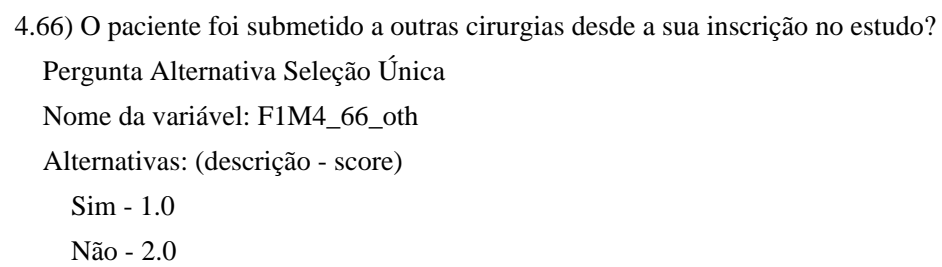

4.69) Houve transfusão pré-operatória antes da outra cirurgia para evitar complicações? Pergunta Alternativa Seleção Única

Nome da variável: _69_oth_ptx

Alternativas: (descrição - score)

Sim -1.0

Não - 2.0

4.70) Houve transfusão durante ou após a outra cirurgia?

Pergunta Alternativa Seleção Única

Nome da variável:_70_oth_tx

Alternativas: (descrição - score)

Sim -1.0

Não - 2.0

4.71) Qual foi a razão para a transfusão na outra cirurgia?

Pergunta Alternativa Seleção Única

Nome da variável: _71_othtx_i

Alternativas: (descriçãa - score)

Agudização da anemia - 1.0

Desenvolvimento de síndrome torácica aguda - 2.0

Outro - 3.0

4.72) Especifique outra razão para a transfusão na outra cirurgia (separe por ; as outras razões para a transfusão) Pergunta Texto

Nome da variável:_72_othtx_o

Número máximo de caracteres permitido: 100

\section{Módulo: 5 - Transplantes de Medula Óssea}

5.1) O paciente recebeu transplante de Medula Óssea desde a sua inscrição no estudo?

Pergunta Alternativa Seleção Única

Nome da variável: F1M5_1_sct

Alternativas: (descrição - score)

Sim -1.0

Não -2.0

5.2) Quantos transplantes de medula óssea?

Pergunta Número Inteiro

Nome da variável: F1M5_2_n_sct 
Intervalo permitido: 1 - 20

5.3) Data do transplante de medula óssea:

Pergunta Data

Nome da variável: F1M5_3_d_sct

Intervalo permitido: 01/01/2013 - 31/12/2016

5.4) Indicações para o transplante de medula óssea: (marque todas as opções que se aplicam)

Pergunta Alternativa Seleção Múltipla

Nome da variável: F1M5_4_sct_

Alternativas: (descrição - nome da variável - score)

Doppler transcraniano anormal - i_tcd - 1.0

Historia de acidente vascular cerebral - i_cva - 2.0

Dor recorrente grave - i_voe - 3.0

Síndrome torácica aguda recorrente - i_acs -4.0

Outra - i_oth - 100.0

5.5) Especifique outra indicação para o transplante de medula óssea (separe por ; as outras indicações para o transplante):

Pergunta Texto

Nome da variável: F1M5_5_sct_o

Número máximo de caracteres permitido: 100

5.6) Instituição em que ocorreu o transplante de medula óssea:

Pergunta Texto

Nome da variável: F1M5_6_ins

Número máximo de caracteres permitido: 100

\section{7) Tipo de doador:}

Pergunta Alternativa Seleção Única

Nome da variável: F1M5_7_don

Alternativas: (descrição - score)

Irmão biológico $\quad-1.0$

Sem relação de consangüinidade $\quad-2.0$

Outro membro da família (não irmão) - 3.0

5.8) Tipo de doador HLA:

Pergunta Alternativa Seleção Única

Nome da variável: F1M5_8_hla

Alternativas: (descrição - score)

HLA compatível

HLA incompatível - 2.0

5.9) Fonte de células-tronco:

Pergunta Alternativa Seleção Única

Nome da variável: F1M5_9_sctype

Alternativas: (descrição - score) 
Medula óssea - 1.0

Sangue periférico - 2.0

Sangue do cordão umbilical - 3.0

\section{Módulo: 6 - Medicamentos}

6.1) O paciente fez uso de algum medicamento desde a sua inscrição no estudo? (O paciente deve estar utilizando o medicamento por, pelo menos, 30 dias)

Pergunta Alternativa Seleção Única

Nome da variável: F1M6_1_med

Alternativas: (descrição - score)

Sim -1.0

Não - 2.0

6.2) Selecione todos os medicamentos usados pelo paciente desde a sua inscrição no estudo: (marque todas as opções que se aplicam)

Pergunta Alternativa Seleção Múltipla

Nome da variável: F1M6_2

Alternativas: (descrição - nome da variável - score)

Algum antibiótico profilático regularmente - _abx - 1.0

Analgésicos por 30 dias seguidos ou mais - _pain - 2.0

Anticonvulsivantes para crises convulsivas - _aed_sz - 3.0

Anticonvulsivantes para dores neuropáticas - _aed_pain - 4.0

Antidepressivos - _dep - 5.0

Anti-hipertensivo - _htn - 6.0

Bronco dilatador inalável - _inh - 7.0

Deferasirox - _exj - 8.0

Deferiprona - _11 - 9.0

Desferoxamina - _des - 10.0

Eritropoietina - _epo - 11.0

Hidroxiuréia - _ hu - 12.0

IECA - Inibidor da Enzima catalizadora da angiotensina - _ace - 13.0

Oxigênio domiciliar - _o2 - 14.0

Varfarina - _war - 15.0

Vitamina D - _vitd - 16.0

Outro(s) medicamento(s) - _oth - 200.0

6.3) Especifique qual o outro medicamentos (separe por ; os outros medicamentos)

Pergunta Texto

Nome da variável: F1M6_3_o

Número máximo de caracteres permitido: 100

Módulo: 7 - Testes de diagnóstico 
7.1) O paciente realizou exame doppler transcraniano desde a sua inscrição no estudo?

Pergunta Alternativa Seleção Única

Nome da variável: F1M7_1_tcd

Alternativas: (descrição - score)

Sim -1.0

Não - 2.0

Planilha: Questões relacionadas ao doppler transcraniano

Itens: (Descrição - Nome da variável)

Doppler transcraniano - F1M7

7.2) Data do doppler transcraniano:

Pergunta Data

Nome da variável:_2_d_tcd

Intervalo permitido: $01 / \overline{0} 1 / 2013$ - 31/12/2016

7.3) Artéria cerebral média esquerda:

Pergunta Número Inteiro

Nome da variável: _3_lmca

Intervalo permitido: 0 - 400

7.4) Artéria cerebral média direita:

Pergunta Número Inteiro

Nome da variável:_4_rmca

Intervalo permitido: 0 - 400

7.5) Distal da carótida interna esquerda:

Pergunta Número Inteiro

Nome da variável:_5_lica

Intervalo permitido: 0 - 400

7.6) Distal da carótida interna direita:

Pergunta Número Inteiro

Nome da variável: 6 rica

Intervalo permitido: 0 - 400

7.7) Qual foi a classificação do resultado do Doppler?

Pergunta Alternativa Seleção Única

Nome da variável: _7_tcd_r

Alternativas: (descriçã̃o - score)

Normal - 1.0

Condiconal - 2.0

Alterado -3.0

7.8) Artéria cerebral anterior esquerda:

Pergunta Número Inteiro

Nome da variável: _8_laca

Intervalo permitido: $0-400$

7.9) Artéria cerebral anterior direita:

Pergunta Número Inteiro

Nome da variável: _9_raca

Intervalo permitido: 0 - 400

7.10) Artéria Cerebral Posterior segmento P1 esquerda (ACP-P1 e):

Pergunta Número Inteiro

Nome da variável:_10_lpca

Intervalo permitido: 0 - 400

7.11) Artéria Cerebral Posterior segmento P1 direita (ACP-P1 d):

Pergunta Número Inteiro

Nome da variável:_11_rpca

Intervalo permitido: 0 - 400 
7.12) Vertebrais esquerdas:

Pergunta Número Inteiro

Nome da variável: 12

Intervalo permitido: 0 - 400

7.13) Vertebrais direita:

Pergunta Número Inteiro

Nome da variável: _13_rv

Intervalo permitido: 0 - 400

7.14) Basilar proximal:

Pergunta Número Inteiro

Nome da variável: _14 rpb

Intervalo permitido: 0 - 400

7.15) O paciente realizou exame ressonância magnética craniana ou tomografia computadorizada desde a sua inscrição no estudo?

Pergunta Alternativa Seleção Única

Nome da variável: F1M7_15_mri

Alternativas: (descrição - score)

Sim - 1.0

Não - 2.0

7.16) Data MRI/TC mais recente:

Pergunta Data

Nome da variável: F1M7_16_d_mri

Intervalo permitido: 01/01/2013 - 31/12/2016

7.17) Registre o resultado mais recente da MRI/TC:

Pergunta Alternativa Seleção Única

Nome da variável: F1M7_17_mri_r

Alternativas: (descrição - score)

Dentro da normalidade - 1.0

Inconclusivo - 2.0

Alterado - 3.0

7.18) A RMI evidenciou moya-moya?

Pergunta Alternativa Seleção Única

Nome da variável: F1M7_18_mri_moya

Alternativas: (descrição - score)

Sim - 1.0

Não - 2.0

7.19) A RMI evidenciou acidente vascular cerebral - Infarto Cerebral Silencioso?

Pergunta Alternativa Seleção Única

Nome da variável: F1M7_19_mri_stroke

Alternativas: (descrição - score)

Sim - 1.0

Não - 2.0

7.20) Alguma outra anormalidade identificada na RMI/TC: 
Pergunta Alternativa Seleção Única

Nome da variável: F1M7_20_mri_abn

Alternativas: (descrição - score)

Sim -1.0

Não - 2.0

7.21) Descreva as outras anormalidades encontradas na RMI/TC:

Pergunta Texto

Nome da variável: F1M7_21_mri_o

Número máximo de caracteres permitido: 100

7.22) O paciente realizou exame ecocardiograma desde a sua inscrição no estudo?

Pergunta Alternativa Seleção Única

Nome da variável: F1M7_22_echo

Alternativas: (descrição - score)

Sim -1.0

Não - 2.0

Planilha: Questões relacionadas ao Ecocardiograma

Itens: (Descrição - Nome da variável)

Ecocardiograma: - F1M7

7.23) Data do Ecocardiograma:

Pergunta Data

Nome da variável:_23_d_echo

Intervalo permitido: $01 / 01 / 2013$ - 31/12/2016

7.24) O Ecocardiograma foi feito durante estado estável / basal?

Pergunta Alternativa Seleção Única

Nome da variável:_24_echo_ss

Alternativas: (descrição - score)

Sim -1.0

Não - 2.0

7.25) Registre o resultado do ecoçardiograma:

Pergunta Alternativa Seleção Única

Nome da variável: _25_echo_r

Alternativas: (descrição - score)

Dentro da normalidade -1.0

Inconclusivo - 2.0

Alterado - 3.0

7.26) Registre a alteração do Ecocardiograma : (marque todas as opções que se aplicam)

Pergunta Alternativa Seleção Múltipla

Nome da variável: _26_echo_abn

Alternativas: (descrição - nome da variável - score)

Estenose mitral Mitral - _ ms - 1.0

Regurgitação mitral - _m $\overline{\mathrm{r}}-2.0$

Estenose tricúspide - ts - 3.0

Insuficiência tricúspide - - tr - 4.0

Estenose aórtica - _as - 5.0

Regurgitação aórtica - _ ar - 6.0

Estenose pulmonar - _ps - 7.0

Regurgitação pulmonar - _pr - 8.0

Cardiomiopatia dilatada - $\_$dc $\quad-9.0$

Cardiomiopatia Hipertrófica - _ hc - 10.0

Outro - o - 100.0

7.27) Especifique qual a outra alteração do ecocardiograma (separe por ; as outras alterações):

Pergunta Texto

Nome da variável:_27_echo_o

Número máximo de caracteres permitido: 100 
7.28) Registre a velocidade do jato da tricúspide:

Pergunta Número Decimal

Nome da variável: 28 tjv

Intervalo permitido: $1.0-5.0$

7.29) Registre a fração de ejeção do ventrículo esquerdo:

Pergunta Número Decimal

Nome da variável: _29_ef

Intervalo permitido: 0.0 - 100.0

7.30) Registre a pressão media da artéria pulmonar:

Pergunta Número Inteiro

Nome da variável: _30_mpa_e

Intervalo permitido: 5 - 170

7.31) Registre a pressão sistólica da artéria pulmonar:

Pergunta Número Inteiro

Nome da variável:_31_spa_e

Intervalo permitido: 5 - 200

7.32) Registre a pressão diastólica da artéria pulmonar:

Pergunta Número Inteiro

Nome da variável:_32_dpa_e

Intervalo permitido: $1-100$

7.33) O paciente realizou cateterismo cardíaco desde a sua inscrição no estudo:

Pergunta Alternativa Seleção Única

Nome da variável: F1M7_33_cat

Alternativas: (descrição - score)

Sim -1.0

Não -2.0

Planilha: Questões relacionadas ao Cateterismo Cardíaco

Itens: (Descrição - Nome da variável)

Cateterismo cardíaco - F1M7

7.34) Data do cateterismo

Pergunta Data

Nome da variável: _34_d_cat

Intervalo permitido: $01 / 01 / 2013$ - 31/12/2016

7.35) O cateterismo foi feito durante estado estável / basal?

Pergunta Alternativa Seleção Única

Nome da variável: _35_cat_ss

Alternativas: (descrição - score)

Sim - 1.0

Não -2.0

7.36) Pressão arterial pulmonar foi medida no cateterismo?

Pergunta Alternativa Seleção Única

Nome da variável: _36_cat_pa

Alternativas: (descrição - score)

Sim - 1.0

Não -2.0

7.37) Pressão arterial pulmonar média no cateterismo

Pergunta Número Decimal

Nome da variável:_37_cat_mpa

Intervalo permitido: $5 . \overline{0}-1 \overline{7} 0.0$

7.38) Pressão arterial pulmonar sistólica no cateterismo:

Pergunta Número Decimal

Nome da variável:_38_cat_spa

Intervalo permitido: 5.0 - 200.0 
7.39) Pressão arterial pulmonar diastólica no cateterismo:

Pergunta Número Decimal

Nome da variável:_39_cat_dpa

Intervalo permitido: $1 . \overline{0}-100.0$

7.40) Resistência vascular pulmonar no cateterismo

Pergunta Número Decimal

Nome da variável: _40_cat_pvr

Intervalo permitido: $0 . \overline{0}-20.0$

7.41) Pressão média de oclusão da artéria pulmonar (pressão ventricular esquerda e diastólica) no cateterismo: Pergunta Número Decimal

Nome da variável:_41_cat_mpawp

Intervalo permitido: $1.0-30.0$

7.42) O paciente realizou teste de função pulmonar desde a sua inscrição no estudo?

Pergunta Alternativa Seleção Única

Nome da variável: F1M7_42_pft

Alternativas: (descrição - score)

Sim -1.0

Não - 2.0

7.43) Data da função pulmonar mais recente:

Pergunta Data

Nome da variável: F1M7_43_d_pft

Intervalo permitido: 01/01/2013 - 31/12/2016

7.44) Registre o resultado mais recente da função pulmonar:

Pergunta Alternativa Seleção Única

Nome da variável: F1M7_44_pft_r

Alternativas: (descrição - score)

Dentro da normalidade - 1.0

Inconclusivo - 2.0

Alterado - 3.0

7.45) O teste de função pulmonar diagnosticou doença pulmonar OBSTRUTIVA crônica?

Pergunta Alternativa Seleção Única

Nome da variável: F1M7_45_pft_copd

Alternativas: (descrição - score)

Sim - 1.0

Não - 2.0

7.46) O teste de função pulmonar diagnosticou doença pulmonar RESTRITIVA crônica?

Pergunta Alternativa Seleção Única

Nome da variável: F1M7_46_pft_crpd

Alternativas: (descrição - score)

Sim - 1.0

Não -2.0

7.47) Alguma outra anormalidade diagnosticada no teste de função pulmonar?

Pergunta Alternativa Seleção Única 
Nome da variável: F1M7_47_pft_o_abn

Alternativas: (descrição - score)

Sim - 1.0

Não - 2.0

7.48) Descreva a alteração do teste de função pulmonar:

Pergunta Texto

Nome da variável: F1M7_48_pft_ab

Número máximo de caracteres permitido: 100

7.49) O paciente realizou urinálise desde a sua inscrição no estudo?

Pergunta Alternativa Seleção Única

Nome da variável: F1M7_49_ua

Alternativas: (descrição - score)

Sim - 1.0

Não - 2.0

7.50) Datada urinálise mais recente:

Pergunta Data

Nome da variável: F1M7_50_d_ua

Intervalo permitido: 01/01/2013 - 31/12/2016

7.51) Registre o resultado mais recente da urinálise:

Pergunta Alternativa Seleção Única

Nome da variável: F1M7_51_ua_r

Alternativas: (descrição - score)

Microalbuminúria (30-300mg / g de albumina na urina creatinina) - 1.0

Macroalbuminúria (> $300 \mathrm{mg} / \mathrm{g}-2 \mathrm{~g} / \mathrm{g}$ albumina na urina para creatinina) - 2.0

Proteinúria faixa nefrótica ( $>2 \mathrm{~g} / \mathrm{g}$ albumina na urina para creatinina) - 3.0

Normal (sem proteína) - 4.0

7.52) O paciente tem coleta de urina de 24 horas realizado desde a sua inscrição no estudo?

Pergunta Alternativa Seleção Única

Nome da variável: F1M7_52_24u

Alternativas: (descrição - score)

Sim -1.0

Não -2.0

7.53) Data da coleta de urina de 24 horas mais recente

Pergunta Data

Nome da variável: F1M7_53_d_24u

Intervalo permitido: 01/01/2013 - 31/12/2016

7.54) Registre o resultado mais recente da coleta de urina de 24 horas:

Pergunta Número Decimal

Nome da variável: F1M7_54_24u_r 
Intervalo permitido: 0.0 - 5000.0

\author{
Módulo: 8 - Resultados Sorológicos \\ 8.1) O paciente realizou teste para Sífilis desde a sua inscrição no estudo? \\ Pergunta Alternativa Seleção Única \\ Nome da variável: F1M8_1_syp \\ Alternativas: (descrição - score) \\ Sim -1.0 \\ Não -2.0 \\ 8.2) Resultado mais recente do Elisa para sífilis: \\ Pergunta Alternativa Seleção Única \\ Nome da variável: F1M8_2_syp_r \\ Alternativas: (descrição - score) \\ Positivo - 1.0 \\ Negativo - 2.0 \\ Indeterminado - 3.0 \\ Não realizado - 4.0
}

8.3) Data do Elisa para sífilis mais recente:

Pergunta Data

Nome da variável: F1M8_3_d_syp

Intervalo permitido: 01/01/2013 - 31/12/2016

8.4) Resultado mais recente do VDRL:

Pergunta Alternativa Seleção Única

Nome da variável: F1M8_4_vdrl

Alternativas: (descrição - score)

Positivo - 1.0

Negativo - 2.0

Indeterminado - 3.0

Não realizado -4.0

8.5) Data do VDRL para sífilis mais recente:

Pergunta Data

Nome da variável: F1M8_5_d_vdrl

Intervalo permitido: 01/01/2013 - 31/12/2016

8.6) O paciente realizou teste para Hepatite desde a sua inscrição no estudo?

Pergunta Alternativa Seleção Única

Nome da variável: F1M8_6_hep

Alternativas: (descrição - score)

Sim -1.0

Não -2.0 


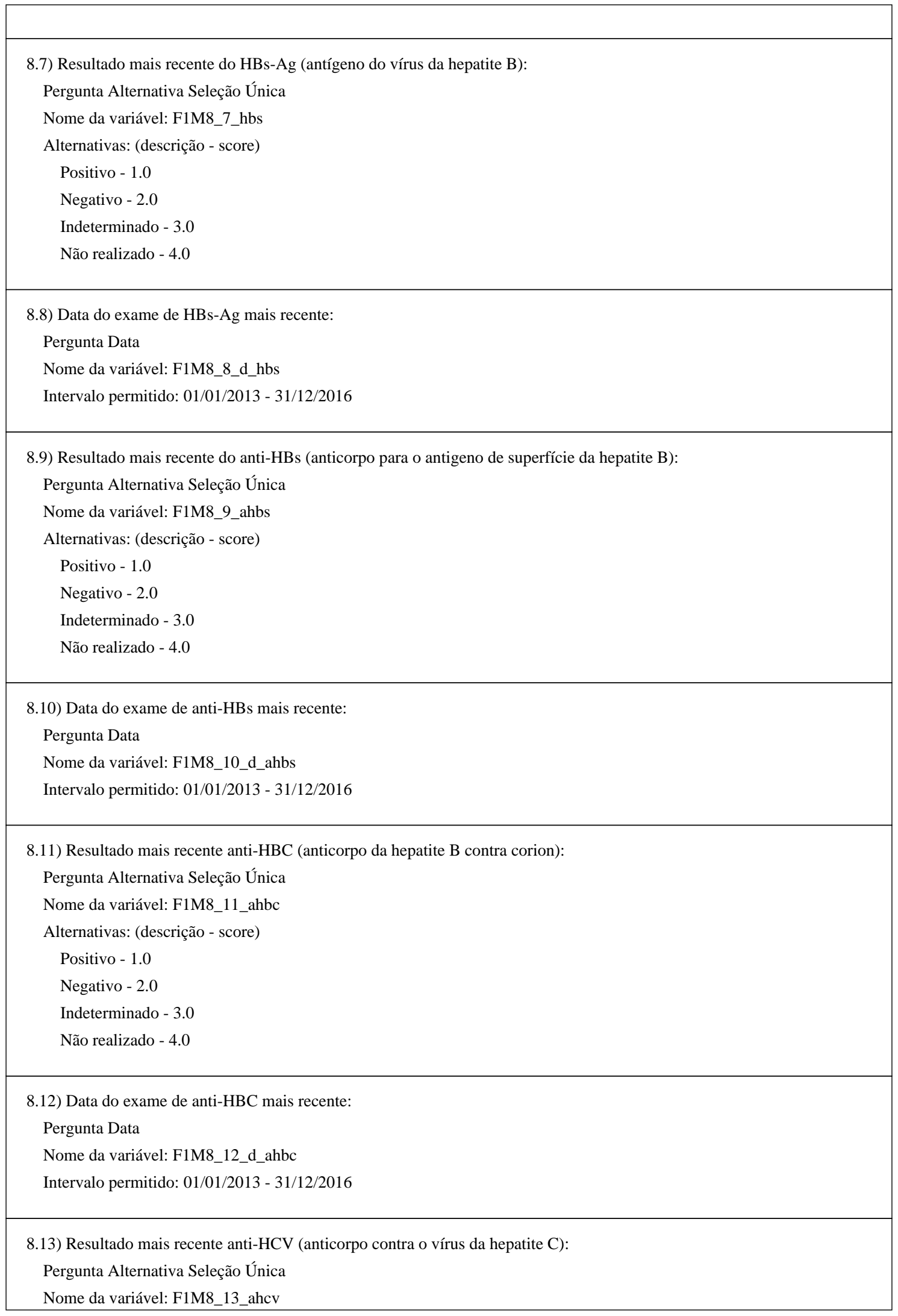


Alternativas: (descrição - score)

Positivo - 1.0

Negativo - 2.0

Indeterminado - 3.0

Não realizado - 4.0

8.14) Data do exame de anti-HCV mais recente:

Pergunta Data

Nome da variável: F1M8_14_d_ahcv

Intervalo permitido: 01/01/2013 - 31/12/2016

8.15) Resultado mais recente NAT HCV :

Pergunta Alternativa Seleção Única

Nome da variável: F1M8_15_nat

Alternativas: (descrição - score)

Positivo - 1.0

Negativo - 2.0

Indeterminado - 3.0

Não realizado - 4.0

8.16) Data do NAT para HCV mais recente:

\section{Pergunta Data}

Nome da variável: F1M8_16_d_nat

Intervalo permitido: 01/01/2013 - 31/12/2016

8.17) O paciente realizou teste para Chagas desde a sua inscrição no estudo?

Pergunta Alternativa Seleção Única

Nome da variável: F1M8_17_cha

Alternativas: (descrição - score)

Sim -1.0

Não - 2.0

8.18) Resultado mais recente ELISA para Chagas:

Pergunta Alternativa Seleção Única

Nome da variável: F1M8_18_cha_r

Alternativas: (descrição - score)

Positivo - 1.0

Negativo - 2.0

Indeterminado - 3.0

8.19) Data do Elisa para Chagas mais recente:

Pergunta Data

Nome da variável: F1M8_19_d_cha

Intervalo permitido: 01/01/2013 - 31/12/2016

8.20) O paciente realizou teste para HIV desde a sua inscrição no estudo? 
Pergunta Alternativa Seleção Única

Nome da variável: F1M8_20_hiv

Alternativas: (descrição - score)

Sim - 1.0

Não - 2.0

8.21) Resultado mais recente do primeiro ELISA para HIV:

Pergunta Alternativa Seleção Única

Nome da variável: F1M8_21_hiv_e1

Alternativas: (descrição - score)

Positivo - 1.0

Negativo -2.0

Indeterminado - 3.0

Não realizado - 4.0

8.22) Data do primeiro Elisa para HIV mais recente:

Pergunta Data

Nome da variável: F1M8_22_d_hive1

Intervalo permitido: 01/01/2013 - 31/12/2016

8.23) Resultado mais recente do segundo ELISA:

Pergunta Alternativa Seleção Única

Nome da variável: F1M8_23_hiv_e2

Alternativas: (descrição - score)

Positivo - 1.0

Negativo - 2.0

Indeterminado - 3.0

Não realizado - 4.0

8.24) Data do segundo Elisa para HIV mais recente:

Pergunta Data

Nome da variável: F1M8_24_d_hive2

Intervalo permitido: 01/01/2013 - 31/12/2016

\subsection{5) Resultado mais recente do Western Blot:}

Pergunta Alternativa Seleção Única

Nome da variável: F1M8_25_hivwb

Alternativas: (descrição - score)

Positivo - 1.0

Negativo - 2.0

Indeterminado - 3.0

Não realizado - 4.0

8.26) Data do Western Blot para HIV mais recente:

Pergunta Data

Nome da variável: F1M8_26_d_hivwb 
Intervalo permitido: 01/01/2013 - 31/12/2016

8.27) O paciente realizou teste para HTLV desde a sua inscrição no estudo?

Pergunta Alternativa Seleção Única

Nome da variável: F1M8_27_htlv

Alternativas: (descrição - score)

Sim - 1.0

Não - 2.0

8.28) Resultado mais recente do ELISA para HTLV:

Pergunta Alternativa Seleção Única

Nome da variável: F1M8_28_htlv_r

Alternativas: (descrição - score)

Positivo - 1.0

Negativo -2.0

Indeterminado - 3.0

8.29) Data do Elisa para HTLV mais recente:

Pergunta Data

Nome da variável: F1M8_29_d_htlv

Intervalo permitido: 01/01/2013 - 31/12/2016

8.30) Resultado mais recente WB HTLV:

Pergunta Alternativa Seleção Única

Nome da variável: F1M8_30_htlvwb

Alternativas: (descrição - score)

Positivo - 1.0

Negativo - 2.0

Indeterminado - 3.0

Não realizado - 4.0

8.31) WB mais recente positivo para:

Pergunta Alternativa Seleção Única

Nome da variável: F1M8_31_htlvwb_r

Alternativas: (descrição - score)

HTLV I - 1.0

HTLV II - 2.0

HTLV I/II - 3.0

HTLV não tipado - 4.0

8.32) Data do Western blot para HTLV mais recente:

Pergunta Data

Nome da variável: F1M8_32_d_htlvwb

Intervalo permitido: 01/01/2013 - 31/12/2016 


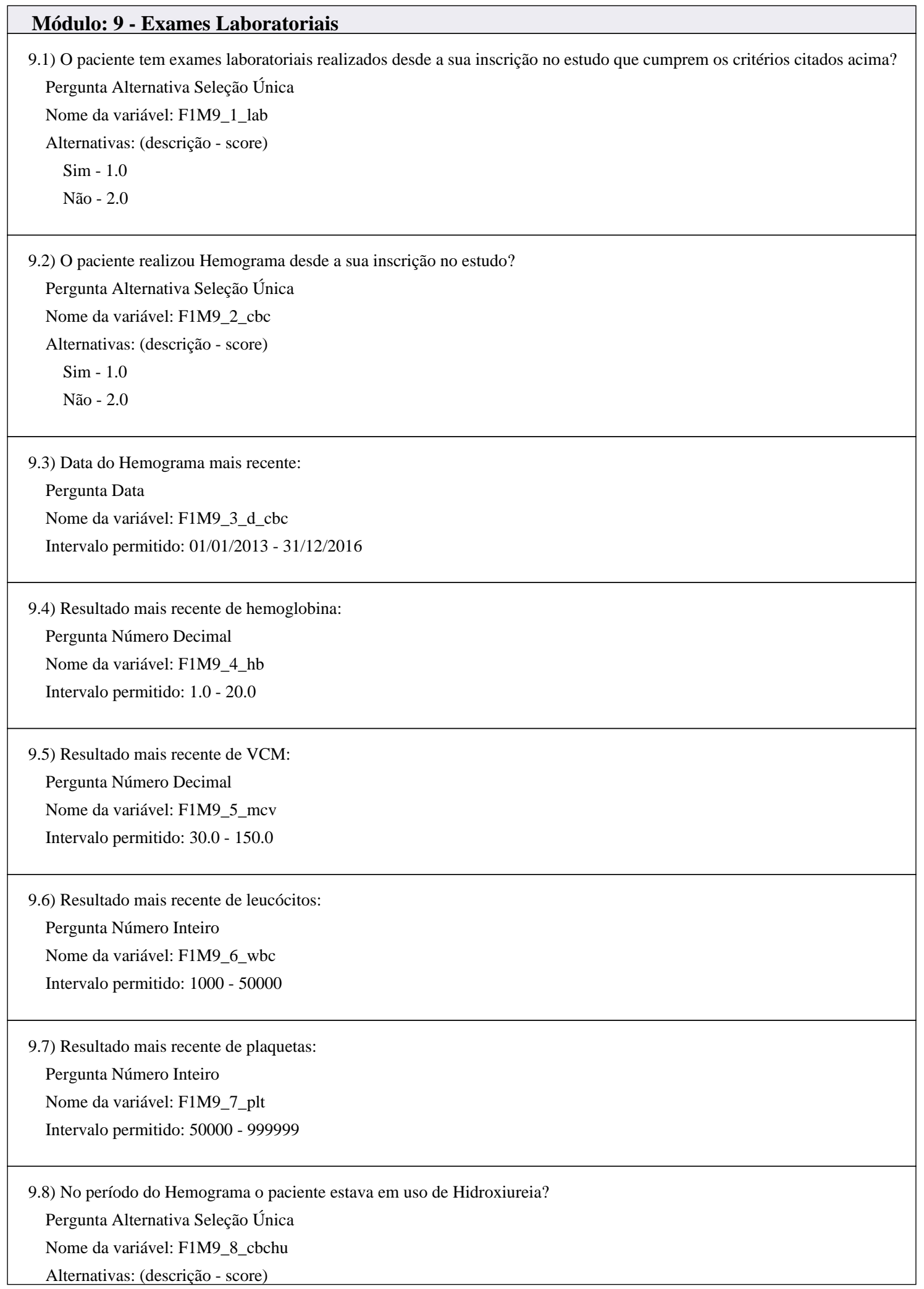


Alternativas: (descrição - score)

Sim -1.0

Não - 2.0

9.9) No período do Hemograma o paciente estava em tratamento com transfusão crônica?

Pergunta Alternativa Seleção Única

Nome da variável: F1M9_9_cbctx

Alternativas: (descrição - score)

Sim -1.0

Não - 2.0

9.10) O paciente realizou exame de reticulócitos (contagem relativa) desde a sua inscrição no estudo? Pergunta Alternativa Seleção Única

Nome da variável: F1M9_10_ret

Alternativas: (descrição - score)

Sim -1.0

Não - 2.0

9.11) Data do exame de reticulócitos mais recente:

Pergunta Data

Nome da variável: F1M9_11_d_ret

Intervalo permitido: 01/01/2013 - 31/12/2016

9.12) Resultado mais recente de reticulócitos (contagem relativa):

Pergunta Número Decimal

Nome da variável: F1M9_12_ret_r

Intervalo permitido: $0.01-100.0$

9.13) No período do exame de reticulócitos o paciente estava em uso de Hidroxiureia?

Pergunta Alternativa Seleção Única

Nome da variável: F1M9_13_rethu

Alternativas: (descrição - score)

Sim - 1.0

Não -2.0

9.14) No período do exame de reticulócitos o paciente estava em tratamento com transfusão crônica?

Pergunta Alternativa Seleção Única

Nome da variável: F1M9_14_retx

Alternativas: (descrição - score)

Sim -0.0

Não - 0.0

9.15) O paciente realizou exame de hemoglobina $\mathrm{F}$ desde a sua inscrição no estudo?

Pergunta Alternativa Seleção Única

Nome da variável: F1M9_15_hbf

Alternativas: (descrição - score) 
Sim -1.0

Não - 2.0

9.16) Data do exame de hemoglobina F mais recente:

Pergunta Data

Nome da variável: F1M9_16_d_hbf

Intervalo permitido: 01/01/2013 - 31/12/2016

9.17) Resultado mais recente de hemoglobina F:

Pergunta Número Decimal

Nome da variável: F1M9_17_hbf_r

Intervalo permitido: $0.01-100.0$

9.18) No período do exame de hemoglobina F o paciente estava em uso de Hidroxiureia?

Pergunta Alternativa Seleção Única

Nome da variável: F1M9_18_hbfhu

Alternativas: (descrição - score)

Sim -1.0

Não - 2.0

9.19) No período do exame de hemoglobina $\mathrm{F}$ o paciente estava em tratamento com transfusão crônica?

Pergunta Alternativa Seleção Única

Nome da variável: F1M9_19_hbftx

Alternativas: (descrição - score)

Sim -1.0

Não -2.0

9.20) O paciente realizou exame de desidrogenase láctica desde a sua inscrição no estudo?

Pergunta Alternativa Seleção Única

Nome da variável: F1M9_20_ldh

Alternativas: (descrição - score)

Sim -1.0

Não - 2.0

9.21) Data do exame de desidrogenase láctica mais recente:

\section{Pergunta Data}

Nome da variável: F1M9_21_d_ldh

Intervalo permitido: 01/01/2013 - 31/12/2016

9.22) Resultado mais recente de desidrogenase láctica:

Pergunta Número Inteiro

Nome da variável: F1M9_22_ldh_r

Intervalo permitido: 0 - 9000

9.23) No período do exame de desidrogenase láctica o paciente estava em uso de Hidroxiureia?

Pergunta Alternativa Seleção Única 
Pergunta Alternativa Seleção Única

Nome da variável: F1M9_23_ldhu

Alternativas: (descrição - score)

Sim -1.0

Não -2.0

9.24) No período do exame de desidrogenase láctica o paciente estava em tratamento com transfusão crônica?

Pergunta Alternativa Seleção Única

Nome da variável: F1M9_24_ldhtx

Alternativas: (descrição - score)

Sim - 1.0

Não - 2.0

9.25) O paciente realizou exame de creatinina desde a sua inscrição no estudo?

Pergunta Alternativa Seleção Única

Nome da variável: F1M9_25_cr

Alternativas: (descrição - score)

Sim -1.0

Não -2.0

9.26) Data do exame de creatinina mais recente:

\section{Pergunta Data}

Nome da variável: F1M9_26_d_cr

Intervalo permitido: 01/01/2013 - 31/12/2016

9.27) Resultado mais recente de creatinina:

Pergunta Número Decimal

Nome da variável: F1M9_27_cr_r

Intervalo permitido: $0.01-15.0$

9.28) No período do exame de creatinina o paciente estava em uso de Hidroxiureia?

Pergunta Alternativa Seleção Única

Nome da variável: F1M9_28_crhu

Alternativas: (descrição - score)

Sim -1.0

Não -2.0

9.29) No período do exame de creatinina o paciente estava em tratamento com transfusão crônica?

Pergunta Alternativa Seleção Única

Nome da variável: F1M9_29_crtx

Alternativas: (descrição - score)

Sim -1.0

Não - 2.0

9.30) O paciente realizou exame bilirrubina total desde a sua inscrição no estudo?

Pergunta Alternativa Seleção Única 
Nome da variável: F1M9_30_tb

Alternativas: (descrição - score)

Sim -1.0

Não - 2.0

\author{
9.31) Data da bilirrubina total mais recente: \\ Pergunta Data \\ Nome da variável: F1M9_31_d_tb \\ Intervalo permitido: 01/01/2013 - 31/12/2016 \\ 9.32) Resultado mais recente da bilirrubina total: \\ Pergunta Número Decimal \\ Nome da variável: F1M9_32_tb_r \\ Intervalo permitido: $0.1-50.0$
}

9.33) No período do exame bilirrubina total o paciente estava em uso de Hidroxiureia?

Pergunta Alternativa Seleção Única

Nome da variável: F1M9_33_tbhu

Alternativas: (descrição - score)

Sim -1.0

Não -2.0

9.34) No período do exame bilirrubina total o paciente estava em tratamento com transfusão crônica?

Pergunta Alternativa Seleção Única

Nome da variável: F1M9_34_tbtx

Alternativas: (descrição - score)

Sim -1.0

Não -2.0

9.35) O paciente realizou exame bilirrubina direta desde a sua inscrição no estudo?

Pergunta Alternativa Seleção Única

Nome da variável: F1M9_35_db

Alternativas: (descrição - score)

Sim -1.0

Não - 2.0

9.36) Data da bilirrubina direta mais recente:

\title{
Pergunta Data
}

Nome da variável: F1M9_36_d_db

Intervalo permitido: 01/01/2013 - 31/12/2016

9.37) Resultado mais recente da bilirrubina direta:

Pergunta Número Decimal

Nome da variável: F1M9_37_db_r

Intervalo permitido: 0.01 - 99.0 
9.38) No período do exame da bilirrubina direta o paciente estava em uso de Hidroxiureia?

Pergunta Alternativa Seleção Única

Nome da variável: F1M9_38_dbhu

Alternativas: (descrição - score)

Sim -1.0

Não -2.0

9.39) No período do exame da bilirrubina direta o paciente estava em tratamento com transfusão crônica?

Pergunta Alternativa Seleção Única

Nome da variável: F1M9_39_dbtx

Alternativas: (descrição - score)

Sim -1.0

Não - 2.0

\author{
Módulo: 10 - Status de Ferro \\ 10.1) Foi realizado exame para medir o status de ferro desde a sua inscrição no estudo? \\ Pergunta Alternativa Seleção Única \\ Nome da variável: F1M10_1_fe \\ Alternativas: (descrição - score) \\ Sim - 1.0 \\ Não - 2.0
}

10.2) Biópsia do fígado foi realizada?

Pergunta Alternativa Seleção Única

Nome da variável: F1M10_2_bx

Alternativas: (descrição - score)

Sim -1.0

Não -2.0

10.3) Data da biópsia do fígado mais recente:

Pergunta Data

Nome da variável: F1M10_3_d_bx

Intervalo permitido: 01/01/2013 - 31/12/2016

10.4) Resultado mais recente da biópsia do fígado:

Pergunta Número Inteiro

Nome da variável: F1M10_4_bx_r

Intervalo permitido: 0 - 50

10.5) Ferritina foi realizada?

Pergunta Alternativa Seleção Única

Nome da variável: F1M10_5_ferr

Alternativas: (descrição - score)

Sim - 1.0 
Não -2.0

10.6) Data da ferritina mais recente:

Pergunta Data

Nome da variável: F1M10_6_d_ferr

Intervalo permitido: 01/01/2013 - 31/12/2016

10.7) Resultado mais recente da ferritina:

Pergunta Número Decimal

Nome da variável: F1M10_7_ferr_r

Intervalo permitido: 0.0 - 99999.0

10.8) Ressonância magnética para medir o status do ferro foi realizada?

Pergunta Alternativa Seleção Única

Nome da variável: F1M10_8_mri

Alternativas: (descrição - score)

Sim -1.0

Não - 2.0

10.9) Data da ressonância magnética para medir o status do ferro mais recente:

Pergunta Data

Nome da variável: F1M10_9_d_mri

Intervalo permitido: 01/01/2013 - 31/12/2016

10.10) Resultado mais recente ressonância magnética ferro hepático:

Pergunta Número Decimal

Nome da variável: F1M10_10_mri_lr

Intervalo permitido: $0.0-50.0$

10.11) Resultado mais recente ressonância magnética ferro cardíaco:

Pergunta Número Decimal

Nome da variável: F1M10_11_mri_cr

Intervalo permitido: 0.0 - 100.0

10.12) Índice de saturação de transferrina foi realizada?

Pergunta Alternativa Seleção Única

Nome da variável: F1M10_12_tran

Alternativas: (descrição - score)

Sim - 1.0

Não - 2.0

10.13) Data do índice de saturação de transferrina mais recente:

Pergunta Data

Nome da variável: F1M10_13_d_tran

Intervalo permitido: 01/01/2013 - 31/12/2016 
0.14) Resultado mais recente do índice de saturação de transferrina:

Pergunta Número Decimal

Nome da variável: F1M10_14_tran_r

Intervalo permitido: $0.0-100.0$

\section{Módulo: 11 - Dados imuno-hematológicos do paciente}

11.1) Os dados imunológicos deste paciente podem ser extraídos do sistema eletrônico do hemocentro?

Pergunta Alternativa Seleção Única

Nome da variável: F1M11_1

Alternativas: (descrição - score)

Sim -1.0

Não - 2.0

11.2) Qual o grupo sanguíneo do paciente?

Pergunta Alternativa Seleção Única

Nome da variável: F1M11_2abo

Alternativas: (descrição - score)
$\mathrm{O}+-1.0$
A+ -2.0
$\mathrm{B}+-3.0$
O- -4.0
A- -5.0
B- - 6.0
$\mathrm{AB}+-7.0$
AB- - 8.0

11.2.1) Este paciente respondeu Sim na questão 11.2 (pat_phenot_i11) no questionário de inscrição? Pergunta Alternativa Seleção Única

Nome da variável: F1M11_2_1ext

Alternativas: (descrição - score)

Sim -1.0

Não -2.0

11.3) Foi realizado fenótipo do paciente?

Pergunta Alternativa Seleção Única

Nome da variável: F1M11_3pheno

Alternativas: (descrição - score)

Sim -1.0

Não - 2.0

11.4) Qual o tipo do teste?

Pergunta Alternativa Seleção Única

Nome da variável: F1M11_4phen_typ 


\begin{tabular}{|c|}
\hline $\begin{array}{l}\text { Alternativas: (descrição - score) } \\
\text { Sorológico - } 1.0 \\
\text { Genético - } 2.0\end{array}$ \\
\hline $\begin{array}{l}\text { 11.5) Sistema Rh Antígenos C: } \\
\text { Pergunta Alternativa Seleção Única } \\
\text { Nome da variável: F1M11_5_uc } \\
\text { Alternativas: (descrição - score) } \\
\text { Positivo - } 1.0 \\
\text { Negativo - } 2.0 \\
\text { Não realizado - } 3.0\end{array}$ \\
\hline $\begin{array}{l}\text { 11.6) Sistema Rh Antígenos c: } \\
\text { Pergunta Alternativa Seleção Única } \\
\text { Nome da variável: F1M11_6_c } \\
\text { Alternativas: (descrição - score) } \\
\text { Positivo - } 1.0 \\
\text { Negativo - } 2.0 \\
\text { Não realizado - } 3.0\end{array}$ \\
\hline $\begin{array}{l}\text { 11.7) Sistema Rh Antígenos E: } \\
\text { Pergunta Alternativa Seleção Única } \\
\text { Nome da variável: F1M11_7_ue } \\
\text { Alternativas: (descrição - score) } \\
\text { Positivo - } 1.0 \\
\text { Negativo - } 2.0 \\
\text { Não realizado - } 3.0\end{array}$ \\
\hline $\begin{array}{l}\text { 11.8) Sistema Rh Antígenos e: } \\
\text { Pergunta Alternativa Seleção Única } \\
\text { Nome da variável: F1M11_8_e } \\
\text { Alternativas: (descrição - score) } \\
\text { Positivo - } 1.0 \\
\text { Negativo - } 2.0 \\
\text { Não realizado - } 3.0\end{array}$ \\
\hline $\begin{array}{l}\text { 11.9) Sistema Rh Antígenos Cw: } \\
\text { Pergunta Alternativa Seleção Única } \\
\text { Nome da variável: F1M11_9_cw } \\
\text { Alternativas: (descrição - score) } \\
\text { Positivo - } 1.0 \\
\text { Negativo - } 2.0 \\
\text { Não realizado - } 3.0\end{array}$ \\
\hline $\begin{array}{l}\text { 11.10) Sistema Kell Antígenos K: } \\
\text { Pergunta Alternativa Seleção Única }\end{array}$ \\
\hline
\end{tabular}




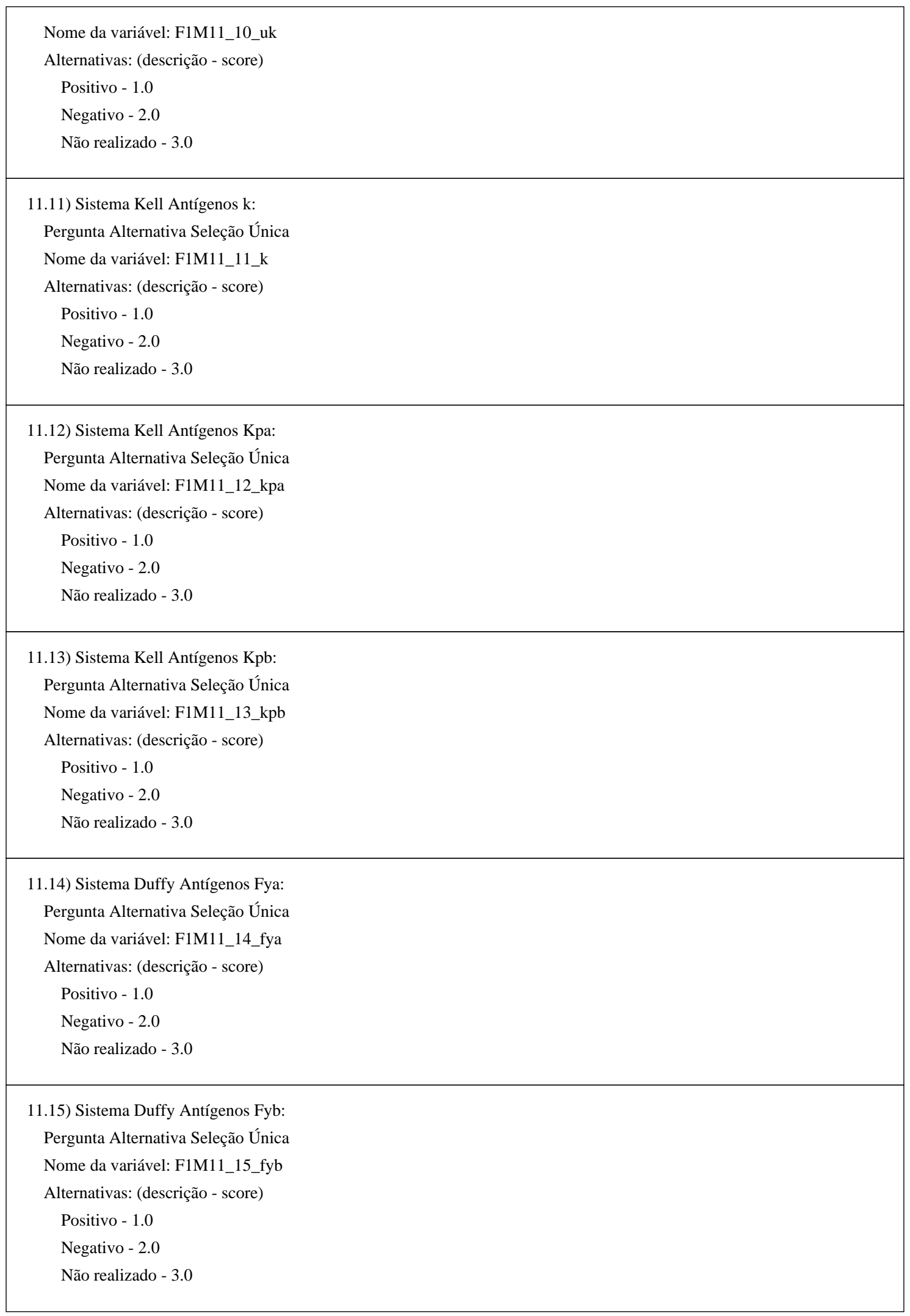




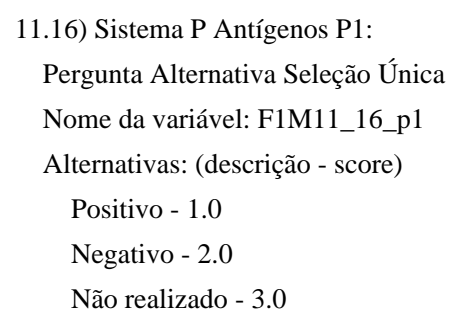

11.17) Sistema Kidd Antígenos Jka:

Pergunta Alternativa Seleção Única Nome da variável: F1M11_17_jka

Alternativas: (descrição - score)

Positivo - 1.0

Negativo - 2.0

Não realizado - 3.0

11.18) Sistema Kidd Antígenos Jkb:

Pergunta Alternativa Seleção Única

Nome da variável: F1M11_18_jkb

Alternativas: (descrição - score)

Positivo - 1.0

Negativo - 2.0

Não realizado - 3.0

11.19) Sistema Lewis Antígenos Lea:

Pergunta Alternativa Seleção Única

Nome da variável: F1M11_19_lea

Alternativas: (descrição - score)

Positivo - 1.0

Negativo - 2.0

Não realizado - 3.0

11.20) Sistema Lewis Antígenos Leb:

Pergunta Alternativa Seleção Única

Nome da variável: F1M11_20_leb

Alternativas: (descrição - score)

Positivo - 1.0

Negativo - 2.0

Não realizado - 3.0

11.21) Sistema MNS Antígenos M:

Pergunta Alternativa Seleção Única

Nome da variável: F1M11_21_m

Alternativas: (descrição - score)

Positivo - 1.0

Negativo - 2.0 
Não realizado - 3.0

11.22) Sistema MNS Antígenos N:

Pergunta Alternativa Seleção Única

Nome da variável: F1M11_22_n

Alternativas: (descrição - score)

Positivo - 1.0

Negativo - 2.0

Não realizado - 3.0

11.23) Sistema MNS Antígenos S:

Pergunta Alternativa Seleção Única

Nome da variável: F1M11_23_us

Alternativas: (descrição - score)

Positivo - 1.0

Negativo - 2.0

Não realizado - 3.0

11.24) Sistema MNS Antígenos s:

Pergunta Alternativa Seleção Única

Nome da variável: F1M11_24_s

Alternativas: (descrição - score)

Positivo - 1.0

Negativo - 2.0

Não realizado - 3.0

11.25) Sistema Lutheran Antígenos Lua:

Pergunta Alternativa Seleção Única

Nome da variável: F1M11_25_lua

Alternativas: (descrição - score)

Positivo - 1.0

Negativo - 2.0

Não realizado - 3.0

11.26) Sistema Lutheran Antígenos Lub:

Pergunta Alternativa Seleção Única

Nome da variável: F1M11_26_lub

Alternativas: (descrição - score)

Positivo - 1.0

Negativo - 2.0

Não realizado - 3.0

11.27) Sistema Diego Antígenos Dia:

Pergunta Alternativa Seleção Única

Nome da variável: F1M11_27_dia

Alternativas: (descrição - score) 
Positivo - 1.0

Negativo - 2.0

Não realizado - 3.0

11.28) Sistema Diego Antígenos Dib:

Pergunta Alternativa Seleção Única

Nome da variável: F1M11_28_dib

Alternativas: (descrição - score)

Positivo - 1.0

Negativo - 2.0

Não realizado - 3.0

11.29) O paciente alguma vez na vida já teve diagnóstico de anticorpos irregulares? Pergunta Alternativa Seleção Única Nome da variável: F1M11_29_anti

Alternativas: (descrição - score)

Sim -1.0

Não - 2.0

11.30) AC eritrocitários C identificados na P.A.I?

Pergunta Alternativa Seleção Única

Nome da variável: F1M11_30_auc

Alternativas: (descrição - score)

Sim -1.0

Não - 2.0

11.31) Data em que o anticorpo eritrocitário $C$ foi identificado pela primeira vez:

Pergunta Data

Nome da variável: F1M11_31_auc_d

Intervalo permitido: 01/01/1920 - 31/12/2017

11.32) AC eritrocitários c identificados na P.A.I?

Pergunta Alternativa Seleção Única

Nome da variável: F1M11_32_ac

Alternativas: (descrição - score)

Sim -1.0

Não - 2.0

11.33) Data em que o anticorpo eritrocitário c foi identificado pela primeira vez:

\section{Pergunta Data}

Nome da variável: F1M11_33_ac_d

Intervalo permitido: 01/01/1920 - 31/12/2017

11.34) AC eritrocitários D identificados na P.A.I?

Pergunta Alternativa Seleção Única

Nome da variável: F1M11_34_ad 


\begin{tabular}{|c|}
\hline $\begin{array}{l}\text { Alternativas: (descrição - score) } \\
\text { Sim - } 1.0 \\
\text { Não - } 2.0\end{array}$ \\
\hline $\begin{array}{l}\text { 11.35) Data em que o anticorpo eritrocitário D foi identificado pela primeira vez: } \\
\text { Pergunta Data } \\
\text { Nome da variável: F1M11_35_ad_d } \\
\text { Intervalo permitido: } 01 / 01 / 1920 \text { - 31/12/2017 }\end{array}$ \\
\hline $\begin{array}{l}\text { 11.36) AC eritrocitários E identificados na P.A.I? } \\
\text { Pergunta Alternativa Seleção Única } \\
\text { Nome da variável: F1M11_36_aue } \\
\text { Alternativas: (descrição - score) } \\
\text { Sim - } 1.0 \\
\text { Não - } 2.0\end{array}$ \\
\hline $\begin{array}{l}\text { 11.37) Data em que o anticorpo eritrocitário E foi identificado pela primeira vez: } \\
\text { Pergunta Data } \\
\text { Nome da variável: F1M11_37_aue_d } \\
\text { Intervalo permitido: } 01 / 01 / 1920 \text { - 31/12/2017 }\end{array}$ \\
\hline $\begin{array}{l}\text { 11.38) AC eritrocitários e identificados na P.A.I? } \\
\text { Pergunta Alternativa Seleção Única } \\
\text { Nome da variável: F1M11_38_ae } \\
\text { Alternativas: (descrição - score) } \\
\text { Sim - } 1.0 \\
\text { Não - } 2.0\end{array}$ \\
\hline $\begin{array}{l}\text { 11.39) Data em que o anticorpo eritrocitário e foi identificado pela primeira vez: } \\
\text { Pergunta Data } \\
\text { Nome da variável: F1M11_39_ae_d } \\
\text { Intervalo permitido: } 01 / 01 / 1920 \text { - 31/12/2017 }\end{array}$ \\
\hline $\begin{array}{l}\text { 11.40) AC eritrocitários Fya identificados na P.A.I? } \\
\text { Pergunta Alternativa Seleção Única } \\
\text { Nome da variável: F1M11_40_afya } \\
\text { Alternativas: (descrição - score) } \\
\text { Sim - } 1.0 \\
\text { Não - } 2.0\end{array}$ \\
\hline $\begin{array}{l}\text { 11.41) Data em que o anticorpo eritrocitário Fya foi identificado pela primeira vez: } \\
\text { Pergunta Data } \\
\text { Nome da variável: F1M11_41_afya_d } \\
\text { Intervalo permitido: } 01 / 01 / 1920 \text { - 31/12/2017 }\end{array}$ \\
\hline
\end{tabular}




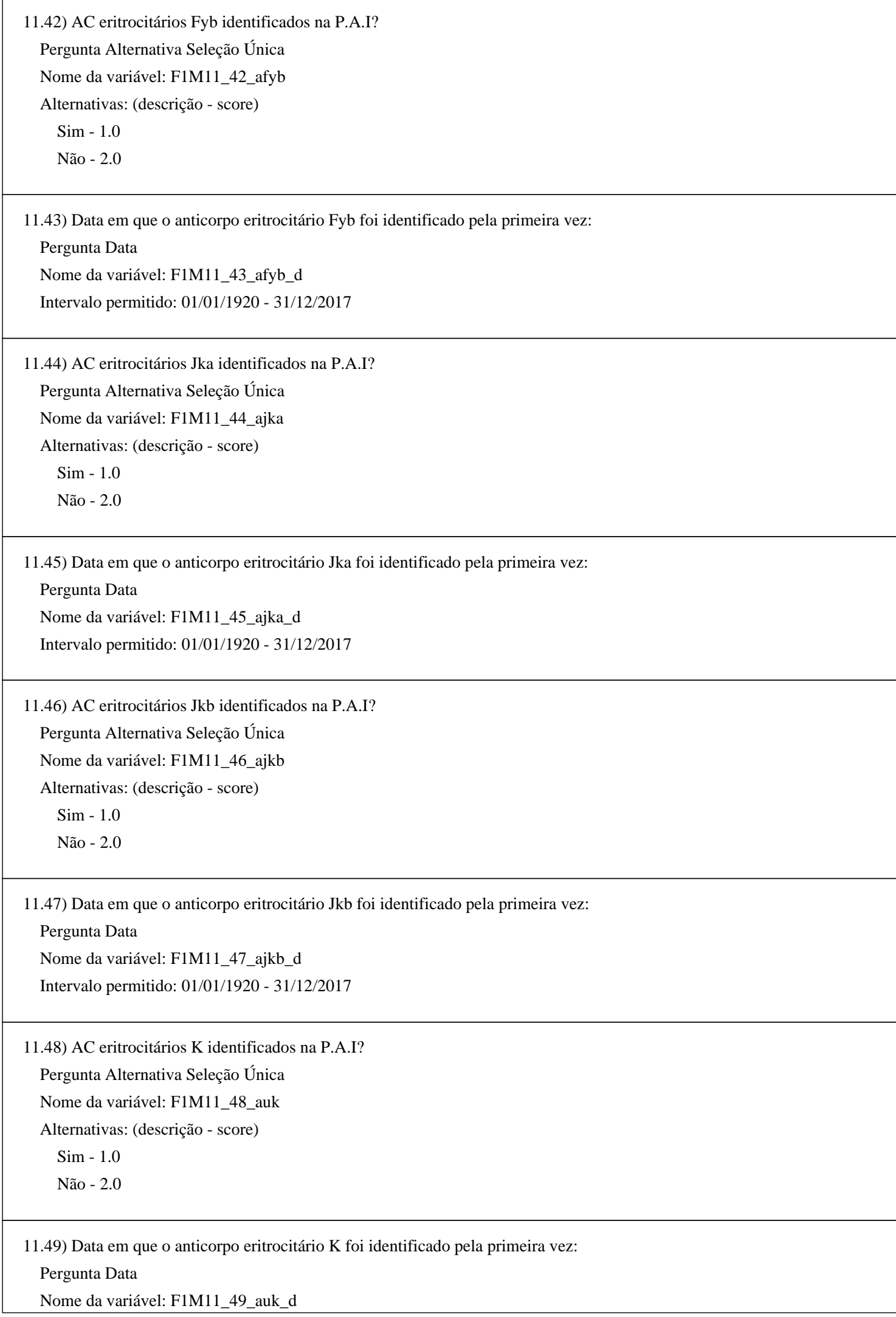


Intervalo permitido: 01/01/1920 - 31/12/2017

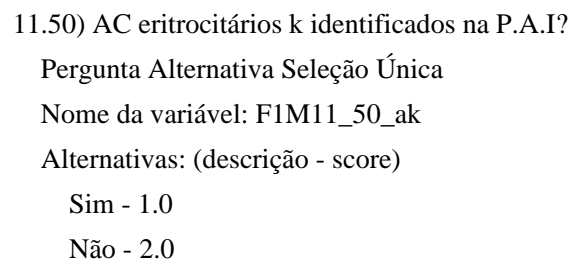

11.51) Data em que o anticorpo eritrocitário $\mathrm{k}$ foi identificado pela primeira vez: Pergunta Data

Nome da variável: F1M11_51_ak_d

Intervalo permitido: 01/01/1920 - 31/12/2017

11.52) AC eritrocitários M identificados na P.A.I?

Pergunta Alternativa Seleção Única

Nome da variável: F1M11_52_am

Alternativas: (descrição - score)

Sim - 1.0

Não - 2.0

11.53) Data em que o anticorpo eritrocitário $M$ foi identificado pela primeira vez:

Pergunta Data

Nome da variável: F1M11_53_am_d

Intervalo permitido: 01/01/1920 - 31/12/2017

11.54) AC eritrocitários Lea identificados na P.A.I?

Pergunta Alternativa Seleção Única

Nome da variável: F1M11_54_alea

Alternativas: (descrição - score)

Sim -1.0

Não - 2.0

11.55) Data em que o anticorpo eritrocitário Lea foi identificado pela primeira vez:

\section{Pergunta Data}

Nome da variável: F1M11_55_alea_d

Intervalo permitido: 01/01/1920 - 31/12/2017

11.56) AC eritrocitários Leb identificados na P.A.I?

Pergunta Alternativa Seleção Única

Nome da variável: F1M11_56_aleb

Alternativas: (descrição - score)

Sim -1.0

Não -2.0 


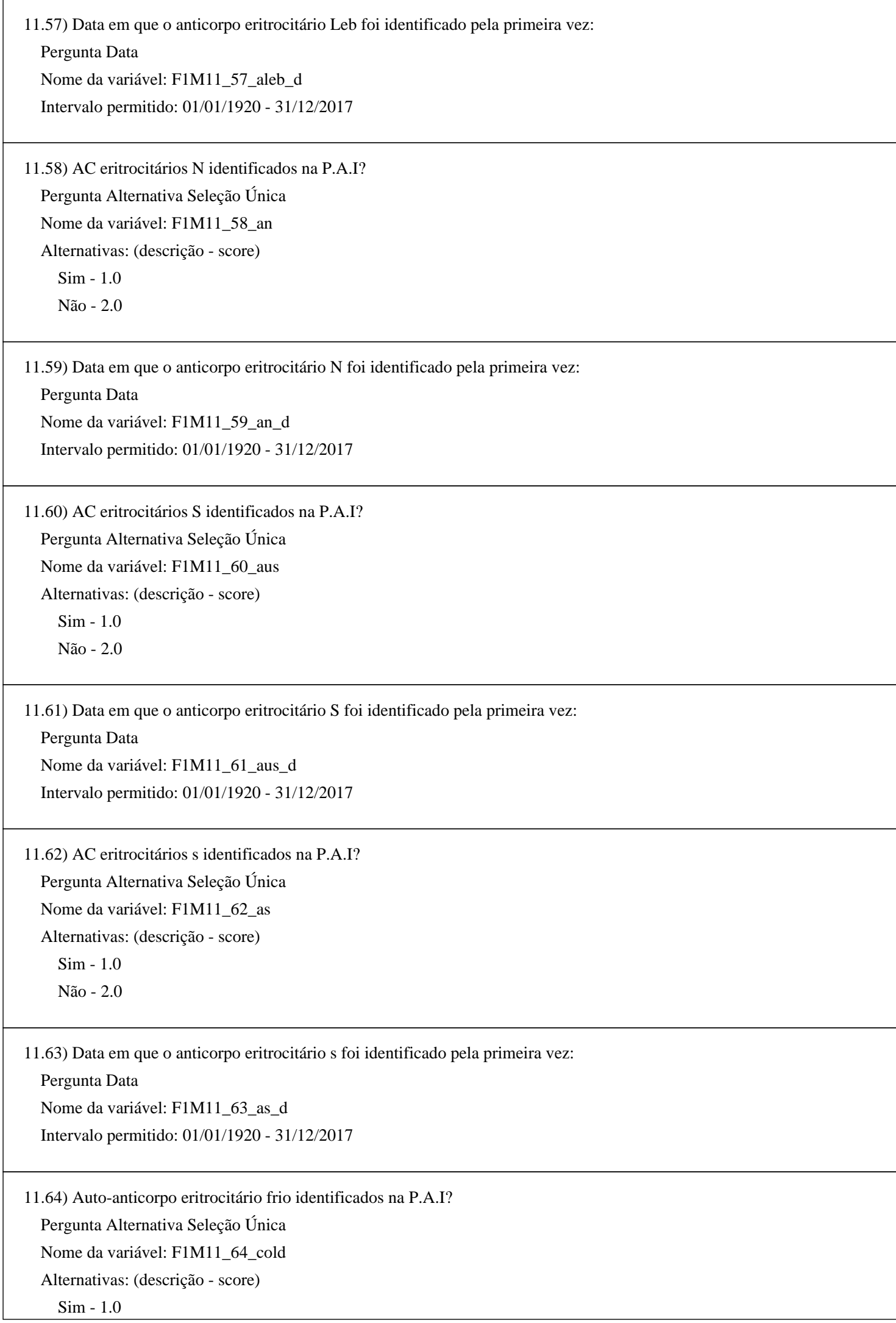


Não -2.0

11.65) Data em que o auto-anticorpo eritrocitário frio foi identificado pela primeira vez:

Pergunta Data

Nome da variável: F1M11_65_cold_d

Intervalo permitido: 01/01/1920 - 31/12/2017

11.66) Auto-anticorpo eritrocitário quente identificados na P.A.I?

Pergunta Alternativa Seleção Única

Nome da variável: F1M11_66_warm

Alternativas: (descrição - score)

Sim -1.0

Não - 2.0

11.67) Data em que o auto-anticorpo eritrocitário quente foi identificado pela primeira vez:

Pergunta Data

Nome da variável: F1M11_67_warm_d

Intervalo permitido: 01/01/1920 - 31/12/2017

11.68) Outro anticorpo eritrocitário identificados na P.A.I?

Pergunta Alternativa Seleção Única

Nome da variável: F1M11_68_o

Alternativas: (descrição - score)

Sim -1.0

Não - 2.0

11.69) Data em que outro anticorpo eritrocitário foi identificado pela primeira vez: Pergunta Data

Nome da variável: F1M11_69_o_d

Intervalo permitido: 01/01/1920 - 31/12/2017

11.70) Especifique qual outro anticorpo eritrocitário identificado (separe por ; os outros anticorpos):

Pergunta Texto

Nome da variável: F1M11_70_o_sp

Número máximo de caracteres permitido: 100

\section{Módulo: 12 - Transfusões no último ano}

12.1) O paciente recebeu transfusão de sangue desde a inscrição no estudo?

Pergunta Alternativa Seleção Única

Nome da variável: F1M12_1_tx

Alternativas: (descrição - score)

Sim -1.0

Não - 2.0 
Planilha: Questões relacionadas à transfusões no último ano

Itens: (Descrição - Nome da variável)

Tranfusão no último ano - F1M12

12.2) Data da transfusão:

Pergunta Data

Nome da variável: _2_tx_d

Intervalo permitido: $01 / 01 / 2013-31 / 12 / 2016$

12.3) Quantas unidades foram transfundidas nessa tranfusão?

Pergunta Número Inteiro

Nome da variável: 3 unit

Intervalo permitido: $1-100$

12.4) Qual a indicação da transfusão? (marque todas opções que se aplicam)

Pergunta Alternativa Seleção Múltipla

Nome da variável: _4_tx

Alternativas: (descrição - nome da variável - score)

Síndrome torácica aguda - _acs - 1.0

Sequestro esplênico - _ss - 2.0

Crise aplástica - _aa - 3.0

Acidente vascular - stro - 4.0

Falência múltipla dos órgãos - _mof - 5.0

Crise de dor / episodio vaso-oclusivo - _voe - 6.0

Preparação pré-operatória - _op - 7.0

Anemia aguda sintomática - anem - 8.0

Transfusões crônicas - _ctt - 9.0

Outra - _o - 100.0

12.5) Especifique qual a outra indicação para transfusão (separe por ; as outras indicações):

Pergunta Texto

Nome da variável:_5_sp tx

Número máximo de caracteres permitido: 100

12.6) Qual o tipo de transfusão?

Pergunta Alternativa Seleção Única

Nome da variável: _6_tx_typ

Alternativas: (descrição - score)

Simples

Transfusão de troca automática -2.0

Transfusão de troca manual - 3.0

12.7) Houve reações associada a transfusão? (marque todas opções que se aplicam)

Pergunta Alternativa Seleção Múltipla

Nome da variável: _7_rx

Alternativas: (descriçã̃o - nome da variável - score)

Sem reação associada

Reação febril não hemolítica - _fnhtr - 2.0

Reação Séptica - _sep - 3.0

TRÁLI - lesão pulmonar aguda relacionada à transfusão - trali - 4.0

SCAT(Sobrecarga circulatória associada a transfusão) - _taco - 5.0

Reação transfusional hemolítica aguda - _ahtr - 6.0

Reação alérgica - _allg - 100.0

12.8) Tipo de reação alérgica:

Pergunta Alternativa Seleção Múltipla

Nome da variável:_8_alg

Alternativas: (descrição - nome da variável - score)

Urticária - _ur - 1.0

Dificuldade respiratória ou hipertensão - _rsp - 2.0

\section{Módulo: 13 - Dados da bolsa/doador}

13) Todos os dados imunológicos da bolsa recebida pelo paciente podem ser extraídos do sistema eletrônico do hemocentro? Pergunta Alternativa Seleção Única

Nome da variável: F1M13_ext 
Alternativas: (descrição - score)

Sim -1.0

Não - 2.0

não recebeu transfusão nos últimos 12 meses / nunca recebeu transfusão - 3.0

Planilha: Questões relacionadas a dados da bolsa

Itens: (Descrição - Nome da variável)

Dados da bolsa - F1M13

13.1) Data da transfusão desta bolsa:

Pergunta Data

Nome da variável: _1_d

Intervalo permitido: $01 / 01 / 2013$ - 31/12/2016

13.2) Identificação da bolsa:

Pergunta Texto

Nome da variável:__2_id

Número máximo de caracteres permitido: 15

13.3) Código do componente desța bolsa: $($ concentrado de Hemácia $=\mathrm{CH}$ )

Pergunta Alternativa Seleção Única

Nome da variável: _3_cod

Alternativas: (descrição - score)

$\mathrm{CH}-1.0$

CHBVI - 2.0

CHD - 3.0

CHDF - 4.0

CHDFI - 5.0

CHDFT - 6.0

CHDFTB - 7.0

CHDFTB $1-8.0$

CHF - 9.0

CHFI - 10.0

CHI -11.0

CHIL - 12.0

Outro - 100.0

13.4) Especifique o outro código do componente desta bolsa (separe por ; os componentes)

Pergunta Texto

Nome da variável:_4_sp_cod

Número máximo de caracteres permitido: 100

\author{
Módulo: 14 - Tratamentos \\ 14.1) O paciente já esteve alguma vez em regime de transfusão crônica? \\ Pergunta Alternativa Seleção Única \\ Nome da variável: F1M14_1_ctt_hx \\ Alternativas: (descrição - score) \\ Sim -1.0 \\ Não -2.0 \\ 14.2) Qual a indicação da transfusão crônica? (marque todas que se aplicam) \\ Pergunta Alternativa Seleção Múltipla \\ Nome da variável: F1M14_2_ct \\ Alternativas: (descrição - nome da variável - score) \\ Doppler transcraniano anormal - _tcd - 1.0 \\ Historia de acidente vascular cerebral - _cva - 2.0 \\ Dor recorrente grave - _voe - 3.0 \\ Síndrome torácica aguda recorrente - _acs - 4.0
}




\begin{tabular}{|c|}
\hline $\begin{array}{l}\text { Infarto cerebral silencioso - _sit }-5.0 \\
\text { Gravidez - _pg - } 6.0 \\
\text { Úlcera de perna - _ulc - } 7.0 \\
\text { Doença vascular cerebral - _cvd }-8.0 \\
\text { Falência renal - _rf - } 9.0 \\
\text { Outra - _o - } 100.0\end{array}$ \\
\hline $\begin{array}{l}\text { 14.3) Especifique a outra indicação para transfusão crônica atual (separe por ; as outras indicações): } \\
\text { Pergunta Texto } \\
\text { Nome da variável: F1M14_3_tx_o } \\
\text { Número máximo de caracteres permitido: } 100\end{array}$ \\
\hline $\begin{array}{l}\text { 14.4) Data de início da transfusão crônica: } \\
\text { Pergunta Data } \\
\text { Nome da variável: F1M14_4_tx_d } \\
\text { Intervalo permitido: } 01 / 01 / 1900 \text { - 31/12/2016 }\end{array}$ \\
\hline $\begin{array}{l}\text { 14.5) Atualmente, o paciente está em tratamento com transfusão crônica? } \\
\text { Pergunta Alternativa Seleção Única } \\
\text { Nome da variável: F1M14_5_ctt_now } \\
\text { Alternativas: (descrição - score) } \\
\text { Sim - } 1.0 \\
\text { Não - } 2.0\end{array}$ \\
\hline $\begin{array}{l}\text { 14.6) Data em que o paciente interrompeu o tratamento com transfusão crônica: } \\
\text { Pergunta Data } \\
\text { Nome da variável: F1M14_6_detx_d } \\
\text { Intervalo permitido: } 01 / 01 / 1900 \text { - 31/12/2016 }\end{array}$ \\
\hline $\begin{array}{l}\text { 14.7) O paciente já fez tratamento com Hidroxiuréia? } \\
\text { Pergunta Alternativa Seleção Única } \\
\text { Nome da variável: F1M14_7_hu } \\
\text { Alternativas: (descrição - score) } \\
\text { Sim - } 1.0 \\
\text { Não - } 2.0\end{array}$ \\
\hline $\begin{array}{l}\text { 14.8) Qual foi a indicação para o tratamento com Hidroxiuréia? (Marque todas as opções que se aplicam) } \\
\text { Pergunta Alternativa Seleção Múltipla } \\
\text { Nome da variável: F1M14_8_hu } \\
\text { Alternativas: (descrição - nome da variável - score) } \\
\text { Dor grave / frequente - _voe - } 1.0 \\
\text { Síndrome Torácica Aguda grave/frequente - _acs - } 2.0 \\
\text { AVC - _cva - } 3.0 \\
\text { Doppler transcraniano alterado - _tcd - } 4.0 \\
\text { Doença vascular cerebral (estreitamento anormal dos vasos cerebrais) - _cvd - } 5.0 \\
\text { Úlcera de perna - _ulc - } 6.0\end{array}$ \\
\hline
\end{tabular}


Hipertensão pulmonar - _ph - 7.0

Outra - o - 100.0

14.9) Especifique a outra indicação para o tratamento com Hidroxiuréia (separe por ; as outras indicações):

Pergunta Texto

Nome da variável: F1M14_9_hu_i_o

Número máximo de caracteres permitido: 100

14.10) Data de início do tratamento com Hidroxiuréia:

Pergunta Data

Nome da variável: F1M14_10_hu_d

Intervalo permitido: 01/01/1900 - 31/12/2016

14.10.1) Estime a adesão do paciente ao tratamento com Hidroxiuréia:

Pergunta Alternativa Seleção Única

Nome da variável: F1M14_10_1_hu_compl

Alternativas: (descrição - score)

Toma hidroxiuréia mais de $75 \%$ do tempo indicado - 1.0

Toma hidroxiuréia de $25 \%$ a $75 \%$ do tempo indicado -2.0

Toma hidroxiuréia menos de $25 \%$ do tempo indicado - 3.0

14.11) O paciente interrompeu tratamento com Hidroxiuréia ? (Considerar Interrupção: Interrupção completa e irreversível, e

NÃO a suspensão temporária devido a algum sintoma ou desconforto ou alteração dos exames laboratoriais)

Pergunta Alternativa Seleção Única

Nome da variável: F1M14_11_hu_interrupt

Alternativas: (descrição - score)

Sim -1.0

Não -2.0

14.12) Data em que o paciente interrompeu o tratamento com Hidroxiuréia:

Pergunta Data

Nome da variável: F1M14_12_dchu_d

Intervalo permitido: 01/01/1900 - 31/12/2016

14.13) Indicação para interromper o tratamento com Hidroxiuréia: (Marque todas as opções que se aplicam)

Pergunta Alternativa Seleção Múltipla

Nome da variável: F1M14_13_dchu

Alternativas: (descrição - nome da variável - score)

Toxicidade hematológica - _htox - 1.0

Toxicidade hepática ou renal - _lrtox - 2.0

Intolerância (dor abdominal, diarreia, vômitos, constipação, cefaleia, tontura, erupção cutânea ) - _int - 3.0

Gravidez - _pg - 4.0

Não adesão ao tratamento - _adh - 5.0

O paciente optou por interromper o tratamento devido à preocupações com a fertilidade - _fert - 6.0

Para iniciar o tratamento com transfusão crônica - _ctt - 7.0

Outra - _o - 100.0 
4.14) Especifique a outra indicação para interromper o tratamento com Hidroxiuréia (separe por ; as outras indicações): Pergunta Texto

Nome da variável: F1M14_14_dchu_o

Número máximo de caracteres permitido: 100

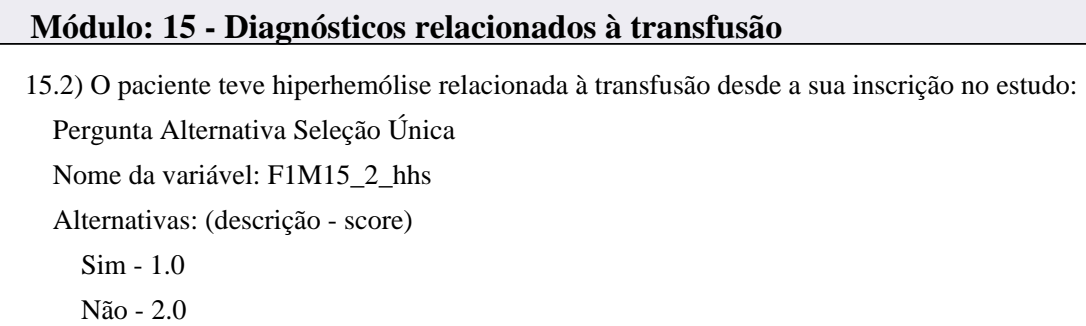

15.2) O paciente teve hiperhemólise relacionada à transfusão desde a sua inscrição no estudo: Pergunta Alternativa Seleção Única

Nome da variável: F1M15_2_hhs

Alternativas: (descrição - score)

Sim -1.0

Não - 2.0

15.3) Data do diagnóstico de hiperhemólise relacionada à transfusão:

Pergunta Data

Nome da variável: F1M15_3_hhs_d

Intervalo permitido: 01/01/2013 - 31/12/2016

15.4) O paciente teve reação transfusional hemolítica tardia desde a sua inscrição no estudo: Pergunta Alternativa Seleção Única

Nome da variável: F1M15_4_dhtr

Alternativas: (descrição - score)

Sim -1.0

Não -2.0

15.5) Data do diagnóstico de reação transfusional hemolítica tardia:

Pergunta Data

Nome da variável: F1M15_5_dhtr_d

Intervalo permitido: 01/01/2013 - 31/12/2016

15.6) O paciente teve hemossiderose transfusional desde a sua inscrição no estudo: (Caso o paciente tenha sido diagnosticado com hemossiderose transfusional antes do período do Acompanhamento 1, mas mantém o diagnóstico, responder "Sim”)

Pergunta Alternativa Seleção Única

Nome da variável: F1M15_6_hemo

Alternativas: (descrição - score)

Sim -1.0

Não - 2.0

15.7) Data do diagnóstico de hemossiderose transfusional: (Marque "Não se aplica" se o diagnóstico de hemossiderose foi feito antes do período de acompanhamento)

Pergunta Data

Nome da variável: F1M15_7_hemo_d

Intervalo permitido: 01/01/2013 - 31/12/2016 
Intervalo permitido: 01/01/2013 - 31/12/2016

\author{
Módulo: 16 - Diagnósticos oftalmológicos \\ 16.1) O paciente realizou exame ocular desde a sua inscrição no estudo: \\ Pergunta Alternativa Seleção Única \\ Nome da variável: F1M16_1_eye \\ Alternativas: (descrição - score) \\ Sim -1.0 \\ Não -2.0 \\ 16.2) O paciente teve hemorragia retiniana desde a sua inscrição no estudo: \\ Pergunta Alternativa Seleção Única \\ Nome da variável: F1M16_2_rh \\ Alternativas: (descrição - score) \\ Sim - 1.0 \\ Não -2.0
}

16.3) Data do diagnóstico de hemorragia retiniana:

Pergunta Data

Nome da variável: F1M16_3_rh_d

Intervalo permitido: 01/01/2013 - 31/12/2016

16.4) O paciente teve hemorragia vítrea desde a sua inscrição no estudo:

Pergunta Alternativa Seleção Única

Nome da variável: F1M16_4_vh

Alternativas: (descrição - score)

Sim -1.0

Não -2.0

16.5) Data do diagnóstico de episódio Hemorragia vítrea:

Pergunta Data

Nome da variável: F1M16_5_vh_d

Intervalo permitido: 01/01/2013 - 31/12/2016

16.6) O paciente teve retinopatia falciforme proliferativa desde a sua inscrição no estudo: (Caso o paciente tenha sido diagnosticado com retinopatia falciforme proliferativa antes do período do Acompanhamento 1, mas mantém o diagnóstico, responder "Sim")

Pergunta Alternativa Seleção Única

Nome da variável: F1M16_6_psr

Alternativas: (descrição - score)

Sim - 1.0

Não - 2.0 
16.7) Data do diagnóstico de retinopatia falciforme proliferativa: (Marque "Não se aplica" se o diagnóstico de retinopatia falciforme proliferativa foi feito antes do período de acompanhamento)

Pergunta Data

Nome da variável: F1M16_7_psr_d

Intervalo permitido: 01/01/2013 - 31/12/2016

\section{Módulo: 17 - Diagnósticos pulmonares: hipertensão pulmonar}

17.1) O paciente teve hipertensão pulmonar desde a sua inscrição no estudo? (Caso o paciente tenha sido diagnosticado com hipertensão pulmonar antes do período do Acompanhamento 1, mas mantém o diagnóstico, responder “Sim”)

Pergunta Alternativa Seleção Única

Nome da variável: F1M17_1_ph

Alternativas: (descrição - score)

Sim -1.0

Não - 2.0

17.2) Como a hipertensão pulmonar foi diagnosticada?

Pergunta Alternativa Seleção Única

Nome da variável: F1M17_2_ph_dx

Alternativas: (descrição - score)

Apenas por eco - 1.0

Apenas por cateterismo - 2.0

Por ambos, eco e cateterismo - 3.0

17.3) Qual tratamento o paciente recebeu para tratar a Hipertensão Pulmonar? (Marque todas as opções que se aplicam)

Pergunta Alternativa Seleção Múltipla

Nome da variável: F1M17_3_phtx

Alternativas: (descrição - nome da variável - score)

Não recebeu tratamento - _no - 1.0

Transfusão crônica - _ctt - 2.0

Hidroxiuréia - _hu - 3.0

Agonista Protaciclina - _pros - 4.0

Antagonista do Receptor da Endotelina - _end - 5.0

Inibidores da fosfodiesterase-5 - _5pd - 6.0

Outro - _o - 100.0

17.4) Especifique outro tratamento recebido para tratar a hipertensão pulmonar (separe por ; o outro tratamento):

Pergunta Texto

Nome da variável: F1M17_4_ph_o

Número máximo de caracteres permitido: 100

\section{Módulo: 18 - Diagnósticos pulmonares: embolismo pulmonar}

18.1) O paciente teve embolismo pulmonar desde a sua inscrição no estudo: 
Pergunta Alternativa Seleção Única

Nome da variável: F1M18_1_pe

Alternativas: (descrição - score)

Sim -1.0

Não - 2.0

18.2) Quantas vezes esse indivíduo teve episódio de embolismo pulmonar desde a sua inscrição no estudo?

Pergunta Número Inteiro

Nome da variável: F1M18_2_pe_n

Intervalo permitido: 1 - 99

Planilha: Questões relacionadas ao episodio de embolismo pulmonar

Itens: (Descrição - Nome da variável)

Embolismo pulmonar - F1M18

18.3) Data do episódio de esmbolismo pulmonar (registre o primeiro dia do episódio, caso o episódio tenha durado mais de 1 dia):

Pergunta Data

Nome da variável: 3 pe d

Intervalo permitido: $01 / 01 / 2013-31 / 12 / 2016$

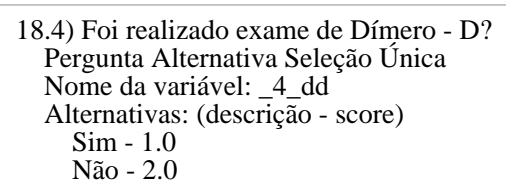

18.5) Valor do Dimero - D:

Pergunta Número Inteiro

Nome da variável: _5_dd_r

Intervalo permitido: $10-\overline{2} 000$

18.6) Foi feita ventilação/escaneamento da perfusão?

Pergunta Alternativa Seleção Única

Nome da variável: _6_vq

Alternativas: (descriçãa - score)

Sim -1.0

Não -2.0

18.7) Qual foi o resultado da ventilação/escaneamento da perfusão?

Pergunta Alternativa Seleção Única

Nome da variável: _7_vq_r

Alternativas: (descrição - score)

Normal - 1.0

Dois ou mais defeitos de perfusão segmentar sem defeitos de ventilação correspondente - 2.0

Um grande defeito de perfusão segmentar e 2 ou mais defeitos moderados de perfusão segmentar sem alterações radiográficas ou de ventilação correspondentes - 3.0

4 ou mais defeitos de perfusão segmentar moderado, sem alterações radiográficas ou de ventilação correspondentes -4.0

Outro - 5.0

18.8) Especifique o outro resultado do exame de ventilação/escaneamento da perfusão (Separe por ; os outros resultados):

Pergunta Texto

Nome da variável:_8_vq_o

Número máximo de caracteres permitido: 100

18.9) A angiografia apresentou defeitos de preenchimento intraluminal?

Pergunta Alternativa Seleção Única

Nome da variável: _9_ang

Alternativas: (descrição - score)

Sim -1.0

Não - 2.0

Angiografia não realizada - 3.0 
18.10) Tomografia computadorizada da artéria pulmonar mostrando defeitos de preenchimento intraluminal? Pergunta Alternativa Seleção Única

Nome da variável: 10

Alternativas: (descrição - score)

Sim - 1.0

Não -2.0

Tomografia computadorizada não realizada - 3.0

18.11) O lavado broncoalveolar evidenciou macrófagos carregados de lipídios?

Pergunta Alternativa Seleção Única

Nome da variável: _11_bal

Alternativas: (descriçãa- - score)

Sim -1.0

Não - 2.0

Lavado broncoalveolar não realizado - 3.0

18.12) O paciente foi transfundido nesse episódio de embolismo pulmonar?

Pergunta Alternativa Seleção Única

Nome da variável:_12_pe_tx

Alternativas: (descrição - score)

Sim -1.0

Não - 2.0

\section{Módulo: 19 - Diagnósticos pulmonares: síndrome torácica aguda}

19.1) O paciente teve síndrome torácica aguda/pneumonia desde a sua inscrição no estudo:

Pergunta Alternativa Seleção Única

Nome da variável: F1M19_1_acs

Alternativas: (descrição - score)

Sim -1.0

Não -2.0

19.2) Quantas vezes esse indivíduo teve síndrome torácica aguda nos desde a sua inscrição no estudo?

Pergunta Número Inteiro

Nome da variável: F1M19_2_acs_n

Intervalo permitido: 1 - 99

Planilha: Questões relacionadas ao episodio de síndrome torácica aguda/pneumonia

Itens: (Descrição - Nome da variável)

Síndrome torácica aguda/pneumonia - F1M19

19.3) Data do episódio de STA (registre o primeiro dia do episódio, caso o episódio tenha durado mais de 1 dia): Pergunta Data

Nome da variável:_3_acs_d

Intervalo permitido: $01 / 01 / 2013-31 / 12 / 2016$

19.4) Saturação de oxigênio mais baixa neste episódio de STA:

Pergunta Número Inteiro

Nome da variável: 4 lowO

Intervalo permitido: 0 - 100

19.5) Menor pressão de oxigênio (PaO2) neste episódio de STA (Marque "Não se aplica" se não houver resultado da menor pressão de oxigênio)

Pergunta Número Inteiro

Nome da variável: 5 lowPaO

Intervalo permitido: 0 - 200 
19.6) Registre os sintomas presentes no dia em que a síndrome torácica aguda foi diagnosticada: (marcar todos que se aplicam)

Pergunta Alternativa Seleção Múltipla

Nome da variável: _6_acs

Alternativas: (descrição - nome da variável - score)

Tosse - _cou - 1.0

Febre - fev - 2.0

Dor no peito - _cp - 3.0

Retração intra-costal - _ret - 4.0

Queimação nasal - _nf - 5.0

Sibilância - _wh - 6.0

Estertores - ral - 7.0

Outro - _o - 100.0

19.7) Especifique o outro sintoma presente no dia do diagnóstico da síndrome torácica aguda: (Separe por ; os outros sintomas)

Pergunta Texto

Nome da variável: 7 acs_o

Número máximo de caracteres permitido: 100

19.8) Foi necessário oxigênio suplementar neste episódio de STA?

Pergunta Alternativa Seleção Única

Nome da variável: _8_acsO2

Alternativas: (descrição - score)

Sim - 1.0

Não - 2.0

19.9) Quantos dias de oxigênio suplementar foram necessários neste episódio de STA?

Pergunta Número Inteiro

Nome da variável: _9_O2d

Intervalo permitido: 0 - 100

19.10) Foi feita ventilação não invasiva com pressão positiva neste episódio de STA? (Por exemplo, CPAP)

Pergunta Alternativa Seleção Única

Nome da variável: _10_cpap

Alternativas: (descriç̧ão - score)

Sim -1.0

$\mathrm{Não}-2.0$

19.11) Quantos dias de ventilação não invasiva com pressão positiva foram necessários neste episódio de STA?

Pergunta Número Inteiro

Nome da variável: _11_cpap_d

Intervalo permitido: 0 - 100

19.12) Foi necessária ventilação mecanica neste episódio de STA?

Pergunta Alternativa Seleção Única

Nome da variável: 12 mv

Alternativas: (descrição - score)

Sim -1.0

Não - 2.0

19.13) Quantos dias de ventilação mecânica foram necessários neste episódio de STA?

Pergunta Número Inteiro

Nome da variável: _13_mv_d

Intervalo permitido: $0-100$

19.14) O indivíduo foi transfundido nesse episódio de síndrome torácica aguda?

Pergunta Alternativa Seleção Única

Nome da variável: _14_acs_tx

Alternativas: (descrição - score)

Sim - 1.0

Não - 2.0

19.15) O paciente foi tratado com broncodilatadores inalatórios durante o episódio de STA?

Pergunta Alternativa Seleção Única

Nome da variável: 15 bd

Alternativas: (descrição - score)

Sim - 1.0

Não -2.0 
19.16) O paciente foi tratado com esteróides durante o episódio de STA?

Pergunta Alternativa Seleção Única

Nome da variável: 16 st

Alternativas: (descrição - score)

Sim - 1.0

Não -2.0

19.17) Durante quantos dias o paciente recebeu esteroides durante o episódio de STA?

Pergunta Número Inteiro

Nome da variável:_17_st_d

Intervalo permitido: 0 - 100

19.18) O paciente fez cultura do trato respiratório durante o episódio de STA?

Pergunta Alternativa Seleção Única

Nome da variável: _18_cx

Alternativas: (descrição - score)

Sim -1.0

Não - 2.0

19.19) O resultado da cultura do trato respiratório durante o episódio de STA foi:

Pergunta Alternativa Seleção Única

Nome da variável: _19_cx_r

Alternativas: (descrição - score)

Positivo - 1.0

Negativo -2.0

19.20) Especifique o microrganismo identificado na cultura do trato respiratório durante o episódio de STA (Separe por ; os outros microrganismos):

Pergunta Texto

Nome da variável:_20_sp_cx

Número máximo de caracteres permitido: 100

19.21) O paciente teve asma desde a sua inscrição no estudo:

Pergunta Alternativa Seleção Única

Nome da variável: F1M19_21_ast

Alternativas: (descrição - score)

Sim -1.0

Não - 2.0

19.22) Data do diagnóstico de asma:

Pergunta Data

Nome da variável: F1M19_22_ast_d

Intervalo permitido: 01/01/2013 - 31/12/2016

\section{Módulo: 20 - Diagnósticos relacionados à anemia}

20.1) O paciente teve episódio aplástico desde a sua inscrição no estudo:

Pergunta Alternativa Seleção Única

Nome da variável: F1M20_1_aa

Alternativas: (descrição - score)

Sim - 1.0

Não - 2.0

20.2) Quantas vezes esse indivíduo teve episódios aplásticos desde a sua inscrição no estudo?

Pergunta Número Inteiro

Nome da variável: F1M20_2_aa_n 
Intervalo permitido: 1 - 99

Planilha: Questões relacionadas ao episódio aplástico

Itens: (Descrição - Nome da variável)

Episódio aplástico - F1M20

20.3) Data do episódio aplástico: (registre o primeiro dia do episódio, caso o episódio tenha durado mais de 1 dia) Pergunta Data

Nome da variável:_3_aa_d

Intervalo permitido: 01/01/2013 - 31/12/2016

20.4) Contagem de Hg mais baixa no episódio aplástico: (Marque "Não se aplica" se a contagem de Hg não foi realizada

Pergunta Número Decimal

Nome da variável:_4_aa_h

Intervalo permitido: $1.0-20.0$

20.5) Contagem de reticulócitos mais baixa no episódio aplástico: (Marque "Não se aplica" se a contagem de reticulócitos não foi realizada)

Pergunta Número Decimal

Nome da variável: _5_aa_rt

Intervalo permitido: $0.0-100.0$

20.6) Registre o resultado da contagem de hemácias no momento da contagem mais baixa de reticulócitos no episódio aplástico (Marque "Não se aplica" se a contagem de hemácias não foi realizada)

Pergunta Número Decimal

Nome da variável:_6_aa_rb

Intervalo permitido: $0.5-15.0$

20.7) Foi feito o teste do parvovírus B19 no episódio aplástico?

Pergunta Alternativa Seleção Única

Nome da variável: 7 aa_b19

Alternativas: (descrição - score)

Sim - 1.0

Não -2.0

20.8) Resultados do teste do parvovirus B19 - DNA:

Pergunta Alternativa Seleção Única

Nome da variável: _8_p_dna

Alternativas: (descriçãa - score)

Positivo - 1.0

Negativo -2.0

20.9) Resultados do teste do parvovirus B19 - IgM:

Pergunta Alternativa Seleção Única

Nome da variável:_9_p_igm

Alternativas: (descrição - score)

Positivo - 1.0

Negativo - 2.0

20.10) O paciente estava usando hidroxiuréia durante o período do episódio aplástico?

Pergunta Alternativa Seleção Única

Nome da variável: _10_aa_hu

Alternativas: (descrição - score)

Sim -1.0

Não - 2.0

20.11) O paciente foi transfundido nesse episódio aplástico?

Pergunta Alternativa Seleção Única

Nome da variável: _11_aa_tx

Alternativas: (descrição - score)

Sim -1.0

Não - 2.0

20.12) O paciente teve anemia auto imune desde a sua inscrição no estudo:

Pergunta Alternativa Seleção Única

Nome da variável: F1M20_12_aiha

Alternativas: (descrição - score) 
Sim -1.0

Não - 2.0

20.13) Data do diagnóstico de anemia auto imune desde a sua inscrição no estudo:

Pergunta Data

Nome da variável: F1M20_13_aiha_d

Intervalo permitido: 01/01/2013 - 31/12/2016

20.14) O paciente teve sequestro esplênico agudo desde a sua inscrição no estudo:

Pergunta Alternativa Seleção Única

Nome da variável: F1M20_14_ss

Alternativas: (descrição - score)

Sim -1.0

Não - 2.0

20.15) Quantas vezes esse indivíduo teve sequestro esplênico agudo nos desde a sua inscrição no estudo?

Pergunta Número Inteiro

Nome da variável: F1M20_15_ss_n

Intervalo permitido: 1 - 99

Planilha: Questões relacionadas episódio de sequestro esplênico agudo

Itens: (Descrição - Nome da variável)

Episódio de sequestro esplênico agudo - F1M20

20.16) Data do episódio de sequestro esplênico: (registre o primeiro dia do episódio, caso o episódio tenha durado mais de 1 dia):

Pergunta Data

Nome da variável:_16_ss_d

Intervalo permitido: 01/01/2013 - 31/12/2016

20.17) Contagem de Hg mais baixa no sequestro esplênico: (Marque "Não se aplica" se a contagem de Hg não foi realizada)

Pergunta Número Decimal

Nome da variável: _17_ss_h

Intervalo permitido: $1 . \overline{0}-\overline{2} 0.0$

20.18) Contagem absoluta de plaquetas (a mais baixa) no sequestro esplênico: (Marque "Não se aplica" se a contagem absoluta de plaquetas não foi realizada)

Pergunta Número Inteiro

Nome da variável: _18_ss_p

Intervalo permitido: 25000 - 999999

20.19) Contagem mais elevada de reticulocitos no sequestro esplênico: (Marque "Não se aplica" se a contagem de reticulocitos não foi realizada)

Pergunta Número Decimal

Nome da variável: _19_ss_r

Intervalo permitido: $0.0-100.0$

20.20) Registre o resultado da hemácias no momento da contagem mais baixa de reticulócitos no sequestro esplênico: (Marque "Não se aplica" se a contagem de hemácias não foi realizada)

Pergunta Número Decimal

Nome da variável:_20_ss_rbc

Intervalo permitido: $0 . \overline{0}-\overline{15} .0$

20.21) O paciente foi transfundido no sequestro esplênico agudo?

Pergunta Alternativa Seleção Única

Nome da variável:_21_ss_tx

Alternativas: (descrição - score)

Sim -1.0

Não -2.0 


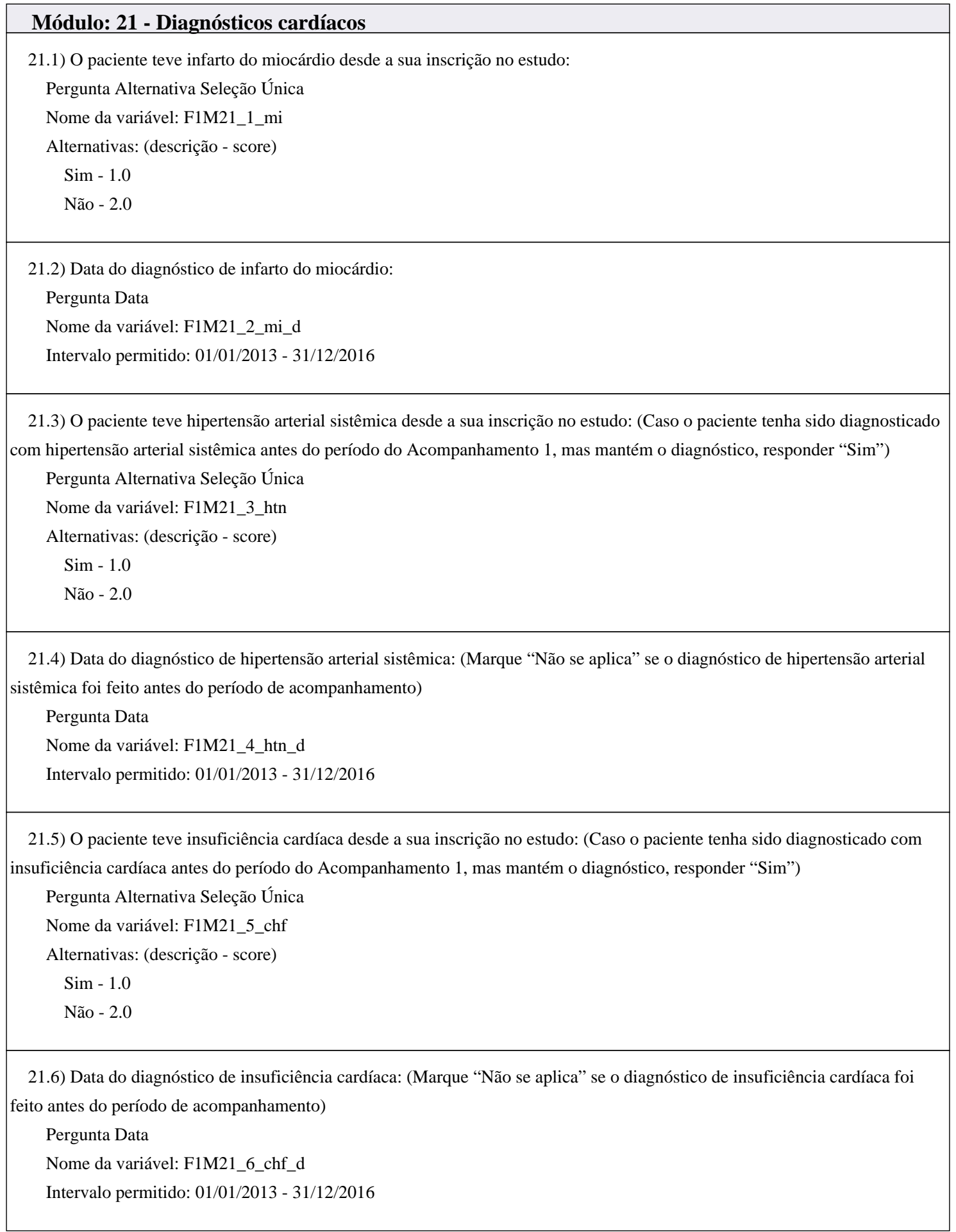

\section{Módulo: 22 - Diagnósticos neurológicos / dor: acidente vascular cerebral isquêmico}




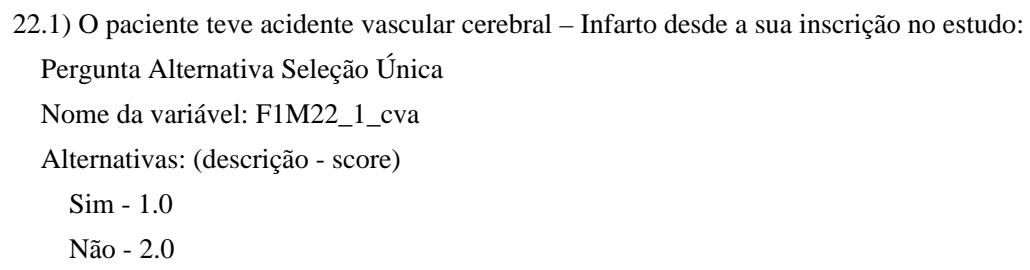

22.2) Quantas vezes esse indivíduo teve Acidente Vascular Cerebral Isquêmico desde a sua inscrição no estudo? Pergunta Número Inteiro

Nome da variável: F1M22_2_cva_n

Intervalo permitido: 1 - 99

Planilha: Questões relacionadas ao episódio de acidente vascular cerebral isquêmico Itens: (Descrição - Nome da variável)

Episódio de acidente vascular cerebral isquêmico - F1M22

22.3) Data do episódio de AVC isquêmico (registrar a data da realização da RMI/TC utilizada no diagnóstico. Se o paciente não fez esses exames, registre o dia no qual os sintomas neurológicos tiveram início) : Pergunta Data

Nome da variável: 3 cva d

Intervalo permitido: $01 / 01 / 2013-31 / 12 / 2016$

22.4) Quais foram os sintomas iniciais do AVC isquêmico? (marque todas as opções que se aplicam)

Pergunta Alternativa Seleção Múltipla

Nome da variável: _4_cva

Alternativas: (descriçãa - nome da variável - score)

Fraqueza nos membros superiors - _ue - 1.0

Fraqueza nos membros inferiores - _le - 2.0

Dificuldade para falar - _spk - 3.0

Alteração do nível de consciência - _loc - 4.0

Alterações na visão - _vis - 5.0

Dificuldade para caminhar - _wlk - 6.0

Convulsões - _sz - 7.0

Outros - _o - 100.0

22.5) Especifique o outro sintoma inicial do AVC isquêmico (Separe por ; os outros sintomas)

Pergunta Texto

Nome da variável: _5_cvasx_o

Número máximo de caracteres permitido: 100

22.6) Quais testes foram realizados para diagnosticar o AVC isquêmico? (marque todas opções que se aplicam e marque não se aplica se o avc foi apenas diagnosticado clinicamente)

Pergunta Alternativa Seleção Múltipla

Nome da variável: _6_cva

Alternativas: (descriçã̃o - nome da variável - score)

Ressonância magnética - MRI - _mri - 1.0

Tomografia computadorizada - $\bar{C} \overline{\mathrm{T}}-$ _ct -2.0

Sem resposta - noans - 3.0

Nenhum (O diagnóstico foi clínico) - _no - 100.0

22.7) Quais tipos de angiografia foram feitos para diagnosticar o AVC isquêmico? (marque todas opções que se aplicam)

Pergunta Alternativa Seleção Múltipla

Nome da variável: _7_cva

Alternativas: (descriçãa - nome da variável - score)

Ressonância Magnética Angiográfica RMA MRA - _mra - 1.0

Angiografia convencional - _an - 2.0

Tomografia computadorizada angiográfica - _cta - 3.0

Sem resposta - noans - 4.0

Nenhum - _no - 100.0 
22.8) Onde foi localizada a isquemia? (marque todas opções que se aplicam)

Pergunta Alternativa Seleção Múltipla

Nome da variável: 8 cva

Alternativas: (descrição - nome da variável - score)

Frontal - _ft - 1.0

Parietal - _ $\mathrm{pr}-2.0$

Sulco central - _sc - 3.0

Substância branca profunda - dp - 4.0

Occipital - _occ - 5.0

Outro - _o - 100.0

22.9) Especifique a outra localização da isquemia (Separe por ; as outras localizações)

Pergunta Texto

Nome da variável: 9 cval o

Número máximo de caracteres permitido: 100

22.10) Foi detectado estreitamento/estenose de algum vaso no AVC isquêmico?

Pergunta Alternativa Seleção Única

Nome da variável: _10_sten

Alternativas: (descrição - score)

Sim -1.0

Não -2.0

22.11) Em qual vaso foi detectado o estreitamento/estenose no AVC isquêmico? (marque todas as opções que se aplicam)

Pergunta Alternativa Seleção Múltipla

Nome da variável: _11 cva

Alternativas: (descrição - nome da variável - score)

Artéria Cerebral Média - _mca - 1.0

Arteria Carótida Interna - _ica - 2.0

Artéria Carótida Anterior - aca - 3.0

Artéria Cerebral Posterior - pca - 4.0

Outro - _o - 100.0

22.12) Especifique o outro vaso onde foi detectado o estreitamento/estenose no AVC isquêmico (Separe por ; vasos): Pergunta Texto

Nome da variável:_12_bv_o

Número máximo de caracteres permitido: 100

22.13) Qual foi o tamanho da lesão causada pelo infarto? (Se houve mais de um infarto, registre a área da maior lesão) Pergunta Número Decimal

Nome da variável:_13_cva_sz

Intervalo permitido: $0.0-500.0$

22.14) De qual lado do cérebro ocorreu o infarto?

Pergunta Alternativa Seleção Única

Nome da variável: 14 cva lc

Alternativas: (descrição - score)

Esquerdo - 1.0

Direito - 2.0

Bilateral - 3.0

22.15) O paciente foi transfundido nesse episódio de AVC isquêmico?

Pergunta Alternativa Seleção Única

Nome da variável: _15_cva_tx

Alternativas: (descrição - score)

Sim -1.0

Não - 2.0

22.16) O paciente recebeu alguma outra terapia para tratar este AVC isquêmico?

Pergunta Alternativa Seleção Única

Nome da variável: _16_cvatx

Alternativas: (descrição - score)

Sim - 1.0

Não -2.0 
22.17) Se sim, qual foi a terapia para tratar este AVC isquêmico? (marque todas as opções que se aplicam)

Pergunta Alternativa Seleção Múltipla

Nome da variável: _17_tx

Alternativas: (descrição - nome da variável - score)

Terapia trombolítica - _thrm - 1.0

Terapia anti-plaquetária (aspirina) - _antplt - 2.0

Outra - o - 100.0

22.18) Especifique a outra terapia para tratar o AVC isquêmico (Separe por ; as outras terapias):

Pergunta Texto

Nome da variável: _18_tx_o

Número máximo de caracteres permitido: 100

\section{Módulo: 23 - Diagnósticos neurológicos / dor: acidente vascular cerebral hemorrágico}

23.1) O paciente teve acidente vascular cerebral - hemorrágico desde a sua inscrição no estudo:

Pergunta Alternativa Seleção Única

Nome da variável: F1M23_1_cvah

Alternativas: (descrição - score)

Sim -1.0

Não - 2.0

23.2) Quantas vezes esse indivíduo teve acidente vascular cerebral hemorrágico desde a sua inscrição no estudo?

Pergunta Número Inteiro

Nome da variável: F1M23_2_cvah_n

Intervalo permitido: 1 - 99

Planilha: Questões relacionadas ao episódio de acidente vascular cerebral hemorrágico

Itens: (Descrição - Nome da variável)

Episódio de acidente vascular cerebral hemorrágico - F1M23

23.3) Data do episódio de acidente vascular cerebral hemorrágico (Registre a data do diagnóstico clínico, caso o episódio tenha durado mais de 1 dia):

Pergunta Data

Nome da variável: 3 cvah d

Intervalo permitido: 01/01/2013 - 31/12/2016

23.4) Foi identificada hemorragia na ressonância magnética ou na tomografia computadorizada?

Pergunta Alternativa Seleção Única

Nome da variável:_4_cvah_ct

Alternativas: (descrição - score)

Sim -1.0

Não -2.0

23.5) Houve fluido espinhal hemorrágico na punção lombar no episódio de AVC hemorrágico?

Pergunta Alternativa Seleção Única

Nome da variável: _5_cvah_lp

Alternativas: (descrição - score)

Sim -1.0

Não - 2.0

Punção lombar não realizada - 3.0

23.6) Houve alguma intervenção neurocirúrgica no episódio de AVC hemorrágico?

Pergunta Alternativa Seleção Única

Nome da variável: 6 cvah ns

Alternativas: (descriçãa - score)

Sim - 1.0

Não - 2.0 
23.7) Classificação da localização do infarto hemorrágico: (marque todas opções que se aplicam)

Pergunta Alternativa Seleção Múltipla

Nome da variável: 7 7 cvah

Alternativas: (descrição - nome da variável - score)

Subdural - _ sbd - 1.0

Subaracnóide ${ }^{-}$_ $\mathrm{sbr}-2.0$

Intracerebral $\quad-$ itc -3.0

Intraventricular - itv - 4.0

Epidural - _epd - $\overline{5} .0$

Anomalia vascular (aneurisma, má formação atrioventricular ou Moya-moya) - _anv - 6.0

Outra - o - 100.0

23.8) Especifique a outra classificação da localização do infarto hemorrágico (Separe por ; as outras classificações): Pergunta Texto

Nome da variável:_8_cvah_1_o

Número máximo de caracteres permitido: 100

23.9) O paciente foi transfundido nesse episódio de acidente vascular cerebral hemorrágico?

Pergunta Alternativa Seleção Única

Nome da variável: _9_cvah_tx

Alternativas: (descrição - score)

Sim -1.0

Não - 2.0

\section{Módulo: 24 - Diagnósticos neurológicos / dor: convulsão}

24.1) O paciente teve convulsão desde a sua inscrição no estudo: (Caso o paciente tenha sido diagnosticado com convulsão antes do período do Acompanhamento 1, mas mantém o diagnóstico, responder "Sim")

Pergunta Alternativa Seleção Única

Nome da variável: F1M24_1_sz

Alternativas: (descrição - score)

Sim -1.0

Não - 2.0

24.2) Data do episódio de convulsão: Registre o primeiro dia do episódio, caso o episódio tenha durado mais de 1 dia (Marque "Não se aplica" se o diagnóstico de convulsão foi feito antes do período de acompanhamento):

Pergunta Data

Nome da variável: F1M24_2_sz_d

Intervalo permitido: 01/01/2013 - 31/12/2016

24.3) O paciente fez Eletroencefalograma (EEG) neste episódio de convulsão?

Pergunta Alternativa Seleção Única

Nome da variável: F1M24_3_eeg

Alternativas: (descrição - score)

Sim - 1.0

Não -2.0

24.4) Registre o resultado de EEG neste episódio de convulsão:

Pergunta Alternativa Seleção Única

Nome da variável: F1M24_4_eeg_r

Alternativas: (descrição - score)

Normal - 1.0

Anormal - 2.0 


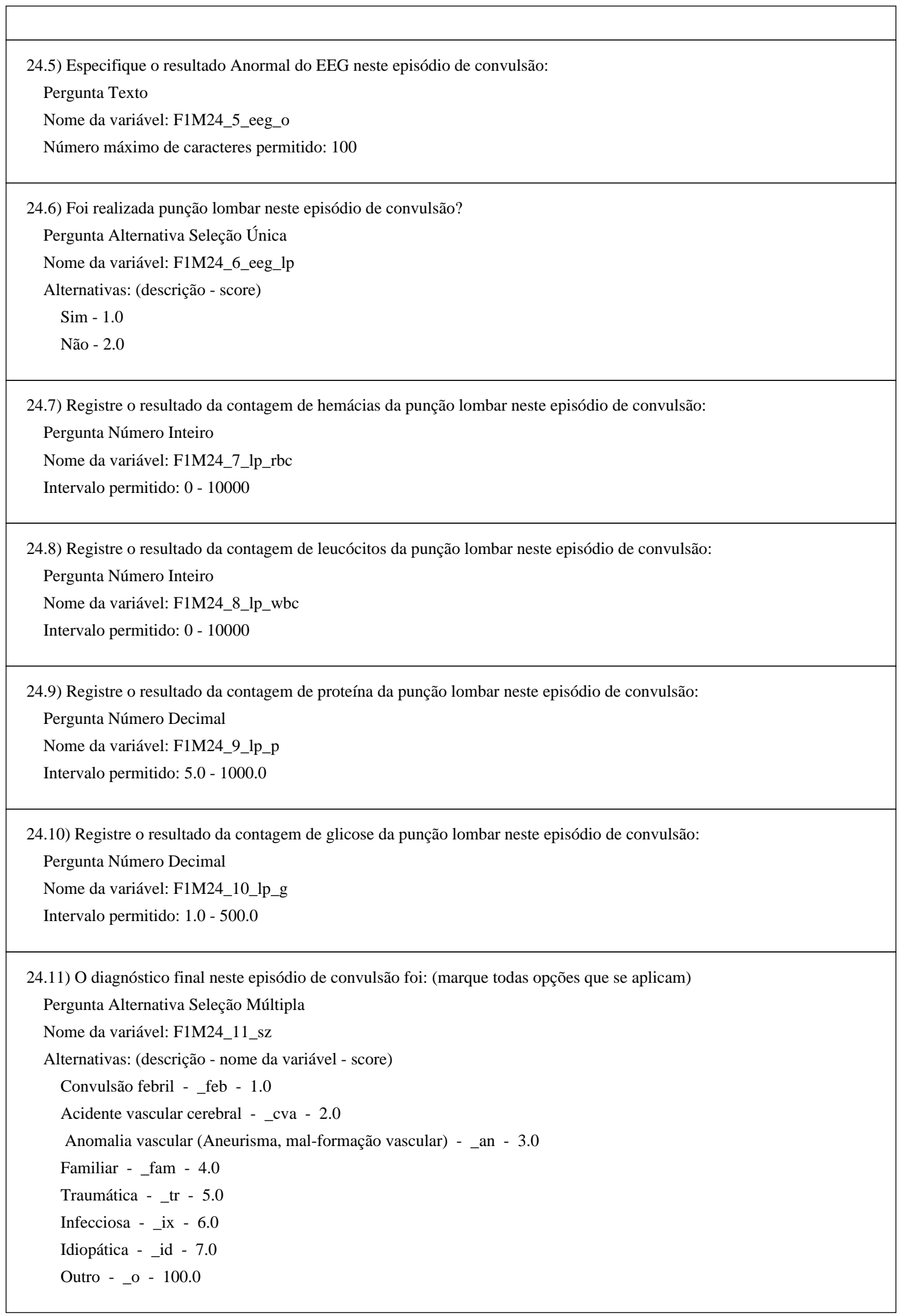


24.12) Especifique o outro diagnóstico final neste episódio de convulsão: (Separe por ; os outros diagnósticos finais):

Pergunta Texto

Nome da variável: F1M24_12_sz_o

Número máximo de caracteres permitido: 100

\section{Módulo: 25 - Diagnósticos neurológicos / dor: ataque isquêmico transitório, dor neuropática,} dactilite

25.1) O paciente teve ataque isquêmico transitório (AIT) desde a sua inscrição no estudo:

Pergunta Alternativa Seleção Única

Nome da variável: F1M25_1_tia

Alternativas: (descrição - score)

Sim -1.0

Não - 2.0

25.2) Data do diagnóstico de ataque isquêmico transitório (AIT) :

Pergunta Data

Nome da variável: F1M25_2_tia_d

Intervalo permitido: 01/01/2013 - 31/12/2016

25.3) O paciente teve episódio doloroso agudo da doença falciforme desde a sua inscrição no estudo:

Pergunta Alternativa Seleção Única

Nome da variável: F1M25_3_voe

Alternativas: (descrição - score)

Sim -1.0

Não - 2.0

25.4) Quantos episódios de dor aguda da doença falciforme o paciente teve desde a inscrição no estudo?

Pergunta Número Inteiro

Nome da variável: F1M25_4_voe_n

Intervalo permitido: 1 - 150

25.5) O paciente teve dor neuropática desde a sua inscrição no estudo: (Caso o paciente tenha sido diagnosticado com dor neuropática antes do período do Acompanhamento 1, mas mantém o diagnóstico, responder "Sim”)

Pergunta Alternativa Seleção Única

Nome da variável: F1M25_5_np

Alternativas: (descrição - score)

Sim -1.0

Não -2.0

25.6) Data do diagnóstico de dor neuropática: (Marque "Não se aplica" se o diagnóstico de dor neuropática foi feito antes do período de acompanhamento)

Pergunta Data

Nome da variável: F1M25_6_np_d

Intervalo permitido: 01/01/2013 - 31/12/2016 


\begin{tabular}{|l|}
\hline \\
\hline 25.7) O paciente teve dactilite (síndrome mão-pé) desde a sua inscrição no estudo: \\
Pergunta Alternativa Seleção Única \\
Nome da variável: F1M25_7_hfs \\
Alternativas: (descrição - score) \\
Sim - 1.0 \\
Não - 2.0 \\
\hline 25.8) Data do diagnóstico de dactilite: \\
Pergunta Data \\
Nome da variável: F1M25_8_hfs_d \\
Intervalo permitido: 01/01/2013 - 31/12/2016
\end{tabular}

\section{Módulo: 26 - Diagnósticos grastrointestinais / hepáticos}

26.1) O paciente teve colecistite desde a sua inscrição no estudo: (Caso o paciente tenha sido diagnosticado com colecistite antes do período do Acompanhamento 1, mas mantém o diagnóstico, responder "Sim")

Pergunta Alternativa Seleção Única

Nome da variável: F1M26_1_chol

Alternativas: (descrição - score)

Sim -1.0

Não -2.0

26.2) Data do diagnóstico de colecistite: (Marque "Não se aplica" se o diagnóstico de colecistite foi feito antes do período de acompanhamento)

Pergunta Data

Nome da variável: F1M26_2_chol_d

Intervalo permitido: 01/01/2013 - 31/12/2016

26.3) O paciente teve colelitíase desde a sua inscrição no estudo: (Caso o paciente tenha sido diagnosticado com colelitíase antes do período do Acompanhamento 1, mas mantém o diagnóstico, responder "Sim")

Pergunta Alternativa Seleção Única

Nome da variável: F1M26_3_stn

Alternativas: (descrição - score)

Sim - 1.0

Não - 2.0

26.4) Data do diagnóstico de colelitíase: (Marque "Não se aplica" se o diagnóstico de colelitíase foi feito antes do período de acompanhamento)

Pergunta Data

Nome da variável: F1M26_4_stn_d

Intervalo permitido: 01/01/2013 - 31/12/2016

26.5) O paciente teve pancreatite desde a sua inscrição no estudo:

Pergunta Alternativa Seleção Única 
Pergunta Alternativa Seleção Única

Nome da variável: F1M26_5_pan

Alternativas: (descrição - score)

Sim -1.0

Não -2.0

26.6) Data do diagnóstico de pancreatite:

Pergunta Data

Nome da variável: F1M26_6_pan_d

Intervalo permitido: 01/01/2013 - 31/12/2016

26.7) O paciente teve sequestro hepático desde a sua inscrição no estudo:

Pergunta Alternativa Seleção Única

Nome da variável: F1M26_7_hs

Alternativas: (descrição - score)

Sim -1.0

Não - 2.0

26.8) Quantas vezes esse indivíduo teve episódio de sequestro hepático desde a sua inscrição no estudo?

Pergunta Número Inteiro

Nome da variável: F1M26__8_hs_n

Intervalo permitido: 1 - 99

Planilha: Questões relacionadas ao episódio de sequestro hepático

Itens: (Descrição - Nome da variável)

Episódio de sequestro hepático - F1M26

26.9) Data do episódio de sequestro hepático (registre o primeiro dia do episódio, caso o episódio tenha durado mais de $1 \mathrm{dia})$ :

Pergunta Data

Nome da variável: _9_hs_d

Intervalo permitido: $01 / 01 / 2013-31 / 12 / 2016$

26.10) Contagem de Hemoglobina mais baixa no sequestro hepático:

Pergunta Número Decimal

Nome da variável:_10_hs_h

Intervalo permitido: $1.0-20.0$

26.11) Contagem de reticulócitos (maior valor) no sequestro hepático:

Pergunta Número Decimal

Nome da variável: 11 hs $r$

Intervalo permitido: $0.0-100.0$

26.12) Registre o resultado da contagem de hemácias no momento da contagem mais baixa de reticulócitos no sequestro hepático:

Pergunta Número Decimal

Nome da variável: _12 hs rbc

Intervalo permitido: 0.5 - 15.0

26.13) Maior valor de bilirrubina direta no sequestro hepático:

Pergunta Número Decimal

Nome da variável: _13_hs_d

Intervalo permitido: $0 . \overline{1}-\overline{30} 0$ 
26.14) O paciente foi transfundido nesse episódio de sequestro hepático?

Pergunta Alternativa Seleção Única

Nome da variável:_14_hs_tx

Alternativas: (descrição - score)

Sim -1.0

Não -2.0

\author{
Módulo: 27 - Tromboembolismo venoso / úlceras de perna \\ 27.1) O paciente teve tromboembolismo venoso desde a sua inscrição no estudo: \\ Pergunta Alternativa Seleção Única \\ Nome da variável: F1M27_1_vte \\ Alternativas: (descrição - score) \\ Sim -1.0 \\ Não - 2.0
}

27.2) Data do diagnóstico de tromboembolismo venoso:

Pergunta Data

Nome da variável: F1M27_2_vte_d

Intervalo permitido: 01/01/2013 - 31/12/2016

27.3) Especifique o local do tromboembolismo: (Separe por ; os locais do tromboembolismo)

Pergunta Texto

Nome da variável: F1M27_3_vte_1

Número máximo de caracteres permitido: 100

27.4) O paciente teve úlceras de perna desde a sua inscrição no estudo: (Caso o paciente tenha sido diagnosticado com úlcera de perna antes do período do Acompanhamento 1, mas mantém o diagnóstico, responder "Sim")

Pergunta Alternativa Seleção Única

Nome da variável: F1M27_4_ulc

Alternativas: (descrição - score)

Sim -1.0

Não - 2.0

27.5) Data do diagnóstico de úlcera de perna: (Marque "Não se aplica" se o diagnóstico de úlcera de perna foi feito antes do período de acompanhamento)

Pergunta Data

Nome da variável: F1M27_5_ulc_d

Intervalo permitido: 01/01/2013 - 31/12/2016

\title{
Módulo: 28 - Necrose avascular
}

28.1) O paciente teve necrose avascular quadril / ombro desde a sua inscrição no estudo: (Caso o paciente tenha sido diagnosticado com necrose avascular antes do período do Acompanhamento 1, mas mantém o diagnóstico, responder “Sim”)

Pergunta Alternativa Seleção Única

Nome da variável: F1M28_1_avn 
Alternativas: (descrição - score)

Sim -1.0

Não - 2.0

Planilha: Questões relacionadas à necrose avascular

Itens: (Descrição - Nome da variável)

Necrose avascular - F1M28

28.2) Local de ocorrência da necrose avascular:

Pergunta Alternativa Seleção Única

Nome da variável: _2_avn_1

Alternativas: (descrição - score)

Cabeça Femoral Direita - 1.0

Cabeça Femoral Esquerda - 2.0

Ombro Direito - 3.0

Ombro Esquerdo - 4.0

Outro osso -5.0

28.3) Especifique o outro osso onde ocorreu a necrose avascular (Separe por ; os outros ossos):

Pergunta Texto

Nome da variável: 3 avn

Número máximo de caracteres permitido: 100

28.4) Data do exame de imagem (se houve mais de uma radiografia/RMI evidenciando necrose avascular nos últimos 12 meses, registre a data do exame com o grau mais elevado de necrose avascular):

Pergunta Data

Nome da variável: 4 _avn_d

Intervalo permitido: $01 / 01 / 2013$ - 31/12/2016

28.5) Tipo de exame de imagem da necrose avascular: (marque todas as opções que se aplicam)

Pergunta Alternativa Seleção Múltipla

Nome da variável: _5_avn

Alternativas: (descrição - nome da variável - score)

Raio X $\quad-\quad \mathrm{Xr}-1.0$

RMI - _mri - 2.0

28.6) Selecione o grau da necrose avascular. Se houve mais de uma radiografia/RMI evidenciando necrose avascular nos últimos 12 meses, registre o grau mais elevado de necrose avascular:

Pergunta Alternativa Seleção Única

Nome da variável:_6_avn_gd

Alternativas: (descrição - score)

Estágio 0 - Raio X/RMI normal - 1.0

Estágio I - Raio X normal, RMI alterada - 2.0

Estágio II - Raio X e RMI alteradas, mas sem colapso da cabeça femoral (sem sinal do crescente) - 3.0

Estágio III - Sinal precoce de achatamento da cúpula e / ou crescente na radiografia ou na RMI; - 4.0

Estágio IV - Achatamento da cabeça do fêmur com estreitamento do espaço articular na radiografia. - 5.0

28.7) Houve indicação médica de cirurgia para tratamento da necrose avascular?

Pergunta Alternativa Seleção Única

Nome da variável: 7 surg

Alternativas: (descrição - score)

Sim - 1.0

Não - 2.0

28.8) Foi feita descompressão cirúrgica da necrose avascular?

Pergunta Alternativa Seleção Única

Nome da variável: _8_core

Alternativas: (descrição - score)

Sim -1.0

Não -2.0

28.9) Foi realizada artroplastia (substituição da articulação) para tratamento da necrose avascular?

Pergunta Alternativa Seleção Única

Nome da variável:_9_jr

Alternativas: (descrição - score)

Sim - 1.0

Não - 2.0 
28.10) Foi dado qualquer outro tratamento para tratar a necrose avascular?

Pergunta Alternativa Seleção Única

Nome da variável: 10avn tx

Alternativas: (descrição - score)

Sim -1.0

Não -2.0

28.11) Especifique o outro tratamento para a necrose avascular: (Separe por ; os outros tratamentos)

Pergunta Texto

Nome da variável: 11 tx o

Número máximo de caracteres permitido: 100

\section{Módulo: 29 - Diagnósticos geniturinários}

29.1) O paciente teve priapismo desde a sua inscrição no estudo: (Marque "Não se aplica" para mulheres)

Pergunta Alternativa Seleção Única

Nome da variável: F1M29_1_pr

Alternativas: (descrição - score)

Sim -1.0

Não -2.0

29.2) Quantos dias o paciente teve pelo menos um episódio de priapísmo desde a sua inscrição no estudo?

Pergunta Número Inteiro

Nome da variável: F1M29_2_pr_n

Intervalo permitido: 1 - 150

Planilha: Questões relacionadas ao episodio de Priapismo

Itens: (Descricão - Nome da variável)

Priapismo - F1M29

29.3) Data do exame no episódio de priapísmo:

Pergunta Data

Nome da variável: _3_pr_d

Intervalo permitido: $01 / 01 / 2013$ - 31/12/2016

29.4) Quanto tempo, em horas, durou o episódio de priapismo?

Pergunta Alternativa Seleção Única

Nome da variável:_4_pr_hr

Alternativas: (descrição - score)

Menos de 1 hora -1.0

1 a 3 horas -2.0

4 a 9 horas -3.0

10 a 15 horas $\quad-4.0$

16 a 20 horas -5.0

Mais de 20 horas -6.0

29.5) Houve "priapismo gago" (Episódios repetitivos de priapismo com duração menor que 4 horas)

Pergunta Alternativa Seleção Única

Nome da variável: _5_pr_st

Alternativas: (descrição - score)

Sim -1.0

Não -2.0

29.6) Como foi feito o tratamento para o priapismo? (Marque todas que se aplicam)

Pergunta Alternativa Seleção Múltipla

Nome da variável: _6_pr

Alternativas: (descriçãa - nome da variável - score)

Tratamento com medicação - _med - 1000.0

Punção - _asp - 1.0

Cirurgia (colocação de prótese) - surg - 2.0

Transfusão - _tx - 3.0

Sem tratamento - _no - 100.0 
29.7) Especifique qual foi o medicamento utilizado (Separe por ; os medicamentos) (Marque não se aplica, caso o paciente não tenha utilizado medicamentos paea tratar o priapismo):

Pergunta Texto

Nome da variável: _7_pr_med

Número máximo de caracteres permitido: 100

29.8) O paciente teve pielonefrite desde a sua inscrição no estudo: (Caso o paciente tenha sido diagnosticado com pielonefrite antes do período do Acompanhamento 1, mas mantém o diagnóstico, responder "Sim")

Pergunta Alternativa Seleção Única

Nome da variável: F1M29_8_pn

Alternativas: (descrição - score)

Sim -1.0

Não - 2.0

29.9) Data do diagnóstico de pielonefrite: (Marque "Não se aplica" se o diagnóstico de pielonefrite foi feito antes do período de acompanhamento)

Pergunta Data

Nome da variável: F1M29_9_pn_d

Intervalo permitido: 01/01/2013 - 31/12/2016

29.10) O paciente teve/tem insuficiência renal AGUDA desde a sua inscrição no estudo:

Pergunta Alternativa Seleção Única

Nome da variável: F1M29_10_arf

Alternativas: (descrição - score)

Sim -1.0

Não -2.0

29.11) Quantas vezes esse indivíduo teve episódio de insuficiência renal AGUDA desde a sua inscrição no estudo?

Pergunta Número Inteiro

Nome da variável: F1M29_11_arf_n

Intervalo permitido: 1 - 99

Planilha: Questões relacionadas ao episódio de insuficiência renal aguda

Itens: (Descrição - Nome da variável)

Episódio de insuficiência renal aguda - F1M29

29.12) Data do episódio de insuficiência renal AGUDA:

Pergunta Data

Nome da variável:_12_arf_d

Intervalo permitido: 01/01/2013 - 31/12/2016

29.13) Nível mais alto de creatinina no episódio de insuficiência renal AGUDA:

Pergunta Número Decimal

Nome da variável:_13_arf_cr

Intervalo permitido: $0 . \overline{0}-2 \overline{5} .0$

29.14) Foi preciso fazer diálise no episódio de insuficiência renal AGUDA?

Pergunta Alternativa Seleção Única

Nome da variável: 14 arf dy

Alternativas: (descrição - score)

Sim -1.0

Não - 2.0 
29.15) Quais os tipos diálise foram necessários no episódio de insuficiência renal AGUDA? (marque todas opções que se aplicam)

Pergunta Alternativa Seleção Múltipla

Nome da variável: _15_dy

Alternativas: (descrição - nome da variável - score)

Hemodiálise - _ hd - 1.0

Diálise peritonial _ _ pd - 2.0

29.16) Data de início da diálise no episódio de insuficiência renal AGUDA:

Pergunta Data

Nome da variável:_16_dy_d

Intervalo permitido: $01 / 01 / 2013$ - 31/12/2016

29.17) O paciente atualmente está em diálise devido à insuficiência renal AGUDA?

Pergunta Alternativa Seleção Única

Nome da variável: _17_dy_now

Alternativas: (descrição - score)

Sim -1.0

Não -2.0

29.18) Data de término da diálise devido à insuficiência renal AGUDA?

Pergunta Data

Nome da variável: _18_dy_end

Intervalo permitido: $01 / 01 / 2013$ - 31/12/2016

29.19) Causa da insuficiência renal AGUDA (marque todas opções que se aplicam)

Pergunta Alternativa Seleção Múltipla

Nome da variável: _19_arf

Alternativas: (descrição - nome da variável - score)

Obstrução renal ou uretal - obs - 1.0

Infecção - _ix - 2.0

Hipovolemia - _hv - 3.0

Medicamentos - med - 4.0

Falência múltipla de órgãos com crise vaso oclusiva - _mof - 5.0

Outro - _o - 100.0

29.20) Especifique a outra causa da insuficiência renal AGUDA: (Separe por ; as outras causas)

Pergunta Texto

Nome da variável:_20_arf_o

Número máximo de caracteres permitido: 100

29.21) O paciente teve/tem insuficiência renal CRÔNICA desde a sua inscrição no estudo: (Caso o paciente tenha sido diagnosticado com Insuficiência Renal Crônica antes do período do Acompanhamento 1, mas mantém o diagnóstico, responder "Sim")

Pergunta Alternativa Seleção Única

Nome da variável: F1M29_21_crf

Alternativas: (descrição - score)

Sim -1.0

Não - 2.0

29.22) Nível mais alto de creatinina da insuficiência renal CRÔNICA desde a inscrição no estudo: Pergunta Número Decimal

Nome da variável: F1M29_22_crf_cr

Intervalo permitido: $0.01-25.0$

29.23) Data do nível mais alto de creatinina da insuficiência renal CRÔNICA desde a inscrição no estudo:

Pergunta Data

Nome da variável: F1M29_23_cr_d

Intervalo permitido: 01/01/2013 - 31/12/2016 
29.24) Foi feito exame para medir o índice de filtração glomerular (IFG (ou clearence de creatinina) da insuficiência renal CRÔNICA desde a inscrição no estudo?

Pergunta Alternativa Seleção Única

Nome da variável: F1M29_24_gfr

Alternativas: (descrição - score)

Sim -1.0

Não - 2.0

29.25) Qual foi o menor Indice de filtração glomerular - IFG (ou clearence de creatinina) na insuficiência renal CRÔNICA dos últimos 12 meses:

Pergunta Número Decimal

Nome da variável: F1M29_25_gfr_r

Intervalo permitido: 1.0 - 200.0

29.26) Qual é a unidade de medida do IFG ou clearance de cratinina registrado na questão 29.25 ?

Pergunta Alternativa Seleção Única

Nome da variável: F1M29_26_gfr_u

Alternativas: (descrição - score)

$\mathrm{mL} / \mathrm{min} / 1.73 \mathrm{~m} 2-1.0$

$\mathrm{mL} / \mathrm{min}-2.0$

29.27) Data do registro do menor IFG (ou clearence de creatinina) no episódio de insuficiência renal CRÔNICA: Pergunta Data

Nome da variável: F1M29_27_gfr_d

Intervalo permitido: 01/01/2013 - 31/12/2016

29.28) A medição direta do IFG no episódio de insuficiência renal CRÔNICA foi feita com inulina, DTPA, EDTA?

Pergunta Alternativa Seleção Única

Nome da variável: F1M29_28_gfr_dm

Alternativas: (descrição - score)

Sim -1.0

Não - 2.0

29.29) O IFG da insuficiência renal CRÔNICA foi estimado pela medida de depuração da creatinina ou foi utilizada uma equação?

Pergunta Alternativa Seleção Única

Nome da variável: F1M29_29_gfr_est

Alternativas: (descrição - score)

Creatinina -1.0

Equação de estimativa (Uso de equação para calcular o clearance de creatinine) - 2.0

Outro - 3.0

29.30) Especifique o outro marcador para estimar o IFG na insuficiência renal CRÔNICA: (Separe por ; os outros marcadores) Pergunta Texto

Nome da variável: F1M29_30_gfr_o

Número máximo de caracteres permitido: 100 


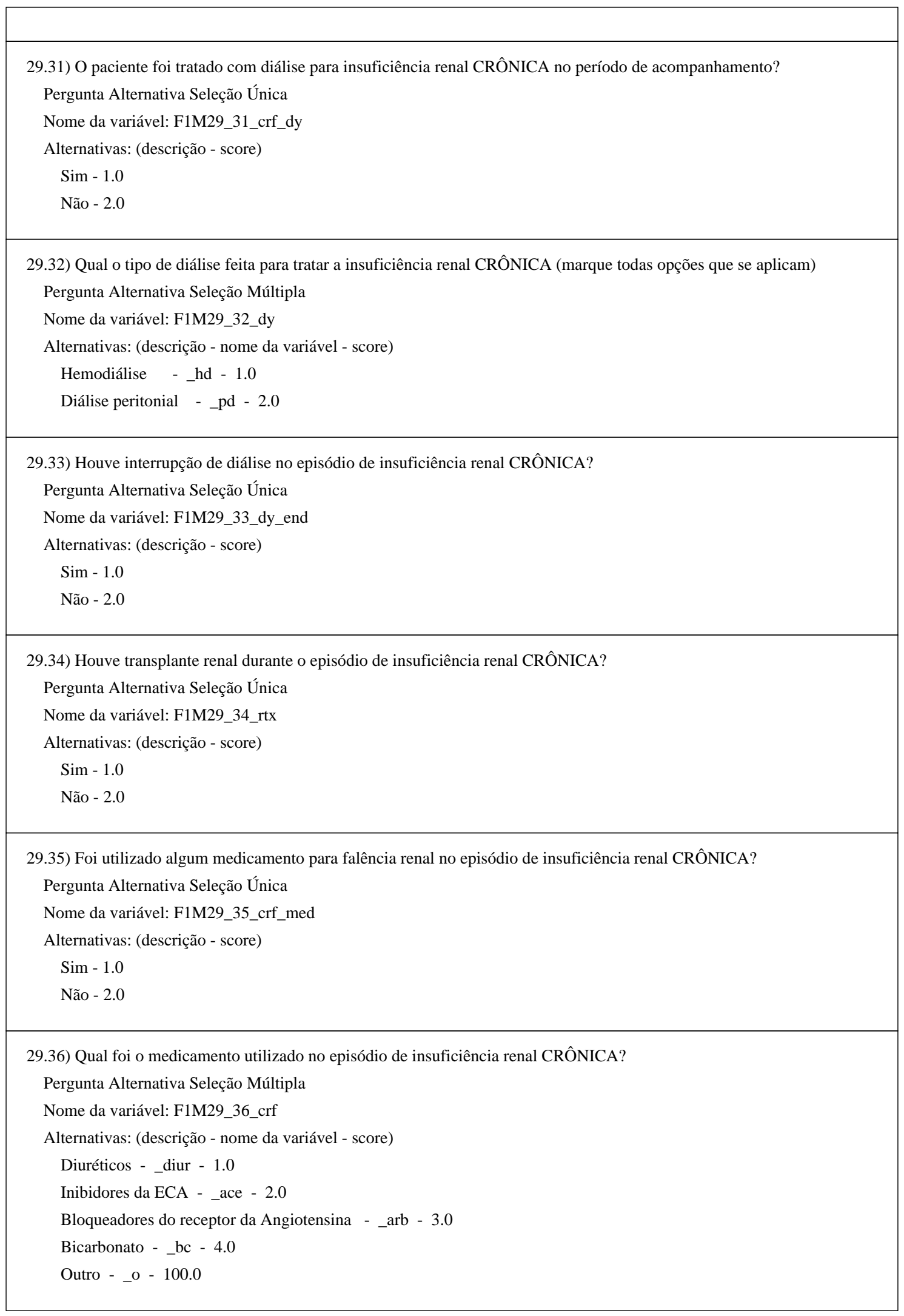


29.37) Especifique o outro medicamento utilizado no episódio de insuficiência renal CRÔNICA: (Separe por ; os outros medicamentos utilizados)

Pergunta Texto

Nome da variável: F1M29_37_med_o

Número máximo de caracteres permitido: 100

\section{Módulo: 30 - Infecções}

30.1) O paciente teve osteomielite (aguda ou crônica) desde a sua inscrição no estudo: (Caso o paciente tenha sido diagnosticado com osteomielite antes do período do Acompanhamento 1, mas mantém o diagnóstico, responder "Sim”)

Pergunta Alternativa Seleção Única

Nome da variável: F1M30_1_om

Alternativas: (descrição - score)

Sim -1.0

Não - 2.0

30.2) Data do diagnóstico de osteomielite: (Marque "Não se aplica" se o diagnóstico de osteomielite foi feito antes do período de acompanhamento)

Pergunta Data

Nome da variável: F1M30_2_om_d

Intervalo permitido: 01/01/2013 - 31/12/2016

30.3) O paciente teve bacteremia desde a sua inscrição no estudo:

Pergunta Alternativa Seleção Única

Nome da variável: F1M30_3_bac

Alternativas: (descrição - score)

Sim -1.0

Não -2.0

30.4) Data do diagnóstico de bacteremia:

Pergunta Data

Nome da variável: F1M30_4_bac_d

Intervalo permitido: 01/01/2013 - 31/12/2016

30.5) O paciente teve meningite desde a sua inscrição no estudo:

Pergunta Alternativa Seleção Única

Nome da variável: F1M30_5_mg

Alternativas: (descrição - score)

Sim - 1.0

Não - 2.0

30.6) Data do diagnóstico de meningite:

Pergunta Data

Nome da variável: F1M30_6_mg_d

Intervalo permitido: 01/01/2013 - 31/12/2016 
30.7) Quantas vezes esse indivíduo teve Bacteremia/Meningite desde a sua inscrição no estudo?

Pergunta Número Inteiro

Nome da variável: F1M30_7_bac_n

Intervalo permitido: 1 - 99

Planilha: Questões relacionadas ao episódio de Bacteremia/Meningite

Itens: (Descrição - Nome da variável)

Bacteremia/Meningite - F1M30

30.8) Foi realizada cultura neste espisodio de Bacteremia/Meningite? (Hemocultura, urina, CSF ou de pele)

Pergunta Alternativa Seleção Única

Nome da variável:_8_cx

Alternativas: (descrição - score)

Sim -1.0

Não -2.0

30.9) Realizou hemocultura neste espisodio de Bacteremia/Meningite?

Pergunta Alternativa Seleção Única

Nome da variável: _9_bcx

Alternativas: (descriçãa - score)

Sim - 1.0

Não -2.0

30.10) Data da hemocultura neste espisodio de Bacteremia/Meningite:

Pergunta Data

Nome da variável:_10_bcx_d

Intervalo permitido: $01 / 01 / 2013$ - 31/12/2016

30.11) Hemocultura neste espisodio de Bacteremia/Meningite foi positiva para bactéria?

Pergunta Alternativa Seleção Única

Nome da variável: _11_bbac

Alternativas: (descrição - score)

Sim -1.0

Não - 2.0

30.12) Bactéria identificada neste espisodio de Bacteremia/Meningite:

Pergunta Texto

Nome da variável: _12_bbac_r

Número máximo de caracteres permitido: 100

30.13) Hemocultura foi positiva para fungos neste espisodio de Bacteremia/Meningite?

Pergunta Alternativa Seleção Única

Nome da variável: _13_bfng

Alternativas: (descrição - score)

Sim -1.0

Não - 2.0

30.14) Fungo identificado neste espisodio de Bacteremia/Meningite:

Pergunta Texto

Nome da variável:_14_bfng_r

Número máximo de caracteres permitido: 100

30.15) Realizou cultura de líquido cefalorraquidiano (CRL) neste espisodio de Bacteremia/Meningite

Pergunta Alternativa Seleção Única

Nome da variável: _15_csf

Alternativas: (descrição - score)

Sim -1.0

Não - 2.0

30.16) Data da cultura CRL neste espisodio de Bacteremia/Meningite:

Pergunta Data

Nome da variável: _16_csf_d

Intervalo permitido: $01 / 01 / 2013$ - 31/12/2016 
30.17) Cultura CRL foi positiva para bactéria neste espisodio de Bacteremia/Meningite?

Pergunta Alternativa Seleção Única

Nome da variável: _17_cbac

Alternativas: (descrição - score)

Sim -1.0

Não -2.0

30.18) Bactéria identificada na cultura CRL neste espisodio de Bacteremia/Meningite:

Pergunta Texto

Nome da variável: 18 cbac r

Número máximo de caracteres permitido: 100

30.19) Cultura CRL foi positiva para fungos neste espisodio de Bacteremia/Meningite?

Pergunta Alternativa Seleção Única

Nome da variável:_19_cfng

Alternativas: (descrição - score)

Sim -1.0

Não - 2.0

30.20) Fungo identificado na cultura CRL neste espisodio de Bacteremia/Meningite:

Pergunta Texto

Nome da variável:_20_cfng_r

Número máximo de caracteres permitido: 100

30.21) Cultura CRL foi positiva para vírus neste espisodio de Bacteremia/Meningite?

Pergunta Alternativa Seleção Única

Nome da variável:_21_cvir

Alternativas: (descrição- - score)

Sim -1.0

Não - 2.0

30.22) Vírus identificado na cultura CRL neste espisodio de Bacteremia/Meningite:

Pergunta Texto

Nome da variável:_22_cvir_r

Número máximo de caracteres permitido: 100

30.23) Realizou cultura de urina neste espisodio de Bacteremia/Meningite?

Pergunta Alternativa Seleção Única

Nome da variável:_23_ur

Alternativas: (descrição - score)

Sim -1.0

Não - 2.0

30.24) Data da cultura de urina neste espisodio de Bacteremia/Meningite:

Pergunta Data

Nome da variável: 24 ur_d

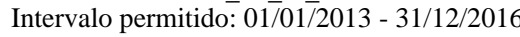

30.25) Cultura de urina foi positiva para bactéria neste espisodio de Bacteremia/Meningite?

Pergunta Alternativa Seleção Única

Nome da variável: 25_ubac

Alternativas: (descrição - score)

Sim -1.0

Não -2.0

30.26) Bactéria identificada na urina neste espisodio de Bacteremia/Meningite:

Pergunta Texto

Nome da variável: 26 ubac r

Número máximo de caracteres permitido: 100

30.27) Cultura de urina foi positiva para fungos neste espisodio de Bacteremia/Meningite?

Pergunta Alternativa Seleção Única

Nome da variável:_27_ufng

Alternativas: (descrição - score)

Sim -1.0

Não -2.0

30.28) Fungo identificado na urina neste espisodio de Bacteremia/Meningite:

Pergunta Texto

Nome da variável:_28_ufng_r

Número máximo de caracteres permitido: 100 
30.28) Fungo identificado na urina neste espisodio de Bacteremia/Meningite:

Pergunta Texto

Nome da variável: 28 ufng $r$

Número máximo de caracteres permitido: 100

30.29) Realizou cultura de pele neste espisodio de Bacteremia/Meningite?

Pergunta Alternativa Seleção Única

Nome da variável:_29_sk

Alternativas: (descrição - score)

Sim -1.0

Não - 2.0

30.30) Data da cultura de pele neste espisodio de Bacteremia/Meningite:

Pergunta Data

Nome da variável:_30_sk_d

Intervalo permitido: 01/01/2013 - 31/12/2016

30.31) A Cultura de pele foi positiva para bactéria neste espisodio de Bacteremia/Meningite?

Pergunta Alternativa Seleção Única

Nome da variável:_31_sbac

Alternativas: (descrição - score)

Sim -1.0

30.32) Bactéria identificada na cultura de pele neste espisodio de Bacteremia/Meningite:

Pergunta Texto

Nome da variável: _32_sbac_r

Número máximo de caracteres permitido: 100

30.33) A Cultura de pele foi positiva para fungos neste espisodio de Bacteremia/Meningite?

Pergunta Alternativa Seleção Única

Nome da variável: 33 _sfng

Alternativas: (descrição - score)

Sim -1.0

Não -2.0

30.34) Fungo identificado ba cultura de pele neste espisodio de Bacteremia/Meningite:

Pergunta Texto

Nome da variável: 34 sfng_r

Número máximo de caracteres permitido: 100

30.35) O paciente foi admitido no CTI nesse episódio de Bacteremia/Meningite?

Pergunta Alternativa Seleção Única

Nome da variável: 35 icu

Alternativas: (descrição - score)

Sim -1.0

Não - 2.0

30.36) No momento do diagnóstico de Bacteremia/Meningite, o paciente estava com cateter venoso central implantado?

Pergunta Alternativa Seleção Única

Nome da variável: _36_cath

Alternativas: (descrição - score)

Sim -1.0

Não - 2.0

30.37) O paciente foi transfundido nesse episódio de Bacteremia/Meningite?

Pergunta Alternativa Seleção Única

Nome da variável: _37_tx

Alternativas: (descrição- - score)

Sim -1.0

Não -2.0

30.38) O paciente teve diagnóstico positivo para Sífilis, Hepatite B, Hepatite C, Chagas, HIV, HTLV e/ou Dengue desde a sua inscrição no estudo:

Pergunta Alternativa Seleção Única

Nome da variável: F1M30_38_ix

Alternativas: (descrição - score) 
$\operatorname{Sim}-1.0$

Não - 2.0

30.39) Houve diagnóstico de infecção por sífilis?

Pergunta Alternativa Seleção Única

Nome da variável: F1M30_39_sy

Alternativas: (descrição - score)

Sim -1.0

Não - 2.0

30.40) Data do diagnóstico de sífilis:

Pergunta Data

Nome da variável: F1M30_40_sy_d

Intervalo permitido: 01/01/2013 - 31/12/2016

30.41) Houve diagnóstico infecção pelo vírus da hepatite B? (Caso o paciente tenha sido diagnosticado com hepatite B antes do período do Acompanhamento 1, mas mantém o diagnóstico, responder "Sim")

Pergunta Alternativa Seleção Única

Nome da variável: F1M30_41_hbc

Alternativas: (descrição - score)

Sim -1.0

Não - 2.0

30.42) Data do diagnóstico de hepatite B: (Marque "Não se aplica” se o diagnóstico de hepatite B foi feito antes do período de acompanhamento)

Pergunta Data

Nome da variável: F1M30_42_hbc_d

Intervalo permitido: 01/01/2013 - 31/12/2016

30.43) Há suspeita de que a infecção por hepatite B foi transfusional? (Marque "Não se aplica" se não houver histórico de transfusão)

Pergunta Alternativa Seleção Única

Nome da variável: F1M30_43_hbc_t

Alternativas: (descrição - score)

Sim -1.0

Não -2.0

30.44) Houve diagnóstico de infecção pelo vírus da hepatite C? (Caso o paciente tenha sido diagnosticado com hepatite C antes do período do Acompanhamento 1, mas mantém o diagnóstico, responder "Sim")

Pergunta Alternativa Seleção Única

Nome da variável: F1M30_44_hcv

Alternativas: (descrição - score)

Sim -1.0

Não - 2.0

30.45) Data do diagnóstico de hepatite C: (Marque "Não se aplica" se o diagnóstico de hepatite C foi feito antes do período de 


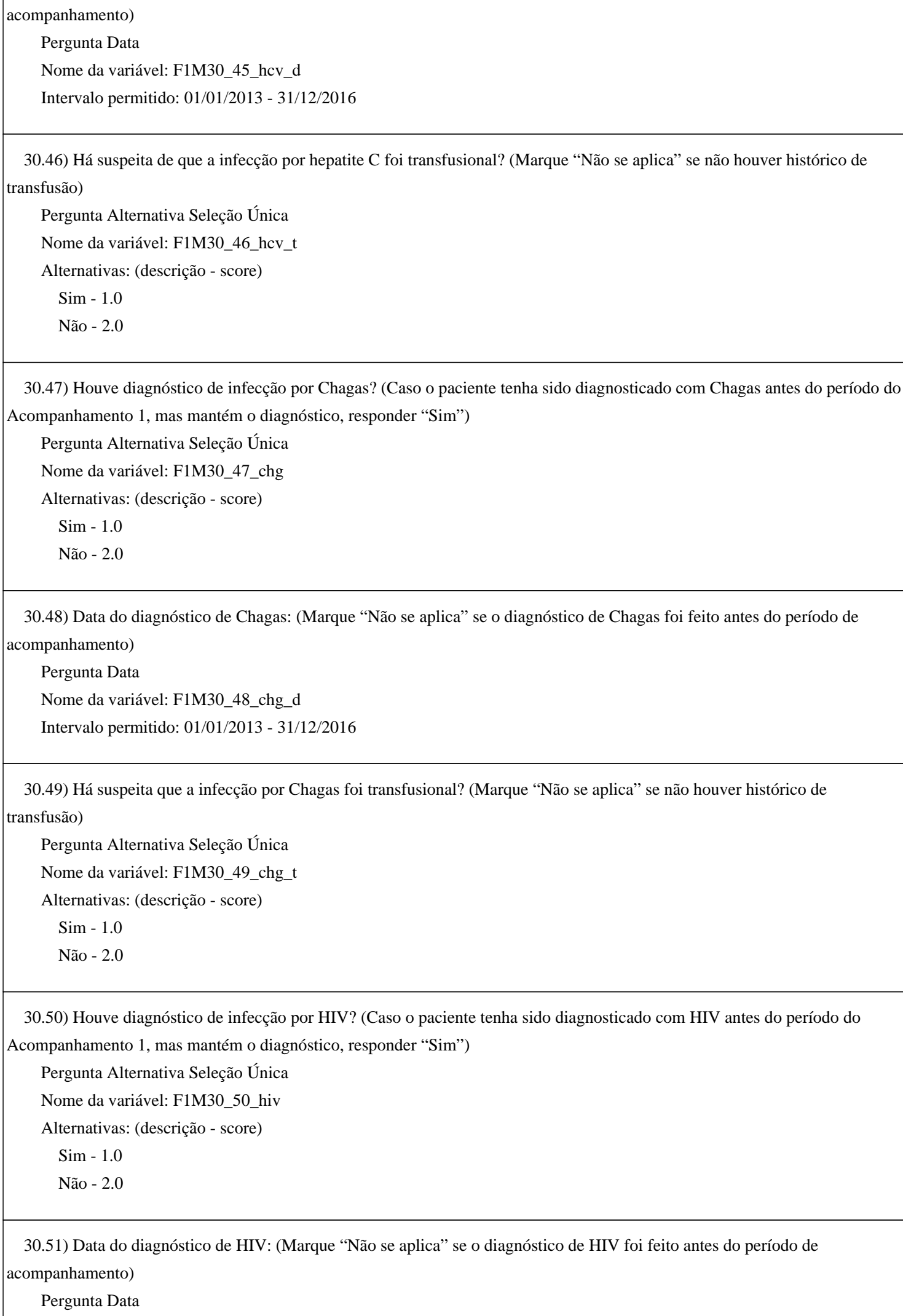

30.46) Há suspeita de que a infecção por hepatite C foi transfusional? (Marque "Não se aplica" se não houver histórico de transfusão)

Pergunta Alternativa Seleção Única

Nome da variável: F1M30_46_hcv_t

Alternativas: (descrição - score)

Sim -1.0

Não - 2.0

30.47) Houve diagnóstico de infecção por Chagas? (Caso o paciente tenha sido diagnosticado com Chagas antes do período do Acompanhamento 1, mas mantém o diagnóstico, responder "Sim")

Pergunta Alternativa Seleção Única

Nome da variável: F1M30_47_chg

Alternativas: (descrição - score)

Sim -1.0

Não - 2.0

30.48) Data do diagnóstico de Chagas: (Marque "Não se aplica" se o diagnóstico de Chagas foi feito antes do período de acompanhamento)

Pergunta Data

Nome da variável: F1M30_48_chg_d

Intervalo permitido: 01/01/2013 - 31/12/2016

30.49) Há suspeita que a infecção por Chagas foi transfusional? (Marque "Não se aplica" se não houver histórico de transfusão)

Pergunta Alternativa Seleção Única

Nome da variável: F1M30_49_chg_t

Alternativas: (descrição - score)

Sim - 1.0

Não - 2.0

30.50) Houve diagnóstico de infecção por HIV? (Caso o paciente tenha sido diagnosticado com HIV antes do período do Acompanhamento 1, mas mantém o diagnóstico, responder "Sim")

Pergunta Alternativa Seleção Única

Nome da variável: F1M30_50_hiv

Alternativas: (descrição - score)

Sim - 1.0

Não - 2.0

30.51) Data do diagnóstico de HIV: (Marque "Não se aplica" se o diagnóstico de HIV foi feito antes do período de acompanhamento)

Pergunta Data 
Nome da variável: F1M30_51_hiv_d

Intervalo permitido: 01/01/2013 - 31/12/2016

30.52) Há suspeita de que a infecção por HIV foi transfusional? (Marque "Não se aplica" se não houver histórico de transfusão)

Pergunta Alternativa Seleção Única

Nome da variável: F1M30_52_hiv_t

Alternativas: (descrição - score)

Sim - 1.0

Não - 2.0

30.53) Houve diagnóstico de infecção por HTLV? (Caso o paciente tenha sido diagnosticado com HTLV antes do período do Acompanhamento 1, mas mantém o diagnóstico, responder "Sim")

Pergunta Alternativa Seleção Única

Nome da variável: F1M30_53_htlv

Alternativas: (descrição - score)

Sim -1.0

Não - 2.0

30.54) Data do diagnóstico de HTLV: (Marque "Não se aplica" se o diagnóstico de HTLV foi feito antes do período de acompanhamento)

Pergunta Data

Nome da variável: F1M30_54_htlv_d

Intervalo permitido: 01/01/2013 - 31/12/2016

30.55) Há suspeita de que a infecção por HTLV foi transfusional? (Marque "Não se aplica" se não houver histórico de transfusão)

Pergunta Alternativa Seleção Única

Nome da variável: F1M30_55_htlv_t

Alternativas: (descrição - score)

Sim -1.0

Não - 2.0

30.56) Houve diagnóstico de infecção por Dengue?

Pergunta Alternativa Seleção Única

Nome da variável: F1M30_56_dng

Alternativas: (descrição - score)

Sim - 1.0

Não - 2.0

30.57) Data do diagnóstico de Dengue:

Pergunta Data

Nome da variável: F1M30_57_dng_d

Intervalo permitido: 01/01/2013 - 31/12/2016

30.58) Há suspeita de que a infecção por Dengue foi transfusional? (Marque "Não se aplica" se não houver histórico de 
transfusão)

Pergunta Alternativa Seleção Única

Nome da variável: F1M30_58_dng_t

Alternativas: (descrição - score)

Sim - 1.0

Não - 2.0

\section{Módulo: 31 - Outros diagnósticos}

31.1) O paciente teve algum outro diagnóstico desde a sua inscrição no estudo?

Pergunta Alternativa Seleção Única

Nome da variável: F1M31_1_o

Alternativas: (descrição - score)

Sim -1.0

Não -2.0

Planilha: Questões relacionadas a outro diagnóstico

Itens: (Descrição - Nome da variável)

Outro diagnóstico - F1M31

31.2) Especifique qual o outro diagnóstico:

Pergunta Texto

Nome da variável:_2_sp

Número máximo de caracteres permitido: 100

31.3) Data que o outro diagnóstico foi identificados pela primeira vez:

Pergunta Data

Nome da variável: _3_o_d

Intervalo permitido: 01/01/2013 - 31/12/2016 
Apêndice E

\section{Questionários de acompanhamento 2 do REDS-III}

\section{Entrevista - Acompanhamento 2}

Codebook impresso em 12/01/2018

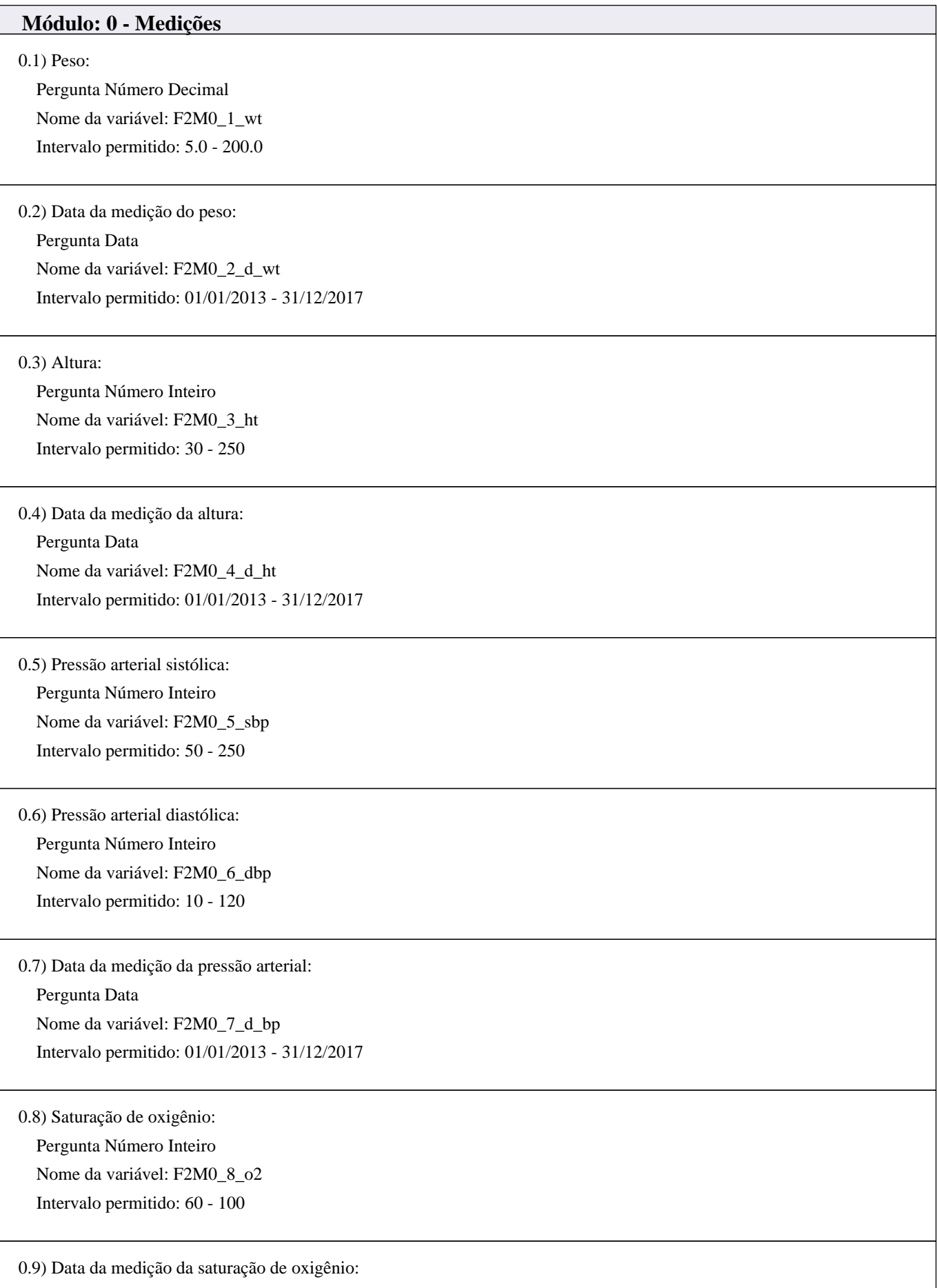


Pergunta Data

Nome da variável: F2M0_9_d_o2

Intervalo permitido: 01/01/2013 - 31/12/2017

0.10) Você está em tratamento com Hidroxiureia atualmente?

Pergunta Alternativa Seleção Única

Nome da variável: F2M0_10_hu

Alternativas: (descrição - score)

Sim -1.0

Não - 2.0

0.11) Você (ou seu filho) se esquece de tomar a hidroxiuréia:

Pergunta Alternativa Seleção Única

Nome da variável: F2M0_11_hu_c

Alternativas: (descrição - score)

Nunca / Raramente esquece - 4.0

De vez em quando esquece -3.0

Às vezes esquece - 2.0

Geralmente esquece - 1.0

Durante todo o tempo esquece - 0.0

\section{Módulo: 1 - Qualidade de Vida}

1) Houve permissão para perguntar as questões sobre Qualidade de Vida?

Pergunta Alternativa Seleção Única

Nome da variável: F2M1_pqol

Alternativas: (descrição - score)

Sim - 1.0

Não - 2.0

1.0) Qual sua idade?

Pergunta Número Inteiro

Nome da variável: F2M1_0_age

Intervalo permitido: 1 - 99

1.1) Nos últimos 12 meses, quantas crises de dor você teve?

Pergunta Alternativa Seleção Única

Nome da variável: F2M1_1_n_p

Alternativas: (descrição - score)

4 ou mais -0.0

$3-1.0$

$2-2.0$

$1-3.0$

Eu não tive crises de dor nos últimos 12 meses - 4.0 
1.2) Quando foi a sua última crise de dor?

Pergunta Alternativa Seleção Única

Nome da variável: F2M1_2_t_p

Alternativas: (descrição - score)

Eu nunca tive um episódio de dor - 0.0

Há mais de 5 anos atrás - 1.0

Há 1-5 anos atrás - 2.0

Há 7-11 meses atrás - 3.0

Há 1-6 meses atrás - 4.0

Há 1-4 semanas atrás - 5.0

Há menos de 1 semana atrás - 6.0

Eu estou tendo um episódio de dor agora - 7.0

1.3) Como você classificaria a gravidade da dor em sua última crise de dor?

Pergunta Alternativa Seleção Única

Nome da variável: F2M1_3_rate_p

Alternativas: (descrição - score)

0 - sem dor -0.0

$1-1.0$

$2-2.0$

$3-3.0$

$4-4.0$

$5-5.0$

$6-6.0$

$7-7.0$

$8-8.0$

$9-9.0$

10 - a pior dor imaginável - 10.0

1.4) Quanto a sua última crise de dor interferiu na sua vida?

Pergunta Alternativa Seleção Única

Nome da variável: F2M1_4_life_p

Alternativas: (descrição - score)

Eu nunca tive uma crise de dor - 0.0

Nem um pouco, eu fiz tudo o que eu costumo fazer - 1.0

Eu tive que reduzir cortar algumas atividades que eu costumo fazer - 2.0

Eu não pude fazer a maioria das atividades que costumo fazer - 3.0

Eu não pude cuidar de mim e precisei da ajuda de familiares ou amigos - 4.0

Eu não pude cuidar de mim e precisei da ajuda constante de familiares, amigos, médicos ou enfermeiros - 5.0

1.5) Quanto tempo durou a sua última crise de dor?

Pergunta Alternativa Seleção Única

Nome da variável: F2M1_5_long_p

Alternativas: (descrição - score)

Eu nunca tive uma crise de dor -0.0

Menos de 1 hora - 1.0

$1-12$ horas -2.0 
$13-23$ horas -3.0

$1-3$ dias -4.0

$4-6$ dias -5.0

1-2 semanas - 6.0

Mais de 2 semanas - 7.0

1.6) Nos últimos 7 dias, com que frequência você teve crises de dor tão fortes que você não pôde fazer nada por um dia inteiro?

Pergunta Alternativa Seleção Única

Nome da variável: F2M1_6_p_day

Alternativas: (descrição - score)

Nunca - 0.0

Raramente - 1.0

Às vezes - 2.0

Frequentemente - 3.0

Sempre -4.0

1.7) Nos últimos 7 dias, com que frequência você teve crises de dor tão fortes que você não pôde sair da cama? Pergunta Alternativa Seleção Única

Nome da variável: F2M1_7_p_bed

Alternativas: (descrição - score)

Nunca - 0.0

Raramente - 1.0

Às vezes - 2.0

Frequentemente - 3.0

Sempre -4.0

1.8) Nos últimos 7 dias, com que frequência você teve dor muito forte?

Pergunta Alternativa Seleção Única

Nome da variável: F2M1_8_sev_p

Alternativas: (descrição - score)

Nunca -0.0

Raramente - 1.0

Às vezes - 2.0

Frequentemente - 3.0

Sempre -4.0

1.9) Nos últimos 7 dias, com que frequência você teve crises de dor tão fortes que você teve que parar de fazer o que estava fazendo?

Pergunta Alternativa Seleção Única

Nome da variável: F2M1_9_p_stop

Alternativas: (descrição - score)

Nunca - 0.0

Raramente - 1.0

Às vezes - 2.0

Frequentemente - 3.0

Sempre -4.0 
Sempre -4.0

1.10) Nos últimos 7 dias, com que frequência você teve crises de dor tão fortes que foi difícil terminar o que você estava fazendo?

Pergunta Alternativa Seleção Única

Nome da variável: F2M1_10_p_finish

Alternativas: (descrição - score)

Nunca - 0.0

Raramente - 1.0

Às vezes -2.0

Frequentemente - 3.0

Sempre -4.0

1.11) Nos últimos 7 dias, com que frequência suas juntas estavam muito duras quando você acordou? Pergunta Alternativa Seleção Única

Nome da variável: F2M1_11_f_stf

Alternativas: (descrição - score)

Nunca - 0.0

Raramente - 1.0

Às vezes - 2.0

Frequentemente - 3.0

Sempre -4.0

1.12) Nos últimos 7 dias, com que frequência suas juntas ficaram muito duras durante o dia?

Pergunta Alternativa Seleção Única

Nome da variável: F2M1_12_stf_day

Alternativas: (descrição - score)

Nunca - 0.0

Raramente - 1.0

Às vezes - 2.0

Frequentemente - 3.0

Sempre -4.0

1.13) Nos últimos 7 dias, com que frequência suas juntas ficaram muito duras durante o dia que você não pôde se mover? Pergunta Alternativa Seleção Única

Nome da variável: F2M1_13_nomove

Alternativas: (descrição - score)

Nunca - 0.0

Raramente - 1.0

Às vezes - 2.0

Frequentemente - 3.0

Sempre -4.0

1.14) Nos últimos 7 dias, com que frequência você acordou tão rígido que você não pôde se mover?

Pergunta Alternativa Seleção Única

Nome da variável: F2M1_14_wake_stf 


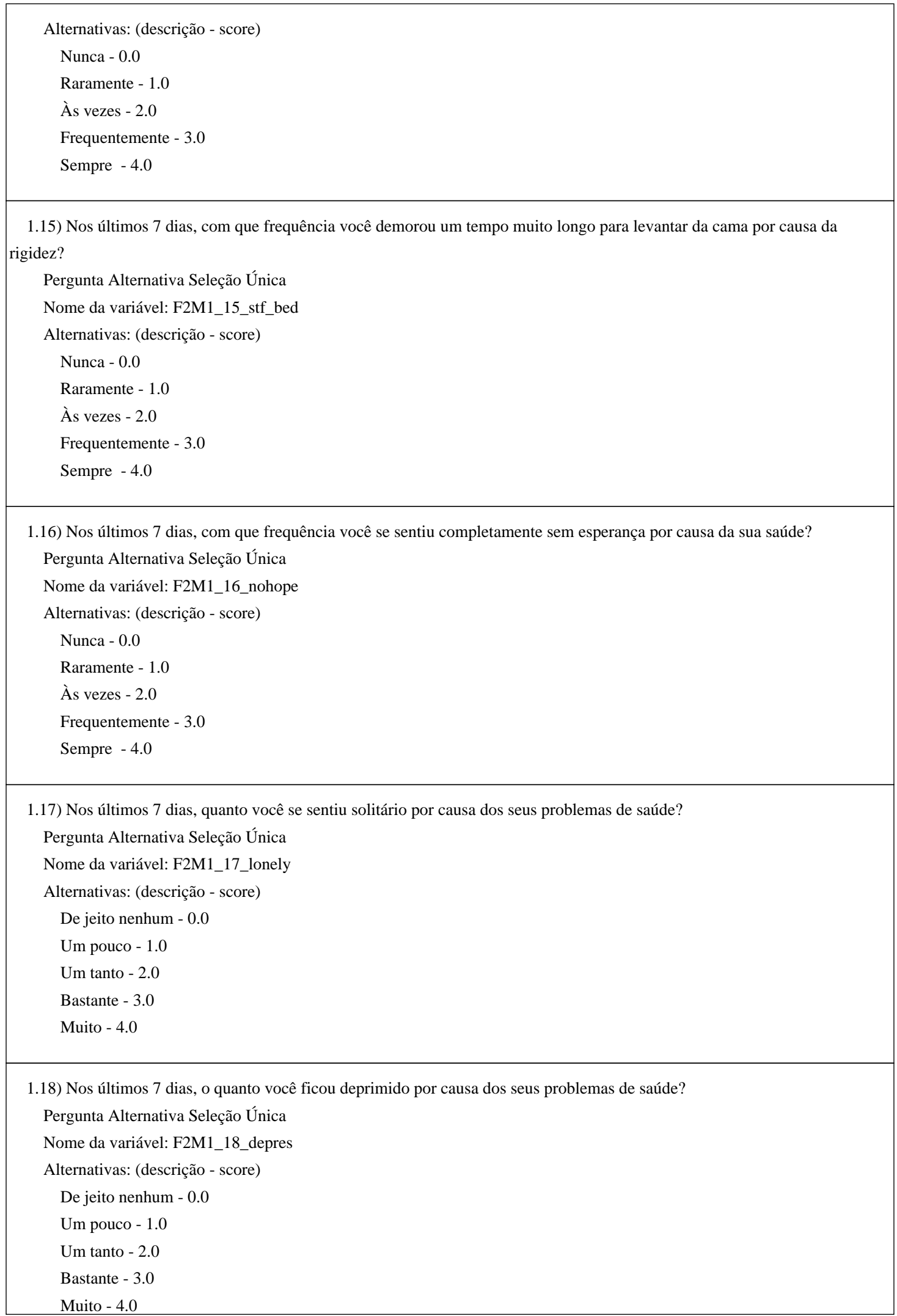


Muito - 4.0

1.19) Nos últimos 7 dias, quanto você se preocupou sobre ficar doente?

Pergunta Alternativa Seleção Única

Nome da variável: F2M1_19_wry_sick

Alternativas: (descrição - score)

De jeito nenhum - 0.0

Um pouco - 1.0

Um tanto - 2.0

Bastante - 3.0

Muito - 4.0

1.20) Nos últimos 7 dias, com que frequência você ficou muito preocupado sobre precisar ir para o hospital?

Pergunta Alternativa Seleção Única

Nome da variável: F2M1_20_wry_hos

Alternativas: (descrição - score)

Nunca - 0.0

Raramente - 1.0

Às vezes - 2.0

Frequentemente - 3.0

Sempre -4.0

1.21) Nos últimos 7 dias, com que frequência você ficou acordado a maior parte da noite porque você não conseguia dormir? Pergunta Alternativa Seleção Única

Nome da variável: F2M1_21_no_slp

Alternativas: (descrição - score)

Nunca - 0.0

Raramente - 1.0

Às vezes -2.0

Frequentemente - 3.0

Sempre -4.0

1.22) Nos últimos 7 dias, com que frequência foi muito fácil para você conseguir dormir?

Pergunta Alternativa Seleção Única

Nome da variável: F2M1_22_eas_slp

Alternativas: (descrição - score)

Nunca - 0.0

Raramente - 1.0

Às vezes - 2.0

Frequentemente - 3.0

Sempre -4.0

1.23) Nos últimos 7 dias, com que frequência você teve muitas dificuldade para dormir?

Pergunta Alternativa Seleção Única

Nome da variável: F2M1_23_trb_slp

Alternativas: (descrição - score) 
Nunca - 0.0

Raramente - 1.0

Às vezes - 2.0

Frequentemente - 3.0

Sempre -4.0

1.24) Nos últimos 7 dias, com que frequência você ficou acordado a noite toda porque você não conseguiu dormir? Pergunta Alternativa Seleção Única

Nome da variável: F2M1_24_up_all

Alternativas: (descrição - score)

Nunca - 0.0

Raramente - 1.0

Às vezes -2.0

Frequentemente - 3.0

Sempre -4.0

1.25) Nos últimos 7 dias, com que frequência você ficou acordado metade da noite porque você não conseguiu dormir? Pergunta Alternativa Seleção Única

Nome da variável: F2M1_25_up_hlf

Alternativas: (descrição - score)

Nunca - 0.0

Raramente - 1.0

Às vezes -2.0

Frequentemente - 3.0

Sempre -4.0

1.26) Nos últimos 30 dias, quanto você dependeu dos outros para cuidar de você por causa da sua saúde?

Pergunta Alternativa Seleção Única

Nome da variável: F2M1_26_oth_help

Alternativas: (descrição - score)

De jeito nenhum - 0.0

Um pouco - 1.0

Um tanto - 2.0

Bastante - 3.0

Muito - 4.0

1.27) Nos últimos 30 dias, com que frequência a sua saúde fez você ter menos disposição para fazer as suas coisas? Pergunta Alternativa Seleção Única

Nome da variável: F2M1_27_h_slow

Alternativas: (descrição - score)

Nunca - 0.0

Raramente - 1.0

Às vezes - 2.0

Frequentemente - 3.0

Sempre -4.0 
1.28) Nos últimos 30 dias, com que frequência sua saúde tornou mais difícil para você realizar suas atividades?

Pergunta Alternativa Seleção Única

Nome da variável: F2M1_28_h_hard

Alternativas: (descrição - score)

Nunca - 0.0

Raramente - 1.0

Às vezes - 2.0

Frequentemente -3.0

Sempre -4.0

1.29) Nos últimos 30 dias, com que frequência sua saúde te impediu de sair?

Pergunta Alternativa Seleção Única

Nome da variável: F2M1_29_h_out

Alternativas: (descrição - score)

Nunca - 0.0

Raramente - 1.0

Às vezes -2.0

Frequentemente - 3.0

Sempre -4.0

1.30) Nos últimos 30 dias o quanto sua saúde tornou difícil para você fazer atividades com seu amigos?

Pergunta Alternativa Seleção Única

Nome da variável: F2M1_30_h_frnd

Alternativas: (descrição - score)

De jeito nenhum - 0.0

Um pouco - 1.0

Um tanto - 2.0

Bastante - 3.0

Muito - 4.0

1.31) Eu sinto muita dor:

Pergunta Alternativa Seleção Única

Nome da variável: F2M1_31_p

Alternativas: (descrição - score)

Nunca $\quad-0.0$

Quase Nunca $\quad-1.0$

Algumas Vezes $\quad-2.0$

Frequentemente $\quad-3.0$

Quase sempre - 4.0

1.32) Eu sinto dor em todo meu corpo:

Pergunta Alternativa Seleção Única

Nome da variável: F2M1_32_p_body

Alternativas: (descrição - score)

Nunca $\quad-0.0$

Quase Nunca $\quad-1.0$

Algumas Vezes $\quad-2.0$ 


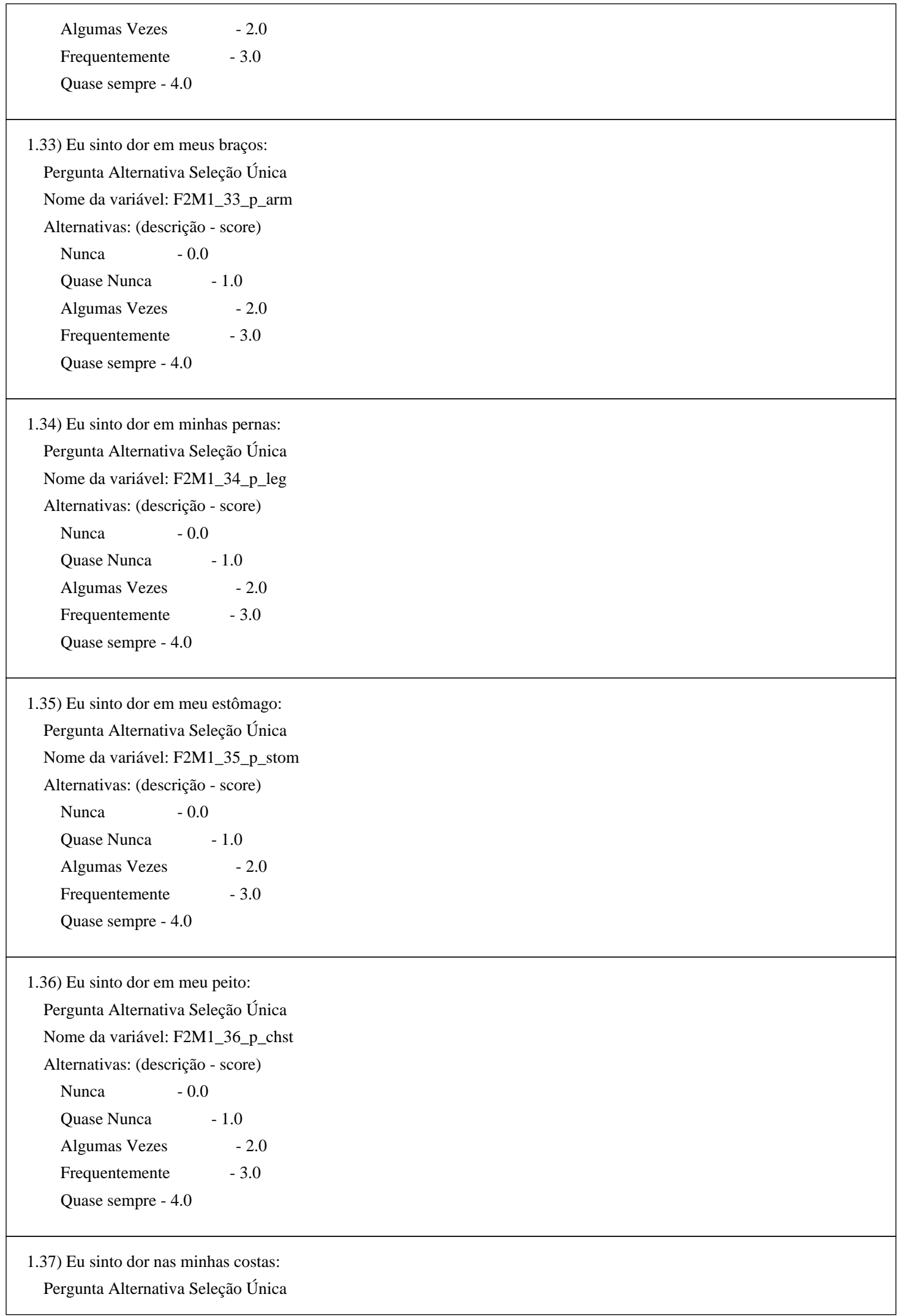




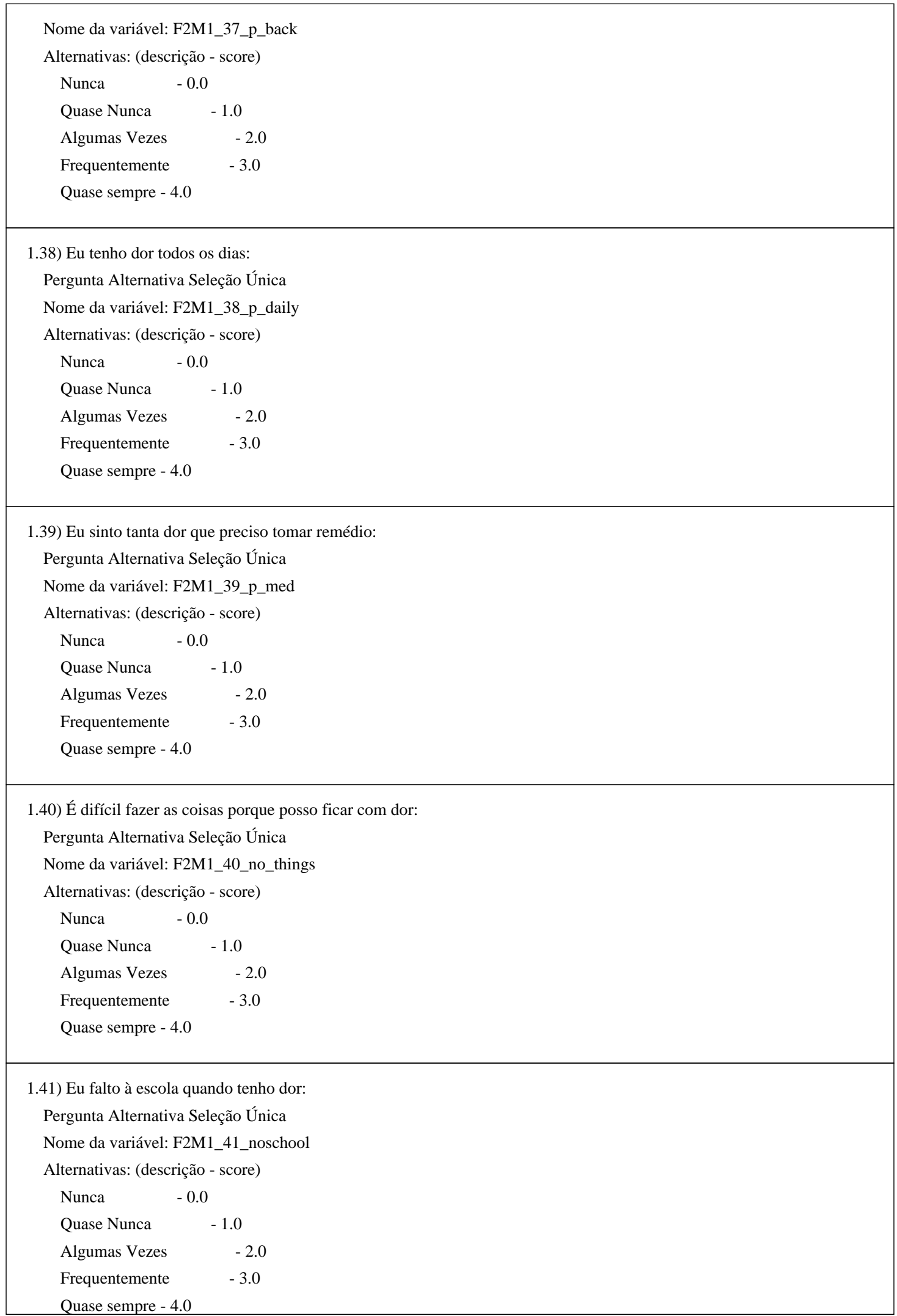


Quase sempre - 4.0

1.42) É difícil correr quando tenho dor: Pergunta Alternativa Seleção Única Nome da variável: F2M1_42_norun Alternativas: (descrição - score)
Nunca $-0.0$
Quase Nunca $-1.0$
Algumas Vezes $\quad-2.0$
Frequentemente $\quad-3.0$
Quase sempre - 4.0

1.43) É difícil me divertir quando tenho dor: Pergunta Alternativa Seleção Única Nome da variável: F2M1_43_nofun Alternativas: (descrição - score)
Nunca $-0.0$
Quase Nunca $-1.0$
Algumas Vezes $\quad-2.0$
Frequentemente $\quad-3.0$
Quase sempre - 4.0

1.44) Eu tenho dificuldade para me movimentar quando tenho dor: Pergunta Alternativa Seleção Única

Nome da variável: F2M1_44_nomove

Alternativas: (descrição - score)
Nunca $\quad-0.0$
Quase Nunca $\quad-1.0$
Algumas Vezes $\quad-2.0$
Frequentemente $\quad-3.0$
Quase sempre - 4.0

1.45) É difícil ficar em pé quando tenho dor:

Pergunta Alternativa Seleção Única

Nome da variável: F2M1_45_nostand

Alternativas: (descrição - score)
Nunca $\quad-0.0$
Quase Nunca $\quad-1.0$
Algumas Vezes $\quad-2.0$
Frequentemente $\quad-3.0$
Quase sempre - 4.0

1.46) É difícil cuidar de mim mesmo quando tenho dor:

Pergunta Alternativa Seleção Única

Nome da variável: F2M1_46_nocare

Alternativas: (descrição - score) 


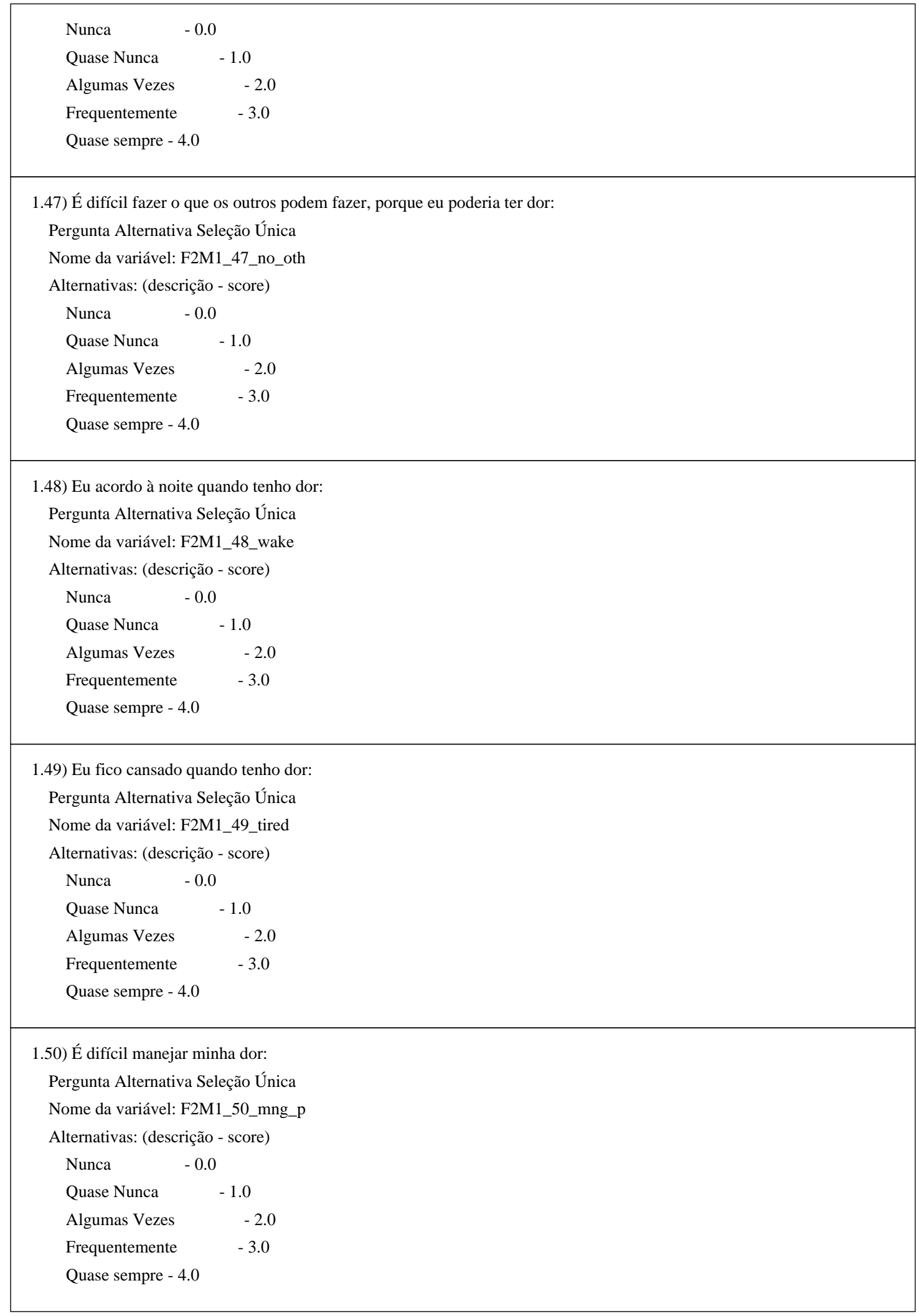




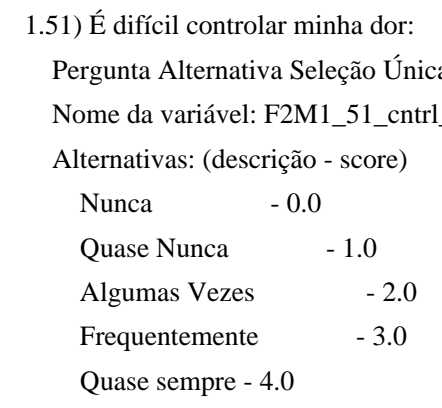

1.52) Eu me preocupo se vou ter dor:

Pergunta Alternativa Seleção Única

Nome da variável: F2M1_52_wor_p

Alternativas: (descrição - score)

$\begin{array}{lc}\text { Nunca } & -0.0 \\ \text { Quase Nunca } & -1.0 \\ \text { Algumas Vezes } & -2.0 \\ \text { Frequentemente } & -3.0 \\ \text { Quase sempre - 4.0 } & \end{array}$

1.53) Eu me preocupo se os outros não saberão o que fazer se eu tiver dor:

Pergunta Alternativa Seleção Única

Nome da variável: F2M1_53_wor_oth

Alternativas: (descrição - score)

$\begin{array}{lc}\text { Nunca } & -0.0 \\ \text { Quase Nunca } & -1.0 \\ \text { Algumas Vezes } & -2.0 \\ \text { Frequentemente } & -3.0 \\ \text { Quase sempre - 4.0 } & \end{array}$

1.54) Eu me preocupo quando estou longe de casa:

Pergunta Alternativa Seleção Única

Nome da variável: F2M1_54_wor_home

Alternativas: (descrição - score)

$\begin{array}{lc}\text { Nunca } & -0.0 \\ \text { Quase Nunca } & -1.0 \\ \text { Algumas Vezes } & -2.0 \\ \text { Frequentemente } & -3.0 \\ \text { Quase sempre - } 4.0 & \end{array}$

Quase sempre - 4.0

1.55) Eu me preocupo se poderei ter que ir a emergência:

Pergunta Alternativa Seleção Única

Nome da variável: F2M1_55_wor_er

Alternativas: (descrição - score)
Nunca
$-0.0$
Quase Nunca
$-1.0$

Algumas Vezes $-2.0$ 


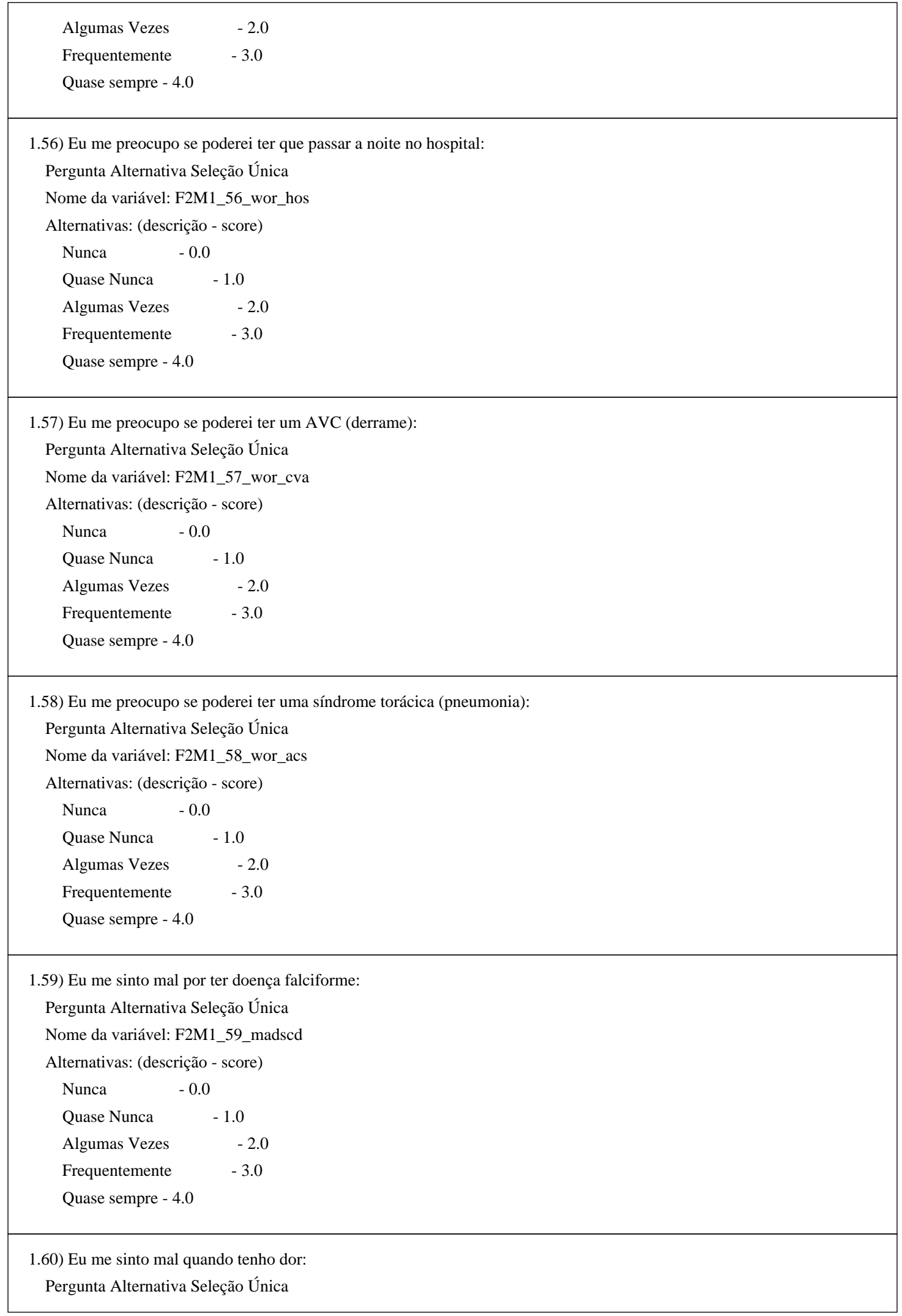


Nome da variável: F2M1_60_madvoe

Alternativas: (descrição - score)

$\begin{array}{lc}\text { Nunca } & -0.0 \\ \text { Quase Nunca } & -1.0 \\ \text { Algumas Vezes } & -2.0 \\ \text { Frequentemente } & -3.0 \\ \text { Quase sempre - } 4.0 & \end{array}$

1.61) É difícil lembrar de tomar meus remédios:

Pergunta Alternativa Seleção Única

Nome da variável: F2M1_61_nomed

Alternativas: (descrição - score)
Nunca
$-0.0$
Quase Nunca
$-1.0$
Algumas Vezes
$-2.0$
Frequentemente
$-3.0$
Quase sempre - 4.0

1.62) Eu não gosto de como me sinto após tomar meus remédios:

Pergunta Alternativa Seleção Única

Nome da variável: F2M1_62_feel_med

Alternativas: (descrição - score)
Nunca $\quad-0.0$
Quase Nunca $\quad-1.0$
Algumas Vezes $\quad-2.0$
Frequentemente $\quad-3.0$
Quase sempre - 4.0

1.63) Eu não gosto do sabor dos meus remédios:

Pergunta Alternativa Seleção Única

Nome da variável: F2M1_63_med_tast

Alternativas: (descrição - score)
Nunca
$-0.0$
Quase Nunca
$-1.0$
Algumas Vezes
$-2.0$
Frequentemente
$-3.0$
Quase sempre - 4.0

1.64) Meus remédios me deixam sonolento:

Pergunta Alternativa Seleção Única

Nome da variável: F2M1_64_med_slp

Alternativas: (descrição - score)
Nunca
$-0.0$
Quase Nunca
$-1.0$
Algumas Vezes
$-2.0$
Frequentemente
$-3.0$
Quase sempre - 4.0 
Quase sempre - 4.0

1.65) Eu me preocupo se meu remédio está funcionando:

Pergunta Alternativa Seleção Única

Nome da variável: F2M1_65_wor_med

Alternativas: (descrição - score)

$\begin{array}{lc}\text { Nunca } & -0.0 \\ \text { Quase Nunca } & -1.0 \\ \text { Algumas Vezes } & -2.0 \\ \text { Frequentemente } & -3.0 \\ \text { Quase sempre - } 4.0 & \end{array}$

1.66) Eu me preocupo se meu tratamento está funcionando:

Pergunta Alternativa Seleção Única

Nome da variável: F2M1_66_wor_tx

Alternativas: (descrição - score)

$\begin{array}{lc}\text { Nunca } & -0.0 \\ \text { Quase Nunca } & -1.0 \\ \text { Algumas Vezes } & -2.0 \\ \text { Frequentemente } & -3.0 \\ \text { Quase sempre - } 4.0 & \end{array}$

1.67) Meus remédios não me fazem sentir melhor:

Pergunta Alternativa Seleção Única

Nome da variável: F2M1_67_no_betr

Alternativas: (descrição - score)

$\begin{array}{lc}\text { Nunca } & -0.0 \\ \text { Quase Nunca } & -1.0 \\ \text { Algumas Vezes } & -2.0 \\ \text { Frequentemente } & -3.0 \\ \text { Quase sempre }-4.0 & \end{array}$

1.68) É difícil contar aos outros quando eu estou com dor:

Pergunta Alternativa Seleção Única

Nome da variável: F2M1_68_tell_oth

Alternativas: (descrição - score)

$\begin{array}{lc}\text { Nunca } & -0.0 \\ \text { Quase Nunca } & -1.0 \\ \text { Algumas Vezes } & -2.0 \\ \text { Frequentemente } & -3.0 \\ \text { Quase sempre - } 4.0 & \end{array}$

1.69) É difícil contar aos médicos e enfermeiros como eu me sinto:

Pergunta Alternativa Seleção Única

Nome da variável: F2M1_69_tell_md

Alternativas: (descrição - score) 


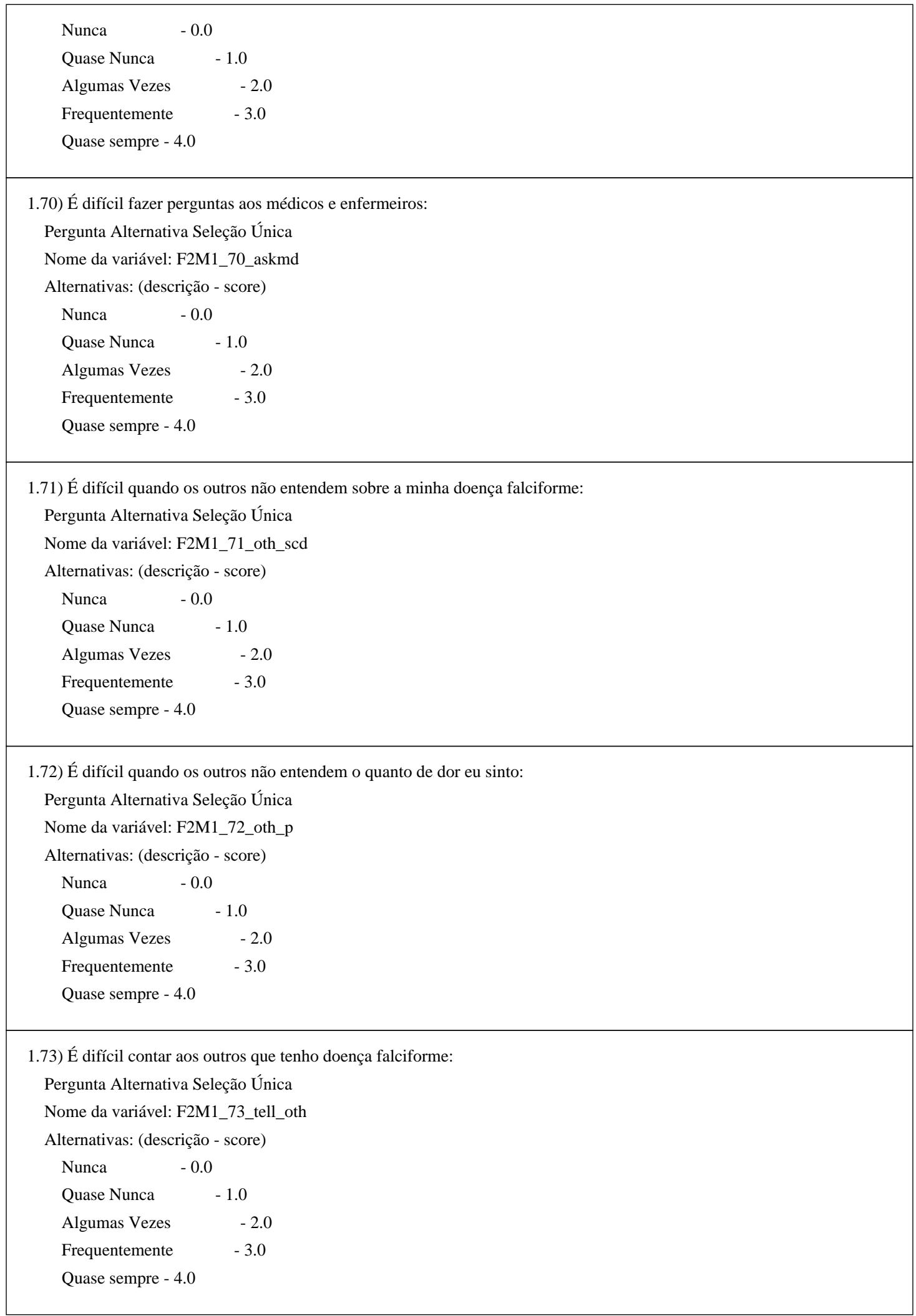




\section{Módulo: 2 - Entrevista}

2.1) Qual o sexo do paciente (registre sem perguntar ao paciente)

Pergunta Alternativa Seleção Única

Nome da variável: F2M2_1_sex

Alternativas: (descrição - score)

Masculino - 1.0

Feminino - 2.0

\section{2) Qual a sua idade?}

Pergunta Número Inteiro

Nome da variável: F2M2_2_age

Intervalo permitido: 0 - 99

2.3) Atualmente você esta estudando?

Pergunta Alternativa Seleção Única

Nome da variável: F2M2_3_sch

Alternativas: (descrição - score)

Sim - 1.0

Não -2.0

2.4) Nos últimos 30 dias, quantos dias de escola você teve que faltar por causa da dor devido à doença falciforme?

Pergunta Número Inteiro

Nome da variável: F2M2_4_m_sch

Intervalo permitido: 0 - 30

2.5) Atualmente você esta trabalhando?

Pergunta Alternativa Seleção Única

Nome da variável: F2M2_5_wor

Alternativas: (descrição - score)

Sim - 1.0

Não - 2.0

2.6) Qual o tipo do seu trabalho?

Pergunta Alternativa Seleção Única

Nome da variável: F2M2_6_ty_wor

Alternativas: (descrição - score)

Autonomo - 1.0

Emprego de tempo integral ( 8 ou mais horas diárias) - 2.0

Emprego de meio horário (menos de 8 horas diárias) - 3.0

2.7) Nos últimos 30 dias, quantos dias de trabalho você teve que faltar por causa da dor devido à doença falciforme?

Pergunta Número Inteiro

Nome da variável: F2M2_7_m_wor

Intervalo permitido: 0 - 30 


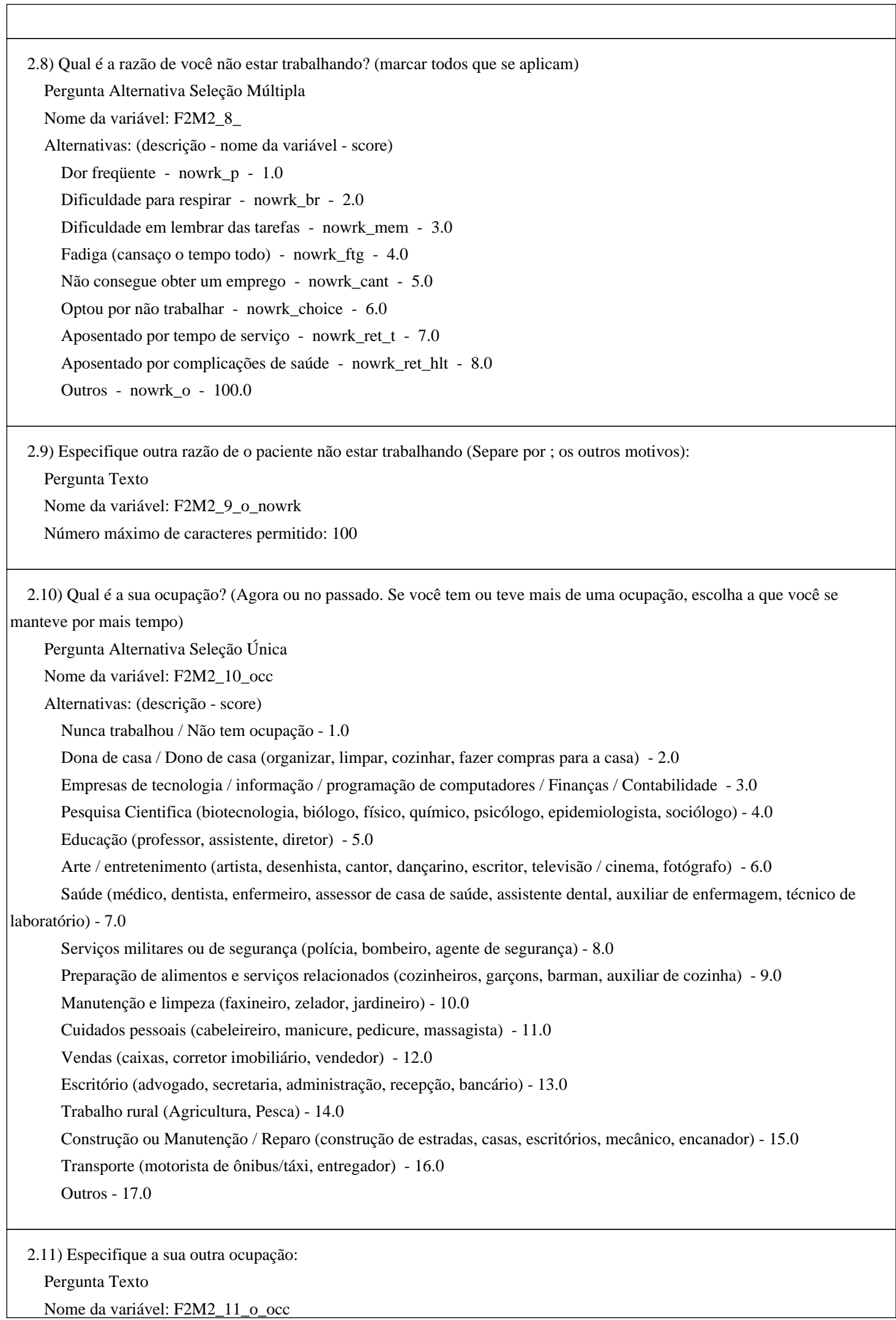


Nome da variável: F2M2_11_o_occ

Número máximo de caracteres permitido: 100

2.12) Nos últimos 30 dias, quantos dias você não foi capaz de realizar suas atividades diárias devido à dor falciforme? Pergunta Número Inteiro

Nome da variável: F2M2_12_n_act

Intervalo permitido: 0 - 30

2.12.1) Nos últimos 30 dias, quantos dias você não foi capaz de realizar suas atividades diárias devido à dor falciforme? Pergunta Número Inteiro

Nome da variável: F2M2_12_1_n_act

Intervalo permitido: 0 - 30

2.12.2) Nos últimos 30 dias, quantos dias você não foi capaz de realizar suas atividades diárias devido à dor falciforme? Pergunta Número Inteiro

Nome da variável: F2M2_12_2_n_act

Intervalo permitido: 0 - 30

2.13) Você recebe algum tipo de benefício social?

Pergunta Alternativa Seleção Única

Nome da variável: F2M2_13_ben

Alternativas: (descrição - score)

Sim -1.0

Não - 2.0

2.14) Qual o tipo de beneficio social você recebe?

Pergunta Alternativa Seleção Múltipla

Nome da variável: F2M2_14_

Alternativas: (descrição - nome da variável - score)

LOAS - Lei orgânica da assistência social - ben_loas - 1.0

TFD - Tratamento fora do domicilio - ben_tfd - 2.0

Aposentadoria por invalidez - INPS / INSS (não considerar aposentadoria por tempo de serviço/contribuição) - ben_inss 3.0

Auxilio doença - ben_ad - 4.0

BPC - Beneficio de prestação continuada - ben_bpc - 5.0

Bolsa familia - ben_bf - 6.0

Cartão carioca - ben_cc - 7.0

Auxilio moradia - ben_am - 8.0

Bolsa escola - ben_be - 9.0

Outros - ben_o - 150.0

2.15) Especifique o outro beneficio social que você recebe (Separe com ; os outros benefício sociais):

Pergunta Texto

Nome da variável: F2M2_15_o_ben

Número máximo de caracteres permitido: 100 


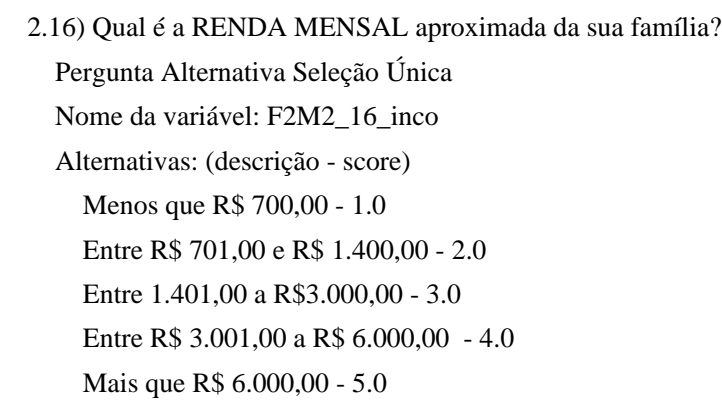

2.17) Você tem plano de saúde?

Pergunta Alternativa Seleção Única

Nome da variável: F2M2_17_ins

Alternativas: (descrição - score)

Sim - 1.0

Não - 2.0

2.18) Qual o tipo do seu plano de saúde? (marque todas que se aplicam)

Pergunta Alternativa Seleção Múltipla

Nome da variável: F2M2_18_t_ins

Alternativas: (descrição - nome da variável - score)

Próprio - _your - 1.0

Empresarial - _corp - 2.0

2.26) Nos últimos 30 dias, quantas consultas não agendadas você fez a algum consultório médico, hospital, pronto socorro ou clínica por causa da doença falciforme?

Pergunta Número Inteiro

Nome da variável: F2M2_26_n_uns

Intervalo permitido: 0 - 31

2.27) Você já teve a primeira menstruação?

Pergunta Alternativa Seleção Única

Nome da variável: F2M2_27_fmc

Alternativas: (descrição - score)

Sim - 1.0

Não - 2.0

2.28) Você entrou na menopausa (sem ciclo menstrual por 1 ano)?

Pergunta Alternativa Seleção Única

Nome da variável: F2M2_28_mps

Alternativas: (descrição - score)

Sim -1.0

Não -2.0

2.29) Você está grávida?

Pergunta Alternativa Seleção Única 
Nome da variável: F2M2_29_cpgt

Alternativas: (descrição - score)

Sim -1.0

Não - 2.0

2.30) Você já esteve grávida alguma vez na vida? (excluir gravidez atual, se aplicável)

Pergunta Alternativa Seleção Única

Nome da variável: F2M2_30_ev_pgt

Alternativas: (descrição - score)

Sim - 1.0

Não - 2.0

Planilha: Questões relacionada a Gravidez

Itens: (Descrição - Nome da variável)

Gravidez - F2M2

2.31) Você recebeu transfusão crônica durante a gravidez (regular ou mensal)?

Pergunta Alternativa Seleção Única

Nome da variável:_31_chtx_pg

Alternativas: (descrição - score)

Sim - 1.0

Não -2.0

2.32) Você recebeu transfusão durante ou 5 dias após o parto?

Pergunta Alternativa Seleção Única

Nome da variável: _32_tx_deliv

Alternativas: (descrição - score)

Sim -1.0

Não -2.0

2.33) Qual foi o tipo de parto?

Pergunta Alternativa Seleção Única

Nome da variável:_33_ty_deliv

Alternativas: (descrição - score)

Parto normal - 1.0

Cesario - 2.0

2.34) A gravidez resultou em:

Pergunta Alternativa Seleção Única

Nome da variável: _34_res_pgt

Alternativas: (descrição - score)

Nascimento a termo ( 9 meses completes e bebe nascido vivo) - 1.0

Nascimento prematuro ( não completou 9 meses e bebe nascido vivo) - 2.0

Aborto (induzido ou espontaneo) - 3.0

2.35) Você andou de moto nos últimos 12 meses?

Pergunta Alternativa Seleção Única

Nome da variável: F2M2_35_mbik

Alternativas: (descrição - score)

Sim -1.0

Não -2.0

2.36) Você andou de moto nos últimos 30 dias?

Pergunta Alternativa Seleção Única

Nome da variável: F2M2_36_mbik_130

Alternativas: (descrição - score)

Sim - 1.0

Não - 2.0 


\begin{tabular}{|l|}
\hline 2.37) Quantos dias nos últimos 30 dias você andou de moto? \\
Pergunta Número Inteiro \\
Nome da variável: F2M2_37_n_mbik \\
Intervalo permitido: 1 - 31 \\
\hline 2.38) Data da entrevista: \\
Pergunta Data \\
Nome da variável: F2M2_38_d_int \\
Intervalo permitido: 01/01/2014 - 31/12/2017 \\
\hline 2.39) Tipo de entrevista? \\
Pergunta Alternativa Seleção Única \\
Nome da variável: F2M2_39_ty_int \\
Alternativas: (descrição - score) \\
Presencial - 1.0 \\
Por telefone - 2.0
\end{tabular}

\section{Módulo: Screening}

2.20) Selecione o hemocentro de recrutamento

Pergunta Alternativa Seleção Única

Nome da variável: F2M2_20_ins

Alternativas: (descrição - score)

Hemominas $\mathrm{HBH}-1.0$

Hemominas JFO - 2.0

Hemominas MOC - 3.0

Hemope - 4.0

Hemorio - 5.0

ITACI - 6.0

\section{Módulo: 2 - Entrevista HBH}

2.19) Nos últimos 12 meses, você recebeu algum tratamento para a doença falciforme em outra instituição? Pergunta Alternativa Seleção Única Nome da variável: F2M2_19_tx_oins Alternativas: (descrição - score)

Sim - 1.0

Não -2.0

2.20.1) HBH - Qual o nome da instituição onde você recebeu tratamento?

Pergunta Alternativa Seleção Múltipla

Nome da variável: F2M2_20_1

Alternativas: (descrição - nome da variável - score) 


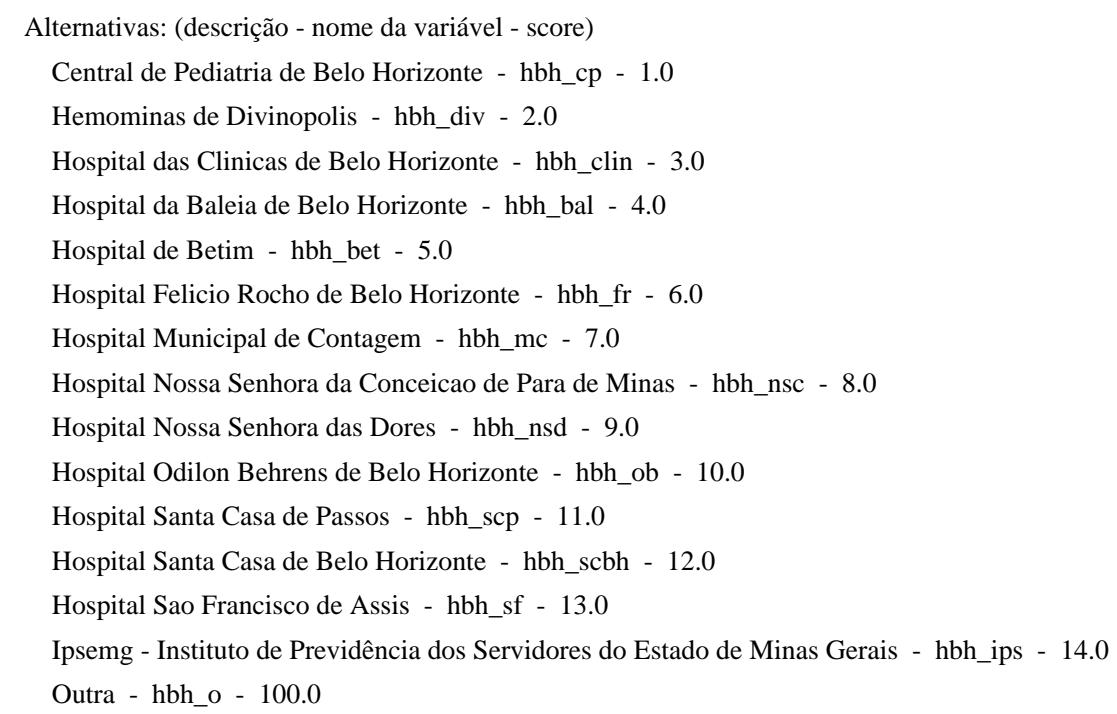

2.21.1) HBH - Especifique a outra INSTITUIÇÃO e CIDADE onde você recebeu tratamento nos últimos 12 meses (Separe por ; as outras instituições):

Pergunta Texto

Nome da variável: F2M2_21_1hbho

Número máximo de caracteres permitido: 100

2.22) Nos últimos 12 meses, você recebeu transfusões de sangue em outra instituição?

Pergunta Alternativa Seleção Única

Nome da variável: F2M2_22_tx_o

Alternativas: (descrição - score)

Sim -1.0

Não - 2.0

2.23.1) HBH - Qual o nome da instituição onde você recebeu transfusão?

Pergunta Alternativa Seleção Múltipla

Nome da variável: F2M2_23_1

Alternativas: (descrição - nome da variável - score)

Central de Pediatria de Belo Horizonte - hbhtx_cp - 1.0

Hemominas de Divinopolis - hbhtx_div - 2.0

Hospital das Clinicas de Belo Horizonte - hbhtx_clin - 3.0

Hospital da Baleia de Belo Horizonte - hbhtx_bal - 4.0

Hospital de Betim - hbhtx_bet - 5.0

Hospital Felicio Rocho de Belo Horizonte - hbhtx_fr - 6.0

Hospital Municipal de Contagem - hbhtx_mc - 7.0

Hospital Nossa Senhora da Conceicao de Para de Minas - hbhtx_nsc - 8.0

Hospital Nossa Senhora das Dores - hbhtx_nsd - 9.0

Hospital Odilon Behrens de Belo Horizonte - hbhtx_ob - 10.0

Hospital Santa Casa de Passos - hbhtx_scp - 11.0

Hospital Santa Casa de Belo Horizonte - hbhtx_scbh - 12.0

Hospital Sao Francisco de Assis - hbhtx_sf - 13.0 
Ipsemg - Instituto de Previdência dos Servidores do Estado de Minas Gerais - hbhtx_ips - 14.0

Outra - hbhtx_o - 100.0

2.24.1) HBH - Especifique a outra INSTITUIÇÃO e CIDADE onde você recebeu transfusão nos últimos 12 meses (Separe por ; as outras instituições):

Pergunta Texto

Nome da variável: F2M2_24_1hbh_otx

Número máximo de caracteres permitido: 100

2.25) Quantas transfusões foram realizadas em outra instituição nos últimos 12 meses?

Pergunta Número Inteiro

Nome da variável: F2M2_25_n_otx

Intervalo permitido: 0 - 100

\section{Módulo: 2 - Entrevista JFO}

2.19) Nos últimos 12 meses, você recebeu algum tratamento para a doença falciforme em outra instituição?

Pergunta Alternativa Seleção Única

Nome da variável: F2M2_19_tx_oins

Alternativas: (descrição - score)

Sim -1.0

Não - 2.0

2.20.2 ) JFO - Qual o nome da instituição onde você recebeu tratamento?

Pergunta Alternativa Seleção Múltipla

Nome da variável: F2M2_20_2

Alternativas: (descrição - nome da variável - score)

Hospital Monte Sinai de Juiz de Fora - jfo_ms - 1.0

Hospital de Cataguases - jfo_cat - 2.0

Hospital Joao Penido de Juiz de Fora - jfo_jp - 3.0

Hospital Santa Isabel de Uba - jfo_si - 4.0

Hospital Universitario de Juiz de Fora - jfo_u - 5.0

Maternidade Terezinha de Jesus de Juiz de Fora - jfo_mtj - 6.0

Santa Casa de Juiz de Fora - jfo_sc - 7.0

Outra - jfo_o - 100.0

2.21.2) JFO - Especifique a outra INSTITUIÇÃO e CIDADE onde você recebeu tratamento nos últimos 12 meses (Separe por ; as outras instituições):

Pergunta Texto

Nome da variável: F2M2_21_2jfo_o

Número máximo de caracteres permitido: 100

2.22) Nos últimos 12 meses, você recebeu transfusões de sangue em outra instituição?

Pergunta Alternativa Seleção Única

Nome da variável: F2M2_22_tx_o 


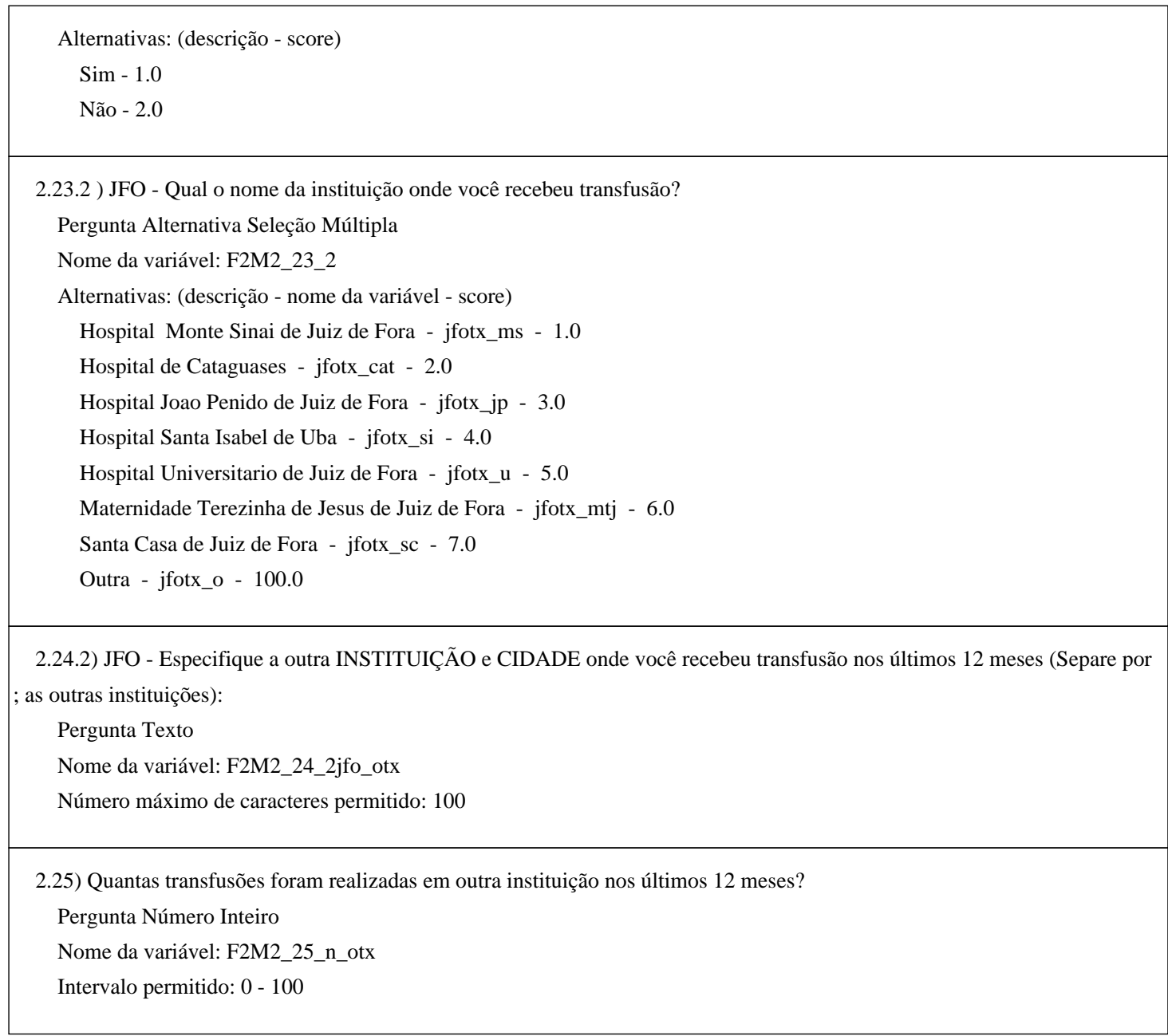

\section{Módulo: 2 - Entrevista MOC}

2.19) Nos últimos 12 meses, você recebeu algum tratamento para a doença falciforme em outra instituição?

Pergunta Alternativa Seleção Única

Nome da variável: F2M2_19_tx_oins

Alternativas: (descrição - score)

Sim -1.0

Não -2.0

2.20.3 ) MOC - Qual o nome da instituição onde você recebeu tratamento?

Pergunta Alternativa Seleção Múltipla

Nome da variável: F2M2_20_3

Alternativas: (descrição - nome da variável - score)

Fundacao Hospital Dr. Moises Magalhaes Freire - moc_mmf - 1.0

Hospital de Bocaiuva - moc_boc - 2.0

Hospital de Brasilia de Minas - moc_bm - 3.0

Hospital Municipal de Januaria - moc_mj - 4.0 
Hospital Pronto Socorro de Varzea da Palma - moc_psvp - 5.0

Hospital Santa Casa de Montes Claros - moc_scme - 6.0

Hospital Sao Vicente de Paula - moc_svp - 7.0

Hospital Universitario de Montes Claros - moc_u - 8.0

Outra - moc_o - 100.0

2.21.3) MOC - Especifique a outra INSTITUIÇÃO e CIDADE onde você recebeu tratamento nos últimos 12 meses (Separe por ; as outras instituições):

Pergunta Texto

Nome da variável: F2M2_21_3moc_o

Número máximo de caracteres permitido: 100

2.22) Nos últimos 12 meses, você recebeu transfusões de sangue em outra instituição?

Pergunta Alternativa Seleção Única

Nome da variável: F2M2_22_tx_o

Alternativas: (descrição - score)

Sim -1.0

Não - 2.0

2.23.3 ) MOC - Qual o nome da instituição onde você recebeu transfusão?

Pergunta Alternativa Seleção Múltipla

Nome da variável: F2M2_23_3

Alternativas: (descrição - nome da variável - score)

Fundacao Hospital Dr. Moises Magalhaes Freire - moctx_mmf - 1.0

Hospital de Bocaiuva - moctx_boc - 2.0

Hospital de Brasilia de Minas - moctx_bm - 3.0

Hospital Municipal de Januaria - moctx_mj - 4.0

Hospital Pronto Socorro de Varzea da Palma - moctx_psvp - 5.0

Hospital Santa Casa de Montes Claros - moctx_scmc - 6.0

Hospital Sao Vicente de Paula - moctx_svp - 7.0

Hospital Universitario de Montes Claros - moctx_u - 8.0

Outra - moctx_o - 100.0

2.24.3) MOC - Especifique a outra INSTITUIÇÃO e CIDADE onde você recebeu transfusão nos últimos 12 meses (Separe por ; as outras instituições):

Pergunta Texto

Nome da variável: F2M2_24_3moc_otx

Número máximo de caracteres permitido: 100

2.25) Quantas transfusões foram realizadas em outra instituição nos últimos 12 meses?

Pergunta Número Inteiro

Nome da variável: F2M2_25_n_otx

Intervalo permitido: 0 - 100 


\section{Módulo: 2 - Entrevista Hemope}

2.19) Nos últimos 12 meses, você recebeu algum tratamento para a doença falciforme em outra instituição?

Pergunta Alternativa Seleção Única

Nome da variável: F2M2_19_tx_oins

Alternativas: (descrição - score)

Sim -1.0

Não -2.0

2.20.4 ) HEMOPE - Qual o nome da instituição onde você recebeu tratamento?

Pergunta Alternativa Seleção Múltipla

Nome da variável: F2M2_20_4

Alternativas: (descrição - nome da variável - score)

Hospital Professor Agamenon Magalhaes de Serra Talhada - pe_pam - 1.0

Hospital das Clinicas De Recife - pe_cr - 2.0

Hospital das Clinicas De Carpina - pe_cc - 3.0

Hospital São Marcos - pe_sm - 4.0

Instituto de Medicina Integral Professor Fernando Figueira - pe_ipff - 5.0

Outra - pe_o - 100.0

2.21.4) HEMOPE - Especifique a outra INSTITUIÇÃO e CIDADE onde você recebeu tratamento nos últimos 12 meses (Separe por ; as outras instituições):

Pergunta Texto

Nome da variável: F2M2_21_4pe_o

Número máximo de caracteres permitido: 100

2.22) Nos últimos 12 meses, você recebeu transfusões de sangue em outra instituição?

Pergunta Alternativa Seleção Única

Nome da variável: F2M2_22_tx_o

Alternativas: (descrição - score)

Sim -1.0

Não -2.0

2.23.4 ) HEMOPE - Qual o nome da instituição você recebeu transfusão?

Pergunta Alternativa Seleção Múltipla

Nome da variável: F2M2_23_4

Alternativas: (descrição - nome da variável - score)

Hospital Professor Agamenon Magalhaes de Serra Talhada - petx_pam - 1.0

Hospital das Clinicas De Recife - petx_cr - 2.0

Hospital das Clinicas De Carpina - petx_cc - 3.0

Hospital São Marcos - petx_sm - 4.0

Instituto de Medicina Integral Professor Fernando Figueira - petx_ipff - 5.0

Outra - petx_o - 100.0

2.24.4) HEMOPE - Especifique a outra INSTITUIÇÃO e CIDADE onde você recebeu transfusão nos últimos 12 meses (Separe por ; as outras instituições):

Pergunta Texto 
Nome da variável: F2M2_24_4pe_otx

Número máximo de caracteres permitido: 100

2.25) Quantas transfusões foram realizadas em outra instituição nos últimos 12 meses?

Pergunta Número Inteiro

Nome da variável: F2M2_25_n_otx

Intervalo permitido: 0 - 100

\section{Módulo: 2 - Entrevista Hemorio}

2.19) Nos últimos 12 meses, você recebeu algum tratamento para a doença falciforme em outra instituição?

Pergunta Alternativa Seleção Única

Nome da variável: F2M2_19_tx_oins

Alternativas: (descrição - score)

Sim -1.0

Não - 2.0

2.20.5) HEMORIO - Qual o nome da instituição onde você recebeu tratamento?

Pergunta Alternativa Seleção Múltipla

Nome da variável: F2M2_20_5

Alternativas: (descrição - nome da variável - score)

Casa de Saude Nossa Senhora de Fatima - rj_csnsf - 1.0

Fundação Municipal Hospitalar de Macae - rj_fmhm - 2.0

Hospital Cardoso Fontes do Rio de Janeiro - rj_cfrj - 3.0

Hospital de Rio Bonito - rj_rb - 4.0

Hospital de Valenca - rj_v - 5.0

Hospital Federal da Lagoa do Rio de Janeiro - rj_fl - 6.0

Hospital Fernando Magalhaes do Rio de Janeiro - rj_fmag - 7.0

Hospital Ferreira Machado do Rio de Janeiro - rj_fmac - 8.0

Hospital Geral Dr. Beda - rj_gdb - 9.0

Hospital Geral Semiu do Rio de Janeiro - rj_gsrj - 10.0

Hospital Menino Jesus - rj_mj - 11.0

Hospital Municipal Souza Aguiar do Rio de Janeiro - rj_msa - 12.0

Hospital Nogueira de Souza do Rio de Janeiro - rj_ns - 13.0

Hospital Rocha Faria de Campo Grande - rj_rfcg - 14.0

Hospital Sao Joao Batista de Volta Redonda - rj_sjb - 15.0

Serviço de Assistência Médico-Cirúrgica Infantil - rj_inf - 16.0

Outra - rj_o - 100.0

2.21.5) HEMORIO - Especifique a outra INSTITUIÇÃO e CIDADE onde você recebeu tratamento nos últimos 12 meses (Separe por ; as outras instituições):

Pergunta Texto

Nome da variável: F2M2_21_5rj_o

Número máximo de caracteres permitido: 100 
2.22) Nos últimos 12 meses, você recebeu transfusões de sangue em outra instituição?

Pergunta Alternativa Seleção Única

Nome da variável: F2M2_22_tx_o

Alternativas: (descrição - score)

Sim -1.0

Não - 2.0

2.23.5) HEMORIO - Qual o nome da instituição onde você recebeu transfusão?

Pergunta Alternativa Seleção Múltipla

Nome da variável: F2M2_23_5

Alternativas: (descrição - nome da variável - score)

Casa de Saude Nossa Senhora de Fatima - rjtx_csnsf - 1.0

Fundação Municipal Hospitalar de Macae - rjtx_fmhm - 2.0

Hospital Cardoso Fontes do Rio de Janeiro - rjtx_cfrj - 3.0

Hospital de Rio Bonito - rjtx_rb - 4.0

Hospital de Valenca - rjtx_v - 5.0

Hospital Federal da Lagoa do Rio de Janeiro - rjtx_fl - 6.0

Hospital Fernando Magalhaes do Rio de Janeiro - rjtx_fmag - 7.0

Hospital Ferreira Machado do Rio de Janeiro - rjtx_fmac - 8.0

Hospital Geral Dr. Beda - rjtx_gdb - 9.0

Hospital Geral Semiu do Rio de Janeiro - rjtx_gsrj - 10.0

Hospital Menino Jesus - rjtx_mj - 11.0

Hospital Municipal Souza Aguiar do Rio de Janeiro - rjtx_msa - 12.0

Hospital Nogueira de Souza do Rio de Janeiro - rjtx_ns - 13.0

Hospital Rocha Faria de Campo Grande - rjtx_rfcg - 14.0

Hospital Sao Joao Batista de Volta Redonda - rjtx_sjb - 15.0

Serviço de Assistência Médico-Cirúrgica Infantil - rjtx_inf - 16.0

Outra - rjtx_o - 100.0

2.24.5) HEMORIO - Especifique a outra INSTITUIÇÃO e CIDADE onde você recebeu transfusão nos últimos 12 meses (Separe por ; as outras instituições):

Pergunta Texto

Nome da variável: F2M2_24_5rj_otx

Número máximo de caracteres permitido: 100

2.25) Quantas transfusões foram realizadas em outra instituição nos últimos 12 meses?

Pergunta Número Inteiro

Nome da variável: F2M2_25_n_otx

Intervalo permitido: 0 - 100

\section{Módulo: 2 - Entrevista ITACI}

2.19) Nos últimos 12 meses, você recebeu algum tratamento para a doença falciforme em outra instituição?

Pergunta Alternativa Seleção Única

Nome da variável: F2M2_19_tx_oins 


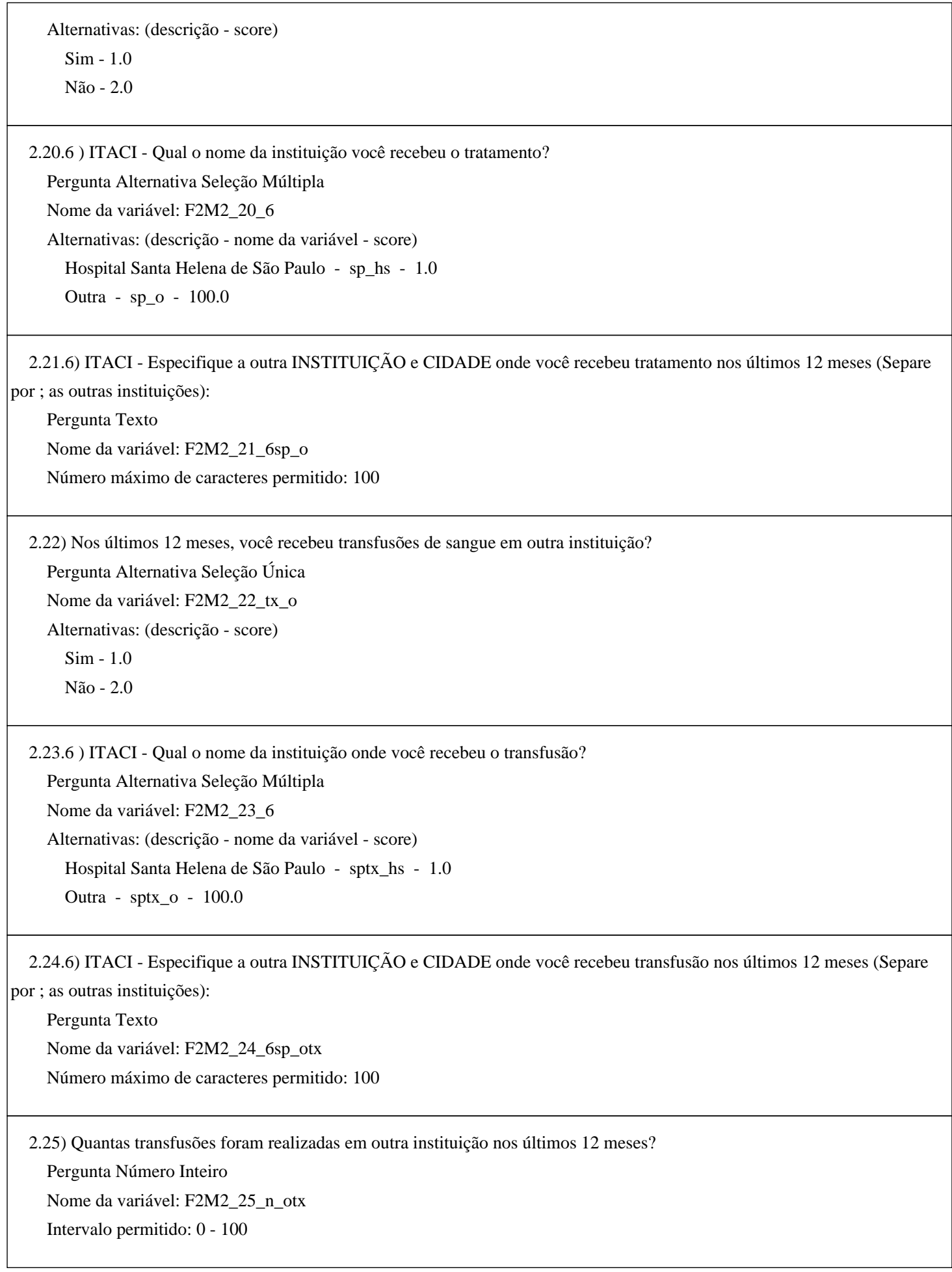

Módulo: 2 - Entrevista - Álcool e drogas 
2.40) Qual a idade do participante? Registre sem perguntar ao paciente.

Pergunta Número Inteiro

Nome da variável: F2M2_40_age

Intervalo permitido: 0 - 150

2.41) Nos últimos 12 meses, você tomou bebida alcoólica (cerveja, vinho, cachaça, uísque, etc)? Pergunta Alternativa Seleção Única

Nome da variável: F2M2_41_drink

Alternativas: (descrição - score)

Sim -1.0

Não - 2.0

2.42) Nos últimos 30 dias, quantos dias você bebeu pelo menos um copo de qualquer bebida alcoólica(cerveja, vinho, cachaça, whisky, rum, etc)? Caso o paciente não tenha ingerido bebida alcoólica nos últimas 30 dias, preencha "0".

Pergunta Número Inteiro

Nome da variável: F2M2_42_30ddrink

Intervalo permitido: 0 - 30

2.43) Nos últimos 12 meses, você usou maconha?

Pergunta Alternativa Seleção Única

Nome da variável: F2M2_43_marij

Alternativas: (descrição - score)

Sim -1.0

Não - 2.0

2.44) Nos últimos 30 dias, quantos dias você usou maconha? Caso o paciente não tenha usado maconha nos últimos 30 dias, preencha " 0 ".

Pergunta Número Inteiro

Nome da variável: F2M2_44_30dmarij

Intervalo permitido: 0 - 30 


\section{Módulo: 3 - Internações hospitalares}

3.1) O paciente teve internações hospitalares no período de acompanhamento 2 ? Pergunta Alternativa Seleção Única

Nome da variável: F2M3_1_hos

Alternativas: (descrição - score)

Sim -1.0

Não -2.0

Planilha: Questões relacionadas a internações hospitalares:

Itens: (Descrição - Nome da variável)

Internação - F2M3

3.2) Data da internação

Pergunta Data

Nome da variável: _2_d_adm

Intervalo permitido: $01 / 01 / 2013$ - 31/12/2017

3.3) Data da alta: (caso o paciente ainda esteja internado, marque "Não se aplica")

Pergunta Data

Nome da variável:_3_d_dc

Intervalo permitido: 01/01/2013 - 31/12/2017 
3.4) Diagnóstico 1:

Pergunta Alternativa Seleção Única

Nome da variável: 4 dx 1

Alternativas: (descrição - score)

Diagnóstico não localizado/Sem $2 \% 3^{\circ}$ diagnóstico - 1.0

Acidente vascular cerebral - Hemorrágico - 2.0

Acidente vascular cerebral - Infarto - 3.0

Anemia auto imune - 4.0

Asma - 5.0

Ataque isquêmico transitório - 6.0

Cardimiopatia - 7.0

Cirurgia programada - 8.0

Colecistite -9.0

Colelitíase - 10.0

Complicações oculares - 11.0

Convulsão - 12.0

Dactilite (síndrome mão-pé) - 13.0

Embolia Pulmonar - 14.0

Episódio aplástico - 15.0

Episodio de dor aguda da doença falciforme - 16.0

Febre, sem diagnóstico específico de infecção - 17.0

Hemossiderose Transfusional - 18.0

Hiperhemólise - 19.0

Hipertensão arterial sistêmica - 20.0

Hipertensão Pulmonar - 21.0

Infarto do Miocárdio - 22.0

Infecções graves - Sepses /bacteremia/Meningite - 23.0

Insuficiência cardíaca - 24.0

Insuficiência Renal - 25.0

Moya - Moya - 26.0

Necrose avascular-quadril / ombro Avascular - 27.0

Neuropatia (dor neuropática) - 28.0

Osteomielite (aguda ou crônica) - 29.0

Outras infeccões - 30.0

Outro diagnóstico não relacionado à Doença Falciforme - 31.0

Pancreatite - 32.0

Pielonefrite - 33.0

Priapismo - 34.0

Reação transfusional hemolítica tardia - 35.0

Sequestro esplênico agudo - 36.0

Sequestro hepático - 37.0

Síndrome nefrótica - 38.0

Síndrome Torácica Aguda/ Pneumonia - 39.0

Úlceras de perna - 40.0

3.5) Se outra infecção (30) ou outro diagnóstico não relacionado à Doença Falciforme (31), especifique: Pergunta Texto

Nome da variável: _5_dx1_o

Número máximo de caracteres permitido: 100 
3.6) Diagnóstico 2:

Pergunta Alternativa Seleção Única

Nome da variável: _6_dx2

Alternativas: (descrição - score)

Diagnóstico não localizado/Sem $2 \% 3^{\circ}$ diagnóstico - 1.0

Acidente vascular cerebral - Hemorrágico - 2.0

Acidente vascular cerebral - Infarto - 3.0

Anemia auto imune - 4.0

Asma - 5.0

Ataque isquêmico transitório - 6.0

Cardimiopatia - 7.0

Cirurgia programada - 8.0

Colecistite -9.0

Colelitíase - 10.0

Complicações oculares - 11.0

Convulsão - 12.0

Dactilite (síndrome mão-pé) - 13.0

Embolia Pulmonar - 14.0

Episódio aplástico - 15.0

Episodio de dor aguda da doença falciforme - 16.0

Febre, sem diagnóstico específico de infecção - 17.0

Hemossiderose Transfusional - 18.0

Hiperhemólise - 19.0

Hipertensão arterial sistêmica - 20.0

Hipertensão Pulmonar - 21.0

Infarto do Miocárdio - 22.0

Infecções graves - Sepses /bacteremia/Meningite - 23.0

Insuficiência cardíaca - 24.0

Insuficiência Renal - 25.0

Moya - Moya - 26.0

Necrose avascular-quadril / ombro Avascular - 27.0

Neuropatia (dor neuropática) - 28.0

Osteomielite (aguda ou crônica) - 29.0

Outras infeccões - 30.0

Outro diagnóstico não relacionado à Doença Falciforme - 31.0

Pancreatite - 32.0

Pielonefrite - 33.0

Priapismo - 34.0

Reação transfusional hemolítica tardia - 35.0

Sequestro esplênico agudo - 36.0

Sequestro hepático - 37.0

Síndrome nefrótica - 38.0

Síndrome Torácica Aguda/ Pneumonia - 39.0

Úlceras de perna - 40.0

3.7) Se outra infecção (30) ou outro diagnóstico não relacionado à Doença Falciforme (31), especifique: Pergunta Texto

Nome da variável: _7_dx2 o

Número máximo de caracteres permitido: 100 
3.8) Diagnóstico 3:

Pergunta Alternativa Seleção Única

Nome da variável: _8_dx3

Alternativas: (descrição - score)

Diagnóstico não localizado/Sem $2^{\circ} / 3^{\circ}$ diagnóstico - 1.0

Acidente vascular cerebral - Hemorrágico - 2.0

Acidente vascular cerebral - Infarto - 3.0

Anemia auto imune - 4.0

Asma - 5.0

Ataque isquêmico transitório - 6.0

Cardimiopatia - 7.0

Cirurgia programada - 8.0

Colecistite -9.0

Colelitíase - 10.0

Complicações oculares - 11.0

Convulsão - 12.0

Dactilite (síndrome mão-pé) - 13.0

Embolia Pulmonar - 14.0

Episódio aplástico - 15.0

Episodio de dor aguda da doença falciforme - 16.0

Febre, sem diagnóstico específico de infecção - 17.0

Hiperhemólise - 18.0

Hipertensão arterial sistêmica - 19.0

Hipertensão Pulmonar - 20.0

Hemossiderose Transfusional - 21.0

Infarto do Miocárdio - 22.0

Infecções graves - Sepses /bacteremia/Meningite - 23.0

Insuficiência cardíaca - 24.0

Insuficiência Renal - 25.0

Moya - Moya - 26.0

Necrose avascular-quadril / ombro Avascular - 27.0

Neuropatia (dor neuropática) - 28.0

Osteomielite (aguda ou crônica) - 29.0

Outras infecções - 30.0

Outro diagnóstico não relacionado à Doença Falciforme - 31.0

Pancreatite - 32.0

Pielonefrite - 33.0

Priapismo - 34.0

Reação transfusional hemolítica tardia - 35.0

Sequestro esplênico agudo - 36.0

Sequestro hepático - 37.0

Síndrome nefrótica - 38.0

Síndrome Torácica Aguda/ Pneumonia - 39.0

Úlceras de perna - 40.0

3.9) Se outra infecção (30) ou outro diagnóstico não relacionado à Doença Falciforme (31), especifique: Pergunta Texto

Nome da variável:_9_dx3_o

Número máximo de caracteres permitido: 100

\section{Módulo: 4 - Histórico de cirurgias}

4.1) O paciente já foi submetido a algum procedimento cirúrgico no período de acompanhamento 2 ?

Pergunta Alternativa Seleção Única

Nome da variável: F2M4_1_surg

Alternativas: (descrição - score)

Sim -1.0

Não - 2.0

4.2) O paciente tem histórico de tonsilectomia no período de acompanhamento 2 ?

Pergunta Alternativa Seleção Única

Nome da variável: F2M4_2_ton

Alternativas: (descrição - score)

Sim -1.0 
Não -2.0

4.3) Data da tonsilectomia:

Pergunta Data

Nome da variável: F2M4_3_d_ton

Intervalo permitido: 01/01/2013 - 31/12/2017

4.4) Houve transfusão pré-operatória antes da cirurgia para evitar complicações na tonsilectomia?

Pergunta Alternativa Seleção Única

Nome da variável: F2M4_4_ton_ptx

Alternativas: (descrição - score)

Sim -1.0

Não - 2.0

4.5) Houve transfusão durante ou após a tonsilectomia?

Pergunta Alternativa Seleção Única

Nome da variável: F2M4_5_ton_tx

Alternativas: (descrição - score)

Sim -1.0

Não - 2.0

4.6) Qual foi a razão para a transfusão na tonsilectomia? (marcar apenas um)

Pergunta Alternativa Seleção Única

Nome da variável: F2M4_6_tontx_i

Alternativas: (descrição - score)

Agudização da anemia - 1.0

Desenvolvimento de síndrome torácica aguda - 2.0

Outro - 3.0

4.7) Especifique outra razão para a transfusão na tonsilectomia (separe por ; as outras razões para a transfusão): Pergunta Texto

Nome da variável: F2M4_7_tontx_o

Número máximo de caracteres permitido: 100

4.8) O paciente tem histórico de esplenectomia no período de acompanhamento 2 ?

Pergunta Alternativa Seleção Única

Nome da variável: F2M4_8_sp

Alternativas: (descrição - score)

Sim -1.0

Não - 2.0

4.9) Data da esplenectomia:

Pergunta Data

Nome da variável: F2M4_9_d_sp

Intervalo permitido: 01/01/2013 - 31/12/2017 


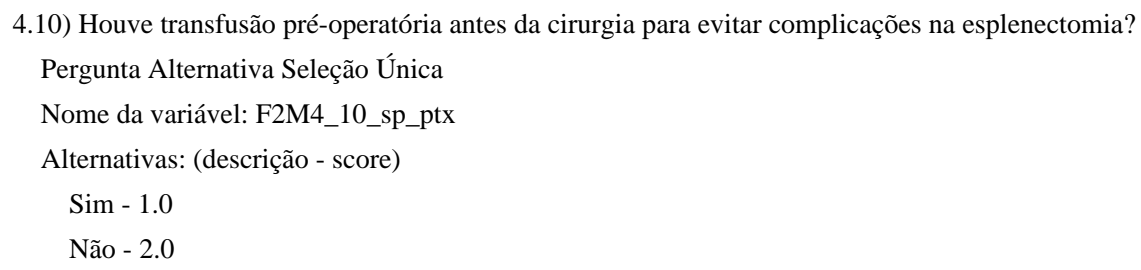

4.11) Houve transfusão durante ou após a esplenectomia?

Pergunta Alternativa Seleção Única

Nome da variável: F2M4_11_sp_tx

Alternativas: (descrição - score)

Sim -1.0

Não -2.0

4.12) Qual foi a razão para a transfusão na esplenectomia? (marcar apenas um)

Pergunta Alternativa Seleção Única

Nome da variável: F2M4_12_sptx_i

Alternativas: (descrição - score)

Agudização da anemia - 1.0

Desenvolvimento de síndrome torácica aguda - 2.0

Outro - 3.0

4.13) Especifique outra razão para a transfusão na esplenectomia (separe por ; as outras razões para a transfusão): Pergunta Texto

Nome da variável: F2M4_13_sptx_o

Número máximo de caracteres permitido: 100

4.14) O paciente tem histórico de colecistectomia no período de acompanhamento 2?

Pergunta Alternativa Seleção Única

Nome da variável: F2M4_14_cho

Alternativas: (descrição - score)

Sim - 1.0

Não - 2.0

\subsection{5) Data da colecistectomia:}

\section{Pergunta Data}

Nome da variável: F2M4_15_d_cho

Intervalo permitido: 01/01/2013 - 31/12/2017

4.16) Houve transfusão pré-operatória antes da cirurgia para evitar complicações na colecistectomia? Pergunta Alternativa Seleção Única

Nome da variável: F2M4_16_cho_ptx

Alternativas: (descrição - score)

Sim -1.0

Não - 2.0 


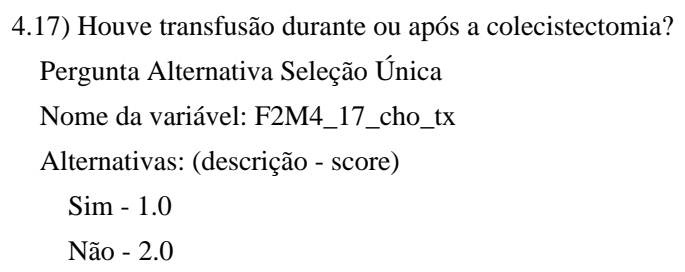

4.18) Qual foi a razão para a transfusão na colecistectomia? (marcar apenas um) Pergunta Alternativa Seleção Única

Nome da variável: F2M4_18_chotx_i

Alternativas: (descrição - score)

Agudização da anemia - 1.0

Desenvolvimento de síndrome torácica aguda - 2.0

Outro - 3.0

4.19) Especifique outra razão para a transfusão na colecistectomia (separe por ; as outras razões para a transfusão): Pergunta Texto

Nome da variável: F2M4_19_chotx_o

Número máximo de caracteres permitido: 100

4.20) O paciente tem histórico de artroplastia de quadril no período de acompanhamento 2 ?

Pergunta Alternativa Seleção Única

Nome da variável: F2M4_20_hip

Alternativas: (descrição - score)

Sim -1.0

Não - 2.0

4.21) Data da artroplastia de quadril:

Pergunta Data

Nome da variável: F2M4_21_d_hip

Intervalo permitido: 01/01/2013 - 31/12/2017

4.22) Houve transfusão pré-operatória antes da cirurgia para evitar complicações na artroplastia de quadril?

Pergunta Alternativa Seleção Única

Nome da variável: F2M4_22_hip_ptx

Alternativas: (descrição - score)

Sim -1.0

Não -2.0

4.23) Houve transfusão durante ou após a artroplastia de quadril?

Pergunta Alternativa Seleção Única

Nome da variável: F2M4_23_hip_tx

Alternativas: (descrição - score)

Sim -1.0

Não - 2.0 


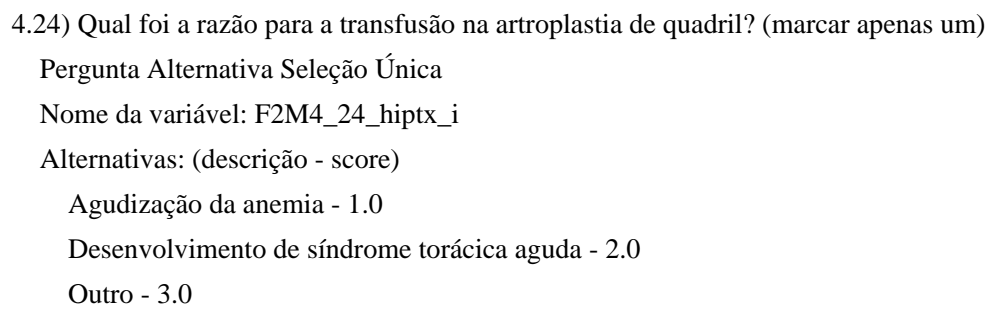

4.25) Especifique outra razão para a transfusão na artroplastia de quadril (separe por ; as outras razões para a transfusão): Pergunta Texto

Nome da variável: F2M4_25_hiptx_o

Número máximo de caracteres permitido: 100

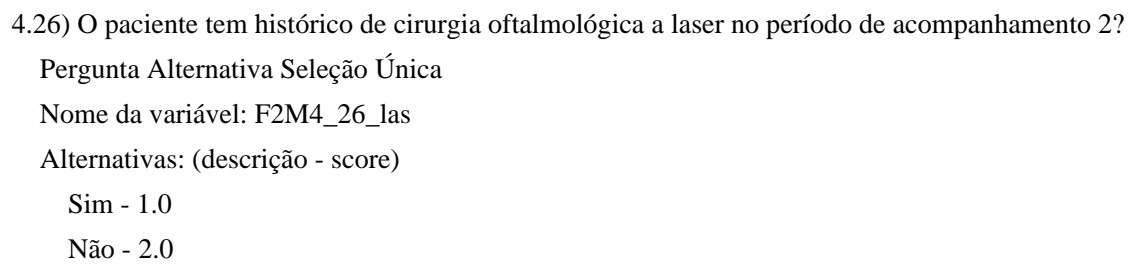

4.28) O paciente tem histórico de vitrectomia no período de acompanhamento 2 ?

Pergunta Alternativa Seleção Única

Nome da variável: F2M4_28_vit

Alternativas: (descrição - score)

Sim - 1.0

Não -2.0

\subsection{9) Data da vitrectomia:}

\section{Pergunta Data}

Nome da variável: F2M4_29_d_vit

Intervalo permitido: 01/01/2013 - 31/12/2017

4.30) Houve transfusão pré-operatória antes da cirurgia para evitar complicações na vitrectomia? Pergunta Alternativa Seleção Única

Nome da variável: F2M4_30_vit_ptx

Alternativas: (descrição - score)

Sim -1.0

Não - 2.0

4.31) Houve transfusão durante ou após a vitrectomia?

Pergunta Alternativa Seleção Única 
Nome da variável: F2M4_31_vit_tx

Alternativas: (descrição - score)

Sim -1.0

Não - 2.0

4.32) Qual foi a razão para a transfusão na vitrectomia? (marcar apenas um)

Pergunta Alternativa Seleção Única

Nome da variável: F2M4_32_vitx_i

Alternativas: (descrição - score)

Agudização da anemia - 1.0

Desenvolvimento de síndrome torácica aguda - 2.0

Outro - 3.0

4.33) Especifique outra razão para a transfusão na vitrectomia (separe por ; as outras razões para a transfusão):

Pergunta Texto

Nome da variável: F2M4_33_vitx_o

Número máximo de caracteres permitido: 100

4.34) O paciente tem histórico de inserção de cateter venoso permanente no período de acompanhamento 2 ?

Pergunta Alternativa Seleção Única

Nome da variável: F2M4_34_incat

Alternativas: (descrição - score)

Sim - 1.0

Não - 2.0

4.35) Data da inserção de cateter venoso:

Pergunta Data

Nome da variável: F2M4_35_d_incat

Intervalo permitido: 01/01/2013 - 31/12/2017

4.36) Qual foi o tipo de cateter venoso?

Pergunta Alternativa Seleção Única

Nome da variável: F2M4_36_cath

Alternativas: (descrição - score)

Cateter totalmente implantado de lúmen simples - 1.0

Cateter totalmente implantado de duplo lúmen - 2.0

Cateter semi implantado/ tunelizado (Hickman, Broviac or Permcath) lúmen simples - 3.0

Cateter semi implantado/ tunelizado (Hickman, Broviac or Permcath) duplo lúmen - 4.0

Cateter Central de Inserção Periférica - PICC - 5.0

Outro -6.0

4.37) Especifique o outro tipo de catéter: (separe por ; os outros tipos de catéter):

Pergunta Texto

Nome da variável: F2M4_37_cath_o

Número máximo de caracteres permitido: 100 


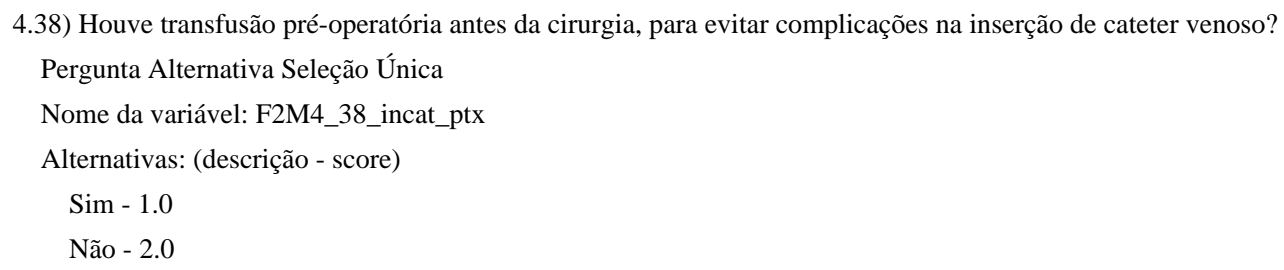

4.39) Houve transfusão durante ou após a inserção de cateter venoso?

Pergunta Alternativa Seleção Única

Nome da variável: F2M4_39_incat_tx

Alternativas: (descrição - score)

Sim -1.0

Não -2.0

4.40) Qual foi a razão para a transfusão na inserção de cateter venoso? (marcar apenas um)

Pergunta Alternativa Seleção Única

Nome da variável: F2M4_40_incatx_i

Alternativas: (descrição - score)

Agudização da anemia - 1.0

Desenvolvimento de síndrome torácica aguda -2.0

Outro - 3.0

4.41) Especifique outra razão para a transfusão na inserção de cateter venoso (separe por ; as outras razões para a transfusão): Pergunta Texto

Nome da variável: F2M4_41_incatx_o

Número máximo de caracteres permitido: 100

4.42) O paciente tem histórico de remoção de cateter venoso permanente no período de acompanhamento 2 ?

Pergunta Alternativa Seleção Única

Nome da variável: F2M4_42_ocat

Alternativas: (descrição - score)

Sim - 1.0

Não - 2.0

4.43) Data da remoção de cateter venoso:

Pergunta Data

Nome da variável: F2M4_43_d_ocat

Intervalo permitido: 01/01/2013 - 31/12/2017

4.44) Houve transfusão pré-operatória antes da cirurgia para evitar complicações na remoção de cateter venoso? Pergunta Alternativa Seleção Única

Nome da variável: F2M4_44_ocat_ptx

Alternativas: (descrição - score)

Sim - 1.0

Não - 2.0 


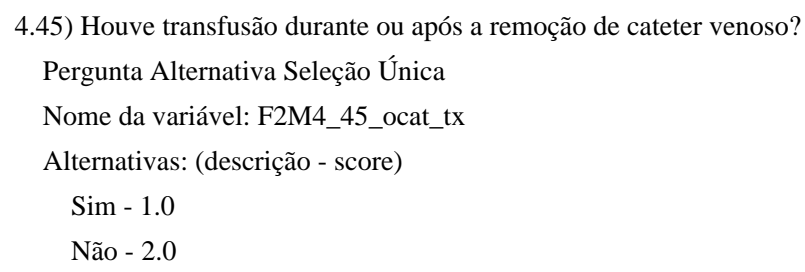

4.47) Especifique outra razão para a transfusão na remoção de cateter venoso (separe por ; as outras razões para a transfusão): Pergunta Texto

4.48) O paciente tem histórico de apendicectomia no período de acompanhamento 2 ? Pergunta Alternativa Seleção Única Nome da variável: F2M4_48_ap Alternativas: (descrição - score)

Sim -1.0

Não - 2.0

4.49) Data da apendicectomia:

Pergunta Data

Nome da variável: F2M4_49_d_ap

Intervalo permitido: 01/01/2013 - 31/12/2017

4.50) Houve transfusão pré-operatória antes da cirurgia para evitar complicações na apendicectomia? Pergunta Alternativa Seleção Única Nome da variável: F2M4_50_ap_ptx Alternativas: (descrição - score)

Sim - 1.0

Não - 2.0

4.51) Houve transfusão durante ou após a apendicectomia? Pergunta Alternativa Seleção Única Nome da variável: F2M4_51_ap_tx Alternativas: (descrição - score)

Sim - 1.0

Não - 2.0 


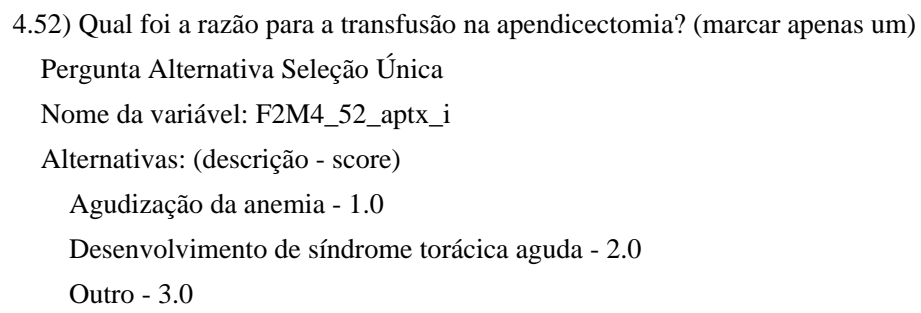

4.53) Especifique outra razão para a transfusão na apendicectomia (separe por ; as outras razões para a transfusão): Pergunta Texto

Nome da variável: F2M4_53_aptx_o

Número máximo de caracteres permitido: 100

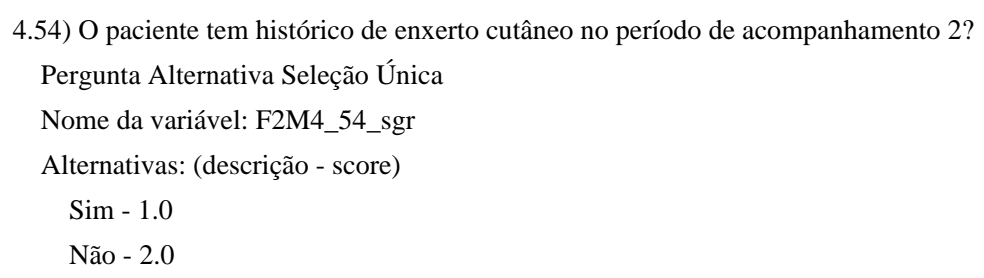

4.56) Houve transfusão pré-operatória antes da cirurgia para evitar complicações no enxerto cutâneo? Pergunta Alternativa Seleção Única Nome da variável: F2M4_56_sgr_ptx

Alternativas: (descrição - score)

Sim - 1.0

Não -2.0

4.57) Houve transfusão durante ou após o enxerto cutâneo?

Pergunta Alternativa Seleção Única

Nome da variável: F2M4_57_sgr_tx

Alternativas: (descrição - score)

Sim -1.0

Não - 2.0

4.58) Qual foi a razão para a transfusão no enxerto cutâneo? (marcar apenas um) Pergunta Alternativa Seleção Única

Nome da variável: F2M4_58_sgrtx_i

Alternativas: (descrição - score)

Agudização da anemia - 1.0

Desenvolvimento de síndrome torácica aguda - 2.0

Outro - 3.0 


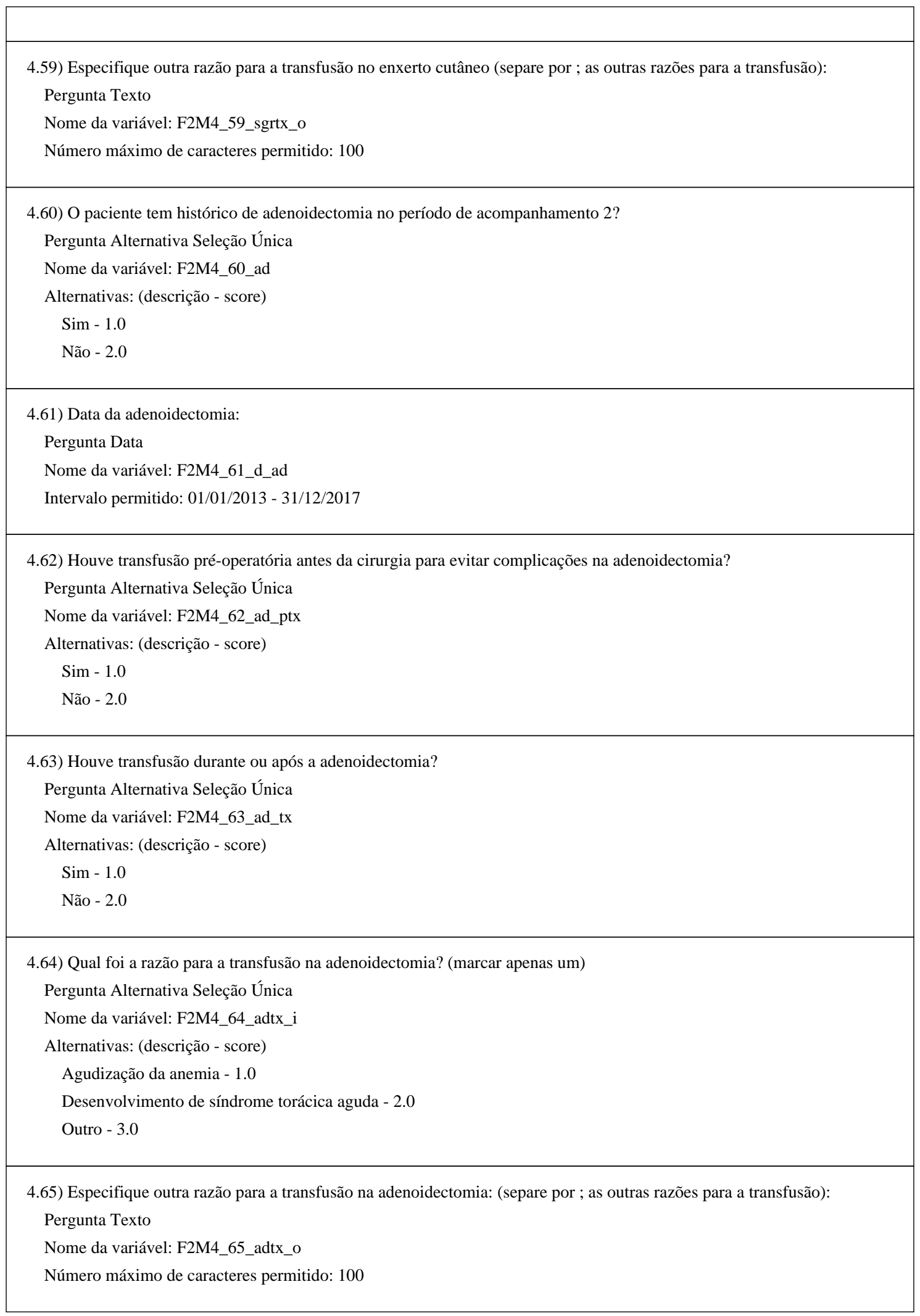




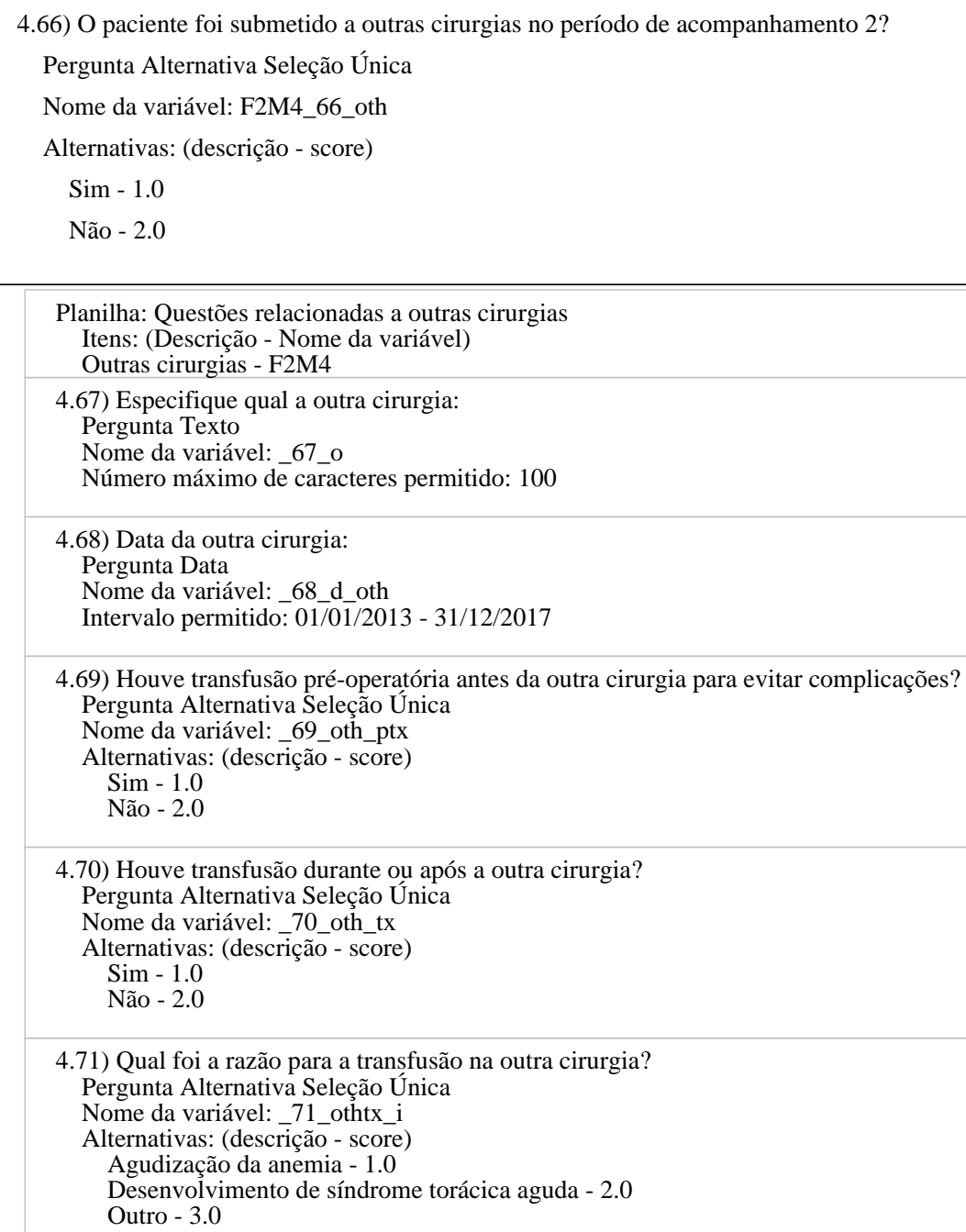

4.69) Houve transfusão pré-operatória antes da outra cirurgia para evitar complicações? Pergunta Alternativa Seleção Única

Nome da variável: _69_oth_ptx

Alternativas: (descrição - score)$$
\text { Sim - } 1.0
$$$$
\text { Não }-2.0
$$

4.70) Houve transfusão durante ou após a outra cirurgia?

Pergunta Alternativa Seleção Única

Nome da variável: _70_oth_tx

Alternativas: (descrição - score)

Sim -1.0

Não - 2.0

4.71) Qual foi a razão para a transfusão na outra cirurgia?

Pergunta Alternativa Seleção Única

Nome da variável: _71_othtx_i

Alternativas: (descrição - score)

Agudização da anemia - 1.0

Desenvolvimento de síndrome torácica aguda - 2.0

Outro - 3.0

4.72) Especifique outra razão para a transfusão na outra cirurgia (separe por ; as outras razões para a transfusão) Pergunta Texto

Nome da variável:_72_othtx_o

Número máximo de caracteres permitido: 100

\section{Módulo: 5 - Transplantes de Medula Óssea}

5.1) O paciente recebeu transplante de Medula Óssea no período de acompanhamento 2?

Pergunta Alternativa Seleção Única

Nome da variável: F2M5_1_sct

Alternativas: (descrição - score)

Sim - 1.0

Não - 2.0

5.2) Quantos transplantes de medula óssea?

Pergunta Número Inteiro

Nome da variável: F2M5_2_n_sct 
Intervalo permitido: 1 - 20

5.3) Data do transplante de medula óssea:

Pergunta Data

Nome da variável: F2M5_3_d_sct

Intervalo permitido: 01/01/2013 - 31/12/2017

5.4) Indicações para o transplante de medula óssea: (marque todas as opções que se aplicam)

Pergunta Alternativa Seleção Múltipla

Nome da variável: F2M5_4_sct_

Alternativas: (descrição - nome da variável - score)

Doppler transcraniano anormal - i_tcd - 1.0

Historia de acidente vascular cerebral - i_cva - 2.0

Dor recorrente grave - i_voe - 3.0

Síndrome torácica aguda recorrente - i_acs -4.0

Outra - i_oth - 100.0

5.5) Especifique outra indicação para o transplante de medula óssea (separe por ; as outras indicações para o transplante):

Pergunta Texto

Nome da variável: F2M5_5_sct_o

Número máximo de caracteres permitido: 100

5.6) Instituição em que ocorreu o transplante de medula óssea:

Pergunta Texto

Nome da variável: F2M5_6_ins

Número máximo de caracteres permitido: 100

\section{7) Tipo de doador:}

Pergunta Alternativa Seleção Única

Nome da variável: F2M5_7_don

Alternativas: (descrição - score)

Irmão biológico $\quad-1.0$

Sem relação de consangüinidade $\quad-2.0$

Outro membro da família (não irmão) - 3.0

5.8) Tipo de doador HLA:

Pergunta Alternativa Seleção Única

Nome da variável: F2M5_8_hla

Alternativas: (descrição - score)

HLA compatível

HLA incompatível - 2.0

5.9) Fonte de células-tronco:

Pergunta Alternativa Seleção Única

Nome da variável: F2M5_9_sctype

Alternativas: (descrição - score) 
Medula óssea - 1.0

Sangue periférico - 2.0

Sangue do cordão umbilical - 3.0

\section{Módulo: 6 - Medicamentos}

6.1) O paciente fez uso de algum medicamento no período de acompanhamento 2? (O paciente deve estar utilizando o medicamento por, pelo menos, 30 dias)

Pergunta Alternativa Seleção Única

Nome da variável: F2M6_1_med

Alternativas: (descrição - score)

Sim -1.0

Não - 2.0

6.2) Selecione todos os medicamentos usados pelo paciente desde a sua inscrição no estudo: (marque todas as opções que se aplicam)

Pergunta Alternativa Seleção Múltipla

Nome da variável: F2M6_2

Alternativas: (descrição - nome da variável - score)

Algum antibiótico profilático regularmente - _abx - 1.0

Analgésicos por 30 dias seguidos ou mais - _pain - 2.0

Anticonvulsivantes para crises convulsivas - _aed_sz - 3.0

Anticonvulsivantes para dores neuropáticas - _aed_pain - 4.0

Antidepressivos - _dep - 5.0

Anti-hipertensivo - _htn - 6.0

Bronco dilatador inalável - _inh - 7.0

Deferasirox - _exj - 8.0

Deferiprona - _11 - 9.0

Desferoxamina - _des - 10.0

Eritropoietina - _epo - 11.0

Hidroxiuréia - _ hu - 12.0

IECA - Inibidor da Enzima catalizadora da angiotensina - _ace - 13.0

Oxigênio domiciliar - _o2 - 14.0

Varfarina - _war - 15.0

Vitamina D - _vitd - 16.0

Outro(s) medicamento(s) - _oth - 200.0

6.3) Especifique qual o outro medicamentos (separe por ; os outros medicamentos)

Pergunta Texto

Nome da variável: F2M6_3_o

Número máximo de caracteres permitido: 100

Módulo: 7 - Testes de diagnóstico 
7.1) O paciente realizou exame doppler transcraniano no período de acompanhamento 2 ?

Pergunta Alternativa Seleção Única

Nome da variável: F2M7_1_tcd

Alternativas: (descrição - score)

Sim - 1.0

Não - 2.0

Planilha: Questões relacionadas ao doppler transcraniano

Itens: (Descrição - Nome da variável)

Doppler transcraniano - F2M7

7.2) Data do doppler transcraniano:

Pergunta Data

Nome da variável:_2_d_tcd

Intervalo permitido: $01 / 01 / 2013$ - 31/12/2017

7.3) Artéria cerebral média esquerda:

Pergunta Número Inteiro

Nome da variável:_3_lmca

Intervalo permitido: $0-400$

7.4) Artéria cerebral média direita:

Pergunta Número Inteiro

Nome da variável:_4_rmca

Intervalo permitido: 0 - 400

7.5) Distal da carótida interna esquerda:

Pergunta Número Inteiro

Nome da variável: _5_lica

Intervalo permitido: 0 - 400

7.6) Distal da carótida interna direita:

Pergunta Número Inteiro

Nome da variável: 6 rica

Intervalo permitido: $0-400$

7.7) Qual foi a classificação do resultado do Doppler?

Pergunta Alternativa Şeleção Única

Nome da variável: _7_tcd_r

Alternativas: (descriçãa - score)

Normal - 1.0

Condiconal - 2.0

Alterado - 3.0

7.8) Artéria cerebral anterior esquerda:

Pergunta Número Inteiro

Nome da variável: 8_laca

Intervalo permitido: $0-400$

7.9) Artéria cerebral anterior direita:

Pergunta Número Inteiro

Nome da variável: _9_raca

Intervalo permitido: $0-400$

7.10) Artéria Cerebral Posterior segmento P1 esquerda (ACP-P1 e):

Pergunta Número Inteiro

Nome da variável: _10_lpca

Intervalo permitido: $0-400$

7.11) Artéria Cerebral Posterior segmento P1 direita (ACP-P1 d):

Pergunta Número Inteiro

Nome da variável: _11_rpca

Intervalo permitido: 0 - 400 
7.12) Vertebrais esquerdas:

Pergunta Número Inteiro

Nome da variável: 12

Intervalo permitido: 0 - 400

7.13) Vertebrais direita:

Pergunta Número Inteiro

Nome da variável: _13_rv

Intervalo permitido: 0 - 400

7.14) Basilar proximal:

Pergunta Número Inteiro

Nome da variável: _14_rpb

Intervalo permitido: $0-400$

7.15) O paciente realizou exame ressonância magnética craniana ou tomografia computadorizada no período de acompanhamento 2 ?

Pergunta Alternativa Seleção Única

Nome da variável: F2M7_15_mri

Alternativas: (descrição - score)

Sim - 1.0

Não - 2.0

7.16) Data MRI/TC mais recente:

Pergunta Data

Nome da variável: F2M7_16_d_mri

Intervalo permitido: 01/01/2013 - 31/12/2017

7.17) Registre o resultado mais recente da MRI/TC:

Pergunta Alternativa Seleção Única

Nome da variável: F2M7_17_mri_r

Alternativas: (descrição - score)

Dentro da normalidade - 1.0

Inconclusivo - 2.0

Alterado - 3.0

7.18) A RMI evidenciou moya-moya?

Pergunta Alternativa Seleção Única

Nome da variável: F2M7_18_mri_moya

Alternativas: (descrição - score)

Sim - 1.0

Não - 2.0

7.19) A RMI evidenciou acidente vascular cerebral - Infarto Cerebral Silencioso?

Pergunta Alternativa Seleção Única

Nome da variável: F2M7_19_mri_stroke

Alternativas: (descrição - score)

Sim - 1.0

Não - 2.0

7.20) Alguma outra anormalidade identificada na RMI/TC: 
Pergunta Alternativa Seleção Única

Nome da variável: F2M7_20_mri_abn

Alternativas: (descrição - score)

Sim -1.0

Não - 2.0

7.21) Descreva as outras anormalidades encontradas na RMI/TC:

Pergunta Texto

Nome da variável: F2M7_21_mri_o

Número máximo de caracteres permitido: 100

7.22) O paciente realizou exame ecocardiograma no período de acompanhamento 2 ?

Pergunta Alternativa Seleção Única

Nome da variável: F2M7_22_echo

Alternativas: (descrição - score)

Sim -1.0

Não -2.0

Planilha: Questões relacionadas ao Ecocardiograma

Itens: (Descrição - Nome da variável)

Ecocardiograma: - F2M7

7.23) Data do Ecocardiograma:

Pergunta Data

Nome da variável:_23_d_echo

Intervalo permitido: $01 / 01 / 2013$ - 31/12/2017

7.24) O Ecocardiograma foi feito durante estado estável / basal?

Pergunta Alternativa Seleção Única

Nome da variável:_24_echo_ss

Alternativas: (descrição - score)

Sim -1.0

Não - 2.0

7.25) Registre o resultado do ecoçardiograma:

Pergunta Alternativa Seleção Única

Nome da variável: _25_echo_r

Alternativas: (descrição - score)

Dentro da normalidade -1.0

Inconclusivo - 2.0

Alterado - 3.0

7.26) Registre a alteração do Ecocardiograma : (marque todas as opções que se aplicam)

Pergunta Alternativa Seleção Múltipla

Nome da variável: _26_echo_abn

Alternativas: (descrição - nome da variável - score)

Estenose mitral Mitral - _ ms - 1.0

Regurgitação mitral - _m $\overline{\mathrm{r}}-2.0$

Estenose tricúspide - ts - 3.0

Insuficiência tricúspide - - tr - 4.0

Estenose aórtica - _as - 5.0

Regurgitação aórtica - _ ar - 6.0

Estenose pulmonar - _ps - 7.0

Regurgitação pulmonar - _pr - 8.0

Cardiomiopatia dilatada - $\_$dc $\quad-9.0$

Cardiomiopatia Hipertrófica - _ hc - 10.0

Outro - o - 100.0

7.27) Especifique qual a outra alteração do ecocardiograma (separe por ; as outras alterações):

Pergunta Texto

Nome da variável:_27_echo_o

Número máximo de caracteres permitido: 100 
7.28) Registre a velocidade do jato da tricúspide:

Pergunta Número Decimal

Nome da variável: 28 tjv

Intervalo permitido: $1.0-5.0$

7.29) Registre a fração de ejeção do ventrículo esquerdo:

Pergunta Número Decimal

Nome da variável: _29_ef

Intervalo permitido: 0.0 - 100.0

7.30) Registre a pressão media da artéria pulmonar:

Pergunta Número Inteiro

Nome da variável: _30_mpa_e

Intervalo permitido: 5 - 170

7.31) Registre a pressão sistólica da artéria pulmonar:

Pergunta Número Inteiro

Nome da variável:_31_spa_e

Intervalo permitido: $5-200$

7.32) Registre a pressão diastólica da artéria pulmonar:

Pergunta Número Inteiro

Nome da variável:_32_dpa_e

Intervalo permitido: $1-100$

7.33) O paciente realizou cateterismo cardíaco no período de acompanhamento 2 :

Pergunta Alternativa Seleção Única

Nome da variável: F2M7_33_cat

Alternativas: (descrição - score)

Sim -1.0

Não -2.0

Planilha: Questões relacionadas ao Cateterismo Cardíaco

Itens: (Descrição - Nome da variável)

Cateterismo cardíaco - F2M7

7.34) Data do cateterismo

Pergunta Data

Nome da variável: _34_d_cat

Intervalo permitido: 01/01/2013 - 31/12/2017

7.35) O cateterismo foi feito durante estado estável / basal?

Pergunta Alternativa Seleção Única

Nome da variável: _35_cat_ss

Alternativas: (descrição - score)

Sim - 1.0

Não -2.0

7.36) Pressão arterial pulmonar foi medida no cateterismo?

Pergunta Alternativa Seleção Única

Nome da variável: _36_cat_pa

Alternativas: (descrição - score)

Sim - 1.0

Não -2.0

7.37) Pressão arterial pulmonar média no cateterismo

Pergunta Número Decimal

Nome da variável:_37_cat_mpa

Intervalo permitido: $5 . \overline{0}-1 \overline{7} 0.0$

7.38) Pressão arterial pulmonar sistólica no cateterismo:

Pergunta Número Decimal

Nome da variável:_38_cat_spa

Intervalo permitido: 5.0 - 200.0 
7.39) Pressão arterial pulmonar diastólica no cateterismo:

Pergunta Número Decimal

Nome da variável:_39_cat_dpa

Intervalo permitido: $1 . \overline{0}-100.0$

7.40) Resistência vascular pulmonar no cateterismo

Pergunta Número Decimal

Nome da variável: _40_cat_pvr

Intervalo permitido: $0 . \overline{0}-20.0$

7.41) Pressão média de oclusão da artéria pulmonar (pressão ventricular esquerda e diastólica) no cateterismo: Pergunta Número Decimal

Nome da variável:_41_cat_mpawp

Intervalo permitido: $1.0-30.0$

7.42) O paciente realizou teste de função pulmonar no período de acompanhamento 2 ?

Pergunta Alternativa Seleção Única

Nome da variável: F2M7_42_pft

Alternativas: (descrição - score)

Sim -1.0

Não - 2.0

7.43) Data da função pulmonar mais recente:

Pergunta Data

Nome da variável: F2M7_43_d_pft

Intervalo permitido: 01/01/2013 - 31/12/2017

7.44) Registre o resultado mais recente da função pulmonar:

Pergunta Alternativa Seleção Única

Nome da variável: F2M7_44_pft_r

Alternativas: (descrição - score)

Dentro da normalidade - 1.0

Inconclusivo - 2.0

Alterado - 3.0

7.45) O teste de função pulmonar diagnosticou doença pulmonar OBSTRUTIVA crônica?

Pergunta Alternativa Seleção Única

Nome da variável: F2M7_45_pft_copd

Alternativas: (descrição - score)

Sim - 1.0

Não - 2.0

7.46) O teste de função pulmonar diagnosticou doença pulmonar RESTRITIVA crônica?

Pergunta Alternativa Seleção Única

Nome da variável: F2M7_46_pft_crpd

Alternativas: (descrição - score)

Sim - 1.0

Não -2.0

7.47) Alguma outra anormalidade diagnosticada no teste de função pulmonar?

Pergunta Alternativa Seleção Única 
Nome da variável: F2M7_47_pft_o_abn

Alternativas: (descrição - score)

Sim -1.0

Não - 2.0

7.48) Descreva a alteração do teste de função pulmonar:

Pergunta Texto

Nome da variável: F2M7_48_pft_ab

Número máximo de caracteres permitido: 100

7.49) O paciente realizou urinálise no período de acompanhamento 2 ?

Pergunta Alternativa Seleção Única

Nome da variável: F2M7_49_ua

Alternativas: (descrição - score)

Sim - 1.0

Não - 2.0

7.50) Datada urinálise mais recente:

Pergunta Data

Nome da variável: F2M7_50_d_ua

Intervalo permitido: 01/01/2013 - 31/12/2017

7.51) Registre o resultado mais recente da urinálise:

Pergunta Alternativa Seleção Única

Nome da variável: F2M7_51_ua_r

Alternativas: (descrição - score)

Microalbuminúria (30-300mg / g de albumina na urina creatinina) - 1.0

Macroalbuminúria (> $300 \mathrm{mg} / \mathrm{g}-2 \mathrm{~g} / \mathrm{g}$ albumina na urina para creatinina) - 2.0

Proteinúria faixa nefrótica ( $>2 \mathrm{~g} / \mathrm{g}$ albumina na urina para creatinina) - 3.0

Normal (sem proteína) - 4.0

7.52) O paciente tem coleta de urina de 24 horas realizado no período de acompanhamento 2 ?

Pergunta Alternativa Seleção Única

Nome da variável: F2M7_52_24u

Alternativas: (descrição - score)

Sim -1.0

Não - 2.0

7.53) Data da coleta de urina de 24 horas mais recente

Pergunta Data

Nome da variável: F2M7_53_d_24u

Intervalo permitido: 01/01/2013 - 31/12/2017

7.54) Registre o resultado mais recente da coleta de urina de 24 horas:

Pergunta Número Decimal

Nome da variável: F2M7_54_24u_r 
Intervalo permitido: 0.0 - 5000.0

\author{
Módulo: 8 - Resultados Sorológicos \\ 8.1) O paciente realizou teste para Sífilis no período de acompanhamento 2 ? \\ Pergunta Alternativa Seleção Única \\ Nome da variável: F2M8_1_syp \\ Alternativas: (descrição - score) \\ Sim -1.0 \\ Não -2.0 \\ 8.2) Resultado mais recente do Elisa para sífilis: \\ Pergunta Alternativa Seleção Única \\ Nome da variável: F2M8_2_syp_r \\ Alternativas: (descrição - score) \\ Positivo - 1.0 \\ Negativo - 2.0 \\ Indeterminado - 3.0 \\ Não realizado -4.0
}

8.3) Data do Elisa para sífilis mais recente:

Pergunta Data

Nome da variável: F2M8_3_d_syp

Intervalo permitido: 01/01/2013 - 31/12/2017

8.4) Resultado mais recente do VDRL:

Pergunta Alternativa Seleção Única

Nome da variável: F2M8_4_vdrl

Alternativas: (descrição - score)

Positivo - 1.0

Negativo - 2.0

Indeterminado - 3.0

Não realizado - 4.0

8.5) Data do VDRL para sífilis mais recente:

Pergunta Data

Nome da variável: F2M8_5_d_vdrl

Intervalo permitido: 01/01/2013 - 31/12/2017

8.6) O paciente realizou teste para Hepatite no período de acompanhamento 2?

Pergunta Alternativa Seleção Única

Nome da variável: F2M8_6_hep

Alternativas: (descrição - score)

Sim -1.0

Não -2.0 


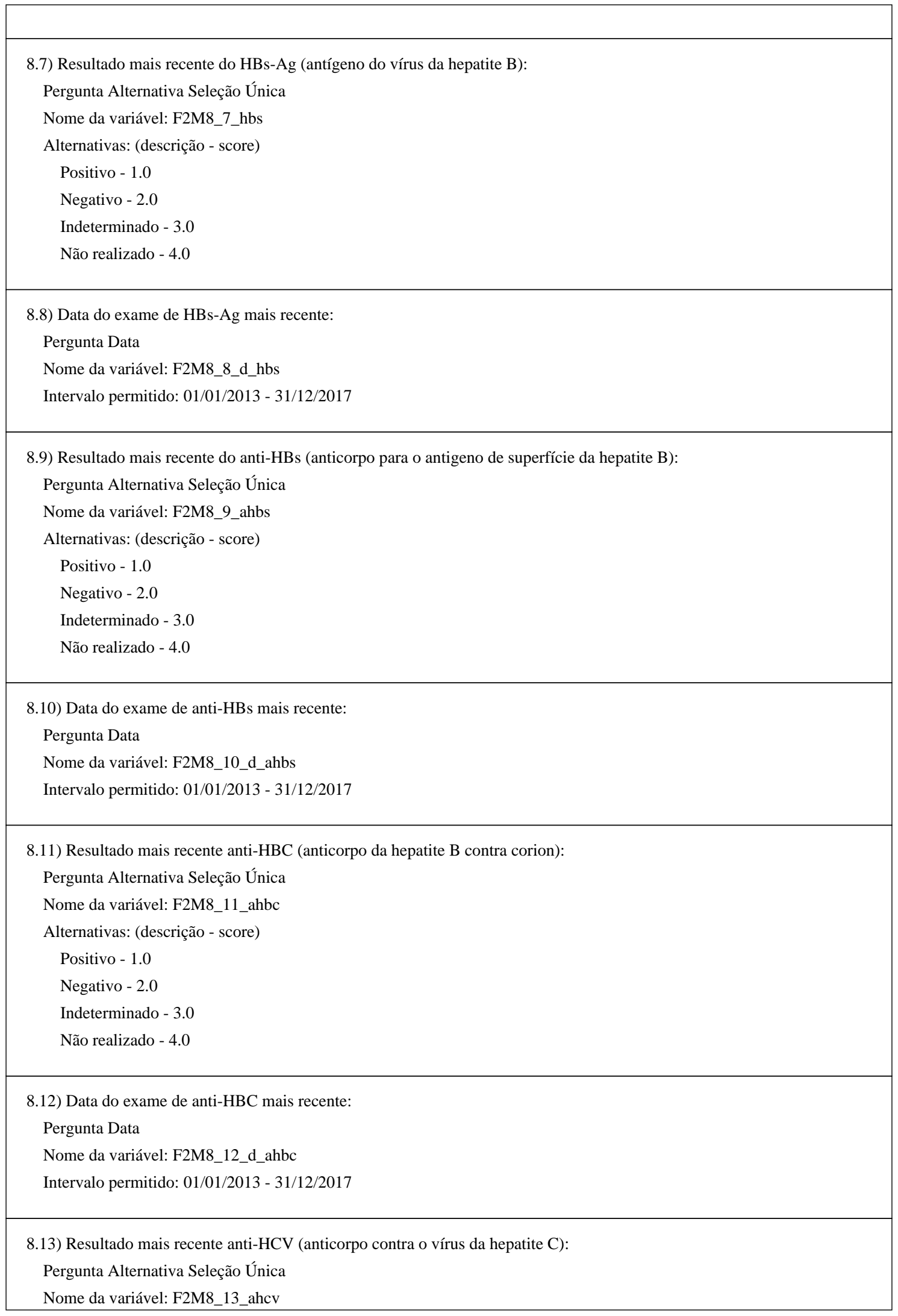


Alternativas: (descrição - score)

Positivo - 1.0

Negativo - 2.0

Indeterminado - 3.0

Não realizado - 4.0

8.14) Data do exame de anti-HCV mais recente:

Pergunta Data

Nome da variável: F2M8_14_d_ahcv

Intervalo permitido: 01/01/2013 - 31/12/2017

8.15) Resultado mais recente NAT HCV :

Pergunta Alternativa Seleção Única

Nome da variável: F2M8_15_nat

Alternativas: (descrição - score)

Positivo - 1.0

Negativo - 2.0

Indeterminado - 3.0

Não realizado - 4.0

8.16) Data do NAT para HCV mais recente:

\section{Pergunta Data}

Nome da variável: F2M8_16_d_nat

Intervalo permitido: 01/01/2013 - 31/12/2017

8.17) O paciente realizou teste para Chagas no período de acompanhamento 2 ?

Pergunta Alternativa Seleção Única

Nome da variável: F2M8_17_cha

Alternativas: (descrição - score)

Sim -1.0

Não - 2.0

8.18) Resultado mais recente ELISA para Chagas:

Pergunta Alternativa Seleção Única

Nome da variável: F2M8_18_cha_r

Alternativas: (descrição - score)

Positivo - 1.0

Negativo - 2.0

Indeterminado - 3.0

8.19) Data do Elisa para Chagas mais recente:

Pergunta Data

Nome da variável: F2M8_19_d_cha

Intervalo permitido: 01/01/2013 - 31/12/2017

8.20) O paciente realizou teste para HIV no período de acompanhamento 2? 
Pergunta Alternativa Seleção Única

Nome da variável: F2M8_20_hiv

Alternativas: (descrição - score)

Sim - 1.0

Não - 2.0

8.21) Resultado mais recente do primeiro ELISA para HIV:

Pergunta Alternativa Seleção Única

Nome da variável: F2M8_21_hiv_e1

Alternativas: (descrição - score)

Positivo - 1.0

Negativo -2.0

Indeterminado - 3.0

Não realizado - 4.0

8.22) Data do primeiro Elisa para HIV mais recente:

Pergunta Data

Nome da variável: F2M8_22_d_hive1

Intervalo permitido: 01/01/2013 - 31/12/2017

8.23) Resultado mais recente do segundo ELISA:

Pergunta Alternativa Seleção Única

Nome da variável: F2M8_23_hiv_e2

Alternativas: (descrição - score)

Positivo - 1.0

Negativo - 2.0

Indeterminado - 3.0

Não realizado - 4.0

8.24) Data do segundo Elisa para HIV mais recente:

Pergunta Data

Nome da variável: F2M8_24_d_hive2

Intervalo permitido: 01/01/2013 - 31/12/2017

\subsection{5) Resultado mais recente do Western Blot:}

Pergunta Alternativa Seleção Única

Nome da variável: F2M8_25_hivwb

Alternativas: (descrição - score)

Positivo - 1.0

Negativo - 2.0

Indeterminado - 3.0

Não realizado - 4.0

8.26) Data do Western Blot para HIV mais recente:

Pergunta Data

Nome da variável: F2M8_26_d_hivwb 
Intervalo permitido: 01/01/2013 - 31/12/2017

8.27) O paciente realizou teste para HTLV no período de acompanhamento 2?

Pergunta Alternativa Seleção Única

Nome da variável: F2M8_27_htlv

Alternativas: (descrição - score)

Sim -1.0

Não - 2.0

8.28) Resultado mais recente do ELISA para HTLV:

Pergunta Alternativa Seleção Única

Nome da variável: F2M8_28_htlv_r

Alternativas: (descrição - score)

Positivo - 1.0

Negativo - 2.0

Indeterminado - 3.0

8.29) Data do Elisa para HTLV mais recente:

Pergunta Data

Nome da variável: F2M8_29_d_htlv

Intervalo permitido: 01/01/2013 - 31/12/2017

8.30) Resultado mais recente WB HTLV:

Pergunta Alternativa Seleção Única

Nome da variável: F2M8_30_htlvwb

Alternativas: (descrição - score)

Positivo - 1.0

Negativo - 2.0

Indeterminado - 3.0

Não realizado - 4.0

8.31) WB mais recente positivo para:

Pergunta Alternativa Seleção Única

Nome da variável: F2M8_31_htlvwb_r

Alternativas: (descrição - score)

HTLV I - 1.0

HTLV II - 2.0

HTLV I/II - 3.0

HTLV não tipado - 4.0

8.32) Data do Western blot para HTLV mais recente:

Pergunta Data

Nome da variável: F2M8_32_d_htlvwb

Intervalo permitido: 01/01/2013 - 31/12/2017 


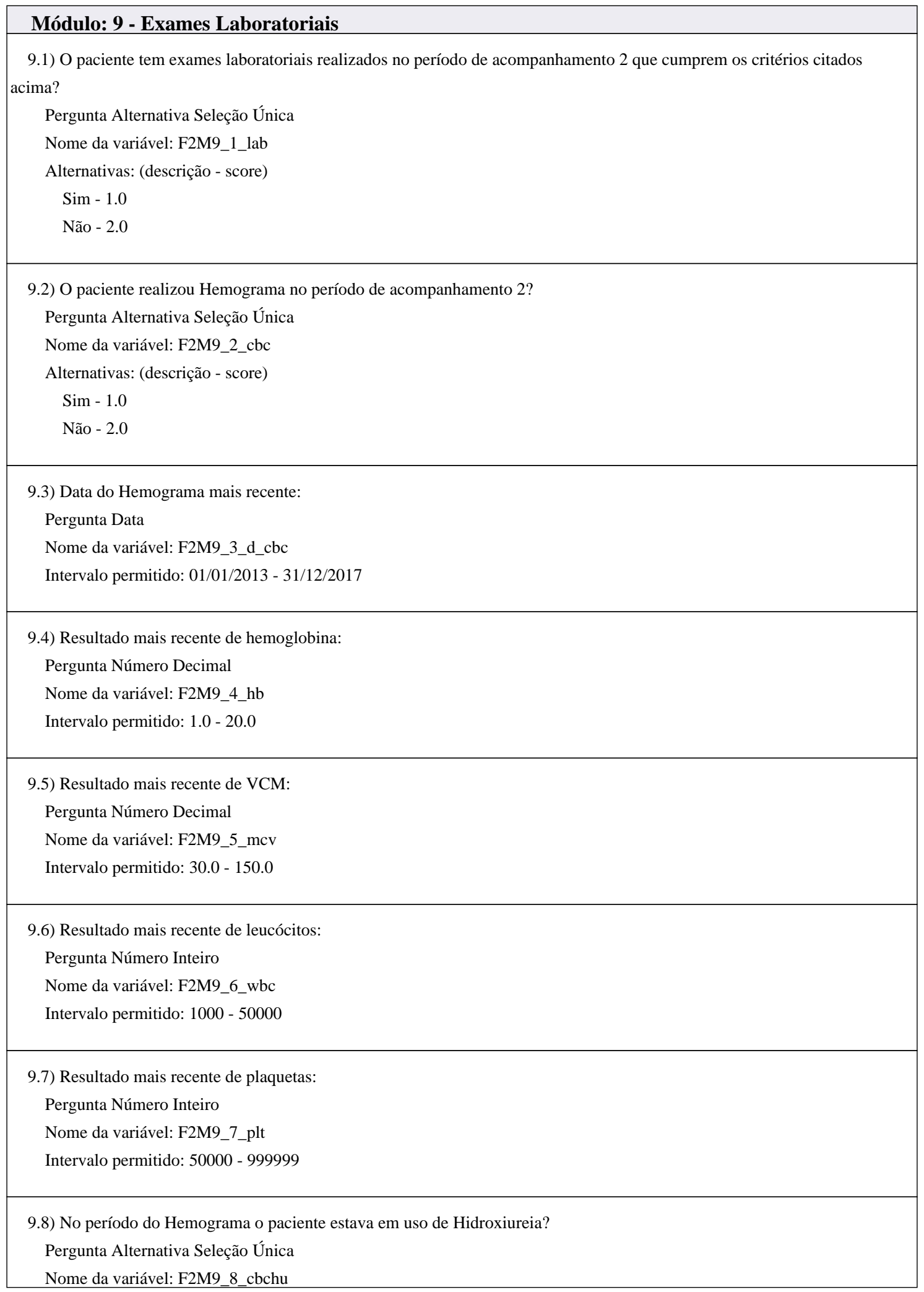


Nome da variável: F2M9_8_cbchu

Alternativas: (descrição - score)

Sim -1.0

Não - 2.0

9.9) No período do Hemograma o paciente estava em tratamento com transfusão crônica?

Pergunta Alternativa Seleção Única

Nome da variável: F2M9_9_cbctx

Alternativas: (descrição - score)

Sim -1.0

Não - 2.0

9.10) O paciente realizou exame de reticulócitos (contagem relativa) no período de acompanhamento 2 ? Pergunta Alternativa Seleção Única

Nome da variável: F2M9_10_ret

Alternativas: (descrição - score)

Sim - 1.0

Não -2.0

9.11) Data do exame de reticulócitos mais recente:

Pergunta Data

Nome da variável: F2M9_11_d_ret

Intervalo permitido: 01/01/2013 - 31/12/2017

9.12) Resultado mais recente de reticulócitos (contagem relativa):

Pergunta Número Decimal

Nome da variável: F2M9_12_ret_r

Intervalo permitido: $0.01-100.0$

9.13) No período do exame de reticulócitos o paciente estava em uso de Hidroxiureia?

Pergunta Alternativa Seleção Única

Nome da variável: F2M9_13_rethu

Alternativas: (descrição - score)

Sim -1.0

Não - 2.0

9.14) No período do exame de reticulócitos o paciente estava em tratamento com transfusão crônica? Pergunta Alternativa Seleção Única

Nome da variável: F2M9_14_retx

Alternativas: (descrição - score)

Sim -0.0

Não - 0.0

9.15) O paciente realizou exame de hemoglobina $\mathrm{F}$ no período de acompanhamento 2 ?

Pergunta Alternativa Seleção Única

Nome da variável: F2M9_15 hbf 
Alternativas: (descrição - score)

Sim -1.0

Não - 2.0

9.16) Data do exame de hemoglobina F mais recente:

Pergunta Data

Nome da variável: F2M9_16_d_hbf

Intervalo permitido: 01/01/2013 - 31/12/2017

9.17) Resultado mais recente de hemoglobina F:

Pergunta Número Decimal

Nome da variável: F2M9_17_hbf_r

Intervalo permitido: $0.01-100.0$

9.18) No período do exame de hemoglobina F o paciente estava em uso de Hidroxiureia?

Pergunta Alternativa Seleção Única

Nome da variável: F2M9_18_hbfhu

Alternativas: (descrição - score)

Sim -1.0

Não - 2.0

9.19) No período do exame de hemoglobina $\mathrm{F}$ o paciente estava em tratamento com transfusão crônica?

Pergunta Alternativa Seleção Única

Nome da variável: F2M9_19_hbftx

Alternativas: (descrição - score)

Sim - 1.0

Não - 2.0

9.20) O paciente realizou exame de desidrogenase láctica no período de acompanhamento 2 ?

Pergunta Alternativa Seleção Única

Nome da variável: F2M9_20_ldh

Alternativas: (descrição - score)

Sim - 1.0

Não - 2.0

9.21) Data do exame de desidrogenase láctica mais recente:

Pergunta Data

Nome da variável: F2M9_21_d_ldh

Intervalo permitido: 01/01/2013 - 31/12/2017

9.22) Resultado mais recente de desidrogenase láctica:

Pergunta Número Inteiro

Nome da variável: F2M9_22_ldh_r

Intervalo permitido: 0 - 9000 


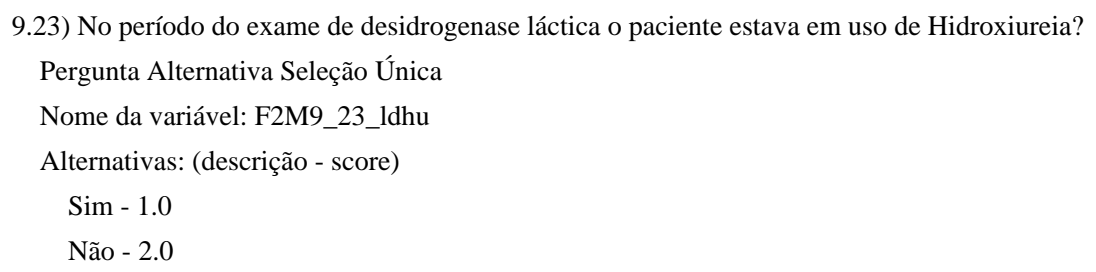

9.24) No período do exame de desidrogenase láctica o paciente estava em tratamento com transfusão crônica? Pergunta Alternativa Seleção Única Nome da variável: F2M9_24_ldhtx

Alternativas: (descrição - score)

Sim -1.0

Não -2.0

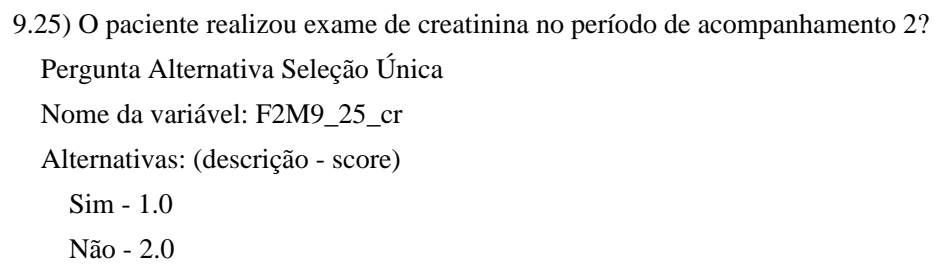

9.27) Resultado mais recente de creatinina:

Pergunta Número Decimal

Nome da variável: F2M9_27_cr_r

Intervalo permitido: $0.01-15.0$

9.28) No período do exame de creatinina o paciente estava em uso de Hidroxiureia?

Pergunta Alternativa Seleção Única

Nome da variável: F2M9_28_crhu

Alternativas: (descrição - score)

Sim -1.0

Não - 2.0

9.29) No período do exame de creatinina o paciente estava em tratamento com transfusão crônica? Pergunta Alternativa Seleção Única

Nome da variável: F2M9_29_crtx

Alternativas: (descrição - score)

Sim - 1.0

Não - 2.0 
Pergunta Alternativa Seleção Única

Nome da variável: F2M9_30_tb

Alternativas: (descrição - score)

Sim -1.0

Não -2.0

9.31) Data da bilirrubina total mais recente:

Pergunta Data

Nome da variável: F2M9_31_d_tb

Intervalo permitido: 01/01/2013 - 31/12/2017

\author{
9.32) Resultado mais recente da bilirrubina total: \\ Pergunta Número Decimal \\ Nome da variável: F2M9_32_tb_r \\ Intervalo permitido: $0.1-50.0$
}

9.33) No período do exame bilirrubina total o paciente estava em uso de Hidroxiureia?

Pergunta Alternativa Seleção Única

Nome da variável: F2M9_33_tbhu

Alternativas: (descrição - score)

Sim -1.0

Não - 2.0

9.34) No período do exame bilirrubina total o paciente estava em tratamento com transfusão crônica?

Pergunta Alternativa Seleção Única

Nome da variável: F2M9_34_tbtx

Alternativas: (descrição - score)

Sim -1.0

Não -2.0

9.35) O paciente realizou exame bilirrubina direta no período de acompanhamento 2 ?

Pergunta Alternativa Seleção Única

Nome da variável: F2M9_35_db

Alternativas: (descrição - score)

Sim -1.0

Não - 2.0

9.36) Data da bilirrubina direta mais recente:

\title{
Pergunta Data
}

Nome da variável: F2M9_36_d_db

Intervalo permitido: 01/01/2013 - 31/12/2017

9.37) Resultado mais recente da bilirrubina direta:

Pergunta Número Decimal

Nome da variável: F2M9_37_db_r

Intervalo permitido: 0.01 - 99.0 


\begin{tabular}{|l|}
\hline \\
\hline 9.38) No período do exame da bilirrubina direta o paciente estava em uso de Hidroxiureia? \\
Pergunta Alternativa Seleção Única \\
Nome da variável: F2M9_38_dbhu \\
Alternativas: (descrição - score) \\
Sim - 1.0 \\
Não - 2.0 \\
\hline 9.39) No período do exame da bilirrubina direta o paciente estava em tratamento com transfusão crônica? \\
Pergunta Alternativa Seleção Única \\
Nome da variável: F2M9_39_dbtx \\
Alternativas: (descrição - score) \\
Sim - 1.0 \\
Não - 2.0
\end{tabular}

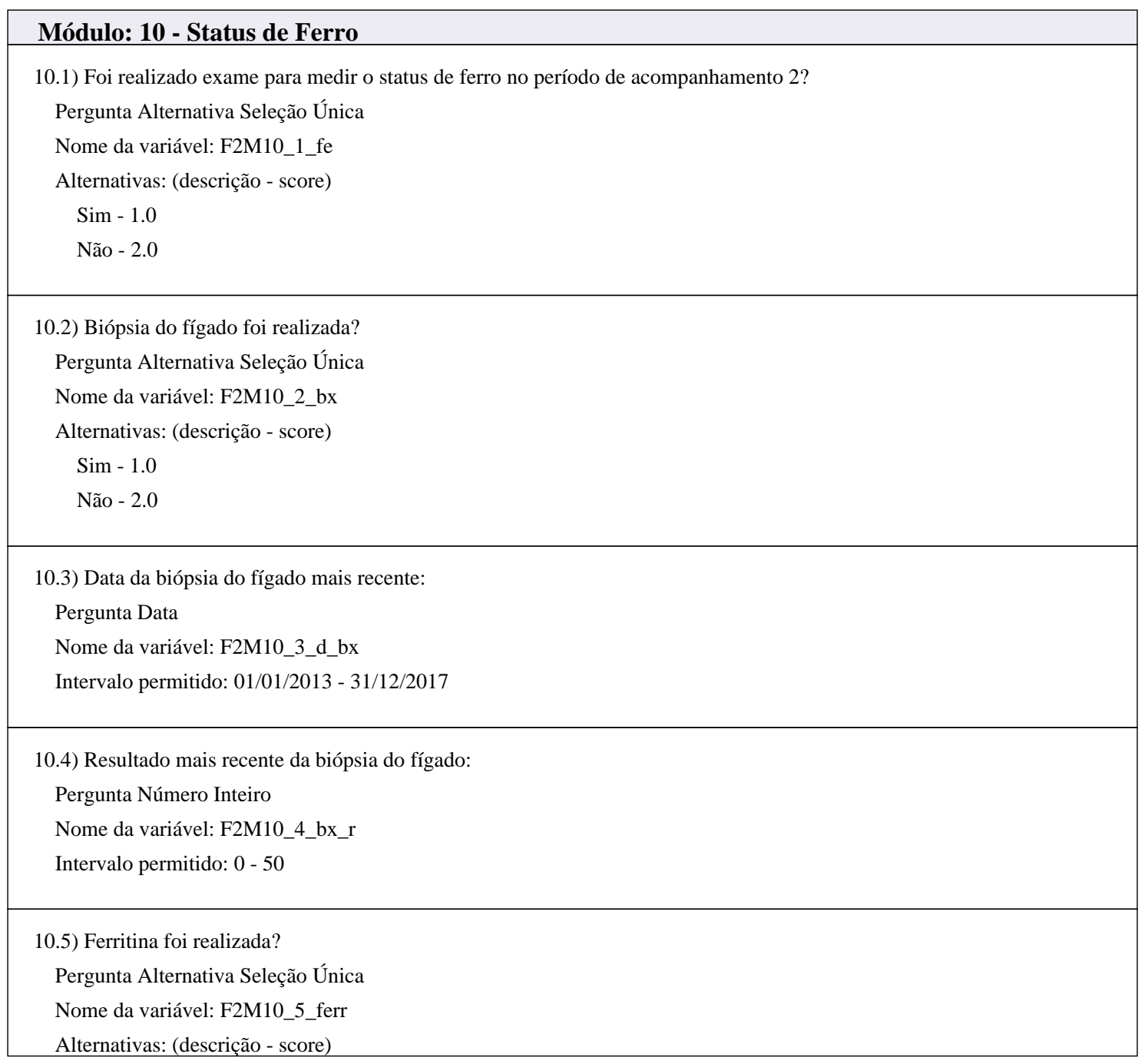


Alternativas: (descrição - score)

Sim - 1.0

Não - 2.0

10.6) Data da ferritina mais recente:

Pergunta Data

Nome da variável: F2M10_6_d_ferr

Intervalo permitido: 01/01/2013 - 31/12/2017

10.7) Resultado mais recente da ferritina:

Pergunta Número Decimal

Nome da variável: F2M10_7_ferr_r

Intervalo permitido: 0.0 - 99999.0

10.8) Ressonância magnética para medir o status do ferro foi realizada?

Pergunta Alternativa Seleção Única

Nome da variável: F2M10_8_mri

Alternativas: (descrição - score)

Sim -1.0

Não - 2.0

10.9) Data da ressonância magnética para medir o status do ferro mais recente:

Pergunta Data

Nome da variável: F2M10_9_d_mri

Intervalo permitido: 01/01/2013 - 31/12/2017

10.10) Resultado mais recente ressonância magnética ferro hepático:

Pergunta Número Decimal

Nome da variável: F2M10_10_mri_lr

Intervalo permitido: $0.0-50.0$

10.11) Resultado mais recente ressonância magnética ferro cardíaco:

Pergunta Número Decimal

Nome da variável: F2M10_11_mri_cr

Intervalo permitido: $0.0-100.0$

10.12) Índice de saturação de transferrina foi realizada?

Pergunta Alternativa Seleção Única

Nome da variável: F2M10_12_tran

Alternativas: (descrição - score)

Sim -1.0

Não - 2.0

10.13) Data do índice de saturação de transferrina mais recente:

Pergunta Data

Nome da variável: F2M10_13_d_tran 
Nome da variável: F2M10_13_d_tran

Intervalo permitido: 01/01/2013 - 31/12/2017

10.14) Resultado mais recente do índice de saturação de transferrina:

Pergunta Número Decimal

Nome da variável: F2M10_14_tran_r

Intervalo permitido: 0.0 - 100.0

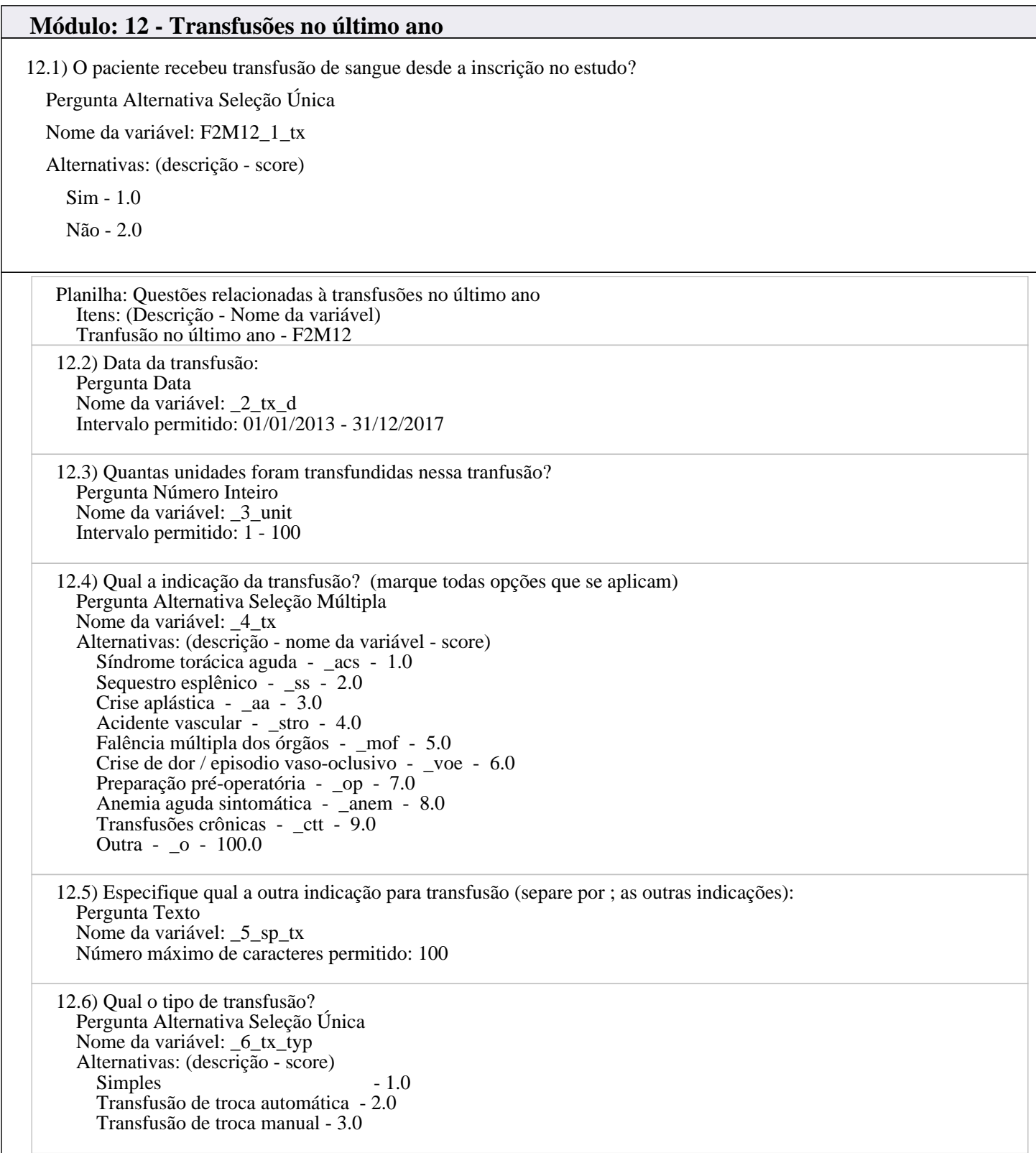


12.7) Houve reações associada a transfusão? (marque todas opções que se aplicam)

Pergunta Alternativa Seleção Múltipla

Nome da variável: 7 rx

Alternativas: (descrição - nome da variável - score)

Sem reação associada

Reação febril não hemolítica - _ fnhtr - 2.0

Reação Séptica - sep - 3.0

TRALI - lesão pulmonar aguda relacionada à transfusão - trali - 4.0

SCAT(Sobrecarga circulatória associada a transfusão) - _taco - 5.0

Reação transfusional hemolítica aguda - _ahtr - 6.0

Reação alérgica - _allg - 100.0

12.8) Tipo de reação alérgica:

Pergunta Alternativa Seleção Múltipla

Nome da variável:_8_alg

Alternativas: (descrição - nome da variável - score)

Urticária - _ur - 1.0

Dificuldade respiratória ou hipertensão - rsp - 2.0

\section{Módulo: 13 - Dados da bolsa/doador}

13) Todos os dados imunológicos da bolsa recebida pelo paciente podem ser extraídos do sistema eletrônico do hemocentro? Pergunta Alternativa Seleção Única

Nome da variável: F2M13_ext

Alternativas: (descrição - score)

Sim -1.0

Não - 2.0

não recebeu transfusão nos últimos 12 meses / nunca recebeu transfusão - 3.0

Planilha: Questões relacionadas a dados da bolsa

Itens: (Descrição - Nome da variável)

Dados da bolsa - F2M13

13.1) Data da transfusão desta bolsa:

Pergunta Data

Nome da variável: _1_d

Intervalo permitido: 01/01/2013 - 31/12/2017

13.2) Identificação da bolsa:

Pergunta Texto

Nome da variável: _2_id

Número máximo de caracteres permitido: 15

13.3) Código do componente desta bolsa: (concentrado de Hemácia $=\mathrm{CH}$ )

Pergunta Alternativa Seleção Única

Nome da variável: _3_cod

Alternativas: (descrição - score)

$\mathrm{CH}-1.0$

CHBVI - 2.0

CHD -3.0

CHDF - 4.0

CHDFI - 5.0

CHDFT - 6.0

CHDFTB - 7.0

CHDFTB $1-8.0$

CHF - 9.0

CHFI -10.0

CHI - 11.0

CHIL - 12.0

Outro - 100.0

13.4) Especifique o outro código do componente desta bolsa (separe por ; os componentes)

Pergunta Texto

Nome da variável:_4_sp_cod

Número máximo de caracteres permitido: 100 


\begin{tabular}{|c|}
\hline Módulo: 14 - Tratamentos - últimos 12 meses \\
\hline $\begin{array}{l}\text { 14.1) O paciente está ou esteve nos últimos } 12 \text { meses (período do acompanhamento 2) em terapia de transfusão crônica? } \\
\text { Pergunta Alternativa Seleção Única } \\
\text { Nome da variável: F2M14_1_tx } \\
\text { Alternativas: (descrição - score) } \\
\text { Sim - } 1.0 \\
\text { Não - } 2.0\end{array}$ \\
\hline $\begin{array}{l}\text { 14.2) Qual a indicação da transfusão crônica? (marque todas que se aplicam) } \\
\text { Pergunta Alternativa Seleção Múltipla } \\
\text { Nome da variável: F2M14_2_tx_id } \\
\text { Alternativas: (descrição - nome da variável - score) } \\
\text { Doppler transcraniano anormal - _tcd - } 1.0 \\
\text { Historia de acidente vascular cerebral - _cva - } 2.0 \\
\text { Dor recorrente grave - _voe }-3.0 \\
\text { Síndrome torácica aguda recorrente - _acs - 4.0 } \\
\text { Infarto cerebral silencioso - _sit }-5.0 \\
\text { Gravidez - _pg - } 6.0 \\
\text { Úlcera de perna - _ulc - } 7.0 \\
\text { Doença vascular cerebral - _cvd - } 8.0 \\
\text { Falência renal - _rf - } 9.0 \\
\text { Outra - _o - } 100.0\end{array}$ \\
\hline $\begin{array}{l}\text { 14.3) Especifique a outra indicação para transfusão crônica atual (separe por ; as outras indicações): } \\
\text { Pergunta Texto } \\
\text { Nome da variável: F2M14_3_tx_o } \\
\text { Número máximo de caracteres permitido: } 150\end{array}$ \\
\hline $\begin{array}{l}\text { 14.4) A terapia de transfusão crônica teve início nos últimos } 12 \text { meses (período de acompanhamento 2)? } \\
\text { Pergunta Alternativa Seleção Única } \\
\text { Nome da variável: F2M14_4_tx_strt } \\
\text { Alternativas: (descrição - score) } \\
\text { Sim - } 1.0 \\
\text { Não - } 2.0\end{array}$ \\
\hline $\begin{array}{l}\text { 14.5) Data de início da transfusão crônica: } \\
\text { Pergunta Data } \\
\text { Nome da variável: F2M14_5_tx_strt_d } \\
\text { Intervalo permitido: 01/01/2015 - 31/12/2017 }\end{array}$ \\
\hline $\begin{array}{l}\text { 14.6) A terapia de transfusão crônica foi interrompida nos últimos } 12 \text { meses (período do acompanhamento 2)? } \\
\text { Pergunta Alternativa Seleção Única } \\
\text { Nome da variável: F2M14_6_tx_stp } \\
\text { Alternativas: (descrição - score) }\end{array}$ \\
\hline
\end{tabular}


$\operatorname{Sim}-1.0$

Não - 2.0

14.7) Data em que o paciente interrompeu o tratamento com transfusão crônica:

Pergunta Data

Nome da variável: F2M14_7_tx_stp_d

Intervalo permitido: 01/01/2015 - 31/12/2017

14.8) O paciente está ou esteve nos últimos 12 meses (período do acompanhamento 2) em tratamento com Hidroxiuréia? Pergunta Alternativa Seleção Única

Nome da variável: F2M14_8_hu

Alternativas: (descrição - score)

Sim -1.0

Não - 2.0

14.9) Qual foi a indicação para o tratamento com Hidroxiuréia? (Marque todas as opções que se aplicam)

Pergunta Alternativa Seleção Múltipla

Nome da variável: F2M14_9_hu_id

Alternativas: (descrição - nome da variável - score)

Dor grave / frequente - _voe - 1.0

Síndrome Torácica Aguda grave/frequente - _acs - 2.0

AVC - _cva - 3.0

Doppler transcraniano alterado - _tcd - 4.0

Doença vascular cerebral (estreitamento anormal dos vasos cerebrais) - _cvd - 5.0

Úlcera de perna - _ulc - 6.0

Hipertensão Pulmonar - _ph - 7.0

Outra - _o - 100.0

14.10) Especifique a outra indicação para o tratamento com Hidroxiuréia (separe por ; as outras indicações):

Pergunta Texto

Nome da variável: F2M14_10_hu_i_o

Número máximo de caracteres permitido: 150

14.11) A terapia com Hidroxiuréia teve início nos últimos 12 meses (período de acompanhamento 2)?

Pergunta Alternativa Seleção Única

Nome da variável: F2M14_11_hu_strt

Alternativas: (descrição - score)

Sim -1.0

Não -2.0

14.12) Data de início do tratamento com Hidroxiuréia:

Pergunta Data

Nome da variável: F2M14_12_hu_strt_d

Intervalo permitido: 01/01/2015 - 31/12/2017

14.13) Estime a adesão do paciente ao tratamento com Hidroxiuréia 
Pergunta Alternativa Seleção Única

Nome da variável: F2M14_13_hu_compl

Alternativas: (descrição - score)

Toma hidroxiuréia mais de $75 \%$ do tempo indicado - 1.0

Toma hidroxiuréia de $25 \%$ a $75 \%$ do tempo indicado -2.0

Toma hidroxiuréia menos de $25 \%$ do tempo indicado -3.0

14.13.1) Qual é a dose, em mg, receitada mais recente do Hidroxiureia?

Pergunta Número Inteiro

Nome da variável: F2M14_13_1_hu_ds

Intervalo permitido: 0 - 5000

14.14) O paciente interrompeu tratamento com Hidroxiuréia ? (Considerar Interrupção: Interrupção completa e irreversível, e

NÃO a suspensão temporária devido a algum sintoma ou desconforto ou alteração dos exames laboratoriais)

Pergunta Alternativa Seleção Única

Nome da variável: F2M14_14_hu_break

Alternativas: (descrição - score)

Sim -1.0

Não -2.0

14.15) Data em que o paciente interrompeu o tratamento com Hidroxiuréia:

\section{Pergunta Data}

Nome da variável: F2M14_15_stp_d

Intervalo permitido: 01/01/2015 - 31/12/2017

14.16) Indicação para interromper o tratamento com Hidroxiuréia: (Marque todas as opções que se aplicam)

Pergunta Alternativa Seleção Múltipla

Nome da variável: F2M14_16_stp_i

Alternativas: (descrição - nome da variável - score)

Toxicidade hematológica - _htox - 1.0

Toxicidade hepática ou renal - _lrtox - 2.0

Intolerância (dor abdominal, diarreia, vômitos, constipação, cefaleia, tontura, erupção cutânea ) - _int - 3.0

Gravidez - _pg - 4.0

Não adesão ao tratamento - _ adh - 5.0

O paciente optou por interromper o tratamento devido à preocupações com a fertilidade - _fert - 6.0

Para iniciar o tratamento com transfusão crônica - _ctt - 7.0

Outra - _o - 100.0

14.17) Especifique a outra indicação para interromper o tratamento com Hidroxiuréia (separe por ; as outras indicações):

Pergunta Texto

Nome da variável: F2M14_17_stp_i_o

Número máximo de caracteres permitido: 150

Módulo: 15 - Diagnósticos relacionados à transfusão 


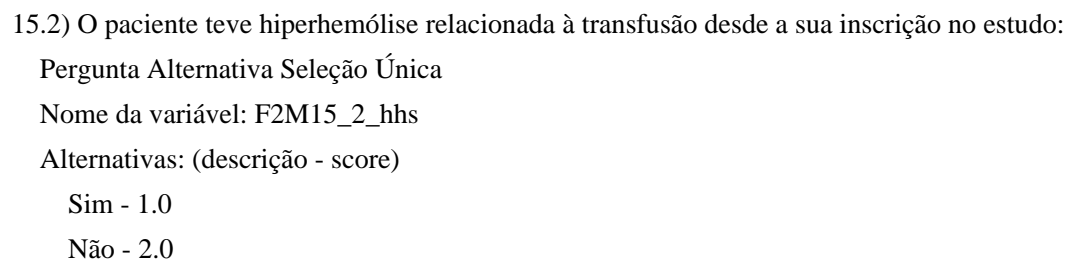

15.3) Data do diagnóstico de hiperhemólise relacionada à transfusão:

Pergunta Data

Nome da variável: F2M15_3_hhs_d

Intervalo permitido: 01/01/2013 - 31/12/2017

15.4) O paciente teve reação transfusional hemolítica tardia no período de acompanhamento 2 :

Pergunta Alternativa Seleção Única

Nome da variável: F2M15_4_dhtr

Alternativas: (descrição - score)

Sim -1.0

Não - 2.0

15.5) Data do diagnóstico de reação transfusional hemolítica tardia:

\section{Pergunta Data}

Nome da variável: F2M15_5_dhtr_d

Intervalo permitido: 01/01/2013 - 31/12/2017

15.6) O paciente teve hemossiderose transfusional no período de acompanhamento 2: (Caso o paciente tenha sido diagnosticado com hemossiderose transfusional antes do período do Acompanhamento 1, mas mantém o diagnóstico, responder "Sim")

Pergunta Alternativa Seleção Única

Nome da variável: F2M15_6_hemo

Alternativas: (descrição - score)

Sim -1.0

Não -2.0

15.7) Data do diagnóstico de hemossiderose transfusional: (Marque "Não se aplica" se o diagnóstico de hemossiderose foi feito antes do período de acompanhamento)

Pergunta Data

Nome da variável: F2M15_7_hemo_d

Intervalo permitido: 01/01/2013 - 31/12/2017

\section{Módulo: 16 - Diagnósticos oftalmológicos}

16.1) O paciente realizou exame ocular no período de acompanhamento 2:

Pergunta Alternativa Seleção Única

Nome da variável: F2M16_1_eye

Alternativas: (descrição - score) 
Sim -1.0

Não - 2.0

16.2) O paciente teve hemorragia retiniana no período de acompanhamento 2 :

Pergunta Alternativa Seleção Única

Nome da variável: F2M16_2_rh

Alternativas: (descrição - score)

Sim -1.0

Não - 2.0

16.3) Data do diagnóstico de hemorragia retiniana:

Pergunta Data

Nome da variável: F2M16_3_rh_d

Intervalo permitido: 01/01/2013 - 31/12/2017

16.4) O paciente teve hemorragia vítrea no período de acompanhamento 2 :

Pergunta Alternativa Seleção Única

Nome da variável: F2M16_4_vh

Alternativas: (descrição - score)

Sim -1.0

Não -2.0

16.5) Data do diagnóstico de episódio Hemorragia vítrea:

Pergunta Data

Nome da variável: F2M16_5_vh_d

Intervalo permitido: 01/01/2013 - 31/12/2017

16.6) O paciente teve retinopatia falciforme proliferativa no período de acompanhamento 2: (Caso o paciente tenha sido diagnosticado com retinopatia falciforme proliferativa antes do período do Acompanhamento 1, mas mantém o diagnóstico, responder "Sim")

Pergunta Alternativa Seleção Única

Nome da variável: F2M16_6_psr

Alternativas: (descrição - score)

Sim -1.0

Não - 2.0

16.7) Data do diagnóstico de retinopatia falciforme proliferativa: (Marque "Não se aplica" se o diagnóstico de retinopatia falciforme proliferativa foi feito antes do período de acompanhamento)

Pergunta Data

Nome da variável: F2M16_7_psr_d

Intervalo permitido: 01/01/2013 - 31/12/2017

Módulo: 17 - Diagnósticos pulmonares: hipertensão pulmonar 
17.1) O paciente teve hipertensão pulmonar no período de acompanhamento 2? (Caso o paciente tenha sido diagnosticado com hipertensão pulmonar antes do período do Acompanhamento 1, mas mantém o diagnóstico, responder “Sim”)

Pergunta Alternativa Seleção Única

Nome da variável: F2M17_1_ph

Alternativas: (descrição - score)

Sim -1.0

Não - 2.0

17.2) Como a hipertensão pulmonar foi diagnosticada?

Pergunta Alternativa Seleção Única

Nome da variável: F2M17_2_ph_dx

Alternativas: (descrição - score)

Apenas por eco - 1.0

Apenas por cateterismo - 2.0

Por ambos, eco e cateterismo - 3.0

17.3) Qual tratamento o paciente recebeu para tratar a Hipertensão Pulmonar? (Marque todas as opções que se aplicam)

Pergunta Alternativa Seleção Múltipla

Nome da variável: F2M17_3_phtx

Alternativas: (descrição - nome da variável - score)

Não recebeu tratamento - _no - 1.0

Transfusão crônica - _ctt - 2.0

Hidroxiuréia - _hu - 3.0

Agonista Protaciclina - _pros - 4.0

Antagonista do Receptor da Endotelina - _end - 5.0

Inibidores da fosfodiesterase-5 - _5pd - 6.0

Outro - _o - 100.0

17.4) Especifique outro tratamento recebido para tratar a hipertensão pulmonar (separe por ; o outro tratamento):

Pergunta Texto

Nome da variável: F2M17_4_ph_o

Número máximo de caracteres permitido: 100

\section{Módulo: 18 - Diagnósticos pulmonares: embolismo pulmonar}

18.1) O paciente teve embolismo pulmonar no período de acompanhamento 2:

Pergunta Alternativa Seleção Única

Nome da variável: F2M18_1_pe

Alternativas: (descrição - score)

Sim -1.0

Não -2.0

18.2) Quantas vezes esse indivíduo teve episódio de embolismo pulmonar no período de acompanhamento 2 ?

Pergunta Número Inteiro

Nome da variável: F2M18_2_pe_n 
Intervalo permitido: 1 - 99

Planilha: Questões relacionadas ao episodio de embolismo pulmonar

Itens: (Descrição - Nome da variável)

Embolismo pulmonar - F2M18

18.3) Data do episódio de esmbolismo pulmonar (registre o primeiro dia do episódio, caso o episódio tenha durado mais de 1 dia)

Pergunta Data

Nome da variável: _3_pe_d

Intervalo permitido: 01/01/2013 - 31/12/2017

18.4) Foi realizado exame de Dímero - D?

Pergunta Alternativa Seleção Única

Nome da variável: _4_dd

Alternativas: (descrição - score)

Sim -1.0

Não - 2.0

18.5) Valor do Dimero - D:

Pergunta Número Inteiro

Nome da variável: _5_dd_r

Intervalo permitido: $10-\overline{2} 000$

18.6) Foi feita ventilação/escaneamento da perfusão?

Pergunta Alternativa Seleção Única

Nome da variável: _6_vq

Alternativas: (descriçãa - score)

Sim -1.0

Não - 2.0

18.7) Qual foi o resultado da ventilação/escaneamento da perfusão?

Pergunta Alternativa Seleção Única

Nome da variável: _7_vq_r

Alternativas: (descrição - score)

Normal - 1.0

Dois ou mais defeitos de perfusão segmentar sem defeitos de ventilação correspondente - 2.0

Um grande defeito de perfusão segmentar e 2 ou mais defeitos moderados de perfusão segmentar sem alterações radiográficas ou de ventilação correspondentes - 3.0

4 ou mais defeitos de perfusão segmentar moderado, sem alterações radiográficas ou de ventilação correspondentes - 4.0

Outro - 5.0

18.8) Especifique o outro resultado do exame de ventilação/escaneamento da perfusão (Separe por ; os outros resultados):

Pergunta Texto

Nome da variável: _8_vq_o

Número máximo de caracteres permitido: 100

18.9) A angiografia apresentou defeitos de preenchimento intraluminal?

Pergunta Alternativa Seleção Única

Nome da variável: _ 9 _ang

Alternativas: (descrição - score)

Sim - 1.0

Não - 2.0

Angiografia não realizada - 3.0

18.10) Tomografia computadorizada da artéria pulmonar mostrando defeitos de preenchimento intraluminal? Pergunta Alternativa Seleção Única

Nome da variável:_10_ct

Alternativas: (descrição - score)

Sim - 1.0

Não -2.0

Tomografia computadorizada não realizada -3.0 
18.11) O lavado broncoalveolar evidenciou macrófagos carregados de lipídios?

Pergunta Alternativa Seleção Única

Nome da variável: _11 bal

Alternativas: (descrição- - score)

Sim - 1.0

Não -2.0

Lavado broncoalveolar não realizado - 3.0

18.12) O paciente foi transfundido nesse episódio de embolismo pulmonar?

Pergunta Alternativa Seleção Única

Nome da variável: _12_pe_tx

Alternativas: (descriçãa - score)

Sim -1.0

Não - 2.0

\section{Módulo: 19 - Diagnósticos pulmonares: síndrome torácica aguda}

19.1) O paciente teve síndrome torácica aguda/pneumonia no período de acompanhamento 2 :

Pergunta Alternativa Seleção Única

Nome da variável: F2M19_1_acs

Alternativas: (descrição - score)

Sim -1.0

Não - 2.0

19.2) Quantas vezes esse indivíduo teve síndrome torácica aguda nos no período de acompanhamento 2 ?

Pergunta Número Inteiro

Nome da variável: F2M19_2_acs_n

Intervalo permitido: 1 - 99

Planilha: Questões relacionadas ao episodio de síndrome torácica aguda/pneumonia

Itens: (Descrição - Nome da variável)

Síndrome torácica aguda/pneumonia - F2M19

19.3) Data do episódio de STA (registre o primeiro dia do episódio, caso o episódio tenha durado mais de 1 dia):

Pergunta Data

Nome da variável: _3_acs_d

Intervalo permitido: $\overline{01} / 01 / 2013-31 / 12 / 2017$

19.4) Saturação de oxigênio mais baixa neste episódio de STA:

Pergunta Número Inteiro

Nome da variável:_4_lowO

Intervalo permitido: 0 - 100

19.5) Menor pressão de oxigênio (PaO2) neste episódio de STA (Marque "Não se aplica" se não houver resultado da menor pressão de oxigênio)

Pergunta Número Inteiro

Nome da variável: _5_lowPaO

Intervalo permitido: 0 - 200

19.6) Registre os sintomas presentes no dia em que a síndrome torácica aguda foi diagnosticada: (marcar todos que se aplicam)

Pergunta Alternativa Seleção Múltipla

Nome da variável: _6_acs

Alternativas: (descrição - nome da variável - score)

Tosse - _cou - 1.0

Febre - fev - 2.0

Dor no peito - _cp - 3.0

Retração intra-costal - _ret - 4.0

Queimação nasal - nf - 5.0

Sibilância - wh - 6.0

Estertores - _ral - 7.0

Outro - _o - 100.0 
19.7) Especifique o outro sintoma presente no dia do diagnóstico da síndrome torácica aguda: (Separe por ; os outros sintomas)

Pergunta Texto

Nome da variável: 7 acs o

Número máximo de caracteres permitido: 100

19.8) Foi necessário oxigênio suplementar neste episódio de STA?

Pergunta Alternativa Seleção Única

Nome da variável:_8_acsO2

Alternativas: (descrição - score)

Sim -1.0

Não - 2.0

19.9) Quantos dias de oxigênio suplementar foram necessários neste episódio de STA?

Pergunta Número Inteiro

Nome da variável: 9 O2d

Intervalo permitido: 0 - 100

19.10) Foi feita ventilação não invasiva com pressão positiva neste episódio de STA? (Por exemplo, CPAP)

Pergunta Alternativa Seleção Única

Nome da variável: _10_cpap

Alternativas: (descrição - score)

Sim - 1.0

Não - 2.0

19.11) Quantos dias de ventilação não invasiva com pressão positiva foram necessários neste episódio de STA?

Pergunta Número Inteiro

Nome da variável: _11_cpap_d

Intervalo permitido: 0 - 100

19.12) Foi necessária ventilação mecanica neste episódio de STA?

Pergunta Alternativa Seleção Única

Nome da variável: _12_mv

Alternativas: (descriçãō - score)

Sim -1.0

19.13) Quantos dias de ventilação mecânica foram necessários neste episódio de STA?

Pergunta Número Inteiro

Nome da variável: _13_mv_d

Intervalo permitido: $0-100$

19.14) O indivíduo foi transfundido nesse episódio de síndrome torácica aguda?

Pergunta Alternativa Seleção Única

Nome da variável: 14 acs tx

Alternativas: (descrição - score)

Sim -1.0

Não - 2.0

19.15) O paciente foi tratado com broncodilatadores inalatórios durante o episódio de STA?

Pergunta Alternativa Seleção Única

Nome da variável: _15_bd

Alternativas: (descrição - score)

Sim -1.0

Não - 2.0

19.16) O paciente foi tratado com esteróides durante o episódio de STA?

Pergunta Alternativa Seleção Única

Nome da variável:_16_st

Alternativas: (descriçãa - score)

Sim -1.0

Não -2.0

19.17) Durante quantos dias o paciente recebeu esteroides durante o episódio de STA?

Pergunta Número Inteiro

Nome da variável: _17_st_d

Intervalo permitido: $0-100$ 
19.18) O paciente fez cultura do trato respiratório durante o episódio de STA?

Pergunta Alternativa Seleção Única

Nome da variável: _18 cx

Alternativas: (descrição - score)

Sim -1.0

Não -2.0

19.19) O resultado da cultura do trato respiratório durante o episódio de STA foi:

Pergunta Alternativa Seleção Única

Nome da variável: _19_cx_r

Alternativas: (descrição - score)

Positivo - 1.0

Negativo -2.0

19.20) Especifique o microrganismo identificado na cultura do trato respiratório durante o episódio de STA (Separe por ; os outros microrganismos):

Pergunta Texto

Nome da variável:_20_sp_cx

Número máximo de caracteres permitido: 100

19.21) O paciente teve asma no período de acompanhamento 2:

Pergunta Alternativa Seleção Única

Nome da variável: F2M19_21_ast

Alternativas: (descrição - score)

Sim -1.0

Não -2.0

19.22) Data do diagnóstico de asma:

Pergunta Data

Nome da variável: F2M19_22_ast_d

Intervalo permitido: 01/01/2013 - 31/12/2017

\section{Módulo: 20 - Diagnósticos relacionados à anemia}

20.1) O paciente teve episódio aplástico no período de acompanhamento 2 :

Pergunta Alternativa Seleção Única

Nome da variável: F2M20_1_aa

Alternativas: (descrição - score)

Sim -1.0

Não -2.0

20.2) Quantas vezes esse indivíduo teve episódios aplásticos no período de acompanhamento 2?

Pergunta Número Inteiro

Nome da variável: F2M20_2_aa_n

Intervalo permitido: 1 - 99

Planilha: Questões relacionadas ao episódio aplástico

Itens: (Descrição - Nome da variável)

Episódio aplástico - F2M20

20.3) Data do episódio aplástico: (registre o primeiro dia do episódio, caso o episódio tenha durado mais de 1 dia)

Pergunta Data

Nome da variável: _3_aa_d

Intervalo permitido: $01 / 01 / 2013$ - 31/12/2017 
20.4) Contagem de Hg mais baixa no episódio aplástico: (Marque "Não se aplica" se a contagem de Hg não foi realizada

Pergunta Número Decimal

Nome da variável: 4 4 aa_h

Intervalo permitido: $1.0-20.0$

20.5) Contagem de reticulócitos mais baixa no episódio aplástico: (Marque "Não se aplica" se a contagem de reticulócitos não foi realizada)

Pergunta Número Decimal

Nome da variável: 5 aa $r$ t

Intervalo permitido: $0.0-100.0$

20.6) Registre o resultado da contagem de hemácias no momento da contagem mais baixa de reticulócitos no episódio aplástico (Marque "Não se aplica" se a contagem de hemácias não foi realizada)

Pergunta Número Decimal

Nome da variável: 6 aa rb

Intervalo permitido: $0.5-15.0$

20.7) Foi feito o teste do parvovírus B19 no episódio aplástico?

Pergunta Alternativa Seleção Única

Nome da variável: _7_aa_b19

Alternativas: (descrição - score)

Sim - 1.0

Não - 2.0

20.8) Resultados do teste do parvovirus B19 - DNA

Pergunta Alternativa Seleção Única

Nome da variável: _8_p_dna

Alternativas: (descrição - score)

Positivo - 1.0

Negativo -2.0

20.9) Resultados do teste do parvovirus B19 - IgM:

Pergunta Alternativa Seleção Única

Nome da variável:_9_p_igm

Alternativas: (descrição - score)

Positivo - 1.0

Negativo -2.0

20.10) O paciente estava usando hidroxiuréia durante o período do episódio aplástico?

Pergunta Alternativa Seleção Única

Nome da variável: _10_aa_hu

Alternativas: (descrição - score)

Sim - 1.0

Não -2.0

20.11) O paciente foi transfundido nesse episódio aplástico?

Pergunta Alternativa Seleção Única

Nome da variável: _11_aa tx

Alternativas: (descrição - score)

Sim -1.0

Não -2.0

20.12) O paciente teve anemia auto imune no período de acompanhamento 2 :

Pergunta Alternativa Seleção Única

Nome da variável: F2M20_12_aiha

Alternativas: (descrição - score)

Sim -1.0

Não - 2.0

20.13) Data do diagnóstico de anemia auto imune no período de acompanhamento 2:

Pergunta Data

Nome da variável: F2M20_13_aiha_d

Intervalo permitido: 01/01/2013 - 31/12/2017 


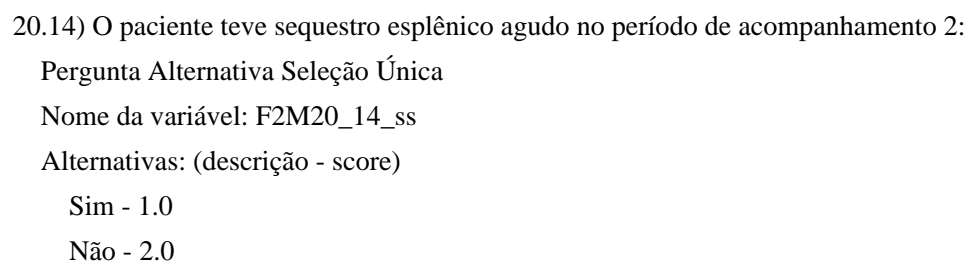

20.15) Quantas vezes esse indivíduo teve sequestro esplênico agudo nos no período de acompanhamento 2 ?

Pergunta Número Inteiro

Nome da variável: F2M20_15_ss_n

Intervalo permitido: 1 - 99

Planilha: Questões relacionadas episódio de sequestro esplênico agudo Itens: (Descrição - Nome da variável)

Episódio de sequestro esplênico agudo - F2M20

20.16) Data do episódio de sequestro esplênico: (registre o primeiro dia do episódio, caso o episódio tenha durado mais de 1 dia): Pergunta Data

Nome da variável: 16 ss d

Intervalo permitido: $01 / \overline{1 /} / 2013-31 / 12 / 2017$

20.17) Contagem de $\mathrm{Hg}$ mais baixa no sequestro esplênico: (Marque "Não se aplica" se a contagem de Hg não foi realizada)

Pergunta Número Decimal

Nome da variável: _17_ss_h

Intervalo permitido: $1.0-20.0$

20.18) Contagem absoluta de plaquetas (a mais baixa) no sequestro esplênico: (Marque "Não se aplica" se a contagem absoluta de plaquetas não foi realizada)

Pergunta Número Inteiro

Nome da variável:__18_ss_p

Intervalo permitido: 25000 - 999999

20.19) Contagem mais elevada de reticulocitos no sequestro esplênico: (Marque "Não se aplica" se a contagem de reticulocitos não foi realizada)

Pergunta Número Decimal

Nome da variável: _19_ss_r

Intervalo permitido: $0 . \overline{0}-\overline{1} 00.0$

20.20) Registre o resultado da hemácias no momento da contagem mais baixa de reticulócitos no sequestro esplênico: (Marque "Não se aplica" se a contagem de hemácias não foi realizada)

Pergunta Número Decimal

Nome da variável: _20_ss_rbc

Intervalo permitido: $0.0-\overline{15.0}$

20.21) O paciente foi transfundido no sequestro esplênico agudo?

Pergunta Alternativa Seleção Única

Nome da variável:_21_ss_tx

Alternativas: (descrição - score)

Sim -1.0

Não -2.0

\section{Módulo: 21 - Diagnósticos cardíacos}

21.1) O paciente teve infarto do miocárdio no período de acompanhamento 2:

Pergunta Alternativa Seleção Única

Nome da variável: F2M21_1_mi

Alternativas: (descrição - score)

Sim -1.0 
Não -2.0

21.2) Data do diagnóstico de infarto do miocárdio:

Pergunta Data

Nome da variável: F2M21_2_mi_d

Intervalo permitido: 01/01/2013 - 31/12/2017

21.3) O paciente teve hipertensão arterial sistêmica no período de acompanhamento 2: (Caso o paciente tenha sido diagnosticado com hipertensão arterial sistêmica antes do período do Acompanhamento 1, mas mantém o diagnóstico, responder "Sim")

Pergunta Alternativa Seleção Única

Nome da variável: F2M21_3_htn

Alternativas: (descrição - score)

Sim -1.0

Não - 2.0

21.4) Data do diagnóstico de hipertensão arterial sistêmica: (Marque "Não se aplica" se o diagnóstico de hipertensão arterial sistêmica foi feito antes do período de acompanhamento)

Pergunta Data

Nome da variável: F2M21_4_htn_d

Intervalo permitido: 01/01/2013 - 31/12/2017

21.5) O paciente teve insuficiência cardíaca no período de acompanhamento 2: (Caso o paciente tenha sido diagnosticado com insuficiência cardíaca antes do período do Acompanhamento 1, mas mantém o diagnóstico, responder "Sim")

Pergunta Alternativa Seleção Única

Nome da variável: F2M21_5_chf

Alternativas: (descrição - score)

Sim -1.0

Não -2.0

21.6) Data do diagnóstico de insuficiência cardíaca: (Marque "Não se aplica" se o diagnóstico de insuficiência cardíaca foi feito antes do período de acompanhamento)

Pergunta Data

Nome da variável: F2M21_6_chf_d

Intervalo permitido: 01/01/2013 - 31/12/2017

\section{Módulo: 22 - Diagnósticos neurológicos / dor: acidente vascular cerebral isquêmico}

22.1) O paciente teve acidente vascular cerebral - Infarto no período de acompanhamento 2:

Pergunta Alternativa Seleção Única

Nome da variável: F2M22_1_cva

Alternativas: (descrição - score)

Sim -1.0

Não - 2.0 
22.2) Quantas vezes esse indivíduo teve Acidente Vascular Cerebral Isquêmico no período de acompanhamento 2 ?

Pergunta Número Inteiro

Nome da variável: F2M22_2_cva_n

Intervalo permitido: 1 - 99

Planilha: Questões relacionadas ao episódio de acidente vascular cerebral isquêmico

Itens: (Descrição - Nome da variável)

Episódio de acidente vascular cerebral isquêmico - F2M22

22.3) Data do episódio de AVC isquêmico (registrar a data da realização da RMI/TC utilizada no diagnóstico. Se o paciente não fez esses exames, registre o dia no qual os sintomas neurológicos tiveram início) :

Pergunta Data

Nome da variável:_3_cva_d

Intervalo permitido: $01 / 01 / 2013$ - 31/12/2017

22.4) Quais foram os sintomas iniciais do AVC isquêmico? (marque todas as opções que se aplicam)

Pergunta Alternativa Seleção Múltipla

Nome da variável: _4_cva

Alternativas: (descrição - nome da variável - score)

Fraqueza nos membros superiors - _ue - 1.0

Fraqueza nos membros inferiores - _le - 2.0

Dificuldade para falar - _spk - 3.0

Alteração do nível de consciência - _loc - 4.0

Alterações na visão - _vis - 5.0

Dificuldade para caminhar - _wlk - 6.0

Convulsões - _sz - 7.0

Outros - _o - 100.0

22.5) Especifique o outro sintoma inicial do AVC isquêmico (Separe por ; os outros sintomas):

Pergunta Texto

Nome da variável: _5_cvasx_o

Número máximo de caracteres permitido: 100

22.6) Quais testes foram realizados para diagnosticar o AVC isquêmico? (marque todas opções que se aplicam e marque não se aplica se o avc foi apenas diagnosticado clinicamente)

Pergunta Alternativa Seleção Múltipla

Nome da variável:_6_cva

Alternativas: (descrição - nome da variável - score)

Ressonância magnética - MRI - _mri - 1.0

Tomografia computadorizada - C $\overline{\mathrm{T}}$ - _ct - 2.0

Sem resposta - _noans - 3.0

Nenhum (O diagnóstico foi clínico) - _no - 100.0

22.7) Quais tipos de angiografia foram feitos para diagnosticar o AVC isquêmico? (marque todas opções que se aplicam)

Pergunta Alternativa Seleção Múltipla

Nome da variável: _- 7 ccva

Alternativas: (descrição - nome da variável - score)

Ressonância Magnética Angiográfica RMA MRA - mra - 1.0

Angiografia convencional - _an - 2.0

Tomografia computadorizada angiográfica - _cta - 3.0

Sem resposta - _noans - 4.0

Nenhum - no - 100.0

22.8) Onde foi localizada a isquemia? (marque todas opções que se aplicam)

Pergunta Alternativa Seleção Múltipla

Nome da variável:_8_cva

Alternativas: (descrição - nome da variável - score)

Frontal - _ft - 1.0

Parietal - _pr - 2.0

Sulco central - _sc - 3.0

Substância branca profunda - _dp - 4.0

Occipital - _occ - 5.0

Outro - o - 100.0

22.9) Especifique a outra localização da isquemia (Separe por ; as outras localizações)

Pergunta Texto

Nome da variável:_9_cval_o

Número máximo de caracteres permitido: 100 
22.10) Foi detectado estreitamento/estenose de algum vaso no AVC isquêmico?

Pergunta Alternativa Seleção Única

Nome da variável: 10 sten

Alternativas: (descrição - score)

Sim -1.0

Não -2.0

22.11) Em qual vaso foi detectado o estreitamento/estenose no AVC isquêmico? (marque todas as opções que se aplicam)

Pergunta Alternativa Seleção Múltipla

Nome da variável: _11_cva

Alternativas: (descrição - nome da variável - score)

Artéria Cerebral Média - _mca - 1.0

Arteria Carótida Interna - _ica - 2.0

Artéria Carótida Anterior - _aca - 3.0

Artéria Cerebral Posterior - _pca - 4.0

Outro - _o - 100.0

22.12) Especifique o outro vaso onde foi detectado o estreitamento/estenose no AVC isquêmico (Separe por ; vasos): Pergunta Texto

Nome da variável:__12_bv_o

Número máximo dē caracteres permitido: 100

22.13) Qual foi o tamanho da lesão causada pelo infarto? (Se houve mais de um infarto, registre a área da maior lesão) Pergunta Número Decimal

Nome da variável: _13_cva_sz

Intervalo permitido: $0.0-500.0$

22.14) De qual lado do cérebro ocorreu o infarto?

Pergunta Alternativa Seleção Única

Nome da variável: _14_cva_lc

Alternativas: (descrição - score)

Esquerdo - 1.0

Direito - 2.0

Bilateral - 3.0

22.15) O paciente foi transfundido nesse episódio de AVC isquêmico?

Pergunta Alternativa Seleção Única

Nome da variável: _15_cva_tx

Alternativas: (descrição - score)

Sim -1.0

Não -2.0

22.16) O paciente recebeu alguma outra terapia para tratar este AVC isquêmico?

Pergunta Alternativa Seleção Única

Nome da variável: _16_cvatx

Alternativas: (descrição - score)

Sim - 1.0

Não - 2.0

22.17) Se sim, qual foi a terapia para tratar este AVC isquêmico? (marque todas as opções que se aplicam)

Pergunta Alternativa Seleção Múltipla

Nome da variável: 17 tx

Alternativas: (descrição - nome da variável - score)

Terapia trombolítica - _thrm - 1.0

Terapia anti-plaquetária (aspirina) - _antplt - 2.0

Outra - o - 100.0

22.18) Especifique a outra terapia para tratar o AVC isquêmico (Separe por ; as outras terapias):

Pergunta Texto

Nome da variável: _18_tx_o

Número máximo de caracteres permitido: 100

\section{Módulo: 23 - Diagnósticos neurológicos / dor: acidente vascular cerebral hemorrágico}

23.1) O paciente teve acidente vascular cerebral - hemorrágico no período de acompanhamento 2:

Pergunta Alternativa Seleção Única 
Nome da variável: F2M23_1_cvah

Alternativas: (descrição - score)

Sim -1.0

Não - 2.0

23.2) Quantas vezes esse indivíduo teve acidente vascular cerebral hemorrágico no período de acompanhamento 2 ?

Pergunta Número Inteiro

Nome da variável: F2M23_2_cvah_n

Intervalo permitido: 1 - 99

Planilha: Questões relacionadas ao episódio de acidente vascular cerebral hemorrágico

Itens: (Descrição - Nome da variável)

Episódio de acidente vascular cerebral hemorrágico - F2M23

23.3) Data do episódio de acidente vascular cerebral hemorrágico (Registre a data do diagnóstico clínico, caso o episódio tenha durado mais de 1 dia):

Pergunta Data

Nome da variável: 3 cvah d

Intervalo permitido: $01 / 01 / 2013-31 / 12 / 2017$

23.4) Foi identificada hemorragia na ressonância magnética ou na tomografia computadorizada?

Pergunta Alternativa Seleção Única

Nome da variável:_4_cvah_ct

Alternativas: (descrição - score)

Sim -1.0

Não - 2.0

23.5) Houve fluido espinhal hemorrágico na punção lombar no episódio de AVC hemorrágico?

Pergunta Alternativa Seleção Única

Nome da variável: _5_cvah_lp

Alternativas: (descrição - score)

Sim -1.0

Não - 2.0

Punção lombar não realizada - 3.0

23.6) Houve alguma intervenção neurocirúrgica no episódio de AVC hemorrágico?

Pergunta Alternativa Seleção Única

Nome da variável:_6_cvah_ns

Alternativas: (descrição - score)

Sim -1.0

Não - 2.0

23.7) Classificação da localização do infarto hemorrágico: (marque todas opções que se aplicam)

Pergunta Alternativa Seleção Múltipla

Nome da variável: _7_cvah_1

Alternativas: (descriçã̃o - nome da variável - score)

Subdural - _sbd - 1.0

Subaracnóide - _sbr - 2.0

Intracerebral $\quad-$ itc -3.0

Intraventricular - _itv - 4.0

Epidural - _epd - $\overline{5} .0$

Anomalia vascular (aneurisma, má formação atrioventricular ou Moya-moya) - _anv - 6.0

Outra - _o - 100.0

23.8) Especifique a outra classificação da localização do infarto hemorrágico (Separe por ; as outras classificações): Pergunta Texto

Nome da variável:_8_cvah_1_o

Número máximo de caracteres permitido: 100

23.9) O paciente foi transfundido nesse episódio de acidente vascular cerebral hemorrágico?

Pergunta Alternativa Seleção Única

Nome da variável:_9_cvah_tx

Alternativas: (descriçã̃o - score)

Sim -1.0

Não - 2.0 


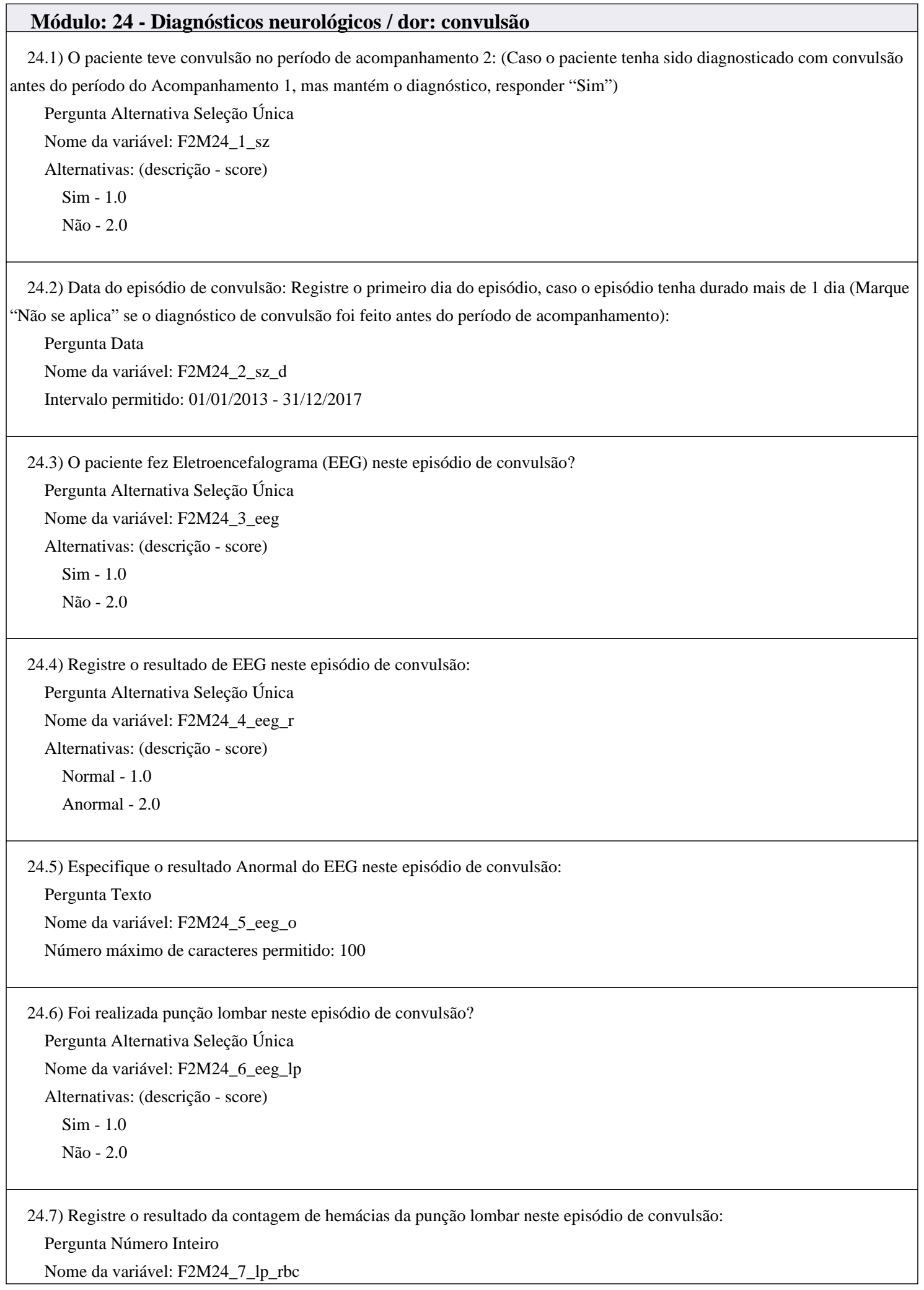


Intervalo permitido: 0 - 10000

24.8) Registre o resultado da contagem de leucócitos da punção lombar neste episódio de convulsão:

Pergunta Número Inteiro

Nome da variável: F2M24_8_lp_wbc

Intervalo permitido: 0 - 10000

24.9) Registre o resultado da contagem de proteína da punção lombar neste episódio de convulsão:

Pergunta Número Decimal

Nome da variável: F2M24_9_lp_p

Intervalo permitido: 5.0 - 1000.0

24.10) Registre o resultado da contagem de glicose da punção lombar neste episódio de convulsão:

Pergunta Número Decimal

Nome da variável: F2M24_10_lp_g

Intervalo permitido: 1.0 - 500.0

24.11) O diagnóstico final neste episódio de convulsão foi: (marque todas opções que se aplicam)

Pergunta Alternativa Seleção Múltipla

Nome da variável: F2M24_11_sz

Alternativas: (descrição - nome da variável - score)

Convulsão febril - _feb - 1.0

Acidente vascular cerebral - _cva - 2.0

Anomalia vascular (Aneurisma, mal-formação vascular) - _an - 3.0

Familiar - _fam - 4.0

Traumática - _tr - 5.0

Infecciosa - _ix - 6.0

Idiopática - _id - 7.0

Outro - _o - 100.0

24.12) Especifique o outro diagnóstico final neste episódio de convulsão: (Separe por ; os outros diagnósticos finais): Pergunta Texto

Nome da variável: F2M24_12_sz_o

Número máximo de caracteres permitido: 100

\section{Módulo: 25 - Diagnósticos neurológicos / dor: ataque isquêmico transitório, dor neuropática,} dactilite

25.1) O paciente teve ataque isquêmico transitório (AIT) no período de acompanhamento 2:

Pergunta Alternativa Seleção Única

Nome da variável: F2M25_1_tia

Alternativas: (descrição - score)

Sim -1.0

Não - 2.0 
25.2) Data do diagnóstico de ataque isquêmico transitório (AIT) :

Pergunta Data

Nome da variável: F2M25_2_tia_d

Intervalo permitido: 01/01/2013 - 31/12/2017

25.3) O paciente teve episódio doloroso agudo da doença falciforme no período de acompanhamento 2 :

Pergunta Alternativa Seleção Única

Nome da variável: F2M25_3_voe

Alternativas: (descrição - score)

Sim -1.0

Não - 2.0

25.4) Quantos episódios de dor aguda da doença falciforme o paciente teve desde a inscrição no estudo?

Pergunta Número Inteiro

Nome da variável: F2M25_4_voe_n

Intervalo permitido: 1 - 150

25.5) O paciente teve dor neuropática no período de acompanhamento 2: (Caso o paciente tenha sido diagnosticado com dor neuropática antes do período do Acompanhamento 1, mas mantém o diagnóstico, responder "Sim”)

Pergunta Alternativa Seleção Única

Nome da variável: F2M25_5_np

Alternativas: (descrição - score)

Sim -1.0

Não -2.0

25.6) Data do diagnóstico de dor neuropática: (Marque "Não se aplica” se o diagnóstico de dor neuropática foi feito antes do período de acompanhamento)

Pergunta Data

Nome da variável: F2M25_6_np_d

Intervalo permitido: 01/01/2013 - 31/12/2017

25.7) O paciente teve dactilite (síndrome mão-pé) no período de acompanhamento 2 :

Pergunta Alternativa Seleção Única

Nome da variável: F2M25_7_hfs

Alternativas: (descrição - score)

Sim -1.0

Não - 2.0

25.8) Data do diagnóstico de dactilite:

Pergunta Data

Nome da variável: F2M25_8_hfs_d

Intervalo permitido: 01/01/2013 - 31/12/2017

Módulo: 26 - Diagnósticos grastrointestinais / hepáticos 
26.1) O paciente teve colecistite no período de acompanhamento 2: (Caso o paciente tenha sido diagnosticado com colecistite antes do período do Acompanhamento 1, mas mantém o diagnóstico, responder "Sim")

Pergunta Alternativa Seleção Única

Nome da variável: F2M26_1_chol

Alternativas: (descrição - score)

Sim -1.0

Não -2.0

26.2) Data do diagnóstico de colecistite: (Marque "Não se aplica" se o diagnóstico de colecistite foi feito antes do período de acompanhamento)

Pergunta Data

Nome da variável: F2M26_2_chol_d

Intervalo permitido: 01/01/2013 - 31/12/2017

26.3) O paciente teve colelitíase no período de acompanhamento 2: (Caso o paciente tenha sido diagnosticado com colelitíase antes do período do Acompanhamento 1, mas mantém o diagnóstico, responder "Sim")

Pergunta Alternativa Seleção Única

Nome da variável: F2M26_3_stn

Alternativas: (descrição - score)

Sim -1.0

Não - 2.0

26.4) Data do diagnóstico de colelitíase: (Marque "Não se aplica" se o diagnóstico de colelitíase foi feito antes do período de acompanhamento)

Pergunta Data

Nome da variável: F2M26_4_stn_d

Intervalo permitido: 01/01/2013 - 31/12/2017

26.5) O paciente teve pancreatite no período de acompanhamento 2 :

Pergunta Alternativa Seleção Única

Nome da variável: F2M26_5_pan

Alternativas: (descrição - score)

Sim - 1.0

Não - 2.0

26.6) Data do diagnóstico de pancreatite:

Pergunta Data

Nome da variável: F2M26_6_pan_d

Intervalo permitido: 01/01/2013 - 31/12/2017

26.7) O paciente teve sequestro hepático no período de acompanhamento 2 :

Pergunta Alternativa Seleção Única

Nome da variável: F2M26_7_hs

Alternativas: (descrição - score)

Sim -1.0

Não -2.0 


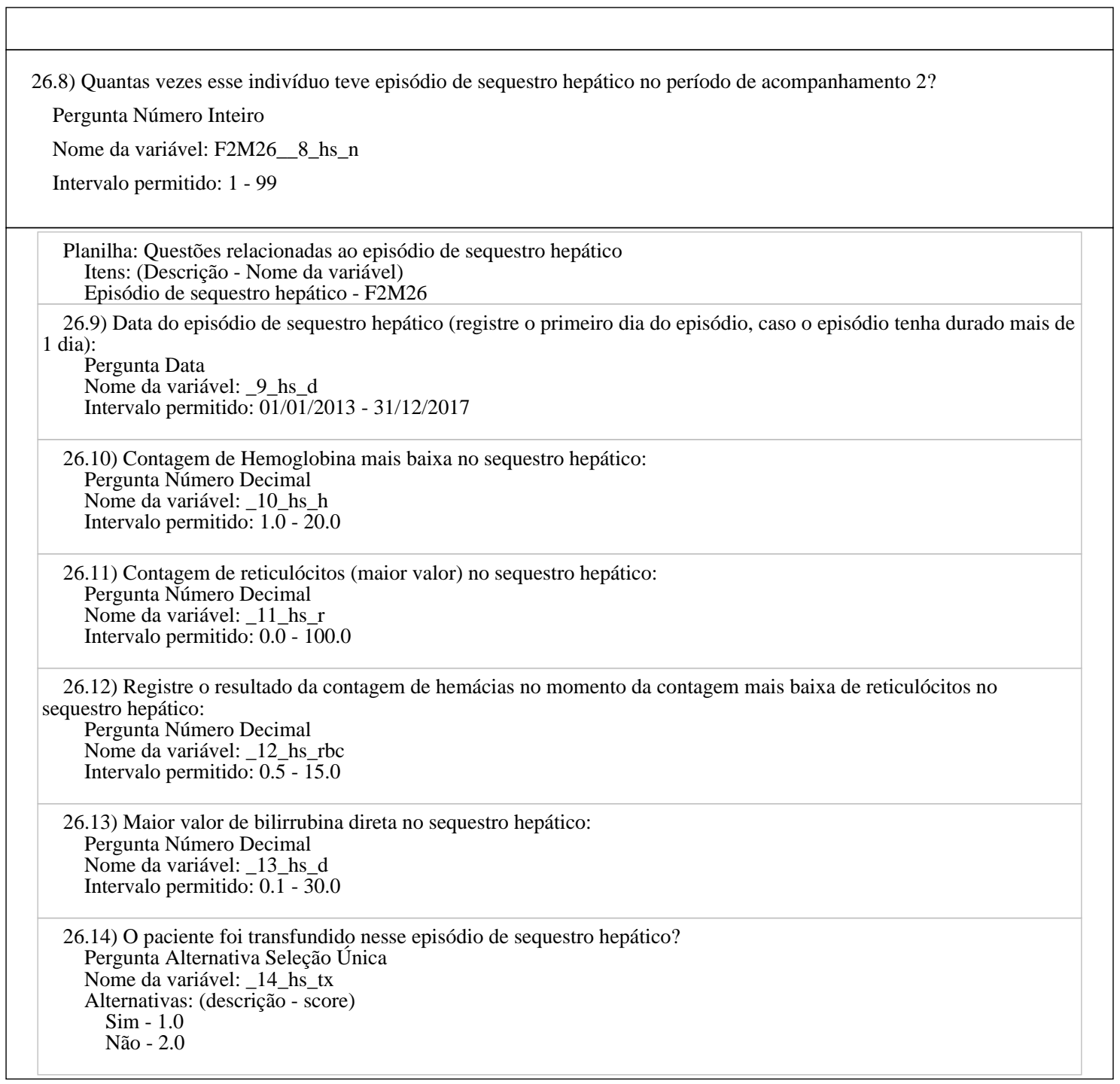

\section{Módulo: 27 - Tromboembolismo venoso / úlceras de perna}

27.1) O paciente teve tromboembolismo venoso no período de acompanhamento 2 :

Pergunta Alternativa Seleção Única

Nome da variável: F2M27_1_vte

Alternativas: (descrição - score)

Sim -1.0

Não - 2.0

27.2) Data do diagnóstico de tromboembolismo venoso:

Pergunta Data

Nome da variável: F2M27_2_vte_d

Intervalo permitido: 01/01/2013 - 31/12/2017 
27.3) Especifique o local do tromboembolismo: (Separe por ; os locais do tromboembolismo)

Pergunta Texto

Nome da variável: F2M27_3_vte_1

Número máximo de caracteres permitido: 100

27.4) O paciente teve úlceras de perna no período de acompanhamento 2: (Caso o paciente tenha sido diagnosticado com úlcera de perna antes do período do Acompanhamento 1, mas mantém o diagnóstico, responder "Sim”)

Pergunta Alternativa Seleção Única

Nome da variável: F2M27_4_ulc

Alternativas: (descrição - score)

Sim -1.0

Não - 2.0

27.5) Data do diagnóstico de úlcera de perna: (Marque "Não se aplica” se o diagnóstico de úlcera de perna foi feito antes do período de acompanhamento)

Pergunta Data

Nome da variável: F2M27_5_ulc_d

Intervalo permitido: 01/01/2013 - 31/12/2017

\section{Módulo: 28 - Necrose avascular}

28.1) O paciente teve necrose avascular quadril / ombro no período de acompanhamento 2: (Caso o paciente tenha sido diagnosticado com necrose avascular antes do período do Acompanhamento 1, mas mantém o diagnóstico, responder "Sim")

Pergunta Alternativa Seleção Única

Nome da variável: F2M28_1_avn

Alternativas: (descrição - score)

Sim -1.0

Não - 2.0

Planilha: Questões relacionadas à necrose avascular

Itens: (Descrição - Nome da variável)

Necrose avascular - F2M28

28.2) Local de ocorrência da necrose avascular:

Pergunta Alternativa Seleção Única

Nome da variável:_2_avn_1

Alternativas: (descrição - score)

Cabeça Femoral Direita - 1.0

Cabeça Femoral Esquerda - 2.0

Ombro Direito - 3.0

Ombro Esquerdo - 4.0

Outro osso -5.0

28.3) Especifique o outro osso onde ocorreu a necrose avascular (Separe por ; os outros ossos):

Pergunta Texto

Nome da variável: _3_avn_o

Número máximo de caracteres permitido: 100

28.4) Data do exame de imagem (se houve mais de uma radiografia/RMI evidenciando necrose avascular nos últimos 12 meses, registre a data do exame com o grau mais elevado de necrose avascular):

Pergunta Data

Nome da variável: _4_avn_d

Intervalo permitido: $01 / 01 / 2013-31 / 12 / 2017$ 
28.5) Tipo de exame de imagem da necrose avascular: (marque todas as opções que se aplicam)

Pergunta Alternativa Seleção Múltipla

Nome da variável: _5_avn

Alternativas: (descrição - nome da variável - score)

Raio X $\quad-\quad \mathrm{Xr}-1.0$

RMI - _mri - 2.0

28.6) Selecione o grau da necrose avascular. Se houve mais de uma radiografia/RMI evidenciando necrose avascular nos últimos 12 meses, registre o grau mais elevado de necrose avascular:

Pergunta Alternativa Seleção Única

Nome da variável:_6_avn_gd

Alternativas: (descriçãa - score)

Estágio 0 - Raio X/RMI normal - 1.0

Estágio I - Raio X normal, RMI alterada - 2.0

Estágio II - Raio X e RMI alteradas, mas sem colapso da cabeça femoral (sem sinal do crescente) - 3.0

Estágio III - Sinal precoce de achatamento da cúpula e / ou crescente na radiografia ou na RMI; - 4.0

Estágio IV - Achatamento da cabeça do fêmur com estreitamento do espaço articular na radiografia. - 5.0

28.7) Houve indicação médica de cirurgia para tratamento da necrose avascular?

Pergunta Alternativa Seleção Única

Nome da variável: _7_surg

Alternativas: (descriçã̃o - score)

Sim -1.0

Não -2.0

28.8) Foi feita descompressão cirúrgica da necrose avascular?

Pergunta Alternativa Seleção Única

Nome da variável: _8_core

Alternativas: (descriçãa - score)

Sim -1.0

Não - 2.0

28.9) Foi realizada artroplastia (substituição da articulação) para tratamento da necrose avascular?

Pergunta Alternativa Seleção Única

Nome da variável:_9_jr

Alternativas: (descriçãa - score)

Sim -1.0

$\mathrm{Não}-2.0$

28.10) Foi dado qualquer outro tratamento para tratar a necrose avascular?

Pergunta Alternativa Seleção Única

Nome da variável:_10avn_tx

Alternativas: (descrição - score)

Sim - 1.0

Não - 2.0

28.11) Especifique o outro tratamento para a necrose avascular: (Separe por ; os outros tratamentos) Pergunta Texto

Nome da variável:_11_tx_o

Número máximo de caracteres permitido: 100

\section{Módulo: 29 - Diagnósticos geniturinários}

29.1) O paciente teve priapismo no período de acompanhamento 2: (Marque "Não se aplica" para mulheres)

Pergunta Alternativa Seleção Única

Nome da variável: F2M29_1_pr

Alternativas: (descrição - score)

Sim - 1.0

Não - 2.0

29.2) Quantos dias o paciente teve pelo menos um episódio de priapísmo no período de acompanhamento 2?

Pergunta Número Inteiro

Nome da variável: F2M29_2_pr_n 
Intervalo permitido: 1 - 150

Planilha: Questões relacionadas ao episodio de Priapismo

Itens: (Descrição - Nome da variável)

Priapismo - F2M29

29.3) Data do exame no episódio de priapísmo:

Pergunta Data

Nome da variável: _3_pr_d

Intervalo permitido: $01 / 01 / 2013$ - 31/12/2017

29.4) Quanto tempo, em horas, durou o episódio de priapismo?

Pergunta Alternativa Seleção Única

Nome da variável: _4_pr_hr

Alternativas: (descriçãa - score)

Menos de 1 hora -1.0

1 a 3 horas -2.0

4 a 9 horas -3.0

10 a 15 horas $\quad-4.0$

16 a 20 horas $\quad-5.0$

Mais de 20 horas -6.0

29.5) Houve "priapismo gago" (Episódios repetitivos de priapismo com duração menor que 4 horas)

Pergunta Alternativa Seleção Única

Nome da variável: _5_pr_st

Alternativas: (descrição - score)

Sim -1.0

Não - 2.0

29.6) Como foi feito o tratamento para o priapismo? (Marque todas que se aplicam)

Pergunta Alternativa Seleção Múltipla

Nome da variável: _6_pr

Alternativas: (descrição - nome da variável - score)

Tratamento com medicação - _ med - 1000.0

Punção - _asp - 1.0

Cirurgia (colocação de prótese) - _surg - 2.0

Transfusão - _tx - 3.0

Sem tratamento - _no - 100.0

29.7) Especifique qual foi o medicamento utilizado (Separe por ; os medicamentos) (Marque não se aplica, caso o paciente não tenha utilizado medicamentos paea tratar o priapismo):

Pergunta Texto

Nome da variável:_7_pr_med

Número máximo de caracteres permitido: 100

29.8) O paciente teve pielonefrite no período de acompanhamento 2: (Caso o paciente tenha sido diagnosticado com pielonefrite antes do período do Acompanhamento 1, mas mantém o diagnóstico, responder "Sim”)

Pergunta Alternativa Seleção Única

Nome da variável: F2M29_8_pn

Alternativas: (descrição - score)

Sim -1.0

Não -2.0

29.9) Data do diagnóstico de pielonefrite: (Marque "Não se aplica" se o diagnóstico de pielonefrite foi feito antes do período de acompanhamento)

Pergunta Data

Nome da variável: F2M29_9_pn_d

Intervalo permitido: 01/01/2013 - 31/12/2017

29.10) O paciente teve/tem insuficiência renal AGUDA no período de acompanhamento 2:

Pergunta Alternativa Seleção Única

Nome da variável: F2M29_10_arf 
Alternativas: (descrição - score)

Sim -1.0

Não - 2.0

29.11) Quantas vezes esse indivíduo teve episódio de insuficiência renal AGUDA no período de acompanhamento 2?

Pergunta Número Inteiro

Nome da variável: F2M29_11_arf_n

Intervalo permitido: 1 - 99

Planilha: Questões relacionadas ao episódio de insuficiência renal aguda

Itens: (Descrição - Nome da variável)

Episódio de insuficiência renal aguda - F2M29

29.12) Data do episódio de insuficiência renal AGUDA:

Pergunta Data

Nome da variável: _12_arf_d

Intervalo permitido: 01/01/2013 - 31/12/2017

29.13) Nível mais alto de creatinina no episódio de insuficiência renal AGUDA:

Pergunta Número Decimal

Nome da variável: _13_arf_cr

Intervalo permitido: $0 . \overline{0}-2 \overline{5} .0$

29.14) Foi preciso fazer diálise no episódio de insuficiência renal AGUDA?

Pergunta Alternativa Seleção Única

Nome da variável:_14_arf_dy

Alternativas: (descrição - score)

Sim -1.0

Não - 2.0

29.15) Quais os tipos diálise foram necessários no episódio de insuficiência renal AGUDA? (marque todas opções que se aplicam)

Pergunta Alternativa Seleção Múltipla

Nome da variável: _15_dy

Alternativas: (descrição - nome da variável - score)

Hemodiálise - hd - 1.0

Diálise peritonial _ _ _ pd - 2.0

29.16) Data de início da diálise no episódio de insuficiência renal AGUDA:

Pergunta Data

Nome da variável:_16_dy_d

Intervalo permitido: 01/01/2013 - 31/12/2017

29.17) O paciente atualmente está em diálise devido à insuficiência renal AGUDA?

Pergunta Alternativa Seleção Única

Nome da variável: _17_dy_now

Alternativas: (descriçãa - score)

Sim -1.0

Não - 2.0

29.18) Data de término da diálise devido à insuficiência renal AGUDA?

Pergunta Data

Nome da variável: _18_dy_end

Intervalo permitido: 01/01/2013 - 31/12/2017

29.19) Causa da insuficiência renal AGUDA (marque todas opções que se aplicam)

Pergunta Alternativa Seleção Múltipla

Nome da variável: _19_arf

Alternativas: (descrição - nome da variável - score)

Obstrução renal ou uretal - _obs - 1.0

Infecção - _ix - 2.0

Hipovolemia - hv - 3.0

Medicamentos - med - 4.0

Falência múltipla de órgãos com crise vaso oclusiva - _mof - 5.0

Outro - _o - 100.0 
29.20) Especifique a outra causa da insuficiência renal AGUDA: (Separe por ; as outras causas)

Pergunta Texto

Nome da variável: 20_arf_o

Número máximo de caracteres permitido: 100

29.21) O paciente teve/tem insuficiência renal CRÔNICA no período de acompanhamento 2: (Caso o paciente tenha sido diagnosticado com Insuficiência Renal Crônica antes do período do Acompanhamento 1, mas mantém o diagnóstico, responder "Sim")

Pergunta Alternativa Seleção Única

Nome da variável: F2M29_21_crf

Alternativas: (descrição - score)

Sim -1.0

Não - 2.0

29.22) Nível mais alto de creatinina da insuficiência renal CRÔNICA desde a inscrição no estudo:

Pergunta Número Decimal

Nome da variável: F2M29_22_crf_cr

Intervalo permitido: $0.01-25.0$

29.23) Data do nível mais alto de creatinina da insuficiência renal CRÔNICA desde a inscrição no estudo: Pergunta Data

Nome da variável: F2M29_23_cr_d

Intervalo permitido: 01/01/2013 - 31/12/2017

29.24) Foi feito exame para medir o índice de filtração glomerular (IFG (ou clearence de creatinina) da insuficiência renal CRÔNICA desde a inscrição no estudo?

Pergunta Alternativa Seleção Única

Nome da variável: F2M29_24_gfr

Alternativas: (descrição - score)

Sim -1.0

Não - 2.0

29.25) Qual foi o menor Indice de filtração glomerular - IFG (ou clearence de creatinina) na insuficiência renal CRÔNICA dos últimos 12 meses:

Pergunta Número Decimal

Nome da variável: F2M29_25_gfr_r

Intervalo permitido: 1.0 - 200.0

29.26) Qual é a unidade de medida do IFG ou clearance de cratinina registrado na questão 29.25?

Pergunta Alternativa Seleção Única

Nome da variável: F2M29_26_gfr_u

Alternativas: (descrição - score)

$\mathrm{mL} / \mathrm{min} / 1.73 \mathrm{~m} 2-1.0$

$\mathrm{mL} / \mathrm{min}-2.0$

29.27) Data do registro do menor IFG (ou clearence de creatinina) no episódio de insuficiência renal CRÔNICA:

Pergunta Data 
Nome da variável: F2M29_27_gfr_d

Intervalo permitido: 01/01/2013 - 31/12/2017

29.28) A medição direta do IFG no episódio de insuficiência renal CRÔNICA foi feita com inulina, DTPA, EDTA?

Pergunta Alternativa Seleção Única

Nome da variável: F2M29_28_gfr_dm

Alternativas: (descrição - score)

Sim -1.0

Não - 2.0

29.29) O IFG da insuficiência renal CRÔNICA foi estimado pela medida de depuração da creatinina ou foi utilizada uma equação?

Pergunta Alternativa Seleção Única

Nome da variável: F2M29_29_gfr_est

Alternativas: (descrição - score)

Creatinina $\quad-1.0$

Equação de estimativa (Uso de equação para calcular o clearance de creatinine) - 2.0

Outro - 3.0

29.30) Especifique o outro marcador para estimar o IFG na insuficiência renal CRÔNICA: (Separe por ; os outros marcadores) Pergunta Texto

Nome da variável: F2M29_30_gfr_o

Número máximo de caracteres permitido: 100

29.31) O paciente foi tratado com diálise para insuficiência renal CRÔNICA no período de acompanhamento?

Pergunta Alternativa Seleção Única

Nome da variável: F2M29_31_crf_dy

Alternativas: (descrição - score)

Sim -1.0

Não - 2.0

29.32) Qual o tipo de diálise feita para tratar a insuficiência renal CRÔNICA (marque todas opções que se aplicam) Pergunta Alternativa Seleção Múltipla

Nome da variável: F2M29_32_dy

Alternativas: (descrição - nome da variável - score)

Hemodiálise - _hd - 1.0

Diálise peritonial - _pd - 2.0

29.33) Houve interrupção de diálise no episódio de insuficiência renal CRÔNICA?

Pergunta Alternativa Seleção Única

Nome da variável: F2M29_33_dy_end

Alternativas: (descrição - score)

Sim -1.0

Não - 2.0

29.34) Houve transplante renal durante o episódio de insuficiência renal CRÔNICA? 
Pergunta Alternativa Seleção Única

Nome da variável: F2M29_34_rtx

Alternativas: (descrição - score)

Sim - 1.0

Não - 2.0

29.35) Foi utilizado algum medicamento para falência renal no episódio de insuficiência renal CRÔNICA?

Pergunta Alternativa Seleção Única

Nome da variável: F2M29_35_crf_med

Alternativas: (descrição - score)

Sim - 1.0

Não - 2.0

29.36) Qual foi o medicamento utilizado no episódio de insuficiência renal CRÔNICA?

Pergunta Alternativa Seleção Múltipla

Nome da variável: F2M29_36_crf

Alternativas: (descrição - nome da variável - score)

Diuréticos - _diur - 1.0

Inibidores da ECA - _ace - 2.0

Bloqueadores do receptor da Angiotensina - _arb - 3.0

Bicarbonato - _bc - 4.0

Outro - _o - 100.0

29.37) Especifique o outro medicamento utilizado no episódio de insuficiência renal CRÔNICA: (Separe por ; os outros medicamentos utilizados)

Pergunta Texto

Nome da variável: F2M29_37_med_o

Número máximo de caracteres permitido: 100

\section{Módulo: 30 - Infecções}

30.1) O paciente teve osteomielite (aguda ou crônica) no período de acompanhamento 2: (Caso o paciente tenha sido diagnosticado com osteomielite antes do período do Acompanhamento 1, mas mantém o diagnóstico, responder "Sim")

Pergunta Alternativa Seleção Única

Nome da variável: F2M30_1_om

Alternativas: (descrição - score)

Sim - 1.0

Não - 2.0

30.2) Data do diagnóstico de osteomielite: (Marque "Não se aplica" se o diagnóstico de osteomielite foi feito antes do período de acompanhamento)

Pergunta Data

Nome da variável: F2M30_2_om_d

Intervalo permitido: 01/01/2013 - 31/12/2017 


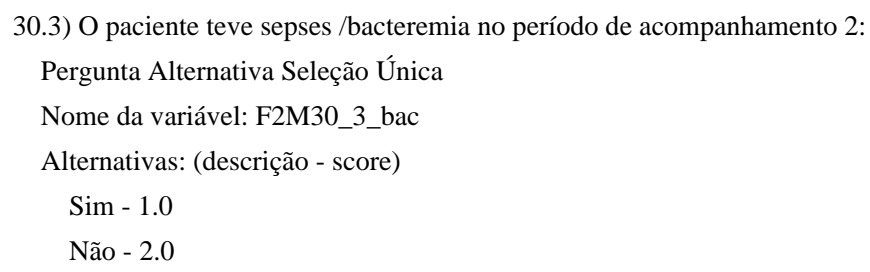

30.4) Data do diagnóstico de bacteremia:

Pergunta Data

Nome da variável: F2M30_4_bac_d

Intervalo permitido: 01/01/2013 - 31/12/2017

30.5) O paciente teve meningite no período de acompanhamento 2:

Pergunta Alternativa Seleção Única

Nome da variável: F2M30_5_mg

Alternativas: (descrição - score)

Sim -1.0

Não -2.0

30.6) Data do diagnóstico de meningite:

\section{Pergunta Data}

Nome da variável: F2M30_6_mg_d

Intervalo permitido: 01/01/2013 - 31/12/2017

30.7) Quantas vezes esse indivíduo teve Bacteremia/Meningite no período de acompanhamento 2?

Pergunta Número Inteiro

Nome da variável: F2M30_7_bac_n

Intervalo permitido: 1 - 99

Planilha: Questões relacionadas ao episódio de Bacteremia/Meningite

Itens: (Descrição - Nome da variável)

Bacteremia/Meningite - F2M30

30.8) Foi realizada cultura neste espisodio de Bacteremia/Meningite? (Hemocultura, urina, CSF ou de pele) Pergunta Alternativa Seleção Única

Nome da variável: _8_cx

Alternativas: (descrição - score)

Sim -1.0

Não - 2.0

30.9) Realizou hemocultura neste espisodio de Bacteremia/Meningite?

Pergunta Alternativa Seleção Única

Nome da variável:_9_bcx

Alternativas: (descrição - score)

Sim -1.0

Não -2.0

30.10) Data da hemocultura neste espisodio de Bacteremia/Meningite:

Pergunta Data

Nome da variável: 10 bcx _d

Intervalo permitido: 01/01/2013 - 31/12/2017 
30.11) Hemocultura neste espisodio de Bacteremia/Meningite foi positiva para bactéria?

Pergunta Alternativa Seleção Única

Nome da variável: _11_bbac

Alternativas: (descrição - score)

Sim -1.0

Não -2.0

30.12) Bactéria identificada neste espisodio de Bacteremia/Meningite:

Pergunta Texto

Nome da variável: 12 bbac r

Número máximo de caracteres permitido: 100

30.13) Hemocultura foi positiva para fungos neste espisodio de Bacteremia/Meningite?

Pergunta Alternativa Seleção Unica

Nome da variável: _13_bfng

Alternativas: (descrição - score)

Sim -1.0

Não - 2.0

30.14) Fungo identificado neste espisodio de Bacteremia/Meningite:

Pergunta Texto

Nome da variável:_14_bfng_r

Número máximo de caracteres permitido: 100

30.15) Realizou cultura de líquido cefalorraquidiano (CRL) neste espisodio de Bacteremia/Meningite

Pergunta Alternativa Seleção Única

Nome da variável: _15_csf

Alternativas: (descrição - score)

Sim -1.0

Não - 2.0

30.16) Data da cultura CRL neste espisodio de Bacteremia/Meningite:

Pergunta Data

Nome da variável:_16_csf_d

Intervalo permitido: $01 / 01 / 2013-31 / 12 / 2017$

30.17) Cultura CRL foi positiva para bactéria neste espisodio de Bacteremia/Meningite?

Pergunta Alternativa Seleção Única

Nome da variável:_17_cbac

Alternativas: (descrição - score)

Sim -1.0

Não - 2.0

30.18) Bactéria identificada na cultura CRL neste espisodio de Bacteremia/Meningite:

Pergunta Texto

Nome da variável:__18_cbac_r

Número máximo de caracteres permitido: 100

30.19) Cultura CRL foi positiva para fungos neste espisodio de Bacteremia/Meningite?

Pergunta Alternativa Seleção Única

Nome da variável: _19_cfng

Alternativas: (descrição - score)

Sim -1.0

Não -2.0

30.20) Fungo identificado na cultura CRL neste espisodio de Bacteremia/Meningite:

Pergunta Texto

Nome da variável: 20 cfng_r

Número máximo de caracteres permitido: 100

30.21) Cultura CRL foi positiva para vírus neste espisodio de Bacteremia/Meningite?

Pergunta Alternativa Seleção Única

Nome da variável: _21_cvir

Alternativas: (descrição - score)

Sim -1.0

Não - 2.0

30.22) Vírus identificado na cultura CRL neste espisodio de Bacteremia/Meningite:

Pergunta Texto

Nome da variável:_22_cvir_r

Número máximo de caracteres permitido: 100 
30.22) Vírus identificado na cultura CRL neste espisodio de Bacteremia/Meningite:

Pergunta Texto

Nome da variável: 22 cvir_r

Número máximo de caracteres permitido: 100

30.23) Realizou cultura de urina neste espisodio de Bacteremia/Meningite?

Pergunta Alternativa Seleção Única

Nome da variável: _23_ur

Alternativas: (descrição - score)

Sim -1.0

Não - 2.0

30.24) Data da cultura de urina neste espisodio de Bacteremia/Meningite:

Pergunta Data

Nome da variável:_24_ur_d

Intervalo permitido: $01 / 01 / 2013$ - 31/12/2017

30.25) Cultura de urina foi positiva para bactéria neste espisodio de Bacteremia/Meningite?

Pergunta Alternativa Seleção Unica

Nome da variável:_25_ubac

Alternativas: (descrição- - score)

Sim -1.0

Não - 2.0

30.26) Bactéria identificada na urina neste espisodio de Bacteremia/Meningite:

Pergunta Texto

Nome da variável:_26_ubac_r

Número máximo de caracteres permitido: 100

30.27) Cultura de urina foi positiva para fungos neste espisodio de Bacteremia/Meningite?

Pergunta Alternativa Seleção Única

Nome da variável: _27_ufng

Alternativas: (descrição - score)

Sim -1.0

Não - 2.0

30.28) Fungo identificado na urina neste espisodio de Bacteremia/Meningite:

Pergunta Texto

Nome da variável: 28 ufng_r

Número máximo de caracteres permitido: 100

30.29) Realizou cultura de pele neste espisodio de Bacteremia/Meningite?

Pergunta Alternativa Seleção Única

Nome da variável: _29_sk

Alternativas: (descrição - score)

Sim - 1.0

Não - 2.0

30.30) Data da cultura de pele neste espisodio de Bacteremia/Meningite:

Pergunta Data

Nome da variável: 30 sk d

Intervalo permitido: 01/01/2013 - 31/12/2017

30.31) A Cultura de pele foi positiva para bactéria neste espisodio de Bacteremia/Meningite?

Pergunta Alternativa Seleção Única

Nome da variável:_31_sbac

Alternativas: (descrição - score)

Sim -1.0

Não - 2.0

30.32) Bactéria identificada na cultura de pele neste espisodio de Bacteremia/Meningite:

Pergunta Texto

Nome da variável:_32_sbac_r

Número máximo de caracteres permitido: 100

30.33) A Cultura de pele foi positiva para fungos neste espisodio de Bacteremia/Meningite?

Pergunta Alternativa Seleção Única

Nome da variável: _33_sfng

Alternativas: (descrição - score)

Sim -1.0

Não - 2.0 
30.33) A Cultura de pele foi positiva para fungos neste espisodio de Bacteremia/Meningite?

Pergunta Alternativa Seleção Única

Nome da variável: 33 sfng

Alternativas: (descrição - score)

Sim - 1.0

Não -2.0

30.34) Fungo identificado ba cultura de pele neste espisodio de Bacteremia/Meningite:

Pergunta Texto

Nome da variável: _34_sfng_r

Número máximo de caracteres permitido: 100

30.35) O paciente foi admitido no CTI nesse episódio de Bacteremia/Meningite?

Pergunta Alternativa Seleção Única

Nome da variável: _35_icu

Alternativas: (descrição - score)

Sim -1.0

Não - 2.0

30.36) No momento do diagnóstico de Bacteremia/Meningite, o paciente estava com cateter venoso central implantado?

Pergunta Alternativa Seleção Única

Nome da variável:_36_cath

Alternativas: (descrição - score)

Sim -1.0

Não -2.0

30.37) O paciente foi transfundido nesse episódio de Bacteremia/Meningite?

Pergunta Alternativa Seleção Única

Nome da variável: _37_tx

Alternativas: (descrição- - score)

Sim -1.0

Não - 2.0

30.38) O paciente teve diagnóstico positivo para Sífilis, Hepatite B, Hepatite C, Chagas, HIV, HTLV e/ou Dengue no período de acompanhamento 2:

Pergunta Alternativa Seleção Única

Nome da variável: F2M30_38_ix

Alternativas: (descrição - score)

Sim -1.0

Não -2.0

30.39) Houve diagnóstico de infecção por sífilis?

Pergunta Alternativa Seleção Única

Nome da variável: F2M30_39_sy

Alternativas: (descrição - score)

Sim - 1.0

Não - 2.0

30.40) Data do diagnóstico de sífilis:

Pergunta Data

Nome da variável: F2M30_40_sy_d

Intervalo permitido: 01/01/2013 - 31/12/2017

30.41) Houve diagnóstico infecção pelo vírus da hepatite B? (Caso o paciente tenha sido diagnosticado com hepatite B antes do período do Acompanhamento 1, mas mantém o diagnóstico, responder “Sim”)

Pergunta Alternativa Seleção Única

Nome da variável: F2M30_41_hbc 
Alternativas: (descrição - score)

Sim -1.0

Não -2.0

30.42) Data do diagnóstico de hepatite B: (Marque "Não se aplica" se o diagnóstico de hepatite B foi feito antes do período de acompanhamento)

Pergunta Data

Nome da variável: F2M30_42_hbc_d

Intervalo permitido: 01/01/2013 - 31/12/2017

30.43) Há suspeita de que a infecção por hepatite B foi transfusional? (Marque "Não se aplica" se não houver histórico de transfusão)

Pergunta Alternativa Seleção Única

Nome da variável: F2M30_43_hbc_t

Alternativas: (descrição - score)

Sim -1.0

Não - 2.0

30.44) Houve diagnóstico de infecção pelo vírus da hepatite C? (Caso o paciente tenha sido diagnosticado com hepatite $C$ antes do período do Acompanhamento 1, mas mantém o diagnóstico, responder "Sim”)

Pergunta Alternativa Seleção Única

Nome da variável: F2M30_44_hcv

Alternativas: (descrição - score)

Sim -1.0

Não - 2.0

30.45) Data do diagnóstico de hepatite C: (Marque "Não se aplica" se o diagnóstico de hepatite C foi feito antes do período de acompanhamento)

Pergunta Data

Nome da variável: F2M30_45_hcv_d

Intervalo permitido: 01/01/2013 - 31/12/2017

30.46) Há suspeita de que a infecção por hepatite C foi transfusional? (Marque "Não se aplica" se não houver histórico de transfusão)

Pergunta Alternativa Seleção Única

Nome da variável: F2M30_46_hcv_t

Alternativas: (descrição - score)

Sim -1.0

Não -2.0

30.47) Houve diagnóstico de infecção por Chagas? (Caso o paciente tenha sido diagnosticado com Chagas antes do período do Acompanhamento 1, mas mantém o diagnóstico, responder "Sim")

Pergunta Alternativa Seleção Única

Nome da variável: F2M30_47_chg

Alternativas: (descrição - score)

Sim -1.0 
Não -2.0

30.48) Data do diagnóstico de Chagas: (Marque "Não se aplica" se o diagnóstico de Chagas foi feito antes do período de acompanhamento)

Pergunta Data

Nome da variável: F2M30_48_chg_d

Intervalo permitido: 01/01/2013 - 31/12/2017

30.49) Há suspeita que a infecção por Chagas foi transfusional? (Marque "Não se aplica" se não houver histórico de transfusão)

Pergunta Alternativa Seleção Única

Nome da variável: F2M30_49_chg_t

Alternativas: (descrição - score)

Sim -1.0

Não - 2.0

30.50) Houve diagnóstico de infecção por HIV? (Caso o paciente tenha sido diagnosticado com HIV antes do período do Acompanhamento 1, mas mantém o diagnóstico, responder "Sim")

Pergunta Alternativa Seleção Única

Nome da variável: F2M30_50_hiv

Alternativas: (descrição - score)

Sim -1.0

Não - 2.0

30.51) Data do diagnóstico de HIV: (Marque "Não se aplica" se o diagnóstico de HIV foi feito antes do período de acompanhamento)

Pergunta Data

Nome da variável: F2M30_51_hiv_d

Intervalo permitido: 01/01/2013 - 31/12/2017

30.52) Há suspeita de que a infecção por HIV foi transfusional? (Marque "Não se aplica" se não houver histórico de transfusão)

Pergunta Alternativa Seleção Única

Nome da variável: F2M30_52_hiv_t

Alternativas: (descrição - score)

Sim -1.0

Não - 2.0

30.53) Houve diagnóstico de infecção por HTLV? (Caso o paciente tenha sido diagnosticado com HTLV antes do período do Acompanhamento 1, mas mantém o diagnóstico, responder "Sim")

Pergunta Alternativa Seleção Única

Nome da variável: F2M30_53_htlv

Alternativas: (descrição - score)

Sim -1.0

Não -2.0 
30.54) Data do diagnóstico de HTLV: (Marque "Não se aplica" se o diagnóstico de HTLV foi feito antes do período de acompanhamento)

Pergunta Data

Nome da variável: F2M30_54_htlv_d

Intervalo permitido: 01/01/2013 - 31/12/2017

30.55) Há suspeita de que a infecção por HTLV foi transfusional? (Marque "Não se aplica" se não houver histórico de transfusão)

Pergunta Alternativa Seleção Única

Nome da variável: F2M30_55_htlv_t

Alternativas: (descrição - score)

Sim - 1.0

Não - 2.0

30.56) Houve diagnóstico de infecção por Dengue?

Pergunta Alternativa Seleção Única

Nome da variável: F2M30_56_dng

Alternativas: (descrição - score)

Sim - 1.0

Não - 2.0

30.57) Data do diagnóstico de Dengue:

Pergunta Data

Nome da variável: F2M30_57_dng_d

Intervalo permitido: 01/01/2013 - 31/12/2017

30.58) Há suspeita de que a infecção por Dengue foi transfusional? (Marque "Não se aplica" se não houver histórico de transfusão)

Pergunta Alternativa Seleção Única

Nome da variável: F2M30_58_dng_t

Alternativas: (descrição - score)

Sim -1.0

Não -2.0

\section{Módulo: 31 - Outros diagnósticos}

31.1) O paciente teve algum outro diagnóstico no período de acompanhamento 2 ?

Pergunta Alternativa Seleção Única

Nome da variável: F2M31_1_o

Alternativas: (descrição - score)

Sim -1.0

Não - 2.0

Planilha: Questões relacionadas a outro diagnóstico

Itens: (Descrição - Nome da variável)

Outro diagnóstico - F2M31 
31.2) Especifique qual o outro diagnóstico:

Pergunta Texto

Nome da variável: 2 sp

Número máximo de caracteres permitido: 100

31.3) Data que o outro diagnóstico foi identificados pela primeira vez:

Pergunta Data

Nome da variável: _3_o_d

Intervalo permitido: 01/01/2013 - 31/12/2017 